UN IVERSITY OF COPENHAGEN

\title{
Global Textile Encounters
}

Nosch, Marie Louise Bech; Zhao, Feng; Varadarajan, Lotika

Publication date:

2014

Citation for published version (APA):

Nosch, M. L. B., Zhao, F., \& Varadarajan, L. (Eds.) (2014). Global Textile Encounters. Oxbow Books. ANCIENT TEXTILE SERIES Vol. 20 
GLOBAL TEXTILE ENCOUNTERS 



\title{
GLOBAL TEXTILE ENCOUNTERS
}

\author{
edited by \\ Marie-Louise Nosch, Zhao Feng \\ and Lotika Varadarajan
}

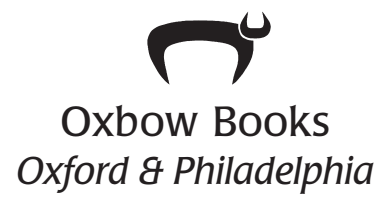


Published in the United Kingdom in 2014 by

OXBOW BOOKS

10 Hythe Bridge Street, Oxford OX1 2EW

and in the United States by

OXBOW BOOKS

908 Darby Road, Havertown, PA 19083

(c) Oxbow Books and the individual contributors 2014

Paperback Edition: ISBN 978-1-78297-735-3

Digital Edition: ISBN 978-1-78297-736-0

A CIP record for this book is available from the British Library

Library of Congress Cataloging-in-Publication Data

Global textile encounters / edited by Marie-Louise Nosch, Zhao Feng and Lotika Varadarajan.

pages $\mathrm{cm}$.-- (Ancient textiles series; VOL. 20)

Includes bibliographical references and index.

ISBN 978-1-78297-735-3 (alk. paper)

1. Clothing and dress--Social aspects. 2. Textile fabrics--Social aspects. I. Nosch, Marie-Louise editor.

II. Zhao, Feng, 1961- editor. III. Varadarajan, Lotika, editor.

GT525.G57 2015

391--dc23

2014039330

All rights reserved. No part of this book may be reproduced or transmitted in any form or by any means, electronic or mechanical including photocopying, recording or by any information storage and retrieval system, without permission from the publisher in writing.

Printed in Malta by Melita Press Ltd.

For a complete list of Oxbow titles, please contact:

UNITED KINGDOM

Oxbow Books

Telephone (01865) 241249, Fax (01865) 794449

Email: oxbow@oxbowbooks.com

www.oxbowbooks.com
UNITED STATES OF AMERICA

Oxbow Books

Telephone (800) 791-9354, Fax (610) 853-9146

Email: queries@casemateacademic.com

www.casemateacademic.com/oxbow

Oxbow Books is part of the Casemate Group

Front cover: A richly embroidered child's Jhabla or tunic patterned with an intercrossing Simurgh (senmurw) and peacocks from the Indian tradition along with floral designs from Persia (Photographed by Ashdeen Z. Lilaowala for the Parzor Foundation; (c) Unesco Parzor).

Back cover: European foliage and scallops form the base of this Parsi embroidered sari (Photographed by Ashdeen Z. Lilaowala for the Parzor Foundation; @ U UNESCO Parzor). 


\section{Contents}

1 Textiles and Elite Tastes between the Mediterranean, Iran and Asia at the End of Antiquity

Matthew P. Canepa

2 Palla, Pallu, Chador: Draped clothing in ancient and modern cultures Mary Harlow 15

3 From Draupadi to Dido: The duties of dress in paintings inspired by the Mahābhārata and the Aeneid Linda Matheson.

4 The Kaftan: An unusual textile encounter in the Scandinavian Late Iron Age Ulla Mannering

5 Ancient Running Animals: Tablet-woven borders from China and Norway Lise Roeder Knudsen

6 The Development of Pattern Weaving Technology through Textile Exchange along the Silk Road Zhao Feng.

7 The Earliest Cotton Ikat Textiles from Nahal 'Omer Israel 650-810 CE Orit Shamir and Alisa Baginski.

8 Northerners: Global travellers in the Viking Age Eva Andersson Strand.

9 Unravelling Textile Mysteries with DNA Analysis Luise Ørsted Brandt

10 The Traceable Origin of Textiles Karin Margarita Frei

11 The World of Textiles in Three Spheres: European woollens, Indian cottons and Chinese silks, 1300-1700 Giorgio Riello 
12 Chinese Silks in Mamluk Egypt

Helen Persson

13 Woven Mythology: The textile encounter of makara, senmurw and phoenix Mariachiara Gasparini

14 Textile in Art: The influence of textile patterns on ornaments in the architecture of medieval Zirikhgeran

Zvezdana Dode

15 Coromandel Textiles: The changing face of consumer demand and weavers' responses 16 th to 18 th century CE Vijaya Ramaswamy.

16 The Jesuit Dilemma in Asia: Being a naked ascetic or a court literate? Selusi Ambrogio.

17 The Colourful Qualities of Desire: Fashion, colours and industrial espionage Vibe Maria Martens.

18 Fashion Encounters: The "Siamoise", or the impact of the Great Embassy on textile design in Paris in 1687 Corinne Thépaut-Cabasset

19 The Chinoiserie of the 17th to 18th-century Soho Tapestry Makers Mette Bruun

20 Exoticism in Fashion: From British North America to the United States Madelyn Shaw

21 Textile Symbolism and Social Mobility during the Colonial Period in Sydney Cove Judith Cameron

22 The Impact of British Rule on the Dressing Sensibilities of Indian Aristocrats: A case study of the Maharaja of Baroda's dress Toolika Gupta

23 Re-imagining the Dragon Robe: China chic in early twentieth-century European fashion Sarah Cheang 
24 Sari and the Narrative of Nation in 20th-Century India Aarti Kawlra

25 From Cool to Un-cool to Re-cool: Nehru and Mao tunics in the sixties and post-sixties West

Michael A. Langkjor

26 Too Old: Clothes and value in Norwegian and Indian wardrobes Ingun Grimstad Klepp, Lill Vramo and Kirsi Laitala....

27 A 'Stinging' Textile: Cultivation of nettle fibre in Denmark and Asia Ellen Bangsbo ....

28 Fist-braided Slings from Peru and Tibet

Lena Bjerregaard

29 Parsi Embroidery: An intercultural amalgam

Shernaz Cama.

30 The Navjote Ceremony and the Sudreh Kushti Lotika Varadarajan

31 Globalization, Identity and T-shirt Communication

Karl-Heinz Pogner

32 India to Africa: Indian Madras and Kalabari creativity

Joanne B. Eicher. 295

33 Textile: The non-verbal language Jasleen Dhamija

Dedication 309

Acknowledgements 



\title{
1 Textiles and Elite Tastes between the Mediterranean, Iran and Asia at the End of Antiquity
}

\author{
MATTHEW P. CANEPA
}

Matthew Canepa teaches ancient art and archaeology in the Department of Art History at the University of Minnesota. His research tends to focus on the intersection of art, ritual, and power in the ancient Iranian world and the Mediterranean. His first book, entitled The Two Eyes of the Earth: Art and ritual of Kingship between Rome and Sasanian Iran (Berkeley, 2009), is the first to analyze the artistic, ritual, and ideological interactions between the Roman and Sasanian empires. It was awarded the 2010 James Henry Breasted Prize from the American Historical Association for the best book in English on any field of history prior to $1000 \mathrm{CE}$. He is currently writing a book exploring the transformation of Iranian art and kingship between the invasions of Alexander the Great and Islam.

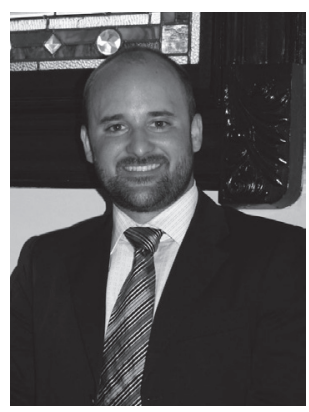

The world of late antiquity (c. 3rd-8th century CE) oversaw the growth of an increasingly interconnected world. Empires, including the late Roman Empire, Sasanian Persia and Sui-Tang China defined themselves in a self-consciously global fashion and strove with one another, to not only control trade, but gain control of the symbolic as well as economic capital that flowed through them. During this period, the late Roman Empire and the Persian Empire of the Sasanian dynasty developed a particularly deep and close relationship. Their court cultures deeply imprinted their identity throughout their lands, all the way to the peripheries from Africa to Central Asia. The history of the late antique Mediterranean and Western Asia is thus a history of their conflict and cooperation. Building on the united empire of the Sui, the Tang dynasty oversaw the expansion of Chinese influence throughout Asia and the emergence of a great, vibrant, cosmopolitan culture. The Tang dynasty was very open to religions, images and objects from the west, and Iranian aristocratic culture exerted a particularly strong influence.

While the desires of elites drove exchange, interlocking merchant networks made Eurasian exchange possible. Syrian and Persian merchant ships connected the Mediterranean, the Arabian Sea, and Indian Ocean with the South China Sea. Merchants from minorities within or on the peripheries of large empires, including Syrians, Jews, Bactrians, Sogdians and Armenians, controlled the land routes from the Chinese capitals through Central Asia and the multiple routes into Iran and thence 
the Mediterranean or, by the northern route, to the Black Sea. These Eurasian trade networks moved a great deal of ornamental and luxury material, feeding the desires of the elites to distinguish themselves with rare goods, images and motifs.

\section{Textiles and Trade}

Silk textiles played an especially important role in this vibrant period of Eurasian exchange. Silk was worth its weight in gold and the silk trade drove a wider range of commercial, intellectual and political exchange. China exported raw silk to Persia and the Mediterranean, and western ornamental motifs and fashion were imported into China. By late antiquity, the Romans and Persians had already developed a voracious appetite for silk. Until the 6th century CE, the Romans imported all their raw silk and silk yarn from China, most often through Persian middlemen. According to legend, in 553/4 Syrian monks smuggled the silk worm cocoons into the Roman Empire and sold them to the court of the emperor Justinian. This established a local Roman silk industry, although the empire still imported a large amount of silk from Persia. The centre of the Roman silk industry was in late antiquity in Constantinople and silk was spun and woven in large imperial factories and small private workshops. Silk textiles were an important element in the official costume of the Roman emperor and his officials, as well as in palace and church wall hangings, curtains and church furnishings, such as altar cloths.

Silk had been known in Iran since the 4th century BCE. The Persians imported their raw silk from China and did not establish a native silk production industry until the 6th century CE. Nevertheless, Persian silk textiles became incredibly popular not only in Rome but also in China. The Sui and Tang dynasties were especially known for their polychrome patterns and textiles woven with gold thread and the Sogdians became very adept at imitating them. The Romans constantly sought alternative markets and routes, though the Sasanian court actively resisted efforts on the part of the Romans to find ways around their monopoly on the silk trade. Under Ohrmazd IV (579-590 $\mathrm{CE})$ the rise of the first Turk Khaganate and its eventual alliance with the Romans threatened Sasanian control over the Silk Road trade and temporarily opened up a route outside the latter's control. Silk clothing was the preserve of the high aristocracy and features, such as gold thread and special colors marked an individual's rank. In this regard, while the silk fabric itself was still valuable, elite consumers paid more and more attention to the ornamental motifs that the silks carried.

\section{Silk and Society}

Textiles and the ornamental motifs they carried were politically and socially important in late antiquity. The material that a textile was made of, its ornamental motifs, and the resulting type of garment, all impacted its prestige and that of the wearer. Roman, Persian and Tang elites defined themselves in a self-consciously global fashion. They 
strove with one another, to not only control this trade, but gain control of the signs of royal and aristocratic distinction that luxury objects carried. While luxury goods and textiles had flowed from China to the Mediterranean in earlier centuries, textiles and textile motifs became especially important markers of power and wealth in this period. Kings and aristocrats took pains to display them on their person as well as in painting, mosaic or sculptural portraits, and textile ornament migrated into royal architectural ornament.

Silk was not only very expensive, but wearing it became a political act in late antique Rome and Iran. Much like Chinese courts, Rome and Persia used clothing and ornament to articulate the differences between official ranks and social classes. Both the Roman and Persian courts would give gifts of clothing to show that an individual was a part of the courtly hierarchy and one could not wear silk, especially purple silk, without official approval. The Sasanian kings imposed visual distinctions between the various classes of nobles and between the nobles and common people with the implementation of sumptuary laws. Wearing silk clothes was a privilege supposedly only bestowed upon the nobility and having gold brocade on one's clothes was reserved for the high nobility and king. In bestowing gifts to their courtiers, the Sasanian kings articulated distinctions within the upper echelon of society too. The Sasanian kings granted silk robes and jewelry to their court to show their favor; these tokens were then worn in the king's presence. The king often showed high honor by giving away his own robes, which he would gift to his family members and close associates.

In the late Roman Empire, when an official would be raised to a high office, a gift of clothing and official insignia often followed. Who was allowed to wear silk, especially purple silk, was strictly legislated. The color purple created from an extremely expensive dye, became closely linked to the person and office of the Roman emperor in late antiquity. Under the emperor Diocletian, the color purple, especially the purple cloak, the paludamentum (Latin) or chlamys (Greek) took its place as the most important symbol of the imperial office. The emperor was the only one who could wear the purple cloak, although senators and high officials could wear small sections of purple on their clothing to mark their status.

When a client king traveled to the court of the Roman or Sasanian king, they received insignia of office, including clothing, that marked their membership in the Roman or Sasanian cultural sphere. The kingdoms on the border between the Roman and Sasanian empires provide several interesting examples both of the two realms' practices of investiture and the client king's careful and creative balancing act of displaying the honors given by the two realms. Rome and Sasanian Iran repeatedly strove with each other to invest client kings in the Caucasus, Pontus, and the Arab borderlands. Despite the subordinate positions the world empires assigned them, the peoples in-between the empires would often shrewdly balance the marks of distinction of the grand imperial strategies, tacitly subverting them. 


\section{Ornament and Elite Identity}

During late antiquity, the popularity of Mediterranean visual culture in Eurasia precipitously declined, with Persian visual culture quickly filling the void both in the Mediterranean, Central Asia and China, and remaining influential long after the fall of the Sasanian dynasty. Set against the larger Eurasian context, Persian courtly images enjoyed an exceptionally wide prestige, popularity, and distribution, used and reinterpreted in Constantinople and Chang'an (Xi'an) even after the Sasanian Empire's demise. The sands of Central Asia, Syria and Egypt as well as tombs and treasuries of European churches have preserved fragments of Persian textiles. Persian ornamental patterns could be very simple, but very visually and symbolically powerful. The most common motifs include symmetrical, geometrical or vegetal motifs, such as the rosette, and animals such as birds, boars, rams, winged horses, or fabulous creatures such as the feline, aquatic avian creature symbolic of Royal Glory of Fourtune (Middle

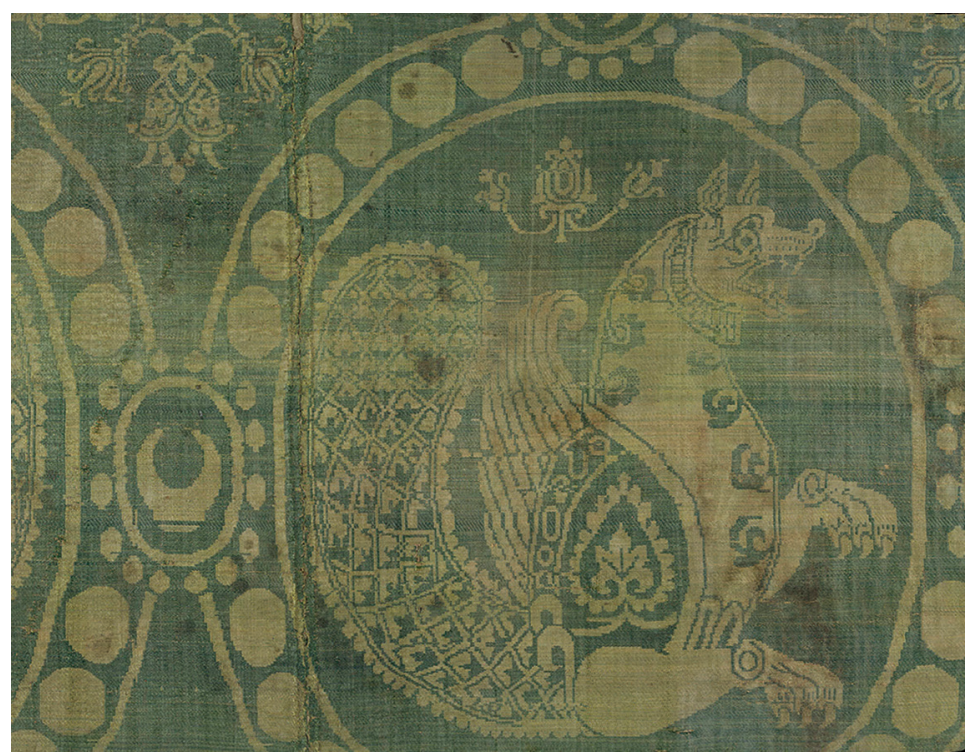

Fig.1.1: Woven silk with beasts in a pearl roundel pattern and rosette motifs. The dominant motif of this silk, now divided between the Victoria and Albert Museum in London and Musée des Arts de la Mode et du Textile in Paris, is a fantastic composite creature with elements of a bird, fish and lion. The creature is set at the centre of interlocking pearl roundels connected by smaller pearl roundels that carry crescent motifs. Quadriform rosettes fill the diamond spaces between the rosettes. This silk is very similar to a number of late antique silks discovered in church treasuries as well as in archaeological contexts in Western and Central Asia. Most importantly, it recalls the ornamental motif that the Sasanian king of kings wears in the 7th-century Sasanian rock relief at Taq-e Bostan and in a fresco representation at the Sogdian palace at Afrasiab (present-day Samarkand, Uzbekistan). The beast is one of a repertoire of late antique Persian animal motifs that are generally understood to represent good fortune or divine protection. Considering that only the king of kings wore this motif, it had specific royal connotations. This silk, known in the Middle Ages as the "Sudarium of St Helen," originally wrapped bones understood to be the relics of St Helen. It, along with the relics, was kept in Rome, and possibly came to Rome after the emperor Heraclius' reconquest of Jerusalem from the Persians in 629. It was stolen from Rome and taken to France in 842 where it was first deposited at the abbey of Hautvilliers and then the church of Saint-Leu-Saint-Gilles in Paris. V\&A inv. 8579-1863 (@ Victoria and Albert Museum, London). 
Fig.1.2: Detail, silk with winged horses in pearl roundels. This silk is one of several textiles that may have come to Egypt during the Sasanian occupation (618/19-628). The Persian occupying force was likely responsible for bringing such silks to Egypt and commissioning local textile workers to create similarly patterned wool textiles. Local elites also appreciated such textile patterns and commissioned their own textiles as well. Its ornamental pattern consists of interlocking pearl roundels. A smaller pearl roundel with a crescent in its interior connects each of the larger roundels to each other. Quadriform rosettes fill the diamond spaces between the rosettes. These, like the motifs in the silk with composite creatures, were another variation of this very popular Persian ornamental motif and are similar to ornamental motifs at Taq-e Bostan. Winged horses occupy the centre of the large medallions. They wear elements that recall Persian royal regalia. A crescent surmounted by a rosette recalls the crescent and star or sun disk of late Sasanian royal crowns. A segmented diadem around the animal's neck is tied by a long, streaming ribbon, and matches the diadem of Khosrow II as portrayed in

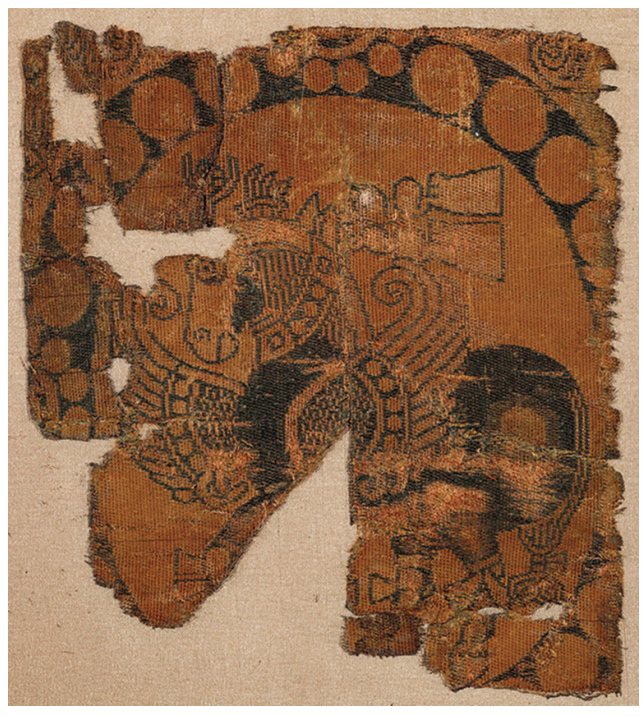
the rock relief of Taq-e Bostan. While the image of the winged horse came to Iranian culture through Hellenistic visual culture, the motif took on a number of royal and religious symbolisms in its new context. It symbolizes the divine royal glory (xwarrah (Middle Persian)) of the rightful Persian king and could carry allusions to the war god, Wahram. Discovered in Antinoe, Egypt, necropolis B, tomb 165 (kept at the Louvre and Musée des Tissus de Lyon). Late 6th-7th century. Paris Louvre Inv. N. E 29210 () Erich Lessing /lessingimages.com).

Persian, $x$ warrah) often called a senmurw in older scolarship (Figs 1.1 and 1.2). These motifs are often set within roundel patterns. The 7th-century rock relief of Taq-e Bostan in present-day Kermanshah Iran contains multiple images of its patron, the king of kings Khosrow II. The rock relief is in the shape of a barrel-vaulted entranceway (ayvan) characteristic of Persian palaces (Fig. 1.3). In addition to the main images at the back of the ayvan (New Persian) portraying the king invested by gods and as a royal hunter, the two side panels contain small, detailed reliefs of the king of kings hunting with his courtiers. (Fig. 1.4) It preserves not only royal activities but also the royal fashion and textile ornament. The sculptural representations of the clothing of the king of kings as well as his courtiers, servants, musicians and even elephant drivers all take pains to record with precision the textile patterns that they carried (Figs 1.5, 1.6, 1.7, 1.8 and 1.9).

The 6th-century church of San Vitale at Ravenna holds one of the most celebrated images of the Emperor Justinian and Empress Theodora as well as some of the most detailed representations of late Roman textiles (Figs 1.10 and 1.11). While Justinian never set foot in the church, or the Italian Peninsula for that matter, and Theodora was likely dead at the time of its completion, the mosaic portraits of the imperial couple were intended to make the imperial presence felt in the province and this very important liturgical space. These are official portraits and, like many other aspects 


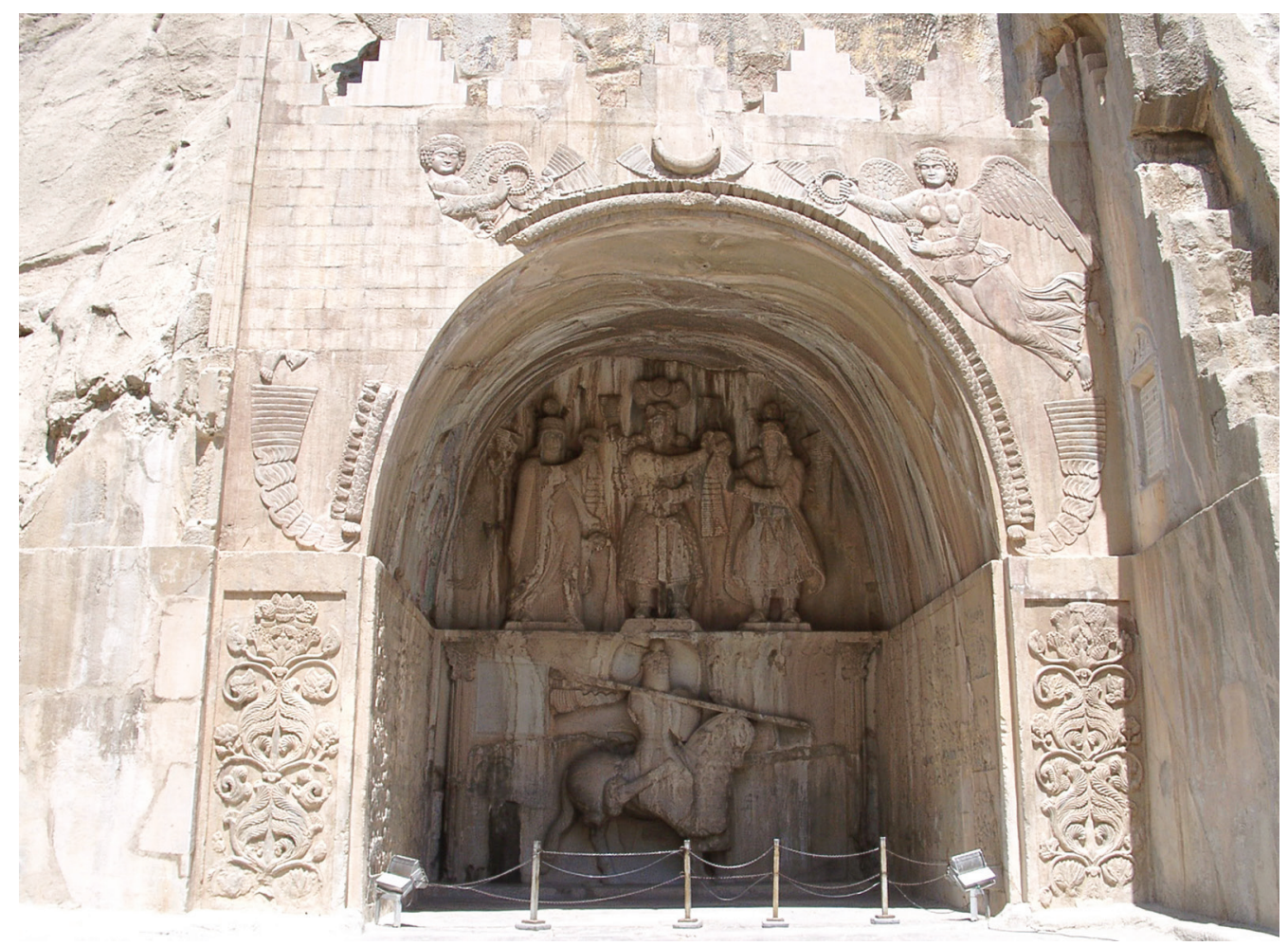

Fig.1.3: Great Ayvan at Taq-e Bostan. This is a large rock-cut barrel vault (Persian ayvan) with monumental high relief sculpture in the rear and detailed low relief sculpture on the side panels. Originally the site of a Sasanian royal hunting retreat, the relief was carved into the cliffs of a mountain where natural springs gushed from the rock. The ayvan recalls the architectural forms of Sasanian palaces. The relief was originally fitted with doors that could close off the face indicating that it was intended to have the additional function of an open-air throne hall. The king of kings Khosrow II (590-628) was the patron of the relief and the fact that it was left unfinished suggests that the king's overthrow after the Roman emperor Heraclius' invasion of the Persian Empire cut work on it short. It is the largest of the site's three rock reliefs. The rear of the relief is divided into two registers. The upper register portrays the king of kings, Khosrow II, at the centre given diadems by the goddess Anahid (left) and god Ohrmazd. Below, the king appears with chainmail covering his face as a horseman holding a shield and spear. First half of the 7th century CE, near Kermanshah, Iran (Photo: Matthew Canepa).

of the church's design and architectural elements, it came from Constantinople and was carefully executed according to preordained regulations. In addition to carefully portraying the emperor's and empress's official crowns and costume as well as those of their courtiers, the mosaic carefully replicates a wide variety of ornamental motifs on the textiles. Theodora and her ladies-in-waiting wear extremely colorful textiles covered in a variety of motifs. While senators accompanying Justinian wear very plain clothing, the emperor and his bodyguard integrate a number of elaborate ornamental motifs. The most important garment in the entire panel is the purple imperial chlamys, which had for centuries been the pre-eminent symbol of Roman imperial power. However, Justinian's chlamys integrates a panel of silk decorated 


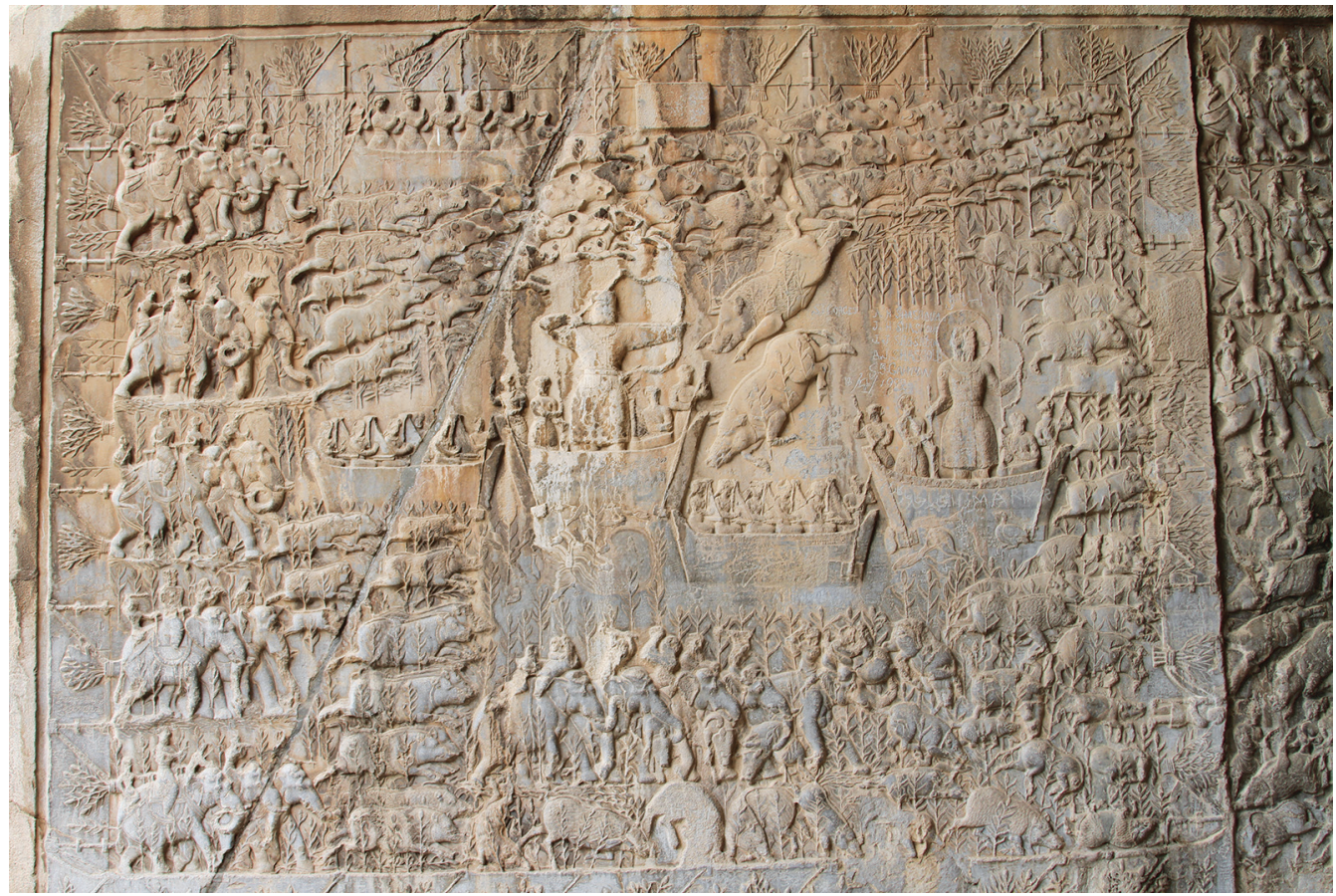

Fig. 1.4: Left side panel, Great Ayvan at Taq-e Bostan. The side panels likely reflect activities that went on at the site. The king appears twice. In both instances the king of kings hunts boar with a bow and arrow and stands in a boat floating in a marshy lake, while elephants drive the quarry into the centre of an enclosure (Photo: Matthew Canepa).

Fig. 1.5: Detail of the caftan of the royal horseman, the Great Ayvan at Taq-e Bostan, 7th century. The king's caftan peaks out from underneath his armor and contains the quadriform rosette motif and composite feline, aquatic avian creatures (Photo: Matthew Canepa).

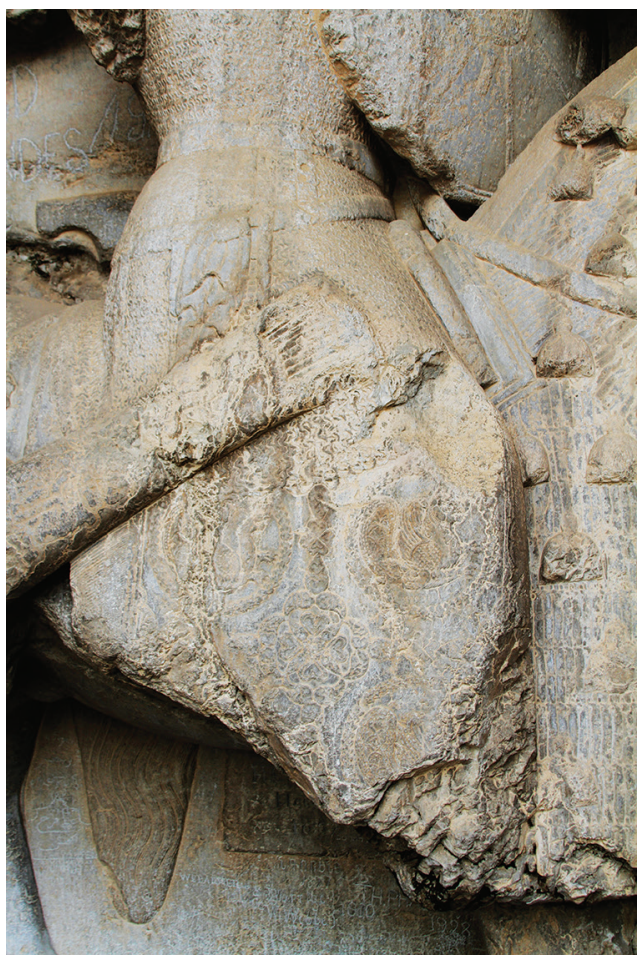




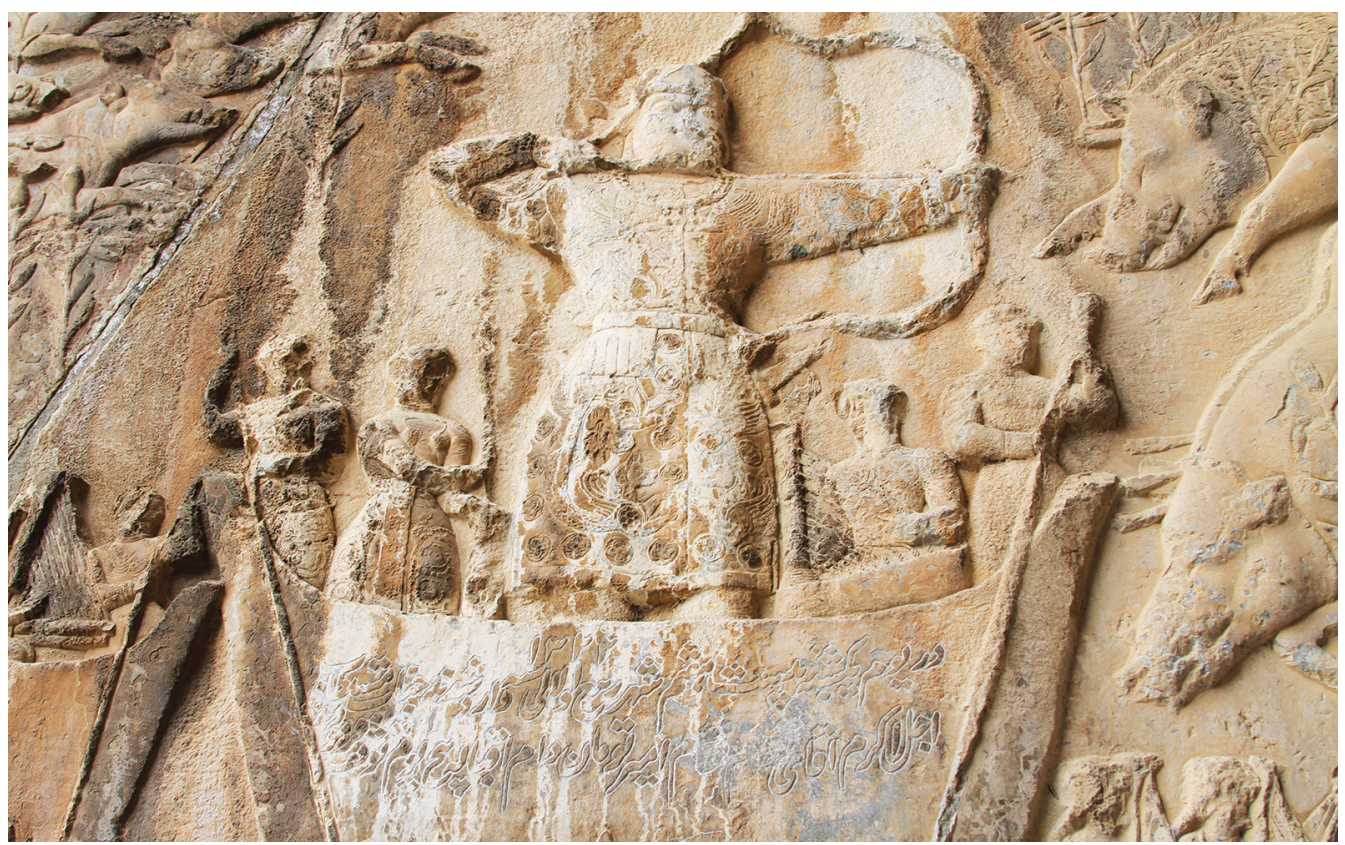

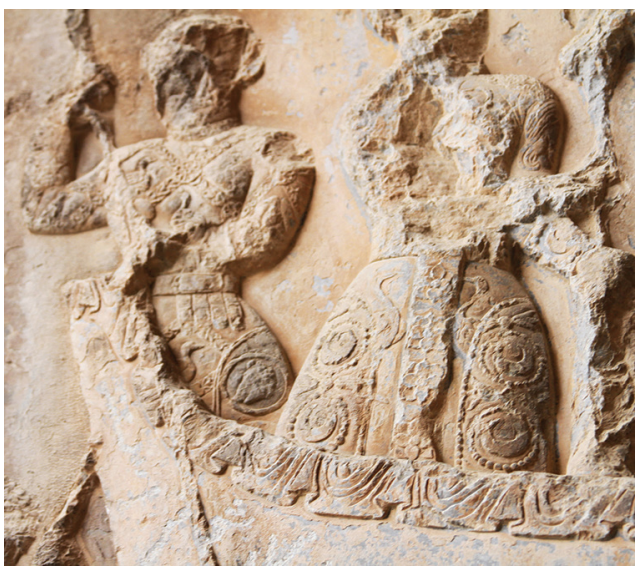

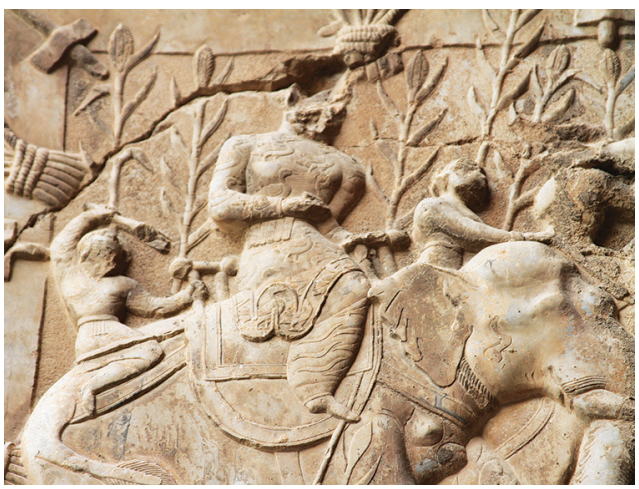

Fig. 1.6: Detail, king of kings, left side panel. Taq-e Bostan, Great Ayvan, 7th century. The king of kings wears a stiff silk caftan that is ornamented with rosette and composite beasts. The king wears an elaborate belt and necklace, both marks of status and honor in Iran (Photo: Matthew Canepa).

Fig. 1.7: Detail, servants, left side panel. Taq-e Bostan, Great Ayvan. These two servants wear elaborately ornamented clothing. Like the belts of honor, these textiles mark them as members of the courtly hierarchy. The figure on the right wears a caftan with pheasants set in the middle of ornamental borders forming diamonds. Panels on the lower part of the caftan are decorated by roundels with the head of a boar at their centre. The figure on the right wears a caftan decorated with cranes. The panels on the lower sides of his caftan contain pearl roundels with crescents at their centre (Photo: Matthew Canepa).

Fig. 1.8: Detail, elephant driver, left side panel. Taq-e Bostan, Great Ayvan. The elephant driver wears a caftan ornamented with ducks or pheasants. This, as well as his size and more elaborate belt, mark him as more important than the smaller servants who accompany him (Photo: Matthew (anepa). 


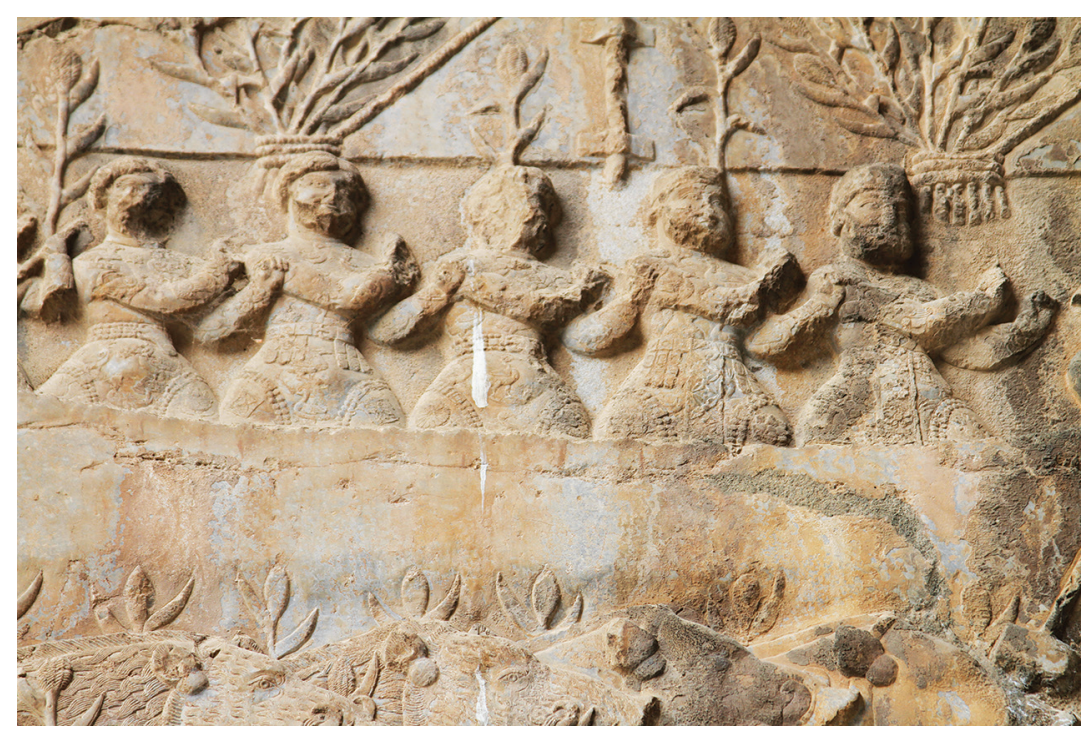

Fig. 1.9: Detail, applauding courtiers, left side panel. Taq-e Bostan, Great Ayvan. These courtiers applaud the king of kings' hunting skills while seated in a boat. Their caftans are all decorated with birds, though the lower side panels differ. Some contain flowers, others rosettes, and still others carry boars' heads (Photo: Matthew Canepa).

with birds in roundels, which do not match contemporary Roman silks, but rather textiles from Persia. What is the purpose of that textile pattern?

Alongside its formal functions like framing, filling, linking or just pleasurably embellishing, ornament could communicate political messages and define identities, which was one of its most important vocations within the context of elite taste and fashion. Aristocrats and sovereigns interacted with foreign ornamental material in order to situate themselves with respect to larger aristocratic common-cultures that were developing across Eurasia. This is most likely the purpose of the birds in roundels decorating Justinian I's imperial chlamys in the San Vitale mosaic.

Ornament, and often ornament perceived as exotic, could define the patron's, as well as the viewer's, relationship with the structure or object with respect to their social place or elite status. Ornament provided a level of allusion and flexibility that the strictly defined genre of imperial regalia and iconography could not. The practice of displaying another culture's ornamental material or even incorporating it into a new context was a tool by which elites could define their identity within their own society or the wider, global visual culture of power. While the purple chlamys and crown defined Justinian's place at the very top of the Roman state and society, the Persian luxury textile pattern integrated into it shows that he controls or at least participates in this global system of aristocratic distinction. The popularity of Iranian or Iranianinspired objects and motifs amongst the imperial elite in Rome often had to do with the role of the exotic motifs in establishing and inculcating difference between social ranks quite independent from their original political or religious context. In this 


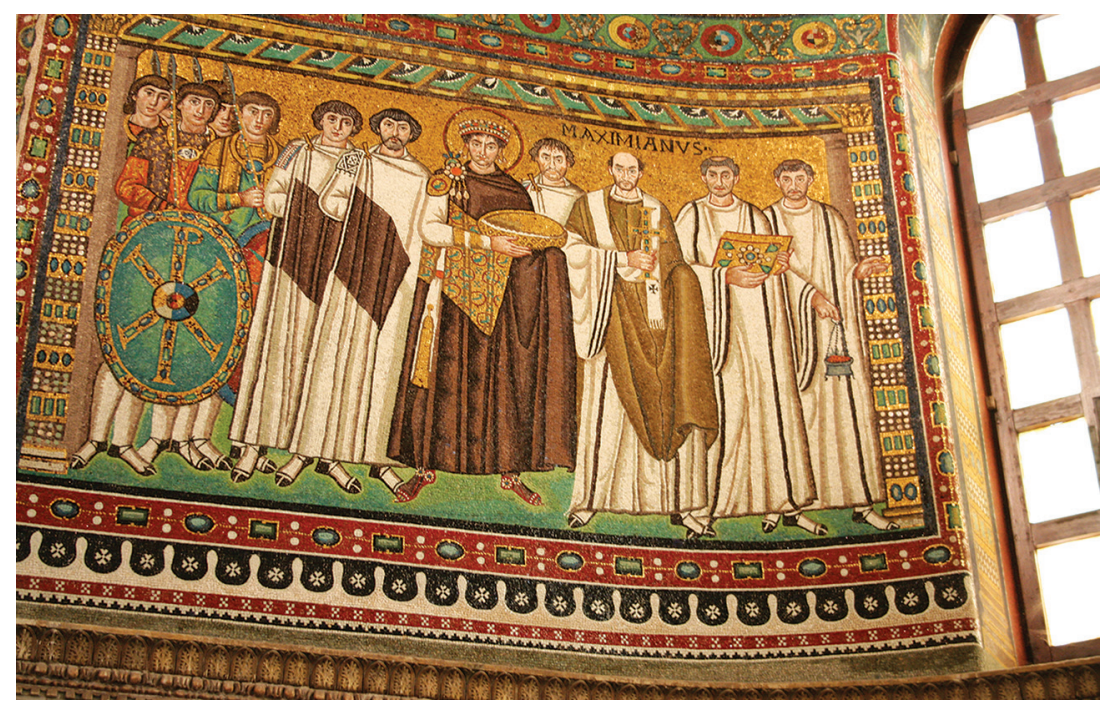

Fig. 1.10: The emperor Justinian I with bodyguard, senators and ecclesiastical hierarchy. Presbytery mosaic, north wall, church of San Vitale, Ravenna, Italy (church dedicated, 547). This image shows the emperor, his senators and bodyguard preceded by members of the clergy processing into the church during the First Entrance of the Divine Liturgy. However, its location in the sanctuary of the church alludes to the fact that the late Roman emperor would enter the sanctuary during the Second Entrance and take communion at the altar like a member of the clergy. Justinian I's purple imperial chlamys contains a panel (tablion (Greek)) decorated with birds in roundels. This motif evokes a wide variety of Persian and Central Asian textiles. Unlike his crown and nimbus, which are the preserve of the Roman emperor alone, the textile motifs allude to a broader marker of wealth and prestige (Photo: Matthew Canepa).

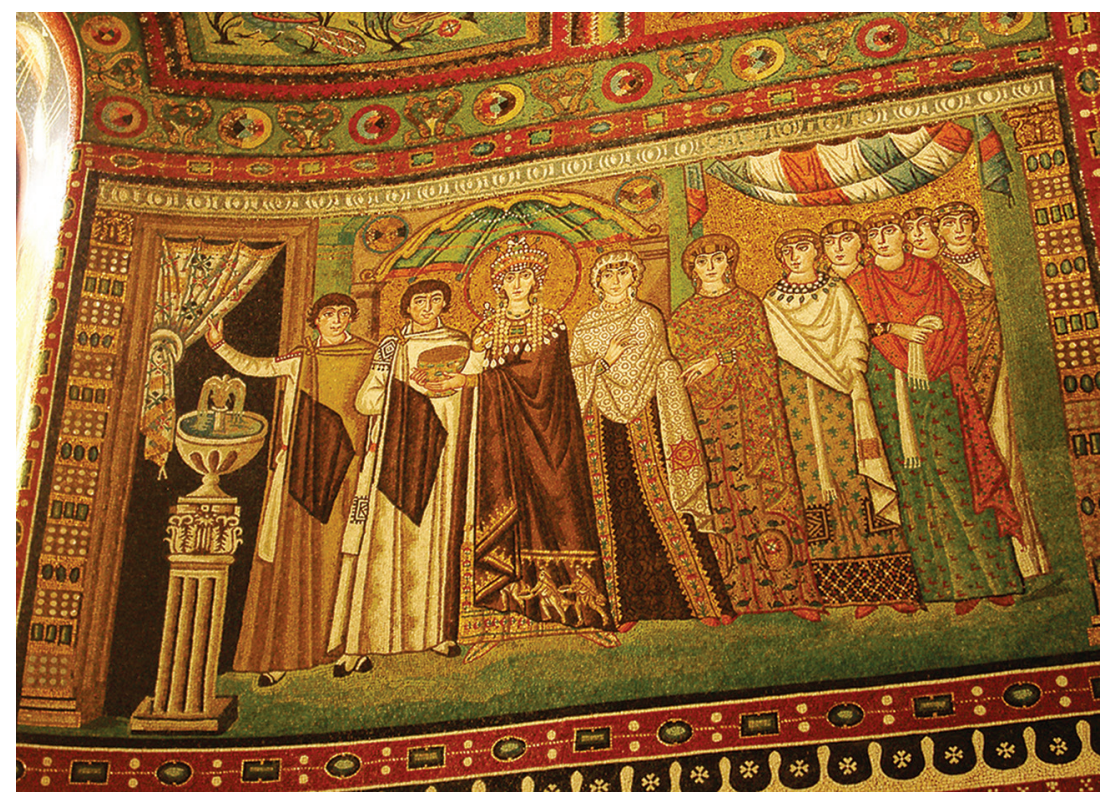

Fig. 1.11: The empress Theodora (r. 527-548) with courtiers. Presbytery mosaic (c. 547), south wall, church of San Vitale, Ravenna, Italy. The empress enters the church from the atrium accompanied by eunuchs, one of whom draws back a silk door hanging decorated with quadriform ornamental motifs, and ladies-in-waiting who wear elaborate textiles that include ornamental motifs of birds, flowers and geometrical motifs (Photo: Matthew Canepa). 
regard, a number of locally manufactured wool textiles from Egypt and Central Asia incorporate the motifs of expensive, imported Persian silk. These reflect the desire of those lower on the social and economic stratum to participate in this world too.

These same Persian motifs, polychrome rosette patterns, symmetrically confronted animals and animals in roundels appear in Sui-Tang China, first as the result of trade and later through imitation. By the late 5th century, Persian silk was being traded in the Tarim Basin and by the early Tang period, imperial weaving workshops produced reproductions of Persian polychrome textiles. After $651 \mathrm{CE}$, these textile motifs were directly introduced by the Sasanian court in exile, which sought refuge under the Tang dynasty and became incorporated into the Tang courtly hierarchy. Motifs such as the symmetrical rosette appear in the clothing of tomb figures and the court costumes of Tang women portrayed in wall paintings. These motifs spread beyond China along with other aspects of Tang aristocratic culture. A textile that came to Japan from China as a gift or export preserved in the Horyu-ji Temple in Nara, Japan, incorporates the symmetrical figures of hunters wearing stylized Sasanian crowns set within pearl roundels (Fig. 1.12).

Prestigious ornamental motifs could often migrate from silk to other types of textiles or even into architectural settings. Ornamental motifs, in the margins of sacred architecture, luxury objects, palaces, tombs and court-costumes, offered a subtle means to comment on a royal or aristocratic patron's identity and manage the economy of courtly hierarchy. The incorporation of foreign motifs into architectural ornament, objects, or clothing in a new cultural context is not always easy to interpret. These range from the late Sasanian textiles, to grand architectural spaces like Justinian I's Hagia Sophia, whose acres of mosaic bear what appears on the surface to be Persian ornamental design. These textile motifs would give the viewer the impression that it was swathed in golden gleaming imported silk, but also show that Justinian controls this type of ornamental mark of prestige (Fig. 1.13). Similarly, the craze for 'western' luxuries in the early Tang dynasty, including food, fashions and entertainments largely imported from the Iranian world, too has been the subject of much study.

Certain craftsmen took foreign motifs normally present in one medium and incorporated them into an entirely different medium and context. However, others did not follow this simple transfer of motifs. The Roman craftsmen who incorporated Persian textile and stucco ornament into the mosaics of Justinian I's Hagia Sophia, the weavers of Sogdian textiles who incorporated Persian and Roman motifs as well as Chinese potters who adapted Persian shapes and motifs all provide examples of this phenomenon.

This period of cross-cultural interaction dramatically changed the visual cultures of the Mediterranean, Western, Central and East Asia. Persian textiles and ornament were especially influential, but as the Romans, Sogdians and Chinese integrated these motifs into their own visual cultures, they soon no longer viewed them as 'foreign'. The end result of this process of late antique exchange was to briefly unite the tastes and visual cultures of Eurasia in a way that would not be seen again for many centuries. 


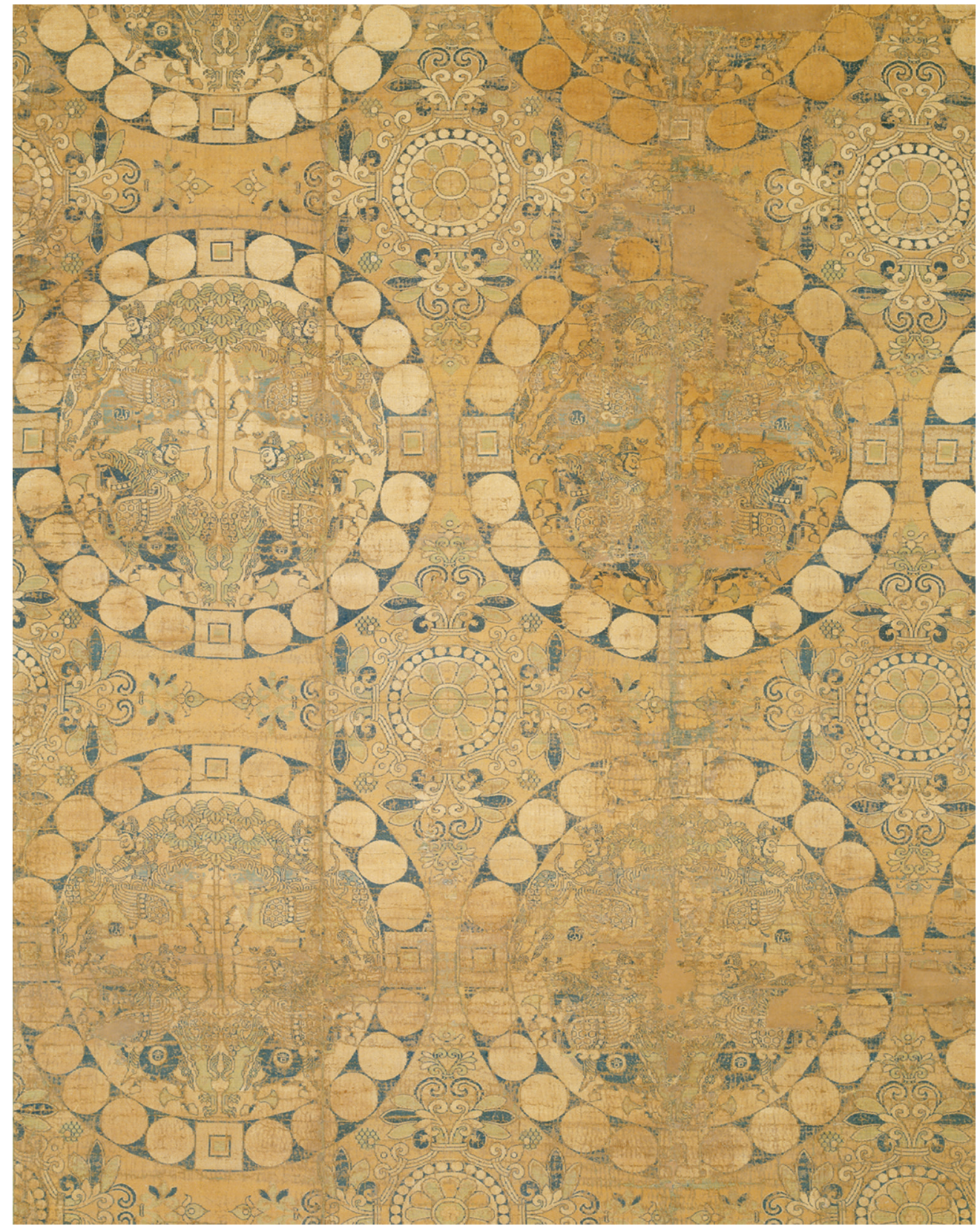

Fig. 1.12: National Treasure Textile with Roundels of Four Lion Hunters on Horseback Horyuji Temple, also known as the Four Celestial Guardians Brocade. Detail of a silk samite with Sasanian-inspired motifs from the treasury of the Horyuji Temple in Nara, Japan, 7th-8th centuries. This textile was likely given as a gift to the temple in the 8th century from Tang China. The textile integrates several popular Persian motifs, such as the image of the king hunting, a motif which was especially popular and widespread in Sasanian art and it was generally adopted across Western and Central Asia as an image of an aristocratic lifestyle. Evoking Persian and Sogdian silks, quadriform vegetal ornaments fill the space between pearl roundels, which form the visual focus. A plant or tree with seven flower motifs sprouting from the top divide the roundels in half. Four horsemen turn on their winged horses drawing arrows 


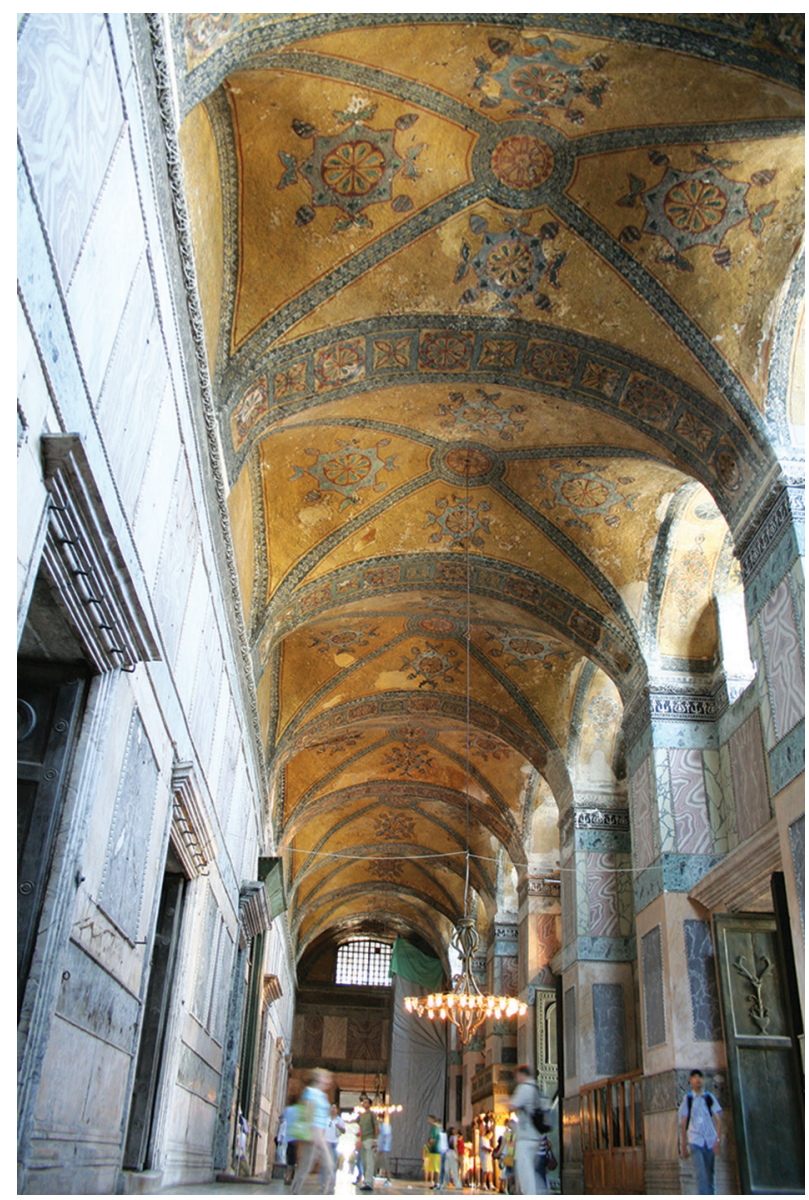

Fig. 1.13: Ornament of the inner narthex mosaics. Hagia Sophia, Istanbul, c. 536. The original mosaics from Justinian I's era, the largest mosaic surface from antiquity, consist entirely of ornamental motifs set against a gold ground. These motifs match no common Mediterranean ornamental motifs, but rather evoke the quadriform ornamental motifs in Persian silk textile patterns. The intended effect was to portray the interior of the Great Church as swathed in precious silk. It also allowed the emperor Justinian to subtly take over this very powerful and open-ended symbol of wealth and power from the Persians. The average Roman viewer would not have recognized these motifs as Persian, just as being luxurious and exotic; however, the aristocracy would have understood that the emperor claimed and took control of these powerful global symbols of wealth and power (Photo: Matthew Canepa).

at a leaping lion behind them in a perfect 'Parthian shot'. The Chinese characters shan (mountain) or li (fortune) decorate the horses' thighs. The horsemen wear stylized regalia derived from Sasanian ruler representation. The crown contains the wings of Wahram, a crescent moon supporting a solar disk very similar to the crown of Khosrow II at Taq-e Bostan. Also similar to Khosrow II, the figures wear chest harnesses and belts that signified high status in Sasanian Persia. Given that it was made for Tang consumption but closely relates to Persian iconography, it is likely it was made with the oversight of the Sogdians. The textile received its name, the Four Celestial Guardians, in the Kamakura period from monks who associated the four hunters with the four Buddhist Lokapalas (Kind permission of (C) Horyu-Ji Temple, Nara, Japan; the photograph is provided by Nara National Museum). 


\section{Further Reading}

Matthew Canepa (2009) The Two Eyes of the Earth: Art and Ritual of Kingship between Rome and Sasanian Iran.

Matthew Canepa (2010) Theorizing Cross-Cultural Interaction Among the Ancient and Late Antique Mediterranean, Near East and Asia Ars Orientalis 38.

Matteo Compareti (2006) The Role of the Sogdian Colonies in the Diffusion of the Pearl Roundel Design, in Matteo Compareti, Paola Raffetta and Gianroberto Scarcia (eds), Erān ud Anērān. Studies Presented to B. I. Mařsak on the Occasion of His 70th Birthday, pp. 149-174.

Annette L. Juliano, Judith A. Lerner and Michael Alram (2001) Monks and merchants: Silk Road treasures from Northwest China Gansu and Ningxia 4th-7th century.

Étienne de La Vaissière (2005) Sogdian Traders: A History. 


\title{
2 Palla, Pallu, Chador: Draped clothing in ancient and modern cultures
}

\author{
MARY HARLOW
}

Mary Harlow held a Guest Professorship at the Centre for Textile Research, University of Copenhagen (2011-13) and is now Senior Lecturer in Ancient History at the University of Leicester. Her primary area of research is the Roman world, and she has published extensively on the subject of Roman dress. Her research also includes work on age and gender in antiquity. Her publications include: Pre-Islamic Dress in the Near East (with L. J. Llewellyn-Jones), in G. Vogelsang-Eastwood (ed.), Berg Enclyopedia of Fashion, vol. 5; Dress in historical narrative: the case of the Historia Augusta, in L. Cleland, M. Harlow and L. J. Llewellyn-Jones (eds), The Clothed Body in Ancient World, pp. 143-153 (2005); A Cultural History of Childhood and the Family vol. 1. Antiquity (ed. with Ray Laurence, 2010); Growing Up and Growing Old in Ancient Rome: A Life Course Approach (with Ray Laurence, 2002). Readers of this chapter may find her following publication of special interest: Dressed women on the streets of the ancient city: what to wear?, in E. Hemelrijk and G. Woolf

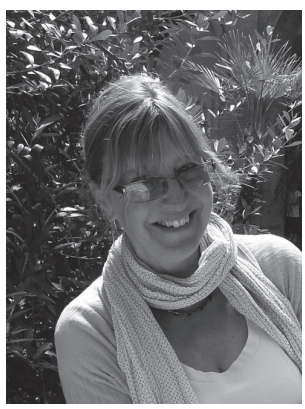
(eds), Gender and the Roman City, pp. 225-241 (2013).

The palla was a rectangular length of cloth which wrapped around the body of a Roman woman, reaching at times to her feet. It covered her upper body, often enclosing the arms, and, like the pallu could be pulled up to cover her head and face.

The pallu is the free upper end of the sari which falls across the breasts, over the shoulder and down the back. It can also be pulled up and used as a veil to cover the head, and even brought further forward to cover the face. As far as I can ascertain, despite the similarity in the names of the pallu and the palla, there is no shared etymological origin.

The chador is a semi-circular garment which covers the body from head to foot. Leaving the face exposed, it covers all clothing underneath from the chin to the ground. It is often dark coloured although in some cultures it can be highly decorated.

Veiling practices of women in the ancient and modern worlds have been the subject of much recent research and continue to fascinate audiences. Anthropological and ethnographical studies of modern veiling have influenced the ways scholars who study the ancient world have approached their material, as modern studies provide first-hand evidence of the myriad motivations and experiences behind female veiling. The voices of ancient Roman women are lost to us but the gestures and the body 
language of draped and veiled female bodies in Roman art survive and intrigue the modern audience who try to imagine how they experienced their clothing.

In order to get some understanding of how Roman women might have manipulated the palla I have taken two examples from modern cultures where a draped garment is also the norm, the pallu from the Indian sari and the chador from Iran. There are worlds of difference between (and within) these societies in respect of the status and roles of women, the histories behind these dress forms and reasons and justifications for covering and uncovering the female body. Here I just take a brief look at dress as worn on a daily basis to see if it might give historians some idea of what it meant for Roman women to move through the

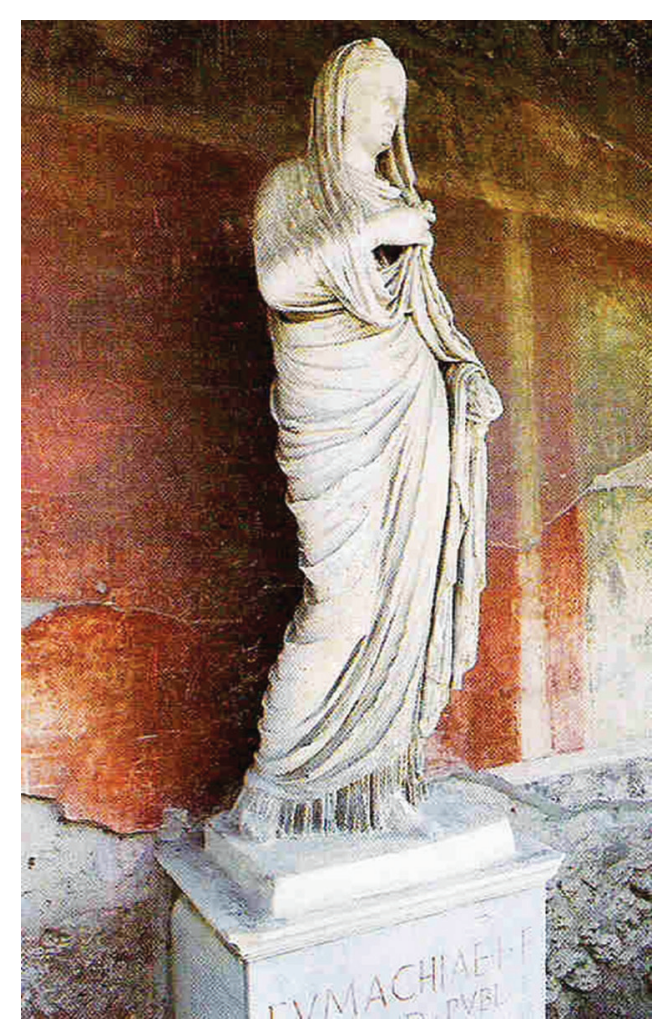

Fig. 2.1: Statue of Eumachia from Pompeii. Here Eumachia wears a large palla which covers her from head to foot with the excess material pulled up and held in a bunch by her left hand while the rest falls over her bent right arm. The pose is meant to idealise modesty. The ambiguity of the palla as a garment of modesty is played out here: the manner of holding it obscures the left breast but the carving appears to accentuate the right, while the fall of the drapery shows the shape of the legs beneath. It is hard to imagine how Eumachia might have walked through the streets in such a garment (Photo: (c) Mary Harlow). streets and maintain the decorum and body image required, but also to look at both more practical and erotic ways of using their clothing. My aim is not a cross cultural or diachronic study of modesty or morality, rather it is an attempt to use modern examples as a tool for thinking about the experiential nature of ancient dress.

The palla, the pallu and the chador have some common elements: they are unpinned, draped and loose garments, or in the case of the pallu, the free part of an intricately arranged sari. They also all serve as elements which can be used to shield the woman from the world. At the same time they share the idea that what lies beneath needs to be protected, but can be revealed in appropriate, or indeed inappropriate, settings.

The palla wraps around the body and the effect it creates can depend on its length and the material it is made from. A large heavy palla can hide the body, or it can be pulled tight across the bust and held close by the arms and thus outline and highlight the female form beneath. Statues of Roman women wearing the palla fall into fairly standardised formats, two examples of which are shown here (Figs 2.1 and 2.2).

In wall paintings another lighter, more transparent palla is portrayed. This is 


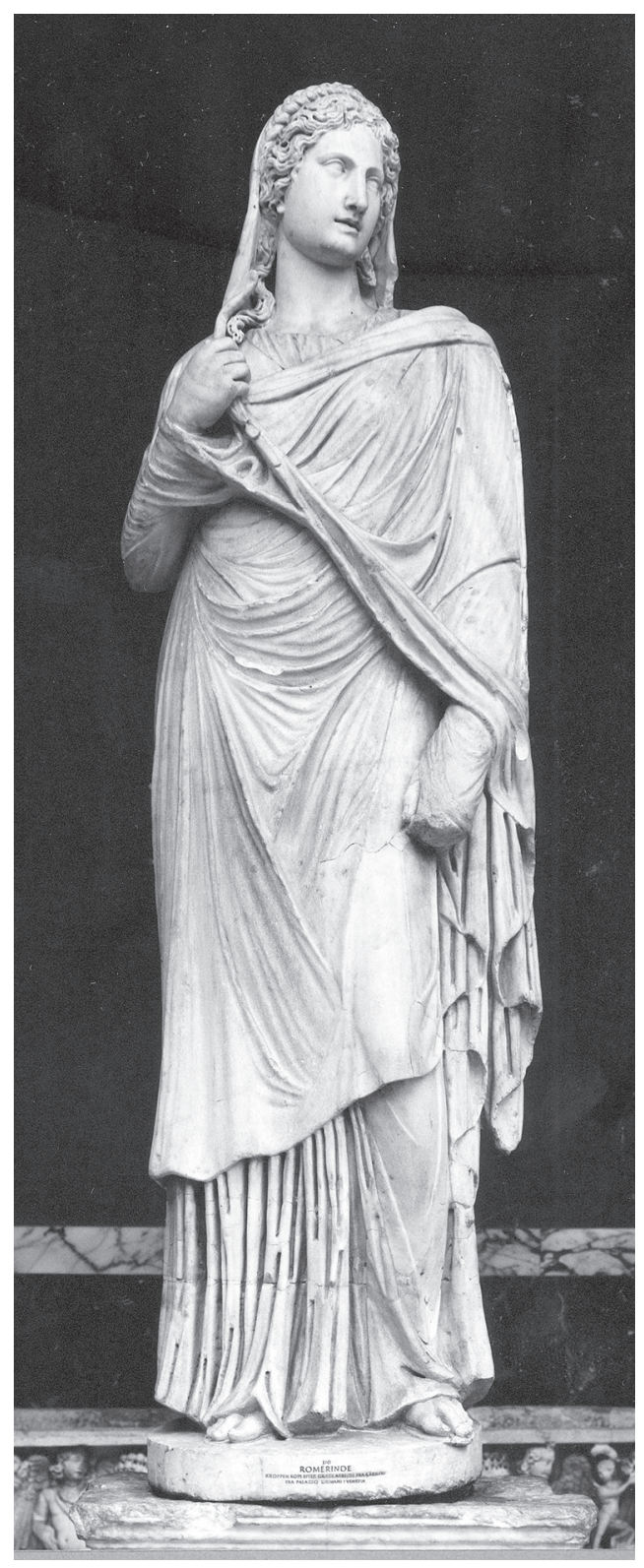

Fig. 2.2: Statue of a woman in the style of the socalled Large Herculaneum woman. The palla swathes the body and is pulled up to cover the head. It is held in place by the left arm crossing the chest and pulling the excess cloth together across the right shoulder and round the body while the right arm is held close to the side. While the body is well covered the carving of the drapery accentuates its shape beneath. Inv. no. IN 1484 f (Ny Carlsberg Glyptotek, Copenhagen; photo: Ole Haupt). often being worn coyly by a figure usually identified as a courtesan or slave (Fig. 2.3).

The palla was the garment that respectable Roman women wore when outside the home; it wrapped around and covered up their bodies, hiding their shape, and also their finery from view. It required both hands to keep it in place, and when pulled up to cover the head and partially hide the face could produce an effect which rendered the wearer virtually unidentifiable. In this way women might conform to society's ideas of appropriate female behaviour: they would not draw attention to themselves,

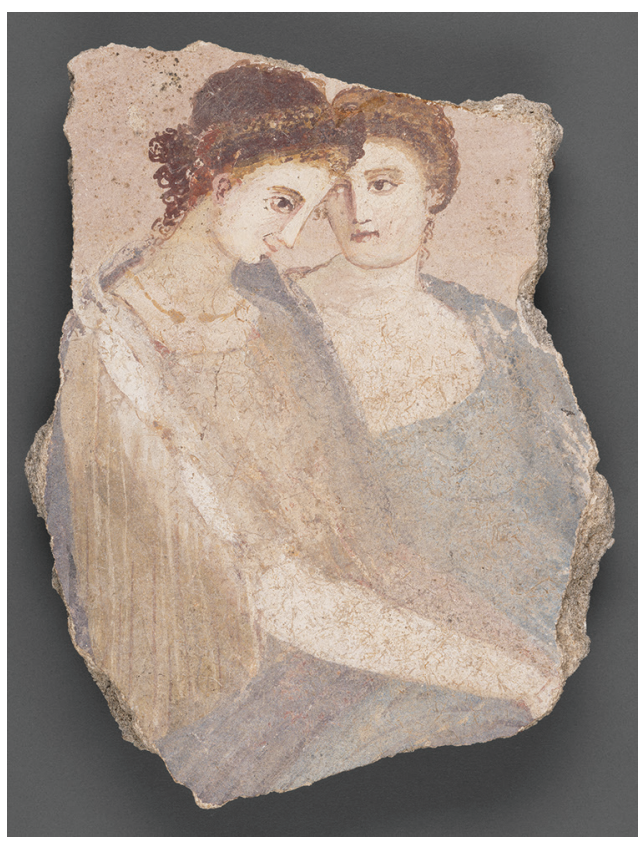

Fig. 2.3: Wall painting showing woman in darker mantle over transparent tunic. Transparent clothing was known in the Roman world; it could be made of wool, linen or of much more expensive silk. Unknown artist. Wall Fragment with Two Women, 1-75 CE, Fresco. Size: H: $28.6 \times$ W: $21.4 \times$ D: $3.8 \mathrm{~cm}$. (Photo: (C) The J. Paul Getty Museum, Villa Collection, Malibu, California, Gift of Barbara and Lawrence Fleischman). 
their body language would be contained and constrained by the palla; and they would concentrate on keeping their garments together rather than on making eye contact with anyone in public. Undoubtedly, this is an ideal that suited upper class life styles, where manual labour, housework and child care was done by slaves.

Upper class men, of course, had opinions on how women should dress. Valerius Maximus (1st century CE) retold a story of an earlier consul who divorced his wife because she went outside with her head uncovered (Sayings 6.3.10); Seneca argued that women should go out with eyes downcast (Controversiae 2.7.6); and from the 4th century CE, Jerome wrote about the ideal woman who, "when she goes out in public does not expose her décolleté nor reveals her neck with her palla thrown back. But one who veils her face and goes about barely exposing one eye, when she needs it to find the way" (Letter 130.8). These writings do not give Roman women a voice: we cannot tell if women internalised society's ideas about how they should dress, or if they ignored them. Occasionally in sculpture and wall paintings we get a glimpse of how women might have manipulated the palla but we have little idea of how women experienced their clothing or how it worked in action on a practical day-to-day basis. It is traditionally thought that women who had to work for a living might wear the palla for warmth and for modesty, and drape it in far more practical ways to suit their activities, but more likely they simply did not wear it. Taking this view however, assumes that such women never aspired to look other than their designated status, surely they might, if they could afford it, own a palla that could give them a different look on occasions? Such questions might be given possible answers by looking at comparative material.

On Iranian streets the chador is a common sight. Women wear it over their other outfits and it acts to make all women look similar. It covers the body from head to foot and needs to be held together as a woman engages in her daily business in the world outside the home. It can be made from a number of materials but is often synthetic, creating a medium weight garment, heavy enough to create the fall in the cloth required to serve its function but light enough to deal with the climate. It hangs loosely from the shoulders, giving the body little or no shape. Women accustomed to wearing the chador presumably do not find it cumbersome or unwieldy and learn the body language required to contain it from an early age. To a western eye, more used to cut and sewn tailored clothing that fits to the body and allows freedom of movement, it is impressive to see women carrying bags of shopping and small children and still keeping the chador closed and in control, even if occasionally they resort to using their teeth to hold it together. The chador, like the palla is worn over other clothing and is taken off once in the privacy of the home. One gets the feeling from reading Roman authors that some of them would have favoured the chador rather than the palla as it is worn in such a way as to create a rather shapeless image (Figs 2.4, 2.5 and 2.6).

The sari is a far more intricately draped garment that produces quite a different body image to the palla and the chador. The long end, however can work in much the same way, depending on how it is worn and manipulated. It was reading the section on the pallu in The Sari by Mukulika Banerjee and Daniel Miller (2003, 29-41) which 


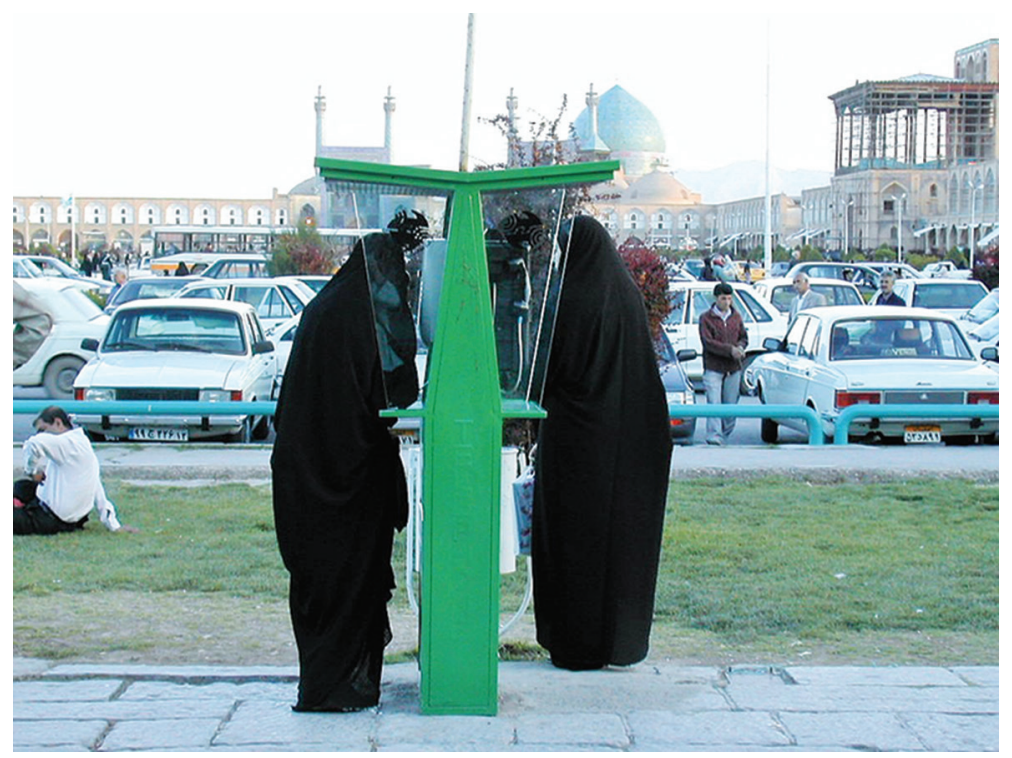

Fig. 2.4: Women in the chador using the public phones in Esfahan (Photo: ( ) Mary Harlow).

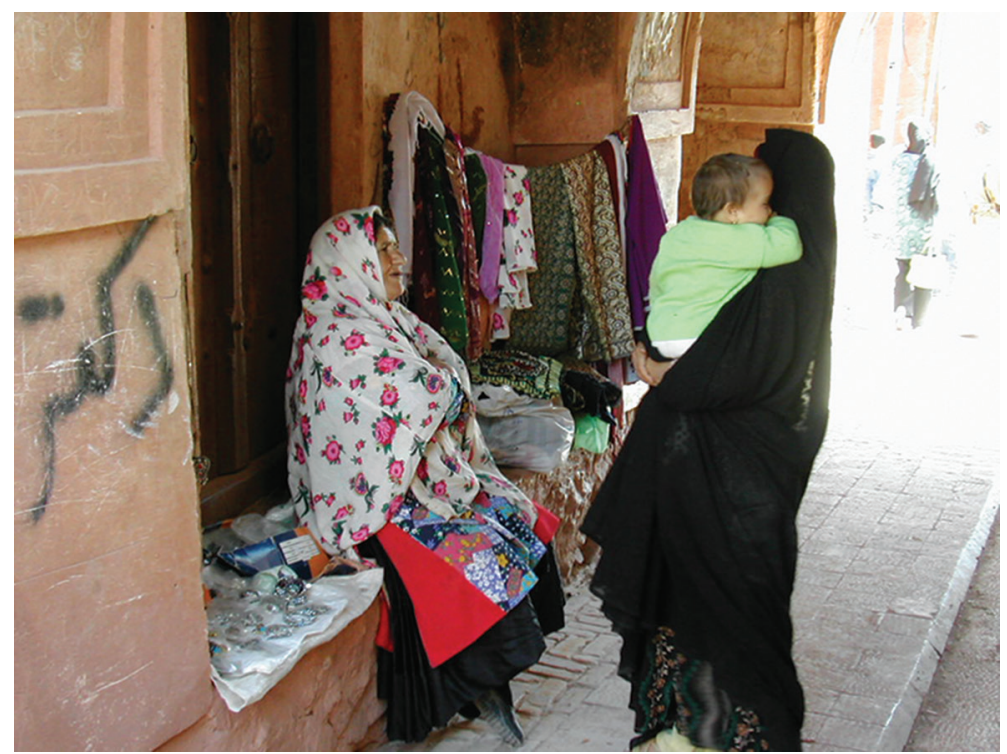

Fig. 2.5: Woman holding child and talking to another woman in a colourful chador (Photo: @ Mary Harlow).

provoked my thoughts on the possibilities for manipulating the palla by Roman women which complement the moralising writings of men or the few visual images which survive. Interviews with Indian men and women reveal the multiple ways the pallu is used. Like the palla it can be pulled up over the head and used as a veil, it can also, if required, be pulled down to cover the whole face. Veiling, of course, is 


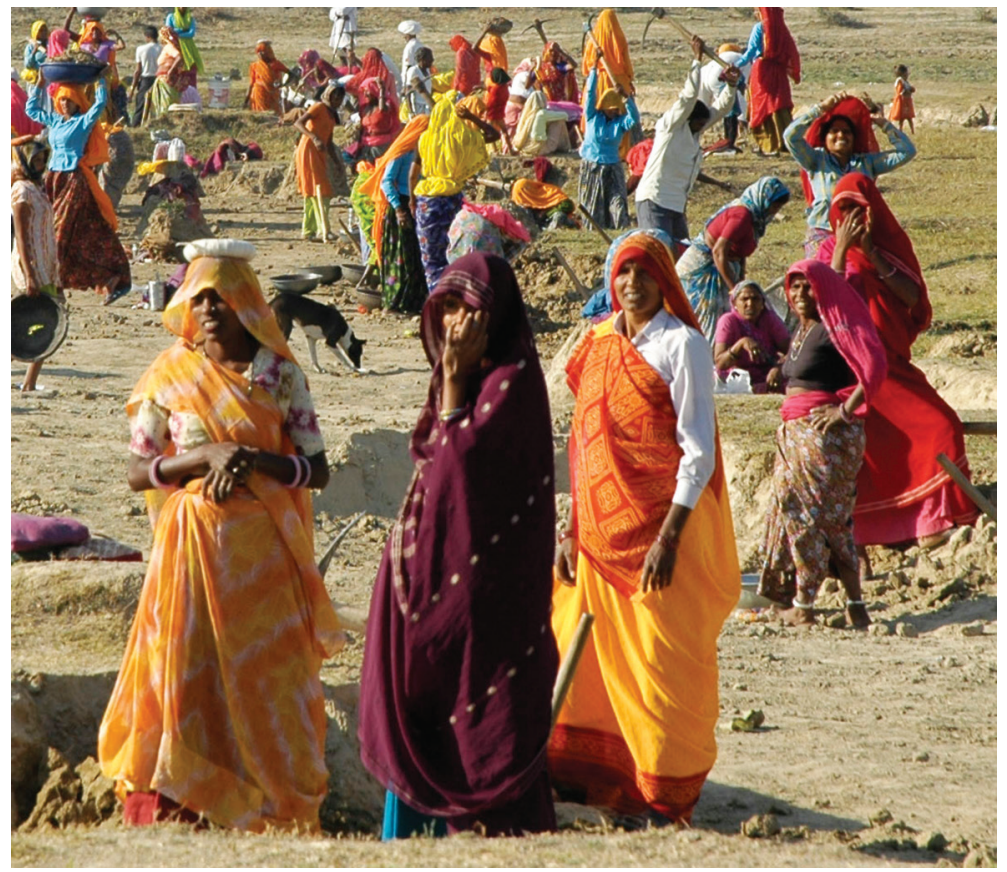

Fig. 2.6: Women with pallu pulled up over the head (Photo: Courtesy of @ Ellen Bangsbo).

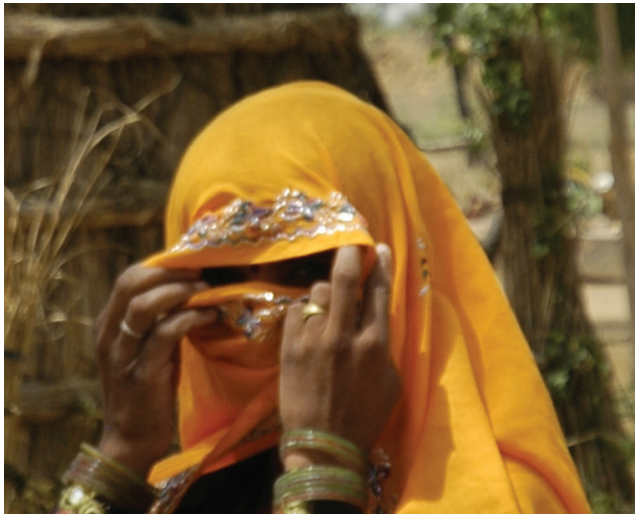

Fig. 2.7: A girl pulling the pallu up to cover all but her eyes, in a manner that the Christian Jerome would have approved of. Rathambore village 2010 (Photo: Courtesy of (C) Ellen Bangsbo). always ambiguous, it is simultaneously about hiding and revealing. It can show respect for traditional mores but it can also be teasing and seductive - this tension between modesty and eroticism is commonly exploited by Indian actresses on screen, and women in everyday life, especially if the sari is made of transparent material. The transparency which disappears in the gathering and layering of the sari across and round the body, is apparent when a single layer is pulled over the head and offers tantalising glimpses of the face beneath (Fig. 2.7).

The pallu is also the most highly decorated part of the sari. Its design and adornment is a selling point in shops and also for women who know that other women make judgements on them by looking at the pallu and assessing the textile, the decoration and workmanship. The Roman palla too could be manipulated as a veil, it could serve as a symbol of the modest subservience or teasing eroticism, as 


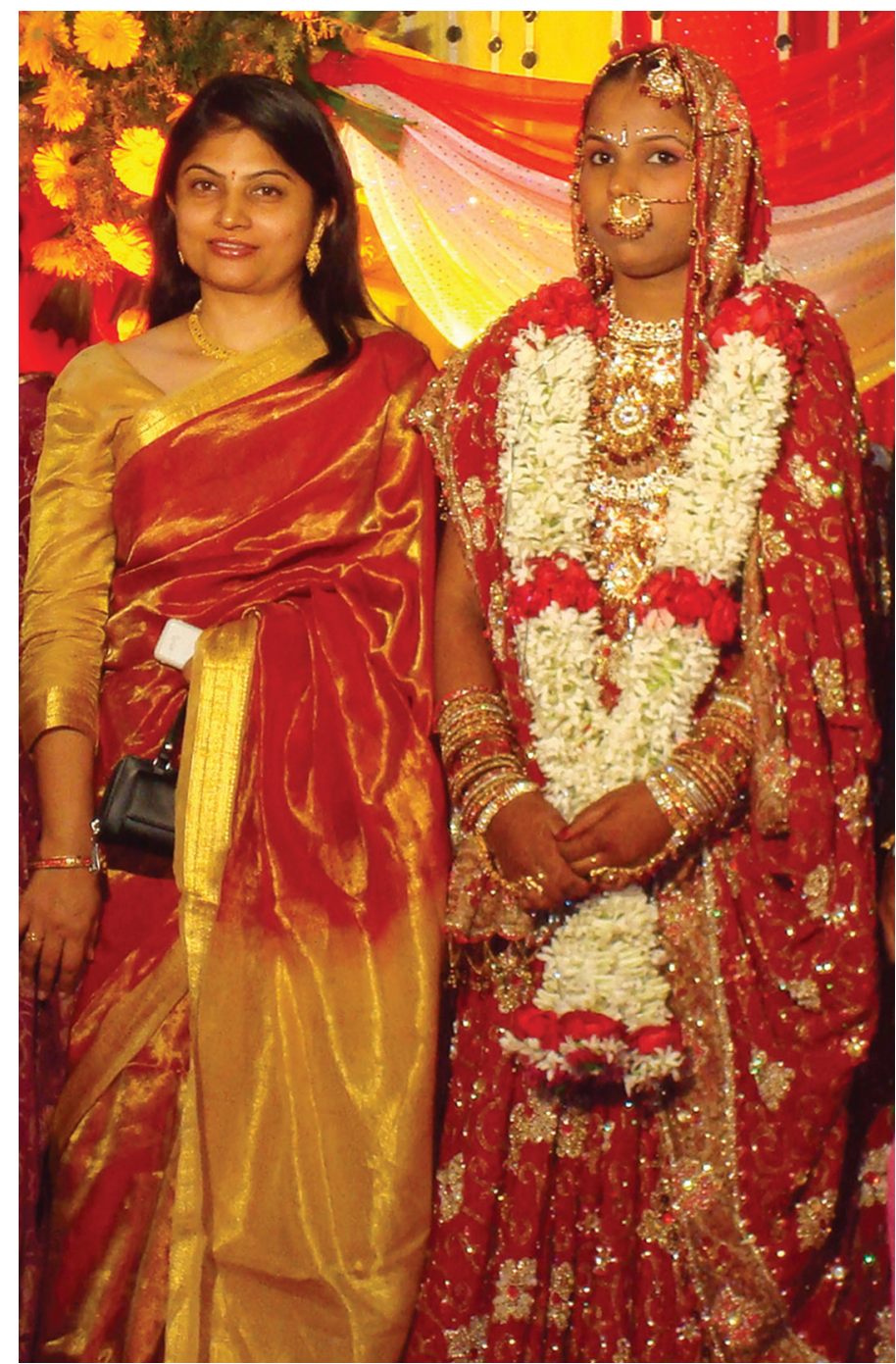

Fig. 2.8: Toolika Gupta and bride showing very rich pallus, the bride with hers pulled up and Toolika with hers draped over her arm (Photo: Courtesy of (c) Toolika Gupta).

the quotation from Jerome illustrates. Its intrinsic worth in terms of the material it was made from (usually wool or in rare cases, silk) would be understood by other men and women who would make value judgements about the status of the wearer, just as is done on Indian streets today (Fig. 2.8).

A further aspect to think about comes from the way working women and mothers use the pallu. All women who wear the sari find ways of making it work in their everyday lives. In activities where the free flowing nature of the pallu might be a hindrance or simply impractical, it is tucked into the waistband, or its extra fabric 
can be bunched and used to carry things. It can be used even more practically to wipe the face, to cover the mouth and nose against smells and pollution, to dust a surface or even to protect the hands when picking up hot dishes. The pallu, however, also invokes emotive memories: children remember the comfort of being wrapped in their mother's pallu, or holding the end for comfort, or for safety in a crowd. It occurs to me that these are also actions I see on a regular basis when I am out in the multi-cultural town in which I live, but have rarely taken note of. There is a pragmatic naturalness to these actions that could be transferred back in time. Our visual evidence for the working women of Rome is minimal and evidence of how they experienced their dress practically non-existent, but there is no reason not to think that textiles might have worked in a similar way, or that women of non-elite classes might not only have worn a palla but that it also served a multiplicity of functions in a similar way to the pallu (Fig. 2.9).

The experiential nature of clothing in the past is lost to us. The surviving evidence leaves us with images that are primarily public and idealising. However, women wore clothes. They chose colours, patterns and fabrics according to their (or their husband's) economic resources to create a look - even if it was within a fairly limited wardrobe range of essentially a tunic covered by some form of mantle - which presumably conformed, more or less, to the social and sartorial rules of their time. The role of the historian is to relate the images of the past to a practical social reality; this is particularly important in the history or dress. Using the ideas provoked by modern female clothing forms, we can at least start that dialogue with the past.

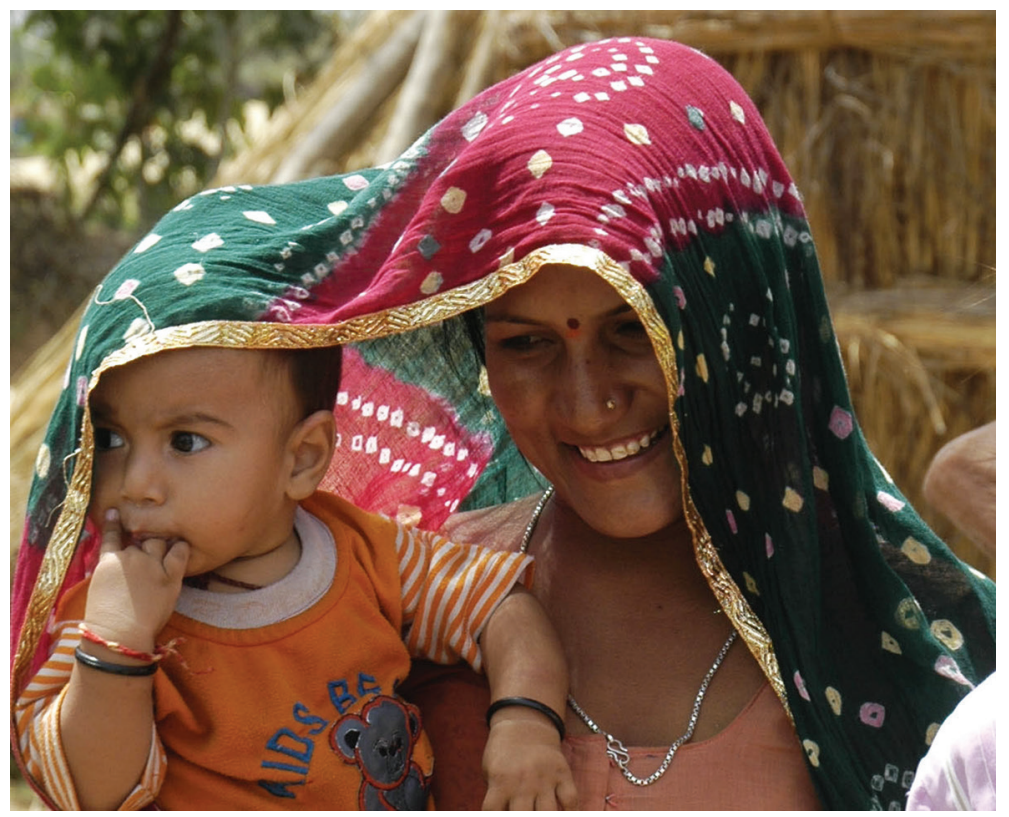

Fig. 2.9: Pallu as protection and comfort for child (Photo: Courtesy of @ Ellen Bangsbo). 


\section{Acknowledgements}

Thanks to Toolika Gupta and Ellen Bangsbo for the use of images, and to Cherine Munkholt for her patience and editorial direction

\section{Further Reading}

Mukulika Banerjee and Daniel Miller (2003) The Sari.

Mary Harlow (2004) Female dress, 3rd-6th centuries AD: the messages in the media, Antiquité Tardive 12, pp. 203-215.

Mary Harlow (2012) Dressing to please themselves: clothing choices for Roman women, in Mary Harlow (ed.), Dress and Identity, pp. 39-48.

Linda Lynton (1995) The Sari: Styles, Patterns, History, Techniques.

Kelly Olson (2008) Dress and the Roman Woman. Self-Presentation and Society. 



\title{
3 From Draupadi to Dido: The duties of dress in paintings inspired by the Mahäbhärata and the Aeneid
}

\author{
LINDA MATHESON
}

Linda Matheson lectures in both the Textiles and Comparative Literature departments at the University of California, Davis, where she recently completed an Individual $\mathrm{PhD}$ in Humanities with Critical Studies in Material Culture. Her dissertation, Divinely Attired examines the contribution of dress to the narrative process of the ancient epics and sacred texts. After having enjoyed a career as a costume designer that spanned more than two decades and more than two continents, including Hollywood and the London stage, Linda returned to school to engage in academic research. This included the study of 17th-century silk in China for her master's thesis. A publication based on this research is Imperial Material: Modern Western Fashion Theory and a Seventeenth-Century Eastern Empire, Dress, the Journal of the Costume Society of America 37:1 (Oct, 2011), pp. 57-82. Another article that links the ancient to the postmodern world is: The 'Age of Enchantment', the 'Age of Anxiety': Fashion Symbols and Brand Persona, in J. H. Hancock II, G. Muratovski, V. Manlow and Anne Peirson-Smith (eds), Global Fashion Branding: History, Luxury and Style (Chicago, 2014).

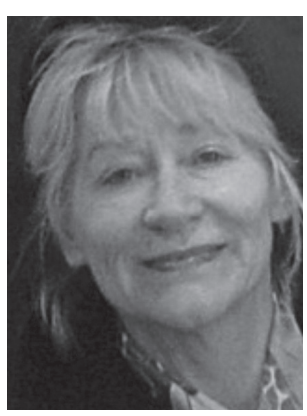

Examining how dress functions as an artistic device to narrate artwork based on literature adds an interesting dimension to the study of both disciplines. Here, we explore how dress 'focalizes' the story presented in three paintings inspired by the Mahäbhärata and Virgil's Aeneid (Bal 2006, 18). The artists of these works enlist dress as a mechanism that focuses and directs the gaze to vital information about the characters and the story being portrayed. For example, an attempt to publically undress Queen Draupadi constitutes the lynchpin scene in the Mahābhārata, and The Disrobing of Draupadi, a painting attributed to the Indian artist Nainsukh (1710-1778), presents this scene and narrates the story through this dress-related act. The act rivets our attention, and supplies a focal point where pertinent story elements converge. Also in Virgil's Aeneid, an epic that chronicles the founding of Rome and features another famous queen named Dido, dress plays an equally pivotal role as seen in Dido and Aeneas, a painting by Nicolas Verkolye (early 1700s), which depicts the scene in the Temple of Juno where the Trojan hero Aeneas, designated founder of Rome, first meets Dido, Queen of Carthage. Finally The Death of Queen Dido a painting by Andrea Sacchi (1599-1661) shows Dido seated beside Trojan armour and about to kill herself 
with Aeneas' sword. It is not my intent to consider the historical correctness of dress in these paintings, or its more traditional roles of protection, decoration and representation, but rather to examine how its telling threads act as artistic devices that provide sites, both stationary and transitional, which focus and lead the mind's eye to information intrinsic to the story.

In the critical scene from the Mahābhärata, Book Two, The Great Hall, Dice Game (Wilmot 2006, 317-485), King Yudhisthira, a brilliant, virtuous, and judicious ruler of enormous stature, loses his entire kingdom, himself and his brothers, and finally in the frenzy of a losing gambler, recklessly wagers his wife, all in a rigged game of dice. The triumphant Kauravas, the King's conniving cousins who organized the game, assume their win and demand Draupadi's appearance, despite her state of undress - she is clad in only one piece of cloth - and in her 'time of month'. They drag her by her luxurious hair into the hall where they attempt to undress her. Draupadi implores Krishna to help. Her faith is rewarded and Dharma's protection revealed. As her sole cloth is torn from her body, it miraculously acquires infinite length and as pulled, unfailingly replaces itself. Unfurling in every colour, weave and weight, this textile, like Dharma's protection, never ends. Uproar breaks out, these swirls of cloth in the centre of the hall signal their reproach and virtuous men shout "shame, shame". The failed attempt to remove the single cloth from Draupadi's body is the scene on which the epic spins. The phenomenon surrounding this act and its ramifications entail banishment to the forest, brutal war, subterfuge and re-entry to the kingdom. This scene is so powerful, so resonant of human feelings and failings that no apparent attempt has been made to repeat it in the history of literature. The artistic challenge however was accepted by an 18th-century painter from Guler whose Pahari ancestors appear in the poem.

According to art historian B. N. Goswamy, Nainsukh combined the interest in mythology and rich colours of the Pahari school with the naturalism of Mughal painting, while elevating imagination over observation (Goswamy and Fischer 2012). The standards of decorum and styles of artistic representation would no doubt be very different from the heroic period in which the poem is set, and perhaps consequently, the artist gives Draupadi more clothing than the text specifically states. In the painting Draupadi wears a skirt and blouse, typical 18th-century dress, accompanied by the most important item - the scarf or dupatta. There is a folding or pleating of time here in that the ancient Hindu story is juxtaposed with 18th-century court life, but on the poignant issue of female purity, inviolability, and the role played by dress, the two unite.

Nainsukh's painting (Fig. 3.1), rendered in gold leaf and richly coloured pigment, depicts a suitably emotional situation. In the lower left part of the composition, Dushasana, the king's evil cousin, pulls a rectangular-shaped textile - the dupatta - from Draupadi. Clad in courageous crimson and pearls, Krishna protests from the balcony; shiny bands encircle the accusing arm that he extends toward Draupadi's violator who insists on the undressing. Pointing to this appalling act, Krishna bestows the prayed-for-protection in the form of vibrantly coloured unending textiles that we see strewn on the floor, for each one that is pulled off is apparently replaced by 


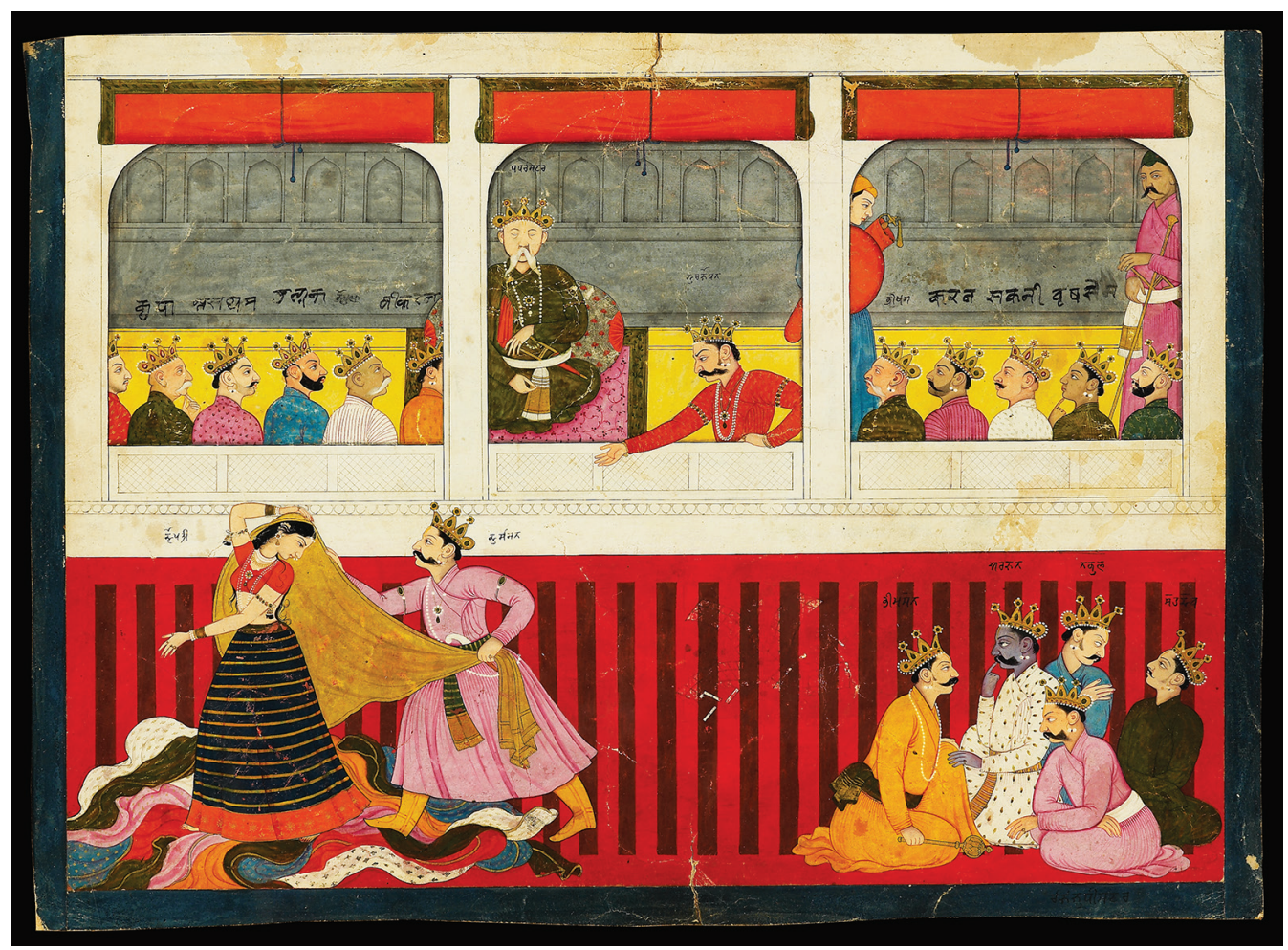

Fig. 3. 1: The Disrobing of Draupadi. Attributed to Nainsukh (1710-1778). Date c. 1765, Mughal Period (1526-1858) India, Punjab Hills, Basohli. Opaque watercolor and gold on paper. Dimensions: frame $36.4 \times 45.9 \times 1.8 \mathrm{~cm}$ (height $\times$ width $\times$ depth), painting $24.6 \times 34.2 \mathrm{~cm}$ (height $\times$ width). Lent by Howard Hodgkin, Accession no. LI118.9 (C) Ashmolean Museum, University of Oxford).

a new one. This phenomenon-of-dress commands the viewer's attention, and is the heart of the imaged narrative from which all other movements and emotions are generated. As the largest most dynamic component of the composition, it disperses the storyline, as well as information regarding cultural norms and practices.

The use of rich pigment to execute the miraculous textiles as well as the clothes, crowns and jewels of the men in the Assembly Hall indicates the wealth and opulence enjoyed by these reigning royals. The costly robes and adornments of these powerful leaders showcase their aspirations and expectations and announce their comfort in exerting control. The predominance of scarlet and gold, akin to the primary hues of red and yellow strengthens this attitude of assertive superiority and affluence and presents a 'heated'- environment. Yet an aura of diminished dominance exists. The placement of the strongest horizontal line in the bottom half of the composition is not hopeful, as the ancient Greeks were first to discover, but rather implies hope's opposite, accentuating the inability of these dignitaries to take appropriate action.

In the scene these kings, nobles and rulers do not exhibit right conduct as decreed by custom. According to Hindu law, men, particularly husbands, protect women from 
any outside male gaze. Five of the men present are married to Draupadi, who in keeping with the custom of polyandry, weds all five Pandava brothers. In the lower right corner of the painting we see five men on their knees in serious conversation, perhaps the Pandava husbands. Unlike the aggressiveness of the background produced by the effect of vertical black lines combined with the red, these men are passively rendered in cloth of retiring blue, absorbent black, apricot, a pale pattern and rose, the faded cousin of red. Their placement, colouring and gestures imply supplication more than pertinent action and act as a rhetoric of persuasion to infer their guilt. The wise sage Vidura, who advises against the game at every juncture, sits on a mat at the back of the balcony just off centre and partially behind a column. Again his placement and demeanour (closed eyes) indicates that his advice went unheeded. The image narrative functions to deny all these men their power and marginalizes them.

This reprehensible act that involves Draupadi's garment projects the plot of the entire epic of the Mahābhārata to its bitter end. That it remains popular today is noteworthy; that it hinges on a meagre piece of cloth - an item of dress - as its pivotal axis is remarkable. Draupadi's dress functions as the dominant element in the original Indian epic and in its 18th-century pictorial version. There are no other women in the painting, and all eyes are drawn to this very female dress-related act whose prominent placement in the composition proclaims its importance. Questions and assumptions about women's status and life in the court interrupt the imagined discourse of male dominance. In this 18th-century painting of the beloved Hindu epic, Draupadi's dupatta narrates the action while it serves to convey ideologically acceptable practices of the cultures and eras it represents.

Another textile-related act was instrumental in the founding of Carthage, the setting of our next work of art. Dido outwits the African king Iarbas, who agrees to let her purchase as much land as she can cover with a bull's hide. When she cuts the hide into thin strips that she uses to outline the perimeter of a large area of land, Iarbas recognizes the trick, but still agrees to his promise and Carthage, Dido's crowning glory, is built. It is here in the Temple of Juno that we attend her first meeting with Aeneas and witness further employment for dress in Virgil's Aeneid (Fitzgerald 1990, 24-26) (Fig. 3.2).

Verkolye depicts the story of the star-crossed lovers by situating them in a classically inspired architectural setting, a testament to Dido's cultural achievements and the sophistication of her court. Central in the composition and to the issue of authority is the dais on which Dido sits, because it raises her above all other mortals. It rests on three well-proportioned steps; their pleasing curves denote the female and their elevation supports her position of power, which we quickly realize is relative. If we divide the painting into horizontal thirds, Dido is above Aeneas, but the goddess Venus is above Dido and immediately above her son, the designated father of Rome. The hierarchy of power is clear, Venus has the last word. If you divide the painting into vertical halves, Dido and her court that includes at least five bare-breasted women are on one side, and Aeneas with his armoured Trojans and his mother make up the other. The contrast between 'nakedness' and 'armour', is stark. Dido heads a leisurely, 


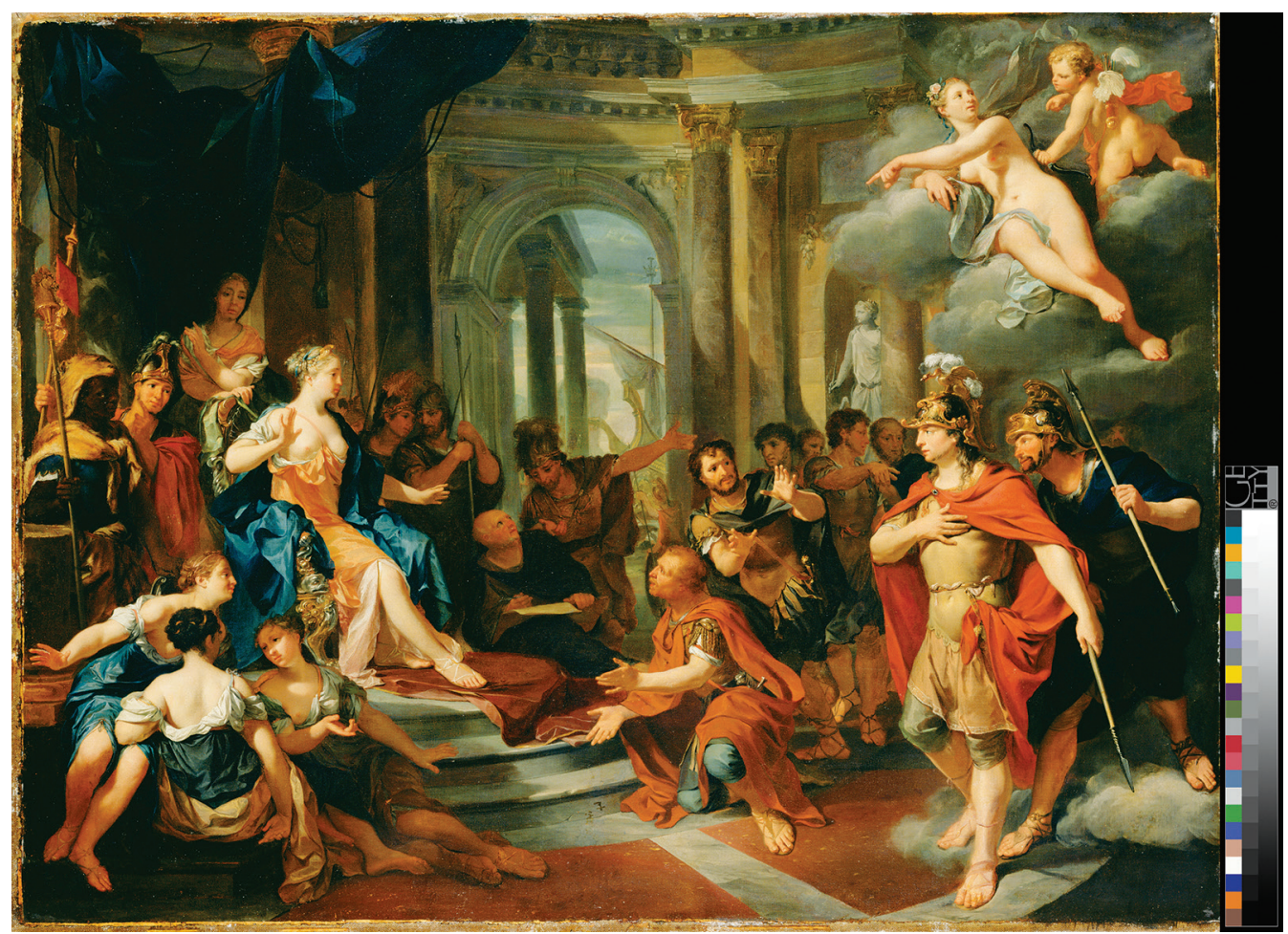

Fig. 3.2: Dido and Aeneas by Nicolas Verkolye, early 18th century, oil on canvas, $87 \times 114.9 \mathrm{~cm}$. Accession no. 71.PA.66 (Photo: The J. Paul Getty Museum, Los Angeles).

elegant, and peaceful but verging-on-decadent Carthage, and Aeneas leads a war-torn group of ragged refugees who have on their side the goddess of love and her capricious son. The curving lines of the steps are repeated in the arches and even in the overall perspective of the painting. They also trace the rosy flesh that translucent gowns cannot contain, and the rendering of Venus and Cupid reinforces this sensuousness. That this court is the creation of a woman, there can be little doubt. All these curves feminize the narrative and therefore 'focalize' the vulnerability of the protagonist.

In this intensely dramatic scene, the Trojan Prince appears at Dido's Court looking "noble as a god" (Fitzgerald 1990,24). Aeneas steps out of a cloud or mist fashioned by Venus to shield him until he is ready to reveal himself; indeed wisps of this protective disguise are still visible at his feet. Securing the link between Aeneas and his mother, Verkolye uses this cloud or mist motif to situate Venus and Cupid in the upper right corner, a placement indicating their superior power from which they look down on frail humanity with whom they play. When Aeneas appears, Queen Dido and some of her attendants react in surprise, while other members of her Court point knowingly to the meddling gods above. It is these same gods that use Ascanius, Aeneas' young son, to infect Dido with love's piercing arrow and make her fall hopelessly in love with this handsome Trojan. Aeneas speaks eloquently to the Sidonian Queen, who 
judging by her posture is intrigued by the looks and deportment, as well as the words, of this traveller from Troy.

The colour scheme for the painting is a complementary one of red and blue with a wide array of tints, tones and shades that meld together the various factions within the composition. Verkolye favours blue for Dido and her court members, while Aeneas and his eldest spokesman, Ilioneus (who kneels before the Queen pleading the case of the Trojans) is pictured in red, blue's opposite on the colour wheel. All of the richness of colour is carried by the clothing, thus the fabric of dress alone provides a lens through which to examine the Court, the spectral contrasts being drawn horizontally, vertically, and schematically.

Framing the Queen and gracing her throne is a luxurious mantle whose folds are beautifully rendered with high distinction between shadow and light. Its drape creates a kind of loosely-enveloping cocoon from which the butterfly-like Dido is emerging, as we see by the slight forward thrust of her scantily-clad torso and the curve (again) of her extended bare leg. Her unarmoured body seems to suggest peace, lack of fear. With its rich fabrication (perhaps silk, judging from its sheen and drape), her mantle serves as a billboard from which to glean information. It suggests the splendour of her Court, and is indicative of pomp and ceremony. The air of nonchalance in its arrangement on the throne suggests the ease with which its owner governs. This is supported by its colour, a restful, deep ocean blue. That Dido's posture indicates her taking leave of this comfortable position is not a trivial point.

Extending the royal welcome, Dido invites Aeneas and his men to a feast at her palace, and to appease custom Aeneas brings her gifts. One such treasure is a cherished sceptre that ultimately facilitates Dido's suicide, the subject of the final painting analyzed in this chapter. Faced with a faithless husband (Dido believed she was wed to Aeneas), and having lost all other suitors as well as command of Carthage, the only alternative for this agonized Phoenician queen is death (Fig. 3.3).

Like Virgil, Sacchi organizes items of dress (my definition of which includes arms and armour) to relate the narrative. The sharp steel of Aeneas' sword, the chosen implement of destruction, crosses the blood-coloured folds of Dido's cloak creating a dark diagonal that points to her heart. This heart, the centre of the composition, is now broken and impels this tragic act. No gracious Court records Dido's last words, but a marital bed and some Trojan clothes bear witness to her end. With her last tearful breath Dido addresses these Dardan vestments, the most prominent of which is Aeneas' armour, as she plunges his royal sceptre into her heart.

As in the Verkolye painting, yet with greater velocity, Dido's cloak arrests our view. Occupying much of the foreground and constituting a large mass of the composition, it exhibits a lustre and drape so magnificent that it acts as a magnet to rivet our gaze and draw us to its folds. The deep red colour evokes royalty, courage and passion, and simultaneously foreshadows the blood that will soon darken its glorious sheen. The colour scheme of this painting is another complementary one that repeats the use of reds and blues, yet unlike Verkolye's brushwork where rosy flesh invites love's caresses, this painting eliminates all colour and joy from Dido's skin to feature her 


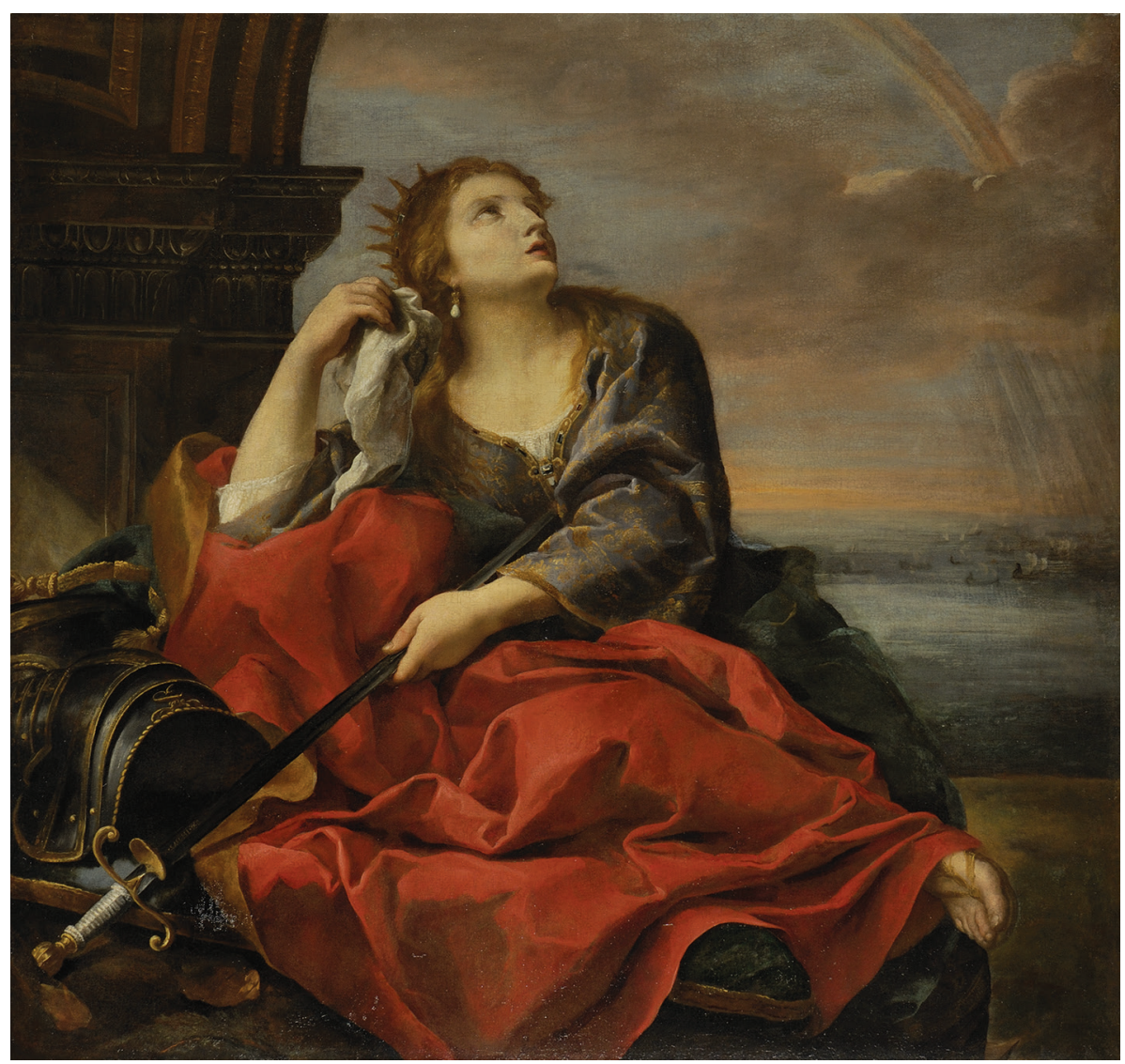

Fig. 3.3: The Death of Queen Dido by Andrea Sacchi (1599-1661) early 17th century. Also known as Didon abandonnée or Didon sur le bûcher, Inv. 179 (Musée des Beaux-Arts de Caen; photo: Martine Seyve).

death as hovering in shadow and darkness. If we divide the painting with a diagonal line, we see that one side is grey-blue, but with glints of red in the blue. Also unlike the Verkolye, those once-powerful feminine curves, both fleshly and architectural, are now barely visible. The column behind Dido's head ends before its arch begins, leaving the only evident curves to the shoulder piece of Aeneas' armour, and a pale section of rainbow in the foreboding sky. These shallow curves suggest little authority, reminiscent of Dido's weakened state of governance and life. Her command has been transferred to Rome's founder, with perhaps a shadowy nod to the afterlife evidenced by the pale rainbow in the darkening sky. No gods lounge in anticipation on swirling mists; instead uninhabited storm clouds nudge the arm that controls the sword. Even the crown on Dido's head resembles thorns that symbolically conjure the crucifixion, and underscore the tragedy in this imminent death.

Dress serves a narrative function in these paintings generated by these two ancient epics. The plot of the Mahābhārata orbits around the unwinding of a garment that 
represents the unwinding of Draupadi's life and the kingdom, while dress items also mark the episodes of Dido's life and death in the Aeneid. In the representative paintings, these dress items act as storehouses and information highways that convey and release the narrative as they negotiate, filter and disperse cultural conventions. We saw this when Draupadi's dupatta shames the men in the assembly hall, and suggests their bad behaviour; we saw it with the contrast of Carthage's female nakedness or 'undress' and Troy's armoured soldiers in Dido's Court; and we saw it again with Aeneas' sword that infers his razor-edged guilt in Dido's death. In all three paintings, items of dress function as artistic devices that focalize the composition and relate the narrative including its cultural traditions.

\section{Acknowledgements}

My deepest gratitude goes to Brenda Deene Schildgen, Distinguished Professor at UC Davis, who read a first draft of this and made pivotal suggestions that enriched this project. Thanks too, to the editors of GTE, Marie-Louise Nosch, Zhao Feng and Lotika Varadarajan as well as to editorial assistant Cherine Munkholt who were wonderfully kind in pointing out sometimes embarrassing errors.

\section{Further Reading}

Mieke Bal (2006) A Mieke Bal Reader.

Brijinder Nath Goswamy and Eberhard Fischer (2012) Pahari Masters: Court Painters of Northern India. Mahābhārata. Book 2: The Great Hall (2006), trans. Paul Wilmot and ed. Richard Gombrich.

Virgil. Aeneid (1992) trans. Robert Fitzgerald. 


\title{
4 The Kaftan: An unusual textile encounter in the Scandinavian Late Iron Age
}

\author{
ULLA MANNERING
}

Ulla Mannering has a PhD in prehistoric archaeology from the University of Copenhagen in Denmark. She is a Senior Researcher and programme manager at the Danish National Research Foundation's Centre for Textile Research at the National Museum of Denmark. She is specialized in prehistoric skin and textile production and costume design in Northern Europe and has published widely, among others, Early Iron Age Craftsmanship from a Costume Perspective, Archäologie in Schleswig, Sonderband, Det 61. Internationale Sachsensymposion 2010, 85-94 (2011); Eva Andersson Strand, Karin Margarita Frei, Margarita Gleba, Ulla Mannering, MarieLouise Nosch and Irene Skals: Old Textiles - New Possibilities, European Journal of Archaeology V 13, 2, 149-173 (2010); Ulla Mannering, Göran Possnert, Jan Heinemeier and Margarita Gleba: Dating Danish textiles and skins from bog finds by

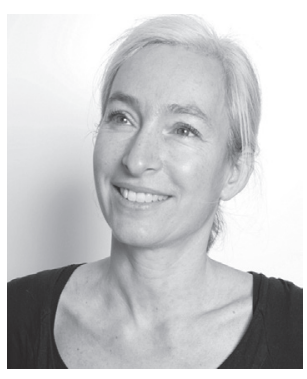
means of ${ }^{14} \mathrm{C}$ AMS, Journal of Archaeological Science 37, 261-268 (2010); Margarita Gleba and Ulla Mannering (eds), Textiles and Textile Production in Europe from Prehistory to AD 400, Ancient Textiles Series 11, (2012). She has also expertise within Roman textiles and costume. Her current research focuses on design and resource exploitation in the Scandinavian Bronze and Early Iron Age societies.

The kaftan, a long-sleeved male garment with a diagonal opening at the front with overlapping edges, is not indigenous to Scandinavia (Jirousek 2010; Knauer 2004). The Scandinavian prehistoric costume tradition builds on a long local development with technologies and costumes adapted to the northern cold (but fertile) environment. Nevertheless, iconographic representations of males clad in kaftans indicate that this special costume item was introduced to Scandinavia in the beginning of the 5 th century CE (Mannering 2008) (Fig. 4.1).

The kaftan appears in the Scandinavian iconography on the so-called gold foil figures which have been found on many archaeological sites, such as settlements and central places throughout Scandinavia. More than 3000 of these gold foil figures have been excavated. The approximately $1 \mathrm{~cm}^{2}$ large gold images belong to a local iconographic tradition depicting detailed human figures which developed quite late compared to other European areas (Fig. 4.2). Gold foil figures are thus an exclusively Scandinavian phenomenon produced by local craftsmen using local models.

Gold foil figures can either display one person or two people facing each other. Approximately a quarter of all identifiable figures are clearly clothed and in spite 


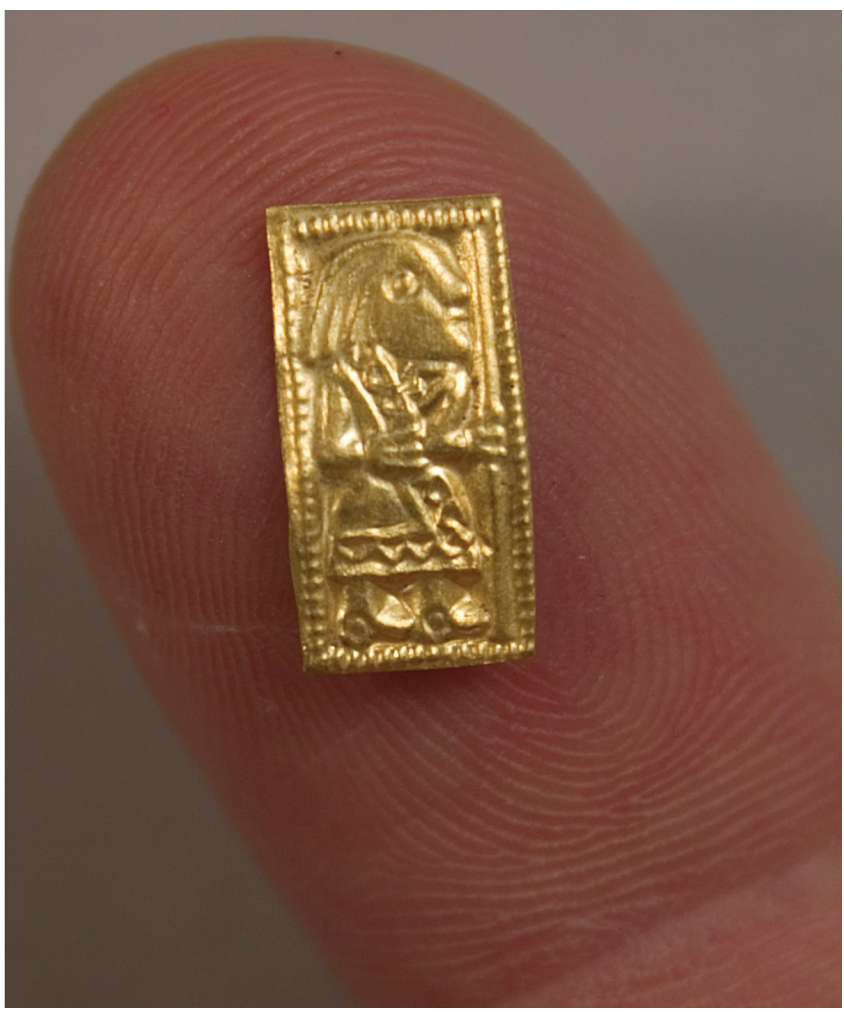

Fig. 4.1: A gold foil figure, placed on a human finger, depicting a male clad in a kaftan-like costume. (C) National Museum of Denmark).

Fig. 4.2 (below): Drawing of a gold foil figure from the Slöinge settlement in Sweden, depicting to the right a male clad in a tunic and trousers and a female to the left wearing a cape and a skirt. At her neck she is wearing a fibula and her hair is covered by a net or a small cap (C) Ulla Mannering, CTR).

of their small size, it is surprising how many details can be distinguished. It was undoubtedly of the greatest importance that the clothing could be recognized, and the gender and identity of the figures deciphered (Mannering 2008).

Most figures, males as well as females are depicted wearing costumes that are also known from the archaeological textile record. Females are clad in capes and dresses or skirts and blouses, and males are dressed in cloaks, tunics and trousers (Fig. 4.3). These are all costume items that are known to have existed and were used in Scandinavia during the Late Iron Age and subsequent Viking Age (400-1050 CE). Only a small group of figures are wearing the kaftan-like

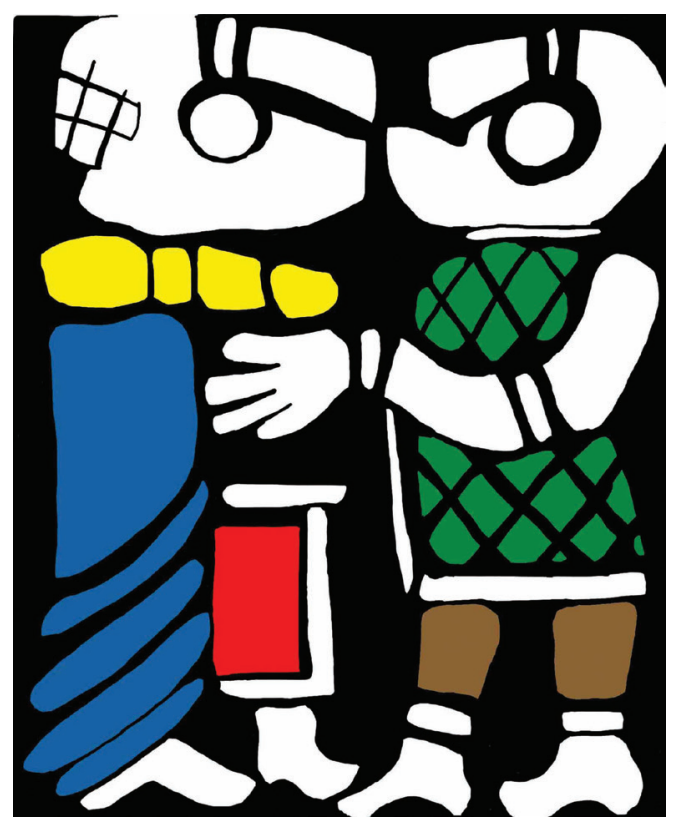




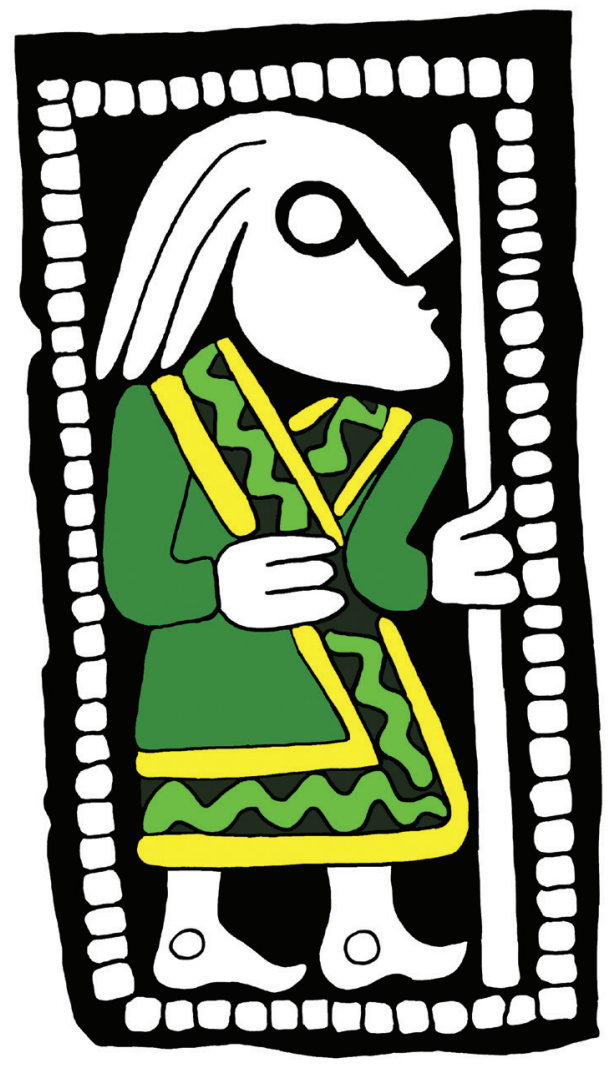

Fig. 4.3: Drawing of a gold foil figure from the Black Earth settlement on Bornholm, Denmark, with the kaftan-like costume highlighted (C) Sidsel Frisch and Ulla Mannering, CTR). costume, characterised by an oblique front edge, a straight lower edge and long sleeves. This indicates that the costume was open at the front and of a similar construction to real finds and depictions of kaftans, for instance those belonging to the horse-riding nomadic Scythian cultures of the Eurasian steppes (Gleba 2008; Jirousek 2010). Further, the garment edges are often decorated with wide borders patterned with dots or zigzag patterns (Fig. 4.3).

Unlike the other costumes depicted on the gold foil figures, the kaftan has until now not been identified among the contemporary archaeological textile finds. Is this because it did not exist in the Scandinavian costume tradition, or, because textile archaeologists have not been able to identify this costume object among the many but very fragmented textile finds? So far there is no simple and straightforward answer to this question.

In the last quarter of the 1st millennium $\mathrm{CE}$, covering the Viking Age (i.e. 800$1050 \mathrm{CE}$ ), Scandinavian textile production reached a highly developed technological stage with locally produced high quality and every day textiles combined with a limited import or trade of luxury textiles in silk and metal threads in gold and silver, and not least, a well-developed fur trade. In Europe, the Vikings were renowned for their contacts and trade networks linking distant areas like the ancient Near East, India and China, but due to the lack of written source from prehistoric times in Scandinavia, only indirect accounts of these cultural meetings between the Scandinavians and the many peoples to their east exist (see, for instance Montgomery 2000).

It is also in this period that the first parallel to the earlier iconographic kaftanlike male costume seen on the gold foil figures, the sleeved jacket, appears in the archaeological textile record. But at this late stage, it is already transformed into a more commonly used costume item worn by both men and woman. At the same time the male kaftan-like costume experiences a decreasing iconographic importance. Altogether this is a very strong indication that the iconographic kaftan-like costume was, in fact, a real costume item that was introduced some centuries earlier. As such, there can be no doubt, that the kaftan was a foreign but physical element which was 
incorporated in the Scandinavian costume tradition. So, who brought the kaftan to Scandinavia and why did it gain such an important position in male costume?

The kaftan-clad male figures are never depicted together with women, and unlike other human figures, they often carry weapons in their hands. Thus, the kaftan-clad males on the gold foil figures have been interpreted as representing warriors or a special male elite group linked to aristocracy. The history of Europe in the 5th to 11th centuries $\mathrm{CE}$ is the history of a continent in constant change. Although influenced by this development, Scandinavia, as an area in the outskirts of the European continent, went through a less turbulent development towards a society with smaller kingdoms and local elites controlling trade, production and possibly religion, but still without a fixed monetary system and state forming rulers. Nevertheless, the militarization of the society due to the increased contact with the post-Roman world required new skills and new ways of organizing society. Most likely the organization and equipment of the Scandinavian armies changed though these contacts which also included auxiliary riding troops from the East and Near East, and this is possibly how the kaftan was introduced to the Scandinavian military elite.

To me, the most fascinating aspect of the kaftan-like costume depicted on the gold foil figures is not that it appears in the Scandinavian costume tradition, but that it was, with its foreign design, so attractive to the Scandinavians, that it was incorporated in their own local costume tradition. Further, the kaftan-like costume is an excellent example of a costume item which at first was incorporated for its special symbolic value and later transformed into a more widespread local style male and female costume item like the sleeved jacket. The appearance of the kaftan-like costume in Scandinavian iconography is thus one of the clearest signs that textiles and costumes were important and used during different and repeated cultural encounters. Thus, the story of the kaftan in the Scandinavian Late Iron Age is a story of how different peoples around the world have influenced each other without even realizing it.

\section{Further Reading}

Margarita Gleba (2008) You are what you wear: Scythian Costume as Identity, in Margarita Gleba, Cherine Munkholt and Marie-Louise Nosch (eds), Dressing the Past, Ancient Textile Series 3, pp. 13-28.

Charlotte Jirousek (2010) The Kaftan and Its Origins, in J. B. Eicher (ed.), Encyclopedia of World Dress, Volume 5, Part 3, pp. 134-138.

Elfriede R. Knauer (2004) A Quest for the Origin of the Persian Riding-Coats: Sleeved Garments with Underarm Openings, in Cäcilia Fluck and Gillian Vogelsang-Eastwood (eds), Riding Costume in Egypt. Origin and Appearance, pp. 7-28.

Ulla Mannering (2008) Iconography and Costume from the Late Iron Age in Scandinavia, in Margarita Gleba, Cherine Munkholt and Marie-Louise Nosch (eds), Dressing the Past, Ancient Textile Series 3, pp. 59-67.

James E. Montgomery (2000) Ibn Fadlan and the Rusiyyah, Journal of Arabic and Islamic Studies, Volume 3, pp. 1-25. 


\title{
5 Ancient Running Animals: Tablet- woven borders from China and Norway
}

\author{
LISE RAEDER KNUDSEN
}

On finishing high school, Lise Ræder Knudsen first worked as a tablet weaver 8 hours a day producing copies of ancient tablet-woven borders in the textile reconstruction workshop at Moesgård Museum, Denmark. Hereafter, she obtained her master's degree in conservation at the Royal Danish Academy of Fine Art, The School of Conservation and is currently head of the Regional Conservation Centre in Vejle, Denmark. Her main fields of expertise are conservation and the technical analysis of archaeological textiles. She has conducted technical analyses of ancient tablet-woven bands and borders since 1981, is involved in publishing most of the earliest and most complicated finds of tablet weaving throughout Europe as well as working on new interpretations of tools used for tablet weaving. Many working hours of practical weaving combined with a scholarly approach have revealed that it is possible to delve deeper into the methods of production and obtain new

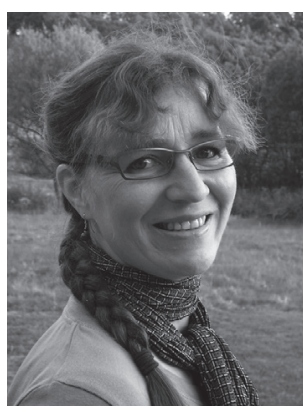
information on new finds as well as old finds. The author received her PhD from the Royal Danish Academy of Fine Art, The School of Conservation for her thesis entitled, Teknologihistorisk analyse af brikvævning fra ældre jernalder - (Technology historic analysis of tabletwoven textiles from the Early Iron Age). Readers of this chapter may find her website <www.tabletweaving.dk> of great interest, especially for research, techniques and reconstructions of tablet weavings.

\section{Tablet Weaving Around the World}

Tablet weaving is an ancient technique for making bands and borders. Very simple tools are required and patterns can be made, which no other weaving technique is able to produce (Fig. 5.1). What is unique is that the warp threads of a tablet weave often are twisted around each other in cords of four threads. This makes it, for instance, possible to produce straight diagonal lines and thus many different patterns, which are not possible to obtain using other looms.

The earliest known finds come from Italy and are dated to the 9th-8th centuries $\mathrm{BCE}$. These borders are mainly edgings of woven garments and they adorn the garments with edges of different colour and tidy the left over fringes from the weaving process in a solid and handsome way. From Iron Age Europe, there are a number of marvelous finds of borders with elaborate tablet-woven patterns in intricate techniques. In Hochdorf in Germany, a Celtic chieftain's grave contained several tablet-woven borders made in intricate techniques. The material was very fine 2-ply threads in blue, purple, 


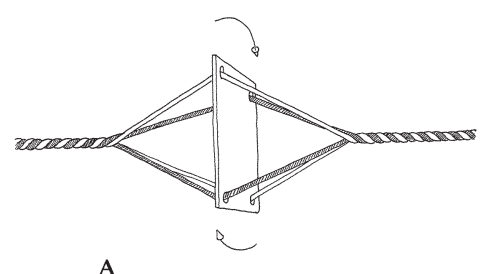

A

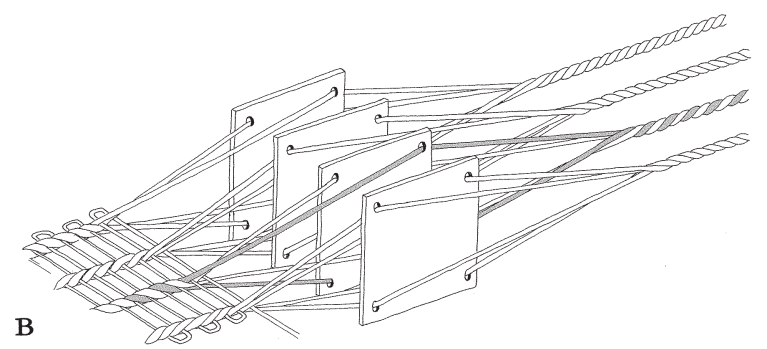

Fig. 5.1: How to weave using tablets: A: Four warp threads are put in each tablet. Twisting the tablet around makes some threads move to the top of the tablet and some to the bottom. B: When put together, several tablets form a band loom. They hang freely in the air and after a weft is passed, the tablets are twisted around a horizontal axis and the weft beaten in (C Lise Ræder Knudsen).

red and yellow colours. Most material was wool but surprisingly some yarn was made of the fine hair of a badger. In the salt mines in Dürrnberg and Hallstatt in Austria, thick layers of waste from the Iron Age were found and different worn out textiles were excavated. Among these were woolen pattern-woven tablet borders dated before the late 3th century BCE. In Scandinavia, the first tablet-woven borders are dated shortly before the beginning of the Common Era. Tablet weaving was at this time primarily a helping technique for holding the warp of the warp-weighted loom in place. Mostly very simple techniques were used in Scandinavia until around the 2th century CE where occasionally borders made in more complex weaving techniques and finer yarns are found. Around the 5th century CE, highly complicated tabletweaving techniques are used, as for instance in the finds from two chieftains' graves from Norway, Evebø-Eide and Snartemo with borders decorated with animal figures and geometrical patterns. At this time, also a very special tablet weaving technique is seen in the archaeological material in Scandinavia and England. A simple tabletwoven border was given a surface of coloured horsehair wrapped around the warp threads in patterns while weaving. Some scholars have seen this technique as a way to imitate a silk surface (Nockert 1991, 103). This points towards a quite new technique of tablet weaving - the brocaded borders, where a simple tablet-woven ground weave is adorned with a brocade thread of silver or gold often covering most of the surface with geometrical patterns. The first tablet-woven brocade bands in Northern Europe derive from the 5th century CE. Numerous sites in 6th to 7th-century England attest that, the brocade material comprised flat strips of gold, later throughout Europe the metal threads were often very thin, flat metal strips wounded around a silk core, but also samples with solid silver brocade are known. Well-preserved samples of both types are known from Viking Age Birka in Sweden and Mammen in Denmark. Later such tablet-woven brocade bands were used on liturgical vestments like mitres, maniples, chasubles and stoles throughout the Middle Ages. One of the most famous finds is the Anglo-Saxon vestments of St Cuthbert from Durham dated around 916 CE where the maniple and stole were embroidered and along the edges tablet-woven borders of red silk and gold had been sewn (Fig. 5.2). 
Museums with ethnographical collections often have samples of brocaded tablet weaving. Examples from Yemen, Israel, Spain and Sicily, among many others, are known. Even today, the same weaving methods and patterns are used in, for instance, Morocco and Tunisia.

To my knowledge, not many finds of tablet weaving from an archaeological context are known from outside Europe, but very many examples of tablet weaving are known from modern times throughout the world. To mention just a few: In Turkey rather coarse bands in simple techniques with patterns in different colours are used, for instance for bridles. The same weaving technique but used with finer yarns is part of the Norwegian traditional costume from Telemark (see chapter by Klepp et al., in this book, where in Fig. 26.3, the lady who is 2nd from right wears a traditional costume from Telemark with a wide tablet-woven belt, and also a smaller tablet-woven one twisted around in a spiral as a headband). It is also found as belts from china and Nepal (Fig. 5.3). In Iran, fine silk bands with double-faced weave bearing verses from the Koran are known. From Indonesia, bags made of many colourful double-woven bands sewn together are known and in Gondar, Ethiopia, huge silk wall hangings woven in a double tablet weaving technique are seen. Curtains from Gondar found partly at the British Museum's collections and partly in those of the Royal Ontario Museum seem to be the largest tablet-woven textile in the world (Figs 5.4 and 5.5).

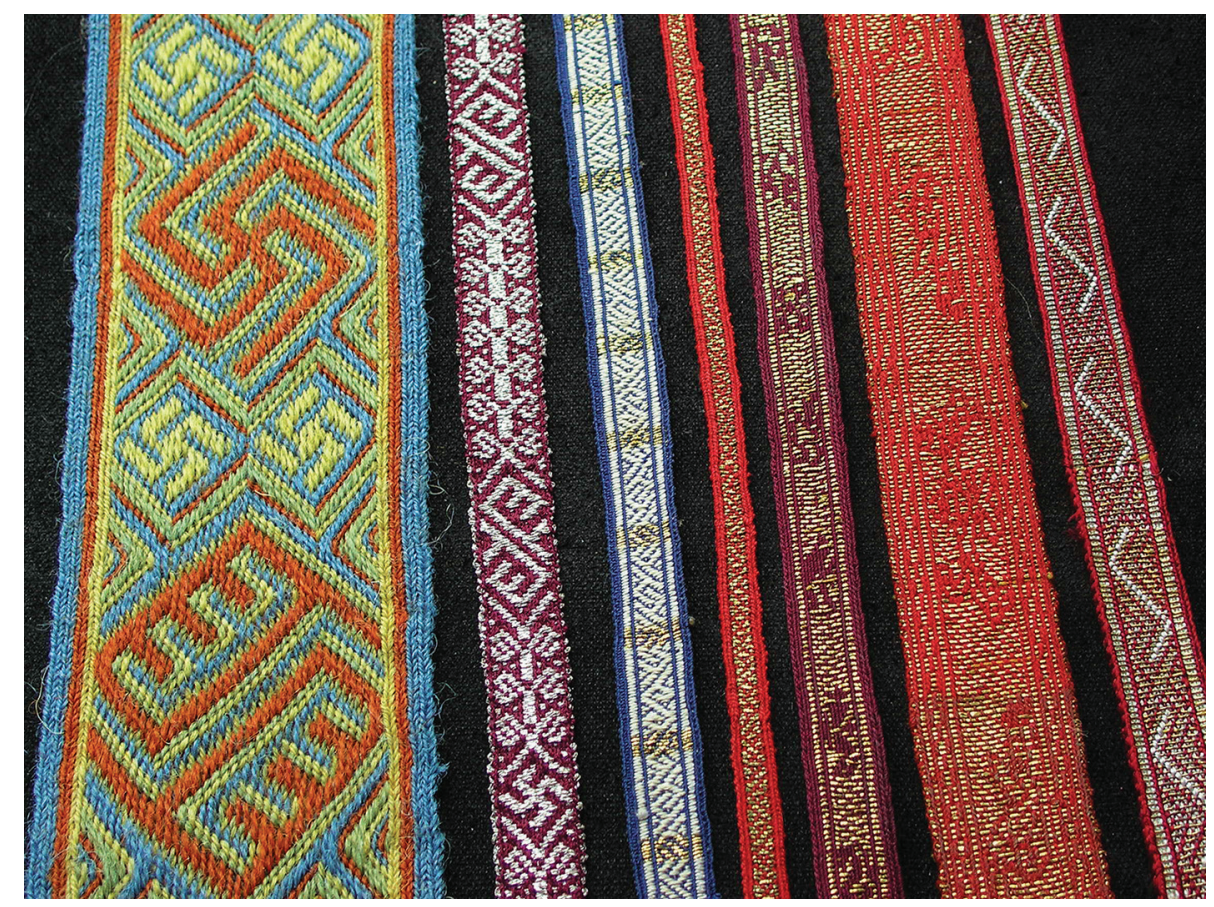

Fig. 5.2: Reconstructions of some tablet-woven borders dated between 450-1300 CE. From left: border from Snartemo, Norway; border from Birka in Sweden, border from Mammen in Denmark; three borders from Durham in England and a border from Schleswig, Germany (৫) Lise Ræder Knudsen). 


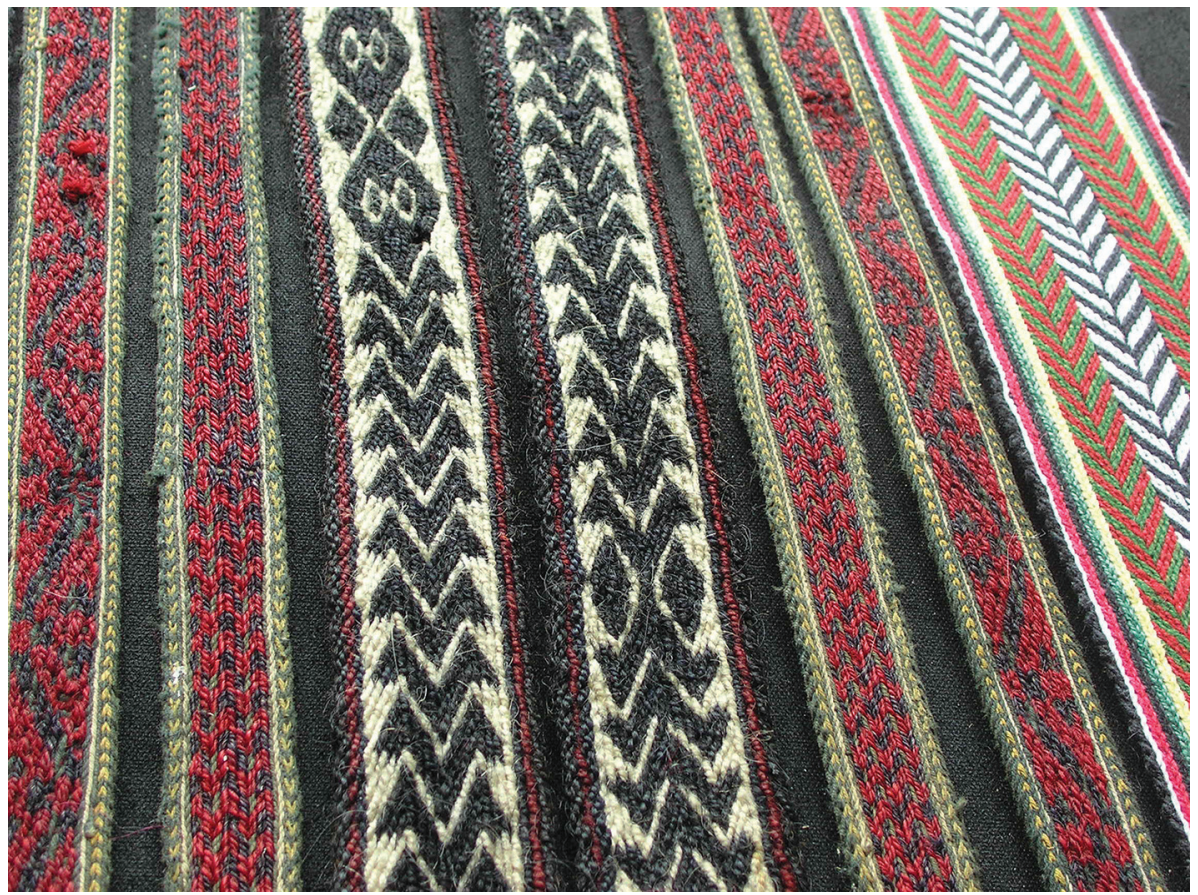

Fig. 5.3: Tablet-woven borders recently bought in Turkey and Nepal by glass-bead expert Torben Sode (ㄷ Lise Ræder Knudsen).

Moreoever, there are bands woven in variations of the same double weaving technique from Tibet, Burma, India, Bulgaria, Caucasus, Greece, Israel and Java. Tablet weaving is found everywhere from Japan to North Africa and Iceland. But there is no evidence of tablet weaving from Australia, South Africa and the Americas (Schuette 1956). As can be seen here, tablet weaving is an ancient technique with many different pattern techniques. And a very interesting feature is that at times, ancient tablet weaving was made in very intricate and unknown techniques requiring a high mathematical ability on the part of the weaver.

\section{The Technique of Tablet Weaving}

In tablet weaving, little square plates of about $5 \times 5 \mathrm{~cm}$ with a hole in each corner form the loom. In each corner of a tablet, a thread is drawn and a number of tablets each having 4 threads is collected in a bunch like a set of cards (Fig. 5.6). Another name for tablet weaving is card weaving. The tablets can be made of different material: bone, wood, leather and recently cardboard and plastic. One end of the threads is secured and fastened in the end to a fixed point, the other end is secured and fastened in the belt of the weaver. The bunch of tablets is raised on their edge and now it is possible to turn the tablets around a horizontal axis parting the upper and lower 

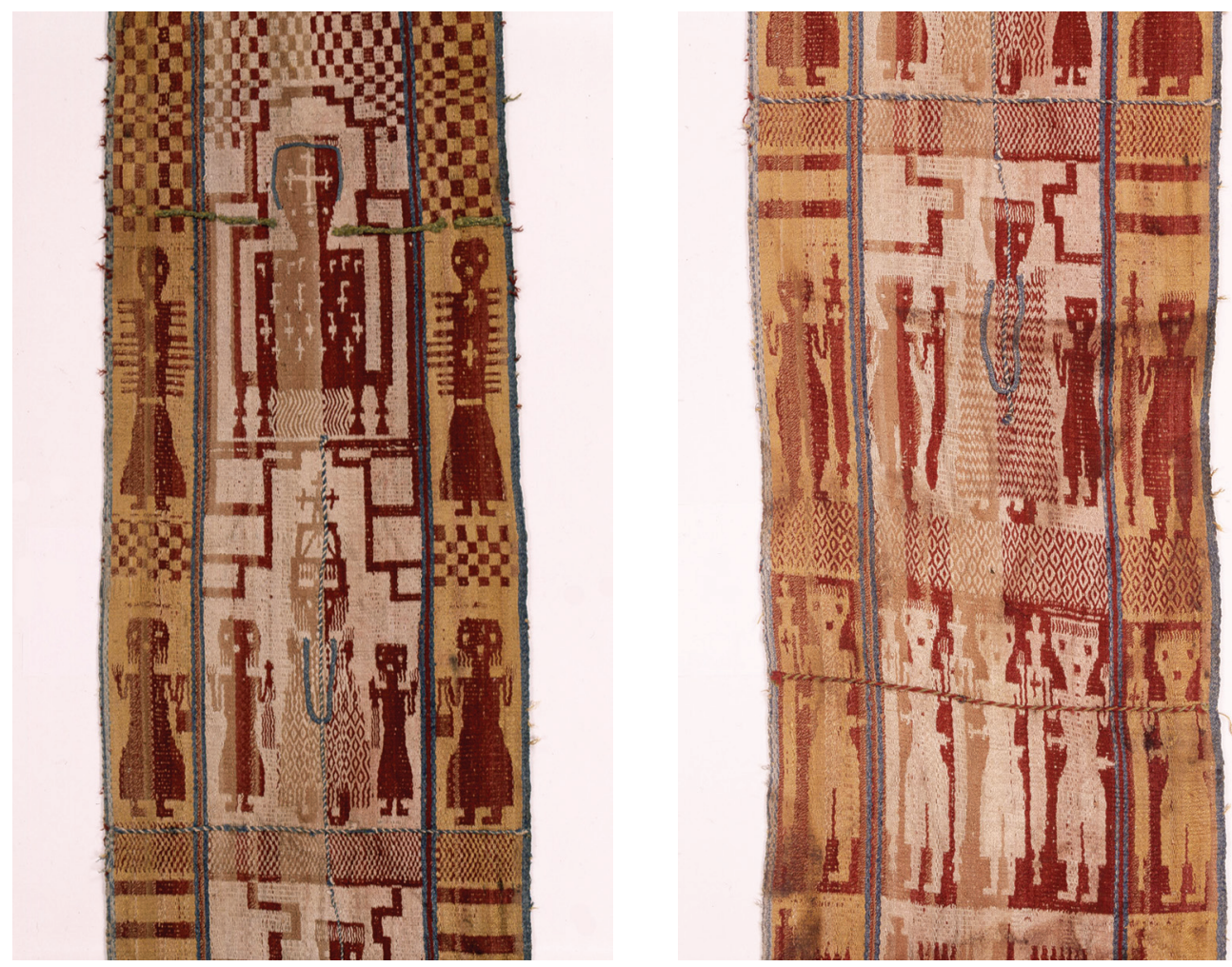

Figs 5.4 (left) and 5.5 (right): Details of silk hanging used to conceal the entrance to the Holy of Holies (Q'edus Q'edusan) of a church in Gondar, Ethiopia measuring $3.06 \mathrm{~m} \times 0.63 \mathrm{~m}$; No. Af1868,1001.22AN295853 and No. Af1868,1001.22AN295855. The curtains are divided into panels each woven using more than 300 tablets. They may have been woven by Jewish or Arabic weavers using Chinese silk and it shows, among other things, King Bakaffa (r. 1722-1730 CE) and his family wearing blue ribbons as a sign of their Christian faith. Furthermore, the soldiers guarding the family are carrying weapons of Indian manufacture. This textile kept at the British Museum is an example of a truly global textile encounter; yet another curtain from the same church kept at the Royal Ontario Museum in Canada is believed to be the largest tablet-woven textile in the world measuring $5.22 \mathrm{~m} \times 2.18 \mathrm{~m}$ (C) Trustees of the British Museum).

layer of threads and thus making a shed. A weft thread is passed through the open shed and the tablets turned again. The four warp threads of each tablet are thus twisted around each other and the many twisted threads of the border are kept in place by the weft thread. This is the simplest and most common variation of tablet weaving, but using different colours in different holes of each tablet, a different colour in different tablets or turning the tablets in different directions make it possible to make endless amounts of different and very complicated patterns. In modern times, mostly the more simple variations are seen, but in ancient times highly complicated techniques were also used. Indeed, some of these techniques have puzzled researchers for years. 


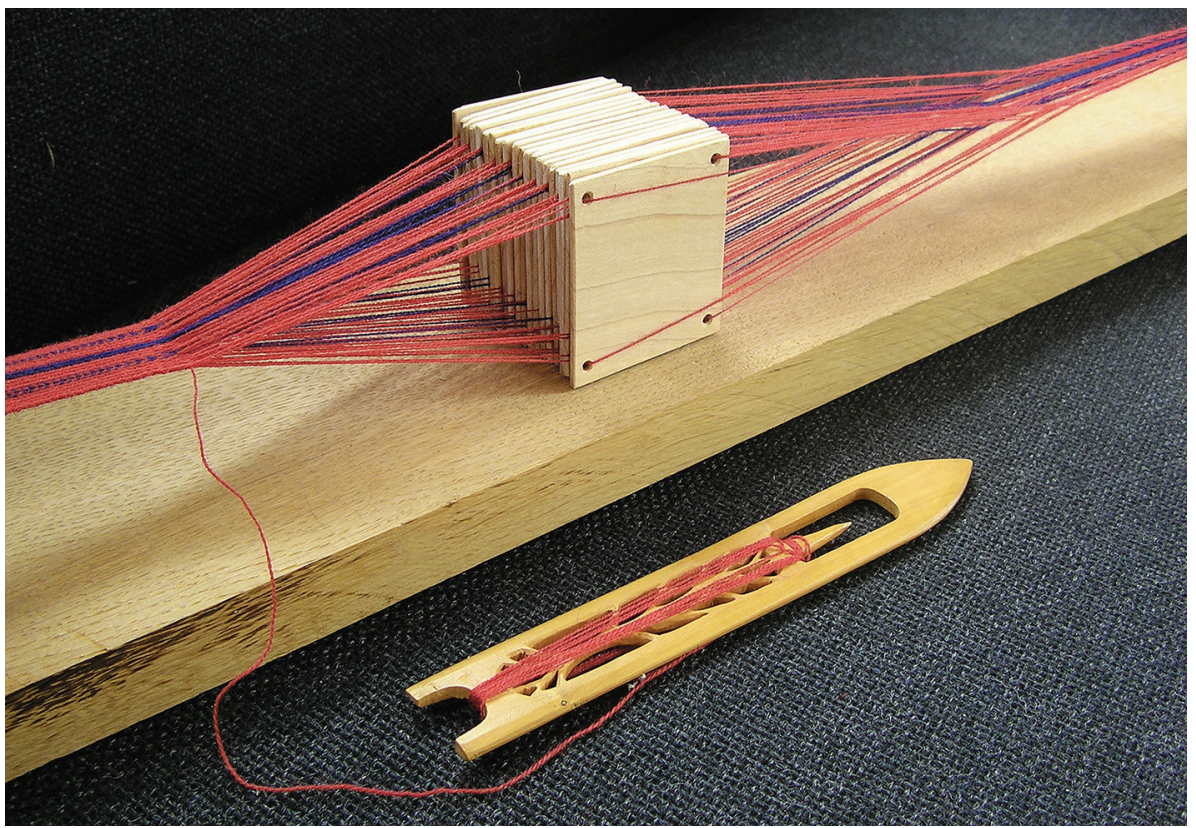

Fig. 5.6: Tablet loom with tablets of about $5 \mathrm{~cm} \times 5 \mathrm{~cm}$. First the weft is inserted in the shed, in this band all the tablets are twisted a quarter turn forward. The shed is cleared, the weft beaten in, and the weft drawn on its place. And the same procedure is repeated until the desired length is achieved (C) Lise Ræder Knudsen).

\section{A Case Study - Running Animals from China and Norway}

Near the Silk Road at Fort Miran, south-east of the Taklamakan Desert in the western part of China a collection of textiles was found by the archaeologist Sir Aurel Stein in 1907 (Stein 1921). Although this was one of the earliest expeditions along the ancient Silk Road exploring archaeological remains, the excavations were carried out very carefully and the results published in both popular and scholarly books. Due to the careful excavation, it is possible to see that the textiles were found together with many paper scraps with Tibetan writing. This is why Stein concluded that the textiles, too, were of Tibetan origin. Today these textiles are on loan in London, at the Victoria and Albert Museum, and the British Museum. More than eight colourful fragments made in the tablet-weaving technique were found. The colours of the textiles are even today fresh, bright and colourful in pink, blue, yellow, red and green. The size of the fragments varies between a few square $\mathrm{cms}$ and larger fragments. The dating of the borders is 8 th century CE. The textiles are extremely well preserved, even though textiles and other organic material normally will disintegrate and disappear after just a few years of burial. But the climate of the Taklamakan Desert is very dry as it is one of the places in the world that lies furthest from the sea, and the climate thus prevented the textiles from degradation.

The most spectacular item of the tablet weavings from Fort Miran is a beautiful broad textile made of two borders sewn together (Fig. 5.7) (Stein 1921, 483). At the 
smallest and upper part of the border, running animals in white on a blue background are seen. The animals are nearly identical and they are running at full speed to the left. The animals are depicted in a lively manner, and both fore- and back legs are raised high to show how fast they are running. It is not immediately clear which animal it is, but the legs have two toes each and at the back of the head something curly is seen. The tail is curved and slim, and curled at the end. In scholarly literature, these animals are interpreted as lions.

The yarn used to produce the border is thin and evenly spun (Fig. 5.8). It looks like very fine sheep wool, but in fact it is made out of yak wool (Ryder 1999). The yak is common in some parts of Tibet, and both a large, brown or black wild form - and a smaller domesticated yak is known. The domesticated yak can have wool of many colours, among them white. The yak is used for travel, for working the sparse fields, for transport, for meat, milk and butter, for wool, skin, and as a pack animal. The wool of the yak varies in quality: The coarsest fibres come from the belly and are used for felt needed for, e.g. tents. The middle quality wool comes from the sides and the rear part of the animal and is used for bags and blankets, while the wool of the neck is extremely fine and resembles the finest wool like Kashmir or Pashmina. The wool used to produce the fine borders from Fort Miran was white and it is obvious that it must have been dyed even though we do not have any dye analysis of the yarn. The dyestuff used to produce the very fine colours was normally from plants and sometimes insects.

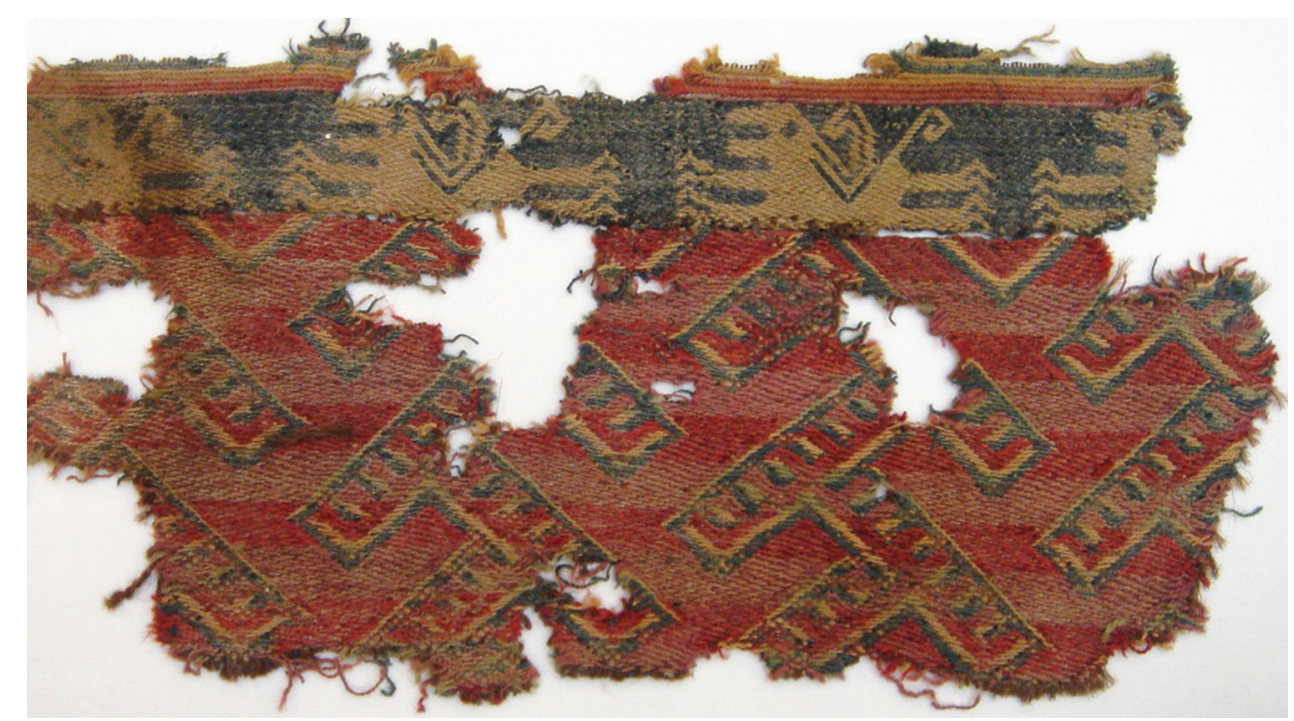

Fig. 5.7: Tablet-woven border dated about 800 CE from Fort Miran in the Taklamakan Desert in China. The border with the animals is sewn together with another border in a red geometrical pattern also woven using tablets. The yarn is made of the finest white yak wool and dyed. The border with the animals was woven using about 40 tablets and the border with its geometrical pattern needed at least 180 tablets, in all about 880 threads were used. This fragment is at present in the British Museum, MAS.622. At the Victoria and Albert Museum, London, another fragment of the same border is kept, and even if it is less well preserved, it is wider than this one. The entire width of the two borders is at least $20 \mathrm{~cm}$ (@ Trustees of the British Museum). 
The pattern with the running animals is woven in a complex tablet technique called $3 / 1$ double faced broken twill, where the warp threads jump over 3 weft threads and then go under one weft thread. The tablets each had 2 white threads and 2 blue threads. If one tablet threaded like this is turned twice forwards - twice backwards twice forwards and so on while inserting a weft for every turn, the colour will remain white on one side and blue on the other. If you displace the turning sequence of the tablets but still turn the individual tablet twice forwards, twice backwards you will still have a band which is white on one side and blue on the other, but now with a diagonal structure. If you then change the turning direction of single tablets, and do it at exactly the right time in the turning sequence, then it will be possible to make a pattern like the running animals. Likewise, the geometrical pattern on a pink and red background on the other border under the running animals can be achieved in somewhat the same way. For the edging of the running animals, 11 tablets of different colours were used at the upper edge and for the animal pattern, 29 tablets were used - all in all 40 tablets. This border was sewn together with the tablet-woven border with the geometrical pattern. This border was woven using at least 180 tablets and each tablet was threaded with a yellow, a dark blue and two red or pink threads.

There are more tablet-woven borders in the same technique preserved from Sir Aurel Stein's excavations in Fort Miran, but to my knowledge there are no other finds

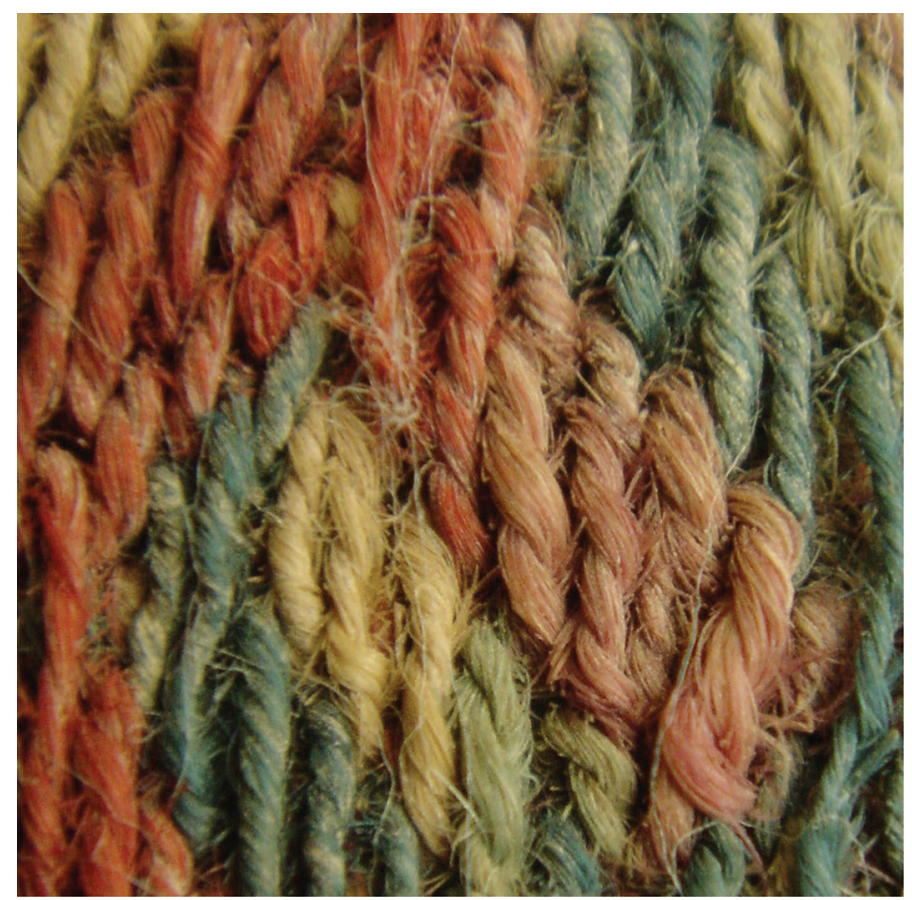

Fig. 5.8: Detailed close up of the tablet-woven border dated about 800 CE from Fort Miran in the Taklamakan Desert in China at present in the collection of the British Museum, MAS.622 (@) Trustees of the British Museum). 
in the special 3/1 double-faced broken twill in China. From Urumqi on the northeastern part of the Taklamakan Desert, a tablet-woven band was found, which seems to belong to an earlier period. It is made in a double weave with a lozenge pattern and is well preserved with yellow, red and brown colours (Schorta 2001, 100).

Some of the fragments from Fort Miran seem to be scraps and cuttings left over from the starting point of a tablet weaving. This fact makes it probable that, these borders were actually produced at Fort Miran, although the yak thread could not have been produced in the area near Fort Miran, as the yak lives in altitudes higher than 3000 metres while Fort Miran is situated near the basin around 600 metres (kind information from anthropologist Ellen Bangsbo). However, it is reasonable to believe that yak fibres were traded as a regional commodity along this part of the Silk Road.

Such tablet-woven borders woven in the complicated 3/1 double-faced broken twill technique are very rare in archaeological finds from prehistoric times, but small fragments are occasionally found. In Scandinavia, we see the first finds from around $200 \mathrm{CE}$, and around 450-500 CE some of the most spectacular and complicated borders produced by tablet weaving are found - and among these, a well-preserved $3 / 1$ doublefaced broken twill border from a chieftain's grave in Evebø-Eide in Gloppen, Norway - a dark blue border with red animals (Fig. 5.9) (Nockert 1991, 94-96). The animals of this border are all different and some of them seem to have the legs downwards and some the legs upwards. It is not immediately obvious which kind of animals they are but one of them has many details in common with the animals on the Chinese border from Fort Miran. This animal depiction has four legs with two toes each, a tail which points up and backwards and something on top of the head which could be horns or ears and an open mouth and an eye very like the running animals from Fort Miran, even though it does not seem to be running as fast - it merely tiptoes (Fig. 5.10). The technique used to produce the band is exactly the same and also in this band, the pattern is produced using threads of two different colours. Here, the tablets are threaded with two blue threads and two red threads.

The material used to produce the Norwegian border is sheep's wool and the quality of the border and the other textiles of the grave leave no question of the place of production. It was homemade in Norway. Also borders with geometrical patterns are found in 5th-century CE graves of Norway, for instance from a chieftain's grave in Snartemo (Nockert 1991, 63-64). Here, a pattern-woven tablet border was found with a geometrical decoration made in nearly the same technique and with a resemblance to the geometrical pattern on the Fort Miran border.

The tablet-woven borders from Fort Miran and Evebö-Eide have so many details in common that it is tempting to look for a connection. In favour of a connection is the relationship between the geometrical animal designs - even if we cannot fully identify the animals - and the technical opportunities of the $3 / 1$ double-faced broken twill. It is intriguing to note that the weavers in Norway and Fort Miran have chosen exactly the same technical solutions for depicting details like the eyes, the shape of the legs, and the way the diagonal lines break the basic structure of the weave in order to enhance the shape of the animals - something which is not at all easy to achieve. 


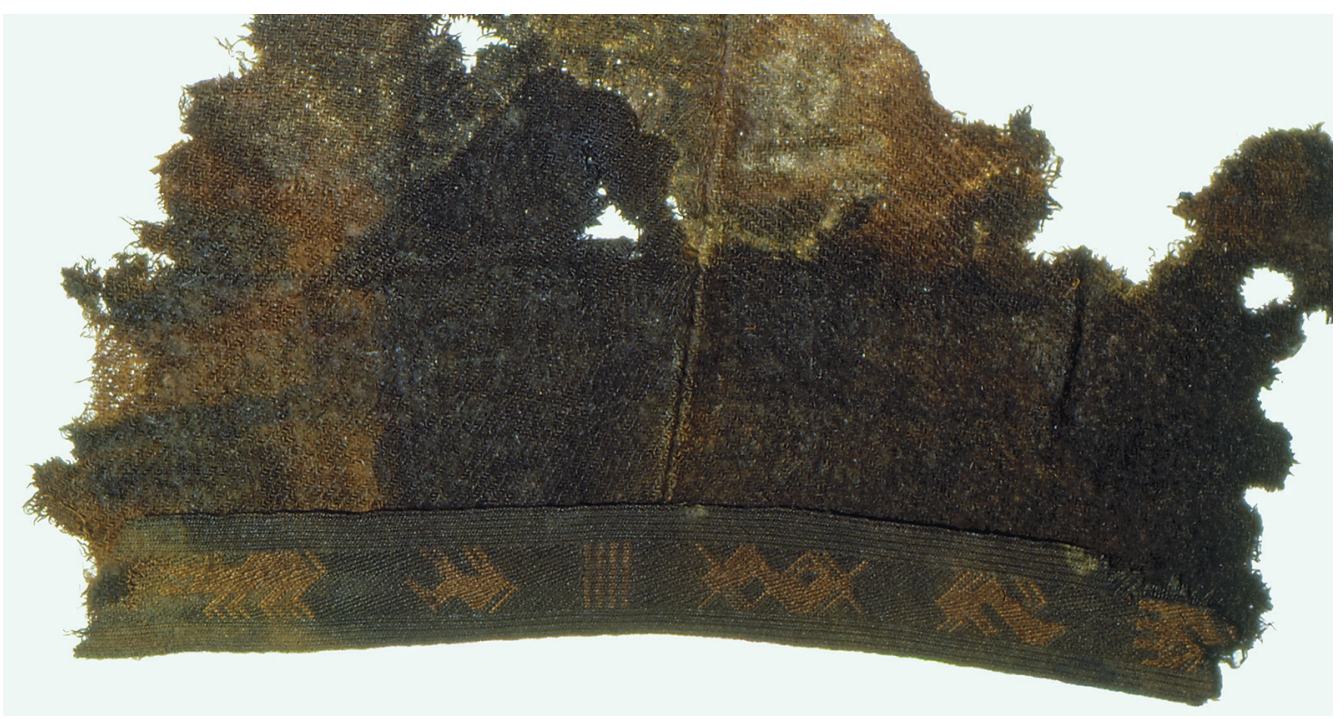

Fig. 5.9: Tablet-woven border found on the tunic in a chieftain's grave from Evebø-Eide in Norway. The intricate weaving technique and design of the animals are similar to the find from Fort Miran (Courtesy of Bergen Museum).

Fig. 5.10: Detailed close up of the far left of the tablet-woven border found on the tunic in a chieftain's grave from EvebøEide in Norway. The colour difference is digitally enhanced using Photoshop, to make weaving details more visible. Note that the legs and the eye of the animal are quite similar to the animals on the border from Fort Miran (Courtesy of Bergen Museum).

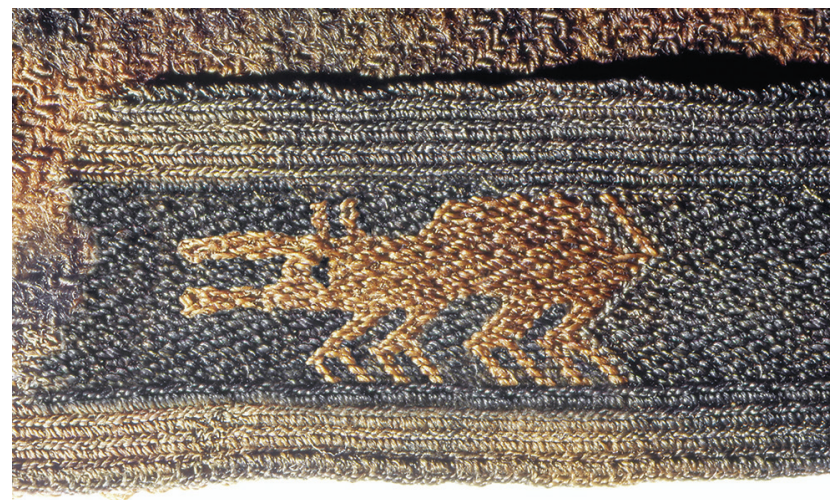

So is this a coincidence or is there a connection? It is difficult to say - a safe answer would be that this is an example of parallel evolution and that these phenomena occur in cultural history as well as in natural history.

Yet, a more interesting assumption would be that this textile-technical 'encounter' could be an indication of trade routes and long-distance connections still to be investigated. Many other materials, techniques and crafts were developed several thousand kilometers away but still found their way to the other end of the world. For instance, the fact that silk came to Northern Europe via the Silk Routes could indicate that techniques, patterns and artefacts also travelled in the opposite direction. 
A tablet-weaving technique known in Norway around $450 \mathrm{CE}$ becomes evident in Fort Miran, made in yak wool, a few hundred years later - at the same time where silk becomes an available commodity in Northern Europe - why not?

\section{Acknowledgements}

I thank Sophie Desrosiers, Ecole des Hautes Etudes en Sciences Sociales, Paris, who first invited me to study technical analyses of the tablet-woven borders from Fort Miran; Helen Persson, Victoria \& Albert Museum, London for kind help and information while studying the fragment; Svein Indrelid, Bergen Museum for permission to use pictures from Evebø-Eide; Veronika Ronge, University of Bonn for discussions on tablet weaving in Tibet; Mogens Koch from the Royal Danish Academy of Fine Arts, School of Conservation for digitalization of pictures from Evebø-Eide; and many thanks to Michael Højlund Rasmussen and Bjørn Højlund Rasmussen for inspiring discussions and help with digital improvement of the pictures.

\section{Further Reading}

The record of the Chinese border with running animals at the V\&A: http://collections.vam.ac.uk/ item/091172/fragment-the-stein-collection/

Free download of Sir Aurel Stein's books on the excavations along the Silk Road: http://dsr.nii. ac.jp/toyobunko/creator/marc_aurel_stein.html.en

Peter Collingwood (1982) The Techniques of Tablet Weaving.

Michael Gervers (2004) The tablet-woven hangings of Tigre, Ethopia: from history to symmetry. The Burlignton Magazine CXLVI, pp. 588-601.

Margareta Nockert (1991) The Högom find and other Migration Period Textiles and Costumes in Scandinavia. Michael Ryder (1999) Ancient fibres from the Silk Route in Central Asia, Textiles Magazine. Manchester Textile Institute, no. 3.

Regula Schorta (2001) A group of Central Asian Woolen Textiles in Abegg-Stiftung Collection, in Fabulous Creatures from the Desert Sands, pp. 79-114. Riggisberger Berichte 10.

Marie Schuette (1956) Tablet Weaving. Ciba Review no. 112, pp. 9-29. 



\title{
6 The Development of Pattern Weaving Technology through Textile Exchange along the Silk Road
}

\author{
ZHAO FENG
}

Zhao Feng is Director of the China National Silk Museum and of the Chinese Centre for Textile Identification and Conservation (CCTIC), Hangzhou. He is also a Professor of History of Textiles and Costume at Donghua University, Shanghai. He began his textile education as a textile engineer and wrote his doctoral thesis in 1997 on $A$ Study on Traditional Looms and Weaving Techniques in China at the China Textile University. Today, he is a foremost authority on ancient Chinese textiles and a widely published author. His encounters of Silk Road textiles in major museums around the world, such as the Metropolitan Museum of Art in the USA, the Musée Guimet in France, and the Victoria \& Albert Museum and the British Museum in the UK have resulted in several important exhibitions and catalogues. Among his major publications are his co-edited publications, China: Dawn of the Golden Age 200-750 AD (2004); Textiles from Dunhuang in UK's collections (2007) and Textiles from Dunhuang in French collections (2012). His most recent publication is co-edited with Dieter Kuhn et al., Chinese Silks (2012), based on his Chinese version Zhongguo Sichou Yishu (2012).

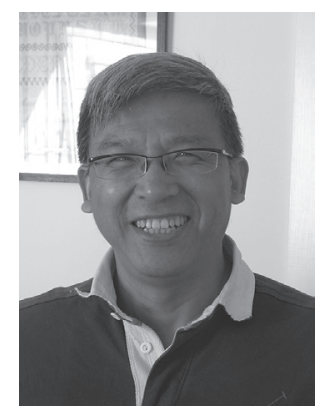

Readers of this chapter may also find his following publications useful: 南宋蚕织图的版本及所见南宋蚕织技术， 《农业考古》1986年第01期/A study of Sericulture Painting from the Southern Song dynasty (11th-12th centuries) and the sericulture and weaving technology, Agricultural Archaeology; Treasures in Silk, an Illustrated History of Chinese Textiles, (1999), ISAT/Costume; Recent Excavations of textiles in China, (Hong Kong, 2002); 新疆地产 绵线织锦研究，《西域研究》2005年01期/On local silk products in Xinjiang, The Western Regions Studies, pp. 51-59); 中国丝绸通史/The General History of Chinese Silks (SuZhou, 2005); Weaving Methods for Westernstyle Samite from the Silk Road in North-western China, Central Asian Textiles and Their Contexts in the Early Middle Ages, Riggisberger Berichte 9, Abegg-Stiftung, (2006), pp. 189-210; 唐系翼马纬锦与何稠仿制波斯锦， 《文物》2010年03期/Tang Style Samite with Pegasus and Persian Textiles Imitated by He Chou, Cultural Relics; Zhao Feng and Yu Ziyong, Legacy of the Desert King (Hong Kong, 2000); Zhao Feng and B. Matbaev, Early Medieval textiles and garments of Ferghana Valley, (2010); Zhao Feng et al. A Study on the Excavations of Silk Fabric from TAM170, pp. 241-267 (Shanghai 2010); Zhao Feng et al. 战国对龙对凤纹锦研究，《文物》2012年07 期/Study on the Textiles with Double-Dragon and Double-Phoenix Designs of the Warring States, Cultural Relics.

Along the Silk Road, several techniques were used to produce patterned textiles, including tapestry weaving, embroidery, carpet knotting, textile printing and patterned textile weaving. Among them, pattern weaving methods constituted the technology that was most highly appreciated by ancient society from east to west. It also changed and developed a great deal when two or more weaving technologies encountered each other on the Silk Road. This paper focuses on the development of pattern weaving technology, including the original weave structures, loom types for weaving patterns, and their weaving methods. 


\section{Jin, Taquete and Samite: Three compound-weave structures}

Jin is a Chinese term for the silk woven with threads of various colours. Technically, it refers to a special weave structure, warp-faced compound tabby, which has been used since the Western Zhou dynasty in the 5th century BCE. During the Warring States period, the 5th to the 3rd centuries BCE, jin silk was widespread, and archaeological finds of jin silk are reported not only from central China, mainly the Chu area (present-day Hunan and Hubei provinces), for instance, one woven in three colours with a dragon, phoenix, dancer, and other mystery motifs (Fig. 6.1), but also from those sites far from central China, for instance, Pazyrik, Russia. More examples of jin silk were excavated along the Silk Road from the late Han dynasty, from Xinjiang in northwest of China, to Palmyra in Syria (Pfister and Bellinger, 1945). They were usually woven in five colours, blue, green, white, red and yellow; sometimes in $1 / 3$ warp-faced compound tabby and sometimes in 1/4 warp-faced compound tabby. The most beautiful and intricate piece representing the highest quality of Han style jin silk is the one found at the site of Niya, Xinjiang (Fig. 6.2). It has the characters wuxing chu dongfang li zhongguo (the five planets all appear in the east) woven into the textile, an expression of great auspicious significance in China. In the 7th century, warp-faced compound $2 / 1$ twill, a new version of the structure, was developed from the warp-faced compound tabby, but it was still written as jin
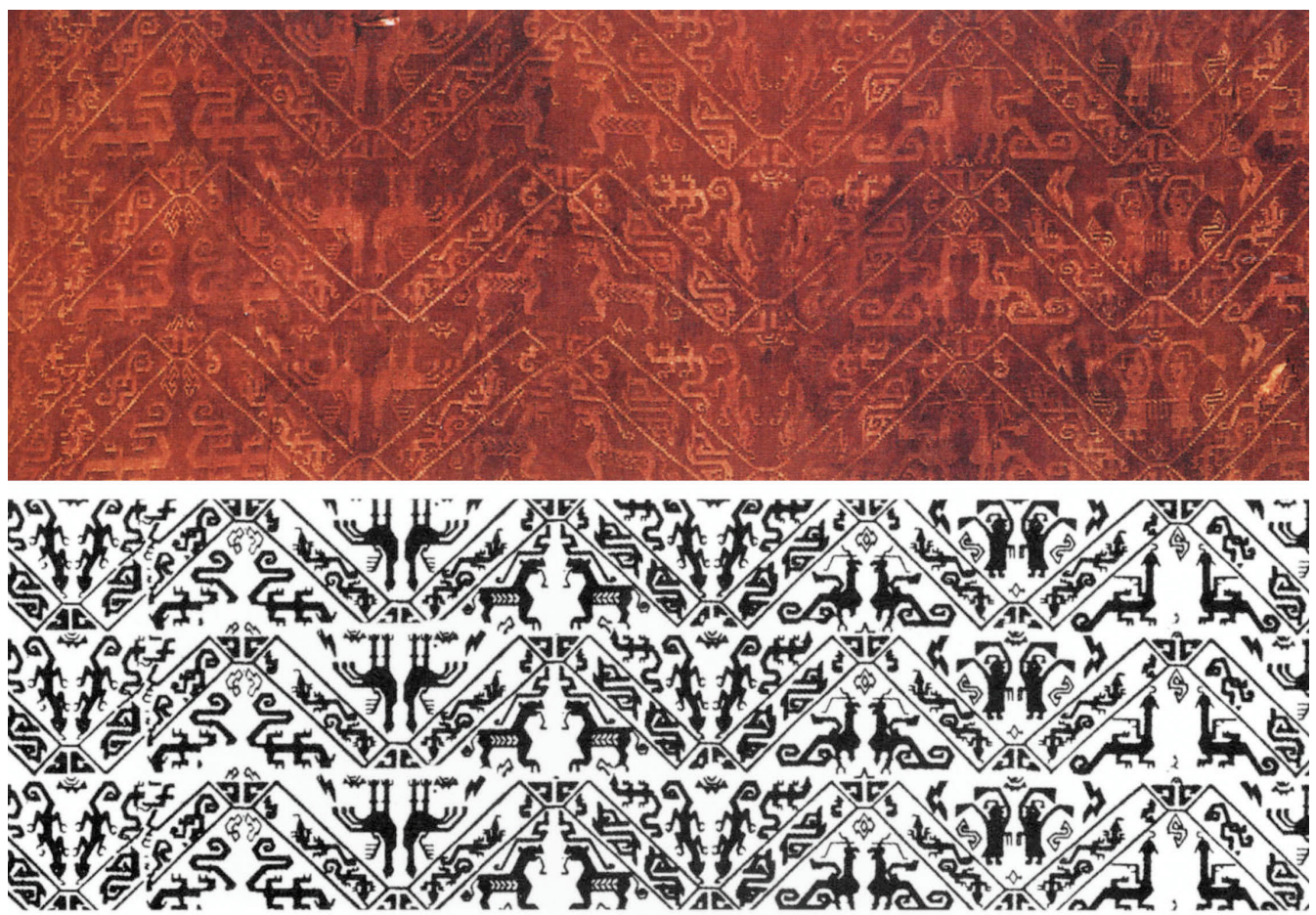

Fig. 6.1: Jin silk with dragon, phoenix and dancer, Mashan, Hubei, Warring States period (Courtesy of Jingzhou Museum, Hubei). 


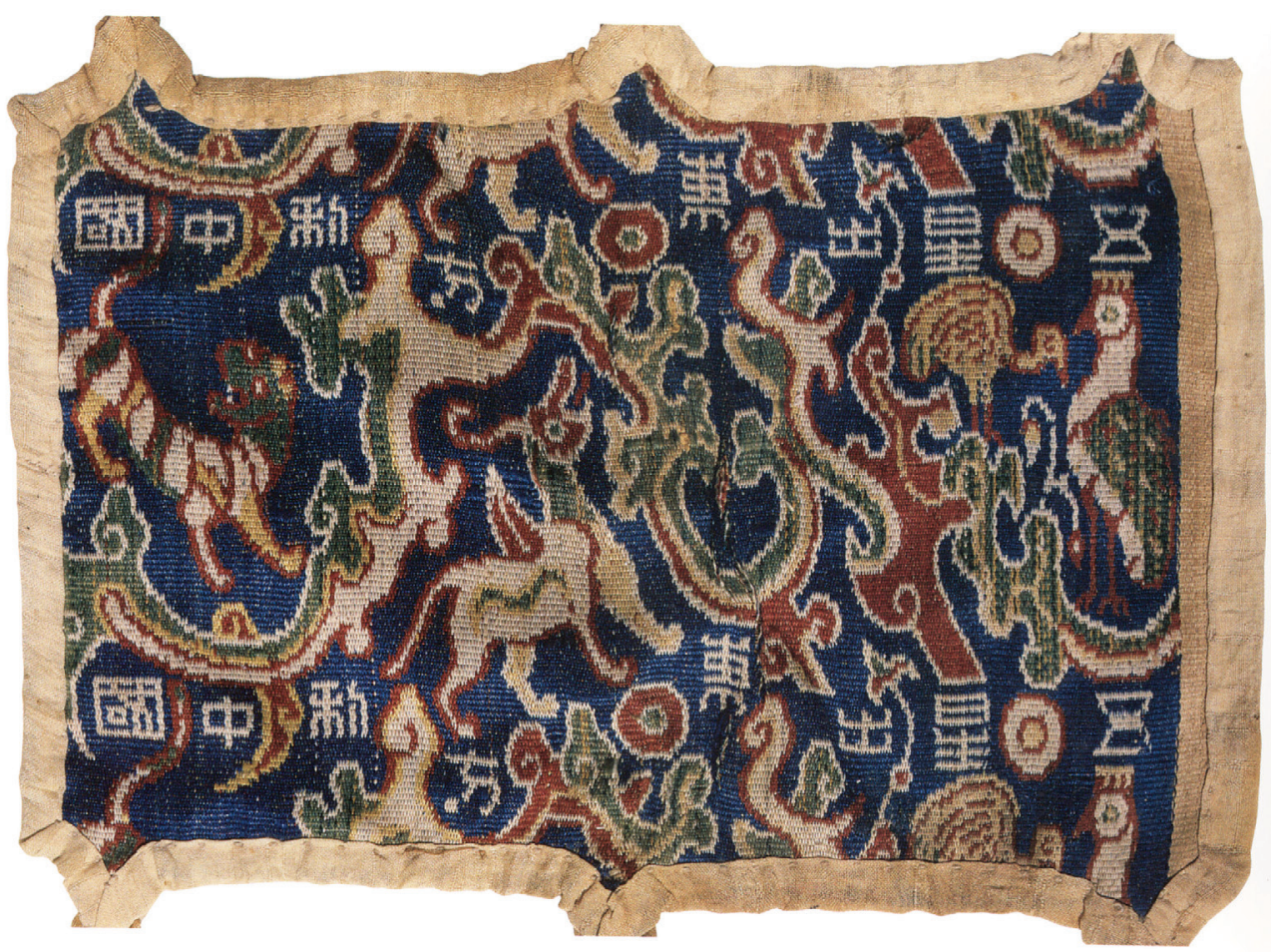

Fig. 6.2: Jin silk with wuxing chu dongfang li zhongguo (The five planets all appear in the east. This is highly auspicious in China), Niya Xinjiang, Han dynasty (Courtesy of Xinjiang Institute of Archaeology, Urumqi).

silk in Chinese documents, although it could more precisely be termed twill jin silk in our terminology.

Taquete is a special term indicating those textiles woven in weft-faced compound tabby weave. Unlike the jin silk where the pattern was woven vertically in the warp, here in taquete the pattern was woven horizontally in the weft. The earliest examples of taquete are found around the Mediterranean area, such as Masada (Israel) and Duro-Europos (Syria) (Pfister and Bellinger 1945, no. 263), including both wool and silk materials. More taquete pieces were found in Niya, Sampula and Yingpan sites in Xinjiang. The most remarkable piece, excavated along with the famous caftan with its pattern of a Hellenistic-style Eros, trees, bulls and goats in red and yellow colours in Yingpan (3rd-4th centuries CE), was a woven rosette and wave design with a brocaded circle in the centre (Fig. 6.3). Another group of taquete was primarily woven with spun silk, which was made of unraveled Chinese silk or local silk cocoons, and examples have been found in archaeological sites from Munchaktepa in Fergana (Uzbekistan), to Zaghunluk, Yingpan and Turfan in Xinjiang, and even Huahai in Gansu (all in China). All these taquete textiles have a similar pattern layout as the jin silk, and a technical structure transformed 90 degrees from jin silk weave, so that the pattern was turned 


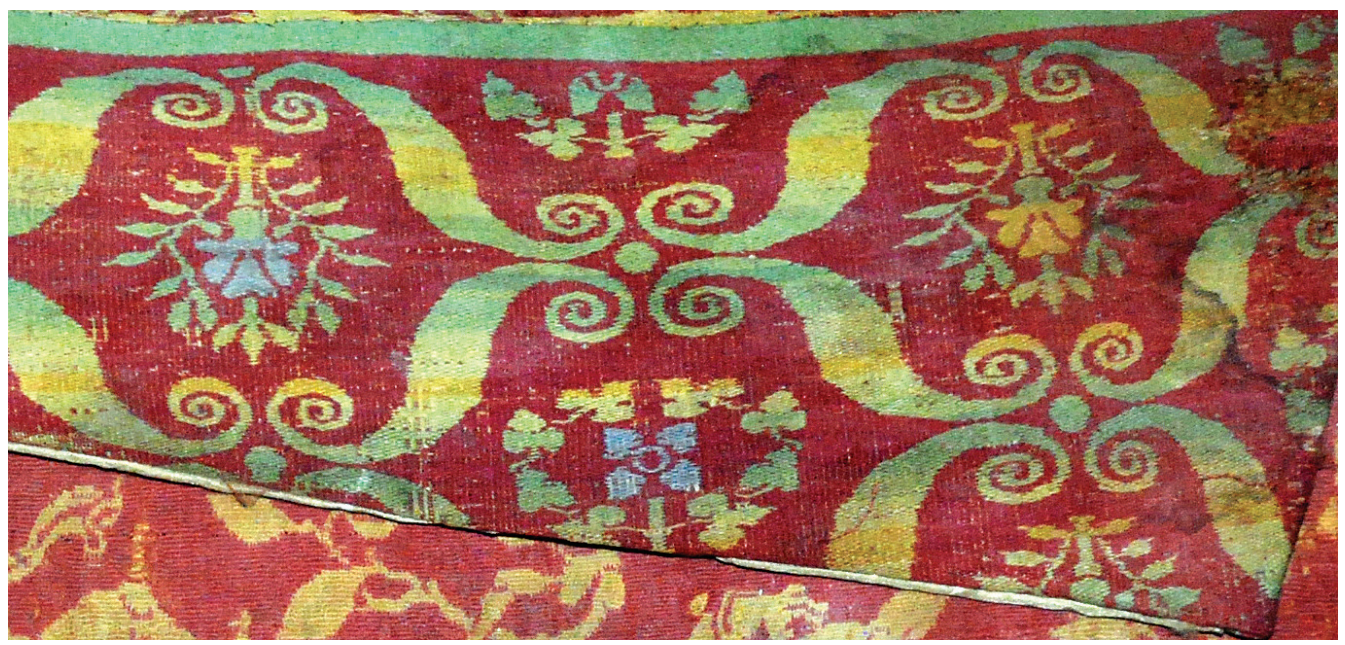

Fig. 6.3: Wool taquete with rosette pattern, Yingpan Xinjiang, 3rd-4th centuries (Courtesy of Xinjiang Institute of Archaeology, Urumqi).

90 degrees and repeated only in the weft direction (i.e. horizontally), not in the warp direction (i.e. vertically) (Fig. 6.4). Therefore, in China, the taquete textile from this period is considered as the imitation of jin silk.

Samite, technically called weft-faced compound twill, is the final step in the development of textile techniques on the Silk Road during the Han and Tang dynasties. Technically, it could be considered as a development from either taquete, after changing the ground weave from tabby to $2 / 1$ twill, or twill jin silk, after turning the warp and weft directions 90 degrees. Samite weave seems to be comparably later than taquete to appear on the Silk Road. The earliest excavated samite silk example, unfortunately only a very tiny fragment cut to make a rope, and thus without a visible pattern, was found at the Munchaktepa site, Fergana, dated back to the 3rd-4th

Fig. 6.4: Silk taquete imitated from Han style jin silk, Zagunluk, Xinjiang, 3rd-4th centuries (Courtesy of Xinjiang Museum, Urumqi).

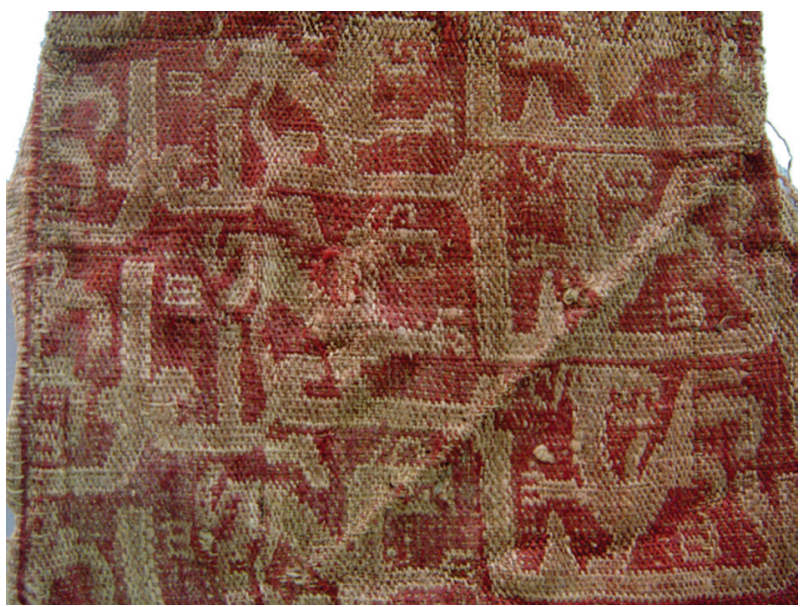


centuries CE. More beautiful samite silks were excavated in the northwest of China, Antinoë in Egypt, Moschevaya Balka in Russia, and some found in medieval cathedrals in Europe, mostly dated to the 7th-8th centuries.

Among those samite silks, there are at least two major types according to the weaving technique and art style of the pattern. The first group is western style samite, or the so-called Zandaniji as many textile researchers in the world term it. Most of the samite silks in western collections and some of those excavated from Turfan in Xinjiang and Dulan in Qinghai belong to this group. Large roundels with pearl or petal circles and animals or birds as a major motif inside were used as preferred patterns on these samite silks. These mostly appeared as single motifs, but sometimes smallersized all over patterns and confronted motifs were also used. The former is exemplified by Persian motifs, such as the boar's head, stag, hunter, and a standing bird holding a ribbon, and the latter by, among others, paired cocks, paired ducks, paired stags and paired ibexes (Fig. 6.5). All of them were produced in the same technique, Z-twisted warps, paired inner warps, a flat surface of the front weft threads, and sometimes threads with mixed colours were used as one weft. The pattern has real repeats only in a weft direction but not in the warp direction.

The second group of samite includes examples found not only at Turfan in early Tang dynasty tombs, Dulan in Qinhai, but also at Shosoin and Horyu-ji in Nara, Japan. They have both western and eastern styles joined together. The design is always in a large size and more symmetrical in both warp and weft directions. The pattern could be either pearl or floral roundels enclosing a major motif in a more Chinese style, or even only a floral medallion. In terms of technique, this group of samite has some distinguishing characteristics, such as the samite with Pegasus roundels found at Astana Turfan (Fig. 6.6) which has paired warps twisted in an S-direction,

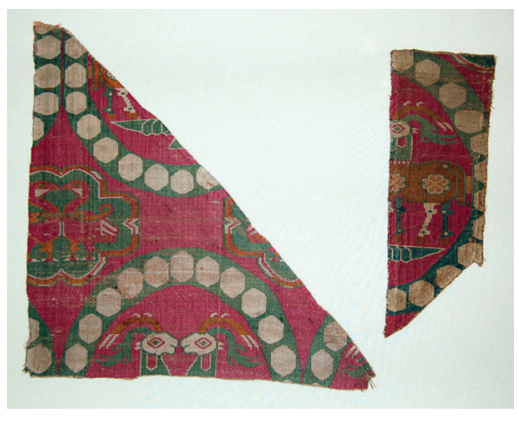

Fig. 6.5: Sogdian samite with pearl roundel and paired ibexes, Dunhuang Gansu, 8th century (above); and its reconstructed pattern (right) (above: (C) Trustees of the British Museum; right: pattern reconstructed by Wang Le).

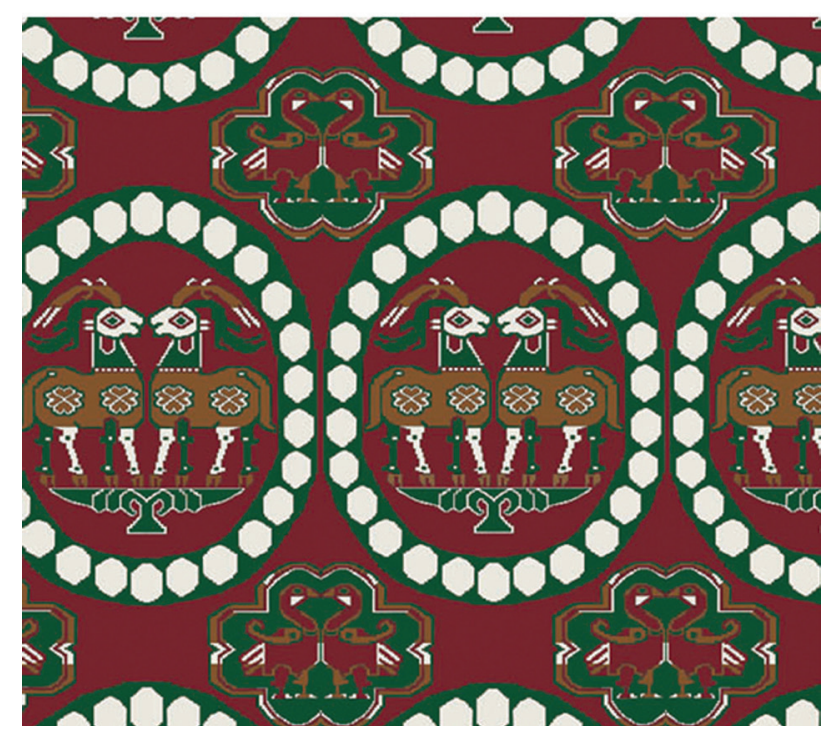



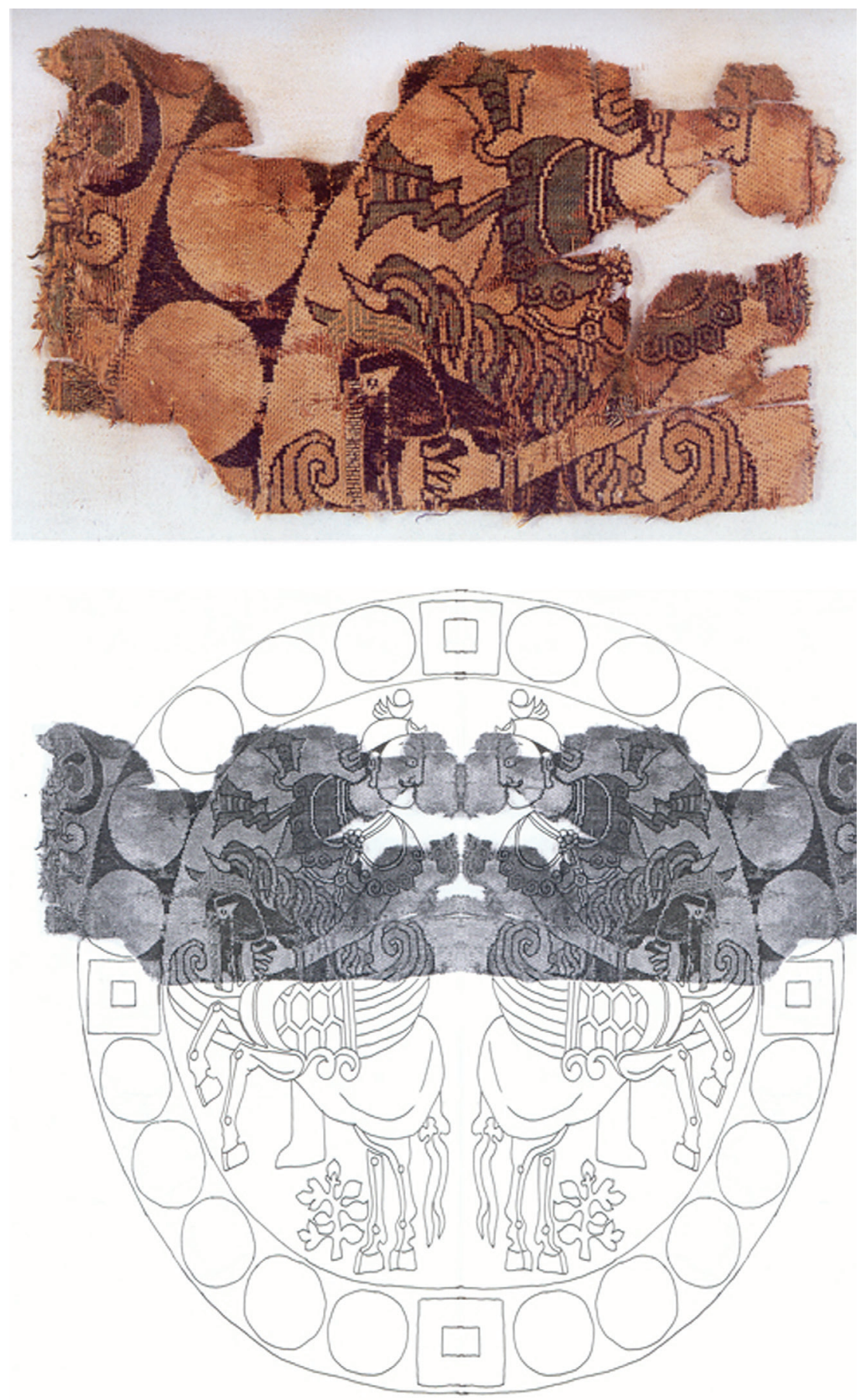

Fig. 6.6: Tang style samite with pearl roundel and Pegasus, Astana, Xinjiang, 7th century (Courtesy of Xinjiang Museum; pattern reconstructed by Zhao Feng). 
and the pattern repeated in both warp and weft directions. Furthermore, on a samite with a roundel with stags found by the Japanese team organized by Kozui Otani (1876-1948) on one of their expeditions to Central Asia (now in a private collection), the confronted stags are more realistic and colourful than the stag from the first group, and the Chinese inscription woven in between two stags, huashu duî lu (floral tree and confronted stags), also shows a strong Chinese influence.

Another piece in the collections of the Horyu-ji Temple, Nara, was woven with four horse riders hunting lions (see Fig. 1.12 in Canepa's chapter in this book). More samite fragments from the same group, such as the floral roundel surrounding a standing phoenix, and the floral roundel enclosing paired birds were found in Turfan, Dulan and Dunhuang.

\section{Repeats in Warp, Weft or both Warp and Weft Directions: Three pattern structures}

To study the loom and weaving technology of especially the patterned textiles, we focus on the pattern structure rather than the weave structure. Indeed, the pattern of textiles from the Silk Road has three basic structures, based on the mechanical pattern repeats in the warp direction, the weft direction, or in both directions.

Most of the jin silks have pattern repeats only in the warp direction. The origin of this can be traced back to, at least, the Warring States period in the 5th century $\mathrm{BCE}$. The famous jin silk woven in three colours with a dragon, phoenix, dancer and other mysterious motifs found at Mashan in Hubei is a very good example where the entire pattern unit runs $5.5 \mathrm{~cm}$ in the warp direction and the full width of the textile from selvedge to selvedge in the weft direction measuring about $50 \mathrm{~cm}$ (see Fig. 6.1). Another example with a dragon, phoenix and tiger found in many different collections, has a pattern unit of $2.3 \mathrm{~cm}$ in the warp and full width of the textile in the weft direction (Fig. 6.7). In both cases, the pattern unit is always narrow in the warp and wide in the weft, but the former is repeated straightforward and the latter mirrored symmetrically. This principle was highly consistent with those jin silks found along the Silk Road from the Han dynasty to the pre-Tang period, i.e. the 2nd century BCE to the 6th century CE.

The second pattern structure, repeating in the weft instead of the warp direction, was used not only on the taquete textiles but also on some samite textiles. All the taquete textiles, no matter whether made of wool or silk, have a pattern unit repeated only in the weft direction, which was also very narrow, with approximately $3-6 \mathrm{~cm}$ in the weft, but along the entire length of the piece in the warp. A textile with a remarkable design of figures, snakes, eagles and grape vines probably from Yinpan in Xinjiang is a good example of the patterns repeated in a symmetrical layout. And a much better example, although it was made in a type of double weave, is the wool textile caftan with Eros, a bull, goat and tree in red and yellow colours found in the same cemetery in Yingpan (Li Wenying 2008) (Fig. 6.8). While some other taquete 


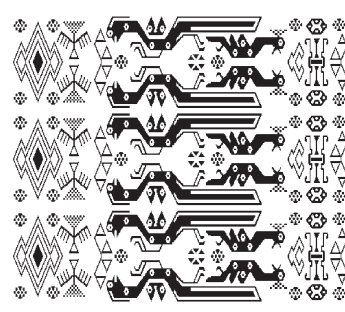

A

B
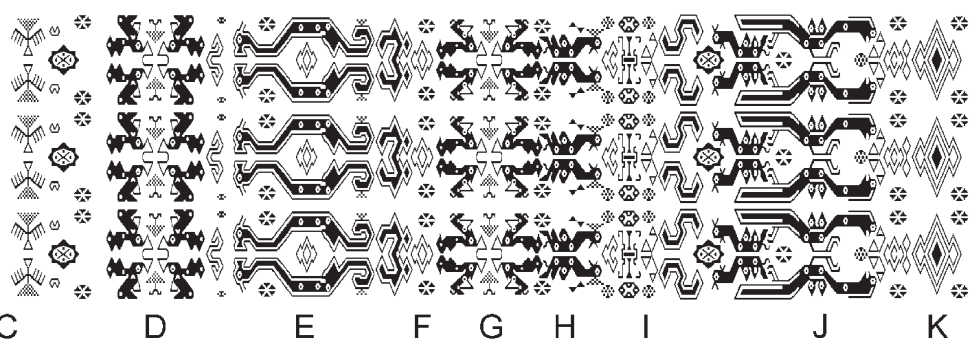

Fig. 6.7: Pattern of jin silk with a dragon, phoenix and tiger, Warring State period, 3rd century BCE (Drawing: Luo Qun).

made of spun silk, also from Yingpan, patterned with clouds, animals and imitated Chinese characters, were repeated either straightforward or as a mirror image repeats in a symmetrical way.

The first group of samite silks, the so-called Zandaniji or the central Asian samite, has a similar layout of the pattern structure to the taquete silk, although the pattern design appears much larger and more circular in shape. For example, a samite silk with two rows of pearl roundels enclosing confronted cocks excavated in Turfan, has a pattern repeated symmetrically in the weft direction, but not in the warp direction (Fig. 6.9). The two rows are slightly different in shape, although they look so similar. In the top row, the cocks have crowns on their heads, while those below have a ribbon or streamer fluttering behind their necks.

On the other hand, however, the twill jin silk and the second group of samite silks in a more Tang style design have an entirely different pattern structure, which is repeated in both warp and weft directions. We have many examples of these, for instance, the samite silk with a pearl roundel and Pegasus excavated from Astana, Turfan, which is now attributed to He Chou's work in the Sui dynasty, around 600 $\mathrm{CE}$. The previously mentioned samite silk with four hunters in the collections of the Horyu-ji Temple (see Fig. 1.12) and another samite with a large medallion in the collections of the Shosho-in, both in Nara, Japan (Matsumoto and Gire, 1984, p. 143), are other complete pattern examples from the early 8th-century High Tang dynasty. Other warp-faced compound twill silks were also woven with various radial floral motifs (Fig. 6.10). The new technology made the new style with its roundel pattern, including the floral roundel enclosing the animal or bird inside, the so-called Duke Lingyang's School, and the floral medallion with or without birds outside, during the Tang dynasty highly popular (Fig. 6.11). The onset of this style can be dated to around the late 6th century, and it became more widely used in the 7th to 9th centuries. At first the pattern was repeated in half the warp width of the loom, and then in equal sizes in both warp and weft directions, with four, six, eight or even more repeats in a loom width. The earliest evidence of textiles with patterns repeated in both warp and weft directions is the textiles from tomb 170 at Astana, Turfan, dated to the mid-6th century, including a jin silk with da wang (great king) and a damask with a roundel of lions. 


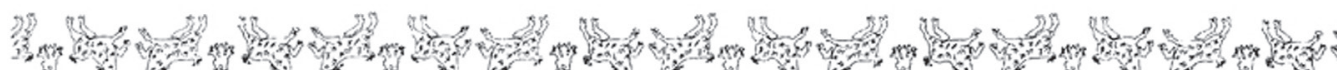
3.

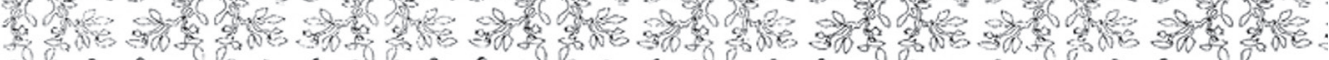

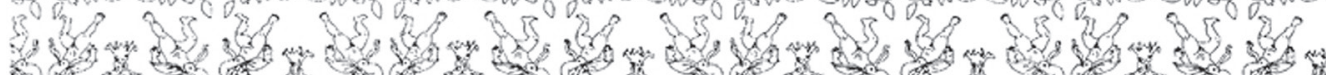
3)

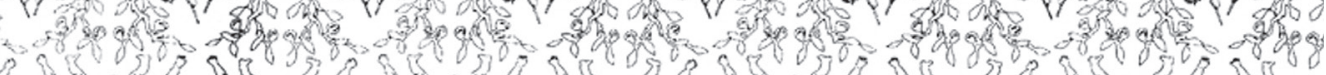

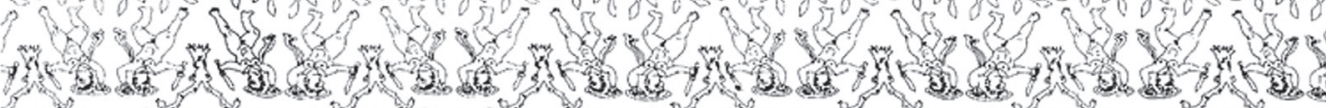

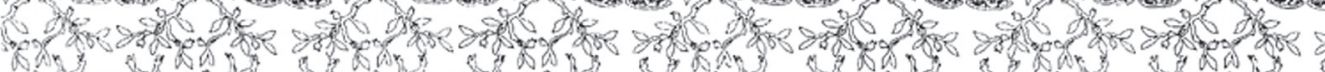

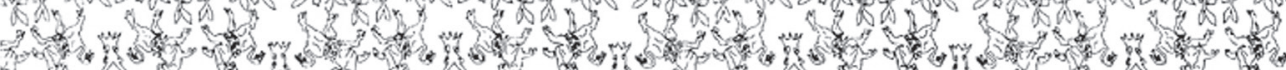

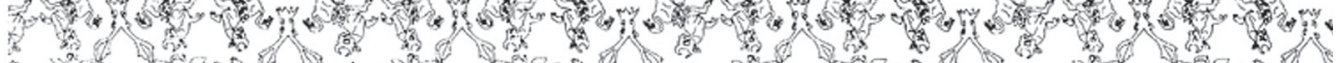

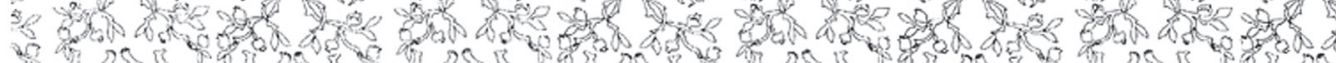

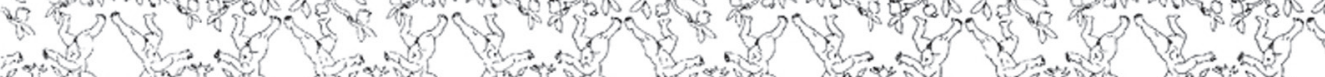

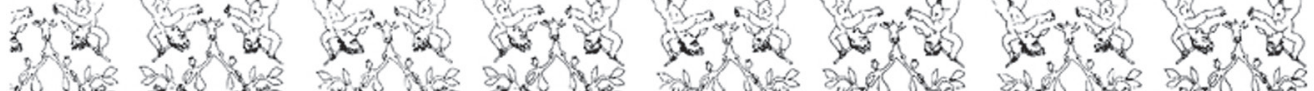

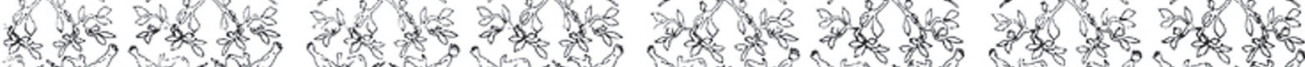

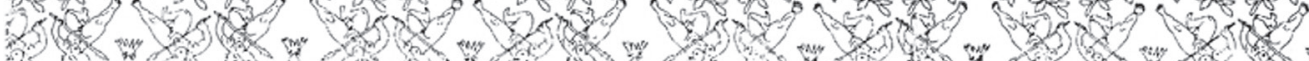

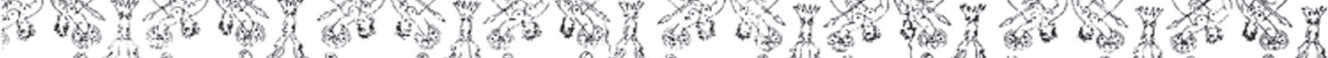
R क

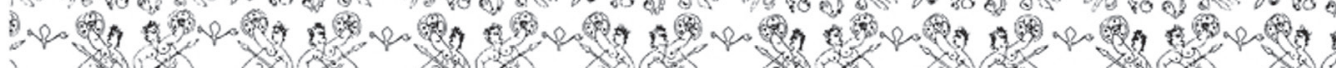
हो 190 an

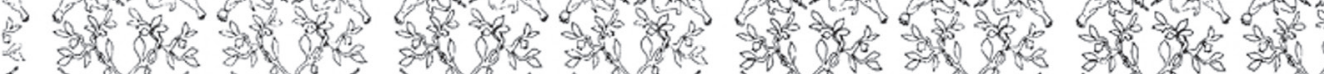

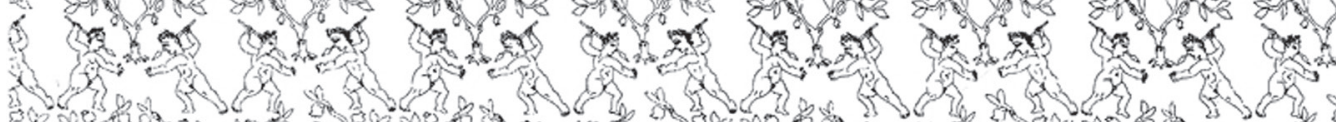
.

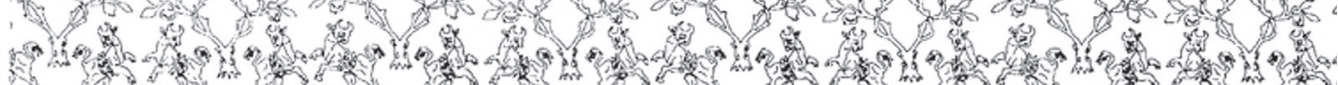
i :

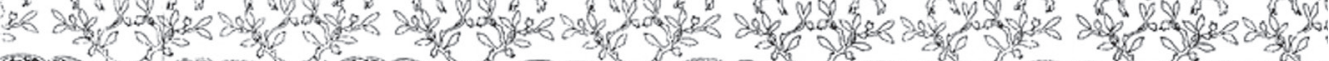
W 1) Hot a

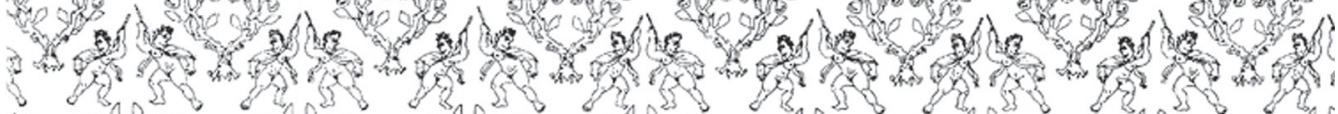

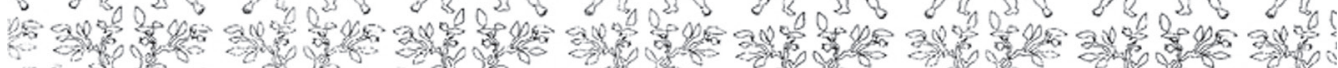
.

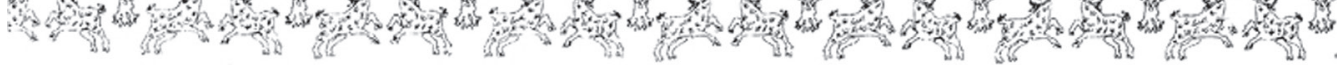

Fig. 6.8: Pattern of the Double weave wool textile with Eros, bull, goat and tree, Yingpan Xinjiang, 4th century (C) Li Wenying). 


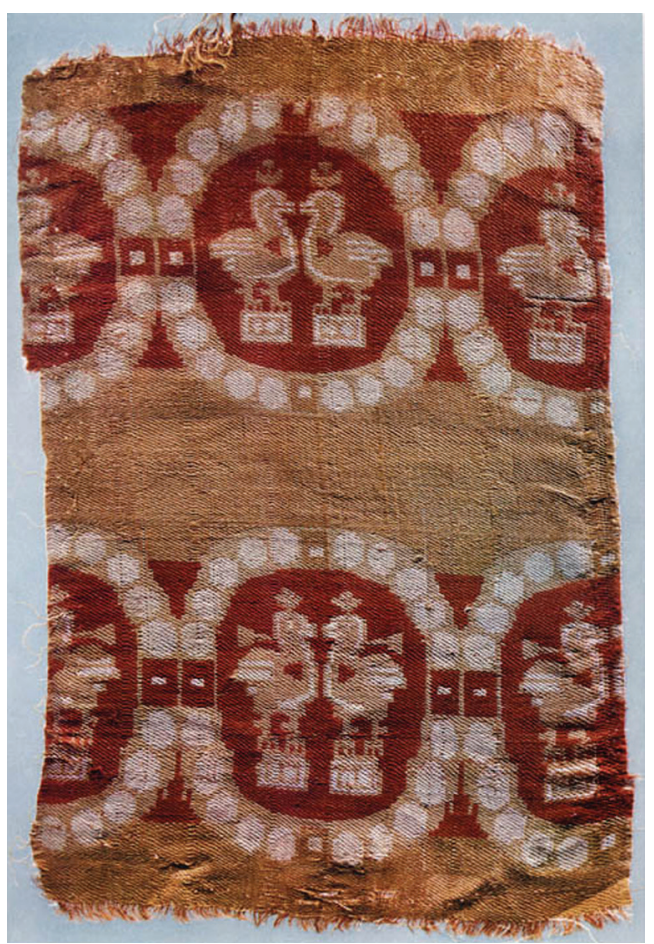

Fig. 6.9: Sogdian samite with confronted cocks, Astana Xinjiang, 7th century (Courtesy of Xinjiang Museum).

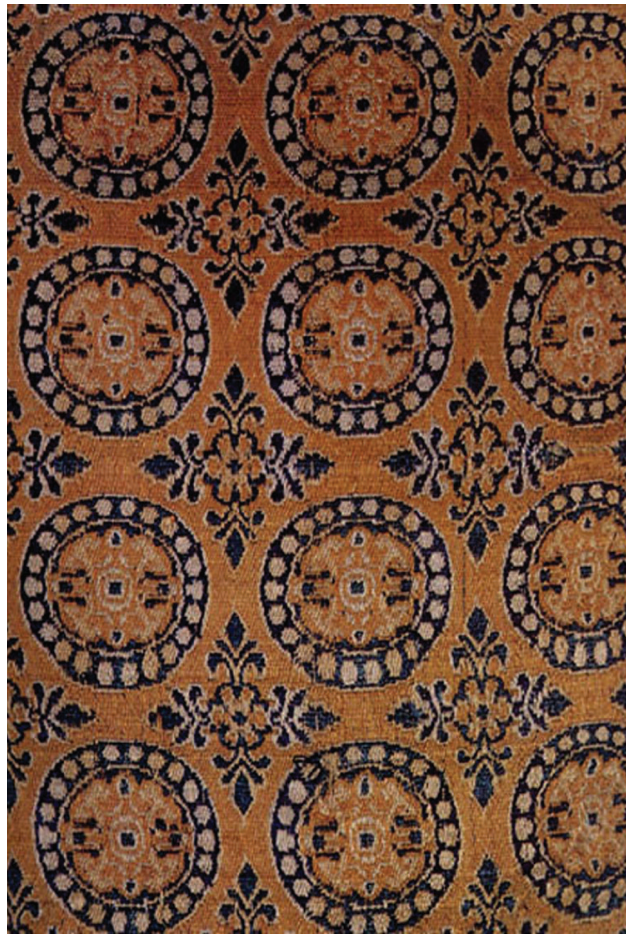

Fig. 6.10: Twill jin silk with small floral medallion, Astana Xinjiang, 7th century (Courtesy of Xinjiang Museum).

\section{The Multi-shaft, Pick-up 1-N Cord System and Drawloom: Three major types of patterning loom}

Based on the three major pattern structures, it is possible to reconstruct the different types of looms that would have enabled people to weave those patterns. But this is not an easy task, especially with regards to the early pattern looms for jin silk. Scholars have already suggested several possibilities for the pattern loom for jin silk production, and two of them seem equally plausible.

The first type is a multi-shaft loom, with or without corresponding treadles. A damask loom with 120 sticks, employed as a shaft with heddles, was, according to the book, Xijingzaji (Miscellaneous Records of the Western Capital), used by Chen Baoguang's wife to weave 25 bolts of damask with a floral pattern. The textile was ordered by the wife of Huo Guang, the regent or commander-in-chief for the young emperor Zhaodi during the latter's reign (94-74 BCE), in Julu, Hebei province (today's Pingxiang). It had taken her 60 days to weave one bolt. Another type of patterning loom, with 50 shafts for 50 treadles and 60 shafts for 60 treadles, probably widely used in Shaanxi province, was also recorded in Sanguozhi (The Records of the Three 


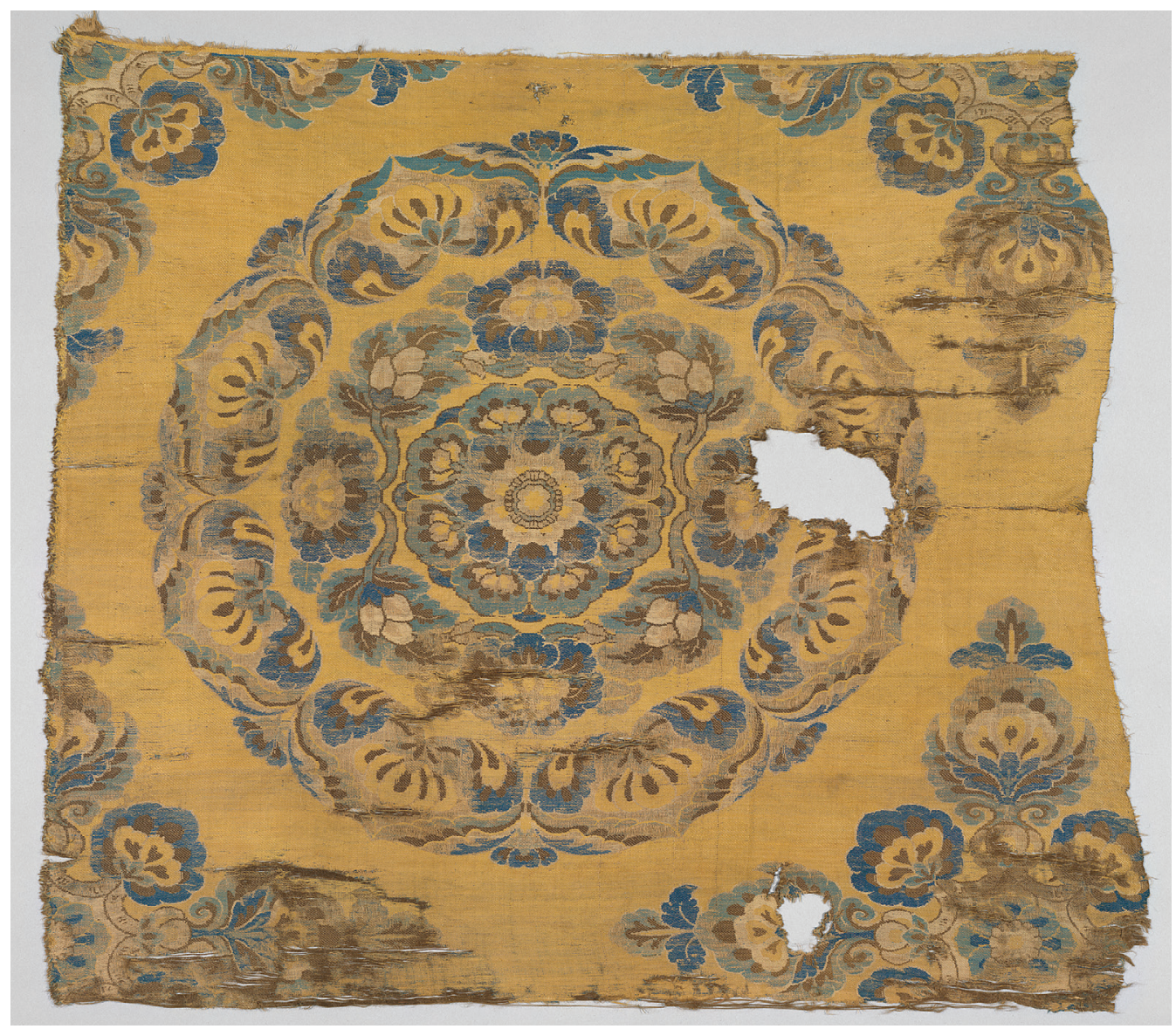

Fig. 6.11: Tang (618-907) style samite with large floral medallion, late 8th-early 9th century; woven silk: weft-faced compound twill $24 \times 28$ in. $(61 \times 71.1 \mathrm{~cm})$ (Image (C) The Metropolitan Museum of Art; Purchase, Joseph Pulitzer Bequest, 1996 (no. 1996.103.1).

Kingdoms). In Pei Songzhi's annotations it is reported that there were 50 treadles for the old 50-shaft damask loom, and 60 treadles for the 60-shaft damask loom.

In other words, the numbers of shafts and treadles on this loom were always equal and each shaft would have operated with one treadle. The same type of pattern loom with corresponding treadles is still used in the villages near Chendu, Shichuan province and Dehong and Linglang, Yunnan province, southwest China (Fig. 6.12). Fortunately, four pieces of pattern loom models (small 3-dimensional looms, with a proportion of 1:6 in comparison to real looms) dating back to the Han dynasty were excavated in 2013 from the Tianguanshan tomb at Laoguan Hill in the northern suburb of Chengdu, Sichuan. These models indicate that the multi-shaft pattern loom, but not the multi-treadle, was the preferred type to weave the Han style jin silk and damask (the excavation report is as yet unpublished). 


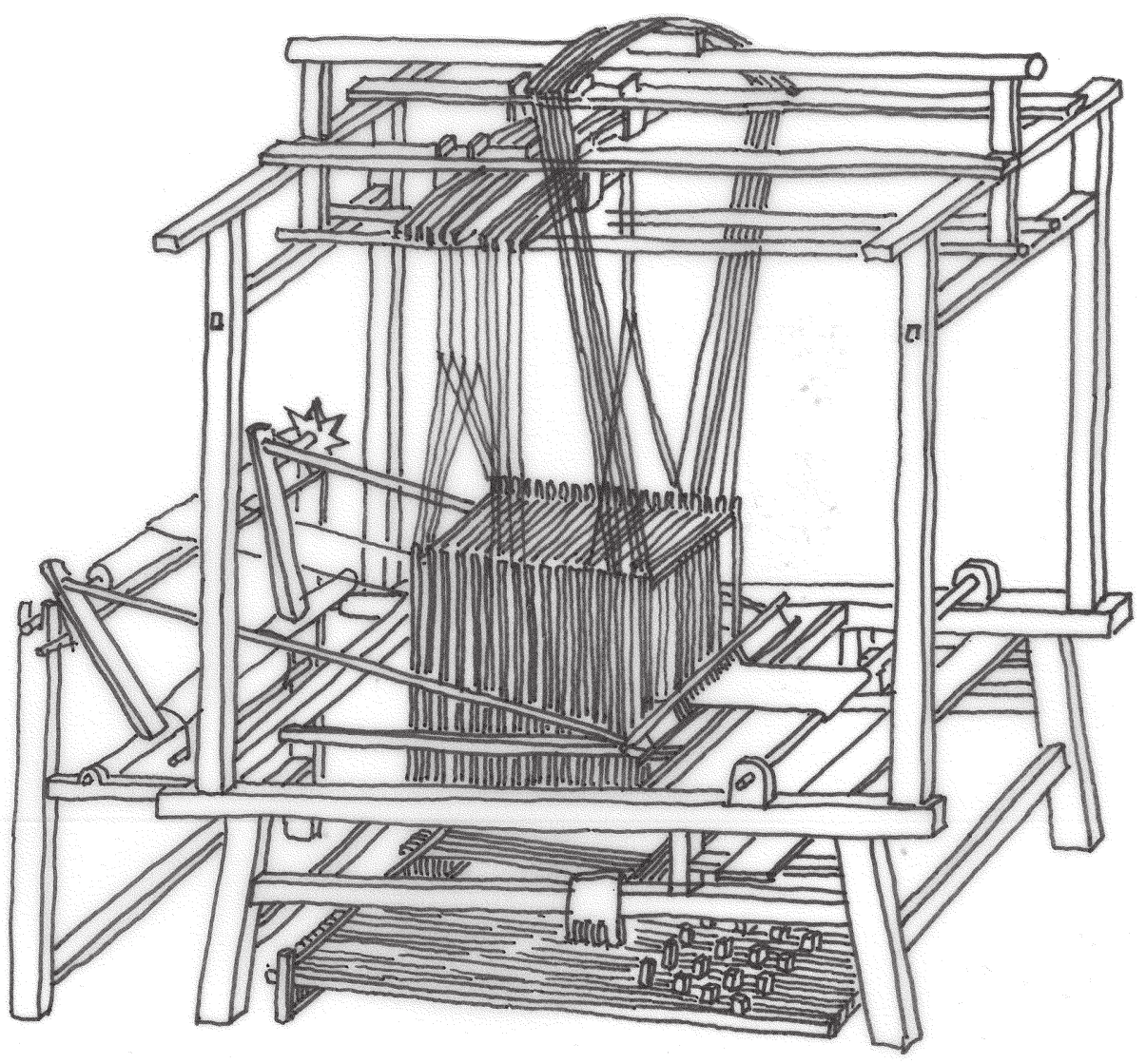

Fig. 6.12: Patterning loom with multi-shafts and multi-treadles, Shuangliu, Sichuan (Drawing: @ Zhao Feng).

Another possibility to weave the Han style jin silk and damask was to use a loom with a lower pattern harness where the position of the harness is lower than the drawloom, and could be controlled and operated by the weaver himself, instead of using a draw-boy to operate the harness or pattern system which could be separated from the loom frame. There are several types of such pattern looms. The harness could be formed on a bamboo cage, or in a curtain shape, even sometimes in a circular frame (Fig. 6.13). The frame could also have one or two treadles for the ground weave. However, both types of pattern looms have a similar principle to make a short pattern unit repeatedly in the warp direction, but always with only one full width unit in the weft direction. This principle is consistent with the pattern structure of the jin silk from the Warring States to the pre-Tang period, so either could be a prototype of the pattern looms for jin silk on the Silk Road.

The Zilu loom, a type of patterning loom employing the pick-up patterning method, is still used in villages in Iran to weave the textiles with pattern repeats in the weft 


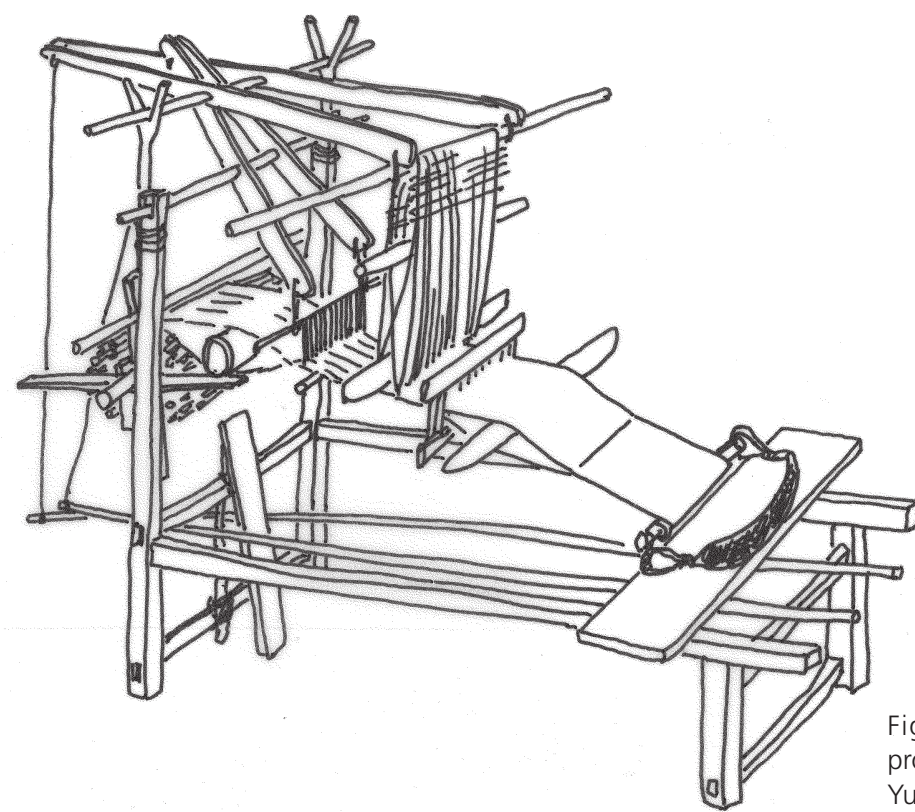

Fig. 6.13: Patterning loom with programme in a circular ring, Dehong, Yunan (Drawing: (C) Zhao Feng).

but not in the warp direction (Fig. 6.14). As we have observed, the Zilu loom could also be a prototype of the loom used to weave the central Asian textiles, the so-called Zandaniji. This loom holds two key components. One is a vertical frame, which holds all the warps in the two beams, a warp beam and cloth beam. The weaver stands in front of the warp and weaves with a shuttle. The other part is a set of harnesses, among which the threads needed for the pattern are picked up and lifted from behind the warp by an assistant, just like the draw-boy on the drawloom. Between these two parts, a 1-N cord system must be used to connect them to repeat the single pattern unit with all the warps in the weft direction. So this patterning method has only the repeats in a weft direction but not in the warp direction, which matches the pattern structures on the taquete textiles and the first group of samite textiles from Central Asia.

The 1-N cord system is a very important invention of the weavers on the western region along the Silk Road, as regards the mechanical patterning technique. In fact, the term 1-N is coined especially for such a system where a single thread can control several cords to form a pattern unit for the warps. In comparison, the system used on the pattern loom with a lower harness is only a 1-1 system, meaning one cord corresponds to one warp thread, so it could only make a pattern repeat in the weft direction. Thus the 1-N system can make several repeats in the width, whereas a 1-1 system makes only one repeat in the width.

The last type of pattern loom that could have been used is a drawloom which combined the two types of patterning methods in order to make pattern repeats in both warp and weft directions. This pattern loom uses not only the true pattern programme 
which is operated by a draw-boy but also the 1-N cord system. This loom has the same significance as that of the drawloom used in the later periods. Thus the invention of the drawloom also attests that it was after a lengthy process of diffusion and reflection of their textile techniques that the Chinese finally completed the drawloom around the 6th century, in the period comprising the end of Northern Dynasties to the beginning of the Tang dynasty. This drawloom is a combination of two systems, a pattern programme and a 1-N cord system, and was recorded in some Chinese documents and poems in the 6th to 7th centuries CE. For instance, in the New Poems on the Jade Stage (vol. 8), the 6th-century poet, Liu Xiaowei mentions that he saw a weaver sitting at a loom which has threads and silk on the top, which may suggest a drawloom to us, and such a loom was illustrated in a painting scroll on sericulture and weaving in the early 12 th century. However, this is still open to scholarly debate (Fig. 6.15).

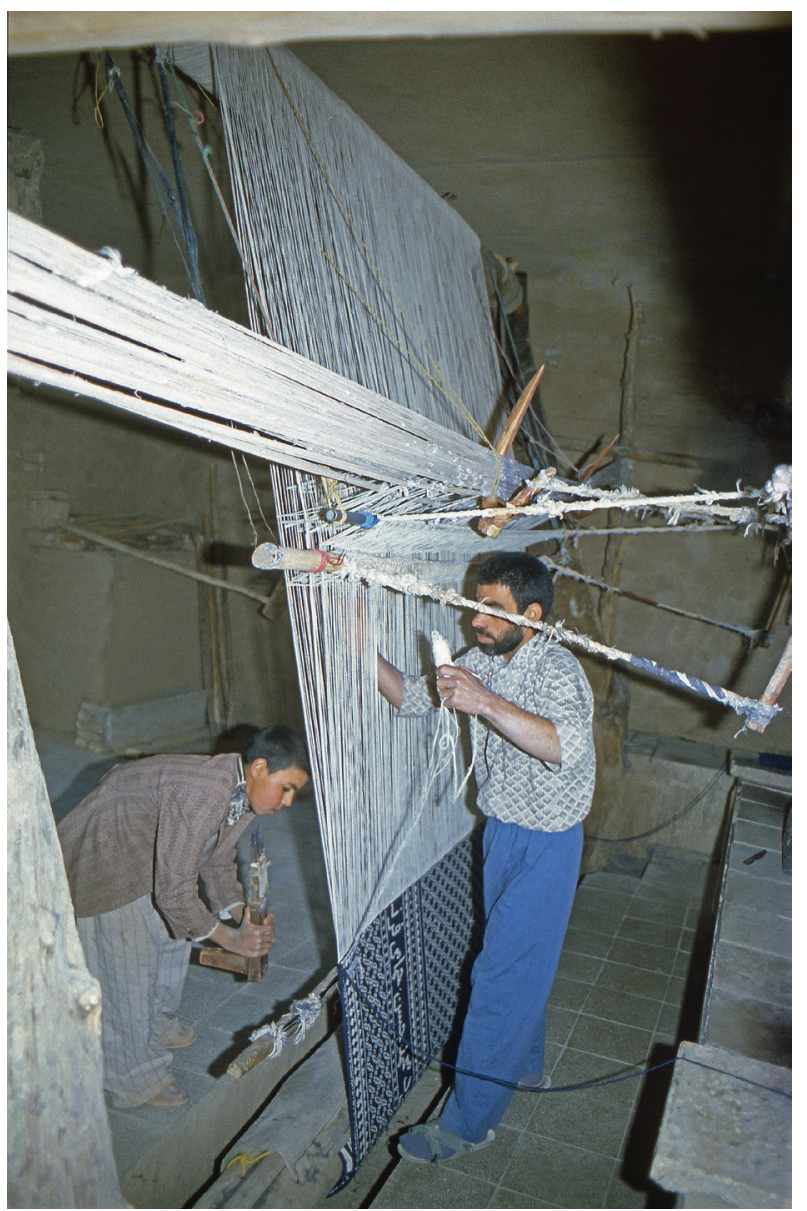

Fig. 6.14: A Zilu weaver at work with an assistant. Meybod, Iran, Dec. 1983. The Zilu loom is a giant two-beam loom for making two-coloured, pileless, cotton carpets (or zilus) (Photo: (C) Jon Thompson 1984; See also Jon Thompson (2003) Looms, Carpets and Talims, in R. Tapper and K. Mclachlan (eds), Technology, Tradition and Survival, pp. 205-216, plates 40-42, Frank Cass, London). 


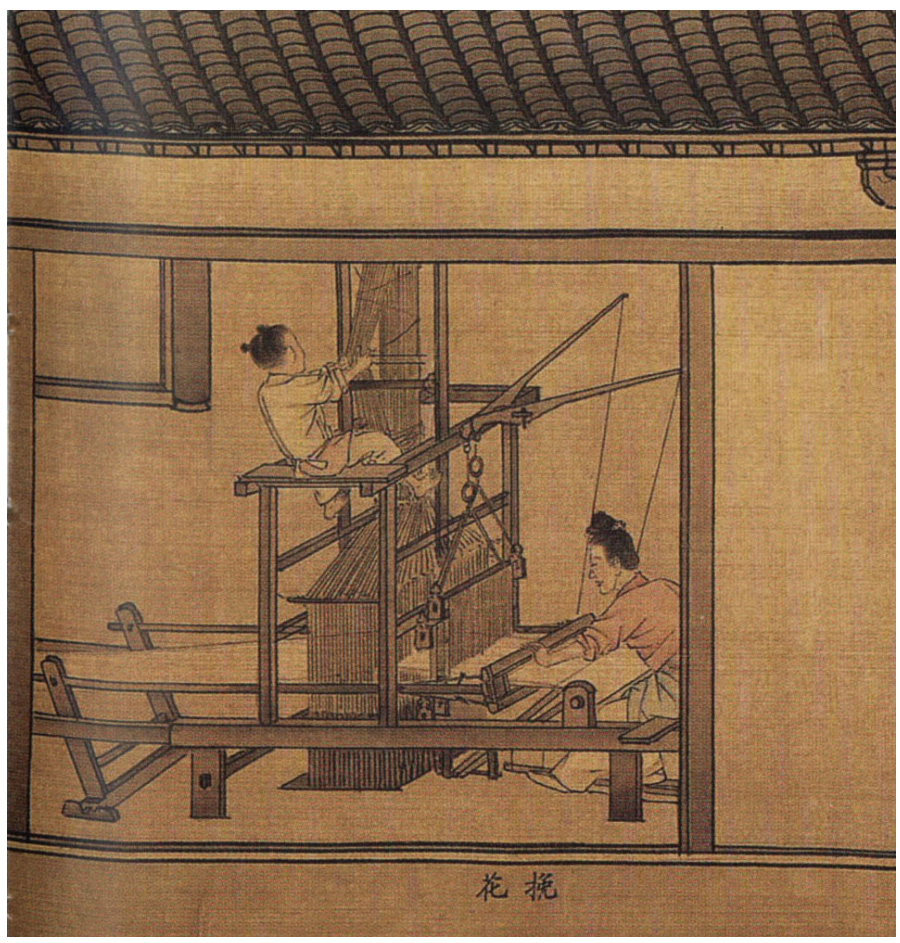

Fig. 6.15: Painting of drawloom, 12th century (Courtesy of the Helongjiang Museum).

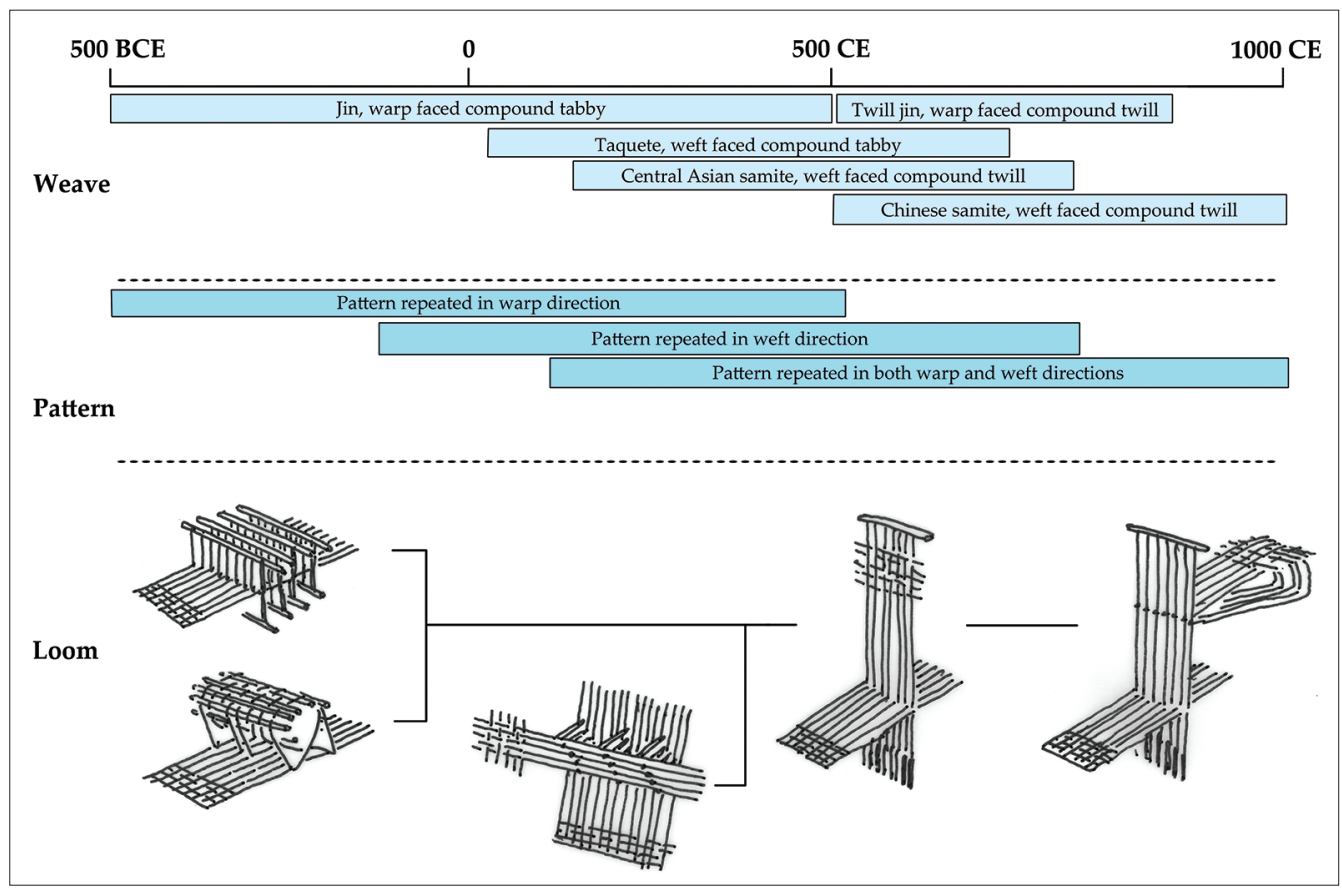

Fig. 6.16: The development of weave, pattern and loom (Drawing: @ Zhao Feng; graphics: Long Bo). 


\section{The Development of the Pattern Weaving Technology Along the Silk Road}

Now we can come to a conclusion. As shown in the sketch (Fig. 6.16), the developments of weave, pattern, and loom did not take place at the same speed, and it is not possible as yet to ascertain their exact development separately. However, taken together, all three aspects enabled a system of technology to develop over time. In this development, the exchange of knowledge and technology through textile encounters, whether through commerce or diplomacy, was crucial. Both China and the countries to its west mutually benefitted from their textile encounters on the Silk Road.

\section{Further Reading}

Kaneo Matsumoto and Jodai Gire (1984) 7th and 8th century textiles in Japan from the Shoso-in and Horyu-ji, Shikosha, Kyoto.

Rodolphe Pfister and Louisa Bellinger (1945) The Excavations at Dura-Europos, Part II: The Textiles.

Dorothy G. Shepherd and W. B. Henning (1959) Zandaniji Identified? In R. Ettinghausen (ed.), Aus der islamischen Kunst: Festschrift fur Ernst zum 75. Geburtstag, pp. 15-40.

Textile Manufacture of Fergana in Antiquity and the Middle Ages (2010) The Institute of Archaeology, Academy of Sciences of Republic of Uzbekistan of Samarkand.

Jon Thompson and Hero Granger-Taylor (1995-1996) The Persian Zilu Loom of Meybod, CIETABulletin 73, pp. 27-53.

James C. Y. Watt and Anne E. Wardwell (1997) When Silk Was Gold: Central Asian and Chinese textiles.

Li Wenying (2008) Excavations of fabric and garment in Tomb 95BYYM15 from Yingpan, ISAT/ Costume.

Xinjiang wen wujuetc, xinjiang wen wuguji da guan, xinjiangmeishu she yingchu ban she, Urumqi, 1999 (Xinjiang Uyghur Autonomous Region Bureau of Cultural Heritage etc., A rand View of Xinjiang's Cultural Relics and Historic Sites, Urumqi). 


\title{
7 The Earliest Cotton Ikat Textiles from Nahal 'Omer Israel 650-810 CE
}

\author{
ORIT SHAMIR AND ALISA BAGINSKI
}

Orit Shamir is currently the Curator of Organic Materials, Israel Antiquities Authority. She holds a PhD in Archaeology and wrote her thesis on Textiles in the Land of Israel from the Roman Period till the Early Islamic Period in the Light of the Archaeological Finds. Her MA thesis in Archaeology was on Textile Production in Eretz-Israel at the Iron Age in the Light of the Archaeological Finds. She has researched and published widely on textiles. Her articles can be seen at: <https:antiquities.academia.edu/ OritShamir>.

Alisa Baginski is a retired senior lecturer of textile history. She was the creator of the textile study collection at the Shenkar College of Textile Technology and Fashion at Ramat-Gan, Israel. She has published widely on textiles, among others, Later Islamic and Medieval textiles from excavations of the Israel antiquities authority, Textile History, 2001, vol. 32, no.1, pp. 81-92 and a book on Coptic textiles, Textiles from Egypt 4th-13th centuries CE (1980).

Their most recent joint publications are Shamir and Baginski, Textile Hoard from Jericho Cave 38 in the Qarantal Cliff. Hoards and Genizot as Chapters in History (2013), pp. 77-88 and Shamir and Baginski, Textile Treasure from Jericho Cave 38 in the Qarantal Cliff Compared to other Early Medieval Sites in Israel. Textile Society of America Symposium Proceedings (2013), pp. 1-11.

Readers of this chapter may also find the following of interest: Baginski and Shamir Early Islamic Textiles, Basketry and Cordage from Nahal 'Omer, Israel. 'Atiqot (1995), 26, 21-42; Shamir, Textiles from Nahal Shahak, Israel. 'Atiqot (1995), 26, 43-48; Shamir, Byzantine and Early Islamic Textiles Excavated in Israel. Textile History (2001), 32, 93-105; Shamir, Textiles and their Find Spots: Finds from Along the Spice Route Joining Petra and Gaza. In S. Schrenk (ed.), Textiles in Situ: Their Find Spots in Egypt and Neighbouring Countries in the First Millennium CE, (2006), pp. 185-194.
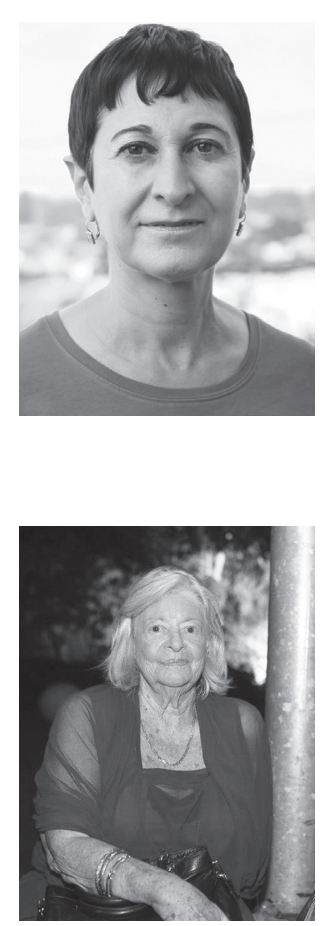

The textiles excavated at Nahal 'Omer in Israel's 'Aravah Valley display a remarkable variety of materials, techniques and dyes, suggesting diverse geographical origins. Most significant are a number of cotton fragments decorated in the warp-ikat technique, which constitute the earliest documented occurrence of this type of textile anywhere in the world.

The site is located c. $40 \mathrm{~km}$ northwest of Petra on the western edge of the 'Aravah with a spring nearby. It appears to have been a farming village on the Spice Routes 
joining Petra, in the Edom Mountains of present-day Jordan, and the mercantile outlets on the Mediterranean Sea, notably Gaza and El Arish (Fig. 7.1). These routes also led to Egypt, to the Arabian Peninsula, to Yemen, to parts of the Persian Gulf and the sea-routes to India, as well as to Mesopotamia, Central Asia, and from there all the way to China. The caravans carried a variety of trade goods as well as spices which were a major economic asset during the Roman, Byzantine and Early Islamic periods. The caravans were also used by pilgrims headed for Mecca (Fig. 7.2). This route had also existed earlier during the Nabataean period (1st century BCE-3rd century CE) (Erickson-Gini and Israel 2013).

The one-dunam ( $0.1 \mathrm{ha}$ ) site is situated on the eastern bank of Nahal 'Omer, and includes remains of 17 rectangular units of dwelling and a mosque occupied during the Early Islamic Period (between 650 and $810 \mathrm{CE}$ ). The date of this material, provided by its archaeological context, has been confirmed by carbon-14 analysis.

Preserved by the arid climate, most of the textile material, much of which had been cut into small pieces, was discovered in middens (waste dumps) and also included basketry and cordage items. Only a few samples were recovered from the remaining ruins of the buildings. The small number of textiles and other artefacts including simple and poor ceramic vessels found in association with these buildings indicate that the

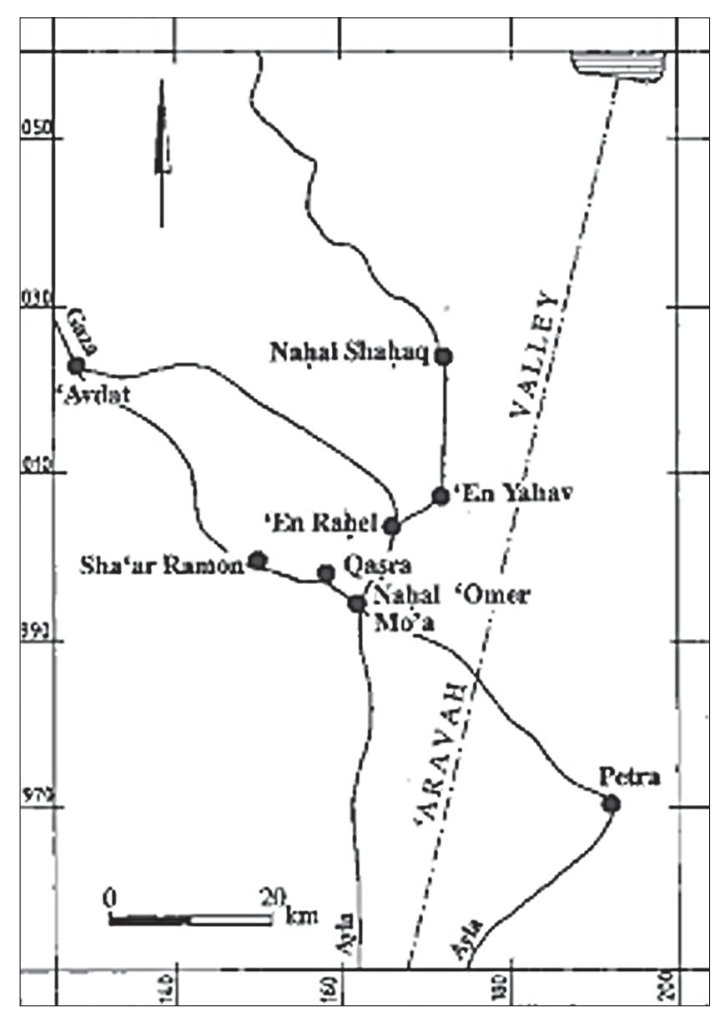

Fig. 7.1: Location of Nahal 'Omer and nearby Spice Route sites (After Baginski and Shamir 1995, p. 21). site was used only for a limited period - the Early Islamic period, having been abandoned by its inhabitants when the route changed its path, moving away from Nahal 'Omer. It is probable that the site provided caravans with shelter, limited water, fodder, and other amenities. This village probably offered welcome relief as long-distance caravan trade was fraught with dangers, such as winter torrents, intense summer heat, and limited water sources, not to mention the danger of enemy raids as occurred in the way stations during the Nabatean period (Erickson-Gini and Israel 2013, 25).

We studied and catalogued 251 textile fragments. Many of the discarded cut and torn pieces appear originally to have come from garments. The composition of the Nahal 'Omer assemblage is remarkable for its high proportion of cotton textiles -153 out of 251 , as cotton is rarely found in 


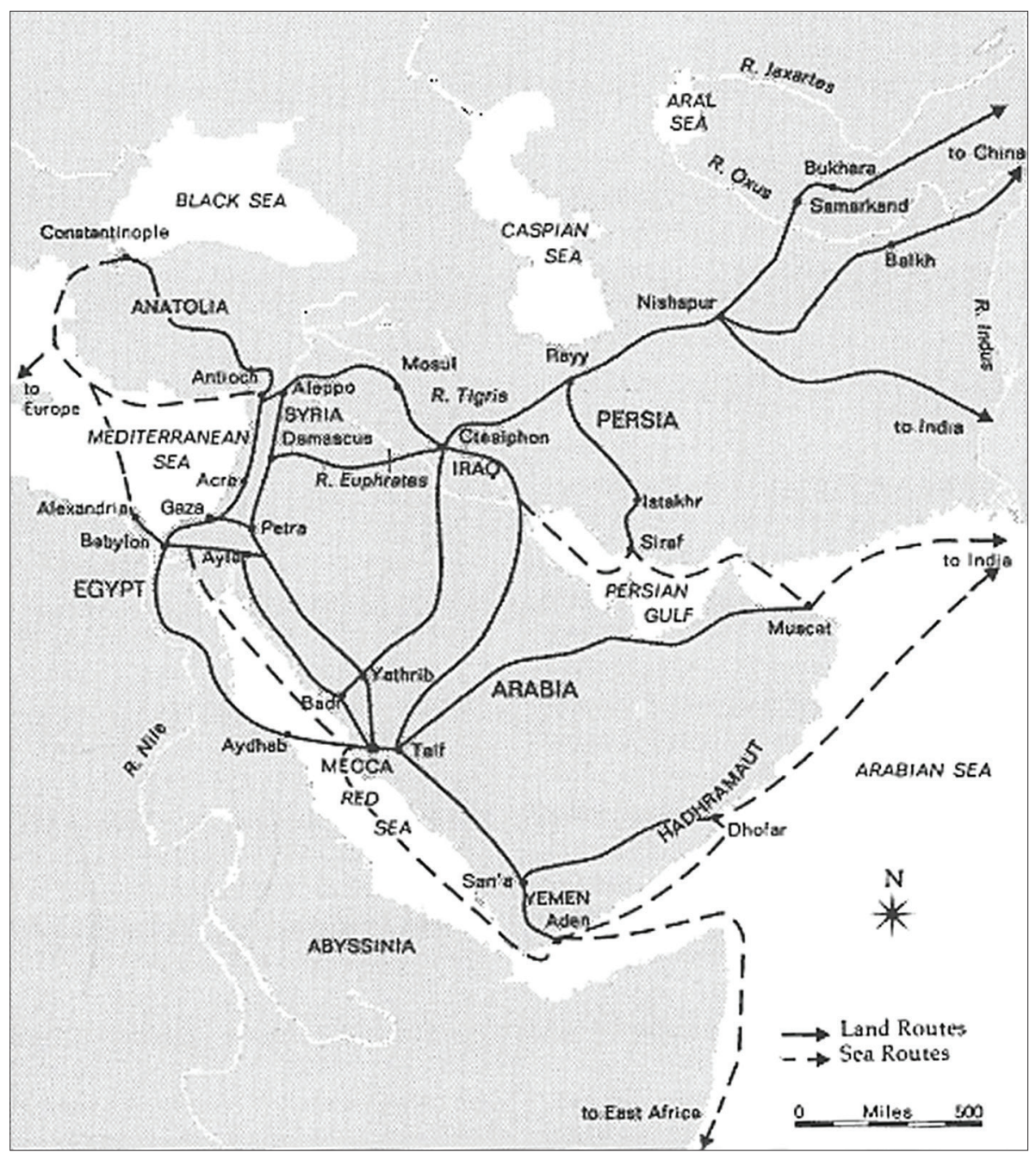

Fig. 7.2: Map of international trade routes at the dawn of the Islamic period (After D. Stewart (1969) Early Islam, p. 13).

this period. Only 4 other cotton textiles have been recovered in other sites from this period in Israel, and it has also been only found in small quantities in the Byzantine period. Three textiles are made of silk, the only silk textiles discovered in the Land of Israel during this period. The other textiles are made of wool or linen.

A small group of eight cotton fragments from Nahal 'Omer are decorated in warpikat technique (Figs 7.3, 7.4, 7.5 and 7.6). This technique forms a pattern by tying, and thus reserving, portions of the yarn - either warp, weft, or both - before dyeing. In warp ikat, only the warp threads are reserved in this manner; the weave structure of the fabric is warp-faced tabby. Weavers who need more precise patterning use warp ikats, where they can see the pattern on the loom. 


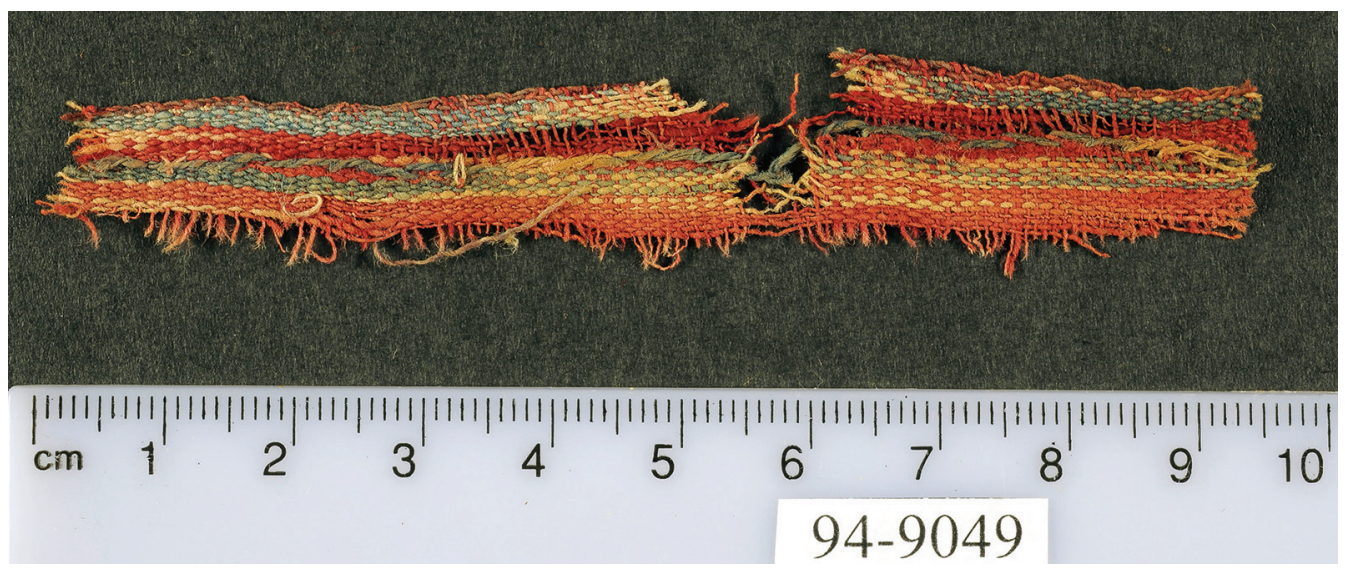

Fig. 7.3: A fragments of the cotton warp ikats found at Nahal 'Omer (@ Israel Antiquities Authority; photo: Clara Amit).

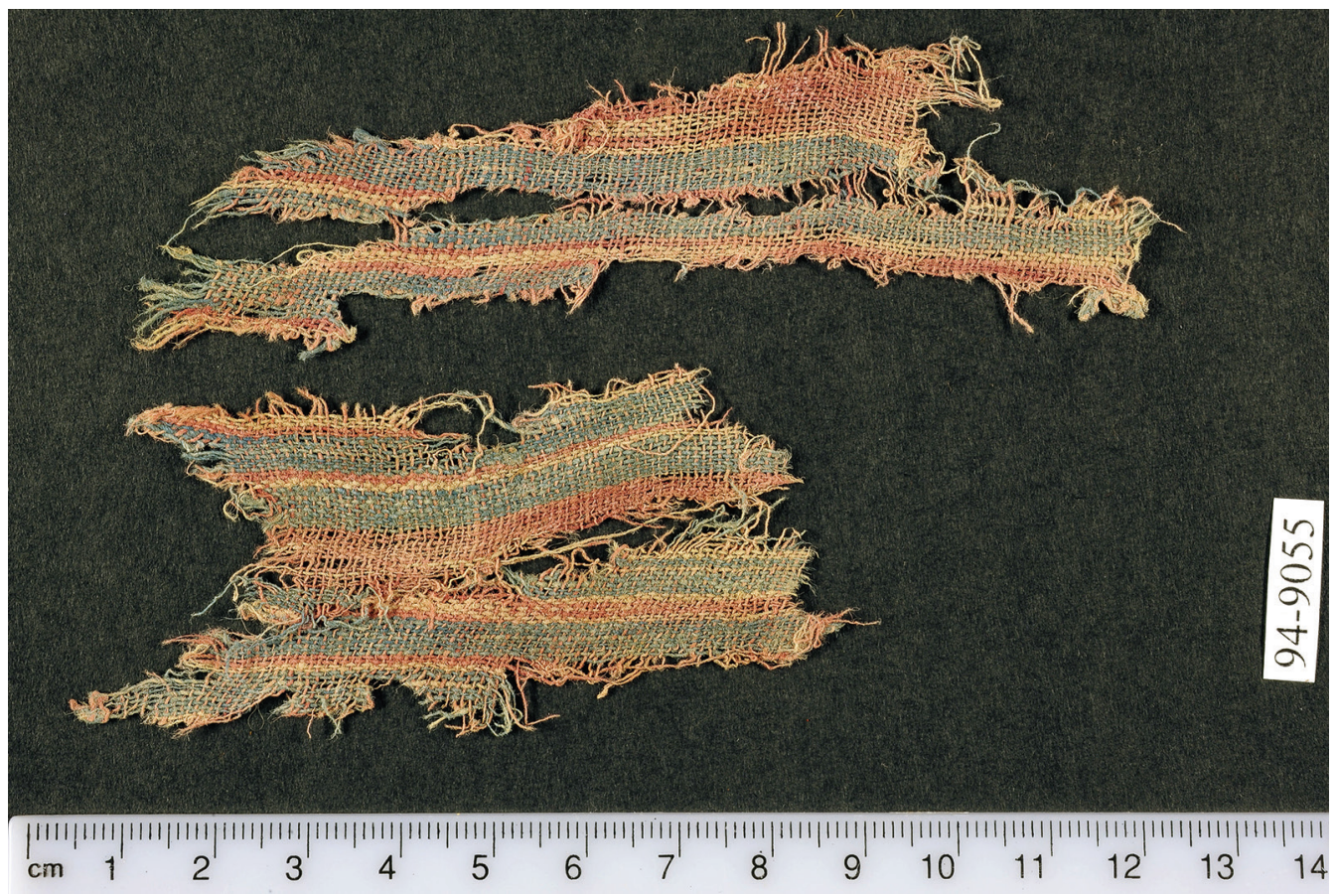

Fig. 7.4: A fragment of the cotton warp ikats found at Nahal 'Omer (@ Israel Antiquities Authority; photo: Clara Amit).

The greater the number and the closer the spacing of warp elements in relation to weft, the more the warp will tend to conceal the weft. If the warp elements hide the weft elements completely, the weft will affect the fabric only by its appearance, and the fabric is said to be warp-faced. Tabby is the simplest and commonest of all weaves. A basic binding system or weave based on a unit of two ends (warp) and two picks (weft), 


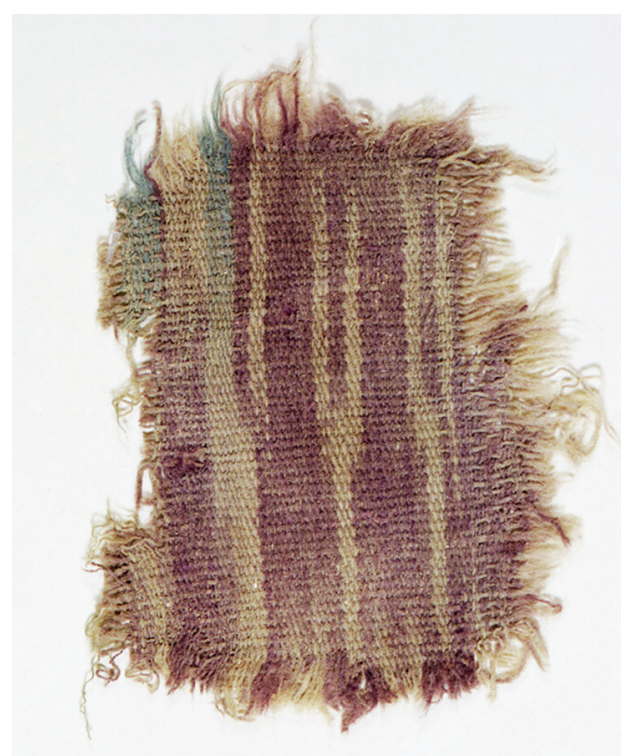

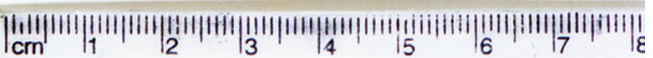

Fig. 7.5: A fragment of the cotton warp ikats found at Nahal 'Omer (@) Israel Antiquities Authority; photo: Clara Amit). in which each end passes over one pick and under the other pick (Burnham 1980, 139). The principle of the weave is that each weft thread passes under and over a single warp-thread. One of its variations is warp-faced, another variation is weftfaced, and a third is extended tabby, with the weft barely visible.

The term ikat, a derivative of the Malay-Indonesian word mengikat meaning 'to tie, to bind', is possibly related to the Semitic root 'qd (Bühler 1972, 31), which carries a similar meaning, for instance, compared with the use of the root in the biblical narrative of the binding of Isaac (Genesis 22:9). The term could have been introduced to the Far East by Near Eastern textile merchants. It seems that ikats were status symbols because of the skill and time their production required.

This intricate technique requires particular expertise in preparing the warp, while the simple weave can be

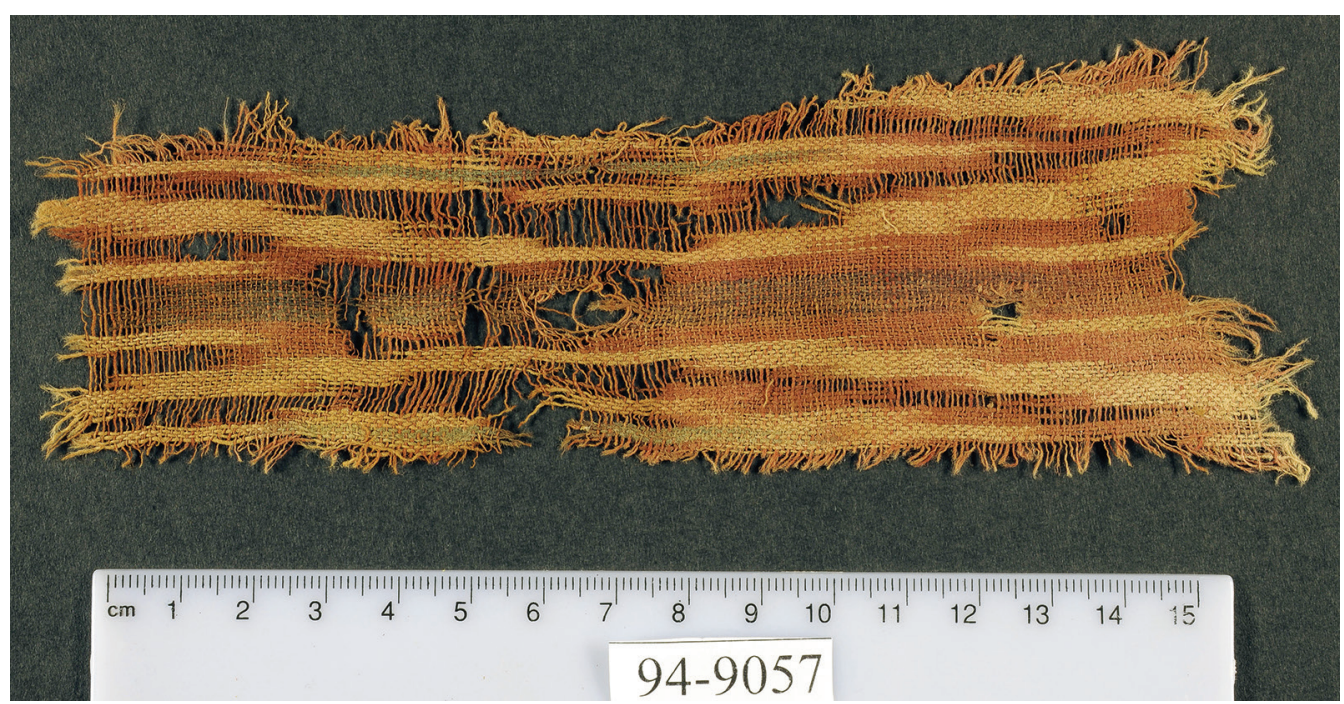

Fig. 7.6: A fragment of the cotton warp ikats found at Nahal 'Omer (๑) Israel Antiquities Authority; photo: Clara Amit). 
performed by less skilled persons. The warp is tie-dyed before weaving to create designs on the finished fabric. The precision of the wrapping determines the clarity of the design. After wrapping, the warp threads are dyed. When finished and unwrapped, the areas under the ties have stayed the original colour. The ikat technique is also practised today, for example in India and Uzbekistan (Fig. 7.7) and it continues to inspire modern designers.

These warp ikat threads are coloured in blue, brown, cream, reddish-brown, red, cream and tan or combinations of these colours dyed with madder (reddish brown and brown) and indigo (blue). Madder (Rubia tinctorum) and indigo could be produced in India or Israel. The patterns consist of 'feathers' and/or lozenges. All the ikat cloths at Nahal 'Omer have threads that are Z-spun - clockwise spun fibres by a spindle, 18-28 threads per $\mathrm{cm}$. Other cotton textiles from Nahal 'Omer are S-spun (i.e. anti-clockwise), the dominant spin direction for thousands of years in the Land of Israel.

Ikat-decorated textiles resembling those discovered at Nahal 'Omer are depicted in cave paintings of the Vakataka Period (late 5th to 6th centuries CE) in Ajanta, India (Fig. 7.8) (Caves 1 and 17: Murti (1974/1977), fig. 114, 471 and 480; Bühler 1972 [III]: 147, 148; fig. 26). There are also several silk fragments of the Asuka Period in Japan (552-644 CE) with warp ikat of a different pattern (Bühler 1972 [I], 23).

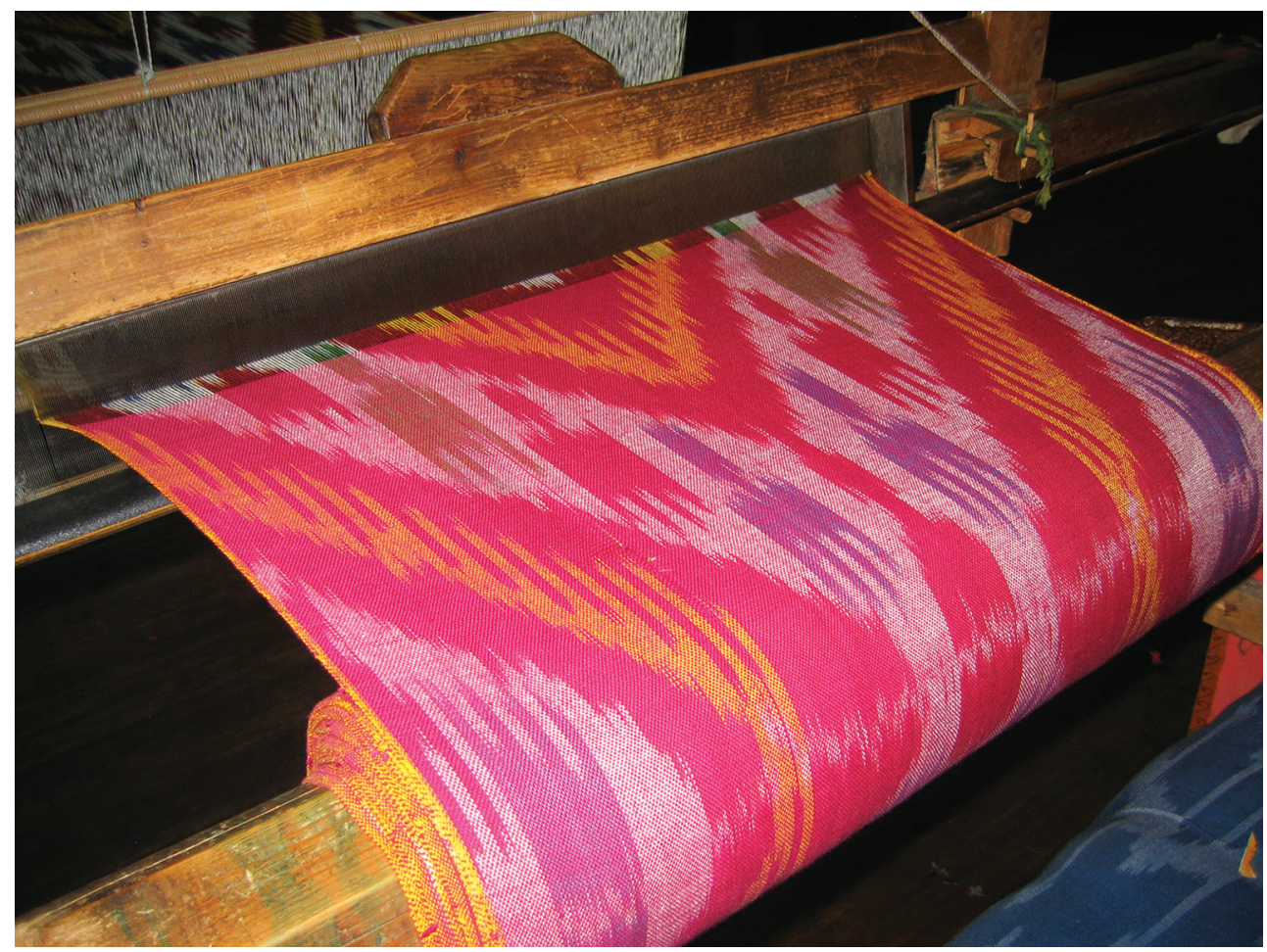

Fig. 7.7: Uzbekistan, ikat (Photo: (C Zvi Shamir). 


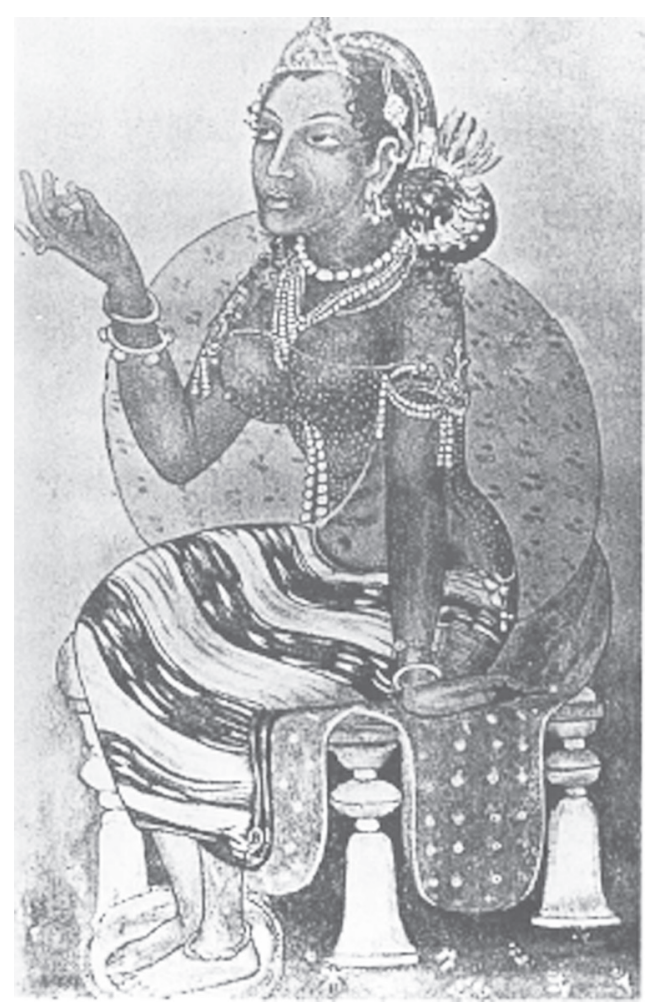

Fig. 7.8: Ikat garment depicted in cave-painting; Ajanta, India (Baginski and Shamir 1995, p. 29, fig. 26. After Madanjeet Singh (1954), India-Paintings from Ajanta Caves, PI. 2 Photo: Madanjeet Singh, UNESCO 1954; reproduced by permission of UNESCO).

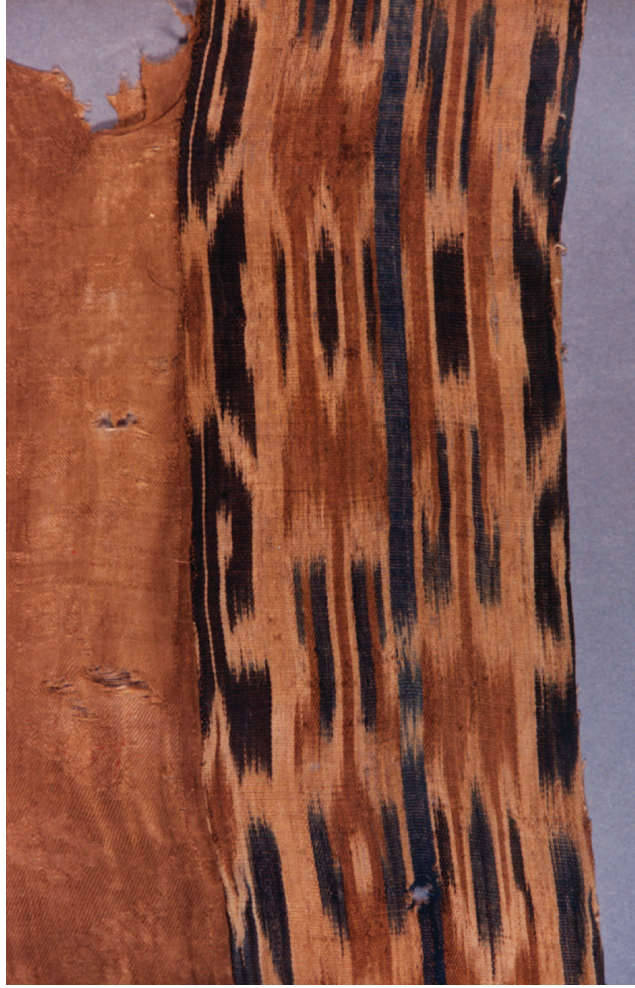

Fig.7.9: A detail of a silk ikat edge on a garment fragment from Dulan, China (Kind permission of Zhao Feng; Qinghai Provincial Cultural Relics and Archaeology Institute).

Some silk fragments with warp ikat were discovered in China in the excavations of Dulan (Qinghai), 8th century CE (Xu 2002, 106; Zhao and Wang 2013, 377) (Fig. 7.9).

The hitherto earliest known cotton ikats were discovered in Egypt (Buhler 1972 [I], 23). The inscriptions they bear reveal their date as 862-864 CE, and their origin in the Tiraz workshops of San'a, Yemen (Bühler 1972 [I]; see also Golombek and Gervers 1977, 92, 98 and 99). The fragments from Nahal 'Omer resemble the Yemenite ikats in patterns, material (cotton), twist direction of the yarn (Z-spun) and thread counts.

Cotton was not grown in the arid 'Aravah or anywhere in the Land of Israel until the 9th century CE; thus, the source of the many cotton textiles must be sought outside the region. The dominance of Z-spun yarns, the typical spin direction for cotton yarns in India and Yemen, contrasts with the local yarn which was twisted in the opposite direction, i.e. S-spun. The ikat decoration also suggests that they were produced at a distant point along the trade route.

During the Umayyad period (660-750 CE) Alexandria was a major commercial centre and point of convergence for goods and people from distant lands. The Frankish 
bishop and pilgrim-traveller Arculf, who visited the region in about $680 \mathrm{CE}$, reports on Alexandrian trade in goods from Ramlah in Palestine, the Arabian Gulf and the Far East (Baldry 1982, 10). As Nahal 'Omer was situated on the road leading from Petra and/or the Red Sea to the Mediterranean, with Ramlah en route, some of the textiles discovered there might have been part of this trade.

The cotton warp ikats, resembling those originating in Yemen and found in Egypt, might have been made in Yemen. However, there is no evidence that the $i k a t$ technique originates in Yemen, and thus it may have been introduced from India. The abovenamed famous wall paintings in the Ajanta Caves and artefacts discovered in Central Asia depict $i k a t$ decorated textiles, which resemble the ikats from Nahal 'Omer as well as those found in Fustat originating from Yemen. From India the techniques spread west as well as east, via the trade routes to China from where the silk warp-ikats most probably originate. An Indian origin for the Nahal 'Omer ikats should also be considered in view of the similarity of the patterns on the textiles to those depicted in the Ajanta cave paintings.

Indeed, by the 6th century $\mathrm{CE}$, a sea route had been established between the west coast of India and Dhofar in southern Arabia, whence goods were transported by land through Yemen and Mecca to Egypt, Syria and the Byzantine provinces.

The Nahal 'Omer ikats constitute the earliest cotton warp ikat decorated textiles excavated in a documented archaeological site to date. Although we have no conclusive evidence regarding their origin, we believe that they were brought to the site by travellers from Yemen or India (Fig. 7.10). It is also possible that the ikat technique developed independently across many different cultures and continents.

The quality of the textiles at Nahal 'Omer attests to the prosperity of the site's inhabitants and the travellers who frequented it. These finds contrast sharply with the rather drab assemblages characterizing nearby sites of the same period. Wool was still dominant in Israel during the Early Islamic Period in sites, such as 'En Evrona, 'En Yahav, Nahal Shahaq and Yotvata except for Nahal 'Omer where cotton is predominant. Nahal 'Omer is the only site in the Land of Israel where silk and cotton textiles were found from the Early Islamic Period, and which can testify to textile encounters with faraway lands.

\begin{tabular}{lll}
\hline Country & Date & Material \\
\hline India & $\begin{array}{l}\text { End of 5th century CE-beginning of 6th } \\
\text { century CE }\end{array}$ & Cotton \\
Japan & End of 5th century CE-beginning of 6 century CE & Silk \\
Nahal Omer & 7th century CE & Cotton \\
China & 8th century CE & Silk \\
Yemen (found in Egypt) & 9th century CE & Cotton \\
\hline
\end{tabular}

Fig. 7.10: Table of $i k a t$ finds (@ The authors). 


\section{Acknowledgements}

We would like to thank Dr Tali Erickson-Gini and Dr Yigal Israel for the unpublished information about Nahal 'Omer.

\section{Further Reading}

John Baldry (1982) Textiles in Yemen: Historical References to Trade and Commerce in Textiles in Yemen from Antiquity to Modern Times. British Museum Occasional Paper 27.

Dorothy K. Burnham (1980) Warp and Weft: A Textile Terminology.

Alfred Bühler (1972) Ikat Batik Plangi. 3 vols.

Rosemary Crill (1998) Indian Ikat Textiles.

Tali Erickson-Gini and Yigal Israel (2013) Excavating the Nabataean Incense Road. Journal of Eastern Mediterranean Archaeology and Heritage Studies 1, pp. 24-53.

Lisa Golombek and Veronika Gervers (1977) Tiraz Fabrics in the Royal Ontario Museum, in V. Gervers (ed.), Studies in Textile History in Memory of Harold B. Burnham, pp. 82-125.

Sivarama Murti (1974/1977) L'art en Inde/The Art of India.

Lotika Varadarajan and Krishna Amin-Patel (2008) Of Fibre and Loom: The Indian Tradition.

Xu Xinguo (2002) Dulan Burial Ground, in Zhao Feng (ed.), Recent Excavations of Textiles in China, pp. 72-109.

Feng Zhao and Le Wang (2013) Glossary of Textile Terminology (Based on the Documents from Dunhuang and Turfan). Journal of the Royal Asiatic Society, vol. 23, pp. 349-387. 



\title{
8 Northerners: Global travellers in the Viking Age
}

\author{
EVA ANDERSSON STRAND
}

Eva Andersson Strand is an archaeologist and associate professor at The Danish National Research Foundation's Centre for Textile Research, SAXO Institute, University of Copenhagen, Denmark. Previously she was a lecturer in Archaeology at Lund University, Sweden. Her primary research areas constitute textile production and craft organisation in Scandinavia during the Iron Age and Viking Age. Additionally, she works with textile production in the Bronze Age Mediterranean and with Experimental Archaeology. She has published numerous works within her research fields, amongst others, articles on the organization of Viking Age textile production. She organized, with Mary Harlow, a workshop in Amman, Jordan along with the Jordan Museum and the University of Leicester on Textile Craft - An Intangible Cultural Heritage. (For results of the workshop, see the blog www.traditionaltextilecraft.dk).

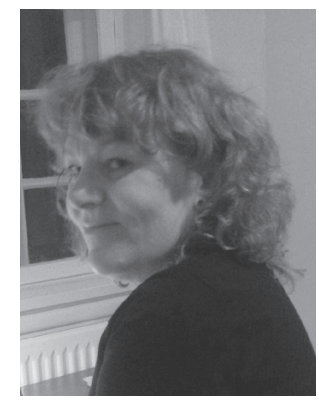

The history of the Vikings, or more correctly, the Northerners still fascinates people all over the world but, in contrast to the imaginary picture of people as horrifying pirates with horned helmets, today, evidence from both written sources and archaeological investigations gives another and more elaborated image.

Their homeland was Scandinavia in Northern Europe but these people were wellknown explorers, merchants and warriors who raided and colonized wide areas from the late 8th to the early 11th centuries. In Europe, they colonized parts of the British Isles and they plundered northern France. In the west, they went to the Faroe Islands, Iceland, and Greenland and long before Columbus, to North America.

In the east, the Northerners also travelled with their longships as far as Constantinople and via the Volga River in Russia, to the Caspian Sea. They may have been known in Eastern Europe as the Rus'. Contemporary Islamic written sources describe them as different from their neighbours, the Slavs in everything from dress to lifestyle. The Rus' expanded east colonising and/or trading and founding trading posts. The dress of the Rus' is described as elaborate with caftan-like coats and wide trousers (Fig. 8.1). Furthermore, when describing the Rus', men, women and children are all mentioned. Another group is the Varangians, sometimes described as an entirely different group from the Rus'. However the Varangians were probably a group of Scandinavian warriors who were serving in the Byzantine military and are 


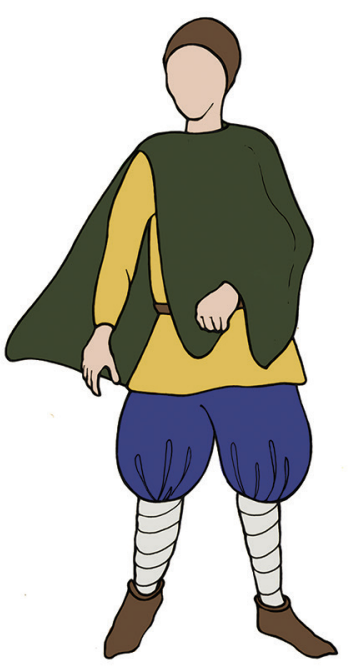

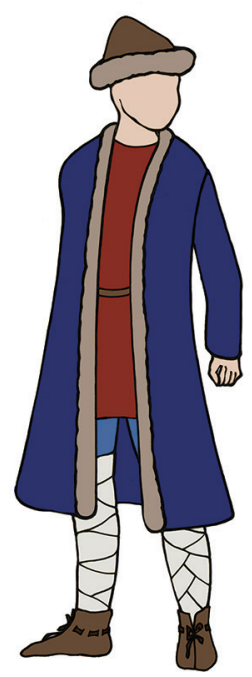

Fig. 8.1: Viking costumes documented in Hedeby (Haithabu in present-day Germany) (Graphics: Sidsel Frisch after Andersson, 2003, p. 42, fig. 11 (Drawing by Tina Borstam after I. Hägg, Die Textilfunde aus dem Haafen von Haithabu, mit Beitragen von G. Grenander Nyberg und H. Schweppe. Berichte über die Ausgrabungen in Haithabi, 20, 1984; I. Hägg Textilfunde aus der Siedlung und aus den Gräbern von Haithabu. Beschriebung und Gliederung. Berichte über die Ausgrabungen in Haithabu, 29, 1991 and Hägg's reconstruction drawing in $\mathrm{H}$. Elsner, Wikinger Museum Haithabu: Schaufester einer frühen Stadt, 1992).

described as men of fearful appearance, dressed in fearful garb - but with no horns on their helmets (Heidenstierna-Jonson 2006, 75-81).

Although the majority of the people were farmers who lived on individual farms or in small hamlets, archaeological evidence from excavations also indicates that some people were living in different types of settlements, e.g. mansions, ports of trade and small towns. There is also obvious evidence of specialised craftsmanship at some sites, for example a production of exclusive jewellery from gold, silver and bronze, elaborate bone and antler work found, for instance in combs, needles and amber objects. Furthermore, the archaeological material confirms that they were working with iron and wood as well as with textile crafts, as they built ships and manufactured big sails so that they could sail all over the world.

The Northerners were also merchants: silver, gold, silk, salt and textiles are examples of what they imported, while they exported furs, tar, honey, amber and perhaps iron and textiles. Certainly many objects reached Scandinavia not only through exchange or trade but also via plundering and remuneration for various services, for example for serving as warriors for various rulers.

In Viking Age society, as in most ancient societies, there was a need for a wide variety of textiles: textiles for clothing, ranging from utilitarian, everyday dress to elite costumes; textiles for furnishing, such as bedding, wall-hangings, carpets and coverings, as well as textiles for a variety of other purposes, such as bags and sacks and, perhaps most importantly, textiles for sails and tents. Unfortunately, no completely preserved costumes dated to the Viking Age have been found, however, there are thousands of textile fragments from different burials that give information on raw material, weaving technique and so forth. Furthermore, there are some depictions of the Northerners, and finally there is information in written texts, for example the Icelandic sagas. Here, we find desciptions of the different types of garments, like shirts, cloaks, trousers, shoes, 
gloves and so on that men and women wore as attire. Additionally, the sagas also mention high-status costumes; military costumes; simple clothing; worn out dress; even magic garments; and textiles given as gifts and textiles for exchange and trade.

Whether the settlement was large or small, textile manufacture for everyday use must have taken up a great deal of time. Knowledge and ability to produce textiles would have been lodged in more than one person, and several people must have been involved in the production process which included the harvesting of fibres, preparing them for spinning, weaving, various finishing processes and finally sewing them into clothing and other products.

About $6 \mathrm{~kg}$ of fibres and 42,000 m spun yarn would have been needed to make two complete Viking Age costumes in a coarse quality for a Viking couple: a male and female (Andersson 2003, pp. 47-48). In order to make 300 outfits, no less than $900 \mathrm{~kg}$ of fibres and 6,300,000 $\mathrm{m}$ spun thread would have been required. As previously mentioned, they also had textiles in their home, like tapestries, tablecloths and bedclothes. The demand and supply of textiles for household needs would have been quite substantial.

But most important of all, sail- and tent cloth were in great demand during the Viking Age. Sails must have been considered just as valuable as the actual ships themselves. Sails are mentioned as gifts and valuable items in the Icelandic sagas and the only time a saga mentions a man weeping is after he lost his sail (Olav den Heliges saga 2:166). A larger longship of 30 pairs of oars would have required a sail of around 120 square metres, while for a smaller trading vessel, 46 square metres may have been sufficient. The main raw material for sails was presumably wool. The tradition for sails made of wool continued upto and including the 19th century in areas such as Iceland and the Faroes. Today, several woollen sails have been reconstructed, and have proved as efficient on the sea as sails made of flax, hemp or synthetic materials. Their size was adapted to that of the vessel, as was the cloth and the quality of the yarn. The production of sailcloth requires a substantial amount of raw material and also a great deal of preparation and weaving time. For a sail of 100 square metres, and with a weight of 500 gr per square metre, hypothetically, at least $50 \mathrm{~kg}$ of wool would have been needed; this is equivalent to 150 sheep. A sail-cloth with a density of 10 threads per $\mathrm{cm}$ is equivalent to a thread quality of $4,000 \mathrm{~m}$ per $\mathrm{kg}$ of wool. The length of spun thread for a sail of 100 square metres runs up to $200,000 \mathrm{~m}$.

One of the most well known Viking towns is Birka is situated on Björkö, a small island in Lake Mälaren, Sweden. Here, there is clear evidence of both international trade and specialised craftsmanship. The settlement area covered an area around 7 hectares of which $6-7 \%$ is excavated. The estimated number of graves outside the settlement area is around 3,000 (Fig. 8.2). The site is dated to 750-970 CE. Here a large number of textiles, approximately 4,800 fragments and also 2,500 textile tools are preserved. The textiles are all from burials, mostly from very rich chamber burials. The analyses of these finds have yielded unique knowledge of various costume details, as well as of raw materials, techniques, and manufacture.

The raw material was, in general, sheep wool and flax. The linen is usually woven in tabby, a simple weaving technique. Furthermore, there are several different types 


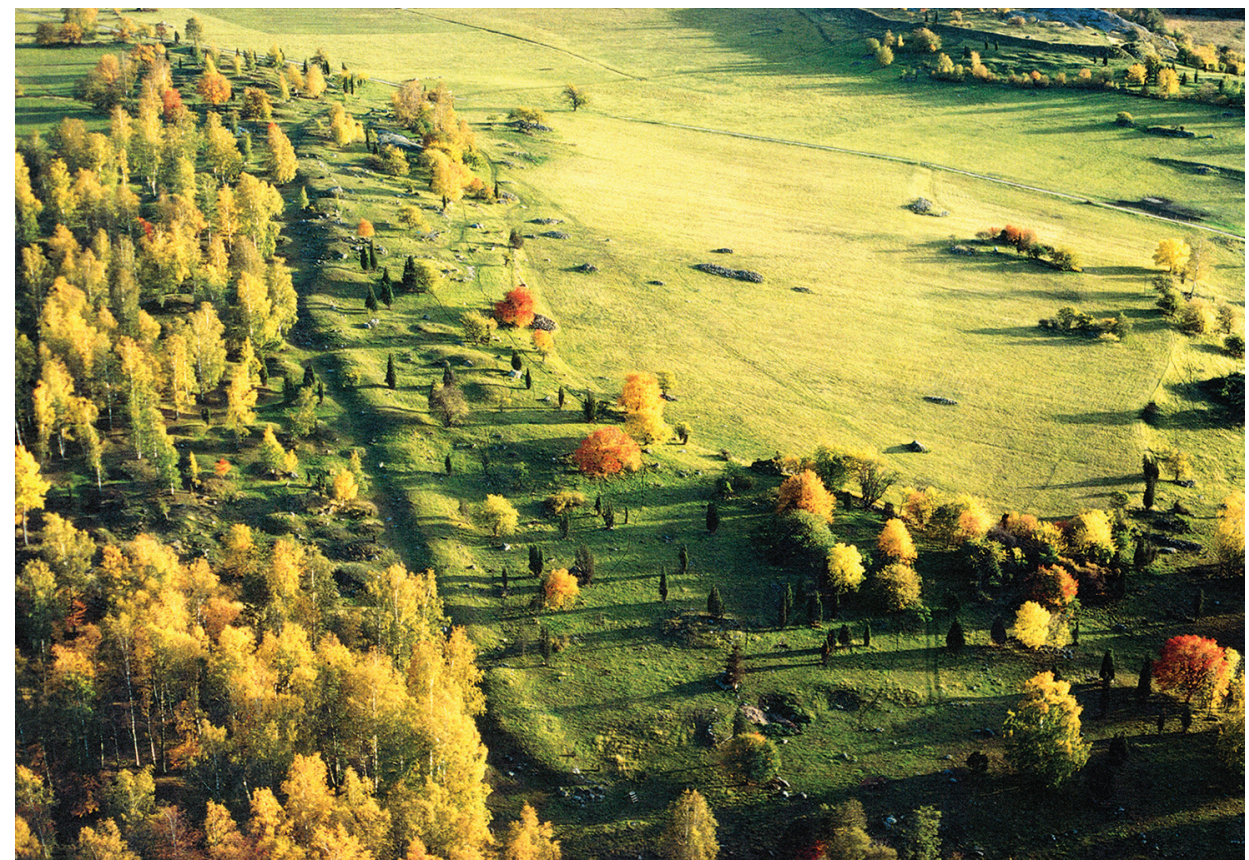

Fig. 8.2: Hemlandet, one of several grave fields on Björkö, outside the Viking town Birka, Sweden (Photo: Courtesy of Björn Ambrosiani ()).

of wool textiles from coarser tabbies to elaborate diamond twills with many threads per $\mathrm{cm}$ (55-60/17 threads/cm). Besides these textiles which are mainly used for costumes, there are also other types of textiles, for example tapestry weaves. These types of textiles could also have been used for bedding, pillows or something similar.

In Birka there are also many finds of tablet-woven bands. Sometimes, the warp is of silk and the weft of silver or gold and the patterns are mostly geometric. Different types of passementerie (decorative trimming for clothes) have been used particularly on the male costumes. Some textiles have been embroidered also with quite elaborate patterns and with metal threads.

It is evident that some of the textiles were produced in Birka itself, but also that some of these textiles would have been imported. Of special interest are the silk fabrics that have also been found. In general, it is plausible that they have been used as decorations on the costumes. There is a unique piece, the only one of its kind from Viking Age Scandinavia (Fig. 8.3). The piece is woven with unspun silk threads (unraveled and unbroken long silk fibres from cultivated silk cocoons) and the ground weave is tabby with geometric patterns. There is gold on top of the silk and on some places, on the gold, passementerie. The passementerie is made of silver rings $c .0 .75$ $\mathrm{mm}$ thick (Fig. 8.4). Agnes Geijer suggested China as the provenence for the silk fabric and she based her conclusion on the pattern and on finds of analogous silk textiles (Geijer 1938, 66). Moreover, there are some other silk textiles from the same 


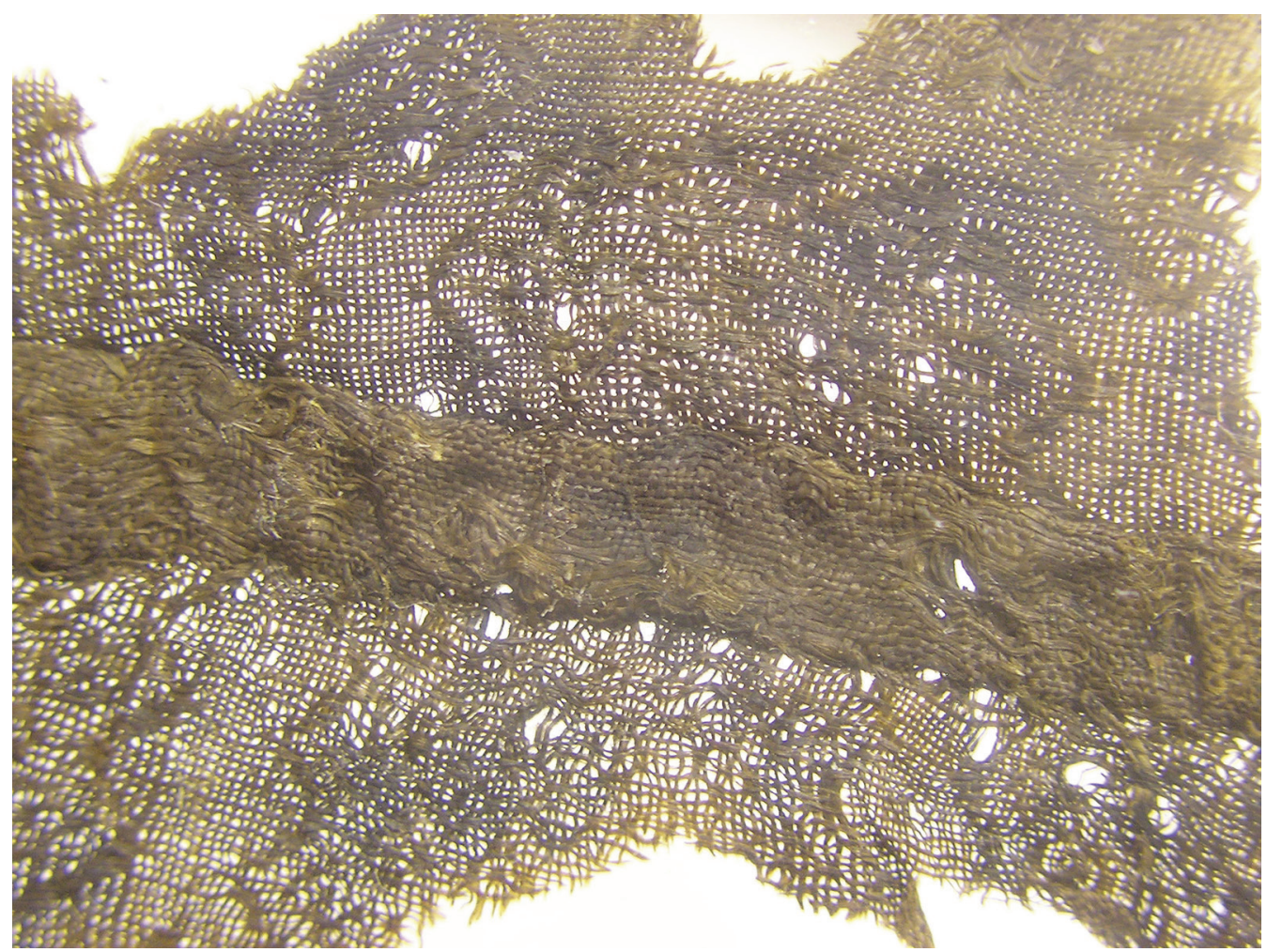

Fig. 8.3: A silk fabric of Chinese origin from the late 10th-century burial in Birka (Photo: Courtesy of Lise Raeder Knudsen (C).

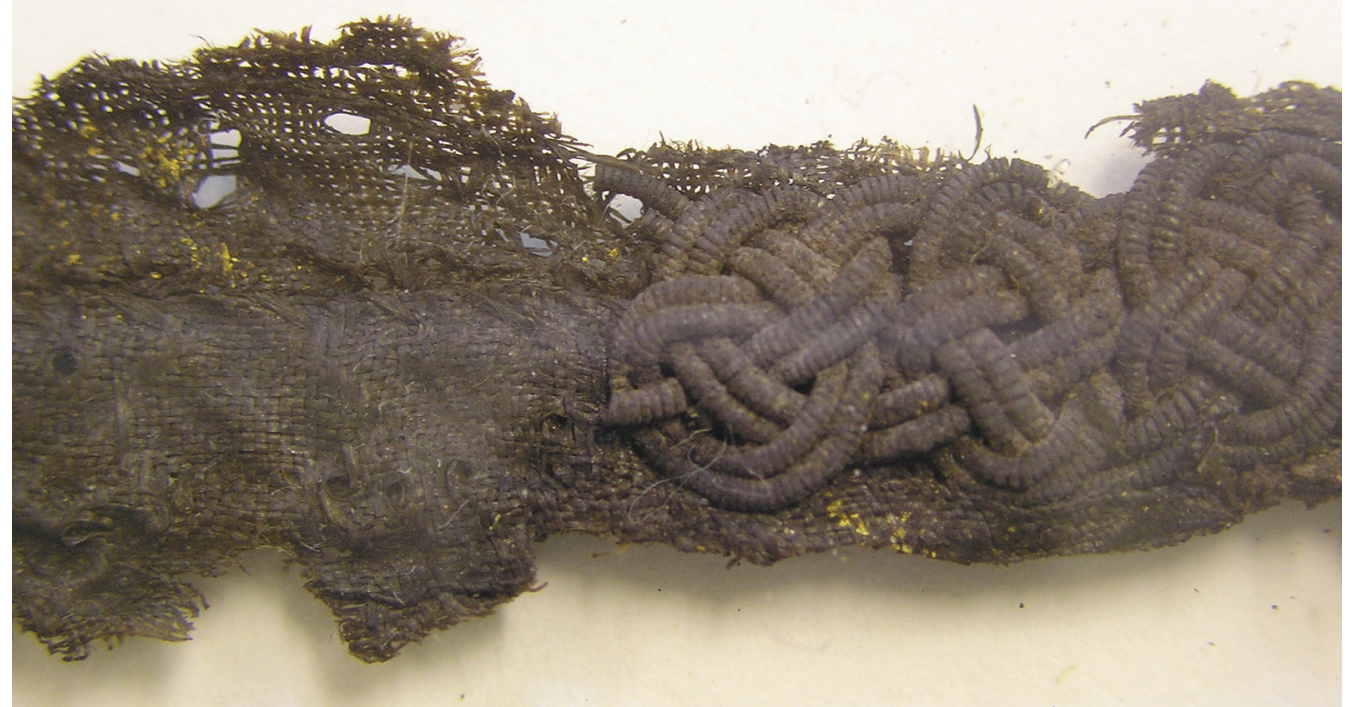

Fig. 8.4: A silk fabric of Chinese origin from the late 10th-century burial in Birka (Photo: Courtesy of Lise Raeder Knudsen (C). 
burial but they are in a different quality and technique. These types of silks are more common and could have come from Byzantium. Additionally, some passementerie work, tablet-woven bands with silk and silver threads, and finally, a fragment of a linen textile have been found in this grave context.

These fabrics are all from one very rich chamber burial (number 944) dated to the second half of the 10th century CE. It is a male grave and the man is buried with several exclusive items, for example a sword, a long knife, a shield, and furthermore, a horse and horse gear. Several of these objects have a clear connection to the south east, for example the falcon sword-chapes and the long knife, the silk textiles and the passementerie work. The textiles preserved are all very fragmentary and a complete costume cannot be reconstructed. The interesting question, however, is who this man was. One possibility is, indeed, that he was a foreigner coming from the east, but it is also plausible that he was one of the Northerners: a merchant, a warrior and/or an adventurer. He might have travelled all the way to Byzans (present-day Istanbul) himself but more likely together with a group. Another question is if he was one of the Varangians, and thereby a warrior participating in tribute gathering and raiding. The objects from this burial could have been given to him as gifts. However, he could also have been a trader who bought or exchanged the items in a market for valuable goods such as furs. Even if we cannot be certain, it is quite plausible that this man travelled himself, especially since this was a time when Northerners travelled, at least, as far as to the Empire of the Khazars and the Caspian Sea. Neither do we know how far he travelled, but we do know that he did come to Birka and that he was buried in a tomb with Scandinavian style objects, but also with exotic ones. Objects that tell us about encounters and connections with many places, and further, a desire for silk and exclusive textiles, all the way from China.

\section{Acknowledgements}

I kindly thank Björn Ambrosiani for constructive remarks and suggestions, Lise Raeder Knudsen for collegial discussions, and Mari-Louise Franzén and Charlotte HedenstiernaJonson for access to study material.

\section{Further Reading}

Eva Andersson (2003) Tools for Textile Production - from Birka and Hedeby.

Helen Clarke and Björn Ambrosiani (1991) Towns in the Viking Age.

Ulla Cyrus-Zetterström (1988) A monochrome patterned silk fabric among the finds from Birka, in Inger Estham and Margareta Nockert (eds), Opera Textilia Variorum Temporum: to honour Agnes Geijer on her ninetieth birthday 26th October 1988, pp. 45-48.

Agnes Geijer (1938) Die Textilfunde aus den Gräbern. Birka III.

Charlotte Hedenstierna-Jonson (2006) The Birka Warrior, the material culture of a martial society. Judith Jesch and Christina Lee, eds, (2014) The Wiley-Blackwell Encyclopedia of the Viking World. Marianne Vedeler (2014) Silk for the Vikings. Ancient Textile Series 15. 


\title{
Unravelling Textile Mysteries with DNA Analysis
}

\author{
LUISE ØRSTED BRANDT
}

Luise Ørsted Brandt has a degree in archaeology from the University of Copenhagen. During her MA she specialized in the analysis of DNA from archaeological materials and wrote her thesis on DNA from prehistoric and historic Danish textiles. She is now a PhD student at the Centre for Textile Research and Centre for GeoGenetics at the University of Copenhagen performing analysis and studying biomolecules from ancient textiles and costumes. Her aim is to investigate how the population of prehistoric sheep changed over time, and how this effected textile production in Denmark both in terms of demand and new opportunities. Another topic is species identification of skins from prehistoric costumes found in Danish bogs.

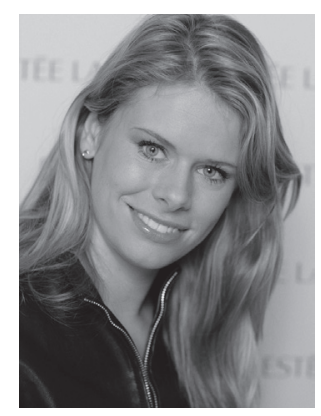

Most people have seen films or read books where the murderer is finally brought to justice because DNA traces on the crime scene match the DNA profile of the suspect. Such analysis is possible as each human being on earth has a unique code of DNA. DNA analysis is simply a technique with which this code can be extracted, amplified and read. DNA analysis can be performed on various organic materials, as e.g. blood, tissue, hair, bone and teeth.

DNA analysis has the power to determine kinship on smaller or larger scale, between individuals, families and populations. In animals, it is possible to determine the breeds and species through DNA analysis and sometimes also their geographical provenance can be determined. This analysis method also has the ability to determine characteristics in the individual that are genetically determined as, for instance sex, the colour of the eyes and genetic diseases.

DNA analysis has been used widely in medical and forensic sciences, but within the last two decades it has also been extensively applied to historical and archaeological material. Recently, the analysis was applied to hair, and this led the way to apply DNA analysis to textiles of wool.

As wool biologically speaking is hair, it is possible to extract and read parts of the DNA code from modern, historical and archaeological textiles manufactured of wool.

Tests of prehistoric Danish textiles showed that DNA was preserved in a textile from the early Iron Age dating to $400-200$ BCE. Presently, the aim is to extract genetic 
information from textiles preserved in the famous oak coffins of the Early Danish Bronze Age, 1700-1100 BCE. DNA from these textiles could characterize Danish sheep in this time period that is the earliest from which textiles exist in Denmark (Figs 9.1 and 9.2). Comparing sheep from the Bronze Age with later time periods could enlighten us as to whether new breeds were introduced to Denmark or if specific genes were preferred in the breeding of sheep.

Karin Margarita Frei, in an isotope analysis performed on a textile radiocarbon $\left({ }^{14} \mathrm{C}\right)$ dated to $350-350 \mathrm{BCE}$, demonstrated that raw materials or entire textiles were exchanged over long distances as early as the Iron Age in Denmark (Frei et al. 2009). Comparing DNA from Danish textiles with DNA from populations of sheep from other parts of Europa and Asia could help answer how much sheep differed between geographic regions. For genetically distinct sheep populations this could answer the question of whether the wool used in Denmark was of local origin, or perhaps imported from other regions with different sheep breeds.

Such results are also highly relevant to other time periods where trade occurred over long distances. It is, for instance, likely that wool textiles that travelled on the Silk Roads could be traced to either Roman or Central Asian populations of sheep. This, however, requires more knowledge of the populations indigenous to the different regions on the Silk Roads.

Thus, DNA from historic and archaeological wool textiles gives us genetic information on the animals used for textile production in prehistory - in the case of textiles of sheep wool, the analysis can enlighten us on the kind of sheep used for wool production.

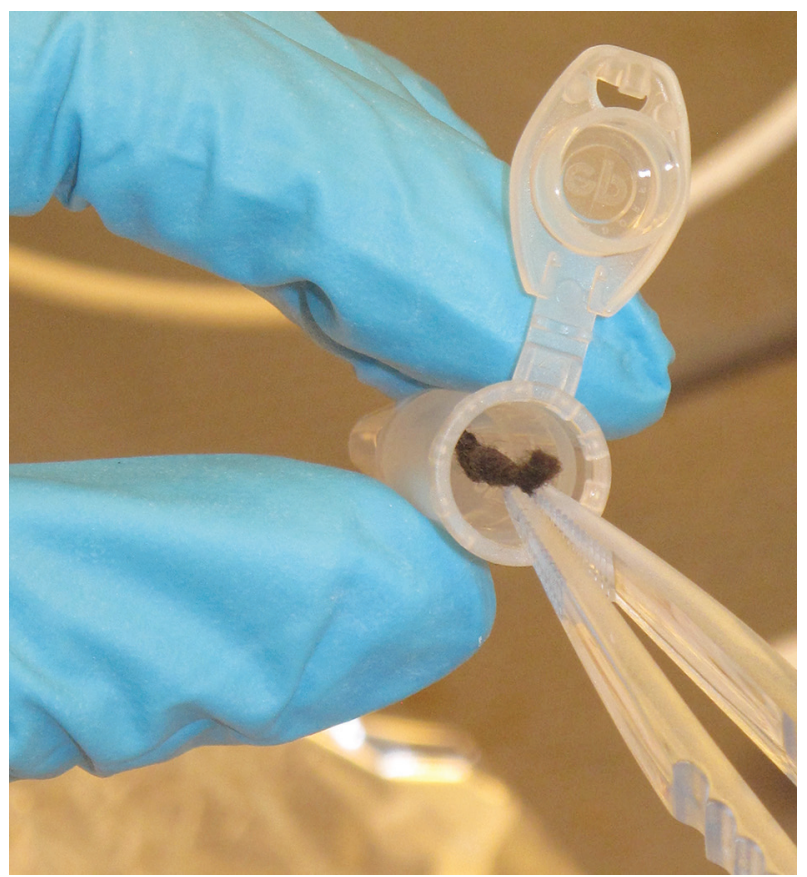

Fig. 9.1: Wool from an oak coffin from the burial mound Borum Eshøj in Jutland, Denmark, is analysed (Photo: Luise Ørsted Brandt). 
Likewise, studying prehistoric sheep bones provides us an opportunity to follow the animals carrying the desired raw material for textile production: wool. The combined history of sheep and wool was of great importance to prehistoric textile production as the availability and quality of wool determined what wool textiles could be produced and thus influenced the textile economy greatly in terms of techniques and craft.

With these potentials, the DNA analysis of prehistoric textiles could enable us to answer many questions that have taken up the minds of textile researchers, such as: what breeds were kept for wool production and what characteristics did they have? Also the question of when and where sheep were initially domesticated is of great interest and is one of the questions molecular biologists try to answer.

Sheep, in Latin Ovis, is a complex genus containing 5-7 wild species, depending on what classification is used and comprise more than 1400 domesticated breeds. Genetic analyses show that all wild species derive from a common ancestor located in Eurasia more that 1.7 million years ago. From there, the sheep population was divided into a population that gave rise to the Middle Eastern and Central Asian species and another population that spread to Siberia and crossed the Bering Strait and entered North America. It has recently been documented genetically, that the ancestor of domesticated sheep is the wild species Ovis Orientalis, called the oriental mouflon that inhabit the Middle East. This is the species that has the closest genetic resemblance to domesticated sheep and thus must be closest related to them (Fig. 9.3).

Wild sheep do not have a furry coat but rather a smooth one like goats. It is not until the 4th millennium BCE that the earliest evidence of woolly sheep appears. Here, the first textiles of wool start to appear and pictures and other art forms begin to distinguish between hairy and wool sheep, and this is also the case in written sources.

Fig. 9.2: The wool sample comes from the blanket that covered the deceased woman in the oak coffin from Borum Eshøj. The coffin was dated by dendrochronology to the years around 1350 BCE corresponding to the Early Bronze Age in Denmark (The National Museum of Denmark; photo: (C) Roberto Fortuna).

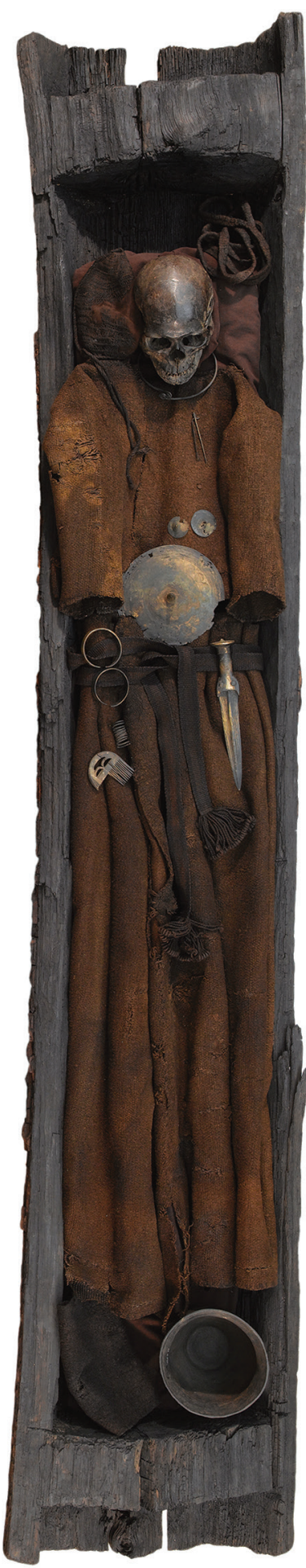




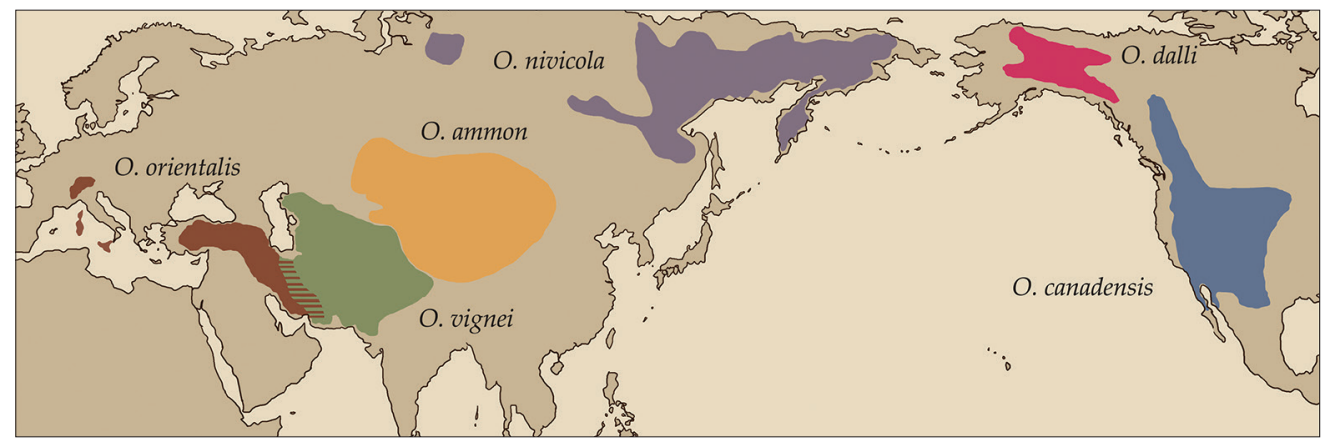

Fig. 9.3: Map of the distribution of Ovis species (Map: Sidsel Frisch, After original map by H. Rezaei and F. Pompanon reprinted from Molecular Phylogenetics and Evolution, vol. 54, Rezaei et al., Evolution and taxonomy of the wild species of the genus Ovis (Mammalia, Artiodactyla, Bovidae) pp. 315-326 (p. 316), (o 2010, with permission from Elsevier).

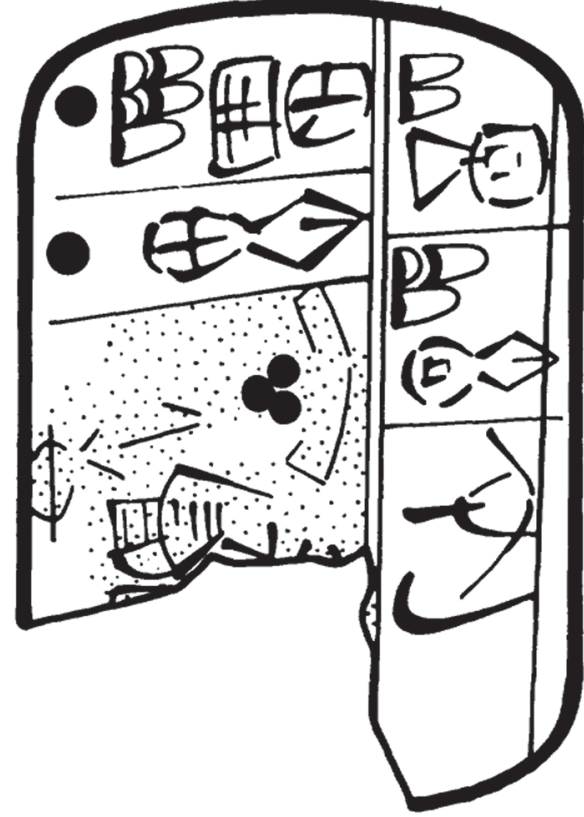

Fig. 9.4: Drawing of a clay tablet from the Mesopotamian city Uruk dated to around 3000 BCE. The sign second from the top to the left is that for 'wool sheep' (After M. W. Green (1980) Animal Husbandry at Uruk in the Archaic Period. Journal of Near Eastern Studies 39, 1-35, p. 20, No. 2 W20274.85 obv. Catalogue of texts, drawn from field photographs. With kind permission from University of Chicago Press).
In the 4th millennium BCE, records on clay tablets from Uruk, the ancient city in Mesopotamia, distinguish "wool sheep". So from this time we know for certain that breeds for different purposes existed. The analysis of DNA can hopefully give us the chance to study such breeds in detail to see if we can point out how they differed and what they could have looked like (Fig. 9.4).

Since the domestication of the sheep, humans took control over their reproduction, and this has undoubtedly led to selective breeding of characters they found favourable, as e.g. a large meat weight or a furrier coat. Genes for as different qualities as milk production, meat weight and the quality of wool are known, and these genes could potentially, if studied over time, reveal decisionmaking in the breeding of sheep and for what specific characters they were bred. Such studies have already been performed of single genes on bones from sheep and other species. 
However, knowing that DNA can also be extracted from wool gives us the possibility to investigate a group of animals that were documentably used for textile production.

The DNA analysis of textiles has only just begun; it holds great potential for answering some of the questions we have about textile encounters globally. Hopefully within the next few years more researchers will take this opportunity to investigate the raw materials and their development.

\section{Further Reading}

Luise Ørsted Brandt, Lena D. Tranekjer, Ulla Mannering, Maj Ringgaard, Karin M. Frei, Eske Willerslev, Margarita Gleba, M. Thomas and P. Gilbert (2011) Characterising the potential of sheep wool for ancient DNA analyses. Archaeol Anthropol Sci, 3, pp. 209-221.

Terry Brown and Keri Brown (2011) Biomolecular Archaeology. An introduction.

Karin M. Frei, Irene Skals, Margarita Gleba and Henriette Lyngstrøm (2009) The Huldremose Iron Age textiles, Denmark: an attempt to define their provenance applying the strontium isotope system, Journal of Archaeological Science 36, pp. 1965-1971.

Hamid R. Rezaei, Saeid Naderi, Ioana C. Chintauan-Marqier, Pierre Taberlet, Amjad T. Virk, Hamid R. Nagash, Delphine Rioux, Mohammad Kaboli and Françoise Pompanon (2010) Evolution and taxonomy of the wild species of the genus Ovis (Mammalia, Artiodactyla, Bovidae). Molecular Phylogenetics and Evolution, 54, pp. 315-326. 



\section{The Traceable Origin of Textiles

\author{
KARIN MARGARITA FREI
}

Karin Margarita Frei was born in Argentina, and has lived in Spain and Denmark. She has a M.Sc. in geology and geochemistry from the University of Copenhagen. She received her PhD in 2010 from the Dept. of Archaeology, SAXO Institute, University of Copenhagen for a cross-disciplinary project with the title Provenance studies of Pre-Roman Iron Age textiles - methods, development and applications. Here she developed a method which allows for an isotope-geochemical characterization of the raw material of ancient textiles. She was awarded the international prize for the best PhD in Archaeometry in 2011 by the Groupe des Méthodes Pluridisciplinaires Contribuant à l'Archéologie (GMPCA). In 2012 she was awarded the For Women in Science Prize by L'Oréal Denmark and UNESCO at the Danish Royal Academy of Science. She is a senior researcher at the National Museum of Denmark, Copenhagen where she continues to apply and further develop isotope analyses for tracing

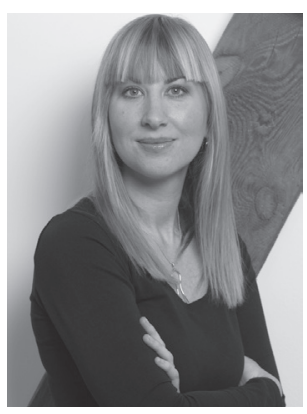
investigations of various kinds.

Textiles are much more than merely interlacing yarns. They are products made by people. Thus, they conceal a tremendous amount of information about the people who made them, the choices they made, their knowhow, and the materials that were available at the time they were made. All these aspects contribute with tiny fragments of information that together unravel key-features of past societies and thus bring us a step closer to the past (Fig. 10.1).

Archaeological textiles - whether they are made of vegetal or animal fibres - are made of perishable materials which decay rapidly unless specific environments allow their preservation. For example, a cold freezing climate has preserved the c. 500-year-old textiles from Inca child mummies in the peak of the high plateau of the volcano of Atacama in the Andes Mountains of South America, Argentina (the highest archaeological site in the world). Furthermore, a dry climate has preserved the textiles that were found in connection with the nearly 4,000-year-old Tarim mummies which were discovered in the Tarim Basin in present-day Xinjiang, China. Also humid anoxic bog environments can preserve organic materials as in the case of the nearly 2,400-yearold textiles from southern Scandinavia. Consequently, highly perishable material can prevail in specific environments leaving us with a unique assemblage of materials that permit us to investigate and uncover new untold stories of our past (Fig. 10.2). 


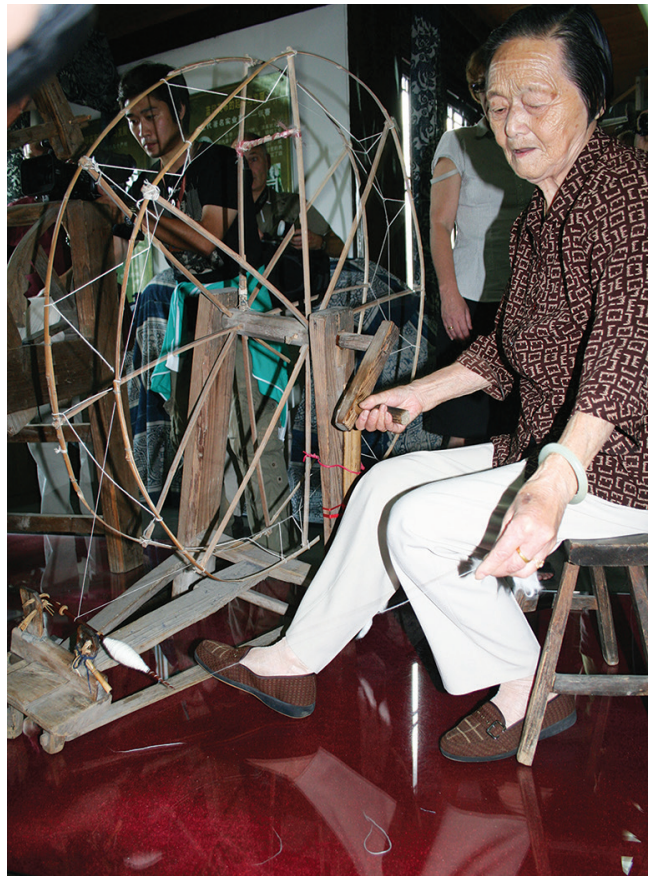

Fig. 10.1: Chinese lady spinning cotton in the Nantong Calico Museum, China (Photo: (c) Karin Margarita Frei).
The more we learn about ancient textiles, the closer we seem to get to know who the people who made the textiles as well as the people who wore the textiles were. To get a step closer to these individuals who lived several millennia ago, novel methodologies based on natural scientific approaches have made it possible to come as close as possible to identify the origin of the ancient textile raw materials. These new developments go as deep as to the atomic scale of the ancient textile fibres in order to characterize the so-called strontium isotope ratios of the fibres (Fig. 10.3).

Only a few milligrams are needed to conduct such analysis, often a small piece of thread is enough, although, at times, the researchers choose to run several samples of the same textile, especially when there seem to be differences between the warp and weft

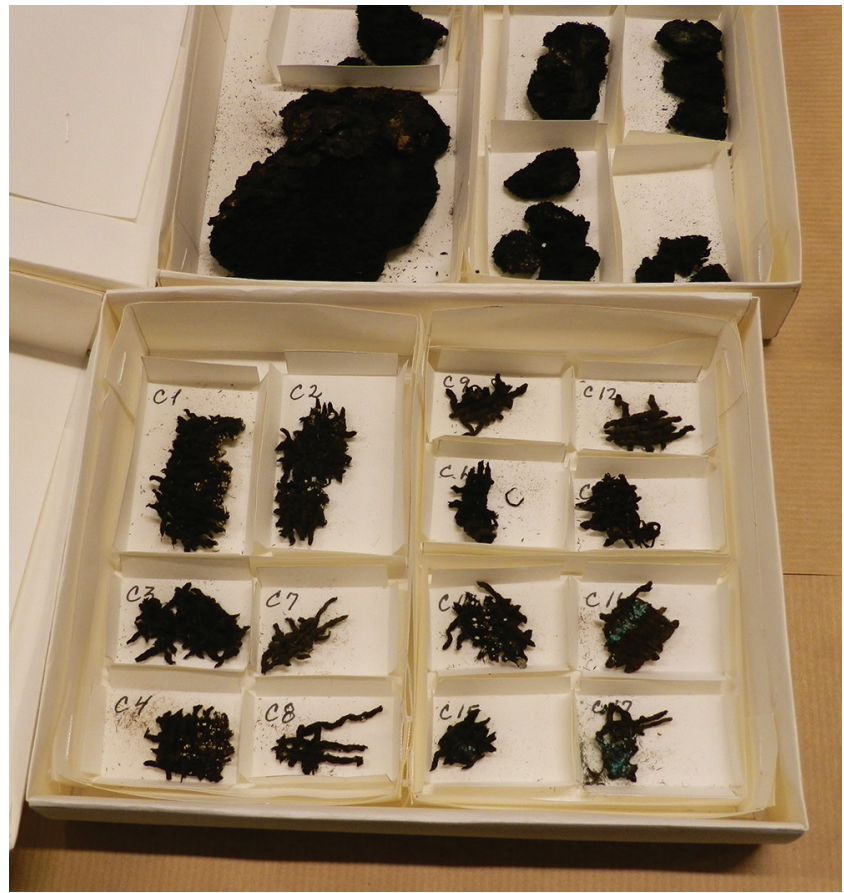

Fig. 10.2: Example of what archaeological textiles can look like when they are only partially preserved. These textiles were recovered in Denmark and were woven during the Scandinavian Bronze Age (1700-500 BCE). These finds are today stored but not on display at the Conservation Department at National Museum of Denmark, due to their small sizes (Photo: () Karin Margarita Frei). 
or in the borders of the textiles. In some cases, the textiles have been shown to be made of material that originated from several places, even though in the first instance they seemed to be homogenous. The first textile that made scholars aware of this possibility was the well-preserved Huldremose wool tubular garment made during the Scandinavian Iron Age (500 BCE-1 CE), and which has been interpreted as being an offering to the gods. The garment was retrieved in a bog in the north-eastern part of Denmark in the end of the 19th century. The garment was homogeneously spun, and assessing by the weaving techniques used to make it, it pointed to a local origin.

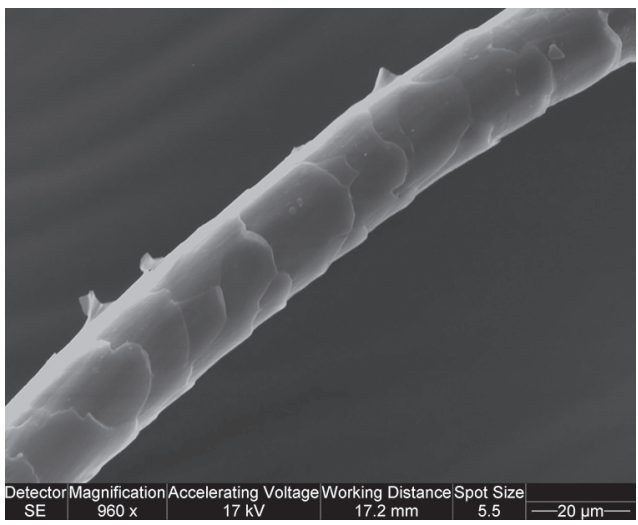

Fig. 10.3: Scanning electron microscopy (SEM) image of a single modern wool fibre after it had been exposed to a highly oxidative treatment developed by Karin Margarita Frei to remove dyestuff, in this particular case madder (Photo: (C) Karin Margarita Frei). However, the strontium isotope analysis showed that the textile was composed of wool that originated from at least three different areas, one area within Denmark and two outside Denmark. This was the first time ever that it was possible to show that ancient societies gathered wool of a very similar qualities from very distant areas to create one single garment; a feature that demonstrates the highly evolved textile knowledge of this ancient society (Figs 10.4 and 10.5).

This novel methodology can be applied to most animal and plant fibre textiles, and even to those which have been dyed. Yet, this methodology has not yet been applied to silk, which is probably the most exquisite textile material in prehistory. It

Fig. 10.4: Conservator Irene Skals (to the left) and Karin Margarita Frei (at right), sampling a total of eleven wool thread samples, weighing less than $20 \mathrm{mg}$ each, from the large, c. 2,400-yearold Huldremose II tubular garment; at the Conservation Department in Brede, National Museum of Denmark (Photo: (C) Karin Margarita Frei).

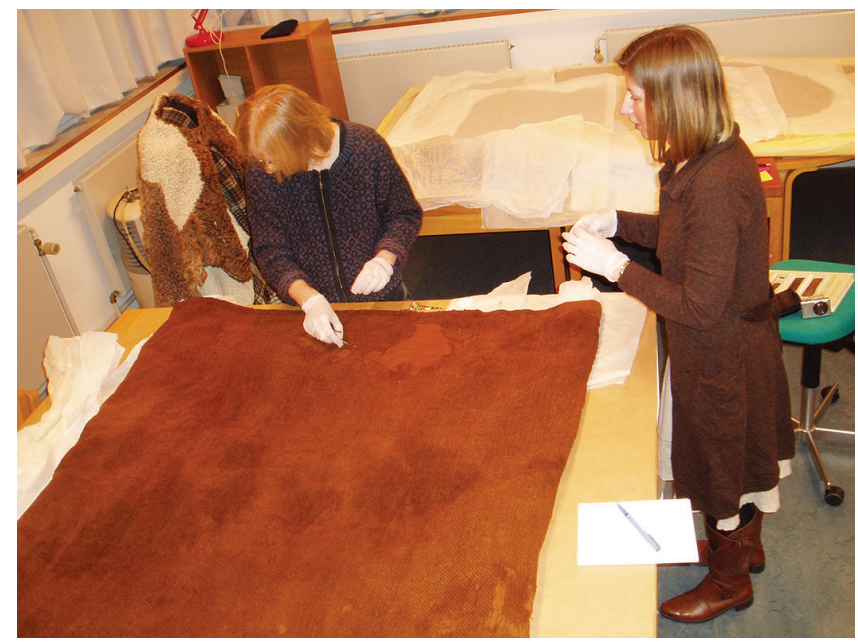




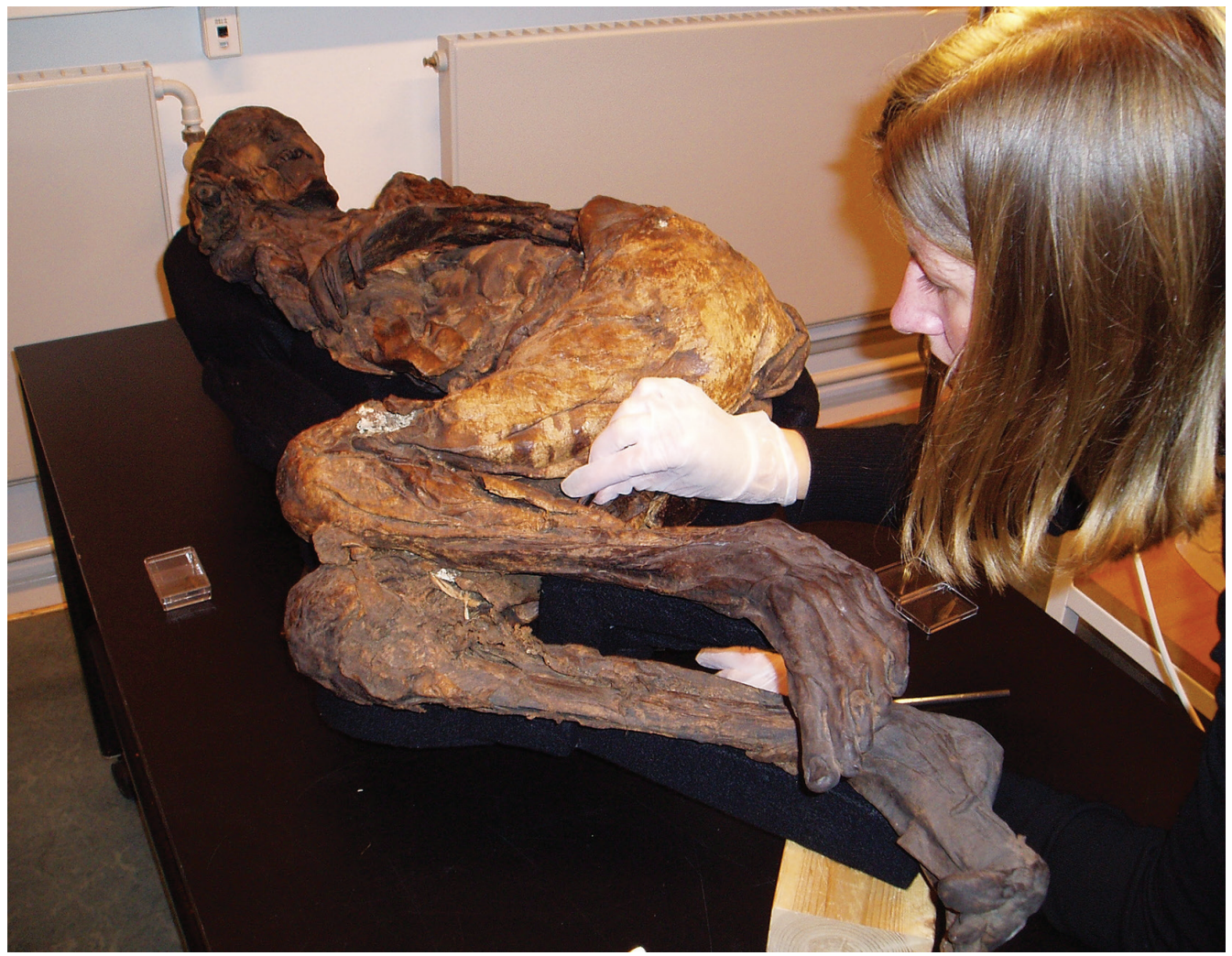

Fig. 10.5: The bog body of the c. 2,400-year-old Huldremose woman (Huldremose I), during an inspection of the body by Karin Margarita Frei at the Conservation Department at Brede, the National Museum of Denmark. During this inspection, plant fibre threads were discovered. Later investigations showed that these plant fibre threads derived from a kind of undergarment made of plants that grew outside Denmark where she was found. Pieces from this textile still stick to the back of the bog body's skin (Photo: (C) Karin Margarita Frei).

is often assumed that the domestication of the most common silk produced by the moth species Bombyx mori was a Chinese development (Fig. 10.6).

Thus, silk finds are often interpreted as signs of early contact between China and the rest of the world. The Silk Road is a direct derivate of these interpretations. However, new evidence of silk from the Indus region dating back in time as far as the first Chinese silks, makes us re-think silk's provenance. We hope that these new developments in the field of textile raw materials tracing methodologies will soon expand to silk and thereby enable textile researchers and archaeologist worldwide to decipher where archaeological silk was originally produced before it was exchanged through various encounters throughout the globe (Figs 10.7 and 10.8). 


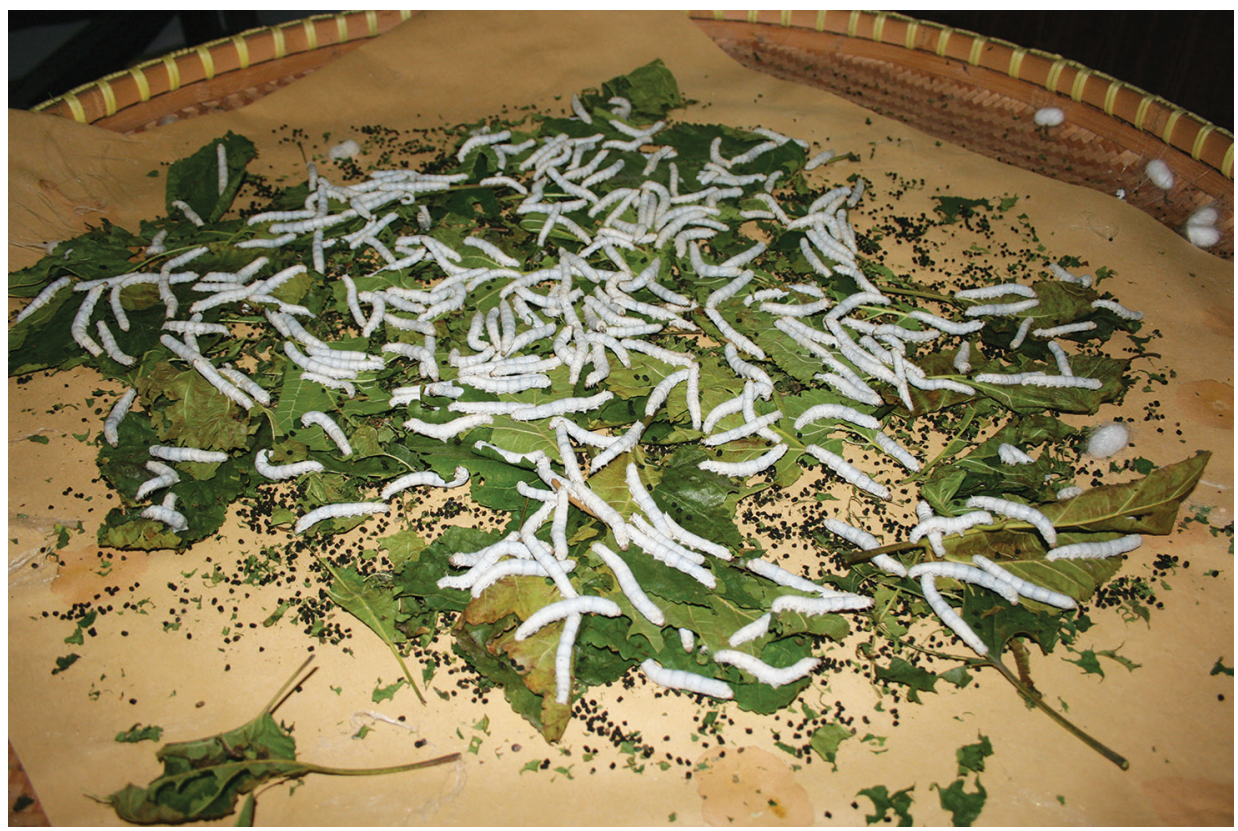

Fig. 10.6: Chinese silk worms eating mulberry leaves and silk cocoons developing as a result. Silk is a natural protein fibre. The best-known type of silk is obtained from the cocoons of the larvae of the mulberry silkworm, Bombyx mori, reared in captivity (sericulture) (Photo: ( ) Karin Margarita Frei).

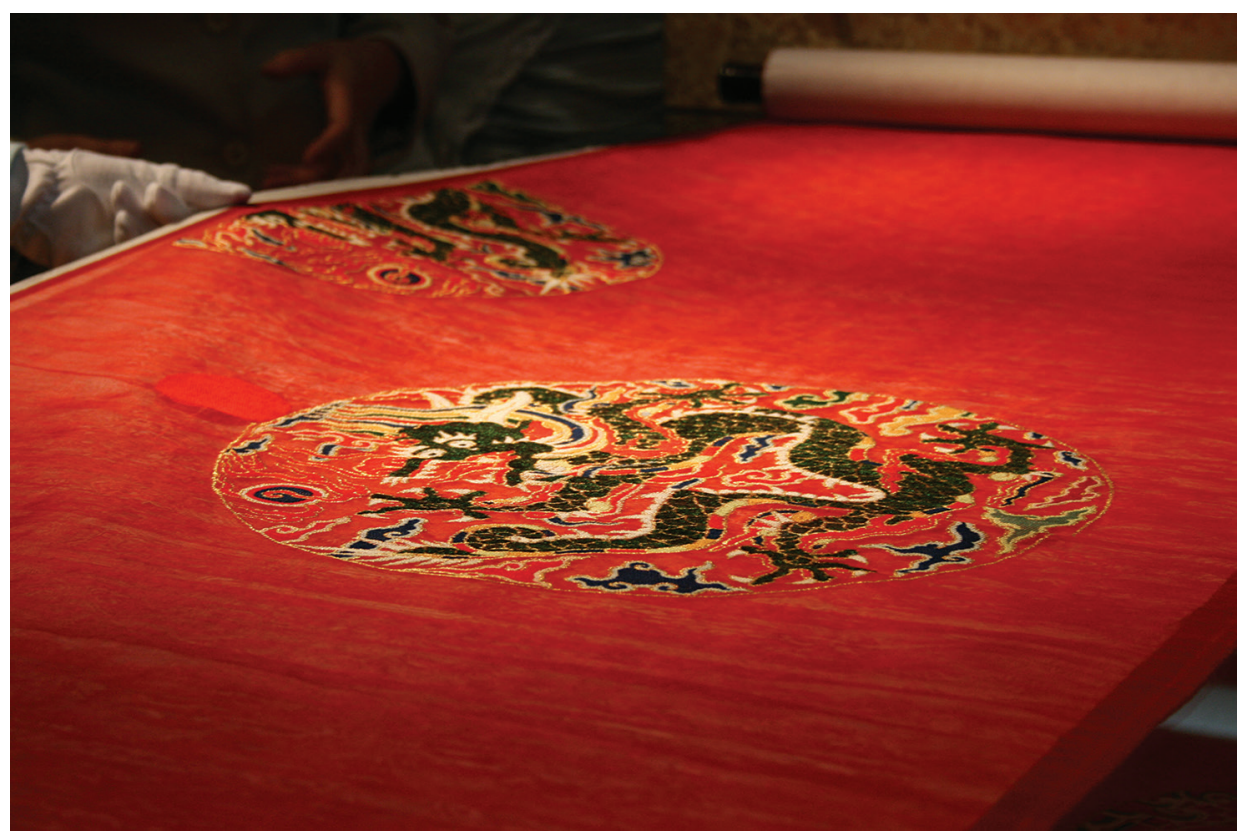

Fig. 10.7: Chinese silk at the Nanjing Textile Research Centre; this silk is so thin and fine woven that it weighs only a few grams (Photo: () Karin Margarita Frei). 


\section{Strontium as a tracing system in archaeology}

- Strontium is a trace element and an alkaline earth metal

- Strontium has four naturally occurring isotopes $88 \mathrm{Sr}(82.53 \%), 87 \mathrm{Sr}(7.04 \%)$, $86 \mathrm{Sr}(9.87 \%)$, and $84 \mathrm{Sr}(0.56 \%)$.

- The strontium isotope trace system relies on the use of two of the four natural occurring isotopes, namely $-87 \mathrm{Sr}$ and $86 \mathrm{Sr}$ - and particularly on the variations of their ratio $87 \mathrm{Sr} / 86 \mathrm{Sr}$.

- The variations of the $87 \mathrm{Sr} / 86 \mathrm{Sr}$ ratio of a geological material (rock, soil, mineral) depend on the combination of initial parent Rubidium ( $\mathrm{Rb}$ ) to daughter Strontium (Sr) ratio, the kind of rock and the age of the material.

- Strontium replaces calcium in mineral lattices and thereby is incorporated to the body tissues through diet and throughout the food chain. Strontium isotope ratios are determined by chemical separation and subsequently measured in a Thermal Ionization Mass Spectrometer (TIMS ).

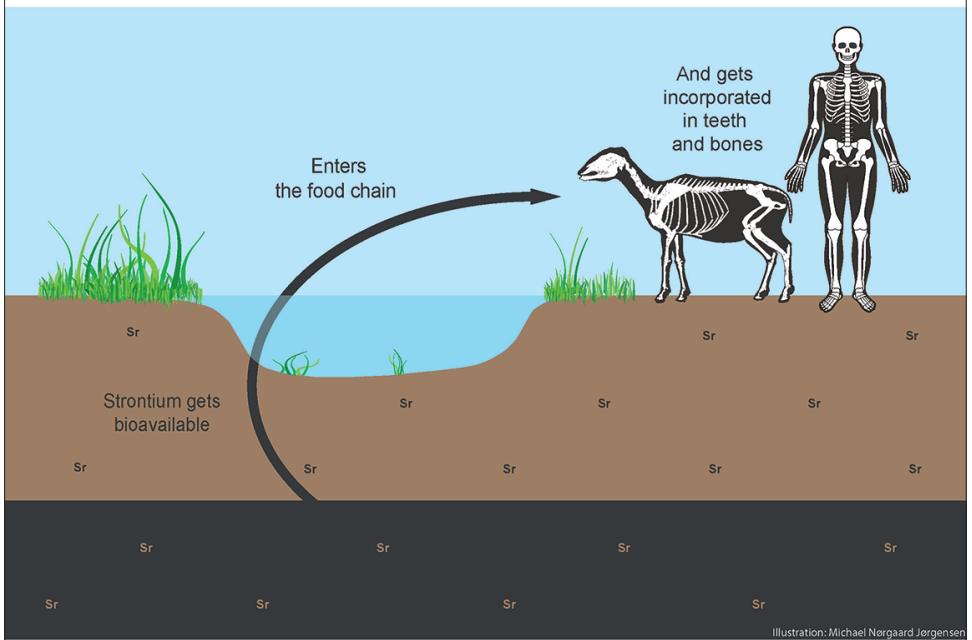

Fig. 10.8: Strontium as a tracing system in archaeology (Text box: @ Karin Margarita Frei; Diagram: Michael Nørgaard Jørgensen).

\section{Further Reading}

Christian Bergfjord, Ulla Mannering, Karin M. Frei, Margarita Gleba, Marie-Louise Nosch, Annemette B. Scharff, Irene Skals, Jan Heinemeier and Bodil Holst (2012) Nettle as a distinct Bronze Age textile plant, Scientific Reports, open access journal, 2, 664; DOI:10.1038/srep00664.

Irene. L. Good, Mark Kenoyer and Richard H. Meadow (2009) New evidence for early silk in the Indus Civilization, Archaeometry, V 51, 457-466.

Gunter Faure (1986) Principles of Isotope Geology.

Karin M. Frei (2014) Provenance of archaeological wool textiles: new case studies, Open Journal of Archaeometry (open access) DOI: http://dx.doi.org/10.4081/arc.2014.5239.

Karin M. Frei, Ulla Mannering, Margarita Gleba, Marie-Louise Nosch and Henriette Lyngstrøm (2009) Provenance of Ancient textiles-a pilot study evaluating the Sr isotope system. Archaeometry, V 51, 2, pp. 252-276.

Karin M. Frei, Irene Skals, Margarita Gleba and Henriette Lyngstrøm (2009) The Huldremose Iron Age textiles, Denmark: an attempt to define their provenance applying the strontium isotope system, Journal of Archaeological Science, V 36, pp. 1965-1971.

Karin M. Frei, Irene Vanden Berghe, Robert Frei, Ulla Mannering and Henriette Lyngstrøm (2010) Removal of natural organic dyes from wool-implications for ancient textile provenance studies, Journal of Archaeological Science, V 37, pp. 2135-2145. 


\title{
11 The World of Textiles in Three Spheres: European woollens, Indian cottons and Chinese silks, 1300-1700
}

\author{
GIORGIO RIELLO
}

Giorgio Riello is Professor of Global History and Culture at the University of Warwick, United Kingdom. He has been a Visiting Professor at Stanford University, the European University Institute, Florence, and the Australian National University. In 2010 he received the prestigious Philip Leverhulme Prize. Giorgio is currently the Director of the Pasold Research Fund, a major funding institution supporting research in textile history. He has written on early modern textiles, dress and fashion in Europe and Asia. He is the author of A Foot in the Past: Consumers, Producers and Footwear in the Long Eighteenth Century (2006) and Cotton: The Fabric that Made the Modern World (2013). He has co-edited several volumes including Shoes: A History from Sandals to Sneakers (2006; 2nd ed. 2011); The Spinning World: A Global History of Cotton Textiles, 1200-1850 (2009; 2nd ed. 2011); and How India Clothed the World: The World of South Asian Textiles, 1500-1850 (2009).

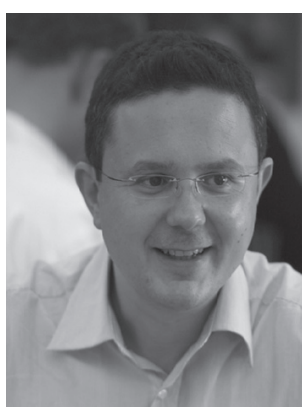
Readers may also find the following works of interest: The Fashion Industry in Western Europe: Materials, in Lise Skov (ed.), Berg Encyclopaedia of World Dress and Fashion: Vol. 8. West Europe, (2010) pp. 81-85, 92-95; Asian Knowledge and the Development of Calico Printing in Europe in the Seventeenth and Eighteenth Centuries, Journal of Global History, (2010), 5:1 pp. 1-29; Beverly Lemire and Giorgio Riello, East and West: Textiles and Fashion in Early Modern Europe, Journal of Social History, (2008) 41:4, pp. 887-916.

The majority of the cloth used for dress, furnishings and other textile purposes up to the invention of synthetics in the early 20th century belonged to four major categories: silks, woollens, cottons and linens. Each of these categories came in a range of qualities and sub varieties dependent on the properties and genetic make-up of the fibre used. Wool and silk are animal fibres; cotton and linen (a cloth produced with either hemp or flax) are instead vegetal fibres. Even if mixes of these fibres were and still are common, this broad categorisation is important for at least three reasons. First, these four groups of fibres had different cultural and monetary values ranging from expensive silks to the coarsest of linen, thus catering for a variety of uses and for the necessities of consumers of different means. Second, their cultivation and manufacturing was not equally distributed across the world. Each fibre had specific poles of specialisation forming a tapestry of manufacturing areas that interacted through the medium of trade. And finally, these fibres, especially woollens and cottons, were subjected to different processes of decoration. This chapter will explore the 
different nature and functioning of what I call 'spheres' of textile production of the early modern (c. 1300-1800) world: that of European woollens, Indian Cottons and Chinese Silks.

It is perhaps a good thing to start with hemp and flax, the key fibres forming a cloth called linen. Around 1300 when our analysis starts, hemp and flax were cultivated in vast areas of central Europe, China, Japan and the Mongol Empire, but also in many parts of the Indian subcontinent. But it was in Europe that linen was truly widespread among consumers. Under the category of linen, in reality, we find a variety of personal and household textiles ranging from diaper cloths for table linen to towels, as well as chequered and striped linens for household consumption, plain linens for shirting and cambrics for dresses. Linen was similarly used for shirts, ruffs (the large collars used especially in the 17th century) and cuffs (Fig. 11.1). In early modern Europe linen provided whiteness in an age in which mud and filth and an aversion to washing oneself with water made cleanliness an expensive and complicated exercise.

The production of linen was one of the major activities of women working within domestic walls. Many peasant households, not just in Europe but also in Asia were busy cultivating hemp and flax and then spinning and weaving these fibres into cloth to be used for domestic consumption or to be sold on the market. This was a production that was labour intensive as it entailed a series of laborious processes that included not just the weeding and cropping of flax and hemp but also breaking, scutching, twisting, shaking, beating, hackling (the removing of residual tow, gum and resin) and supervising the long retting, the putrefaction of the fibre that could

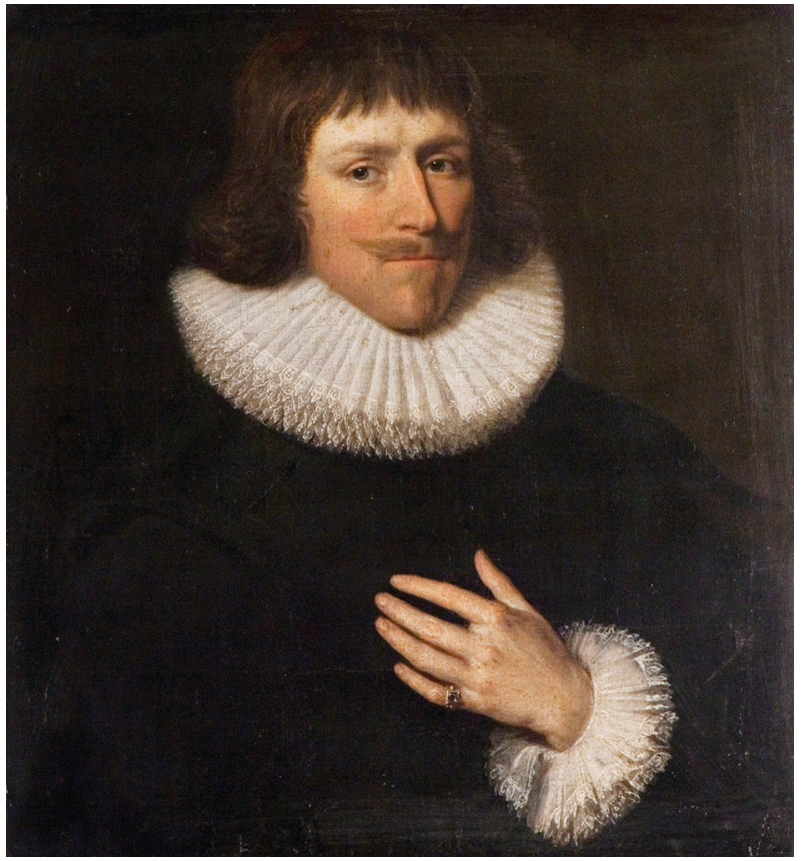

Fig. 11.1: Originally believed to be the portrait of Thomas Fairfax, Third Lord Fairfax (1612-1671) of Denton, Yorkshire, this half-length portrait shows a wealthy man wearing a black doublet with a falling laceedged linen ruff and cuffs as was fashionable in Europe in the first half of the 17th century. Oil on canvas, $24.75 \times 23.37 \mathrm{~cm}$; 28-1867, Given by Melmoth Walters (C) Victoria and Albert Museum, London). 
take up to eighteen months (Fig. 11.2). In many ways linen was unsuitable to become a truly 'global' fibre and today its use is confined to high-quality garments to be worn mostly in summer and where a crumpled look is desired.

The other three remaining fibres enjoyed instead more success in the long run. Perhaps the earliest of them all to be appreciated worldwide was silk. Among all natural fibres, it is the one that has most preserved its exotic connotations. Sensual, rich in texture and unique for its glossy shine, natural silk remains today the most appreciated fabric not just in Europe but globally. Its origin can be located in China. Sericulture was already well known and widespread across China before the Common Era and became an integral part of the Empire's agrarian economy during the following 2000 years (Fig. 11.3). Legend says that two monks smuggled silk cocoons in their canes out of China and presented them to the court of the Byzantine emperor Justinian in Constantinople in $552 \mathrm{CE}$. In the following 500 years sericulture and silk weaving came to be performed in the Middle East and silk cultivation and processing reached Italy in the 14 th century.

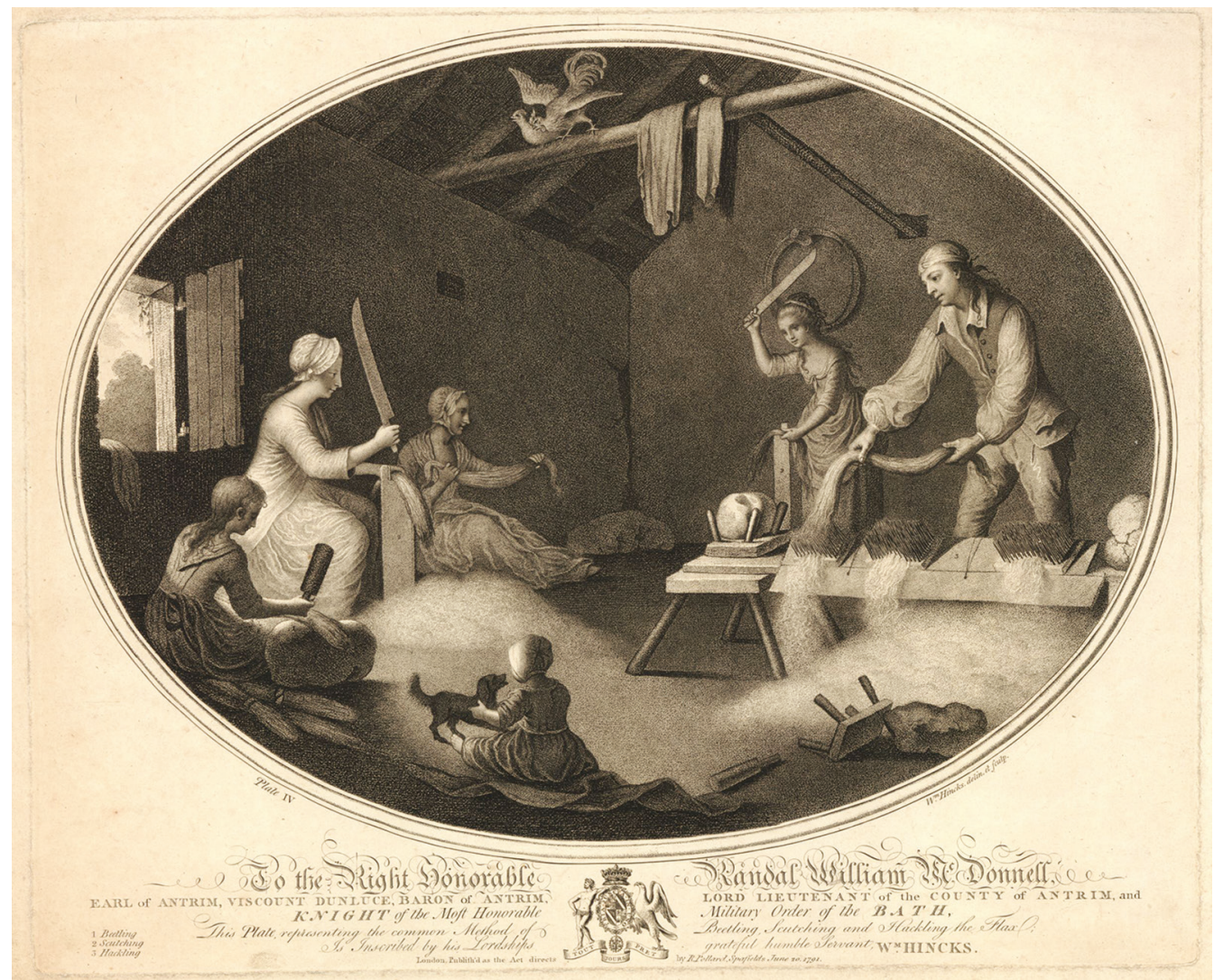

Fig. 11.2: Common method of beetling, scutching and hackling the flax by William Hincks. Hand-colour engraving, published in London, 1791, no. 1877,0113.373, AN549913 (C) The Trustees of the British Museum). 


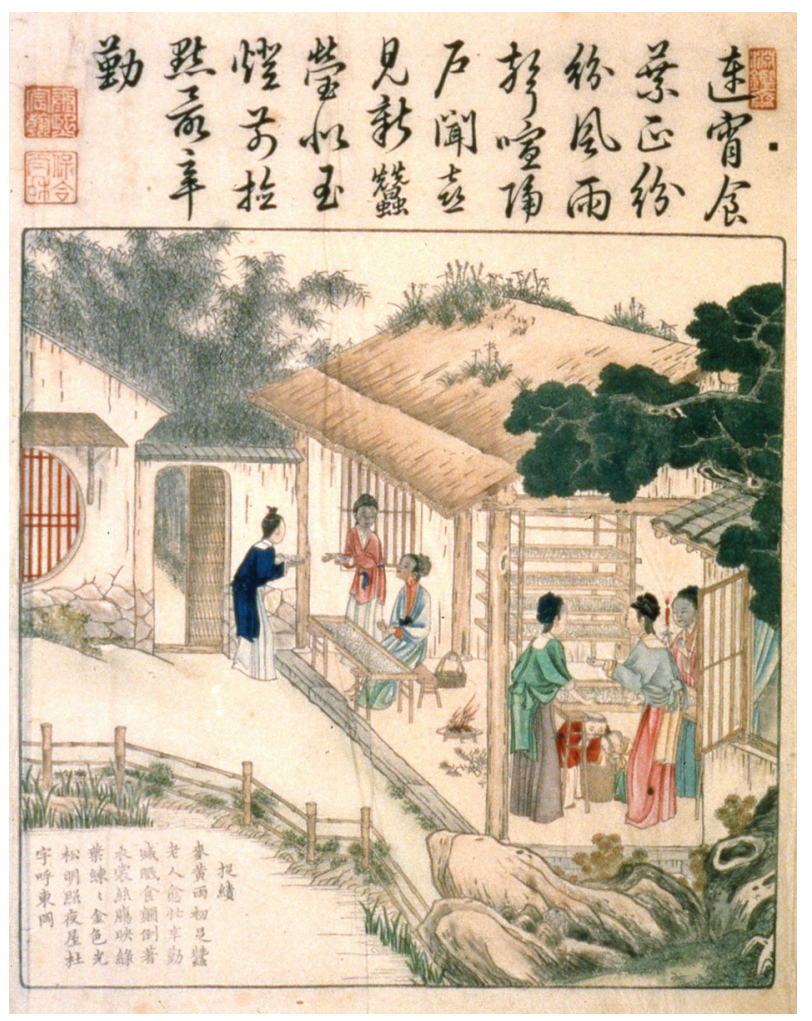

Fig. 11.3: Based on a 12th-century version, the Yuzhi gengzhi tu (Imperially Commissioned Illustrations of Agriculture and Sericulture) contains 46 woodblock prints showing the processes involved in rice growing and sericulture and is accompanied by verses by the Kangxi Emperor. It was produced in Beijing in 1696. The illustration shows women checking silk cocoons; Asia Department, no. $1949,0709,0.11949,0709,0.1$ (ङ) The Trustees of the British Museum).

Still the majority of silks consumed in Eurasia in this period were produced either in China or the Middle East and were traded through what came to be known as the 'silk roads', a series of trading routes extending from China all the way to Europe, the backbone of global trade before the age of maritime exploration after 1500. The appeal of Asian silks can hardly be minimized. Some historians have suggested that the very birth of fashion is connected with the adoption of Asian silks in Europe (Monnas 2008). Expensive Asian silks were, however, only at the reach of the noble and powerful (what we might call the super-rich of the time) as in the case of the Doge of Venice (Fig. 11.4) seen sporting a beautiful dress of silk either produced in Istanbul or more probably in Venice in imitation of Middle Eastern silk (Molà 2000).

Even when in the 17th and 18th centuries places like London (the area of Spitalfields) and the city of Lyon in France became major producers of silks, this type of cloth remained at the reach of the few and has remained such until the present. One might say that silk was indeed the first global textile, but its geographic extension was not matched by a similar high level of penetration into people's wardrobes. This was particularly the case in Europe where the vast majority of people wore linen for their undergarments and wool cloth for their outer garments. Wool textiles, too, came in a range of different types and a variety of price tags: there were the heavy and expensive broadcloths, the fine and sometime equally costly worsteds, the lighter and 


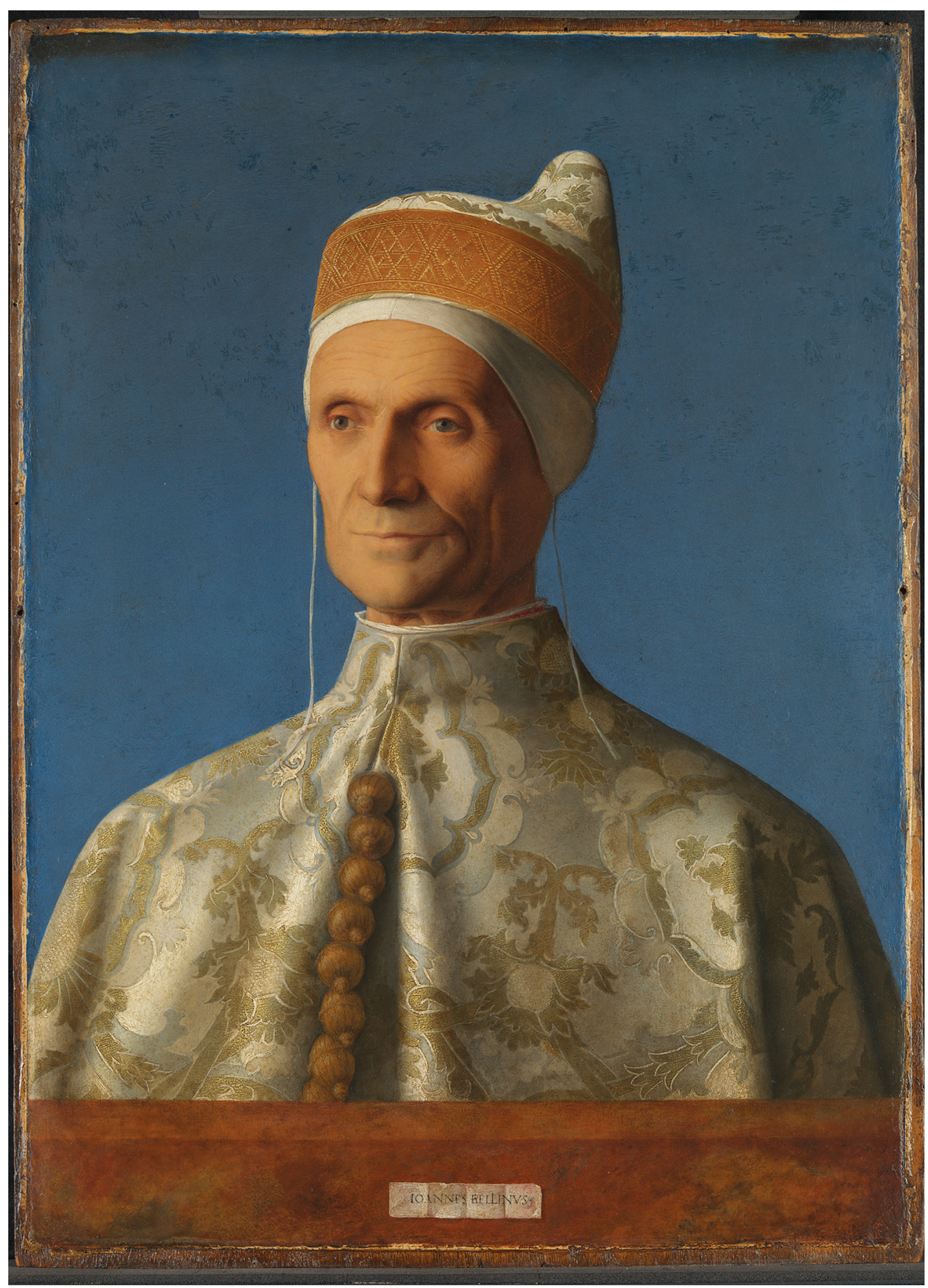

Fig. 11.4: Giovanni Bellini, Portrait of Doge Leonardo Loredan; no. 1501-04 NG 189 (Photo: () The National Gallery, London). 


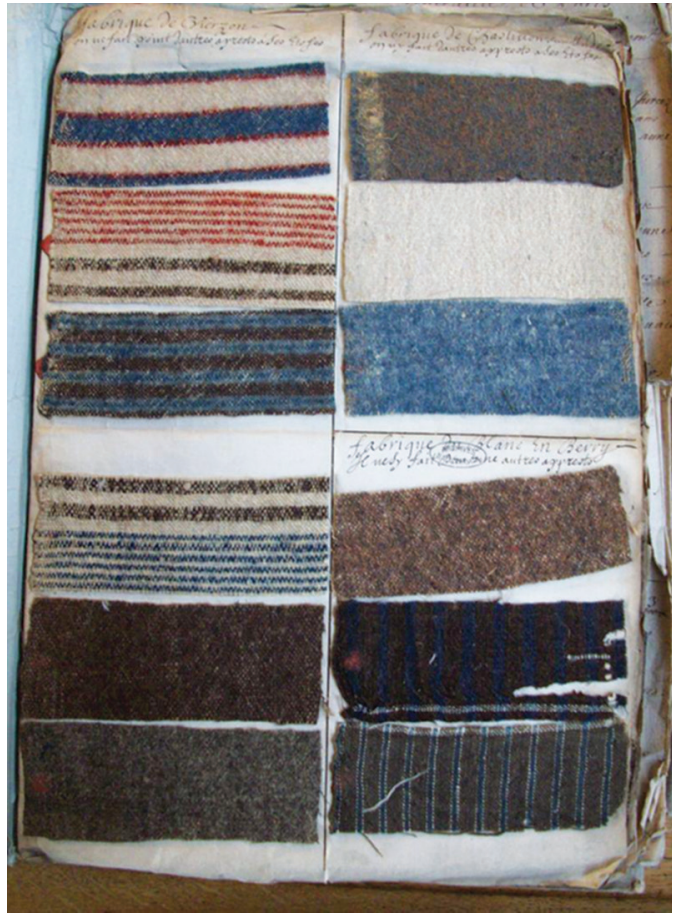

Fig. 11.5: French woollens, swatches, 1716 (@) Archives Nationales (France); cote F/12/649).

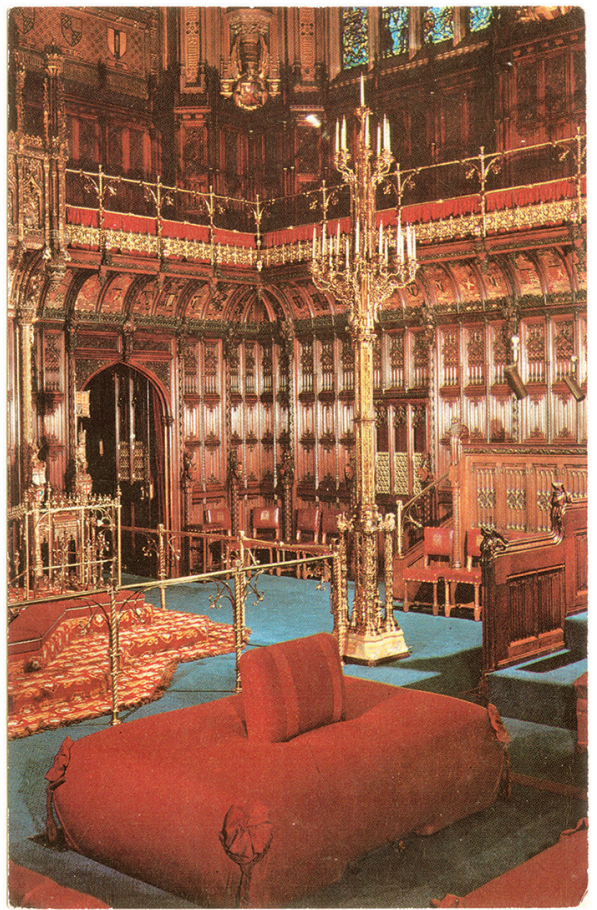

Fig. 11.6: Woolsack in the British House of Parliament. Postcard (Private Collection).

cheaper 'new draperies' introduced in the 16th and 17th centuries, and several mixes with other fibres (Fig. 11.5). The peculiarity of woollen textiles was that in the early modern period their production depended entirely on the supply of wool produced within Europe (Fontana and Gayot 2004). For more than half a millennium, Europe remained a land of wool and the golden fleece came to represent the riches of the continent's manufacturing economy. None more so than in England where woollen cloth constituted the majority of the island's exports up to the year 1800 . Here, the celebrated woolsack - the Lord Chancellor's wool-stuffed seat - in the House of Lords is the very symbol of the country's wealth and tradition (Fig. 11.6).

The third area of Eurasia was characterised instead by cotton (Fig. 11.7). India had probably domesticated the cotton plant in antiquity and by the end of the first millennium was developing a highly sophisticated industry producing a variety of cotton products ranging from light fabrics such as muslin to heavier and more colourful chintzes and calicos (Riello 2013). By the 15th century, India had emerged as the most prominent area for the manufacturing of cotton textiles for trade across the known world. India excelled not just in spinning and weaving (a phenomenon that could also be seen in China), but also in the dyeing and decoration of the cloth 


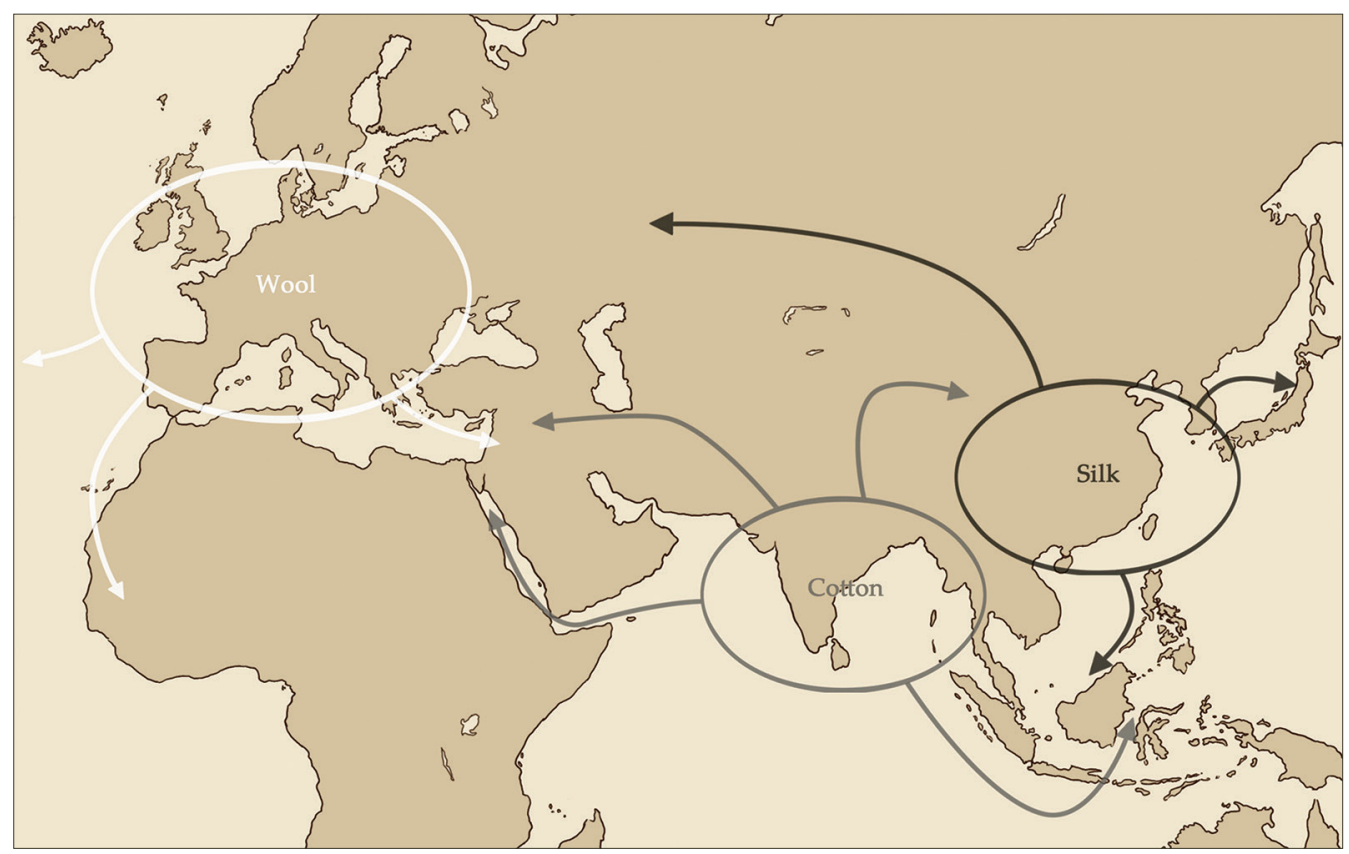

Fig. 11.7: The three areas of textiles and their trade in the medieval and early modern world (Drawing: Sidsel Frisch, after original by Giorgio Riello).

through the media of printing and painting. Richly decorated Indian cotton textiles produced on the Coromandel and Malabar coasts, in Gujarat and in other areas such as Rajasthan were traded by a diverse range of groups including Gujarati, Arab, Jewish and Armenian merchant communities.

As the trade of Chinese silk cloths was extensive, so was that of Indian cotton textiles. They were traded as far as West Africa in the west (via a series of intermediaries that were part of the Trans-Saharan caravan trade) to Japan in the east. Ruth Barnes, formerly curator of South Asian textiles at the Ashmolean Museum in Oxford, has identified hundreds of fragments excavated in Old Fustat near Cairo dated from the 14th and 15th centuries as produced in Gujarat in India (Fig. 11.8). What is even more astonishing is that several of them are identical to contemporaneous textiles collected in Southeast Asia (especially the Sulawesi islands) and dated to the same period (Fig. 11.9). The similarity of their design and their common provenance is an indicator of the scale, complexity and extension that the trade in Indian textiles had already reached at such an early date (Barnes 1997, 8-9).

The availability of the raw materials seems to have been a major barrier to the spread of any of the four basic fabrics across the globe. This was particularly the case for cotton and wool: just as sheep were not as widespread in Asia, so cotton was not as cultivated in Europe. With the exception of some cotton cultivated in Sicily, Southern Italy and Spain, during the Middle Ages, Europe's engagement in 

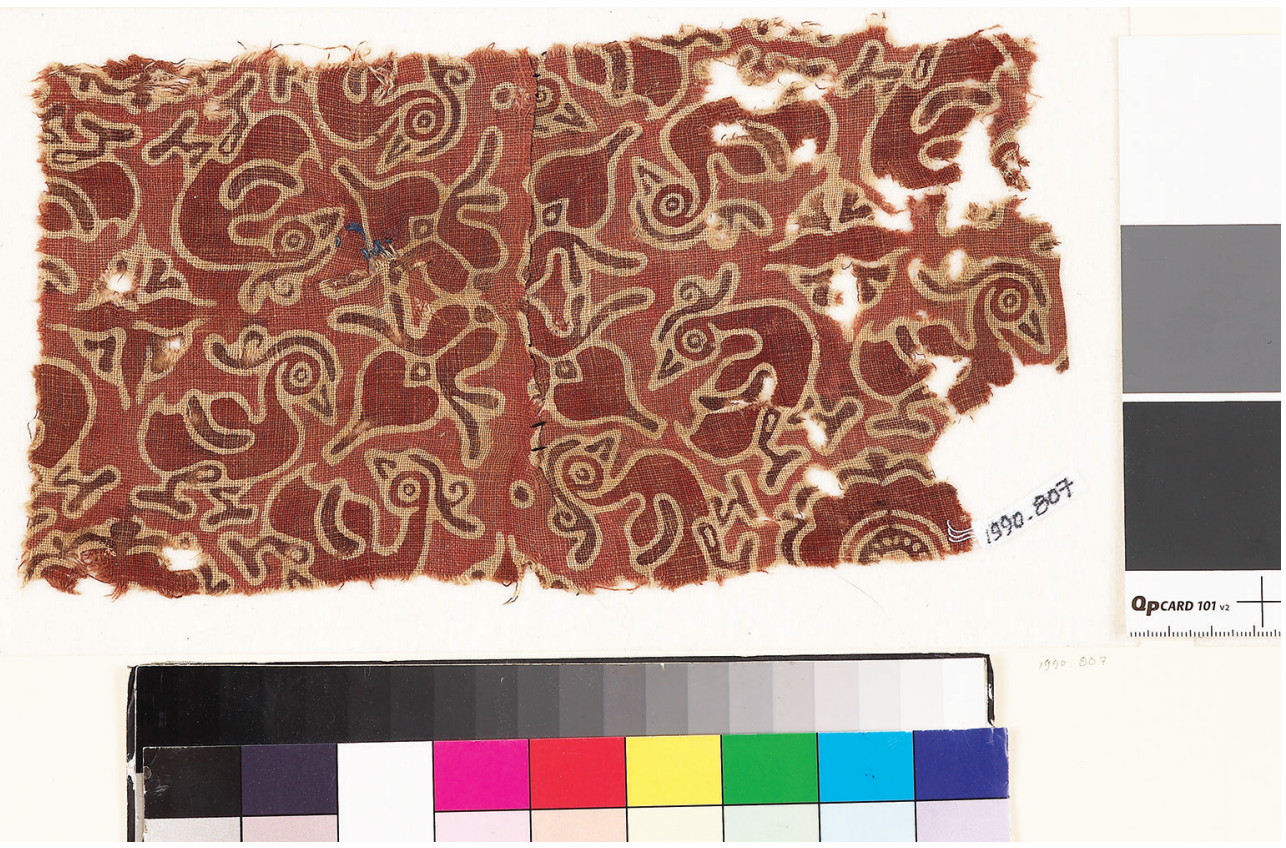

Fig. 11.8: Printed Indian cottons, 14th century, excavated in Old Cairo (๑) Ashmolean Museum, University of Oxford).

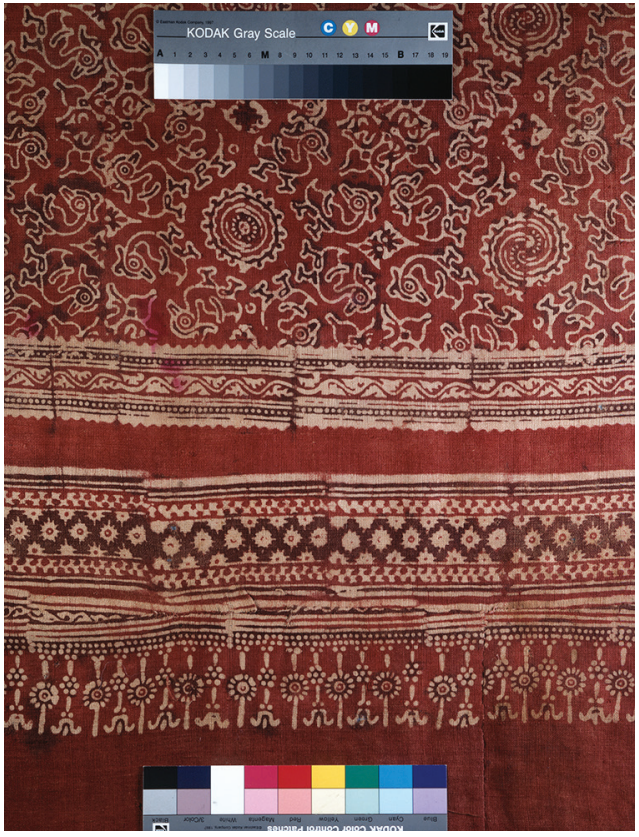

Fig. 11.9: Ceremonial cloth 'Maa', produced in Gujarat, 14th century, found in the Sulawesi Islands (C Ashmolean Museum, University of Oxford). cotton textile production was restricted to modest raw material supplies coming from the Middle East, in particular from Syria. Cotton textiles produced in Europe remained a niche industry producing mostly fustians (mixed flax and cotton) and bombazine (mixed cotton and silk) in Italy and Southern Germany from the 13th century onwards (Mazzaoui 1981) (Fig. 11.10).

Clearly trade was the rational response to a global specialisation of production with products being in high demand and fetching premium prices outside their respective 'sphere' where they were appreciated as something different (exotic) and uncommon (rare). But such an explanation only partially accounts for the success of different cloths. This is because consumers do not just appreciate the properties of the fibre itself (sheen 
for silks, warmth for woollens, softness for cotton, and the coolness of linen) but also the properties and appeal of the cloth produced from such fibres.

I wish to concentrate on cotton and wool for the remainder of this chapter as in many ways over the past centuries and before the invention of synthetics, these were the two most promising fibres and fabrics to become truly global. Yet today wool accounts for possibly as little as five percent of all textiles, while cotton retains well over fifty percent of the world's fibre market. Why is this the case? From its very medieval and early modern beginning, woollens - the specialisation of Europe - seem to have been in demand only in certain parts of the world. They were appreciated across all of Europe and by the 17th and 18th centuries woollen textiles were equally in high demand in the Americas, especially among European settlers. French and English woollens were also in demand in the Middle East, in particular in the Ottoman Empire. But attempts to sell them to other parts of Asia faced failure. The European East India companies' correspondence is replete with complaints about the poor sale of English, French and other European woollen cloth in India, China and Japan. The relative failure of European woollens

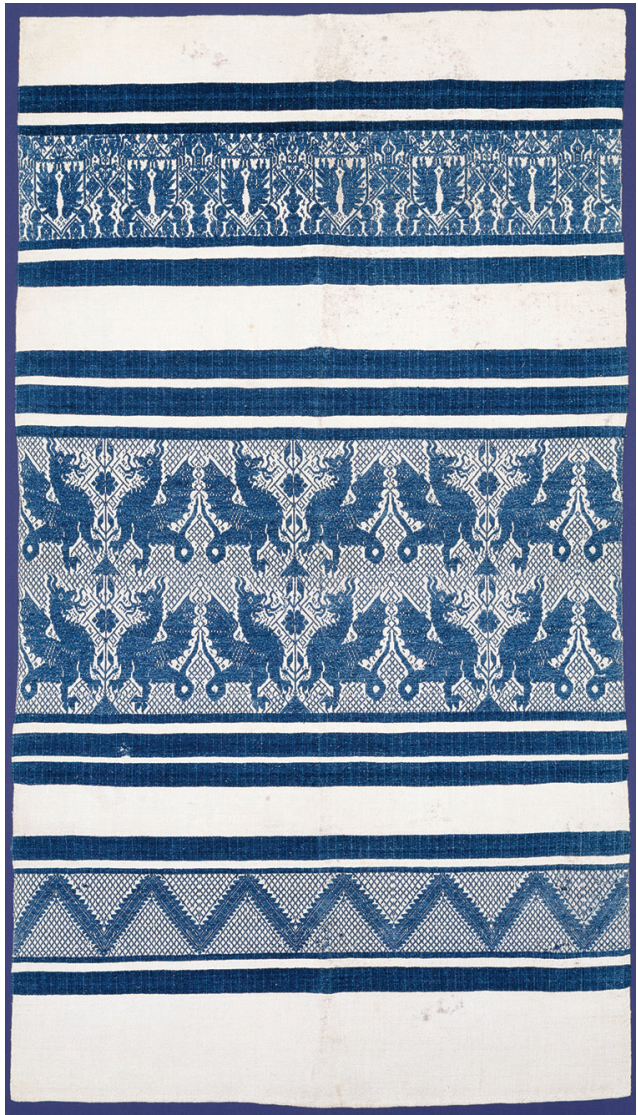

Fig. 11.10: Perugia Towel (tovaglia) is usually translated as tablecloth or napkin, but their use was in both ecclesiastical and secular. They were produced in the 15th century in the city of Perugia in Central Italy. They were a typical medieval European 'cotton' with a linen warp and a cotton weft (T.12-1916, given by W. B. Chamberlin through The Art Fund; Victoria and Albert Museum, London). in Asia is often explained by emphasising the superior qualities of the local fibre - cotton - that produces a cloth that is soft and does not itch when in contact with the skin. Others have pointed out that woollens might have been unsuitable for the warm climates of parts of Asia, as indeed they were when worn by Europeans in the form of three-piece suits for men and heavy woollen skirts for ladies. Yet these objections forget the good material properties of wool (such as its 'breathing' of bodily sweat) and the fact that several parts of Asia are indeed colder than Europe.

It was a difference in the way in which design and decoration were created on wool and on cotton that made the fortune of the latter and the failure of the former. A material difference of fibres and cloth led to different processes in their 'patterning' 


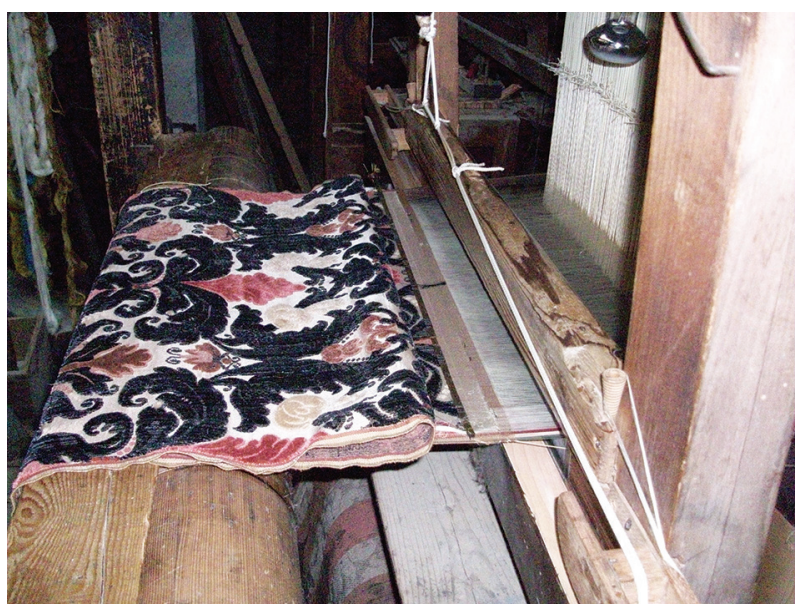

Fig. 11.11: In Europe textile design was created through the medium of weaving and the setting up of looms was a long and costly procedure. Production of silken velvet using an 18th-century European loom. Manifattura Bevilacqua, Venice, 2009 (Photo: () Giorgio Riello).

or 'fashioning'. Whilst cottons were suitable to be printed and painted, woollens (not unlike silks) were patterned through the medium of weaving (Fig. 11.11). I have explained in greater detail elsewhere the importance of this difference in the creation of design on cloth, allow me here simply to summarise (Riello 2013). Europe excelled in the creation of design through the mediums of weaving and embroidering (Fig. 11.12 top part). Embroidery was one of the most common occupations in early modern Europe and gave work to thousands of professionals and millions of women. Patterning through weaving was instead the result of increasingly complex looms, the most complicated being those used for the production of expensive velvets with multiple wefts. Textile 'design' was created through the weaving of the yarn, the mixing of fibres and the use of different colours. The decoration of a cotton cloth in India could have not been more different: here design was created through dyeing, printing and painting (often all three of them together - Fig. 11.12 lower part), a process that entailed a different set of skills based on knowledge of dyes, mordants (to fix the colour), processes of waxing the cloth, bleaching it and, of course, the carving of wood blocks (Fig. 11.13).

The difference between a woven and a printed textile is one of cost but also one of beauty. To set up a loom was an expensive and long activity. In Europe the abundance of colour and design on a textile was an indicator of its value. Any change in textile design was expensive as it implied weeks, if not months, of work in setting up the loom. By contrast printing, painting and dyeing were more flexible (Fig. 11.14). One had to simply change the mordant to create new shades and colours. Cotton was a fibre more suitable than flax, hemp, wool or silk for absorbing dyes and printing on. This partially explains why, starting with India, the processes of printing and painting were adopted in other areas of Asia where cotton cultivation and textile manufacturing developed around the year $1000 \mathrm{CE}$. In China woven cotton textiles were at the high-end of the market, but dyed and printed fabrics (yaobanbu) produced 


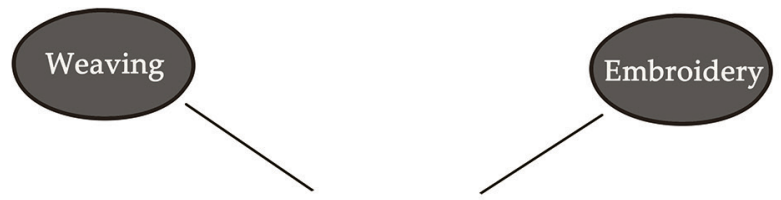

\section{'FASHIONING'}

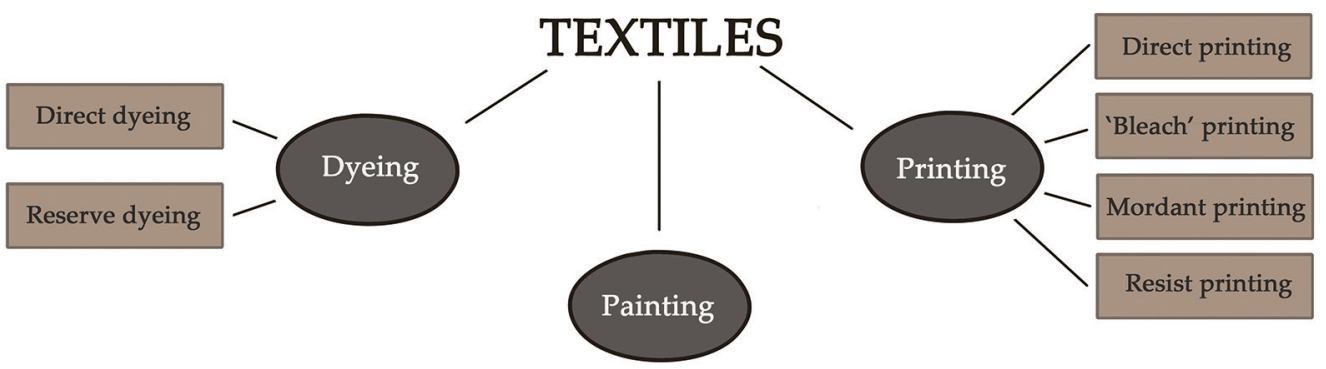

Fig. 11.12: Creating design on cloth in Europe and India in the early modern period (@ Giorgio Riello).

Fig. 11.13: The printing of cotton cloth as performed in the workshop belonging to Mr Khatri in Kutch, Gujarat, 2005 (Photo: (C) Giorgio Riello).

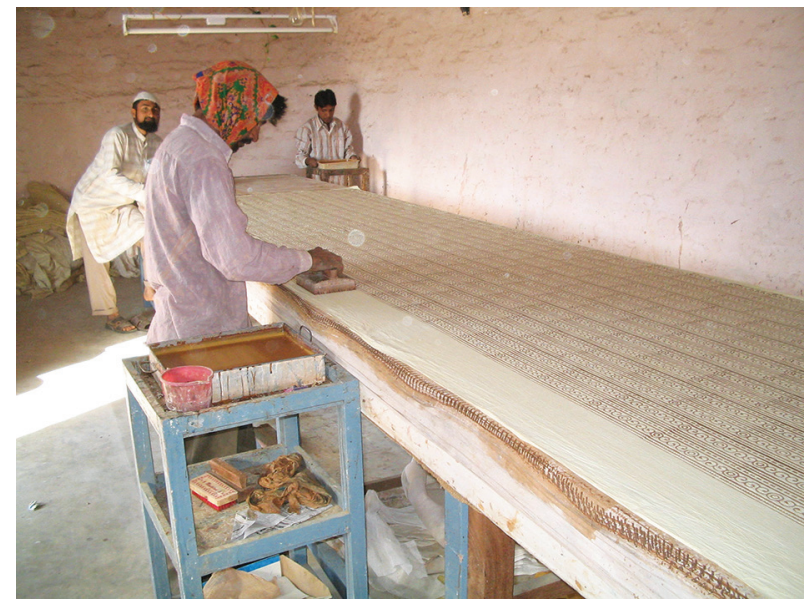

by using stencilling, resist dyeing and block printing were already popular in the late Song dynasty. Similarly, South-east Asian consumers appreciated the printed and painted textiles from India and at the same time developed their own specialisation in the manufacturing of ikats and batiks. (Ikat is based on the weaving of yarn that had previously been dyed by knotting it. Batik is based instead on the use of wax to prevent the dye from penetrating the cloth).

European clothmakers had attempted to engage in the technique of printing by using woollen cloth. This experiment carried out in the later Middle Ages in presentday Germany was not successful. The lack of cotton and little familiarity with cotton 


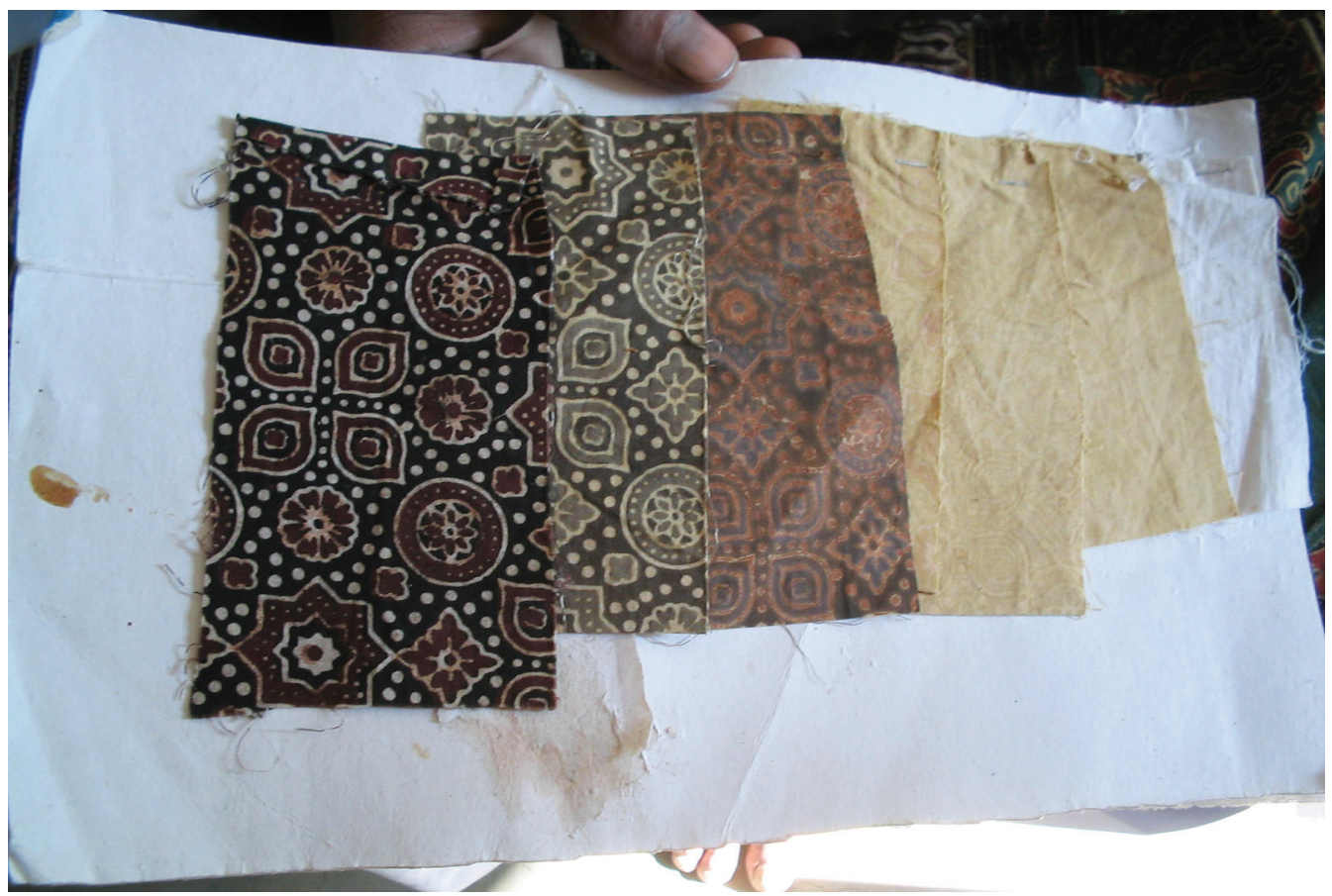

Fig. 11.14: Different colours and designs can be obtained by varying the use of dyes and mordants, but without changing the wooden block. Cloth swatches of traditional cotton cloth produced with vegetable dyes by Mr Khatri in Katch, Gujarat by using different mordant processes, 2005 (Photo: () Giorgio Riello).

textiles made the process of printing difficult to learn and replicate (Fig. 11.15). It was only with the importation of cottons from Asia and with the learning of the process in India between the last quarter of the 17th and the first quarter of the 18th century that Europe came to produce for the first time printed textiles. Linens, fustians and white Indian cotton cloths were printed in one of the many printworks that appeared across Europe between 1675 and the mid-18th century, the most famous of which is Oberkampf's fabrique in Jouy-en-Josa (Fig. 11.16) near Paris.

It was Europe's learning of how to print on cotton - and later of mechanised spinning and weaving of this fibre - that ensured for cotton worldwide success, something that wool and woollens never achieved. Wool remained instead a less versatile fibre, quite unsuitable to be printed on. By the early 20th century, it had acquired some of the exclusive characteristics that came to be shared with silks: high price and good quality. Cotton, by contrast, has had continuous success - even during the peak of synthetics' popularity in the second half of the 20th century - something partially due to the properties of the fibre, and partially to its versatility in conveying design and decoration through printing. 


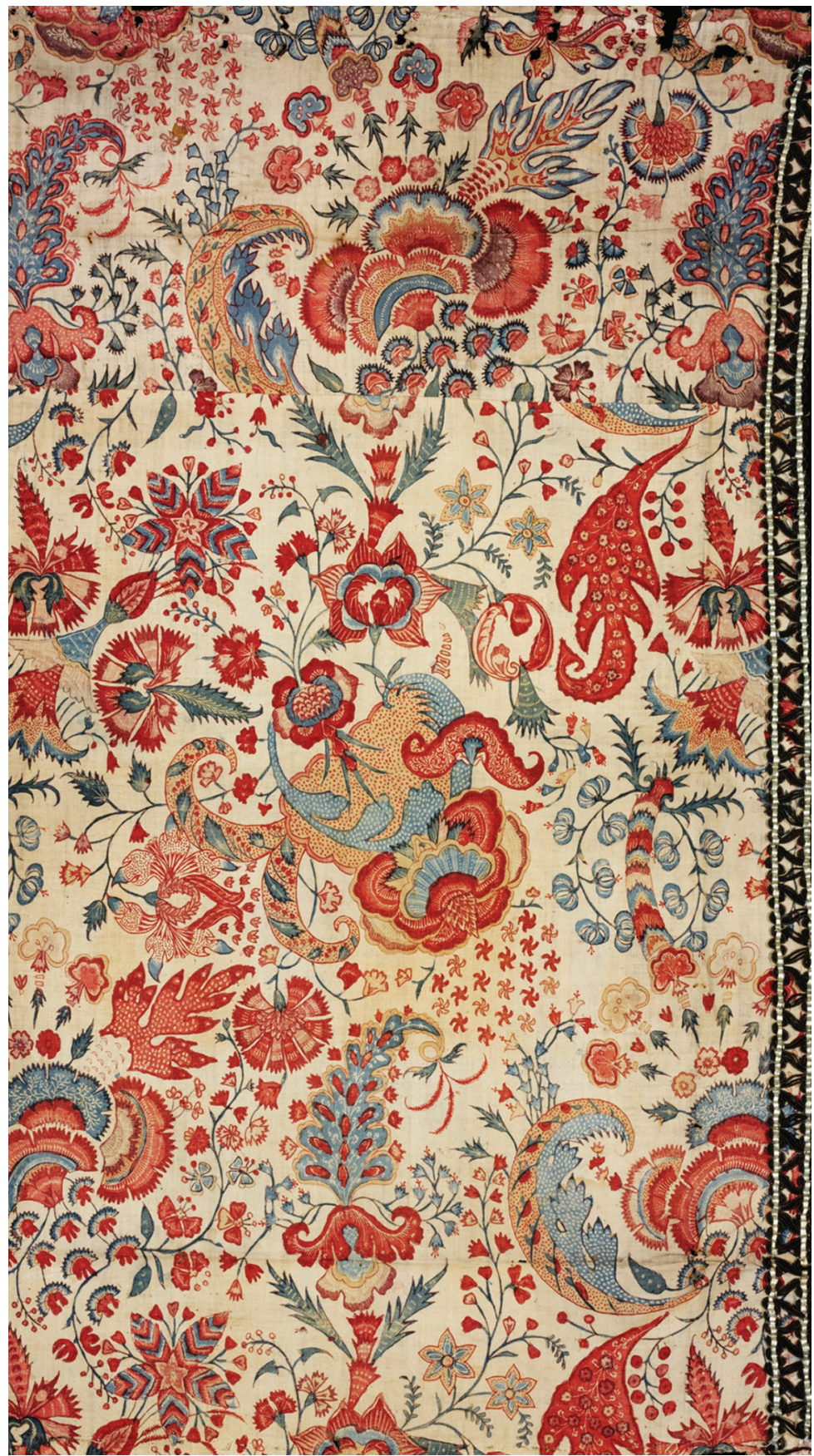

Fig. 11.15: Palampore, a large painted and dyed cotton bed covering or hanging produced on the Coromandel Coast of India for the European market, c. 1710-20, IM.56-1919. Europeans loved the vibrancy of colours and the bold motifs of Indian textiles, though often requested that they should changed to suit European taste. These objects provided an incentive for Europeans to learn the 'secret' of painting and printing on cotton (C) Victoria and Albert Museum, London). 


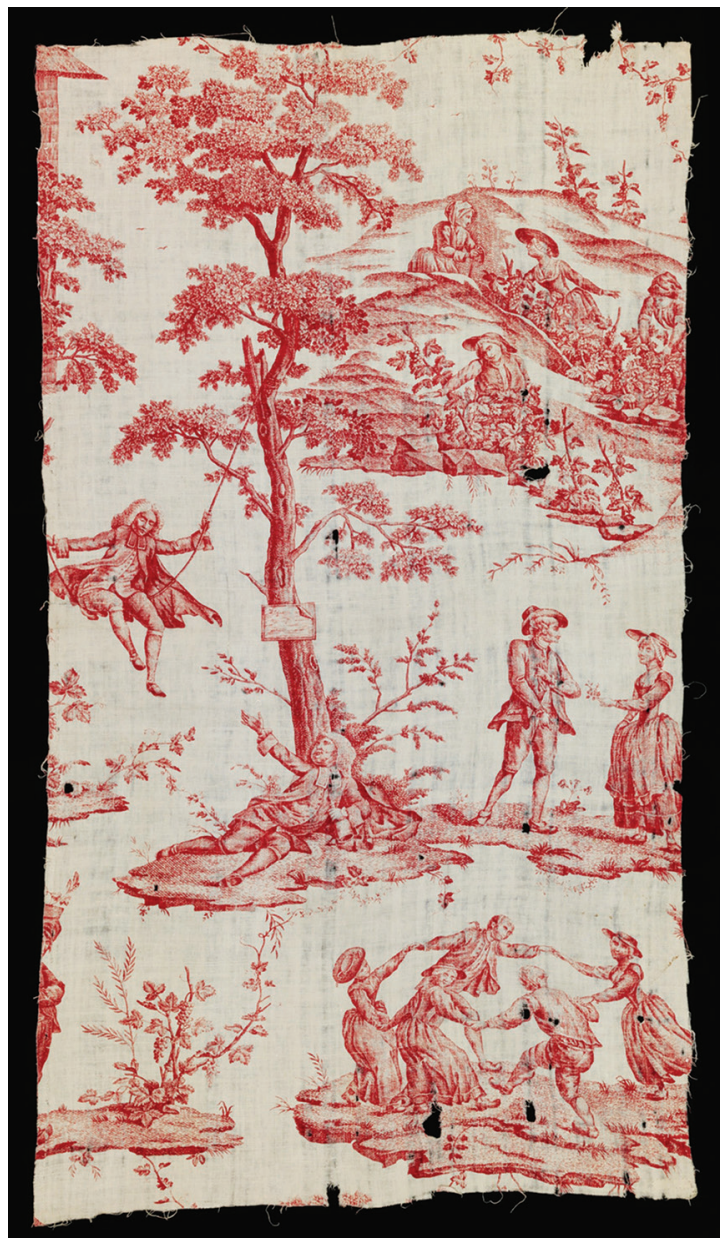

Fig. 11.16: Toile used as furnishing fabric and representing a grape harvest printed by Oberkampf in c. 1785, T.494-1919. In the second half of the 18th century, European calico printers developed a distinctive aesthetic vocabulary through the use of copper printing (unknown in Asia at the time). The most celebrated producer at the time was Christophe-Philippe Oberkampf (1738-1815) who opened his printwork at Jouy-en-Josas, a village near Paris the 1760s (Victoria and Albert Museum, London).

\section{Acknowledgements}

The research for this chapter has been made possible by the financial assistance of The Leverhulme Trust (Leverhulme Research Grant and Philip Leverhulme Prize).

\section{Further Reading}

Ruth Barnes (1997) Indian Block-Printed Textiles in Egypt. The Newberry Collection in the Ashmolean Museum, Oxford.

Giovanni Luigi Fontana and Gérard Gayot, eds, (2004) Wool: Products and Markets (13th-20th century). Maureen Fennell Mazzaoui (1981) The Italian Cotton Industry in the Later Middle Ages, 1100-1600.

Luca Molà (2000) The Silk Industry of Renaissance Venice.

Lisa Monnas (2008) Merchants, Princes, and Painters: Silk Fabrics in Italian and Northern Paintings, 1300-1500.

Giorgio Riello (2013) Cotton: The Fabric that made the Modern World.

Mary Schoeser (2003) World Textiles: A Concise History. 


\title{
12 Chinese Silks in Mamluk Egypt
}

\author{
HELEN PERSSON
}

Helen Persson has been at the Victoria and Albert Museum, London, since 2001 and is the curator of Chinese textiles and dress in the Asian Department. She obtained her first degree in archaeology at the University of Stockholm and her second in History of dress at the Courtauld of Institute, London, in 1999.

Helen's special interests include Chinese export textiles and the archaeologist Sir Aurel Stein (1863-1943). She has lectured and published extensively on textiles from the Silk Road, among others Textiles from Dunhuang in UK Collections, edited by Zhao Feng (2007). She contributed to the V\&A publication Medieval and Renaissance Art: People and Possessions edited by G. Davies and K. Kennedy (2009) with a text on Mongol silks and the Italian silk industry. Helen's next research project will be on the Chinese export textiles in the $V \& A$ collection.

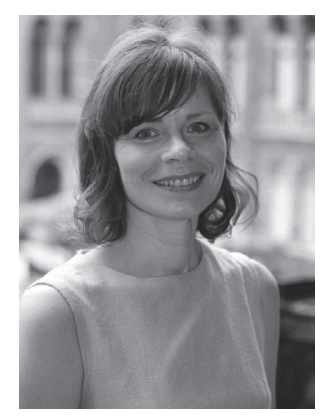

From the last quarter of the 19th century, an enormous amount of textiles were unearthed from the sands of Egypt. With the introduction of Christianity, burial practices changed markedly: mummification gradually discontinued and the dead were buried fully dressed, sometimes with several pieces of clothing and also wrapped and padded with a variety of textiles. Owing to Egypt's dry climate, this was a treasure trove of well-preserved and colourful textiles, dating from the early Roman occupation to the medieval period. Consequently, the artefacts were dug up and sold to museums, collectors and cultural institutions all over the world.

The Victoria and Albert Museum in London (V\&A) has one of the largest early Egyptian textile collections in the UK (comprising more than 2,000 fragments), of which the majority are the so-called 'Coptic' textiles, easily recognised by their figurative woollen tapestry weaves. 'Coptic' textiles are primarily the products of people who lived in Egypt during the early centuries of the Christian era but who were not necessarily Christian in their personal beliefs. Of course, not all of the textiles found in Egypt were originally made there. Some of the wools and pattern woven silks were imported from the larger Mediterranean area, for example from Syria or Byzantium.

However, five blue silk damask fragments stand out. Although the blue and white colour scheme, often using two shades of blue, is seen in several silks from the Mamluk period, the design is distinctive. Their patterns include Chinese-looking motifs and 


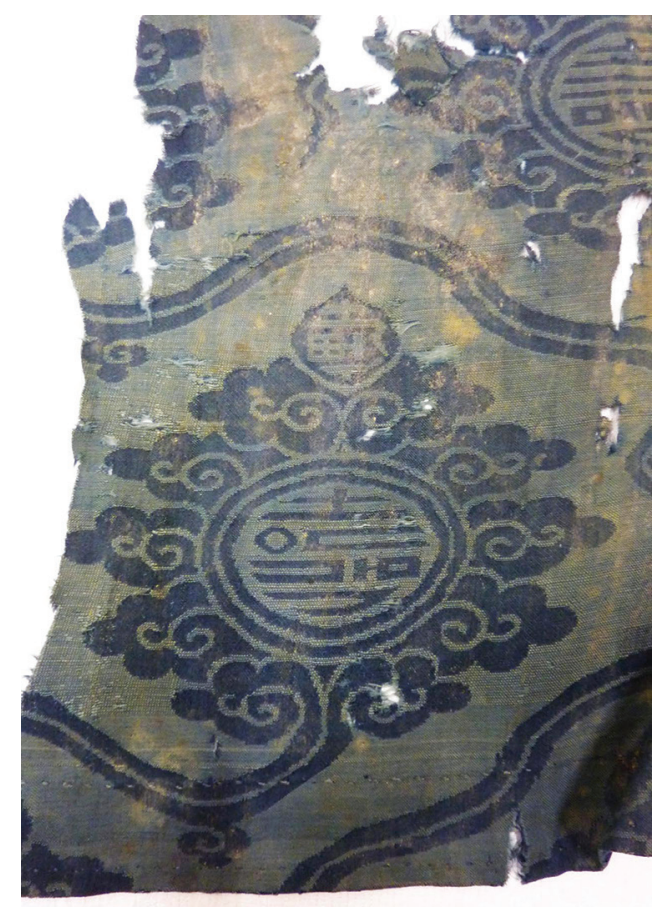

Fig. 12.1: Detail of one of the blue damasks showing a cloud palmette motif with versions of the Chinese character for longevity ('shou'). Satin damask in silk, Mongol Empire, 1293-1341. Museum no. 1106-1900 (Photo: (c) Victoria and Albert Museum, London). display clear Chinese characters (Fig. 12.1). They are broadly dated between the late 13th century and the mid-15th century $\mathrm{CE}$. These fragments were acquired among several other Egyptian textile fragments by the museum in 1898 and 1900 from three different collectors who claimed their textile batches came from "tombs at El-Azam, near Asyut". At the time, no comments were made about the possible origin of these specific textiles in their acquisition files. Were these damasks made in China and exported all the way to Egypt?

\section{The Mongols}

The earliest evidence of Chinese silk in the West is from an Egyptian tomb dated to 1000 BCE and from the early medieval times several pieces have been discovered in Church treasures and as funeral wrappings for the elite (Fig. 12.2). Indeed, Chinese silks have a long history of lucrative trade and the allure of the exotic, either obtained in trade or gifts to envoys. The Silk Roads connected China and the Far East with the Mediterranean and the Far West since ancient times, but the trade routes were revived in the 13th century by the Mongol rulers. At its greatest extent, the Mongol Empire (1206-1405) stretched from Eastern Europe to the Korean Peninsula, covering western Russia in the north and extending into South-east Asia and to Syria in the south. Also China was ruled by the Mongols under the Yuan dynasty (1271-1368).

This vast, transcontinental Mongol era witnessed the greatest expansion of trade and tribute in Eurasian history. Traders, as well as diplomats and missionaries, travelled more freely than ever before across Mongol domains, resulting in trade on a lavish scale and direct contact between Europe and China (Vollmer et al. 1983, 85). The Mongols valued commerce, and silk fabric being one of the most valuable exchange products, the extensive traffic in artisans and craftsmen, particularly the skilled weavers, had a critical impact during this time.

At least three settlements of textile workers were established in the northernmost regions of China and the adjacent Uyghur areas. Contemporary records suggest figures of up to 3,000 Muslim households, mostly weavers, to have been moved from Central 


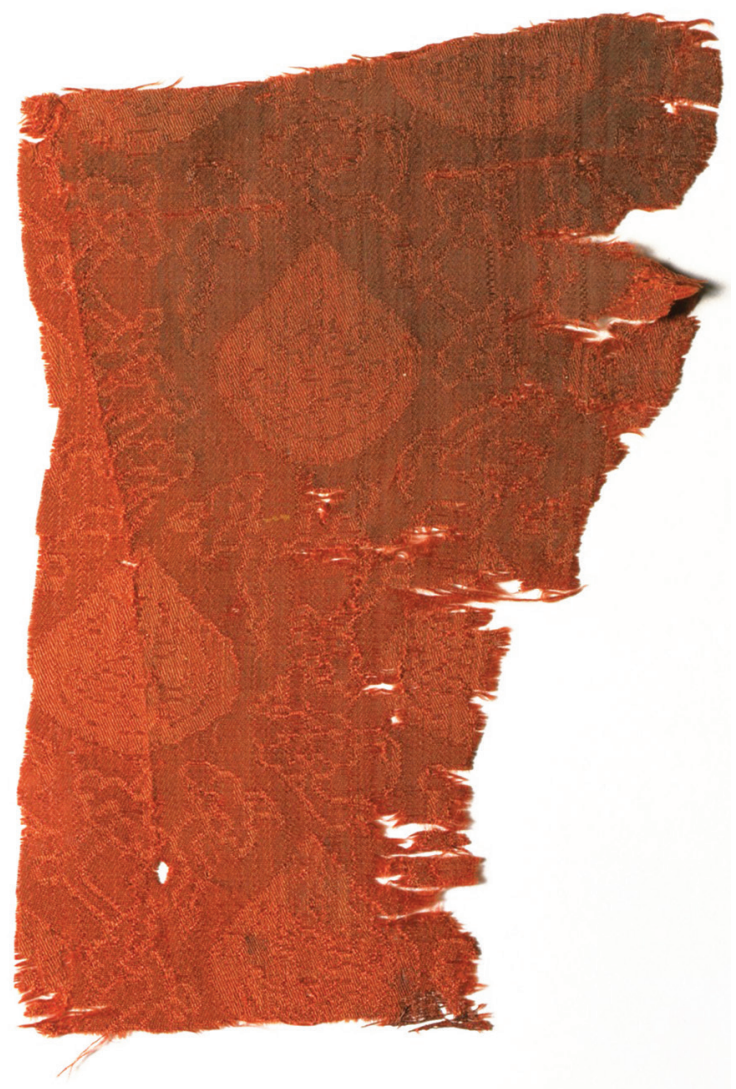

Fig. 12.2: Damasks like this were in high demand from European rulers and feature frequently in European paintings from the second half of the 13 th century. The stitching holes and seam lines suggest a possible past use as part of a vestment. Twill damask in silk, probably China, 1275-1350. Museum no. 7046-1860, from the Bock Collection (Photo: (c) Victoria and Albert Museum, London).

Asia to one of these settlements, Xunmalin, a site in Hebei province (Rossabi 1998, 87), indicating the grand scale of human traffic.

All three textile communities were inhabited by weavers of diverse backgrounds Central Asian, Muslims, Uyghur, and Chinese - exploiting the skills of the best artisans from the Mongol domain. The Mongols also settled Chinese craftsmen in eastern Central Asia. These multi-cultural colonies enabled the intermingling of techniques and designs.

Perhaps the most famous Mongol textile is the nasij or panni tartarici, the cloth of gold which had immense commercial and artistic value. This textile was usually executed in a new weave structure called lampas. The pattern is composed of weft floats bound by a binding warp which is added to a ground weave formed by a main warp and a main weft (Burnham 1980, 82) (Fig. 12.3). Gold was particularly important in Mongol culture and the production of textiles woven in gold was encouraged throughout the empire. Not only was cloth of gold in prevalent use by the Mongol elite (Watt 2010, 247), but it was also a highly desirable commodity in Europe and the Mamluk Empire. 


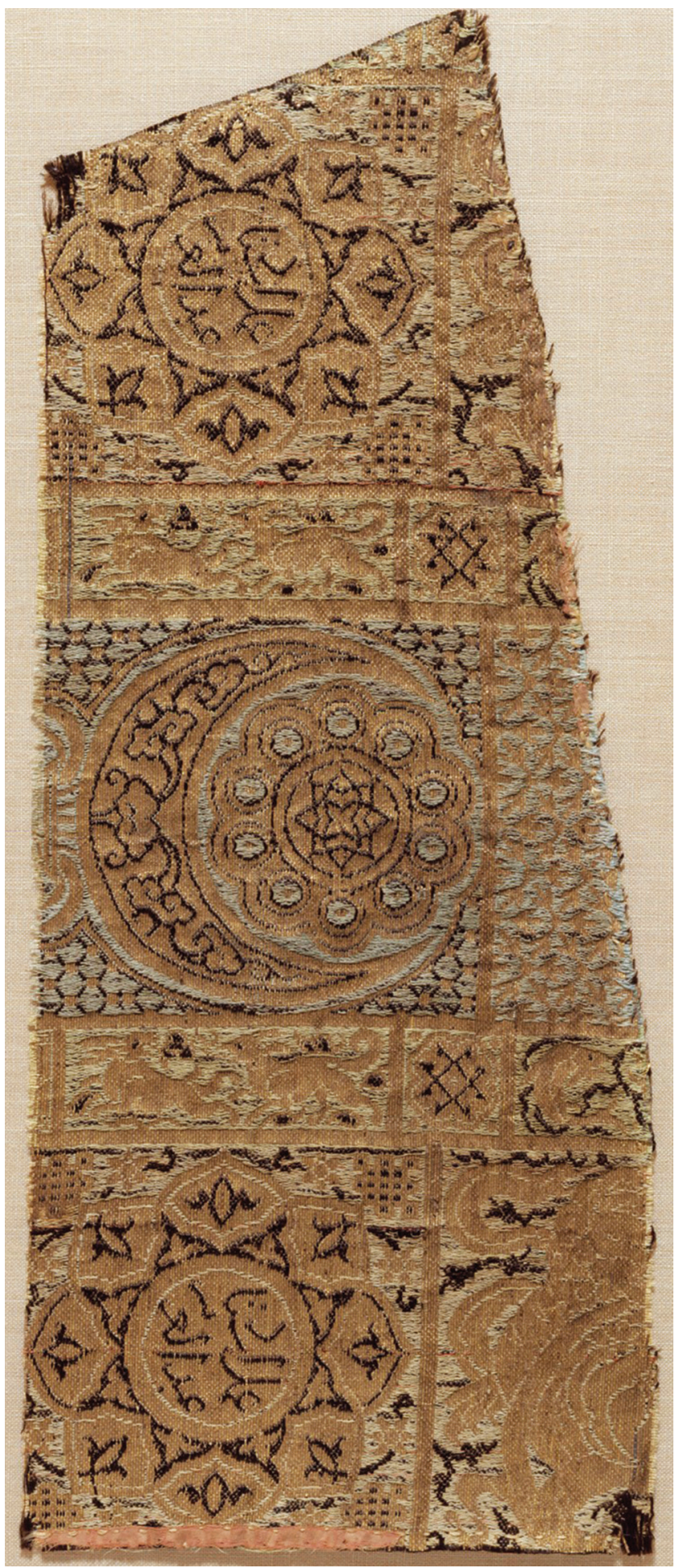

Fig. 12.3: This cloth of gold fragment is typical of the fusion of Sino-Islamic motifs, including lions playing with balls, geometric interlace, paired running animals, and a crescent moon containing cloud scrolls. Lampas in gold and silk, probably Greater Iran, 1300-1350. Museum no. 8639-1863, from the Bock Collection (Photo: () Victoria and Albert Museum, London). 


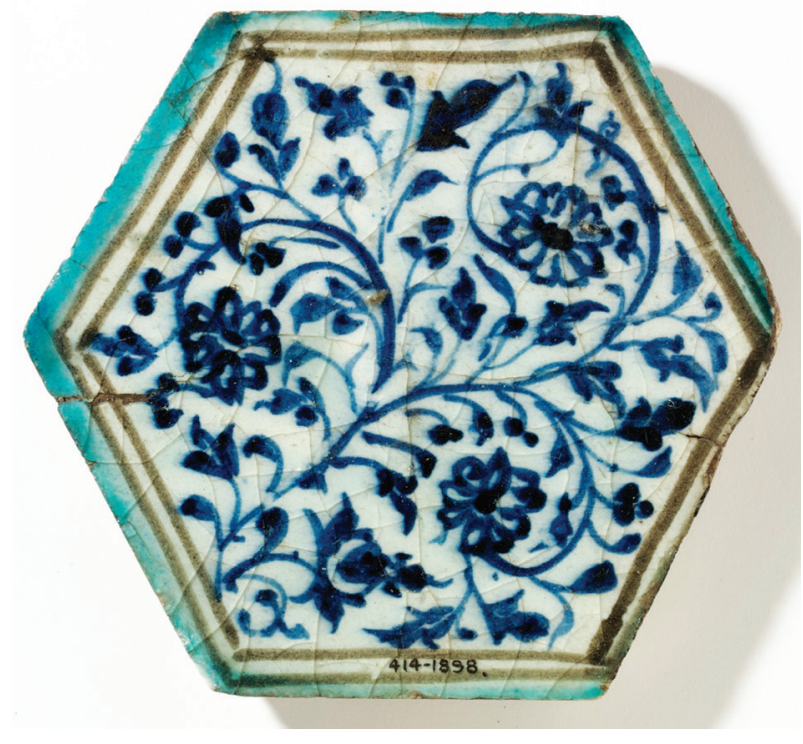

Fig. 12.4: Mamluk artists reworked the new decorative ideas from East Asia to their own unique hybrid. Fritware, Syria, 1420-1450. Museum no. 414-1898 (Photo: (C) Victoria and Albert Museum, London).

Egypt was ruled by the Mamluk sultans during 1250-1517 and famously resisted the Mongol invasion on several occasions. The Mamluk sultans controlled not only Syria and Egypt but also parts of North Africa and the Hijaz with its Holy Cities of Mecca and Medina. Still, trade flourished between the two empires and East Asian textiles and other goods were imported to the Mamluk domain via the Mongols (Fig. 12.4). Chinese art was highly admired in the medieval Middle East, and the decoration of Mamluk objects in general show a strong Chinese influence (Pietrovsky and Pritula 2006, 46-47).

\section{The Fragments}

The Chinese-looking blue silk fragments were discovered in the necropolis of El-Azam, near Asyut in Upper Egypt, according to the collector who sold them to the V\&A. Asyut had one of the highest Coptic Christian populations in Egypt and the tombs of many regional leaders may be found here which document the area's historical significance.

The silk fragments show two different patterns (Fig. 12.5). Two of the fragments, nos. 753-1898 and 1106-1900, have a pattern made up of two shades of blue showing rows of teardrop-shaped cloud palmette surmounted by a smaller teardrop shape, both of which contain a version of the Chinese character for longevity ('shou'). The tails of one row of cloud palmettes extend to the right and those of the next row to the left. Both fragments have remains of seams and gores, indicating that they originally were sections of a garment (Fig. 12.6). The three others, nos. 754-1898, 1108-1900 and T.67-1958, are in blue and silvery beige, showing circular medallion pattern also with the stylized Chinese character shou and in between these medallions the motif of a flaming jewel is depicted. They also have remains of seams, pointing to their original 

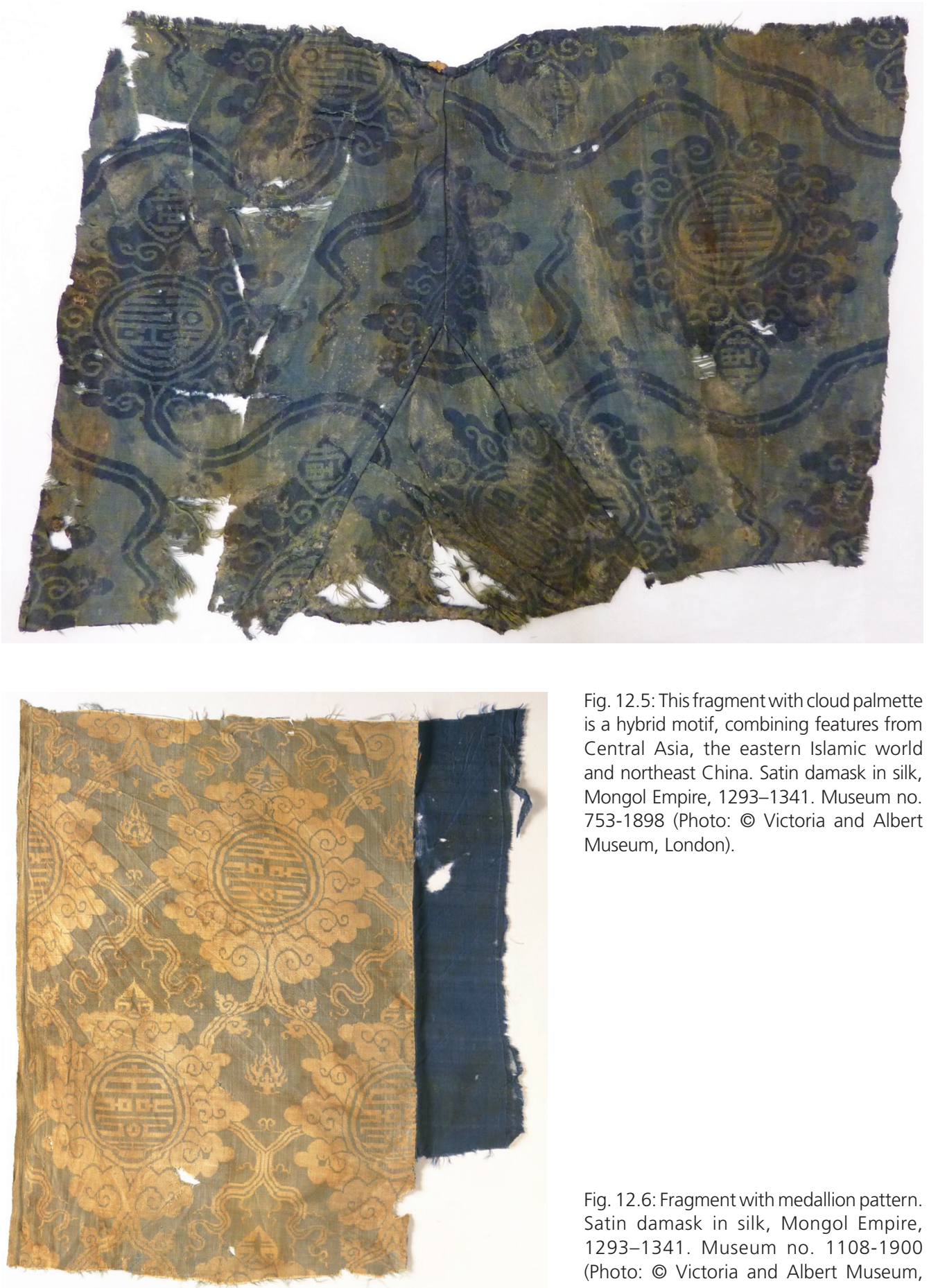

Fig. 12.5: This fragment with cloud palmette is a hybrid motif, combining features from Central Asia, the eastern Islamic world and northeast China. Satin damask in silk, Mongol Empire, 1293-1341. Museum no. 753-1898 (Photo: (C) Victoria and Albert Museum, London).

Fig. 12.6: Fragment with medallion pattern. Satin damask in silk, Mongol Empire, 1293-1341. Museum no. 1108-1900 (Photo: (C) Victoria and Albert Museum, London). 
use as parts of clothing. It is noteworthy that the tailoring, in both groups of fragments, appears not to have taken into account the proper orientation of the Chinese character, but has also utilised it upside down (Fig. 12.7). This suggests that at least the tailoring was done in a context where the reading of Chinese characters was irrelevant.

Furthermore, the designs in both groups of fragments demonstrate a hybrid patterning, a fusion of different cultural repertoires.

The fragments came to the museum via three different collectors in 1898 and 1900. This is not unusual. At the time, it was common practice among dealers and collectors alike to cut out the decorative elements or cut up large fabrics, such as garments or hangings, and to sell them piece-by-piece in order to obtain maximum profit. Similar fragments of both the palmette and medallion-patterned silks can be found in the Metropolitan Museum of Art in New York (Watt 2010, 263), The Hermitage in St. Petersburg (Piotrovsky and Pritula 2008, 166-167) and the Museum of Islamic Art in Cairo. It is possible that originally they all came from the same garments.

Fig. 12.7: This fragment appears to originally have been a section of a tunic showing an armhole and trimmed neck, but the pattern of the Chinese character has been utilised upside-down. Satin damask in silk, Mongol Empire, 1293-1341. Museum no. 754-1898 (Photo: (C) Victoria and Albert Museum, London).

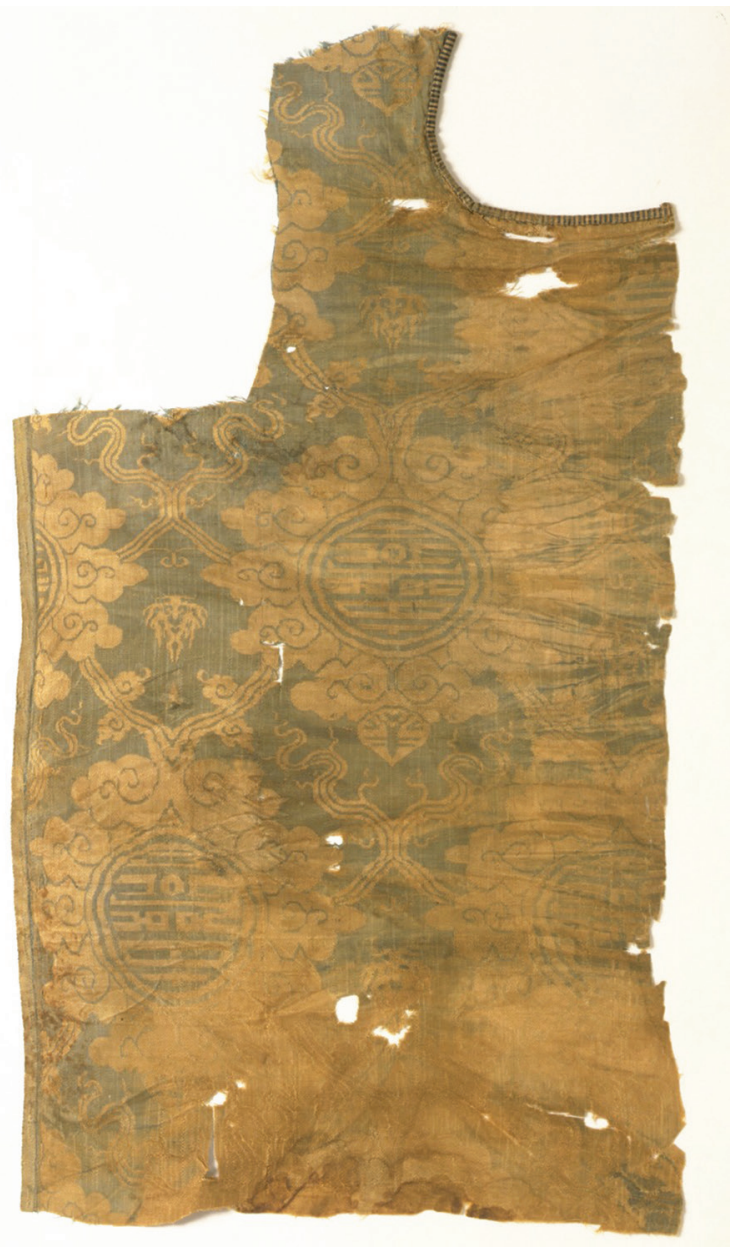


Some of the fragments (nos. 753 and 754-1898) were purchased from Henry Wallis, in a batch of 66 textile fragments, all found in Egypt (M/1/W330/3, Nominal Files, V\&A Archives). Henry Wallis was an English Pre-Raphaelite painter, writer and collector with a great interest in archaeology. He provided the V\&A with hundreds of textile fragments from Egypt.

Mr Wallis writes in a letter to the V\&A dated 16 July 1898 that, "They were offered to me last winter as the result of a recent discovery of a Xtian [Christian] necropolis at El Azam, in Upper Egypt ...". He also mentions that he has seen "specimens of a similar kind, some probably of this find" abroad and with other dealers in Cairo (MA/1/W330/3, Nominal Files, V\&A Archives), which could very well be the other pieces now held in other museum collections.

The other fragments, nos. 1106-1900 and 1108-1900 came from Major Myers's large collection of Egyptian material (MA/1/M3321/2+3, Nominal Files, V\&A Archives). William Joseph Myers was a military officer and comes across today as something of a magpie, as he purchased and collected indiscriminately wherever he was stationed. While in Egypt, Major Myers purchased Coptic textiles from Michel Casira, a dealer in Cairo, from whom also the fragment no. T.67-1958 came (Fig. 12.8). It actually arrived in the Museum in 1898 with several other Egyptian textiles from Monsieur Casira (MA/1/M3321/3, Nominal Files, V\&A Archives).

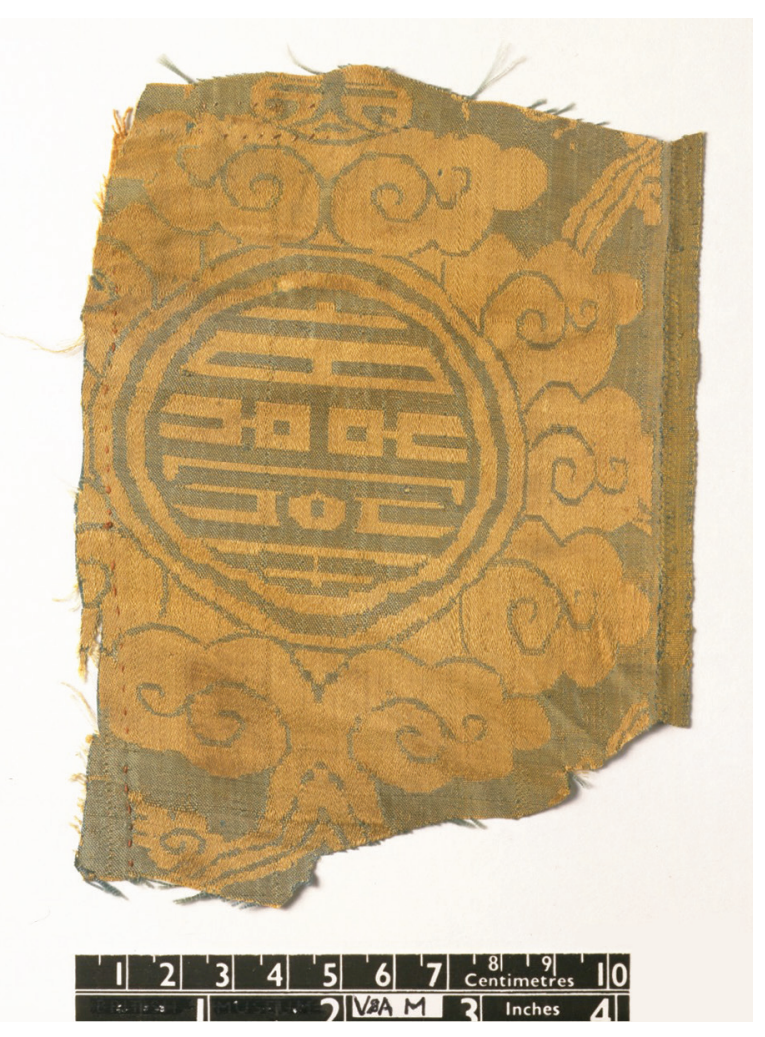

Fig. 12.8: There is a tiny remnant of plain woven linen still attached to the back of this fragment, indicating that once it was lined or edged. Satin damask in silk, Mongol Empire, 1293-1341. Museum no. T.67-1958 (Photo: C) Victoria and Albert Museum, London). 
Despite their different acquisition sources, all the textile fragments are woven in the same technique: 5 -end satin, [satin is one of the basic weaves characterised by the points of binding being separated in all directions by one or more warp threads and one or more weft threads]. In the textile fragments discussed here, the warp threads pass over 5 wefts before the point of binding with a z-spun paired warp and no apparent twist to the weft [the direction of the spinning of threads of the warp and weft is indicated by the letters S and $\mathrm{Z}$, or the filaments/fibres may not be spun at all. Here, two warp threads are running parallel throughout the weave instead of a single warp thread which is more common]. Some of the fragments appear finer, and some have slightly compressed motifs, which might indicate a derivation from different loom lengths. However it can also be explained by the fragments being from different parts of the length as irregularities in weaves are not unusual.

Fortunately, all the fragments have parts of their selvedges intact and it is clear that there are two types: one in satin and one ribbed warp-faced [i.e. where the selvedge is marked with ribs horizontally with warp threads dominating on the surface]. This suggests that the fragments are not likely to have been produced in the same workshop.

Even more interestingly, the selvedges of the blue fragments, and overall technical information, are similar to two other textile fragments from the tombs of El-Azam in the V\&A, nos. 769-1898 and 1158-1900. They were also acquired from Mr Wallis and Major Myers, respectively (MA/1/W330/3 and MA/1/M3321/2+3, Nominal Files, V\&A Archives) (Fig. 12.9).

This blue silk damask is woven with rows of palmettes diagonally placed and alternately reversed in direction. Each is outlined by leaf ornament and encloses an Arabic inscription surrounding a five-pointed leaf. The inscription reads "nâsir al-dunya wa al-din muhammad ibn qalawun" giving the name and title of a Mamluk

Fig. 12.9: The design of this fragment shows strong influences of Chinese style but with an Arabic inscription. The patterning and structure is similar to the fragments with a Chinese character. Satin damask in silk, Mongol Empire, 1293-1341. Museum no. 769-1898 (Photo: () Victoria and Albert Museum, London).

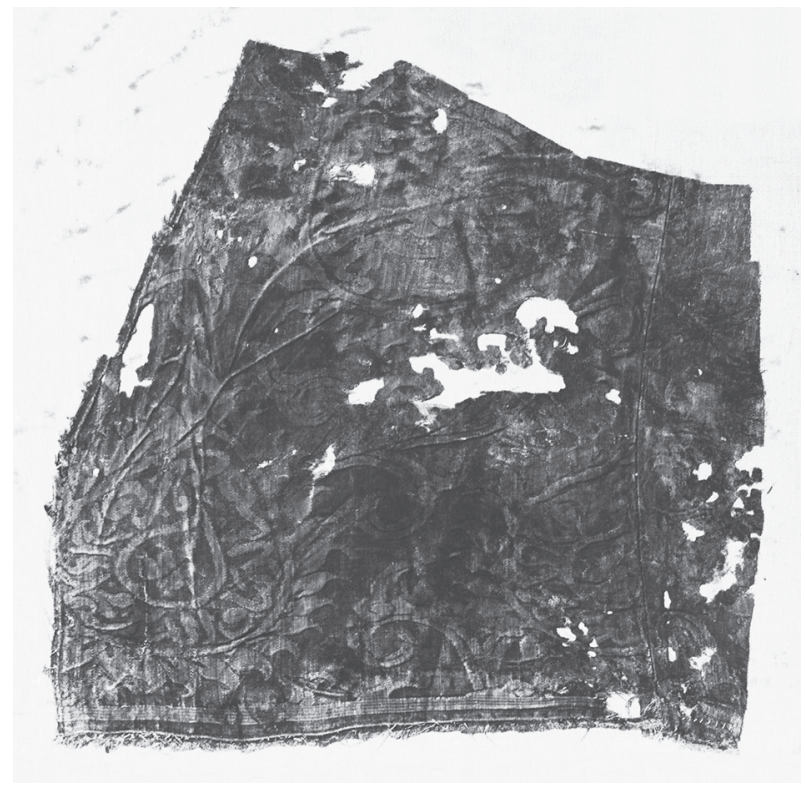




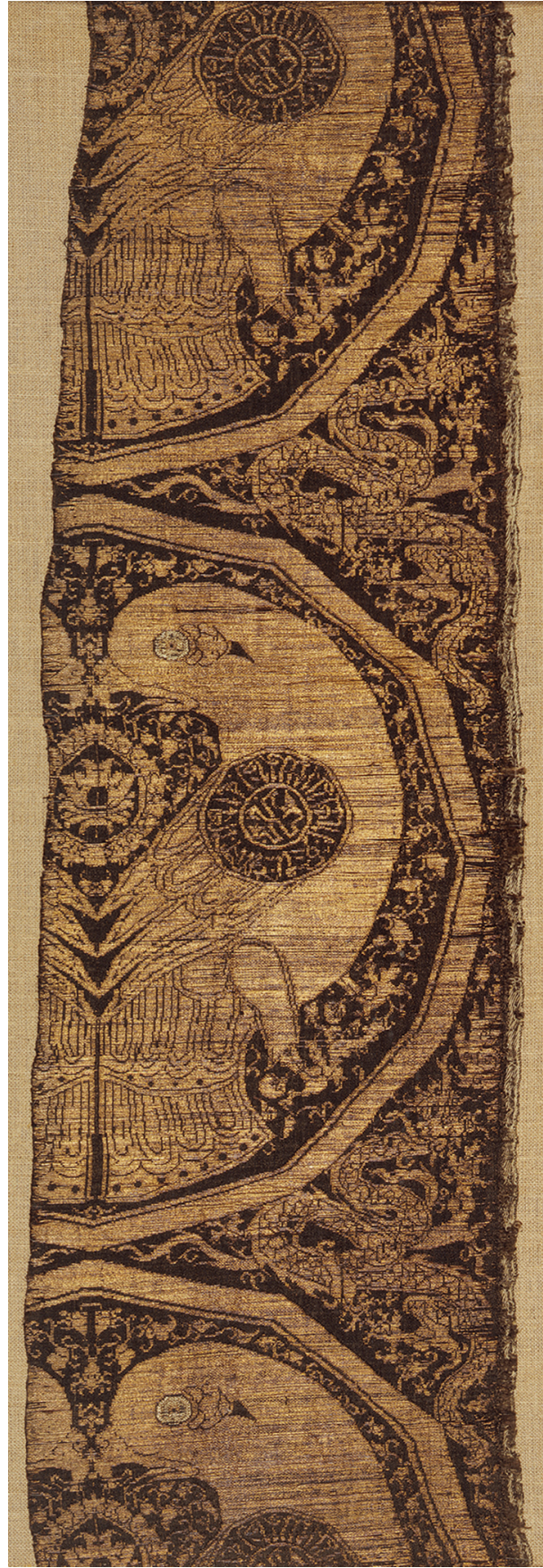

Fig. 12.10: The famous gold fabric with paired parrots and dragons from the Marienkirche in Lübeck, Germany. Inv. no. KGM 1875,258 (C) Kunstgewerbemuseum Staatliche Museen zu Berlin; photo: Hans-Joachim Bartsch). sultan, considered to refer to al-Nasir alDin Muhammad who ruled intermittently between 1293 and 1341. It is likely that all damasks discussed here were made during his reign.

\section{Place of Manufacture}

Richly woven textiles in particular from eastern Mongol regions were traded in great quantities with the Ilkhanid territory (Persia, present-day Azerbaijan and parts of present-day Turkey), the Mamluk realm and Europe. The Mongols also employed silks as payments and grants to the nobles; as rewards for civilian and military officials; as currency; as tribute; and as diplomatic gifts.

The style of the Arabic inscription of textile fragments nos. 769-1898 and 11581900 is similar to the famous gold fabric with paired parrots and dragons from the Marienkirche in Lübeck, Germany (Fig. 12.10). This textile has been associated with Abu al-Fida's eyewitness account of the 700 silks inscribed with Nasir al-Din's name that were sent to the Mamluk sultan by Abu Said to commemorate the peace treaty in $1323 \mathrm{CE}$. Exciting as that may be, precious textiles have been a vital part of diplomatic missions for a very long time.

Some of the silk fabrics bearing Mamluk titles may have been diplomatic gifts to the Sultan, as perhaps the one in Lübeck due to the gold thread, but the V\&A fragments were found in Egyptian Christian burials, and bear no apparent sign of having been intended as ceremonial gifts. Nevertheless, the use of Mamluk colours and Mamluk inscription in a foreign fabric certainly indicates that the textiles were intended for export to Egypt and Syria (Wardwell 1988, 100ff), and most likely aimed at 


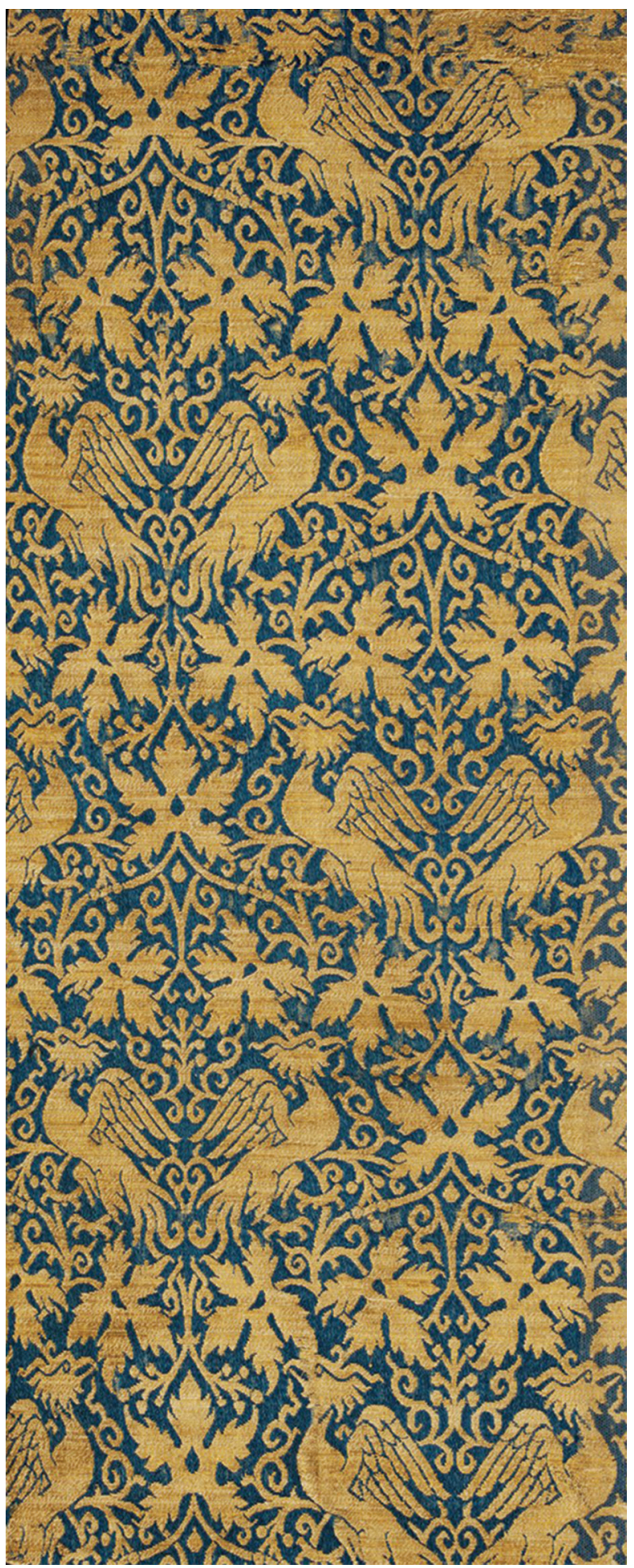

Fig. 12.11: The birds are similar to the Chinese phoenix, while the vine leaves are of Lucchese influence, but the use of almost pure gold suggests that it was produced in the eastern Islamic part of the Mongol Empire. Lampas in gold and silk, probably Greater Iran, 1350-1400. Museum no. 769-1894 (Photo: C) Victoria and Albert Museum, London). 
the more affluent market. The acquisitions of objects that are rare and expensive enhance the status of the owner. Furthermore, textiles with woven or embroidered Arabic and Persian inscriptions (tiraz) carried messages associated with power and authority. The textiles with Chinese characters probably fell within the same category. Although the Egyptians could not read the characters and the textiles were utilised upside-down for the garments, it most likely communicated the wearer's social status and demonstrated wealth.

Similar textiles have not been found in China or Central Asia, strongly suggesting that they indeed were textiles for a targeted market.

The structure of the blue silk damasks, the z-spun paired warp, is similar to the foundation warp of the nasij [the lampas technique described earlier] This structure is characteristic for nasij woven in the eastern Islamic world, and this is therefore perhaps indicative of the origins of the blue silk damasks in the V\&A. It remains possible that they were made in China, but their place of manufacture is more likely to be in the eastern parts of the Islamic world due to their structure.

Textiles from the Mongol domain of this period defy any attempt at definition. With the flourishing trade of the Mongol Empire, designs migrated across cultural boundaries, combining a mixture of traditional Chinese motifs, Middle Eastern elements and local Central Asian repertoires, and for a brief period there was an international decorative repertoire in Chinese, Middle Eastern, Mamluk and Lucchese silks (Fig. 12.11). Entire colonies of skilled artisans of mixed ethnicity were created, which facilitated a kind of hybrid development in textile art and its technology bewildering textile historians today.

Asian silks later than about 1400 are not found in European church treasuries and tombs, reflecting the interruption of the Silk Road trade with the fall of the Mongol power.

\section{Acknowledgements}

I wish to thank Hero Granger-Taylor for confirming the weave, and I am grateful to Hedley Swain and Maria Sardi for their comments on my text.

\section{Further Reading}

Dorothy K. Burnham (1980) A Textile Terminology: Warp \& Weft.

Mikhail B. Piotrovsky and Anton D. Pritula (2008) In Palaces and Tents: Islamic World from China to Europe.

Mikhail B. Piotrovsky and Anton D. Pritula (2006) Beyond the Palace Walls: Islamic Art from the State Hermitage Museum. Islamic Art in a World Context.

Morris Rossabi (1998) Behind the Silk Screen: Movements of Weavers in Asia, Seventh to Fourteenth Centuries, Orientations, 29, no. 3, pp. 84-89.

John E. Vollmer, Edward J. Keall and Evelyn Nagai-Berthrong (1983) Silk Roads China Ships.

Anne E. Wardwell (1988/1989) Panni Tartarici: Eastern Islamic silks woven with gold and silver (13th and 14th centuries), in Islamic Art, III, 1988-1989, pp. 95-173.

James C. Y. Watt, ed., (2010) The World of Khubilai Khan: Chinese Art in the Yuan Dynasty. 


\title{
13 Woven Mythology: The textile encounter of makara, senmurw and phoenix
}

\author{
MARIACHIARA GASPARINI
}

Mariachiara Gasparini was born in Salerno, Italy, in 1980. She studied Latin and ancient Greek at the Benedictine Abbey of Cava' de Tirreni (est. 1011), where she obtained the Diploma of Classical Studies in 1998. In 2005, she graduated from the University of Eastern studies of Naples (est. 1732) with a thesis, The techniques of brocade along the Silk Road in the XIII century. She lived and worked five years between China and United States of America. In 2008, she obtained a certificate in Fashion Studies from Parsons The New School of Design, New York City where she specialized in Textile Rendering and Fashion Foundation. In 2010, she was accepted at the Sotheby's Institute of Art in London where she specialized in East Asian Art. Her final dissertation obtained a merit evaluation at the end of 2011 and was published in 2013 with the title, The Silk Covers of the Admonitions Scroll. Aesthetic and Visual Analysis. Since November 2012 she has been a PhD student at the Graduate School in Transcultural Studies of the Cluster of Excellence "Asia \& Europe in a Global Context" at the University of Heidelberg. Her research focuses on the unpublished Turfan textile collection held at the Asian Art Museum of Berlin and the de-codification of Central Asian motifs in Europe. She is also a member of the Textile Society of America, the CIETA and the Association for Asian Studies.

Long ago, when human beings and animals shared the land of many gods and goddesses, the perception of surrounding water, earth and heaven gave light to an exceptional vision of the wonders of creation called 'myth'. From East to West, humans have tried to explain it through their imagination. Mythology is just another view of the history of the world. "Myth, then, is always an account of a 'creation'; it relates how something was produced, began to be. Myth tells only of that which really happened, which manifested itself completely. The actors in myths are Supernatural Beings. They are known primarily by what they did in the transcendent times of the beginnings" (Eliade 1968, 6). The concept of myth is related to local traditions and rites that have changed over the centuries. Figures and characters were transformed and adapted in Asia as well in Europe; however, similarities appear everywhere. The term 'Asia' itself in Greek mythology is the name of a Nymph of Lydia in present-day Turkey. Before the modern era, to westerners the land beyond Greece was the magic area of fabulous monsters and incredible stories. The makara, semurw and phoenix found their way along the Silk Roads, lost their original meaning and became the 
decorative motifs on many different surfaces. The transposition of these on silk grounds was only another way to wear 'the Supernatural' and get close to the gods. If "living a myth implies a genuinely religious experience, since it differs from the ordinary experience of everyday life" (Eliade 1968, 19), 'weaving' and 'wearing' a myth could be a further adaptation of religious functions. In the modern era, ancient textiles were reproduced and adapted to the canonized western religions founded on one God; nevertheless, the creation and the use of these surfaces can be traced back in the history of different Eurasian polytheistic cultures.

Belonging to Indian tradition, the makara is a half terrestrial and half aquatic animal related to Ganga the Goddess of the river Ganges, and Varuna, the God of the sea. With the hybrid features of an elephant, crocodile and fish, in China it became 'the dragon-fish'. As a decorative motif in Indian and South-east Asian temples, as an emblem of the God of love, Kamadeva or as handles of the Chinese Longquan celadons of the Southern Song period (1127-1279 CE) this mythological beast was transferred to the Mediterranean area. The Ambon of the St. Pantaleone Cathedral in Ravello, Italy, is probably one of the best examples that show the metamorphosis of this mythological animal. Dated to the 12th century, the Ambon is decorated with two scenes of Jonah and the whale. A canine head with a fish body, wings and feet is how the medieval representation of a whale was depicted in Europe. The water beast is just the transfer of a common imagery that has its roots in Asia. The lampas - a luxury fabric with complex weave including two warp systems and two or more weft systems - with a magnificent composition of makaras, flowers and phoenixes in golden threads on a pink-gold background woven in Daidu (present-day Beijing) or in Central Asia in the 13th century is just one of many textiles which arrived in Europe during the Mongol period (Fig. 13.1). The type of makara woven appears very similar to the Biblical whale in Ravello; although the tail is not curly and the wings are stretched upwards, the figure seems almost identical to the one on marble. This type of textile in Italy belongs to the category of nacchi, nachetti or nasicci (Rosati 2010), a transliteration of the term "nasij or cloth of gold, textiles in which both ground and pattern are gold, with the design merely delineated by the silk foundation weave" (Watt and Wardwell 1997, 127). Sometimes it was also recorded as panno tartarico (tartar cloth) or panno tarsico (tarsic cloth). Over the following centuries, many Asian motifs like the makara were deconstructed, absorbed and represented in Lucca, Italy.

A lampas dated to the 14th century, woven in Italy and preserved in Berlin, is a multiple depiction of a water creature surrounded by a dog and a sort of phoenixsenmurw that most likely was inspired by the Indian makara and the Persian senmurw. It was Iranian tradition that widely influenced Central Asian weavings to create the figure of the senmurw. Although it is recorded as a flying creature, its size and its canine head make it looks like a dog with wings. Occasionally confused with the figure of the phoenix, it is related to the idea of wisdom. The senmurw or eagle-wolf is a mythological creature with a triple nature: terrestrial, aquatic and aerial. It was first described in the Sassanid period (3rd-7th century CE) as an emblem of royalty.

The senmurw falls into the vast category of 'compound' beasts, guarantors of 


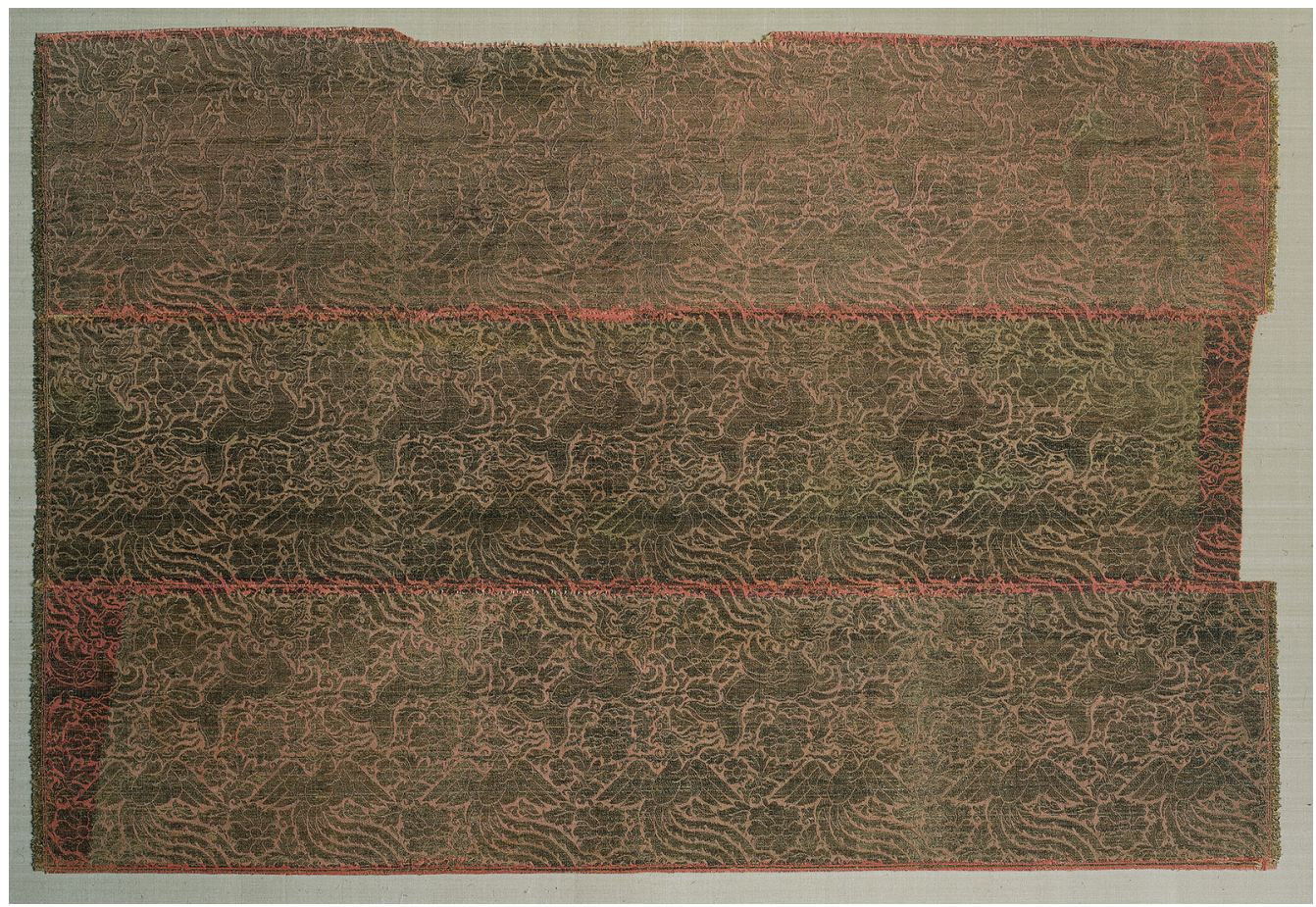

Fig. 13.1: Makaras, Phoenixes and Flowers, 13th century. Central Asia or Daidu. Lampas, silk and gold thread; 51.3 $\times 75.6 \mathrm{~cm}$ (@) The Cleveland Museum of Art, Purchase from the J. H. Wade Fund 1991.5). (Three vertical sections in the Cleveland Museum of Art and two in the David Collection, Copenhagen).

seasonal renewal and of fertility, in other words, of the very cycle of life and death. Passage to the beyond and traumatic transitions or changes of state were necessary to achieve 'rebirth' (Romano 1994, p. 135). Like the makara, around the 12th or 13th century, this creature reached Spain and Southern Italy, where it was used not only as an iconographic motif on sacred vestments, but also as an emblem of salvation in churches. Also recognised as a gryphon, this ancient beast is part of a classic iconographic patrimony, representing the link between the terrestrial world and the beyond. Perhaps originating in Mesopotamia, it is depicted sometimes with an eagle's head and sometimes with a lion's head and it spread to both the Middle East and Central Asia. It seems also that during the Sassanid period, the Iranian gryphonsenmurw spread beyond the area thanks to the flourishing trade of goods such as silk. Thus, the myth remained preserved, in a way, frozen in time. In a free composition with more terrestrial features, a sort of dog-senmurw appears with a phoenix and Kashmirlike patterns on Italian lampas housed in the Victoria and Albert Museum in London (Fig. 13.2). This is far from the scheme of roundels that characterizes most Central Asian or Sassanian weavings; Italian lampas are mainly woven with deconstructed figures. This deconstruction became the basic and important characteristic of motifs in Italian silk production. 
Among mythological beasts, another well-known animal in the East as well in the West is the phoenix. Known in China as fenghuang, it has been described as an animal with the body of a wild swan, the throat of a swallow, the beak of a hen, the neck of a snake, a tail made up of clumps of feathers of various lengths, the head of a crane, the crest of a mandarin duck and the curved back of a tortoise. In addition, it was said that it appeared only when the

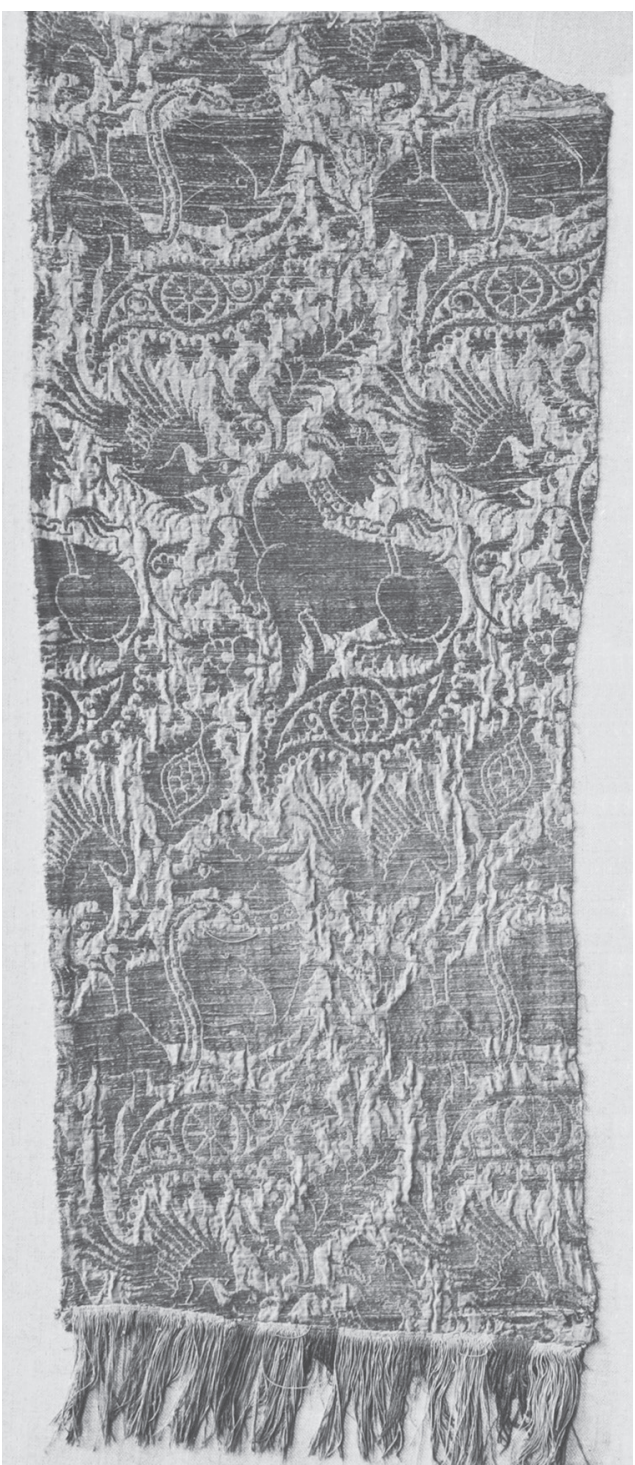

Fig. 13.2: Lampas with sort of dog-senmurws surrounded byeagles or phoenixes and Kashmir-like patterns. Warp82.6 $\mathrm{cm}$, weft $31.7 \mathrm{~cm}$, Italy, 14th cent. Museum no. 1304-1864 (C) Victoria and Albert Museum, London). country was at peace and disappeared with the disorder provoked by war. For this reason, it was considered a symbol of peace. In the West, however, it has different connotations. The phoenix is a bird which sacrificed itself to the flames, but was reborn from the ashes. Through the Ilkhanate (1256-1353 CE) - a state of the Mongol Empire that stretched from Turkey to Eastern Iran - birds resembling phoenixes were transmitted to the Mediterranean and figured on silk from Lucca and Venice. Figure 13.3 belongs to the same period and it has been classified as a Central Asian weaving. Found in Iran, it does not seem to belong to Chinese manufacture; the phoenix and the other unknown mythological beast woven in a free scheme resemble the Italian textile style. However, up to the present there is no evidence of a similar animal on other textiles (Watt and Wardwell 1977, 149150). Between the 13th and 15th centuries, many woven textiles were decorated with phoenixes. The presence of this bird became part of complex compositions made of different elements. Both Asian and Italian workshops produced a great quantity of lampas, diapers (a woven pattern consisting of a small repeating design, often of diamonds) and brocades with golden flying or standing phoenixes or similar birds. Lucca was famous for its production of the diaper, but the weaving of lampas with brocaded details created magnificent two-dimensional patterns based on Central Asian samites (a 


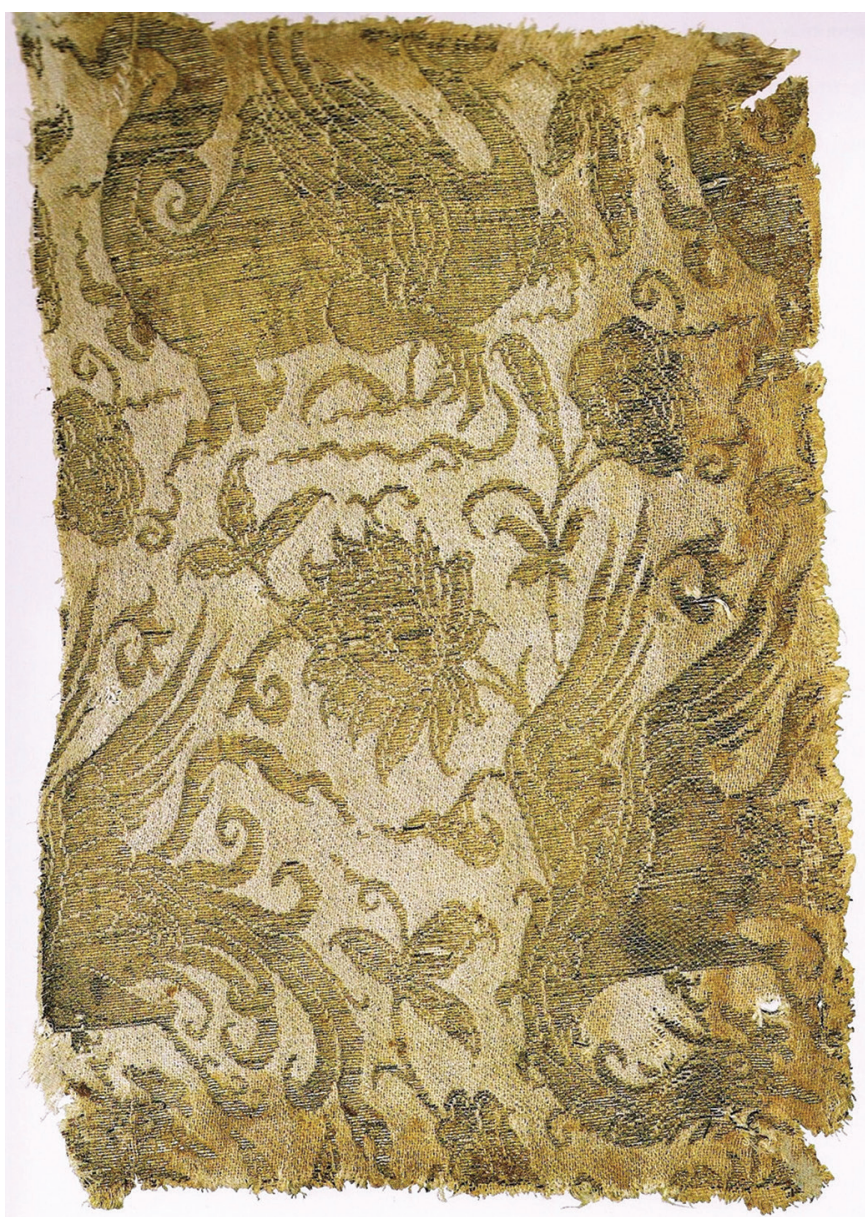

Fig.13.3: Textile with a phoenix, winged animal and flowers. Back view. Central Asia. 13th-early 14th century. New York, Metropolitan Museum of Art. Silk and metallic thread lampas. Warp 9 5, weft $16 \times 61 / 2$ in. (23.7 $\times 16.5 \mathrm{~cm}$ ) (The Metropolitan Museum of Art, Gift of Mrs Howard J. Sachs, in memory of Arthur Upham Pope, 1973 (1973.269) (C) 2014. Image copyright The Metropolitan Museum of Art/Art Resource/SCALA, Florence).

compound twill fabric including two warp systems and a weft of two or more series of threads).

Although Central Asia constituted a heterogeneous cultural combination of Islamic, Persian, Turkic, Chinese, Indian, Tibetan and Russian elements, the production and transfer of identical or similar motifs created a unique historical identity. First during the Tang (618-907 CE) and then the Mongols (as the Yuan dynasty 1279-1368) the ancient Sogdiana (some areas of the present Uzbekistan and Tajikistan) was an important junction along the Silk Road. The great production of faced compound weavings with bead roundels and animals served as an artistic matrix for later media. The cross-cultural interchange of symbols and mythological animals, sometimes misnamed or misunderstood, became part of the European textile heritage during and 
after the medieval period. The trading of goods along the Silk Road from Asia to Europe carried Zoroastrian, Buddhist and Islamic artistic elements that were incorporated into Western Christianity. The personal perception of these elements was adapted to local contexts, sometimes exaggerated or personalized. In Marco Polo's Milione (probably dated 1298) he describes fabulous creatures and people and different types of textiles he had heard about during his travels.

Makaras, senmurws and phoenixes were transferred across Eurasia partly due to the resettlement of many craftsmen from China to Central Asia or into Iranian territories and vice versa. This helped spread various textile techniques which in combination create a global heritage. In Europe besides inspiring local production, many Asian textiles were used for liturgical vestments and elite robes. Zoomorphic elements were easily combined with inscriptions. Apart from some well-known items like the funerary costume of Cangrande della Scala (1291-1329) in Verona, the Tiraz of Abu Bakar in the David Collection in Copenhagen, or two textiles in the Museum of Decorative Arts of Berlin - one with coiled dragons and an Arabic inscription and the other with Sassanian parrots, Arabic inscriptions and Chinese ideograms - the quantity of later European weavings in many western museum collections is an evident sign of the strong Asian artistic influence.

In terms of artistic production, the period between the 12th and 14th centuries was one of the most flourishing on the Eurasian continent. The great Mongol Empire (1206-1368) that spread from China to the Near East mixed together and developed a variety of styles. Through the Ilkhanate ('subject khan' that included some areas of present-day Afghanistan, Pakistan, Turkmenistan, Iran, Iraq, Arzebaijan, Armenia, Syria and Turkey) a new visual language was transmitted to Europe. Textiles seem to have in particular brought Chinese and Islamic motifs to the West. Moreover, luxury textiles were used as currency along the Silk Roads. Yet in the other direction, the four Maritime Republics in the Italian Peninsula - Amalfi, Venice, Pisa and Genoa - played an important role in trade with the east. These cities had to face Saracen and foreign attacks in the Mediterranean area; however, thanks to their maritime activity they were able to build strong relationships between Europe and the Byzantine Empire. If Amalfi was more active on the North Africa side, Venice focused on the Near East until the 16th century, when together with the Lega Santa, it won the Battle of Lepanto in 1571. The Tabula Amalphitana (The Amalfi board) was the oldest maritime code written in the 12th century in use until the 16th for the commercial trading in the Mediterranean Sea. In Sicily and in Puglia, especially during the Crusades, many cities became emporia for trading with Palestine. Golden and purple textiles, tabbies, linen, silk and other arts and crafts were imported. Therefore, this period created a very important cross-cultural bridge between East and West. With the arrival of textiles, patterns and motifs were imported and Asian myths were unwittingly transferred into Europe. At the same time, it is possible that Persian communities recorded in Sicily imported their artistic heritage. Mythological animals were also depicted on the ceiling of the Palatine Chapel in Palermo, which seems to have many elements belonging to the Iranian rather than to the Fatimid tradition. 
The strong link between textiles and architecture was particularly close in this period. Based on the Chinese tradition of linking the figures of the Emperor and Empress to the images of the dragon and the phoenix, many blue and turquoise Iranian tiles from the summer camp at Takht-i Sulayman in Northern Iran were decorated with this combination of animals, which shows a clear Mongol influence. The starshaped tiles enclosing mythological figures that decorated Islamic buildings had corresponding motifs in the contemporary Italian churches. The original chinese and also Indian animals, indeed, were assimilated and transformed into Persian senmurw or Italian pistrice. As the emblem of Positano on the Amalfi coast in Southern Italy, a medieval pistrice decorates the tower of the Cathedral of St Maria Assunta. Although already known in classical Greek and Roman mythology, this figure that resembles a makara, a senmurw or a dragon, was also employed to represent a whale (Fig. 13.4). Thus, a woven surface became a sort of matrix that created stylistic prototypes for the decoration of various media.

The three textiles presented here are a few good examples of the great variety produced in that period. Sometimes, it is not possible to identify weavings as belonging to a specific workshop, with the exception of a few with inscriptions that confirm a Chinese-Central Asian production, as they carry different elements. Motifs with Asian mythology were overproduced and in due course probably lost their original meaning. However, even if mere decorative motifs, they have to be considered as a key factor in the history of the art's transmission. It is not by coincidence that some geometrical compositions produced in this period have corresponding patterns in architecture. Often these were sketched on paper and used as instruction for decorating ceramic, silver and buildings. Similar motifs were reproduced on manuscripts and miniatures as well. Even if in terms of designs they are very similar, textiles woven in this period in China, Central Asia, Near East and Italy have different structures. In Italy golden and silver threads employed for patterns were made by gilded animal substrates, whereas in China paper was preferred.

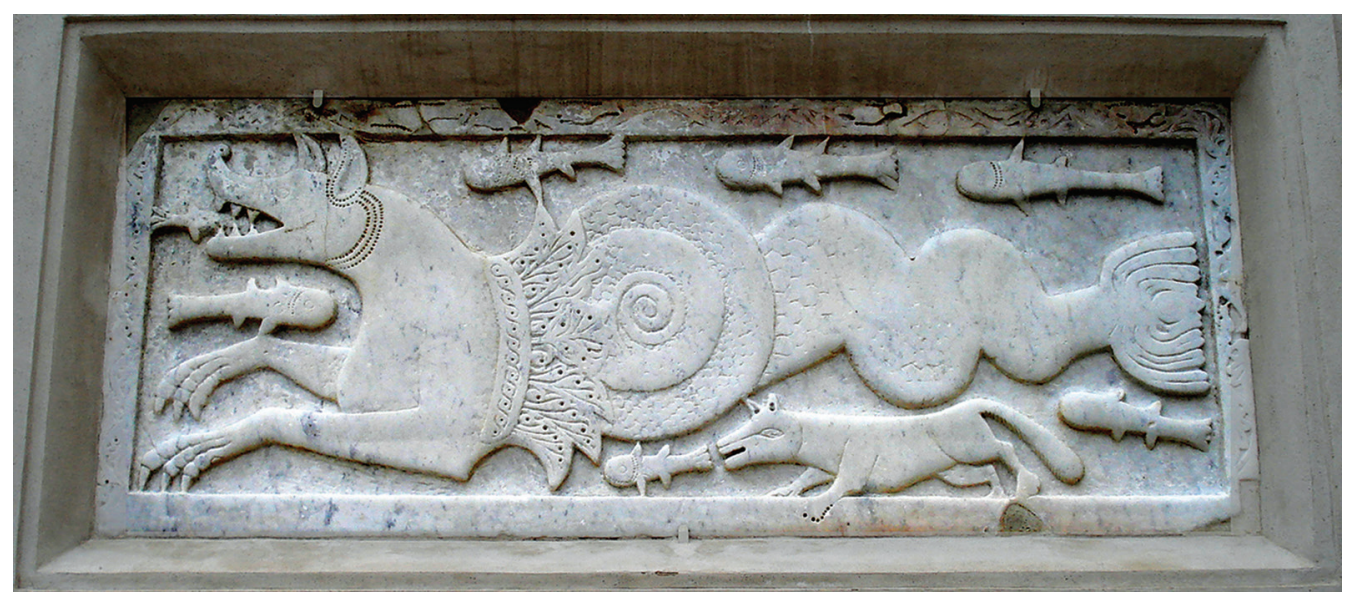

Fig. 13.4: Pistrice, Cathedral of St Maria Assunta, Positano, Italy. Marble bas-relief, 12th cent. (Photo: CMariachiara Gasparini). 
The textile encounter of makaras, senmurws and phoenixes was due to the great eclecticism of the Mongols who are said to have conquered a large area of Eurasia 'by horses and their original shaman belief'. Once their empire was established, the mythology was carried and transferred on silk from one end to another to become part of the local religions. The Christian West, by wearing clothing imbued with Asian traditional rituality assimilated it into its cultural substrate. Islam, on the other hand, avoided most of these foreign religious patterns; however, just a few of these earlier Mongol components continued to be still visible in later Islamic artistic contexts. The original freedom that had characterized the empire of Genghis Khan was 'canonized' by his progeny. The discovery of sacred vestments in many Italian and European churches draw our attention to the assimilation of pagan elements. Also as one of the four animals described in the Apocalypse, the flying lion became the zoomorphic depiction of St Mark and the emblem of Venice. Animals have indeed always carried supernatural powers that link heaven and earth. Although they were included in the ancient mythological entourage, animals were part of daily human life; therefore, they became the main inspiration and the matrix to create a parallel world. The transit from mythology to rituality was strengthened with the development of arts and commercial trades. In Europe, the deconstruction and the canonization of ancient Asian motifs followed local trends. Mythology was simply adapted to everyday Western Christianity. Beside motifs and patterns, raw silk and dye tools were also imported from Asia to create European textiles. At the end of the 13th century, Christian representations began to substitute animal figures that were reduced to surrounding decorative motifs. Although the encounter of different animals on woven surfaces occurred many centuries before the Mongol Empire, cross cultural interactions between the 13th and 14th centuries created a strong and important textile matrix in the history of weaving. Textile was, and still is, one of the main media of human heritage transmission and records the development of human beings in the history of the world.

\section{Further Reading}

Mircea Eliade (1968) Myth and Reality.

Heleanor B. Feltham (2010) Lions, Silks and Silver: The Influence of Sasanian Persia, no. 206, (October). Sino-Platonic Papers (http://www.sino-platonic.org/news_archive.html).

Stefano Giordano (1996) The Palatine Chapel in the Norman Palace.

George Francis Hill (1923) Alexander the Great and the Persian Lion-Griphon, The Journal of Hellenistic Studies, vol. 43, part 2, pp. 156-161.

Maria Carlotta Romano (1994) Il Senmurv, in Maria Teresa Lucidi (ed.), La seta e la sua via [Silk and its road], 135-137.

Maria Ludovica Rosati (2010) Migrazioni tecnologiche e interazioni culturali. Chinoiserie ed esotismo nell'arte tessile italiana del XIII e del XIV secolo [Technological migration and cross cultural interactions. Chinoiserie and exoticism into Italian textile art between XIII and XIV century]. OADI Rivista dell'osservatorio per le arti decorative in Italia, no. 2. http://www.unipa.it/oadi/ oadiriv/?page_id=464. Accessed: January 24, 2012).

James C. Y. Watt and Anne E. Wardwell eds (1997) When Silk was Gold. Central Asian and Chinese Textiles. 


\title{
14 Textile in Art: The influence of textile patterns on ornaments in the architecture of medieval Zirikhgeran
}

\author{
ZVEZDANA DODE
}

Zvezdana Dode is a senior researcher at the Southern Scientific Centre of the Russian Academy of Sciences and an expert on medieval costume and textiles of the North Caucasus and Central Asia. She has a PhD from The Oriental Institute at the Russian Academy of Science in Moscow on The phenomena of the medieval costume from the North Caucasus in the context of the history and culture of Eurasia. She is Professor of Archaeology and Art History at Stavropol State University, and serves as Curator at Stavropol State Museum, and was an Andrew W. Mellon Fellow at The Metropolitan Museum of Art, New York.

She is the author of over 70 articles and 3 monographs in primarily Russian and English and has presented over 30 papers at conferences and symposiums in China, Russia, USA, Ireland and France. Readers of this chapter may also be interested in her Russian book, Средневековый костюм народов Северного Кавказа: Очерки истории/3.В. Доде. - М.: Восточная литература, 2001; and her Chinese article (2006) Chinese, Iranian, and Central Asian traditions in silks' design of the Mongolian period from the Golden Horde ulus Dzhuch. Cultural Relics of the East, 6 (19), pp. 43-49.

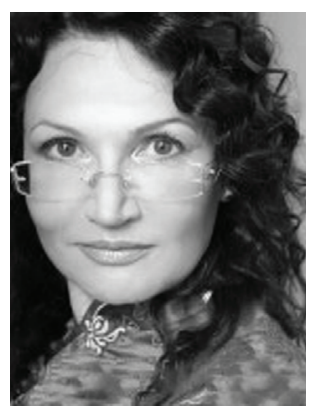

Textiles are a very important type of historical evidence. They are also an important art-historical source for ornamental patterns found in other forms of decorative arts. Costly and beautiful imported silks have always been a source of inspiration for local artists who copied images from foreign textiles onto items of their own art tradition. This allows us to understand the nature and directions of the relationships between peoples who did not have written sources, and we can date objects of local culture by these relationships.

An example of this is found in Dagestan (Russian North Caucasus) in a mountain village which is known today by its Turkic name Kubachi, but which in the Middle Ages was called by the Persian name Zirikhgeran; in both languages, this translates as 'Makers of Chain Mail'. Nowadays, the village is a famous centre for original jewellery art. At the turn of the 14th century, stone reliefs were produced here which show entire scenes including people as well as real and imaginary animals. For a long time, it was thought that these scenes depicted subjects of local folk culture. There are, however, no scenes from the folk mythology of the Northern Caucasus found on the reliefs. Therefore, the comparative analysis of ornaments on the reliefs and on 
other artefacts from the same period becomes important for the cultural attribution and the dating of the reliefs themselves. Today, we have at our disposal many cases of correspondences between Kubachi reliefs and imported objects made from wood, metal, glass and, in particular, textile. The style and contents of ornaments on Mongolperiod textiles is similar, or even identical, to that on the Kubachi reliefs. Here, we will look in particular at the close similarity between pictures on the reliefs, on the one hand, and on textiles from archaeological contexts in the North Caucasus and neighbouring areas, on the other.

How did artistic motifs spread? Early researchers of the Kubachi reliefs assumed that objects of applied art, primarily fabrics, played a key role in the cultural exchange between various regions of the world. They emphasized the links of ornamental patterns and style of the stone reliefs from Dagestan with the décor of items of decorative applied art made of wood, metal and textile, but they never offered any systematic analysis of parallel series of objects. Let me explain: Decorative techniques and images used by the Kubachi stone carvers do, indeed, have very broad parallels in objects of applied art of the medieval world. However, the use of a large number of cases with varying degrees of similarity is of no scholarly value for the artistic and culture-historical analyses of an object; it is much more important to identify cases with direct correspondences between the images on the Dagestani monuments, on the one hand, and contemporaneous imported articles of glass, metal and silk, on the other hand.

Let us also make one obvious point. The Kubachi stone carvers did not just directly copy textile ornaments. The specifics of the decorative techniques in architecture and in weaving are explained by different artistic objectives and by different properties of the physical media. The style and contents of the ornaments on the Kubachi reliefs and on fabrics of the Mongol period of the late 13th to 14th centuries were, in fact, quite close if not identical. of special interest are parallels between the ornamental patterns on the stone reliefs and on silk fabrics found in closed archaeological contexts, i.e. in nomadic burials of the Mongol period in the North Caucasus and adjacent regions. These similarities can be used to specify and substantiate the dating of a specific group of Kubachi reliefs. They are also important in order to identify the cultural and historical context in which the monuments emerged.

\section{Deer and Does}

A stone window tympanum in Makhachkala is decorated with the image of a doe or gazelle. This image is matched by the figure of an animal woven on silk from the Mongol-period cemetery of Verbovij Log (Fig. 14.1).

On another Kubachi relief now in the State Hermitage Museum, a deer is enclosed in an arabesque frame ( $\mathrm{SH}$, inv. no. TP-138 a, b). A direct correspondence can be identified between this image and the deer on the Yuan Dynasty silk lampas from which a ceremonial Mongol garment had been made (kept in the collection of Anna 

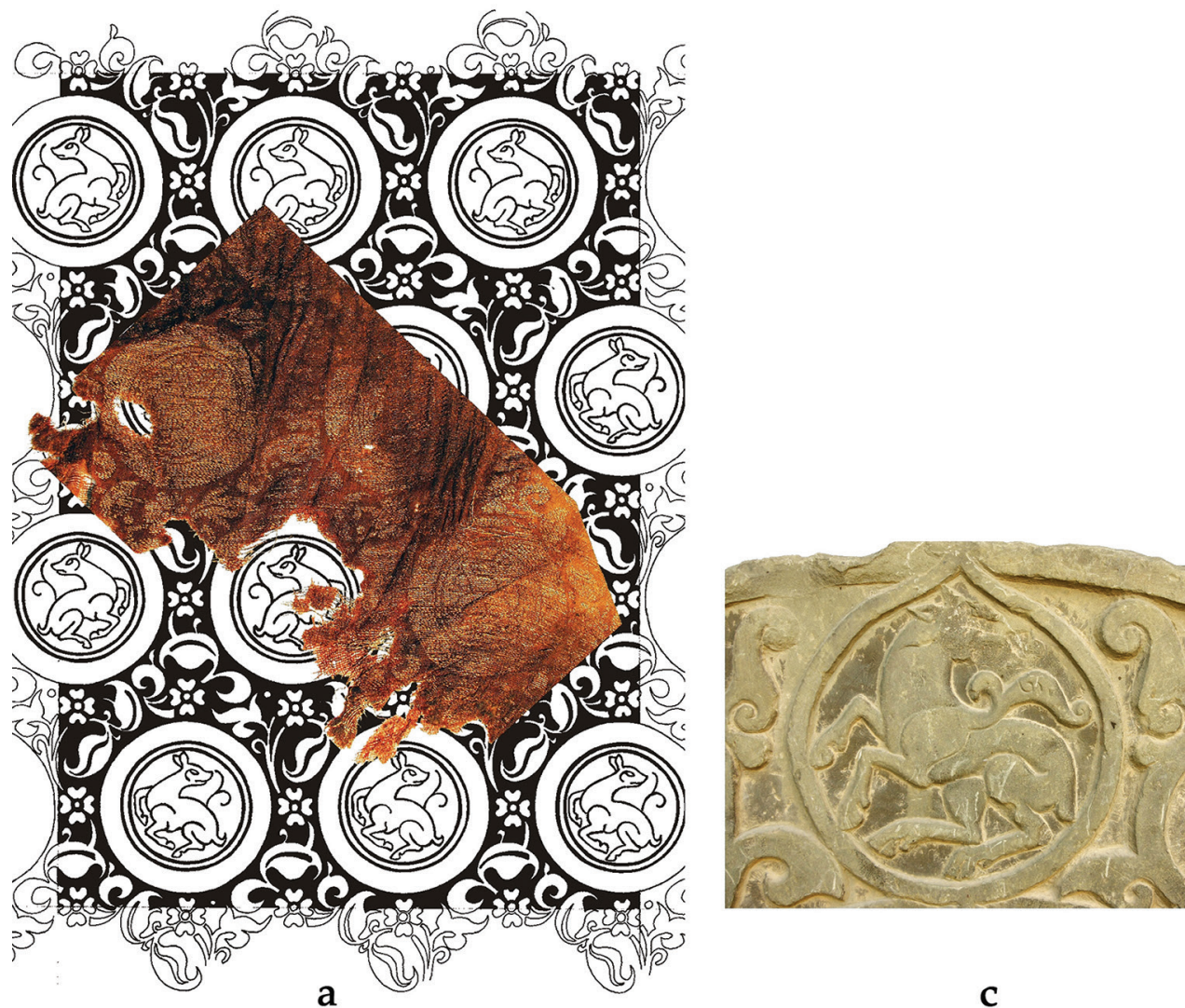

c

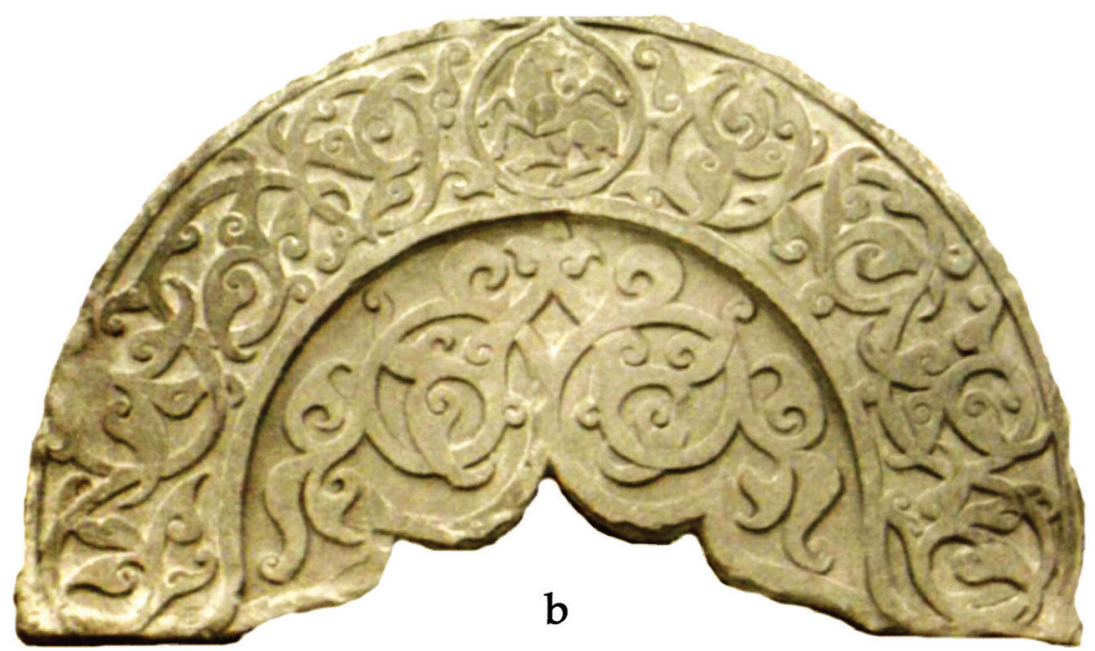

Fig.1: a) Cloth with an image of deer; Silk and gold thread from the cemetery of Verbovij Log (Photo and drawing, Computer design: M. Hiteeva); b) Lunette windows depicting floral ornament and deer; c) Detail of $1 \mathrm{~b}$ (After Dode (2010), p. 76, fig. 39; Historical and Architectural Museum of the Republic of Dagestan in Makhachkala; Photo: A. Belinsky). 
and Fabio Rossi): running animals are placed in the centre of a figure frame the inner space of which is filled with vegetal ornament (cf. Dinwiddie (ed.), 2004, 50, fig. X.7).

Based on the artistic parallels between animal figures on silk fabrics of the Mongol period and the two Kubachi reliefs discussed above, these reliefs can be dated to the period of Mongol rule in the North Caucasus, i.e. the last third of the 13th to the first half of the 14th centuries.

\section{Feline Predators}

A feline predator without mane occurs on the Kubachi stone reliefs more frequently than any other animal. This figure is very much like images on decorative art objects of the Mongol period, for example in toreutics, i.e. artistic metalworking or ceramics. A similar image is found on a perfume vial made of stained glass by a Syrian craftsman in $1270 \mathrm{CE}$. This predator is also shown in the coat of arms of the famous Egyptian Sultan Beybars. Figures of panthers, dragons, griffins, phoenixes and sphinxes in the ornamental patterns of the Kubachi reliefs are unrelated to local mythology; they were transferred to stone decoration from imported objects of decorative applied art.

Let us compare the image of the feline predator on the Kubachi reliefs and on 'Mongol' silk fabrics (Fig. 14.2). Two relevant artefacts exist: the composition on a stone relief preserved above the entrance door of the private home of Zenab Chamsutinova in the lower quarter of Kubachi village (Fig. 14.2a); and the decoration of the headgear from the Jukhta cemetery (late 13th-14th cent.) (Fig. 14.2b). Although the heads of the animals point in different directions, the two aretefacts have an obvious resemblance. Despite the differences in materials and techniques used by the respective artisans, not only do they match in the techniques used to present the animal, they also share details of the vegetal ornament.

Another closely similar image of the predator is on Chinese silk fabrics made in workshops of the Yuan Dynasty. This silk was used to make a sort of decorative sheath for the boots that are now kept in the China National silk Museum in Hangzhou (Fig. 14.3).

\section{The Trefoil Motif}

Let us now examine the vegetal décor on the relief and in the embroidery of the headgear (Fig. 14.4). According to some specialists who have dealt with this question, the 'Kubachi' type of trefoil flower which is the principal ornamental motif in the décor of the Kubachi bronze cauldrons and stone reliefs could not be a borrowing from elsewhere. This emphatic statement of unquestionably local origin of local culture is a standard position in the discourse of North Caucasus research. Actually, this opinion should not be surprising to the detached observer: People around the world are so attached to their place of origin and the artefacts from there that they refuse to acknowledge that ideas may have come from elsewhere. In consequence, 


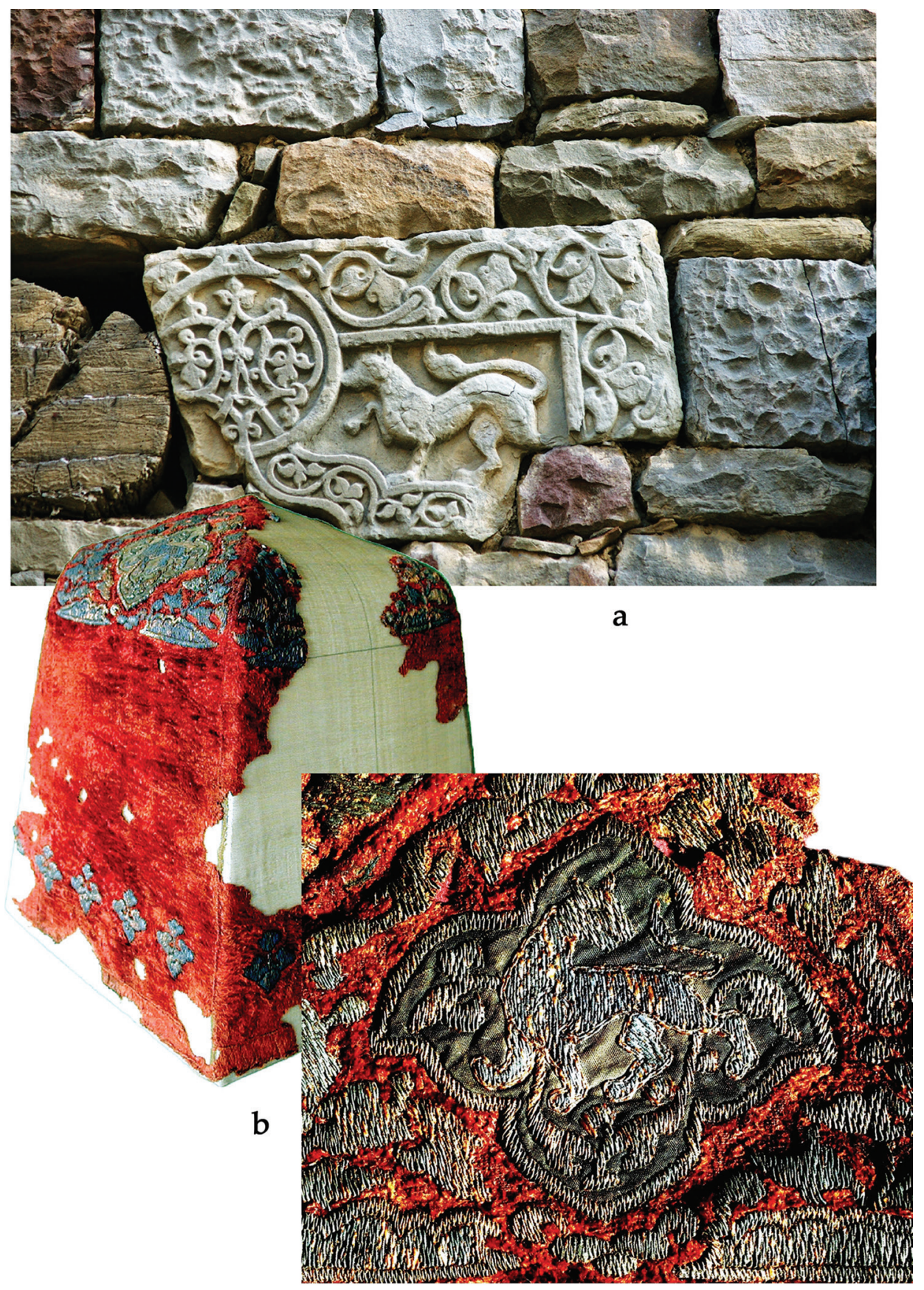

Fig. 14.2: a) Relief depicting the feline predator in the wall of the Zenab Chamsutinov's house in the lower quarter of the village of Kubachi, Autumn 2008 (Photo: A. Belinsky); b) Headdress and fragment applique and embroidery on a hat from the cemetery of Dzhuhta, Stavropol Territory. Silk velvet and gold thread (Museum Heritage Stavropol; Computer design: M. Hiteeva). 


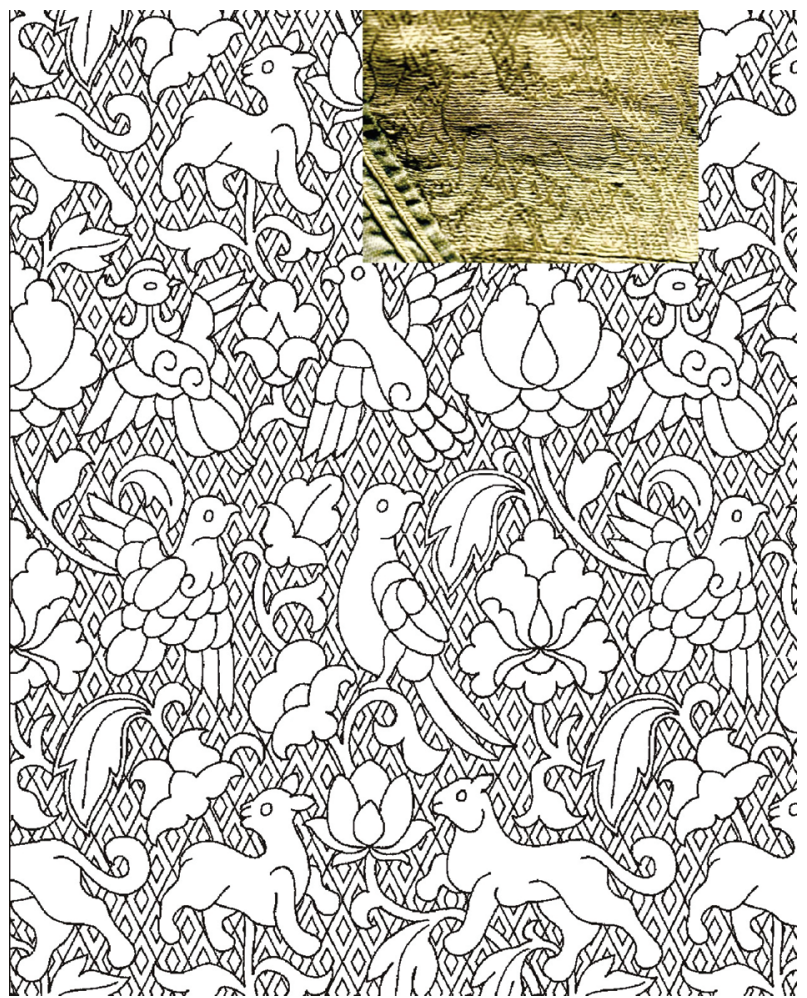

Fig. 14.3: The predator is woven on Chinese silk fabrics made in workshops of the Yuan Dynasty. This silk was used to make a sort of decorative sheath for the boots. Fragment and drawing of ornament on a textile from the China National Silk Museum in Hangzhou, inv. no. 3121 (Photo: A. Belinskiy; drawing: M. Hiteeva; After Zhao Feng (2004) Silk Dress with Golden Threads: Costumes and Textiles from Liao and Yuan Periods, pp. 11-15. fig. XII.4, p. 62, in Donald Dinwiddie (ed.), Style from the Steppes Silk Costumes and Textiles from the Liao and Yuan Periods - 10th-13th century, Exhibition catalogue, Rossi \& Rossi).
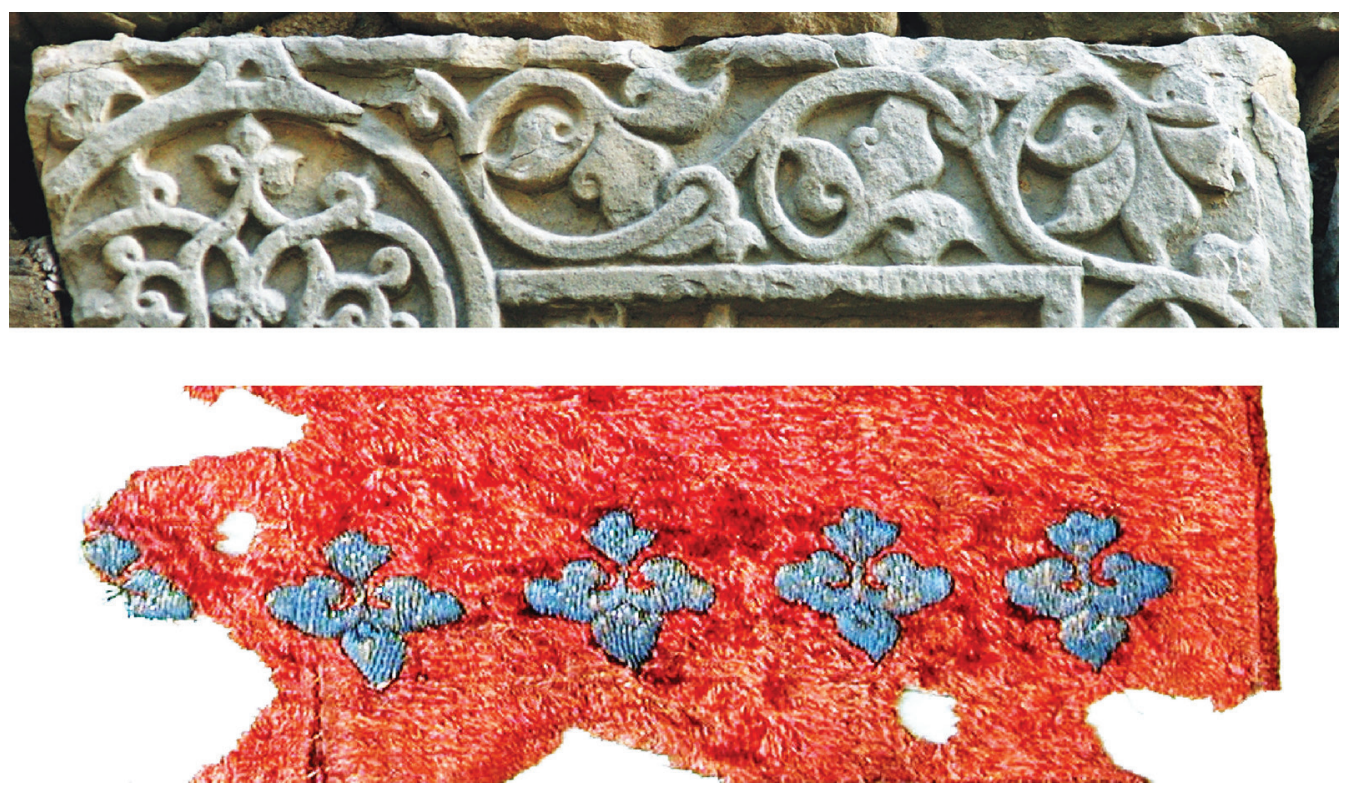

Fig. 14.4: A detail of the trefoils on the stone relief from Kubachi in fig. 14.2a, and detail of embroidery on the hat from Dzhuhta in fig. 14.2b (Southern Scientific Center of the Russian Academy of Sciences). 
local culture is all too often represented as a phenomenon of unchangeable nature, a timeless constant. In our case, however, there are good reasons to believe that a certain group of the Kubachi monuments bears the imprint of imperial Mongol culture, and the hypothesis of local origin becomes an obstacle to an understanding of the fascinating imperial phenomenon.

We can illustrate this by looking at the griffins and lions depicted by the Kubachi artisans. There certainly are griffons, but these are not special Kubachi griffons, just as there never were any Old Russian or Old French griffons. If we compare the Kubachi figures with those created under the known influence of imperial Mongol culture, we can see direct borrowing and imitation. The assumption of exclusively local origins can hardly explain the minute matches of details on 'Mongol' silks and on Kubachi stone art. So, of course, Zirikhgeran was open to external cultural influences - which should not be surprising, seeing that neither Iran nor China could resist this Imperial culture which became a Eurasia-wide phenomenon.

Our objectives do not include a search for the prototypes of the Kubachi trefoils. What is important for our purposes is to register the correspondence between this decorative element on the stone reliefs and on the embroidery of the Jukhta hat found outside Dagestan. Images of the trefoil are widely represented on other media, for example, a hearth slab representing the Sirins (SH [The State Hermitage], inv. no. TP-98), and a window lunette with sphinxes (SH, inv. no.TP-141, 142), which allows placing them in the 'Mongol' group of Kubachi monuments. The same motif was used in the skirt ornament on the bronze cauldron from Kubachi, representing a rider wearing a North Caucasus costume (SH, inv. no. TP-200).

In all ornamental images examined here, stability of motif and form can be traced despite differences in style and technique.

\section{Sphinxes}

Sphinxes are an ever-present component in the compendium of symbols of the Mongol Empire. The figures of sphinxes on the Kubachi lunette window (Fig. 14.5a) are comparable to the sphinxes on early 13th-century silk that was used to make the right inner flap of the robe excavated at Mingshui, Damaoqi, Inner Mongolia (Fig. 14.5b). Similar images of sphinxes are present on numerous bronze mirrors found in many regions, including Dagestan, all apparently made in the same shape (Fig. 14.5c).

\section{Train of Animals}

The main image on lunettes was frequently framed in a frieze with figures of real and fabulous animals and birds following one another. One of the best examples is the tympanum of a double-span arched window from Kubachi which is now in the Smithsonian Museum in Washington (Fig. 14.6a). This distinct composition uses the flat-relief technique (bas-relief) with elements of engraving. The archivolt of the arc 


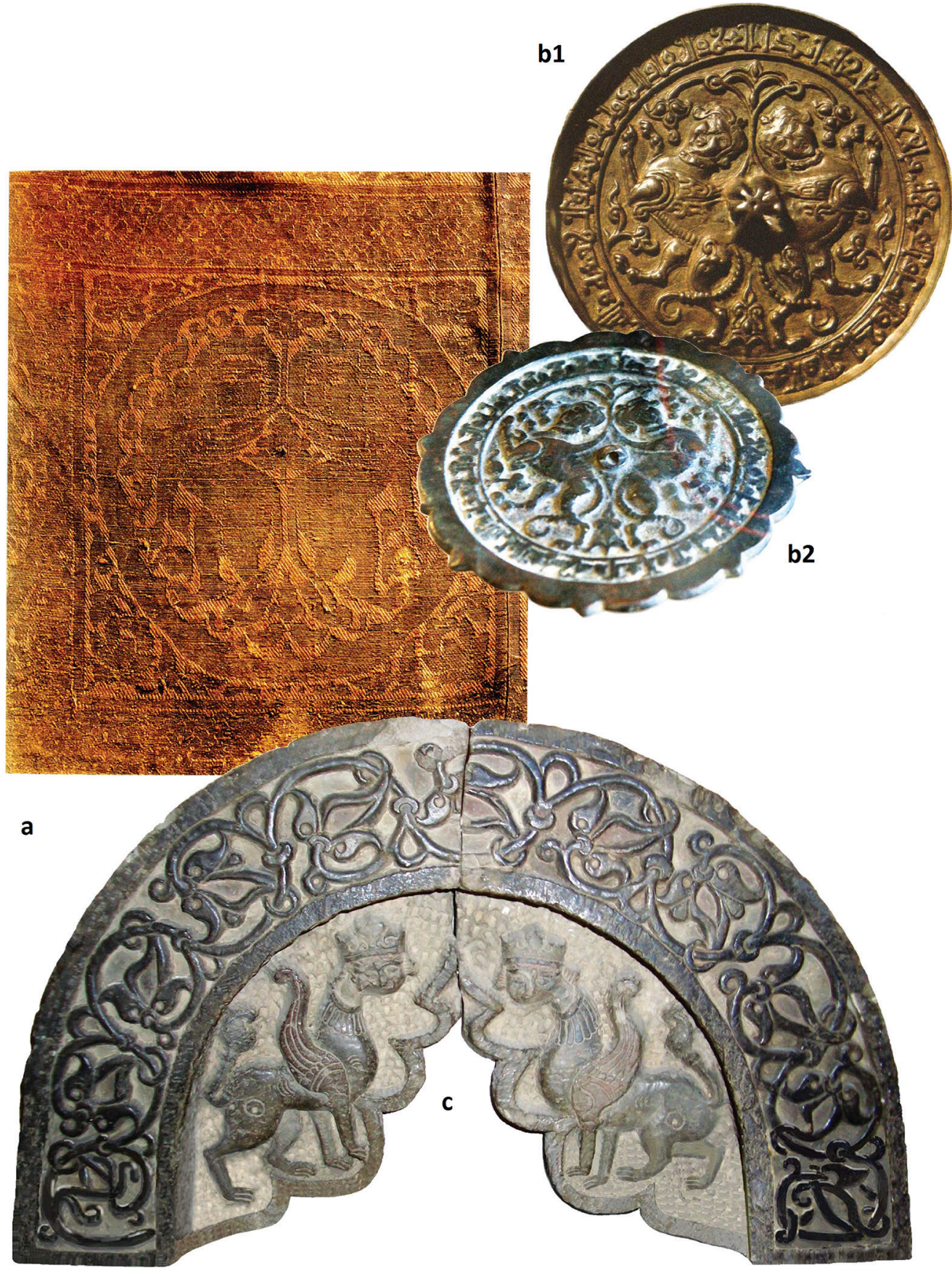

Fig. 14.5: a) Cloth with the image of sphinxes; Silk and gold thread. Huhote Museum, Inner Mongolia, China; b) Bronze mirrors (b1: Copyright ( $)$ The al-Sabah Collection, Dar al-Athar al-Islamiyyah, Kuwait. National Museums of Kuwait (LNS 102 M) and b2: After Dode (2010), p. 89, fig. 51; Historical and Architectural Museum of the Republic of Dagestan, Makhachkala); c) Lunette windows depicting sphinxes. Dagestan. Inv. no. TP-141, 142 (The State Museum Hermitage, St Petersburg; Photograph @) The Hermitage Museum; Photo: Z. Dode). 
is filled with various animals in a train heading from both sides towards the feline predator placed in the centre. Intertwined stalks of plants occur between the figures of the animals. The same vegetal motif as on the archivolt is used to decorate the tie between the arcs on the bottom edge of the tympanum. The image comes to look like an ornament, and the animal figures overlap the rich décor transforming the image into a carpet-like pattern. The plane of the tympanum is occupied by a symmetrical composition: two predators turning back to look at each other. The artistic manner of the stone carver suggests knowledge of the proportions, confidence with perspective and motion, skill in the combination of images into the desired form, and stylistic and decorative interpretation of animals' body parts. A Capra mountain goat with long, downward-curving horns similar to one placed in the lower left corner of the Washington relief is represented in a State Hermitage frieze featuring Mongol wrestlers (SH, inv. no. TP-154).

The decorative and compositional solution of this and other friezes on the Kubachi window tympanums has its parallels in the artistic composition of mirrors found at Golden Horde sites of the North Caucasus. For example, the fragment of a bronze mirror from the kurgan cemetery Sharakhalsun 5 shows a clockwise train of animals following one another (Fig. 14.6b). Presumably, the complete composition represented four pairs of animals, each consisting of a predator in pursuit of a deer. The background space, just as in the Kubachi relief, is filled with vegetal ornamentation. The motif of a predator chasing its prey is also present on the reliefs of Kubachi. The fragment of a tympanum frieze now in the State Hermitage (inv. no. TP-136) includes the picture of a dragon chasing a hoofed animal (Fig. 14.6c). The bottom part of this frieze is decorated with dragon heads.

of special interest for the purposes of dating the Dagestani reliefs and cauldrons is the steel mirror inlaid with gold from the Topkapı Museum of Istanbul. The mirror is dated to the early 13 th century (Fig. 14.6d).

The image of an animal with a tail ending in a dragon's head is known from the design of an Iranian silk textile dated to around the 11th or 12th century. The same motif of combining body parts of different animals persisted on silk textiles of the Mongol period. There are winged lions and griffons on the mid-13th century, Central Asian lampas in Cleveland Museum. The lions have tails that end in dragons' heads while the griffons' tails terminate in feline heads (Fig. 14.7a). The very same motif was used by the artisan who created the bronze pot from Kubachi (Fig. 14.7b).

\section{Quatrefoils}

Quite frequently, images on Kubachi reliefs are enclosed in pearl-shell quatrefoils. This artistic technique is typical of the decorative art of the Mongol period and occurs on metal objects, pottery and textiles.

Compositions on some reliefs match the character of silk ornamental patterns of the Mongol period. This is true not only for individual elements, but for architecture 


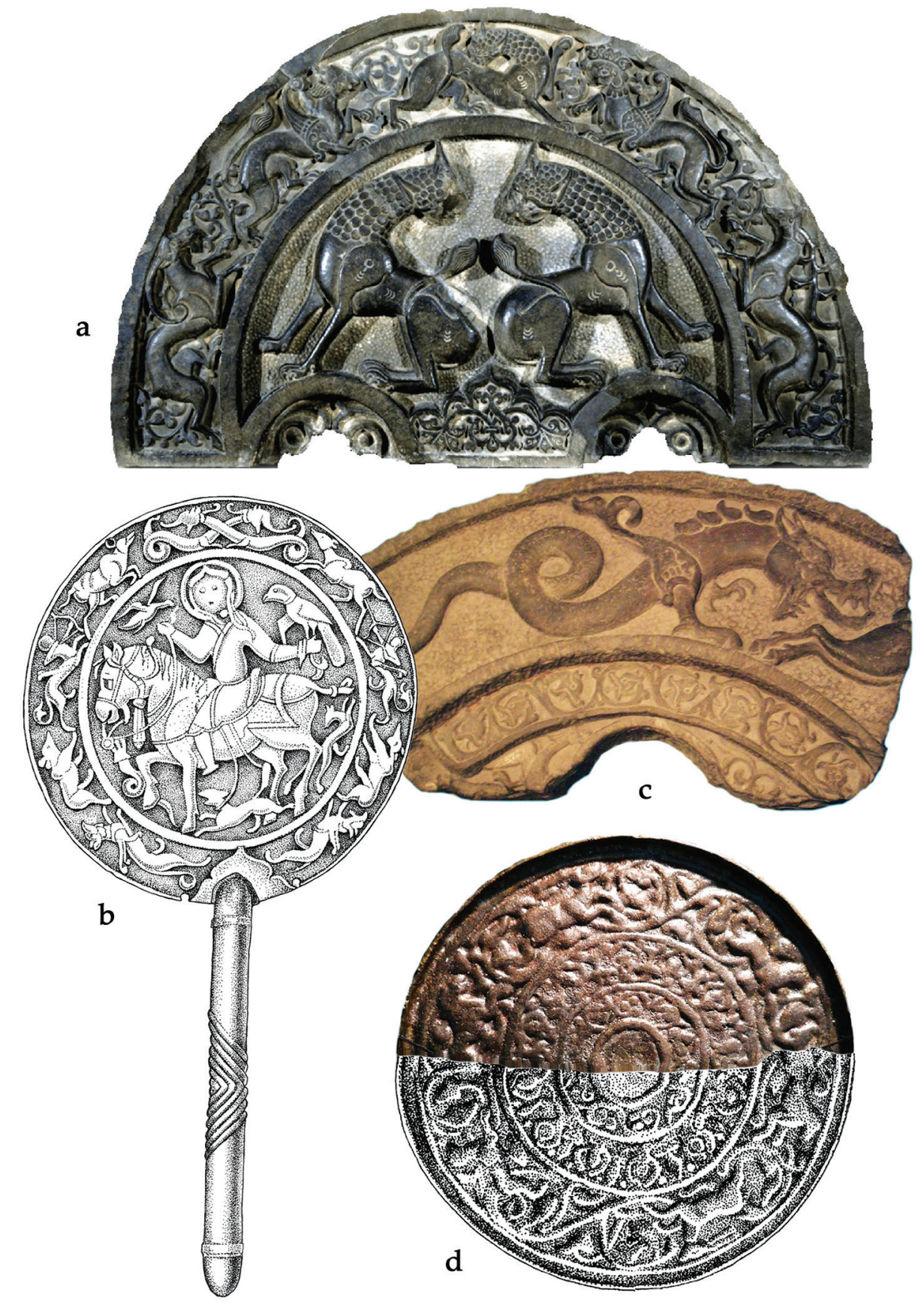

Fig. 14.6: a) Lunette windows depicting a procession of animals (Freer Gallery of Art, Smithsonian Institution, Washington, D.C.: Purchase, F. 1936.5); b) Bronze mirror, North Caucasus (Photo and drawing: I. Oleinik; Computer design: M. Hiteeva); c) Fragment of tympanum with dragon, $72 \times 90 \mathrm{~cm}$. Dagestan, village of Kubachi. 14th-15th century. Inv. no.TP-136 (@ The State Hermitage Museum, St Petersberg; Photo: Z. Dode); d) Bronze mirror, inv. no. TSM 2/1792 (Topkapi Museum; Drawing: M. Hiteeva). 


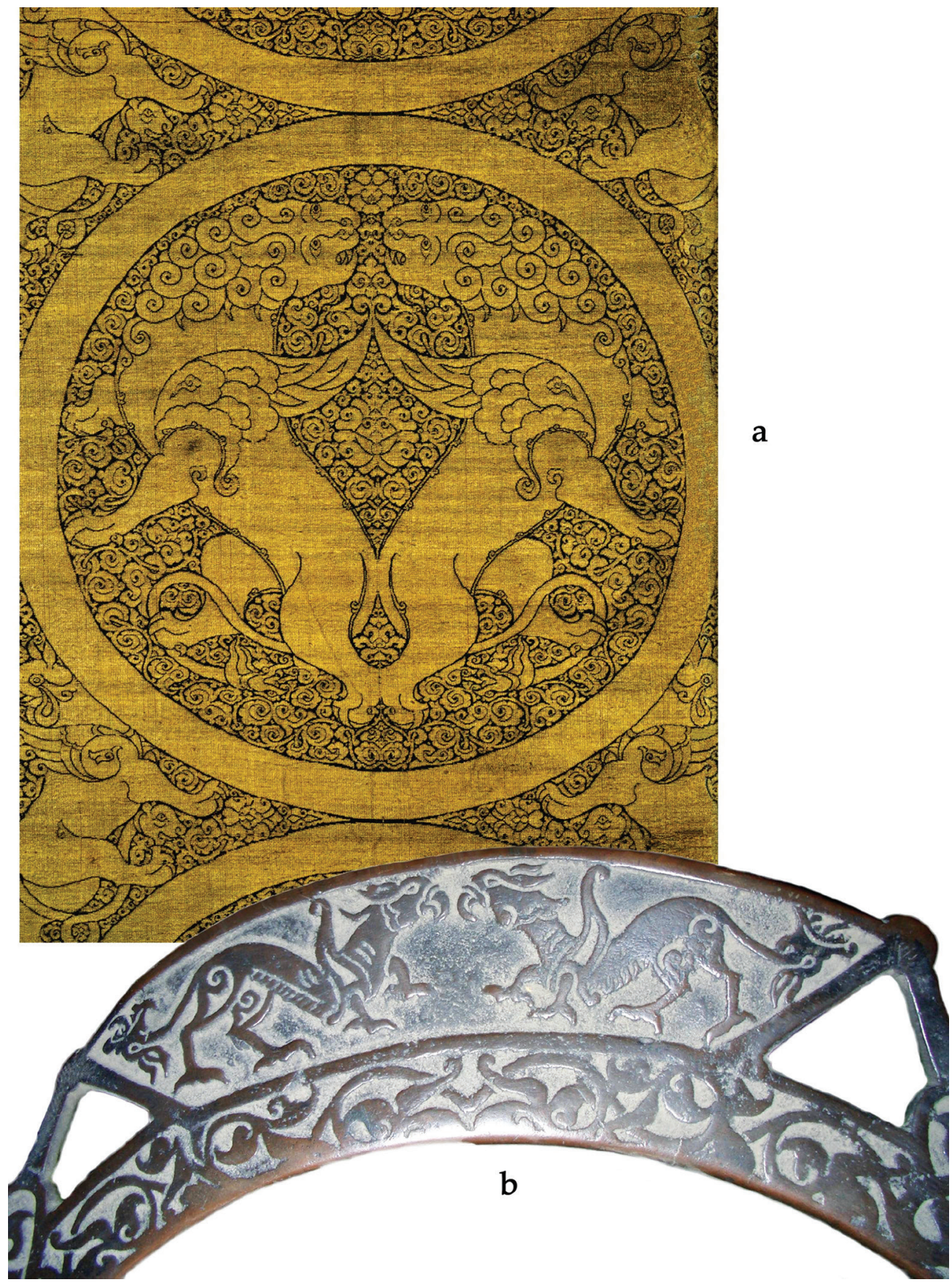

Fig. 14.7: a) Detail of Cloth of Gold, Winged Lions and Griffins, c. 1240-1260. Central Asia, II-khanid (Mongol) period. Silk, gold thread; lampas weave, $124.0 \times 48.8 \mathrm{~cm}$. (@ The Cleveland Museum of Art, Purchase from the J. H. Wade Fund 1989.50); b) Fragment of bronze pot (kettle), Kubachi (Photo: Z. Dode). 
overall. The image with dancers and a musician on the rectangular stone slab from Kubachi, now in the State Hermitage (inv. no. TP-148), is enclosed in a figure frame shaped like a quatrefoil (Fig. 14.8a). Between the main figures, semi-quatrefoils are placed filled with trefoil images. This composition has parallels in the design on some silk fabrics from the 13th-14th centuries (Fig. 14.8b). The main motifs of their ornamental patterns are geometric shapes: circles, drops and quatrefoils placed in staggered rows in the main field of the cloth. The space between these shapes was filled with small decorative elements of patterned background or other geometric shapes on smaller scale (Fig. 14.8.b).

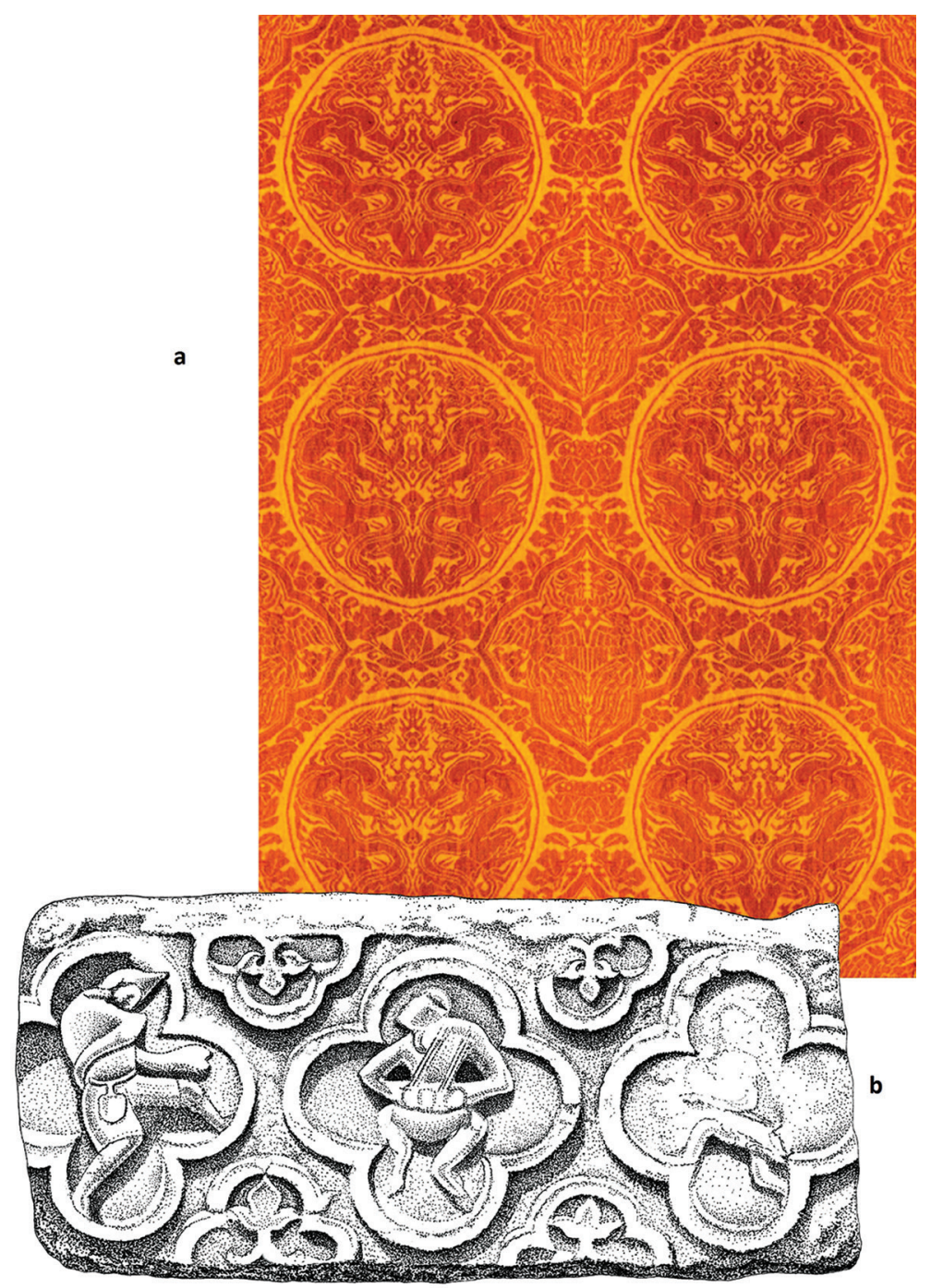

Fig. 14.8: a) Silk cloth with quatrefoils (After Zhao Feng, 1999, p. 275, cat. 09.03); b) A dancer and musician on a stone slab, Kubachi (Drawing: M. Hiteeva). 


\section{Conclusions}

The range of cultural and artistic parallels discussed above demonstrates how the decorative applied art of Kubachi was influenced by the universal culture of the Mongol Empire. Having recognized this, it is possible to identify more precisely the period when the group of reliefs in question was created. It is thought that the power of the Ilkhans in Dagestan increased in the last third of the 13th century, bringing to an end the forced isolation of the highlands of Dagestan which now extended their relations with Transcaucasia and the domains of the Golden Horde. Broad contacts continued until the early 14th century. The construction of public buildings which were probably decorated with reliefs requires strong centralized government. This time - the last third of the 13th century to the early 14th century - is the period to which these monuments must be dated.

The decorative applied art of Zirikhgeran-Kubachi, and the medieval stone plastic art, in particular, tended to use mythical images, emblems and symbols of significance. From the heart of the Mongol Empire, cultural influences extended in all directions towards the periphery. In this system of signs, the set of symbols of the Empire's culture was perceived as something natural and unquestionably significant. We can see two overlapping cultural fields where signs are aligned with the feudal hierarchy. As two mythological streams - imperial and local - joined, they gave rise to a specific artistic expression. The group of Kubachi reliefs that we have examined is unique in that it throws light on the art of architecture, including the architectural décor of the age of the Mongol Empire, which was lost in other regions. The emblematic nature of the representations of foreigners on the stone plastics of Zirikhgeran-Kubachi is today gaining a historical dimension. It is hard to imagine that reliefs depicting Mongols with costumes represented in ethnographically thorough detail were used as architectural decoration on buildings after these people had disappeared from the historical arena of the North Caucasus. Reliefs with pictures of Mongols and ornamental motifs of the Mongol period are monuments of the same time and the same cultural circle: they decorated the architectural ensemble built in Kubachi in the last third of the 13th to the early 14th century. Some of these medieval reliefs are still preserved in the walls of Kubachi houses today.

\section{Further Reading}

Donald Dinwiddie ed. (2004) Style from the Steppes. Silk Costumes and Textiles from the Liao and Yuan Periods 10th to 13th Century.

Zvezdana Dode (2010) Kubachi Reliefs. A Fresh Look at Ancient Stones. Materials for the study of historical and cultural heritage of the Northern Caucasus, Vol. X.

James C. Y. Watt and Ann E. Wardwell (1997) When Silk Was Gold. Central Asian and Chinese Textiles. Feng Zhao (1999) Treasures in Silk. 



\title{
15 Coromandel Textiles: The changing face of consumer demand and weavers' responses 16 th to 18 th century CE
}

\author{
VIJAYA RAMASWAMY
}

\begin{abstract}
Vijaya Ramaswamy learnt her history of South Indian textiles at the grass roots level by observing and interacting with the weavers and their families in Salem, her grandparents' town. She travelled to weaving villages all over South India, lived with weaving communities, participated in their festivals and listened to their many songs. In her recent book titled The Song of the Loom from 2013, she has recorded these songs before they are lost forever and vanish from the collective memories of weavers. Her special contribution to the field of Textile History is her in-depth knowledge of and experience with the weavers and specially their womenfolk. This has resulted in many books and articles which are histories written from below of South Indian weavers and textiles. Her PhD thesis was entitled, Weaving Communities of medieval South India- A Socio-Economic Survey. She has been a professor of history at the Jawaharlal Nehru University Delhi since 2004. She is the author of seminal works, such as The Genesis and Historical Role of the Master-Weavers in South Indian Textile Production, Journal of the Economic and Social History of the Orient, 28:3, (1985) pp. 294-325; Textiles and Weavers in Medieval South India (1985); and Textiles and Weavers in South India (2006).
\end{abstract}

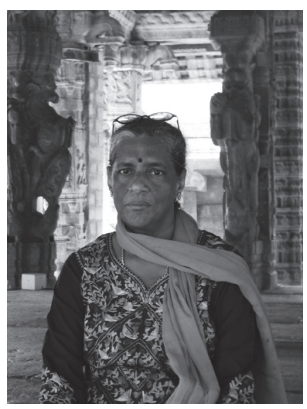

The rise and decline of Coromandel textiles constitutes one of the most fascinating and at the same time tragic chapters in Indian history. During the period of the Chola Empire from roughly the 10th to the 13th century, the textiles of the Coromandel Coast had a more or less fixed market catering to the temple, the court and South Indian society at large. The dynamics of textiles as an item of foreign trade became apparent for the first time during the period of the Vijayanagar Empire, which dominated Deccan history from the 14th to the 16th century. The commercial importance of Coromandel textiles reached its peak in the course of the next two centuries.

The Mughal Empire in the North and the ubiquitous presence of Arab and Armenian traders in the Deccan brought in cross-cultural fertilization in Coromandel textile production. It was in 1498 that Vasco da Gama set foot in Calicut paving the way for Portuguese entry into South India in the 16th century. The Portuguese were followed in quick succession by the Dutch, the English and the French. For the next hundred years Indian cotton was king and Europe was in the grip of what economic historians describe as 'the calico craze'. Indian textiles were used in the Middle East, 
Africa and Europe not merely as dress material but also as coverlets, bedspreads and wall hangings. The joint English sovereigns, William (reigned 1689-1702) and Mary (reigned 1689-1694), are described in the late 1680s as being resplendent in Indian calico. Daniel Defoe, the author of Robinson Crusoe, commented that Indian calico, which at one time was thought fit to be used only as door mats, was now (in the 17th century) being used to adorn royalty. In order to cater to the newly opened up global market for Coromandel textiles, cloth varieties and even designs began to reflect these global cultural encounters.

This chapter focuses on the changing face of consumer demand for Coromandel textiles from the 16th to the 18th century and its impact on indigenous textile varieties and designs.

The 16th century constituted a landmark in terms of changes in the nature and volume of the internal demand and the opening up of new markets abroad. The process of urbanisation and the growth of the professional and artisan classes under state and temple patronage, which had slowed down in the 13th-14th centuries, now began to revive. This, combined with the creation of a new bureaucracy, leading to an increase in the demand for fine cloth. Of the lower classes, it has been repeatedly stated by travellers that they wore very scanty clothing because of the climate. Abdur Razzak says, "The blacks of this country have the body nearly naked; they wear only bandages around the middle called lankoutah, which descend from the navel to above the knee. As to the Mussalmans, thy dress themselves in magnificent apparel after the manner of the Arabs." (Major ed., 1974, 17). However Marco Polo writing roughly during the same period does comment that both upper class Hindus as well as Muslims wore fine muslin on account of the heat, for which variety there was great demand (Yule and Cordier eds, 1903, vol. ii, 361). In the 16th century accounts of the Vijayanagar Empire, such as that of the Portuguese chroniclers Domingo Paes and Fernao Nuniz (Sewell ed., 1963), the Muslim (predominantly Persian) influence on court costumes, is obvious. The wearing of doublets and skirts in rich Persian brocades as well as caps by both men and women have been described by the Portuguese and Dutch chroniclers. Apart from Indian cotton, the satins and damasks (khanqabs) of Persia and the brocades of China were very popular with the Deccan nobility. Ludovico Di Varthema in his description of the aristocracy of Vijayanagar states: "the men of condition wear a short shirt, and on their head a cloth of gold and silk in the Moorish fashion..." (Jones 1863, 53). The islamization of sartorial habits without any corresponding capitulation to 'Muslim' political power is an intriguing trajectory of the Indo-Islamic cross-cultural fertilization. Paes and Nuniz refer also to the use of Mecca velvets in the construction of tents and the decoration of buildings (Sewell ed., 1963, 264).

The Portuguese and Dutch influences on native costumes combining with Persian and Turkish influences resulted in a curious admixture of sartorial styles, best reflected in a couple of Golconda Rumals dated around 1640 from the Coromandel Coast. These Golconda Rumals (literally 'kerchiefs', but more in the nature of wall hangings or decorative painted cloth) are preserved in the National Museum, Delhi). 
While the prosperity of the Vijayanagar kingdom and the lavish life-style of the upper classes both in Vijayanagar and in the Deccan Sultanates led to increased demand for fine cloth, the demand for better varieties of textiles also came from a new section. The emergence of a new bureaucratic class, the Nayaks and Poligars or Palayakkarar (the representatives of the people in the Palayam, an administrative/ geographical unit), must also have increased the consumption of fine Coromandel cloth (Ramaswamy 2006, 68-69). This increase in the domestic use of fine cloth can, however, only be surmised and cannot be stated in terms of the actual volume. The popularity of the Pulicat textiles in Gujarat and Malabar is evidenced by Duarte Barbosa (Dames ed., 1944, vol. II: 132, 153, 172). The internal market for Coromandel textiles follows a criss-cross pattern since not only did the textiles of Pulicat and Kanchipuram travel to the west coast but Masulipatnam textiles also moved to Calicut on the Malabar coast. Golconda muslins are said to have been popular among the upper classes in Goa and Calicut. Tome Pires also states that the Masulipatnam calicoes and muslins were gathered at Goa which was a transit point for their further export to foreign markets (Cortesao ed., 1944, vol. I, 5 8). At the same time, their internal consumption is confirmed by inscriptional evidence, one of which (dated 1586) refers to the remission of customs on Sellapattu and Pattavali Pattu (fine muslin and patola/ikat) made to the Nanadesi merchant guild by the official authorities at Kanchipuram (see South Indian Temple Inscriptions edited by T. N. Subramanyam, 1953 vol. II, inscription no. 446). Both Sella (a muslin or loosely woven fine cotton and Patola (a double ikat with an identical pattern on both sides) are products of North Coromandel and they were, hence, obviously being imported into Kanchipuram.

In the context of consumer demands outside the country, Coromandel textiles were crucial to the operation of the triangular spice trade. This trade initially dominated by the Arab traders was later largely taken over by the Portuguese and the Dutch. The Hindu merchants, called chettis, however offered a tough challenge to the efforts to monopolize the spice trade. In this triangular trade, low grade Coromandel textiles were sold in the Malay Archipelago and the spices of the region - cloves, cinnamon and cardamom (known as the 'three Cs') were taken into the Gulf Region by the Arabs and into Europe by the Dutch and the Portuguese. A series of significant treaties between Sadasivaraya and the Portuguese marked their entry into this trade which was taken over by the Dutch in the 17th century.

From the Coromandel Coast, either from the port of Masulipatnam or San Thome (Mylapur), calico (unbleached cotton fabric) was shipped to, among others, Achin, Priamam in Sumatra, to Bantam in Java and to Malacca. Malacca was a trade entrepot from where the Coromandel textiles were re-exported. Duarte Barbosa, referring to the coloured cotton (chintz) of Pulicat and Mylapur, says that they were worth much money in Malacca, Pegu and Sumatra. He also refers to the popularity of Masulipatnam chintz in Pegu (Ramaswamy 1985, 70). Caesar Fredrick also substantiates Barbosa's statement by saying that the only commodity of San Thome for which there was demand in Pegu was: 
...the white cloth made of bambast woven and painted, so that the more that kind of cloth is washed, the more lively they show their colours which is a rare thing... (the reference is to dyeing with the chay root - Caesar Fredrick (also written as Federici) The Travels of Caesar Federici. In Samuel Purchas - His Pilgrims (1905) vol. X, 127).

From Barbosa's account we know that the demand for the Pulicat textiles extended right upto the Gulf of Siam, i.e. Patani, Singora, Tennaserim and Cambodia. It is noteworthy that the finer varieties of Masulipatnam muslin which captured the European market in the 17th century found no echo in the eastern markets. The demand in the lands of the Malay Archipelago was for the Pulicat chintz which sold in these regions as Tape or Tape Sarassas. These were cheap and required little or no stitching since they were worn like sarongs (Moreland ed., 1934, 27-28). Referring to the particularism of the Malay market, Floris comments:

But a great oversight hath been committed in the bespeaking of the pattas, dragons, sallalos etc. for they have all of them, a little narrower edge and the upright Malay cloth must be without it.... I had never believed it, that so small a fault could cause so great an abatement in price. (Moreland ed., 1934, 71; see also Ramaswamy 1985, 122)

The other source of demand for Coromandel textiles lay in the direction of the Red Sea - Ormuz, Aden, Arabia Felix and Africa. Unlike the East, the demand in the West Asian market was for the finer varieties of textiles but this was met by the Cambaya (Gujrat) cloth rather than the Masulipatnam muslins. However, the Middle Eastern market did create demand for a variety of cloth called Telia manufactured in the Andhra region to suit desert conditions. The Telia uses yarn soaked in gingelly oil for a period of 16 days and treated with an iron mordant. This cloth was meant for the desert regions where sandstorms and heat radiation were very great. The Telia was thus treated to ward off heat and keep the body cool besides being dust-proof. Moreover, in the desert regions there was always greater water scarcity and the advantage of the Telia which is coloured with strong vegetable dyes like madder is that it does not require frequent washing. It was the Middle Eastern market which had created the Telia and the variety went out with the decline of the Deccan Sultanates and the shrinking of the market. By the 18th century when the British East India Company lost interest in the promotion of Indian textiles and the Red Sea route more or less closed down, the Telia also went into a long period of eclipse. An attempt at its revival is being made only now by the All India Handloom Board (Fig. 15.1).

As with the Telia, quite a few textile varieties associated with Muslim weaving traditions almost died out in the 17th-18th centuries under Company rule. The Muslim carpet weavers of Adoni, Warangal and Ellur, the Mashroo (or Mashru) and Himroo (a cotton and silk fabric patterned with Persian designs) weavers of Aurangabad who had been renowned for their weaving under the Qutbshahis and Nizamshahis, died in large numbers during the famines of the 18th century. The Jamdani (fine cotton with brocaded patterns in cotton and gold threads) and Jamewar (shawls of pashmina wool) of Paithan (Aurangabad) were rich textiles suited to the 


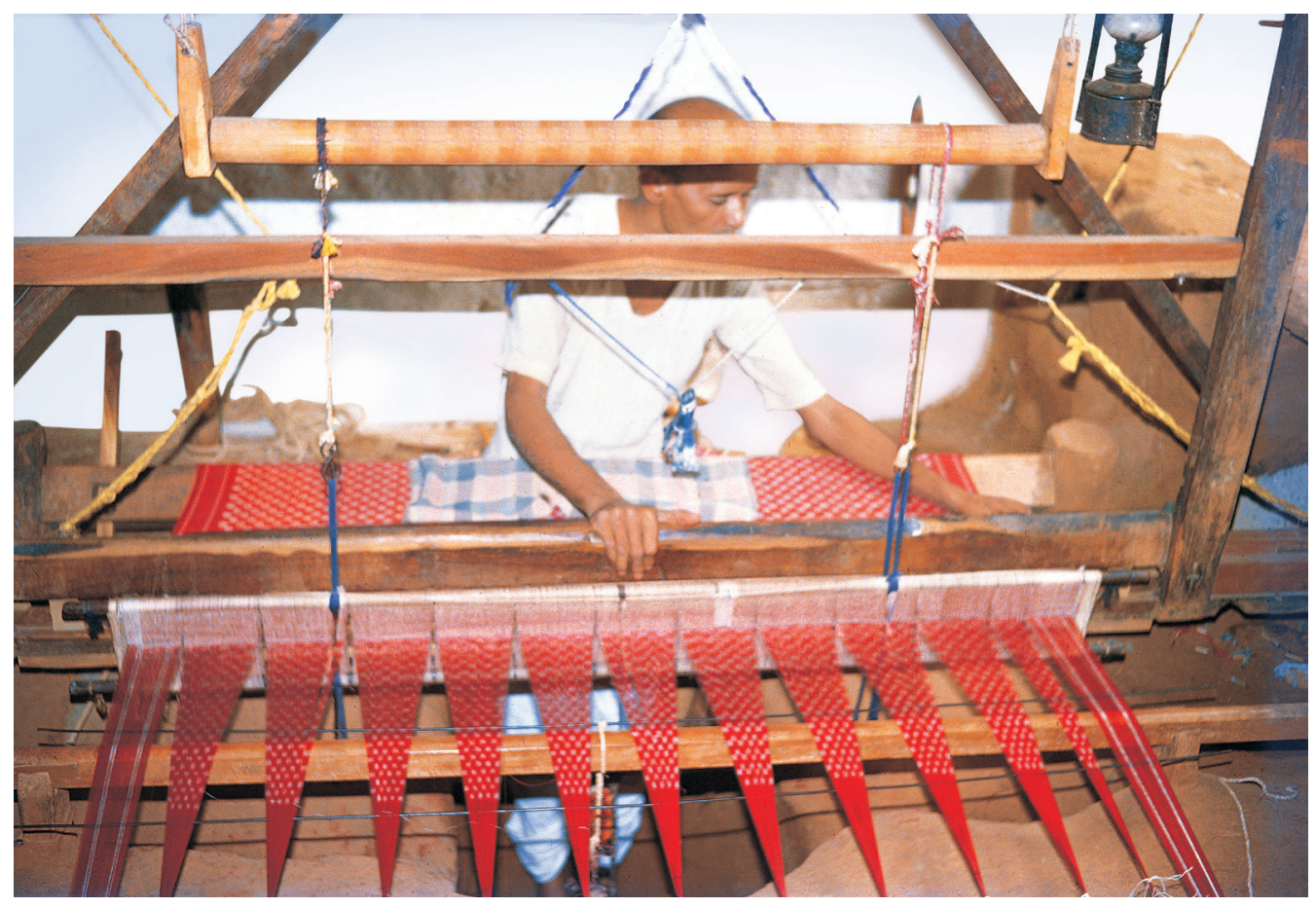

Fig.15.1: Telia is woven using the tie and dye technique with yarn of either cotton or silk, soaked in oil (usually gingelly) for a period of 16 days. Telia production was confined to a few pockets of Andhra Pradesh such as Puttapakka, Kayyalaguda and Pochchampalli. The picture was taken by the author at the place of Sri G. Ramulu, master-weaver, at Puttapakka in 1986 (Photo: () Vijaya Ramaswamy).

tastes of the Deccani aristocracy. The weaving of Mashroo, the silk-cotton textiles, was specifically connected with Islam and the demands of the Muslim elite. The Mashroo was initially created as prayer mats which had a silk warp and cotton weft. The Muslim nobility had a preference for luxury fabrics like silks and satins but Islamic tenets forbade them to use silk which was made from the silk cocoon. Therefore, an ingenious textile was devised which would have a thin cotton layer between the silk and the wearer of it! This was the Mashroo called Kotni in the local parlance. By the 18th century, all these varieties had begun to languish for want of patronage and are today curio pieces to be found in the Salar Jung Museum and the Jagdish and Kamla Mittal Museum, both at Hyderabad.

With the Portuguese, followed by the Dutch and the English, Coromandel textiles began to figure as an important trade item in the triangular slave trade. In Africa, Coromandel cloth was exchanged for slaves and the coarse blue Salempores were used mainly to clothe the slaves. Hence, the reference to Salempores as 'slave cloth' in Company records. The cloth destined for the African market was also called 'Balagate' after the name of the place where it was produced, Balaghat near Cochin. This coarse printed cloth was also called Chinde or Tapechinde. 
The Kalamkari (Persian word, literally kari = working with and kalam = pen) was a textile tradition which began as an aesthetic variety patronized by the Sultanates especially in the regions of Golconda and Bijapur. In the Muslim markets, the handpainted Kalamkaris with big floral designs or the tree of life motif were popular as 'kanats' (tent cloth), while at the same time a special tradition in Hindu Kalamkari also developed. These were usually pictorial depictions of Hindu mythological stories like the Ramayana, Mahabarata or the Bhagavat Purana where the story would be narrated directly beneath each pictorial depiction in the Telugu script. The Kalamkaris continued to be popular during the period of the European Companies as wall hangings (Fig. 15.2).

It was in the 17th century that consumer demand for Coromandel textiles was generated in England and in certain other European countries. The British were in fact trying to substitute the expensive French lawns, cambric and linen with the Coromandel calico. This then was the beginning of the 'calico craze' in which the European companies bought up anything the weavers produced and generated a 'boom' situation for the Coromandel weavers. The fine muslin Betilles were much in demand in Europe as neckcloths while the Pallampores, the printed chintz of Masulipatnam were used as coverlets in England.

The originality and creativity of the Coromandel weavers gradually declined in the course of the 17th century. The putting out system, meaning system of giving advances, destroyed their economic independence while their creativity was impaired by the supply of musters to them by both the Dutch and the English agents. The

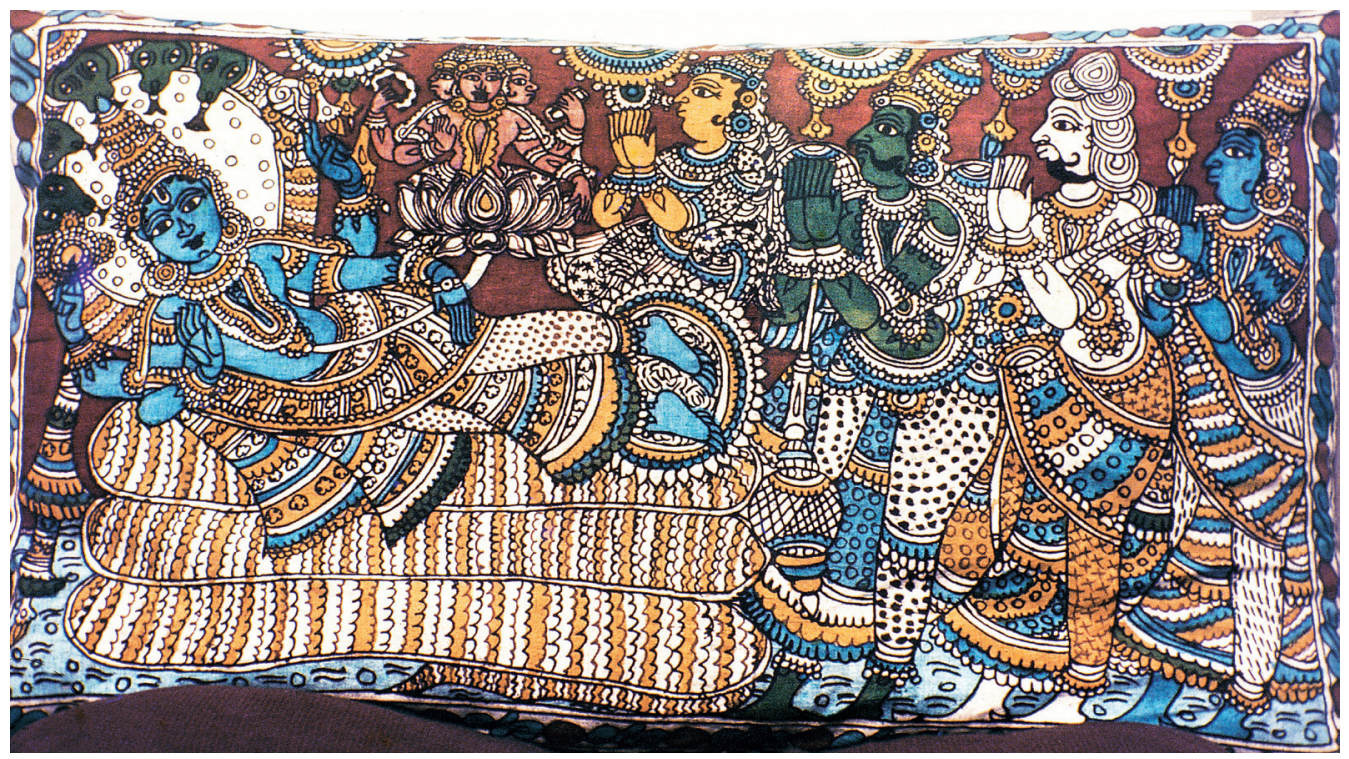

Fig.15.2: A Kalamkari painted textile from Andhra Pradesh showing Vishnu (regarded as the 'Universal Protector' among the Hindu Gods) reclining on the huge snake Adisesha while the other Gods like Brahma (the Creator) Siva (the destroyer) and Indira (the God of Gods) pay their respects to him (Photo: @ Vijaya Ramaswamy). 
weavers were asked to work to "the perfection of the pattern". Nevertheless, even within the given constraints, the weavers continued to exercise their imagination. The consumer demand of the European market co-mingled with their own aesthetic/ artistic traditions resulting in curious effects which may or may not be aesthetically pleasing. Christian themes, such as the adoration of the Virgin Mary with child, or secular themes, like gentlemen hunting with dogs, are intermingled in these textiles with natives in brightly coloured Deccani costumes bordered by the kalka design or the tree of life motif! One outstanding example of such admixtures, the result of the rapidly changing face of consumer demand inadequately understood by native weavers, is the huge wall hanging (dated around 1640) in the Victoria and Albert Museum in London (Fig. 15.3). The scenes are a remarkable amalgamation of Indian, Persian and European dress; Indo-Persian and Venetian artefacts and Indian palace architecture. An aesthetically intriguing yet pleasing sample of the co-mingling of two world views in the imagination of the weaver is a 350-year-old cloth in the possession of the Saurashtra (Pattunulkara) community of Uraiyur depicting the East India Company ship placed side by side with the traditional flower design called thazhampu. In the weaver's imagination, the Company ship seems to have invoked the might of the British Empire which became reflected in his everyday world as unequal interactions with Company Agents and middlemen (Fig. 15.4).

As the Manchester and Lancashire mills in England began to produce their own cloth, the textile lobby in Great Britain caused the passing of the first of the bans on Coromandel calico in 1700. This was to be followed by several other, more stringent acts. In the course of the 18th century, the world of the South Indian weaver was fragmented by the imposition of musters or patterns by the English and Dutch agents which were totally at variance with their own rich colour schemes and culturally and ritually embedded motifs. The weavers were moved out of their villages and brought into the work-houses to weave under the watchful supervision of the Company agents and their deputies who were oftentimes the master-weavers who became careedars or intermediaries for the Companies.

Gradually the Manchester lobby of textile manufacturers which spearheaded the ban on Indian textiles succeeded in edging out the products of the Indian looms. Not only did the weavers lose their foreign market but India itself was flooded with the cheap mill made cloth of the imperial country. The words attributed to Lord Bentinck, the Governor of India in the 1820s - that "the bones of the cotton weavers are bleaching the plains of India" - are a dramatic but apt description of the fate of the Coromandel weavers in the late-colonial era.

\section{Acknowledgements}

I am grateful to my CTR friends for the lively interactions. A very special 'thank you' to Cherine for logistical, editorial and emotional support. 


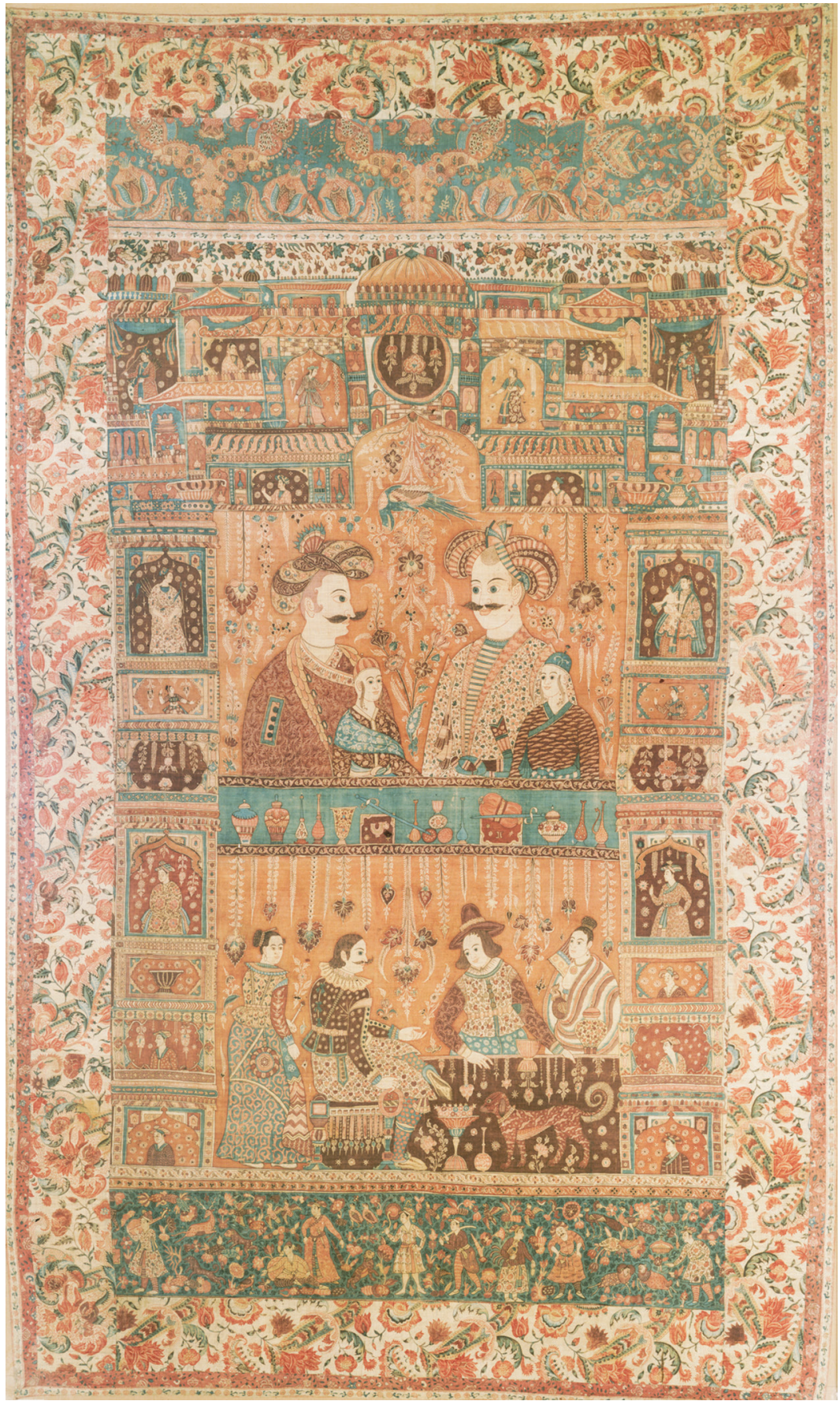

Fig. 15.3: A painted and dyed cotton wall hanging from the Coromandel Coast, India, made around 1640-1650, displaying an amalgamation of Indian, Persian and European dress; Indo-Persian and Venetian artefacts and Indian palace architecture. The added border is from the 18th century; Museum no. 687-1898 (๑) Victoria and Albert Museum, London). 
Fig. 15.4: Motif of the East India Company ship interspersed with the traditional flower motif on the body of the saree with silver leaf motif on the borders. This saree was in the possession of the Saurashtra weavers when the author interviewed them at Uraiyur near Tiruchirapalli in 1986 (Photo: (C) Vijaya Ramaswamy).

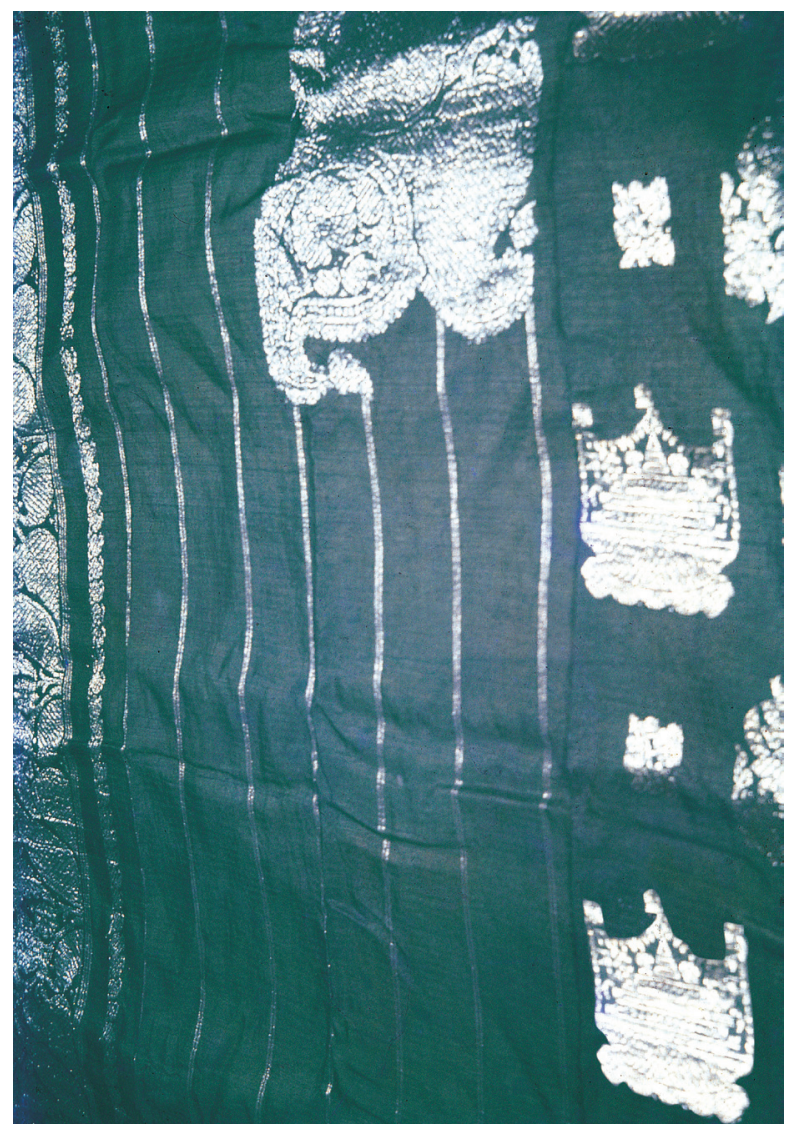

\section{Writings of Travellers}

Duarte Barbosa: The Book of Duarte Barbosa, vol. II, edited by M. L. Dames (1944).

Marco Polo: The Book of Ser Marco Polo, 2 vols, edited by Henry Yule and Henri Cordier (1903).

Fernao Nuniz and Domingo Paes: The Chronicle of Fernao Nuniz and The Narrative of Domingo Paes, in A Forgotten Empire edited by Robert Sewell (1963).

Di Varthema of Bologna: The Itinerary of Ludovico Di Varthema of Bologna, translated from the original Italian edition of 1510 by John Winter Jones, with Sir Richard Carnac Temple (1863, Reprint 1997). Abdur Razzaq: The Travels of Abdur Razzaq, in India in the Fifteenth Century edited by R. H. Major (1974). Tome Pires: The Suma Oriental of Tome Pires, vol. I edited by A. Cortesao (1944). Peter Floris: The Voyage of Peter Floris edited by W. H. Moreland (1934).

\section{Further Reading}

Giorgio Riello and Tirthankar Roy eds, (2009) How India Clothed the World: The World of South Asian Textiles 1500-1850.

Giorgio Riello and Prasannan Parthasarathy eds., (2009) The Spinning World: A Global History of Cotton Textiles 1200-1800.

Philip Wagoner (1996) Sultan Among Hindu Kings: Dress, Titles and the Islamicization of Hindu Culture in Vijayanagara, Journal of Asian Studies, vol. 55, No. 4 (Nov.) pp. 851-880. 



\title{
16 The Jesuit Dilemma in Asia: Being a naked ascetic or a court literate?
}

\author{
SELUSI AMBROGIO
}

Selusi Ambrogio holds a PhD in History of Philosophy from the University of Urbino (Italy) where he wrote a thesis on Orientalism in modern Europe with a focus on the image of China and India within the Histories of Philosophy from the late 16 th to early 18th century. He also holds an MA in Asian Languages (Sanskrit and Chinese) from the University of Bologna, and an MPhil in the History of Philosophy from the University of Macerata (Italy). He studied Chinese language and culture in the academic year 2013-14 at the East China Normal University in Shanghai. In the academic year 2014-15 he is in charge of the course "History of Chinese thought" at the University of Macerata.

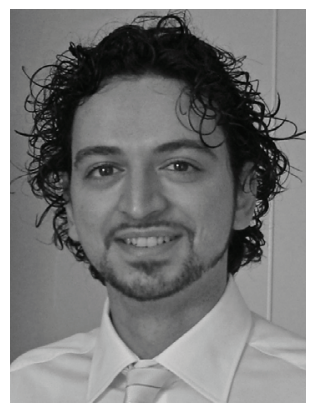

Dress played a crucial role in 16th-century European missionary activity in China and India, a role that is somewhat neglected in traditional histories of the subject. In order to tone down their "foreignness", appear non-threatening and fit into the social class to which they addressed themselves, certain Jesuit missionaries took the step of adapting their outer appearance. How this encounter occurred and the extent to which it was not always appreciated by those back home in Europe is briefly recounted here.

When Jesuit missionaries turned their eyes towards China in the 16th century, it was an almost unknown and mysterious land. Ancient Greek and Latin sources on China were scarce and always marginal. Il Milione by Marco Polo, as well as accounts by other voyagers and tradesmen, was imaginative, full of inaccuracies and generalizations when speaking of local habits. In general, trade relations with China were still limited. The first Christian missionaries who entered China in 1289 were Franciscans, who were later expelled from China along with other foreign missionaries in 1368. Afterwards, the first who tried again to re-enter China was the Jesuit, Francis Xavier, after having preached in India, Indonesia and Japan between 1542 and 1552. Unfortunately, he died from a fever in Shangchuan Island on the 3rd December 1552, while trying to reach mainland China. For the next 30 years, missionary action in China was only directed towards Portuguese Macau. Thereafter, the first European missionaries who were able to enter mainland China again were the Jesuits Matteo Ricci and Michele Ruggieri - first by settling in the city of Zhaoqing - in 1583. 
Before obtaining this exceptional permission from the Chinese bureaucracy, they did their best to learn the Chinese language and local habits. This was the first Western attempt to learn and understand this civilization. Matteo Ricci wrote in Chinese on cartography, mnemotechnics, literature, history, and many other subjects. For the western public, he wrote with Ruggeri on the ancient Chinese civilization. In China, after many initial difficulties, Ricci became famous and well-reputed among the literates and officials. In 1598, he arrived in Beijing and in 1601 he was the first European to be invited to enter the Forbidden City. This is the well-known story of Ricci's mission in China.

Here however, we are concerned with the way in which Ricci interacted with the Chinese upper class. He used a large and complex system of devices, based primarily on his knowledge of both Chinese and European classics. Secondly, he spread the scientific and technical knowledge of the European Renaissance among the learned Chinese. And, no less importantly, Ricci devoted a large amount of his time to make friends, in order to be protected and accepted as a member of the community of literates, as attested by numerous letters between him and his Chinese friends as well as his book On Friendship. Many letters report that Ricci went to China only "to make friends" (Ricci 2001). These relationships with people coming from such a different culture were possible only because he presented himself as an interesting foreigner and always in a non-threatening way - a sort of "Western Christian in Chinese skin".

That "skin" obviously regards appearance, clothes and garments in general. Ricci and Ruggeri entered China having the status and the appearance of a Tiānzhú sēng (天箨僧 monk from India) or héshang (和尚, Buddhist monk or osciano). However, as reported by Ricci himself, the status as monk (héshang) or bonzo (a term coined by Francis Xavier from the Japanese bōzu 坊主) was quite low and denoted an unlearned monk. Thus, with the license of their master Valignano in October 1594, they changed their status and became "learned monks" (rúsēng 儒僧) or "superior monks" (shàngsēng 上僧). This is just their first change of status, because in April 1595, Ricci presented himself as "a cultivated person with powers" (dàorén 道人) or a "lay monk" (jūshi 居 $士)$. Within twelve years, the Jesuit missionary became a "lay monk with alchemical powers who came from the West", because this status was the highest he could reach (Song Liming 2010). And that is why he was allowed to enter the Forbidden City.

As Jesuits, Ricci and Ruggeri wore the typical simple black gown, their head and face well shaved. Entering China, they had not only arrived from India - where Ricci had spent four years - but they also looked like Buddhist monks:

[Ricci] informed Father Valignano that it was absolutely necessary to let their hair and beards grow, because that made them appear humble and [...] nobody was shaven apart from Osciani [Buddhist monks], who worship Idols (Ricci-Trigault 2000, 230-231).

They needed to differentiate themselves from Buddhists to become prestigious interlocutors. Chinese bureaucrats, who were often also refined men of letters, wore formal silk dress when they met each other and spent an important part of their spare time in conversation at each other's residences. This was the new "skin" of 
the Jesuits, necessary in order to evangelize the Chinese upper class. Ricci described his new garment, in many writings, in particular, in the Letter to Acquaviva, written in Nanchang and dated 4th November 1595:

\begin{abstract}
[...] I have acquired a silk robe for solemn visits, and others for ordinary ones. The one for solemn events, as used by men of letters and eminent persons, is made of ruby ["paonazza scura"] silk with long and large open sleeves; around the low hem there is a half span trimming of very bright turquoise silk, and the same trimming runs around armholes and collar up to the belt. The belt is made of the same fabric as the robe, and from it many pendants flutter down to the ground, similar to the belt of our widows. Also the shoes are made of silk with decorations; the headdress has similarities with our bishops' one. The Chinese people wear that robe when they visit someone, for instance to make friends or during a solemn celebration or when they meet an eminent person. The host always appears in a similar robe or one that befits his status, and [to wear that silk robe] makes me seem very authoritative (Ricci 2001, 308-309, author's translation).
\end{abstract}

In another Letter (Ricci 2001, 217-218) Ricci told his confrere, Duarte that a mandarin, who received him without interest before his change of wardrobe, and thus of status, welcomed him warmly, when he was dressed as a literate and offered him a banquet. This mandarin questioned him about his new status and Ricci explained that when they had arrived in China the first time, they were persuaded to wear a simple bonzi's robe, and so they were misled. He thanks God for this new status, as "God's invention" (Ricci 2001, 258).

We may ask: Did Ricci as a Jesuit priest have the permission of his superiors to wear silk clothes, let his beard and hair grow, move about in a palanquin and act often more as a layman than as a monk? A possible answer might be found in the Constitution of the Jesuit Society by Saint Ignatius of Loyola, the founder of the Jesuit missionary Society (written in Spanish from 1542 and edited in Latin for the first time in 1558). In pars. VI, chap. II, where he gives rules on the pauper's way of life for Jesuits, Loyola prescribes three rules to be respected on dress: 1. It must be appropriate; 2 . It should be in conformity with the customs of the place where the Jesuit is a missionary; 3 . The dress should not contradict the profession of poverty (\$15). The silk robe is appropriate and accommodated but not humble. Furthermore, Loyola excludes silk as a possible fabric for garments. However, a few lines later, he says that when a valuable dress is needed for the purpose of better evangelization, if not used in everyday life, an exception could be allowed by the Superiors of the Society. Loyola highlights this point as Jesuits should devote a large part of their activity to evangelizing the upper classes, because only in this way can the spreading of the Christian message be as universal as possible, descending hierarchically from the elite at the top to the larger base below (pars. VII, chap. II, § 1). Thus, Loyola expresses an ambiguity in his guidelines between the Jesuit profession of poverty and the mission to convert the richer part of a society.

Before Ricci, Francis Xavier had to cope with the same difficulty during his stay in Japan. Meeting daimyo Yoshikata and the dignitaries, he had to present himself as a valuable interlocutor, and thus wore a silk robe and carried gifts, acting more 
like an ambassador than a monk (Lacouture 2003, 124-125). In the period between Xavier and Ricci, a real 'silk or cotton controversy' took place. This was initiated by Father Cabral, Superior of the Jesuits in Japan, who was strictly in favour of the observance of poverty. The dispute was so serious that Rome sent Father Valignano to resolve it. Alessandro Valignano, remembering Xavier's approach, allowed the use of silk for advancement of missionary aims (Noll 1997, 216). The problem was only temporarily solved, because this evident incompatibility between poverty and silken clothes reappeared many times later on (when the Jesuits were no longer the sole missionaries in Asia).

Figure 16.1 shows Matteo Ricci wearing a western gown, but, if we closely observe his robe, questions arise. The colour of the dress is black as is usual for Jesuits, but the shape is unusual and the headdress is very high. What I want to suggest is that the original portrait by Pereira (b. Yu Wenhui) has been modified (perhaps in Italy) in order to better suit Jesuit style and be more acceptable for western Christians in Rome. Perhaps, the original robe would look more like the one in Figure 16.2, which represents the reconstruction of Ricci's dress based on the descriptions I mentioned above. This doubt arose during a conversation with Prof. Filippo Mignini, one of the leading scholars on Matteo Ricci, while admiring a copy of this portrait in his office in May 2011.

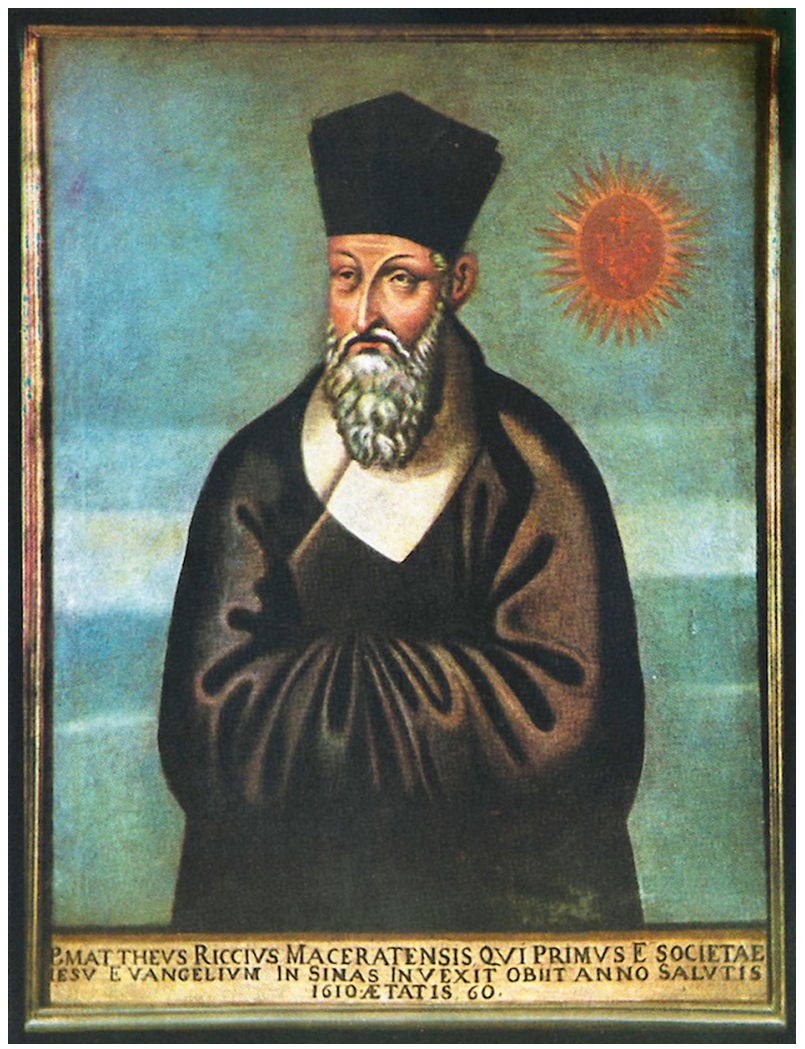

Fig. 16.1: Matteo Ricci 1 Emmanuel Pereira (born Yu Wen-Hui), Portrait of Matteo Ricci, Beijing 1610, Church of the Holy Name of Jesus, Rome; FEC (Fondo Edifici di Culto), Interior Ministry, Rome, inventory number 68 . Oil on canvas. This is the first known portrait representing Ricci. At a glance, Ricci's way of being dressed looks typical for a Jesuit. But, if we examine the robe and the accessories carefully, many details would seem unusual or even strange. If we imagine opening the black robe and seeing the white part of the collar opened, the two sides would not correspond. The long collar from the left descends to the opposite side under the right arm, as is usual in mandarin style. The large armholes are also typical of the Chinese fashion. The representation of both hands hidden in armholes is a very common posture in Chinese portraits. The headdress does not look perfectly Chinese but neither is it a normal Jesuit one. Hence it could be a Chinese headdress modified later on in Rome (Photo: Fondo Edifici di Culto, amministrato dal Ministero dell'Interno - Dipartimento per le Libertà civili e l'Immigrazione - Direzione Centrale per l'Amministrazione del Fondo Edifici di Culto, Rome). 
The question of dress also had an impact on the Jesuit evangelization of India. In the 16th century, India had been better known to Europeans than China, from both ancient and modern sources, and missionaries had arrived earlier, as we learn from Xavier's biography, the intention being to use India as the base for evangelizing the rest of Asia. Yet, when Roberto de Nobili reached Goa in 1605 , he realized the ineffectiveness of the evangelization method used until then as missionaries did not learn the local languages or try to understand the ancient Indian civilization, generally preferring to stay within the Portuguese enclaves. Thus evangelization was rather superficial and scarely tolerated by Indians. Jesuit success in East Asia, particularly in China, suggested the use of Ricci's method in India. Ricci was a Chinese literate among Chinese literates, and de Nobili understood the necessity of being an Indian among Indians ("indus inter indos"), specifically a Brahmin (brāhmaṇa) or a renouncing ascetic (samnnyāsin). De Nobili also thought it was useful to present himself as a "Roman Brahmin", actually belonging to a noble Italian family as his family name suggests.

However, his method had many opponents among theologians, who were geographically far from evangelization missions and their difficulties. They formed an opposition against de Nobili and wrote a point by point letter of accusations against him stating that his methods were superstitious and illicit. Roberto de Nobili and his confreres replied to every imputation in a long letter called the "First apology" (Dahmen 1931, author's translations, from now Ap.).

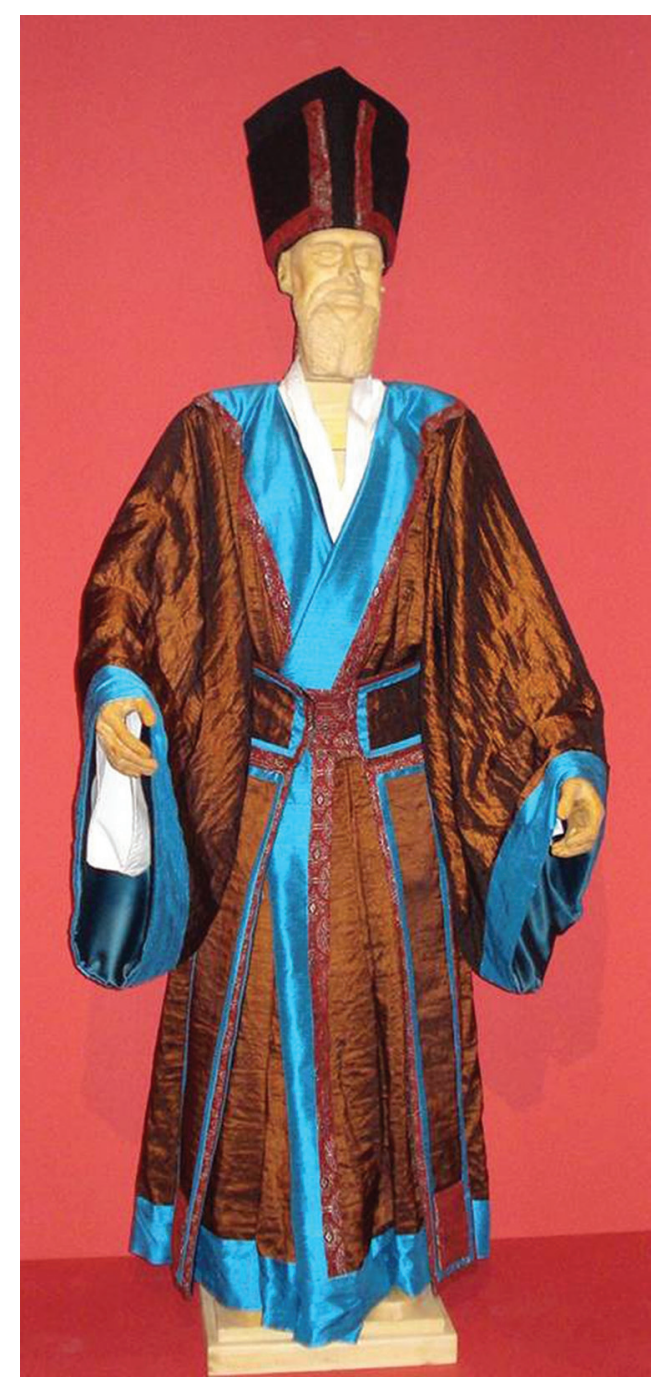

Fig. 16.2: Matteo Ricci 2. Photograph taken during the itinerant exhibition, Meeting of cultures in the China of the Ming (2010). This a reconstruction of Ricci's dress as described by him in the Letter I quoted in the body of the text. We can see the clear Chinese look of this solemn robe befitting upper class men. The robe is made of ruby and turquoise silk, with a long belt and decorated shoes all made of precious silks. The headdress, although too high, is typical of Chinese literate style. Comparing Fig. 16.1 with Fig. 16.2, we can notice a few important similarities, amongst them, the shape of the collar, the large armholes and the headdress. All these elements belong evidently rather to the Chinese style than to the European (Photo: with kind permission of Prof. Mignini of the Ricci Institute, Macerata, Italy). 


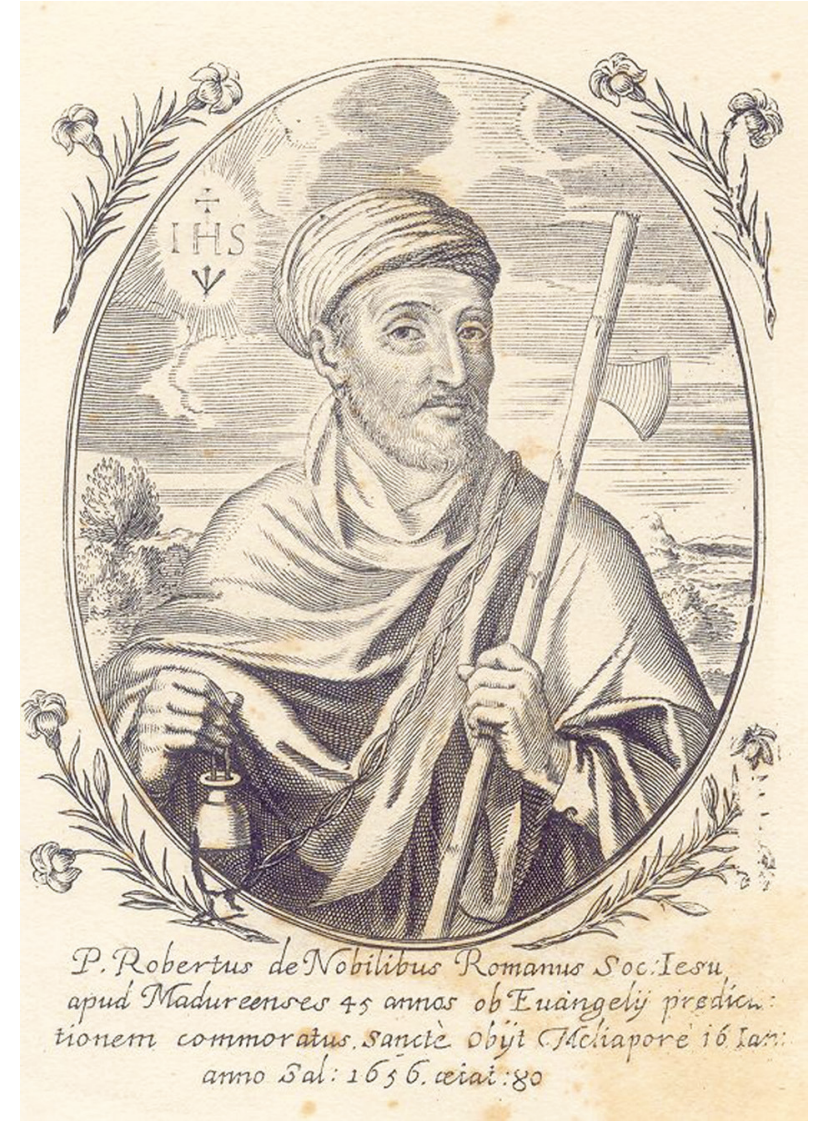

Fig. 16.3: Roberto de Nobili. Gravure from Alfred Hamy (1893), Galerie illustrée de la Compagnie de Jésus: Album de 400 portraits choisis parmi les plus beaux, les plus rares ou les plus importants, et reproduits, en héliogravure, vol. 6, plate 1. De Nobili wears the typical Indian robe for meditation, very simple and undecorated, here, he is not bare breasted as he is sometimes depicted. He has the thread hung over his left shoulder, it is clearly the Brahmin thread (yajñopavitam) because of the three strands composing it. De Nobili later abandoned his status of Brahmin, in order to take that of ascetics, who burn their threads as a symbol of their renunciation to the mundane world (Photo: Boston Public Library, http://archive.org/ details/galerieillustr06hamy).

Most of this reply is devoted to proving the necessity for missionaries in India to look and act as Indians.

I quote only the most important accusations on de Nobili's dressing: "He dresses as gurus and samnyāsin [ascetic] and he wears the traditional Indian thread as a Brahmin and a kșatriya [members of the military or reigning order]" (Ap., 58). In Figure 16.3, de Nobili is represented as in the first status he achieved: he has the thread of the Brahmin (in Sanskrit yajñopavita) hung over his left shoulder. At first, de Nobili explained in his response that guru is just a general term for a learned person or teacher ("Doctorem vel magistratum") and that a samnyāsin (in text "Sanias") is someone abstaining ("perfecte abnegationem et rescindentiam", Ap., 59) from goods and women. Thus, for a Jesuit monk to be considered as a guru or a samnyāsin is not inappropriate. Regarding the thread, de Nobili and his confreres had also allowed new converts to wear it, thus increasing the scandal. De Nobili answered: "I wore it as long as it seemed necessary for me to achieve a high reputation and win a good appraisement, but for nine months I have worn it no more". In India, the thread was a sign of the status of the upper classes and de Nobili understood this well. Following Loyola in the evangelization of 
the upper classes, he needed to be recognized as belonging to the same high social group. He wore the thread, with a clearly visible cross attached. However, at the time he was writing, he wore it no more, because he learned that the samnyāsin abandons all worldly symbols to attain the status of an ascetic. Thus, he allowed converts to wear the thread but he himself refrained as it was inappropriate for his new ascetic status. We see that de Nobili changed his status twice, first to that of a Brahmin and then to that of samnyāsin, as Ricci did in China, at first looking like a Buddhist monk and then living as a Chinese literate.

De Nobili then suggested a more precise method for discerning between what was acceptable and not acceptable for new converts - with the intention of setting a general framework which would include modes of dress, behaviour, symbols, etc. (Ap., 95-111). What was related to local religion was unacceptable and what was merely usage in civil life, i.e. pertaining to the non religious sphere, was acceptable. However, this distinction was often not that simple and led to new controversy. The most interesting point of de Nobili's method is that a habit that had civil origins and later acquired a religious meaning could not be refused, but had rather to be restored to its often lost original meaning; the implementation of which required some study of ancient Indian texts and traditions to ascertain the original meaning of Indian habits.

The Brahmin thread and samnyāsin robe were thus seen to have both civil functions as well as origins. Obviously, today this interpretation is no longer acceptable, however, in de Nobili's understanding of India, whatever is related to caste, is civil. De Nobili's intention is indeed to prove the feasibility of introducing the Christian faith into the Indian culture. The thread is just a caste symbol. The thread ceremony makes a child into a Brahmin, it denotes only the entrance into a well defined social group (Ap., 100). The fundamental evidence of this civil origin, apart from Indian written sources, is given by de Nobili as follows: the samnyāsin, the ascetic who leaves the mundane world, gives up the thread because, in leaving the society, he cannot preserve this symbol of belonging (Ap., 123). Ascetics, in de Nobili's mind, do not leave their religious beliefs but only their civil role. For de Nobili, this demonstrates the civil, and not religious, meaning of the thread. Obviously, he considered himself and the local Jesuits as the true experts of Indian culture and not as theologians from far away.

To this theoretical argument, de Nobili added a practical one: the Jesuits wear Indian robes not to become Indian believers or heathen, but with an evangelical goal, to convert as many Indians as possible. The way of dressing in a society divided into rigid castes, based on the pure and impure dichotomy, is fundamental in approaching possible converts. A Brahmin could never preserve his status in social intercourse with a non-Brahmin, as otherwise he would lose his purity. Thus, the Jesuit missionary needs to dress and act as a Brahmin to convert him. This is the "right cause" reason ("justa datur causa", Ap., 105).

Furthermore, de Nobili offered a historical or authoritative reason: Jesuits in China did the same. At least twice, he cited the confreres of China, who dressed as bonzi or as literates (Ap., 102, 109), also reporting the double changing of status of the Jesuits in China: at first as bonzi (Buddhist monks) and as literates a few years later. 
De Nobili's reference to Ricci changing status proves a common thread between the two men and the two experiences. De Nobili was inspired by Ricci and he considered the Chinese mission as authoritative. Moreover, de Nobili mentions Japan as the first place where Jesuits dressed as bonzi, while Ricci did not mention the Japanese case of Francis Xavier. Perhaps, that was because Francis Xavier did not achieve a real change of status, but only that of a momentary changing of wardrobe (more in the sense intended by Loyola as I mentioned above. What happens with Ricci and de Nobili is more than a simple changing of garments, it is a deeper and more complete adaptation to the society in which they operated. That is why Ricci and de Nobili's method is often called in Latin adaptatio (adaptation). De Nobili's method had official papal approval with the Romanae sedis Antistes (31st January 1623), but that does not mean a general approval of the method of adaptation by the entire Catholic world.

Both Ricci and de Nobili in their own way testify to the first steps of Orientalism, they were unusually open-minded, and sort of pioneering anthropologists for their time. They deeply understood the keys to the Chinese and Indian civilisations, they were aware of the impossibility of erasing all ingrained ancient habit at the moment of conversion. However, they were in no way objective as a modern anthropologist or orientalist would be, they had a clear apologetical (or religious) aim in their approach to society and ancient sources, that of evangelization. In conclusion, we could ask: if "the gown does not make the friar", could the right garments ever make a mandarin literate or a samnyāsin? The answer is personal to each reader. However, Ricci looked and acted like a mandarin, de Nobili like a samnyassin, but in their heart and soul they were missionaries. The classical saying is true: no matter whether a Jesuit is dressed like a mandarin or a samnyāsin, he is still a Jesuit.

\section{Further Reading}

Pierre Dahmen (1931) Robert de Nobili, l'Apôtre de Brahmes. Première apologie, 1610.

Jean Lacouture (2003) Jesuit: A Multibiography.

Mark A. Noll (1997) Turning points: decisive moments in the history of Christianity.

Matteo Ricci (2001) Lettere (1580-1609). Edited by F. D'Arelli.

Matteo Ricci (2009) On Friendship. Trans. T. Billings.

Ricci-Trigault: Matteo Ricci and Nicolas Trigault (2000) Della entrata della Compagnia di Giesù e Christianità nella Cina.

Song Liming (2010) Father Matteo Ricci's change in status in light of four Chinese Poems, in F. Mignini (ed.) Matteo Ricci. Encounter Between Civilizations in Ming Dynasty China, pp. 92-99. 


\title{
17 The Colourful Qualities of Desire: Fashion, colours and industrial espionage
}

\author{
VIBE MARIA MARTENS
}

Vibe Maria Martens, historian, with a background in Danish and British colonial history. She has worked with textile studies at the Danish National Research Foundation's Centre for Textile Research, University of Copenhagen (2010-1012) and attended a variety of conferences and workshops, such as those in conjunction with the EUfunded Fashioning the Early Modern research programme. In 2012 she commenced a PhD research programme at the European University Institute in Florence, Italy, with the project, "Indian Textiles in Seventeenth- and Eighteenth-Century Denmark: Colonialism and the Rise of a Global Consumer Culture".

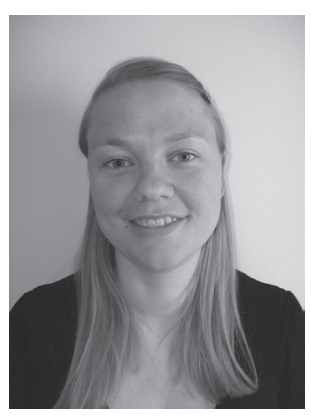

When the Portuguese in 1498 managed to find the direct sea route between Europe and India, it marked the onset of a new era in history. Indian textiles and other goods, such as spices, had previously been traded indirectly along various sea and land routes, such as the Silk Roads and across the Indian Ocean, and through the ports of Hormuz and Aden. The newly found direct sea route held much promise of profitable adventures to the Europeans and a larger export market for the Indians, who already had a large trading network for Indian textiles in Asia, but who hitherto had limited exports to Europe. Following the Portuguese were the Dutch and the English, who were later followed by other European colonial powers also keen to explore options of profit from the perceived lucrative trade with India. Although spices were originally one of the primary trading goods from India to Europe, textiles eventually came to play an equal, if not larger, role in the trade. Several factors were in place to create the European societies of the mercantilist period, but the possibilities of trade with India via the newly found sailing route was one circumstance necessary to create and satisfy the desires of the Europeans for exotic, luxurious or simply different, products, such as the Indian printed, painted or embroidered cottons. At the end of the 18th century, India was the source of a quarter of all textiles produced across the globe, and an even larger part of the textiles traded via the seas (Riello and Roy 2009, 6). 
The 17th century saw a great increase in demand for Indian textiles by entire European populations - from all strata of society. These textiles started their rise to popularity as furnishing textiles used in the home, for example as palampores, bedspreads, or wall hangings (Fig. 17.1). During the course of the 18th century, the demand for Indian textiles spread to dress fashions, and the textiles were thus converted from exotic to staple goods (Lemire 2003, 66). Some have argued that the Indian textiles formed the basis of a consumer revolution, which transformed the history of European fashion, manufacture and economy, paving the way for industrialisation (Riello and Roy 2009, 12). In order to have created this consumer revolution, Indian textiles had very specific qualities which marked them as different to the textiles typically manufactured in Europe in the 17th century. First and foremost, they were cheap, or at least generally cheaper than wool and silk textiles produced in Europe. Second, they were made in hitherto unseen designs, and European merchants quickly developed ways of ensuing that Indian textiles for the European market were designed in patterns of the latest fashion to suit European taste (Fig. 17.2). Images of exotic and unknown flowers or animals fascinated the European consumers, in particular the British consumer, who found themselves fascinated by the evolving studies of botany (Lemire 2003, 69). This fascination transferred into the fashions, and the Indian textiles are a prime example of how European political and intellectual trends of the time were translated into the realm of fashionable dress.

Another central quality of the Indian textiles was the colours. Indian textile production made use of ancient crafts to dye and pattern the cotton textiles, which created brilliance and fastness of colour (Riello 2010). John Ovington, during his time in Surat in India wrote that:

In some things, the artisans of India out-do all the ingenuity of Europe, viz., the painting of chintes [painted or printed cotton cloth, "pintado" in Portuguese, sometimes glazed] or calicoes [generic name for cotton cloth, which often refers to printed or painted cotton], which in Europe cannot be paralleled, either in their brightness and life of colour. (Ovington quoted in Beverly Lemire and Giorgio Riello (2008) East \& West: Textiles and Fashion in Early Modern Europe. Journal of Social History, vol. 41, no. 4, (Summer) 887-916, p. 893).

The dye techniques signified that a hitherto unknown colour palette to Europe could be applied to the textiles, to create multicoloured masterpieces in intricate patterns with very small and precise detailing. The dyeing techniques used in India also meant that the textiles, and their colours, had a longer durability than textiles produced in Europe. The Indian textiles could be washed several times before losing the strong colouring, whereas textiles dyed with European techniques would fade quickly.

The processes and technology of Indian textile dyeing were unknown to Europeans until around the 1760s. Due to the various qualities of the Indian cotton textiles and their success in Europe, several European states employed several strategies to first quench the popularity of the textiles, and when that failed, they attempted to obtain the technology, thus ensuring that similar textiles could be manufactured in Europe and sold with profit going to the European coffers and not to the East India trading companies, various merchants or other individuals. Multiple pieces of sumptuary 


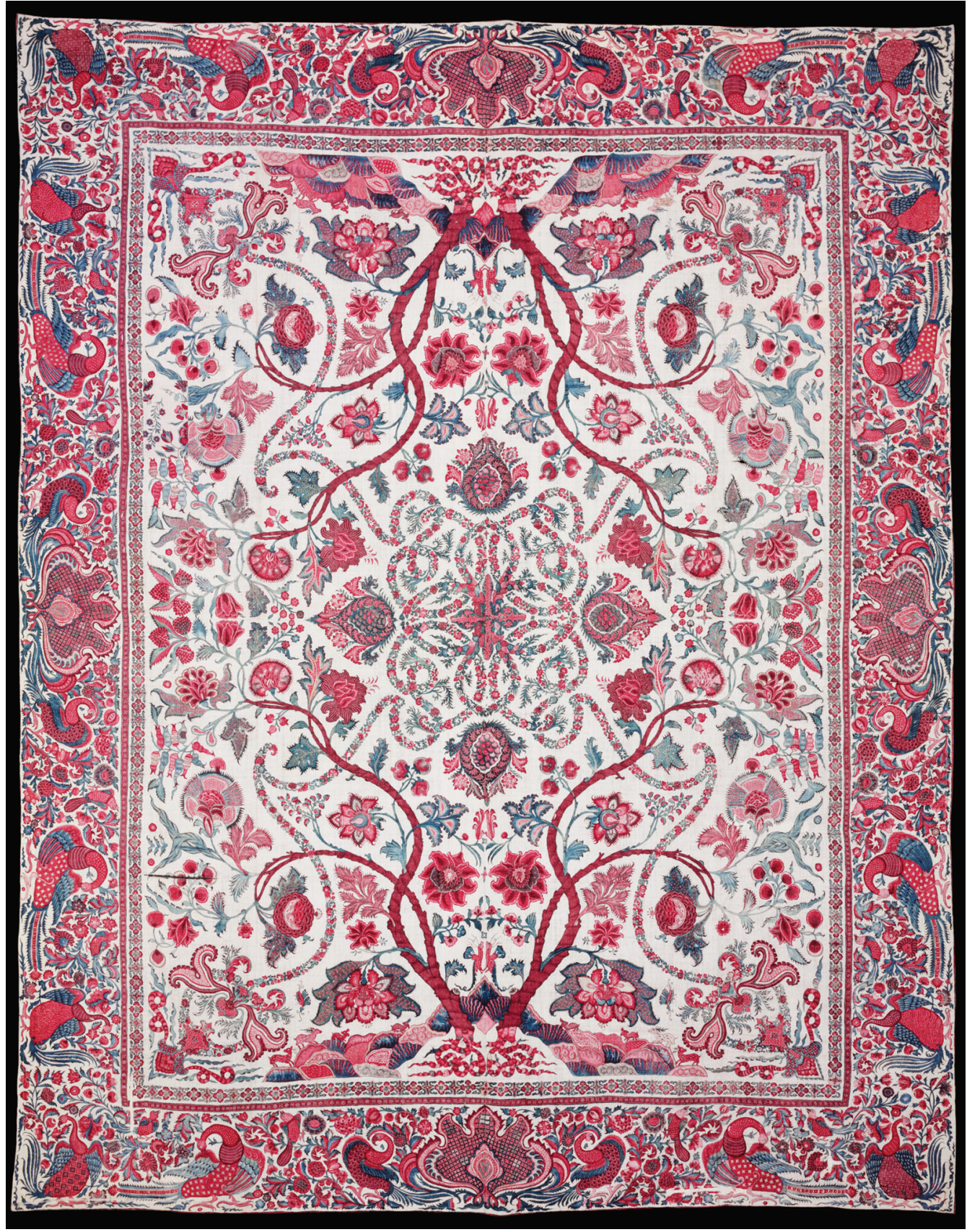

Fig. 17.1: Bed or wall hanging (palampore), painted and dyed cotton (chintz). Coromandel Coast, for the European market, mid-18th century; Inv. no. IS.10-1976. The first fashion for Indian textiles came with textiles for the home, such as this bed- or wall hanging. Motifs of exotic flowers, trees and animals are evident in this textile, and identifies the textile as having been produced for the European market (C) Victoria and Albert Museum, London). 


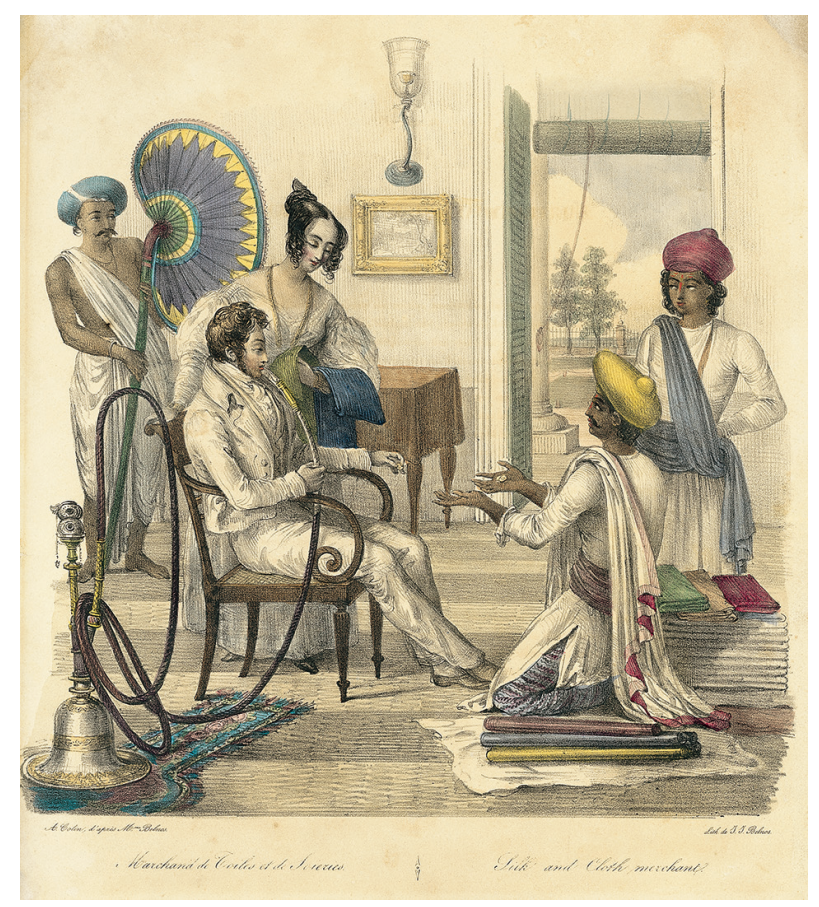

Fig. 17.2: European agent ordering textiles. Hand-coloured lithograph, 1832. Agents could also bring patterns to be applied to printed cotton textiles or woven textiles when ordering, to attempt to ensure that the exported textiles from India would sell well in Europe and be part of the latest fashion (@ The TAPI Collection).

legislation had long been in place across Europe, previously mostly concerned with social issues, i.e. to protect the status of certain classes and banning those in the lower social strata from wearing gold or certain luxurious types of textiles. As the craze for Indian cottons spread across Europe, sumptuary legislation became increasingly concerned with the protection of national textile production and thus the larger national economy. The next strategy was to copy the Indian methods of production, so that the Europeans could produce their own calico, a cheap, printed cotton with famously exotic patterns, of similar quality to that manufactured in India.

To do that, the European powers or other European institutions, such as the various Christian missions, sent agents or missionaries to India to obtain detailed accounts of how the dyeing process took place. Several countries, France, England, the Netherlands and Denmark, either by bribery or in other ways, managed to secure knowledge and evidence of the dyeing processes in such detail, that with some experiments, European manufacturers could produce similar textiles in similar qualities and colours. This was essentially a type of industrial espionage. Early accounts are from the Netherlands, such as that of Daniel Havart who in 1693 wrote a description of the dyeing processes but with less detail than the later accounts of the 18th century (Hofenk de Graaf 2004, 353). Also amongst the agents sent to India to uncover the dye technologies were missionaries, a naval officer and two botanists: M. De Beaulieu, a French naval officer of the French East India Company who wrote his account around 1734; the Jesuit, Father Coeurdoux in his letters written between 1742 and 1747; the British botanist William 
Roxbourgh in 1795; and the Danish botanist and missionary for the Halle Mission, Johann Peter Rottler in 1802 (Irwin and Brett 1970, 36-58; Rottler 1802, 158-171). Thus, although missionaries had several reasons for their missionary activities in India, this one in particular had economic gain as its sole motive. To possess the knowledge of Indian textile production processes was both valuable and prestigious.

Through the knowledge gained by the detailed accounts supplied by various Europeans in India, European merchants were able to either directly copy or at least transfer some of the methods of production and dyestuffs to textile production in Europe by the end of the 18th century. Whether they directly copied or only adopted some features of the Indian dyeing technology and process is unknown, but regardless of which methods were actually used, it is likely that the European merchants were still dependent on Indian plants for dyes. Especially the red dye, chay root (Oldenlandia umbellata), had not previously been used in Europe, where madder was applied to produce a red colour (Hofenk de Graaf 2004, 355). We do not know, however, if this dye stuff was imported into Europe, but indigo to dye blue certainly was. Thus, although the centre for cotton textile production shifted from India to Europe, India still played

Fig. 17.3: Dye recipe book, 19th century, possibly Henry Fielding Bros. London, 1824; Inv. no. T.12-1956. There are several examples of these dye recipe books from the European textile producing centres of the late 18th and 19th centuries, such as this one from England, but also from Mulhouse in France. These dye books testify to the attention given to dyes in the design of cotton textiles ( $\odot$ Victoria and Albert Museum, London).

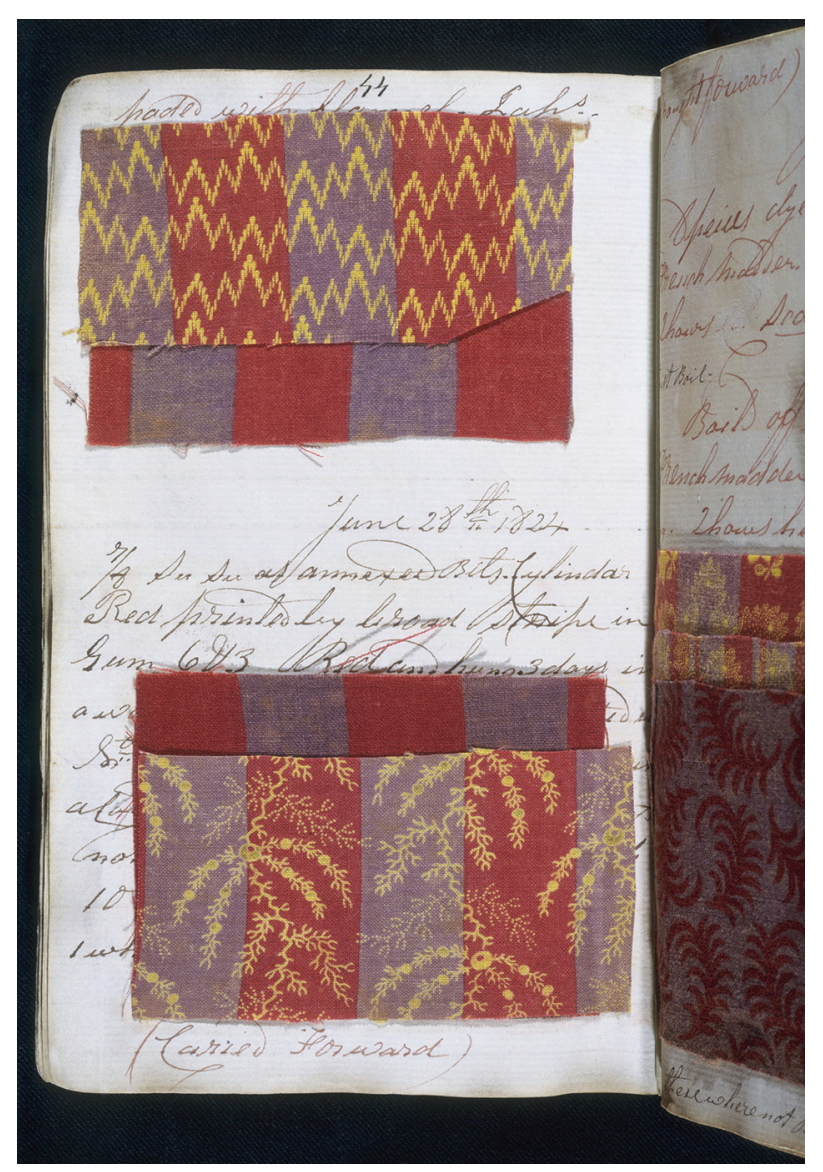


a vital role in the continuity of the demand and production of cotton goods. Major centres of cotton textile production were Manchester in Great Britain and Mulhouse in France (Fig. 17.3).

Indian cotton textiles were one of the first widespread global commodities which many people gained access to as their popularity grew. It is the story of how a fashion can develop, and how fashion, politics and economics are interlinked, in this particular case to colonies in countries and regions foreign to most Europeans at the time. It is also a story of how a country, in this case India, could make use of foreign desires for influence and profit. The Indian cotton textiles is perhaps the earliest case of a fashion craze, which caused a product to become truly global, something of a certain quality and colour, which was desirable to Europeans - evidently the colourful qualities of desire.

\section{Further Reading}

Judith H. Hofenk de Graaff (2004) The Colourful Past. Origins, Chemistry and Identification of Natural Dyestuffs.

John Irwin and Katharine B. Brett (1970) Origins of Chintz.

Beverly Lemire (2003) Domesticating the Exotic: Floral Culture and the East India Calico Trade with England, c. 1600-1800. Textile, 1: 1, pp. 64-85.

Giorgio Riello (2010) Asian knowledge and the development of calico printing in Europe in the 17th and 18th centuries. Journal of Global History 5, pp. 1-28.

Giorgio Riello and Prasannan Parthasarathi (2009) The Spinning World. A Global History of Cotton Textiles, 1200-1850.

Giorgio Riello and Tirthankar Roy eds, (2009) How India Clothed the World: The World of South Asian Textiles, 1500-1850.

Johann Peter Rottler (1802) Cattun-Skildring, eller Maaden, hvorpaa de Indiske Sirtser forfordiges, in Skrivter af Naturhistorie-Selskabet. 


\section{Fashion Encounters: The "Siamoise", or the impact of the Great Embassy on textile design in Paris in 1687}

\section{CORINNE THÉPAUT-CABASSET}

Post-doctoral Research Fellow at the Victoria and Albert Museum London/HERA (Humanities in the European Research Area) "Fashioning the Early Modern: Creativity and Innovation in Europe 1500-1800" (2010-2013), Corinne Thépaut-Cabasset is currently working on the life of European courts in the early modern period with a focus on royal and princely wardrobes. She has collaborated on recent international conferences on the history of dress and the global market in 2012: The making of a Monarchy for the modern world, Kensington Palace (London), Innovation before the Modern: Cloth and Clothing in the Early Modern World, Pasold Research Fund Conference 2012 in Stockholm, Global Commodities: The Material Culture of Early Modern Connections, 1400-1800, Global History and Culture Centre University of Warwick. She has published a book, L'Esprit des modes au Grand Siècle (Paris, CTHS, 2010) on the Mercure Galant fashion articles.

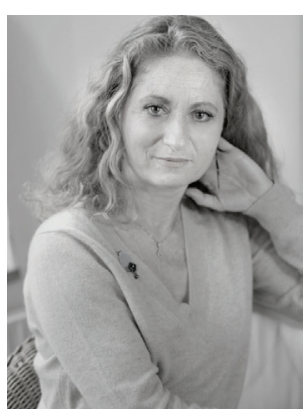

The French court journal, the Mercure Galant (published in 1672-1711) had a section dedicated to new fashions and trends. This reveals just how varied the vocabulary describing textiles and the cut of clothes in the late 17th century was. Fashion appears to have been as immediate as public and court events themselves, arriving and disappearing rapidly. In the late 17th century, China, India and Siam (presentday Thailand) were the new sources of inspiration for the fashion trade. Sleeves à la Pagode, taffeta de la Chine, gowns à la Sultane or à la Persane, fans à la Siamoise entered fashion vocabulary in France.

The impact of the Siamese embassy to the court of Louis XIV in September 1686 offers one key example of a fabric that became popular, yet changed in its composition over the fifty years following the embassy. The visit of the ambassadors from Siam was a sensational event reported in the press, and it inspired great curiosity in Siamese culture and manners among the French (Fig. 18.1). The extraordinary visit, its duration (September 1686 to January 1687), the ambassadors' stay with the royal family, their spectacular reception by the king and in other parts of the kingdom, created a tremendous series of events which were attended and reported in the public in many ways, notably through print, in the press and in engravings.

Soon after the ambassadors' visit to Versailles and Paris, Parisian merchants launched a new fabric called the "Siamoise". It seems that this was a lightweight 


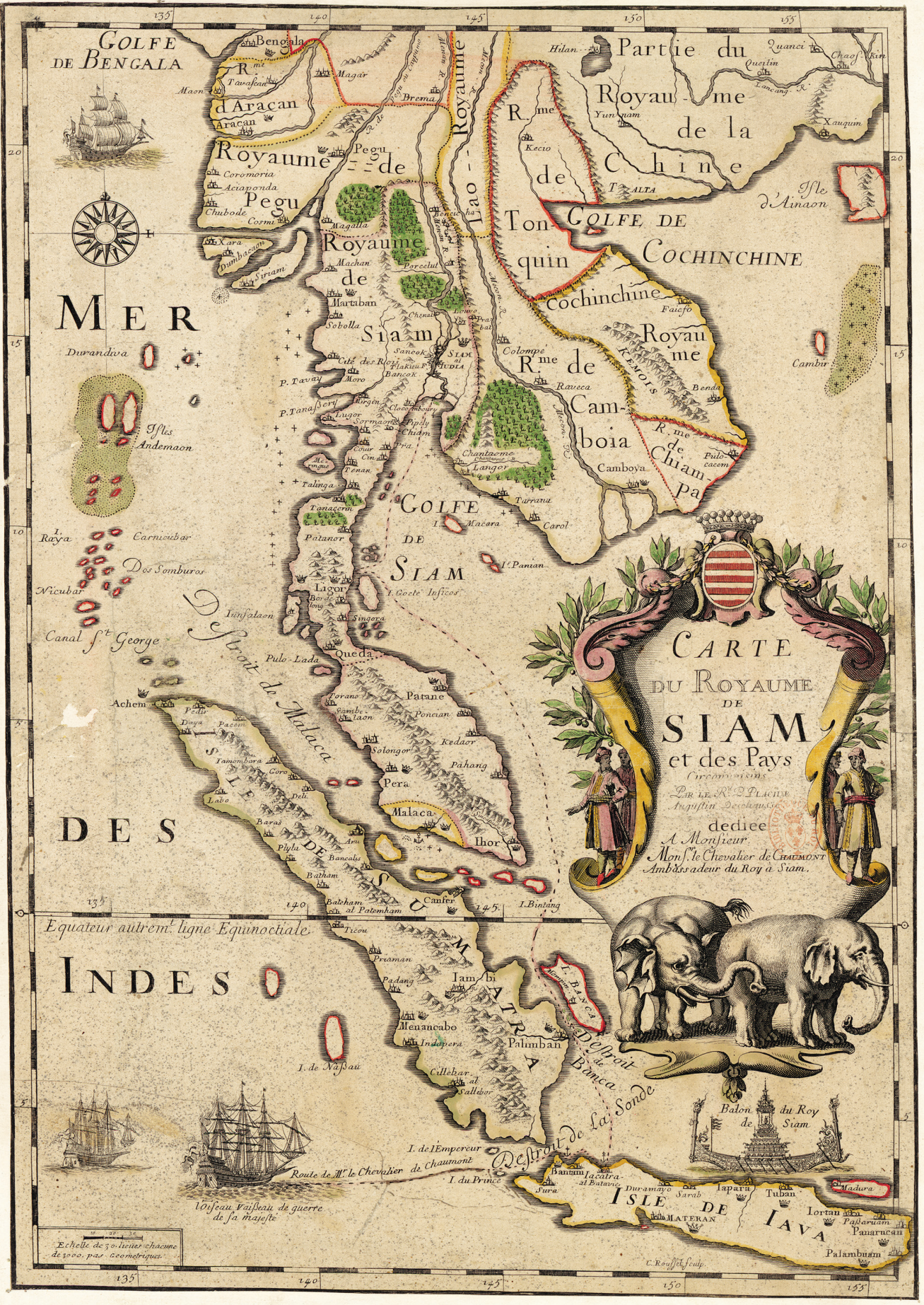

Fig. 18.1: A map of the Kingdom of Siam by Placide de Sainte-Hélène (1648-1734) and C. Rousset, GED-7970 (Bibliothèque nationale de France, Paris). 
striped fabric, echoing that worn by the ambassadors from Siam. We do not know for certain if French manufacturers intended to imitate a fabric originally made in Siam, or merely used that fabric as a source of creativity and inspiration (Fig. 18.2). What we do know for certain is that among the gifts sent by the King of Siam to the King of France, Louis XIV, were some pieces of fabric (Mercure Galant, Paris 1686). This might well have inspired astute merchants to create a new French fabric at that time. Whether it referred to a French or a Siamese fabric, the term "Siamoise" was one used by merchants in the press and on fashion plates, and the new trend was launched soon after the event.

In June 1687, in the section describing the new fashion for summer, the Mercure Galant reported that a special kind of wool fabric striped with many colours is called "Siamoise", and was selling well for textile merchants. Made for the summer season, this wool fabric was as light and soft as the light cotton fabric called muslin (mousseline), striped in various colours, and was ranked by textile merchants along with figured satin fabrics (satins façonnés). In other words, it was related to all the fibres commonly used for fashionable dress - wool, silk and cotton.

Fig.18.2: The Royal Almanach for the year 1687, representing the Great Embassy of Siam in France during the year 1686. To celebrate the new year 1687 the royal calendar choose the brightest public event that had taken place at the French court in 1686: The great embassy of the King of Siam to the King Louis XIV for the establishment of commerce with people from the East. This plate combines many engravings showing the different events related to the royal embassy from Siam to France, from the arrival of the ambassadors in Brest, their magnificent entrance in Paris, their royal audiences and visit to Versailles. This embassy was sent to seal a commerce treaty between France and the kingdom of Siam. The two figures at the bottom represent France and Siam in their own clothing, holding hands in sign of good alliance and friendship. Louis XIV had received the ambassadors in pomp and glory in the very new hall of mirrors in Versailles Palace. BnF Estampes, Cliché RC-B-08810 (Bibliothèque nationale de France, Paris).

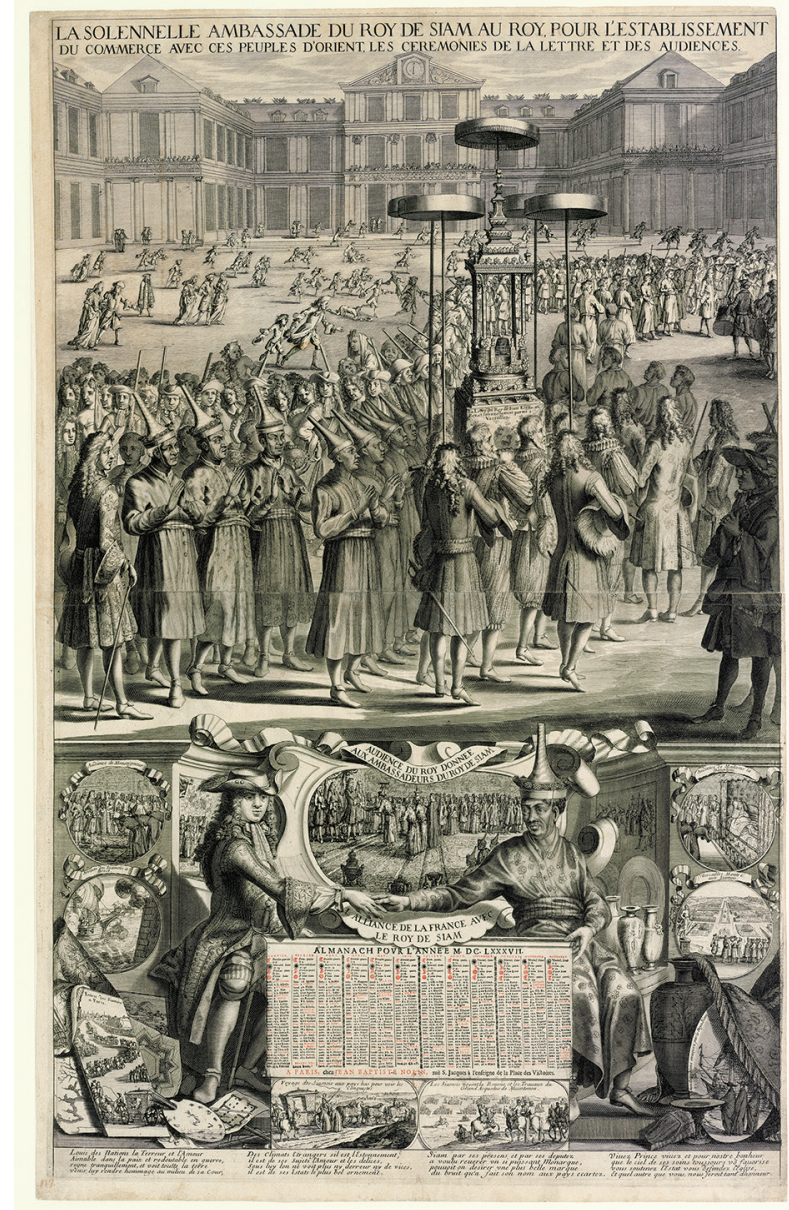


Fashion plates made by François Arnoult and Dieu de Saint-Jean depict the fashion for the summer of 1687. In his plate, Dieu de Saint-Jean shows a woman of high rank, standing in a nightgown (déshabillé) made of "Siamese" fabric (étoffes siamoise). She holds in her right hand a closed fan (Fig. 18.3).

In the same year, and in a similar manner, François Arnoult produced another fashion plate of a woman in a summer gown (habit d'esté) made of Siamese fabric (Fig. 18.4).

These two plates commented on by the Mercure galant suggest that the Siamese fabric manufactured in France was made of silk in the beginning. By the early 18th

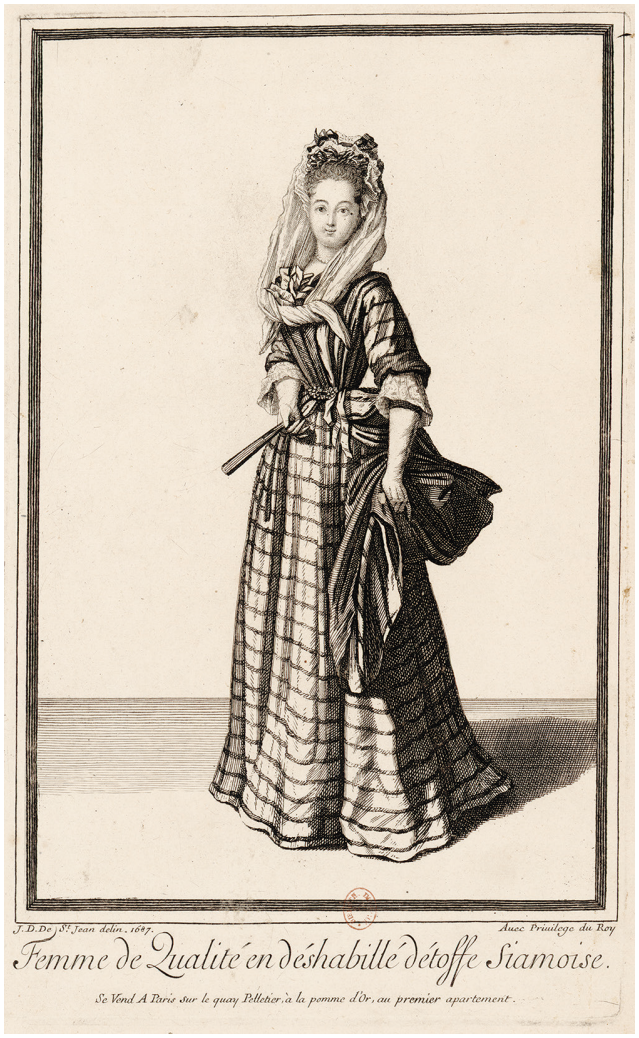

Fig. 18.3: Femme de qualité en déshabillé d'étoffe siamoise. Fashion plate by the French artist Dieu de Saint-Jean in 1687, of a distinguished lady in nightgown made of 'Siamese' fabric. This depicts a woman wearing a nightgown made of a light, striped fabric made in France called "Siamoise". Nightgowns were more comfortable and informal garment to wear at home. This one seems to have no buttons, and wraps the body. The sleeves are rolled over the arm. Her head is dressed with lace and covered by a veil. BnF Estampes. Res-QB-201 (63)-Fol (p. 40), Cliché G156475 (Bibliothèque nationale de France, Paris).

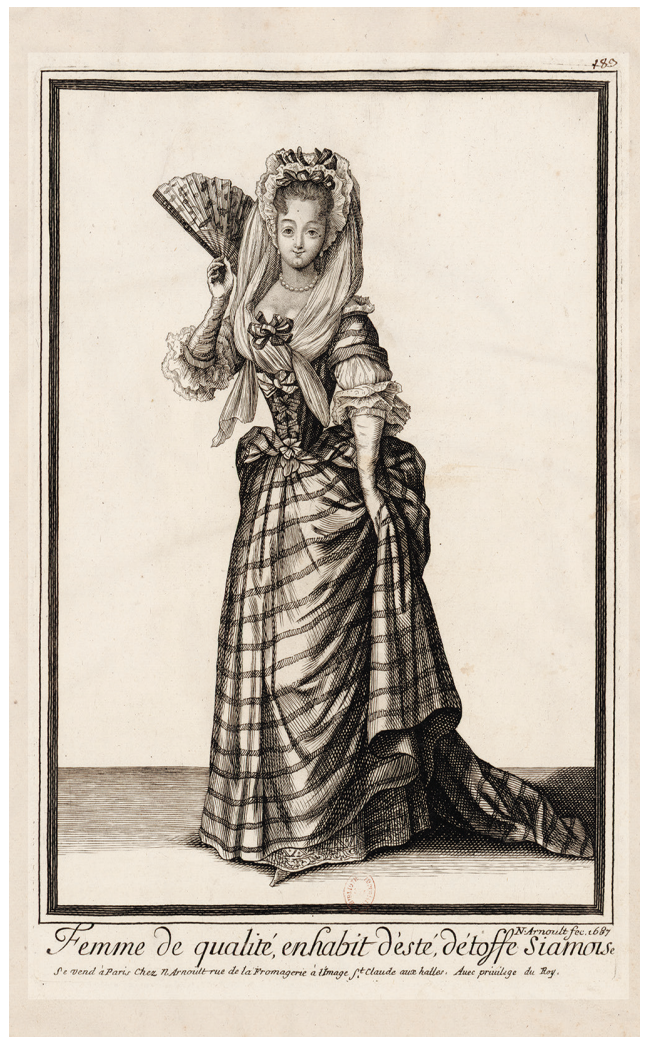

Fig. 18.4: Femme de qualité en habit d'été d'étoffe siamoise. Fashion plate by the French artist François Arnoult in 1687, of a noblewoman wearing a summer gown in 'Siamese' fabric. This shows a woman dressed for the summer season. She is wearing a fashionable dress - an opened coat and a skirt - in striped fabric called "Siamoise". This fashion figure is clearly following the Mercure Galant's description from June 1687: the coat and dress bodice are fastened with knots of ribbons. The gloves are glazed, the fan decorated with figures painted in gold and silver, is called a fan "à la siamoise". BnF Estampes. Res-QB-201(63)-Fol (p. 42), Cliché G156480 (Bibliothèque nationale de France, Paris). 
century, it seems to have been associated with cotton rather than a silk fabric. J. Savary des Bruslons, in his dictionary of trade and commerce in 1723, described this fabric as made of silk and cotton, noting that it had been seen for the first time in France when the Siamese ambassadors came to France.

In 1736, French royal manufactures in Normandy were still producing a striped or checked cotton fabric called "Siamoise", as a collection of fabric samples in the Bibliothèque Nationale in Paris reveals. This collection was put together to show the range of textiles made in France at the time, and here under Etoffes de Meslay feature three samples of striped cottonades ou siamoises (Fig. 18.5).

Obviously, the "Siamese" fabric was not an imported product and probably not even an imitation of an original fabric from Siam or China. Very sophisticated by the end of the 17th century, it became more common in the course of the 18th century.

Fig. 18.5: Etoffes de Meslay. Samples of cotton striped fabric in 1736, from a Book of samples collected for the Duke of Richelieu's collection (18th century). The fabric samples are of French textile manufacture from the 1730s. This page shows three fabric samples made of cotton fabric called "Siamoise". This striped cotton fabric was made in Normandy until the end of the 18th century. BNF EST: Lh-45-Fol, fol. 107-110 (Bibliothèque nationale de France, Paris).

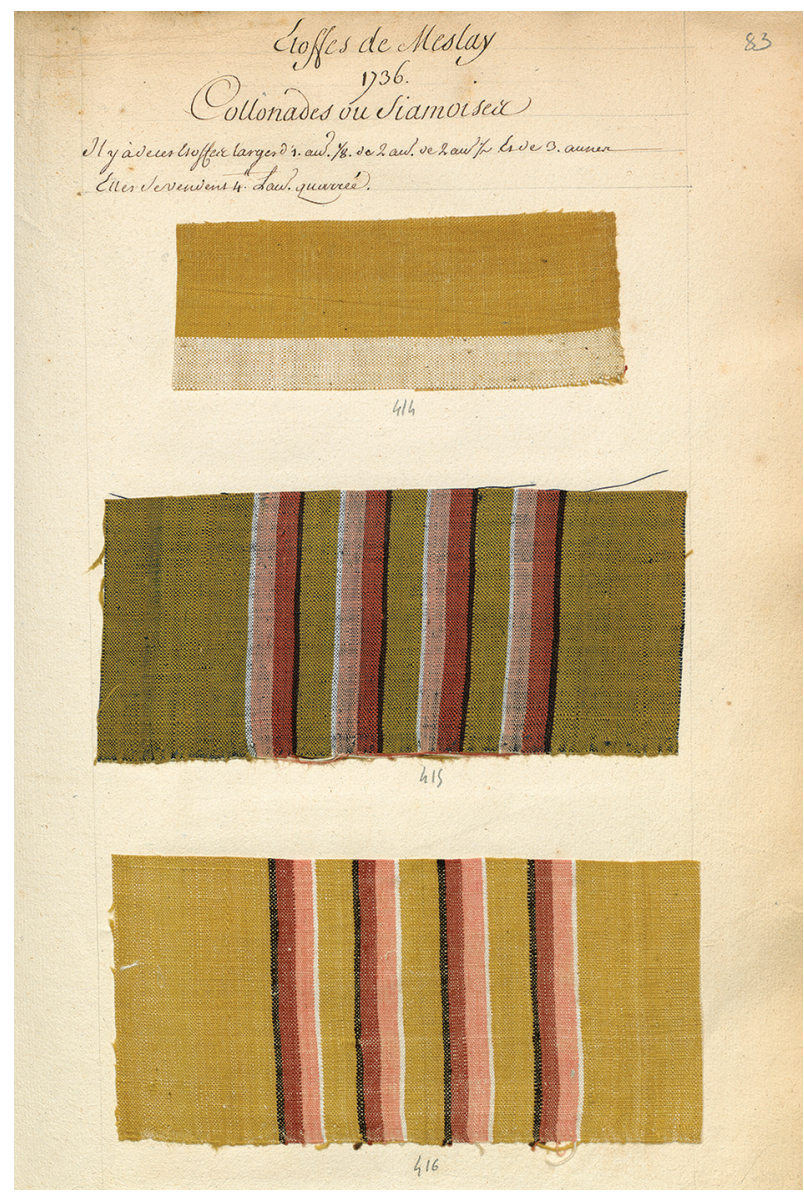




\section{Acknowledgements}

Dr Lesley E. Miller, Lead curator Europe 1600-1800, Senior curator (Textiles and Fashion before 1800), Furniture, Textiles and Fashion department, The Victoria and Albert Museum, London. Author photo by (c) Caroline Martin.

\section{Further Reading}

Margaret C. Jacob (2006) Strangers Nowhere in the World: The Rise of Cosmopolitism in Early Modern Europe. Michelle Jennifer Jones (2004) Sexing la mode: Gender, Fashion and Commercial Culture in Old Regime France.

Daniel Roche (1997) The culture of clothing: Dress and Fashion in the Ancien Régime. 


\title{
19 The Chinoiserie of the 17th to 18th-century Soho Tapestry Makers
}

\author{
METTE BRUUN
}

Mette Bruun holds a Master of Arts in Art History from the University of Copenhagen. She is specialized in medieval Islamic textiles and contemporary textiles. She wrote her MA thesis on technical textiles and their relation to smell and the body. She has a professional background as a teacher of textile crafts and has worked for many years as a teacher of design and art history. Since 2002, she has been a guest lecturer at the David Collection in Copenhagen - primarily in the Islamic collection. In 2009 she organized the conference Future Textiles - Technological and Intelligent Textiles and in 2011 the conference Spandex to Sportstech - Fashion and Innovation in Sportswear. She is a guest editor together with Michael Langkjaer of a theme issue devoted to sportswear in Fashion Practice: The Journal of Design, Creative Process and the Fashion Industry (Bloomsbury Publishing). Currently she works as administrator at the Danish National Research Foundation's Centre for

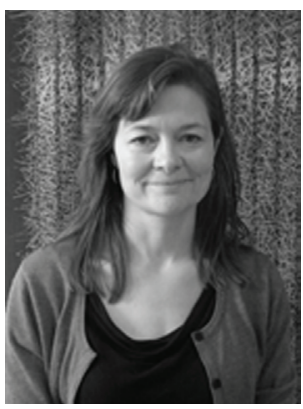
Textile Research.

Europe's great fascination of the East and the recurring craze for eastern products and arts have their roots in the Middle Ages. The eastern allure was greatly inspired by fabulous tales by explorers like Marco Polo's Books of the Marvels of the World (early 14th century), about his time in the service of the Mongol ruler, Kublai Khan in China, and heightened even further by later more or less fictionalized accounts like The Travels of Sir John Mandeville (c. 1371).

When actual mass commerce commenced in the 17th century, eastern products and knowledge were made accessible to a wider European population, and by the early 18th century, knowledge of the East, and especially China, was more firmly rooted within the well-educated European population than might be understood today (Porter 2010, 21). Through their East India companies, commerce was monopolized at first by Spain and Portugal but England and Holland set up their own companies during the 17th century along with other countries. Soon Chinese products became mass imports. In spite of this, Eastern products maintained their allure and fascination because of their exotic nature and the prestige they gave to the middle class owners.

To the general public, the whole area from Cape of Good Hope to Canton in China was called East India, Japan and India included. Accordingly, the artworks produced in Europe in oriental style were called "Indian", "Chinese" or "Japan". 
Imported Chinese wares like porcelain, silks and lacquer made a deep impression upon European artisans who sought to emulate the motifs of the exotic goods into their arts and crafts. Amongst these artisans were tapestry weavers.

The centre of European tapestry weaving in the 17th century was France, but it needs to be stated that, also in Soho in London and surrounding areas of England, high quality tapestries were made. Many of these had chinoiserie motifs, like mountainous landscapes, pagodas, tea drinking ceremonies, fabulous birds, mandarins, dragons and phoenixes.

Amongst the foremost weavers from Soho were John Vanderbank and Joshua Morris, both renowned for their tapestries in the chinoiserie style. An example of this is the Soho tapestry in the David Collection, in Copenhagen, Denmark (Fig. 19.1). A characteristic of the Soho tapestries is that they contain "oriental" motifs on small islands scattered over a dark background and that the motifs decrease in size from bottom to top, giving the illusion of depth. The motifs would be interchangeable to conform to the required size of the tapestry and taste of the future owner.

Edith A. Standen (1980) has named the group that the David Collection tapestry belongs to after its most prominent motif "The Tent". Under a large canopy on supporting beams in the middle of the tapestry "Indian" or "Chinese" figures relax on carpets. Other motifs include prominent figures and their servants, musicians and small houses. A smaller version of "The Tent" is known to exist but its location is unknown.

The Soho tapestry in the David Collection closely resembles a tapestry in The Art Institute of Chicago attributed to the workshop of John Vanderbank (Fig. 19.2). He was a Flemish weaver, born in Paris, who was appointed yeoman arras worker to the Great Wardrobe in London in 1689 to take care of the royal household's furnishing. The border of the David Collection piece is unusual compared to other Soho tapestries in that it contains several types of Chinese-looking porcelain. In comparison, the border on the tapestry from the Art Institute of Chicago has small flowers and branches.

The David Collection has dated their piece to c. 1730. Vanderbank died in 1717, but it seems likely that both tapestries were made by the same tapestry maker or in the same workshop. When Vanderbank died, it appears that his workshop was carried on by his wife and later his son Moses Vanderbank, but in 1749 the workshop closed down entirely.

The European artisans working in the chinoiserie style gathered their motifs from many sources - not all of them of Chinese origin. If they did not have access to genuine Chinese goods, they used pattern books with engraved models for chinoiserie that were very popular during the 17th century in European artistic circles, and other publications were often made by writers and illustrators who had not been to the East themselves. This is also evident in, for example motifs on Meissen porcelain or chinoiserie paintings of the period by Francois Boucher and other rococo artists.

A very popular source was Johan Nieuhof's illustrations of his travels in China, India and Brazil 1653-70 (Fig. 19.3). He was a Dutch traveller of the Dutch East India Company. Direct use of his illustrations is seen in some of the Soho tapestries. 


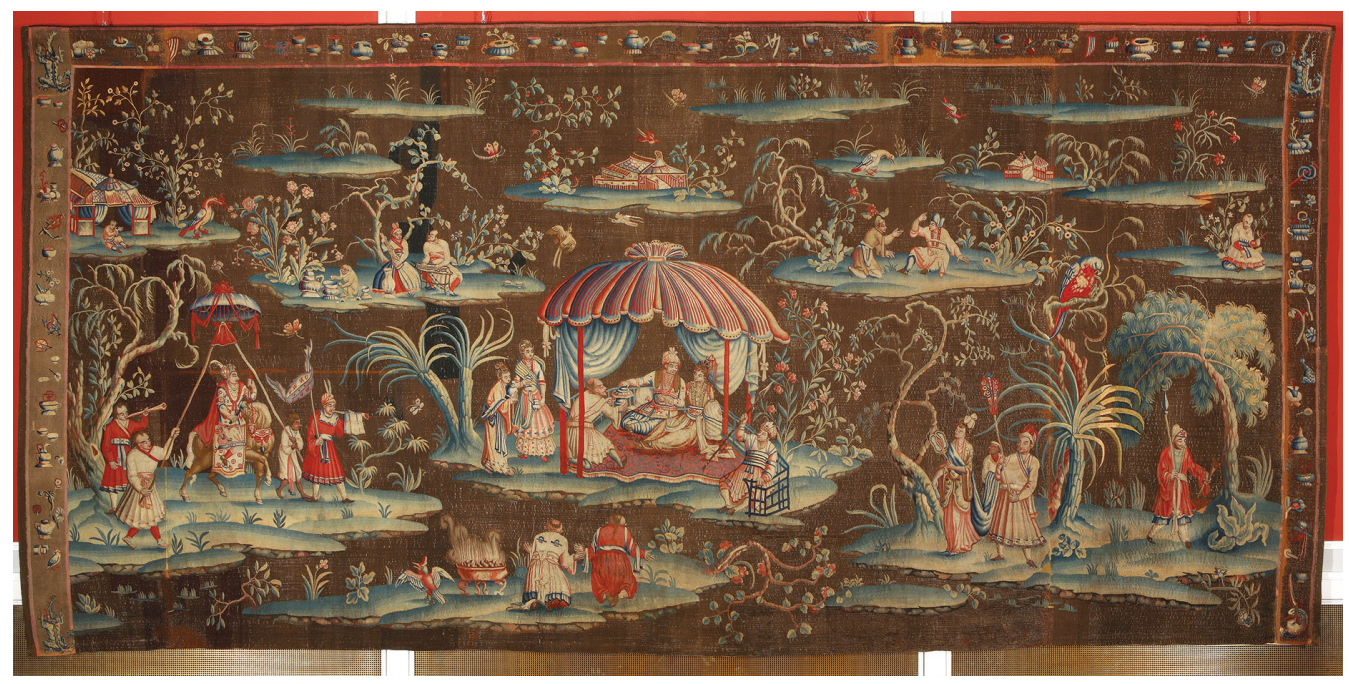

Fig. 19.1: Soho Tapestry, wool and silk, England, c. 1730, Inv. no. 18/1978 (David Collection, Copenhagen; (C) photo: Pernille Klemp).

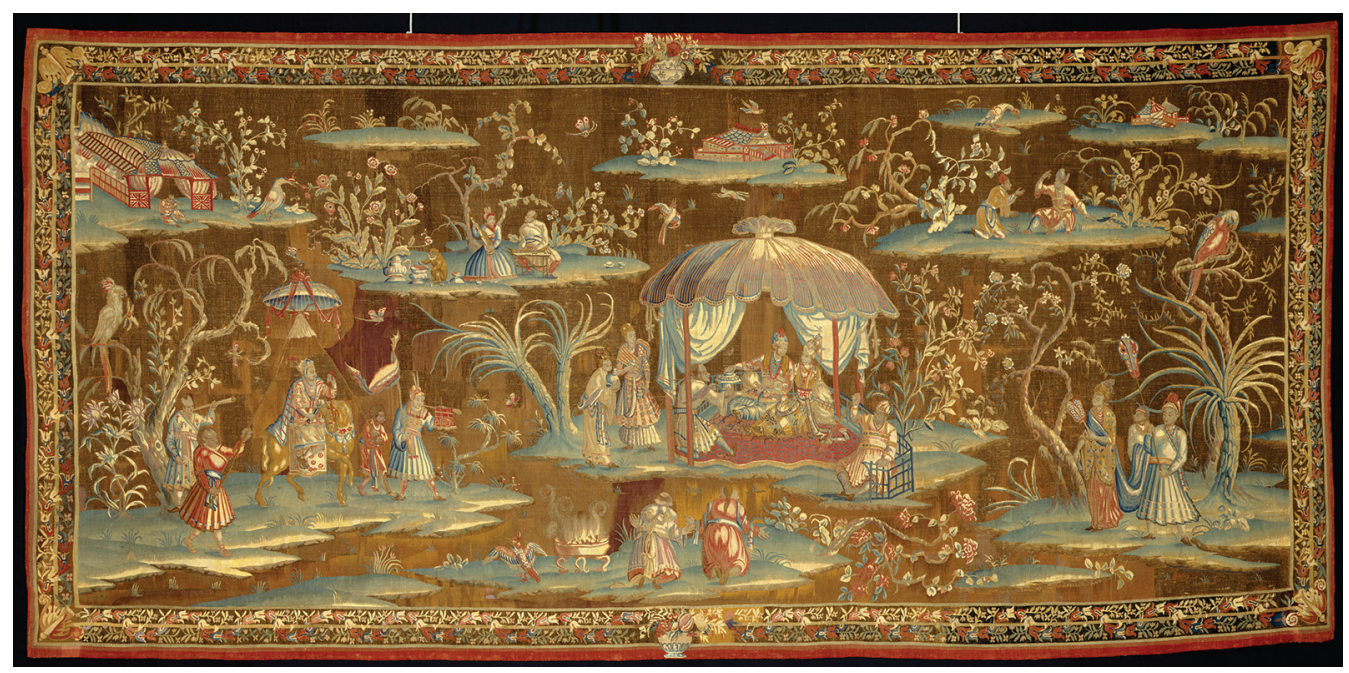

Fig. 19.2: Soho Tapestry, The Tent, from an Indo-Chinese or Indian Series, 1700/25, Woven at the workshop of John Vanderbank (d. 1717), Michael Mazaeind or Leonard Chabaneix (d. 1708/09) London, England. Wool and silk, slit and double interlocking tapestry weave $482.8 \times 230 \mathrm{~cm} / 1901 / 8 \times 901 / 2 \mathrm{in}$. (Purchased by the Decorative Arts Committee through the Richard T. Crane Jr. Memorial Fund for European Decorative Arts, 1949. 124. Photography (C) The Art Institute of Chicago).

The Soho Tapestries are said to be in the "Indian manner". A group of tapestries with oriental motives in "the Indian manner" from Soho was ordered for the Kensington Palace in the late 17th century (Edith A. Standen 1980, 119). The Soho tapestries draw their inspiration from Chinese lacquered screens in which one would also see individual motifs on a black background diminishing in size from bottom to 


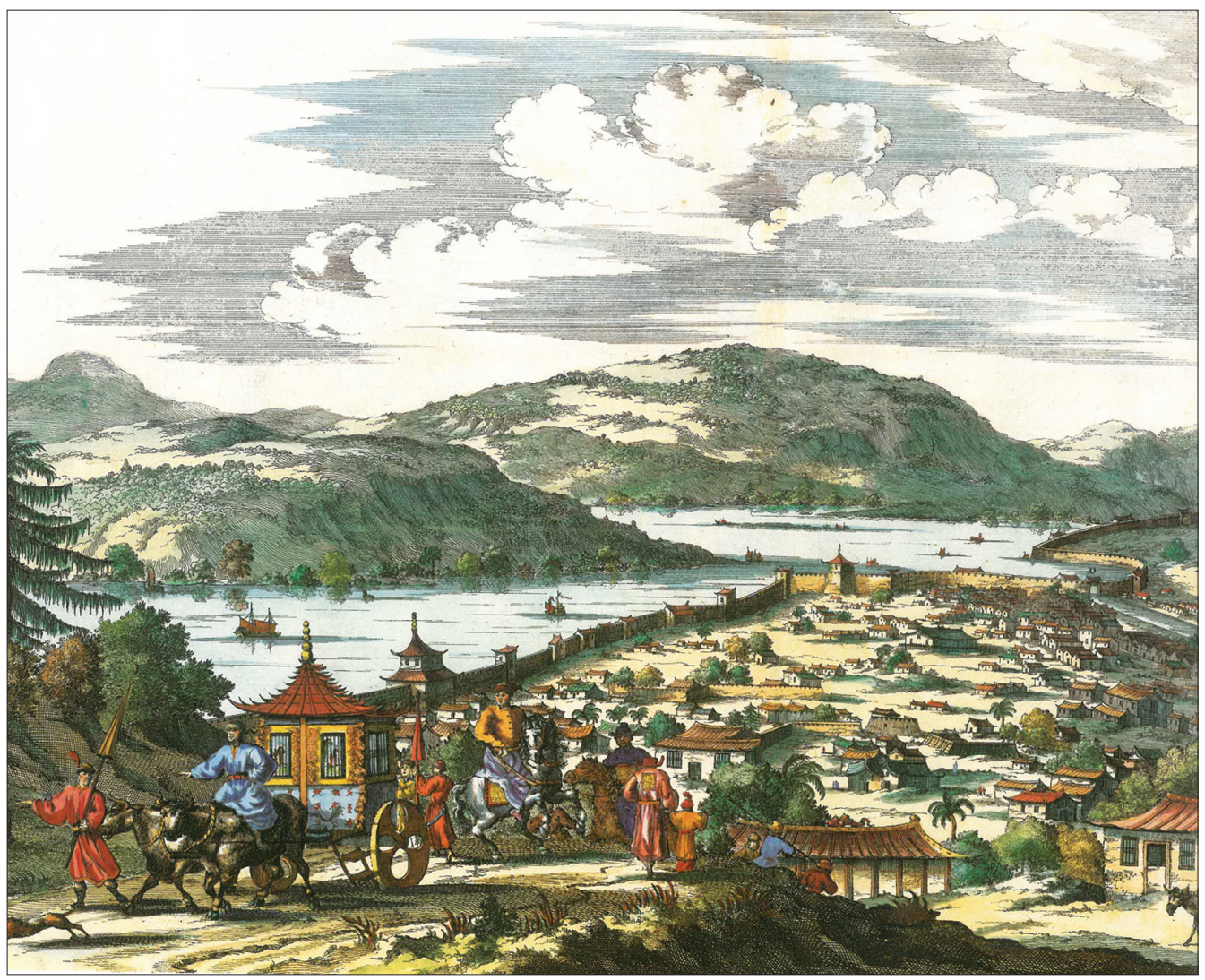

Fig. 19.3: Detail of Johan Nieuhoff's Embassy, carriage, 1665 (With kind permission from Archivio White Star; After Giani Guadalupi, China through the Eyes of the West, pp. 132-133; White Star, Milan 2004).

top. Chinese and Japanese lacquer was surrounded with great prestige, and already from the beginning of the 17th century, English craftsmen began to make their own "japanning" to accommodate the market for fashionable goods. (Fig. 19.4).

The "Chinese" motifs were often mixed with motifs of Indian, African or Native American origin together with decorative elements like Comedia del Arte costumes. Miniature paintings from India and Turkey, such as Figure 19.6, were also favourite contributors to the sources of motifs in the tapestries, which is perhaps most apparent in the depiction of musicians in the tapestries.

The ornamental style of the David Collection tapestry (see Fig. 19.1) is, like most European chinoiserie, a mixture of inspiration from Chinese, Indian and Japanese artwork. The dark background of the tapestry suited the baroque style perfectly as it corresponded to the dramatic appeal that was sought after at the time and the display of porcelain on the border corresponded to the mania for curiosity collections by the well-to-do all over Europe. Sir John Vanderbank is known for around 50 individual tapestries. The rather large productions must have been in response to the huge 


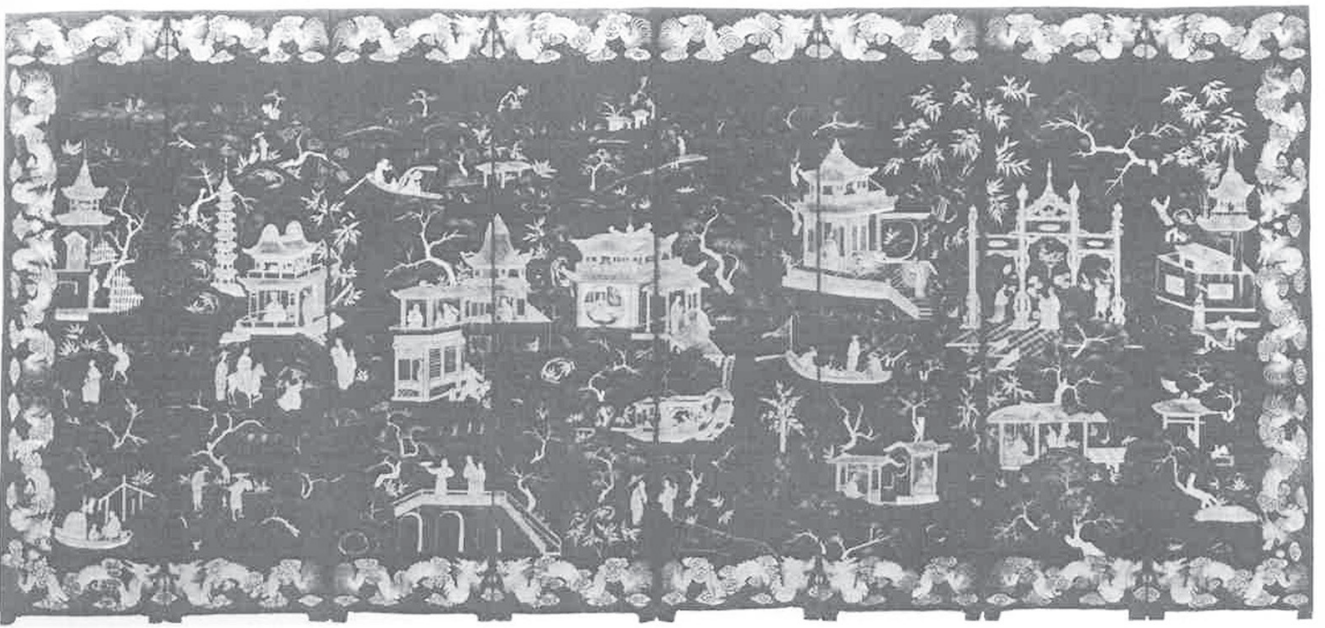

Fig. 19.4: Chinese lacquer screen, 18th century (With kind permission from Sotheby's; after Edith A. Standen 1980, p. 127, fig. 11).

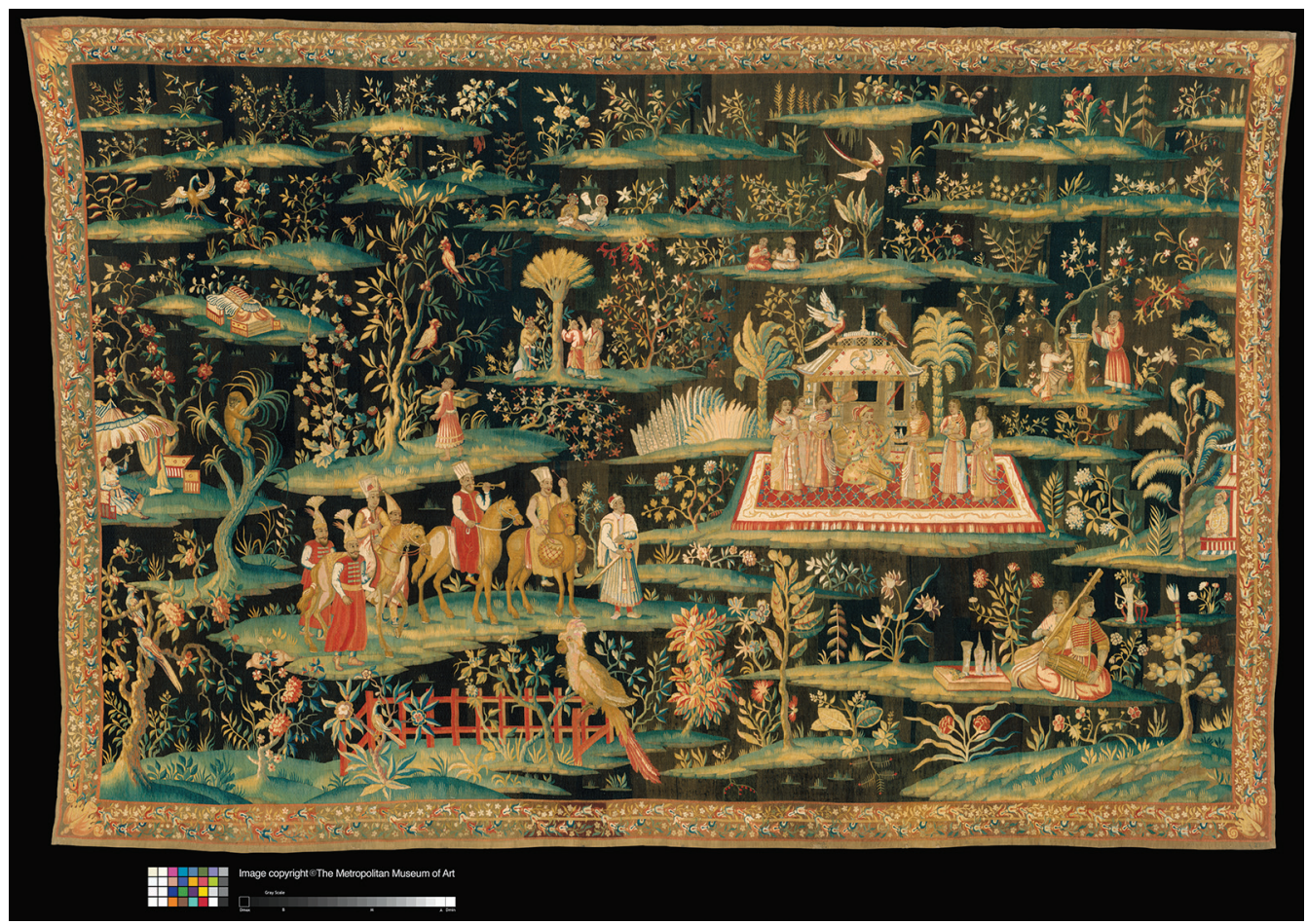

Fig. 19.5: The Toilet of the Princess. Attributed to John Vanderbank (active c. 1680-1717), Great Wardrobe tapestry Workshop, London, 1690-1715, Tapestry Weave, wool and silk, $305 \times 391 \mathrm{~cm} / 10 \mathrm{ft}$ × $12 \mathrm{ft}$. 10. The Metropolitan Museum of Art, New York, gift of Mrs George F. Baker, 1953 53.165.1 (Image (C) The Metropolitan Museum of Art). 


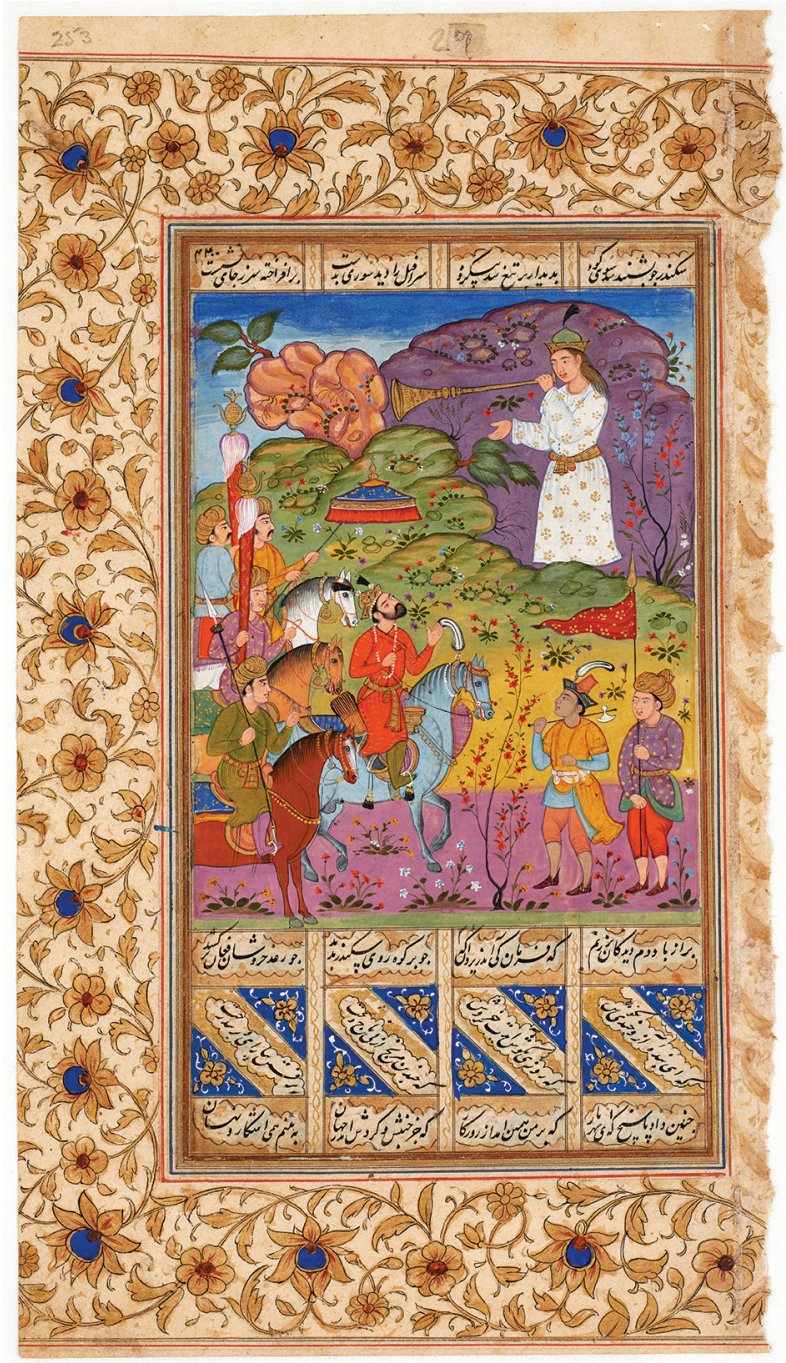

Fig. 19.6: Miniature painting, India, from a copy of Firdawsi's Shah-nama "Iskandar Sees the Angel Israfil," India; 1600-1610, Inv. no. 1a/1977 (David Collection, Copenhagen; photo: () Pernille Klemp).

demand for both wall hangings and decorative items in the "Indian manner". As the rococo style developed further, lighter colours took over and wall hangings were gradually replaced by wallpaper.

\section{Further Reading}

David Porter (2010) The Chinese Taste in Eighteenth-Century England.

Edith A. Standen (1980) English Tapestries "After the Indian Manner". Metropolitan Museum Journal 15, pp. 119-142.

Oliver Impey (1977) Chinoiserie. The Impact of Oritental Styles on Western Art and Decoration. 


\title{
20 Exoticism in Fashion: From British North America to the United States
}

\author{
MADELYN SHAW
}

Madelyn Shaw is an independent curator specializing in the exploration of American history and culture through textiles and dress. She has held curatorial and administrative positions at the New Bedford Whaling Museum; The Museum of Art Rhode Island School of Design (RISD); The Textile Museum (Washington, DC) and the Museum at the Fashion Institute of Technology (New York). Recent publications include, Silk in Georgia, 1732-1840: Sericulture to Status Symbol, in Proceedings of the Third Biennial Henry D. Greene Symposium (2008), and H. R. Mallinson \& Company, in American Silk: Entrepreneurs \& Artifacts, 1830-1930 (2007), winner of the Millia Davenport Award. She recently completed a Civil War sesquicentennial book and travelling exhibition project titled: Homefront \& Battlefield: Quilts \& Context in the American Civil War for the American Textile History Museum, Lowell, Massachusetts. Readers of this chapter will also find her following work pertinent: Carolyn Schnurer, Contemporary Fashion (2002, available at http://www.encyclopedia.com).

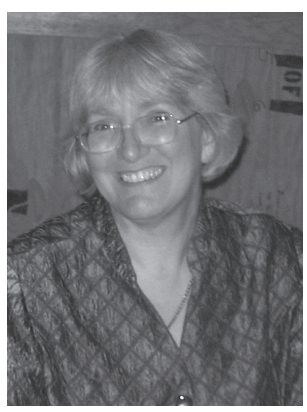

Exoticism as it applies to fashion can be defined as viewing "the other" in a romantic light, resulting in mining other cultures for styles, motifs, techniques, silhouettes, colors, patterns - all the elements of design - in order to create a marketable design novelty. This is not a new or even recent phenomenon. Every cross-cultural contact since human history began has transferred designs, techniques, and styles between or among the cultures involved. Cultural borrowing usually begins with direct contact between cultures, such as commerce or conquest. The borrowing can be as simple as adopting novel motifs or patterns for surface design, or a particular silhouette or cut of a garment, or a distinctive technique. Current events in a distant locality, or its landscapes, streetscapes, plants and animals can also act as a spur to the romantic imagination. We must not assume, however, that only in the west is the exotic "foreign" appropriated. The taste for the romance of exoticism has inspired cultures around the world with an appreciation for the beauty, creativity, and techniques of the original inspirations. Novelty is a global desire, and the lure of exoticism is felt in many cultures.

Although colonists in British North America were themselves inhabiting a new frontier, it did not evoke a romantic exoticism, but a life of hard work and often of danger. Colonists therefore looked to Asia - the unfamiliar East, just as 
Europeans did, for fashionably exotic goods. When the Dutch and British East India companies established trading posts in India in the early 17th century, one of the first commodities they traded for was the colorful, washable, cotton fabric known to Europeans as chintz, calico, indiennes, or pintado (hand-painted or block-printed). In 1677, for example, the cargo of the ship Ruth, heading for Maryland from London, was seized for non-payment of the hire of the ship and seamen's wages. In addition to yardage of osnabrig, fustian, jeans, dowlas, serge, and broadcloth packed in bales and trunks, there was a listing for 19 painted calico gowns - not ready-made clothing, but lengths of patterned India-export cottons suitable for women's apparel (Merritt 1956, 33-36). An inventory of a New York shop kept by Margreta van Varick, taken in 1696, included yardage of plain, flowered, and striped calico (Van Varick 1962: 1-6; 1-13). By the 1730s, merchants were selling a wide variety of fabrics imported from India and China, such as the exotic sounding "Carridaries [cherryderries], ... Cherconna [Cherconall] Romalls, Bandannoes, Silk Lungee Romalls, Persians and China Taffaties" offered by Philadelphia shop owner Robert Strettell according to the Pennsylvania Gazette, May 25, 1738.

Also mentioned in the advertisement were the brightly coloured and patterned silk squares imported from India for use as neckerchiefs and pocket handkerchiefs. Originally patterned by the tie-dye process known in India as bandhani (tie-dyeing woven cloth rather than tie-dyeing yarns before they are woven, commonly called by its Indonesian name, ikat), they became known in England and America in the 18th century as bandannas. Between 1778 and 1782, during the American Revolutionary War, Abigail Adams of Quincy, Massachusetts, asked her husband John (then a diplomat in France, and later the second President of the U.S.) to send goods she could resell for much needed cash, including India silk handkerchiefs and "bengalls... persian Silk, and Bandana handkerchiefs" from India (Butterfield et al. 1975, 216-331). Over time, the Indian merchants also offered block-printed bandannas with designs and colors geared to Western tastes, and by the late 18th century, such goods were also being imitated by English manufacturers.

Eighteenth century male colonists also followed their European cousins in appropriating the banyan, a term that to 17th- and 18th-century Europeans meant a simply cut and loose-fitting long robe or dressing-gown modeled on a style worn in India - and perhaps originally based on the Japanese kimono. East India Company agents in India adopted the banyan during the hottest weather in place of the formal waistcoat and coat combination fashionable in Europe. Even the word banyan was borrowed to describe the garment: originally banyan (sometimes spelled banian or banjan) was the name by which Indian tradesmen, who wore such a robe, were known. Made originally of thin silks and printed cottons, banyans in the west were sometimes stitched of more costly silk damasks. The style was very popular in Colonial America; New Englanders wore banyans of silk or wool, while for southern gentlemen, who faced long, hot, humid summers, the original Indian (or imitation Indian) cottons remained popular. Several wealthy merchants in Boston, Massachusetts in the mid18th century had their portraits painted by John Singleton Copley wearing luxurious 
banyans of expensive silk damasks, including the brothers Nicholas and Thomas Boylston. Such informal apparel for formal portraits speaks to their solid positions in society, and the degree of sophistication they wished to project. More conservative attire characterized those who felt less secure (Fig. 20.1).

In the 18th century, Orientalism was a common design theme in many European arts, including fashion and textiles. Sometimes it embraced one culture: designs by French artist Jean-Baptiste Pillement (1728-1808), for example, included pagodas and figures in Chinese dress. A book of his designs, A New Book of Chinese Ornaments, was published in England in 1755, and many copperplate printed cottons and woven silks can be found with Pillement-inspired chinoiserie patterns. Between 1774 and 1811, all cotton fabrics woven specifically for export were marked by using blue warp threads in the selvage. These threads can be found in several extant chinoiserie design textiles, indicating that such patterns were sold on the American market (Fig. 20.2).

Although North Americans had been importing exotic Asian goods via England before the American Revolution, only after the war ended were American merchants freed from Britain's restrictive Navigation Acts. Almost immediately, they joined in trade to the Levant, India, and the Far East. New England ships brought back many kinds of silk goods from China and India after the Revolution and throughout the 19th century. Silks in the "Chinese taste" were popular in the 18th century when both European silks with chinoiserie designs and painted silks from China ornamented the

Fig. 20.1: Nicholas Boylston (1716-1771), 1767, Boston, Massachusetts. By artist, John Singleton Copley, 1738-1815 (American) Oil on canvas; $127.3 \times 101.1 \mathrm{~cm}$ (50 1/8 × 39 13/16 in.) framed: $145.4 \times 120$ $\times 10.2 \mathrm{~cm}(571 / 4 \times 471 / 4 \times 4$ in. $)$ Harvard Art Museums/Fogg Museum, Harvard University Portrait Collection, Bequest of Ward Nicholas Boylston to Harvard College, 1828, H90. Adopted from India, the banyan was a common informal garment in the wardrobes of colonial American men. Few had the means to combine exoticism with luxury, however, as in the costly silk damask banyans worn by wealthy Boston merchant Nicholas Boylston and his brother Thomas in their portraits by John Singleton Copley (Photo: Imaging Department (c) President and Fellows of Harvard College).

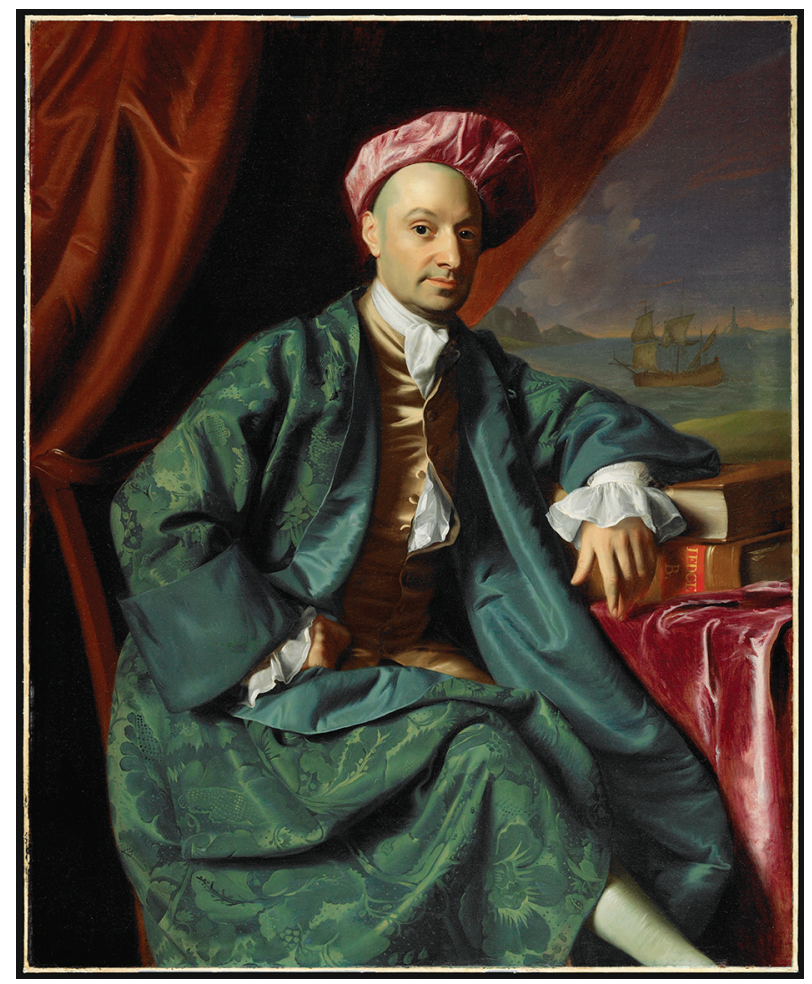




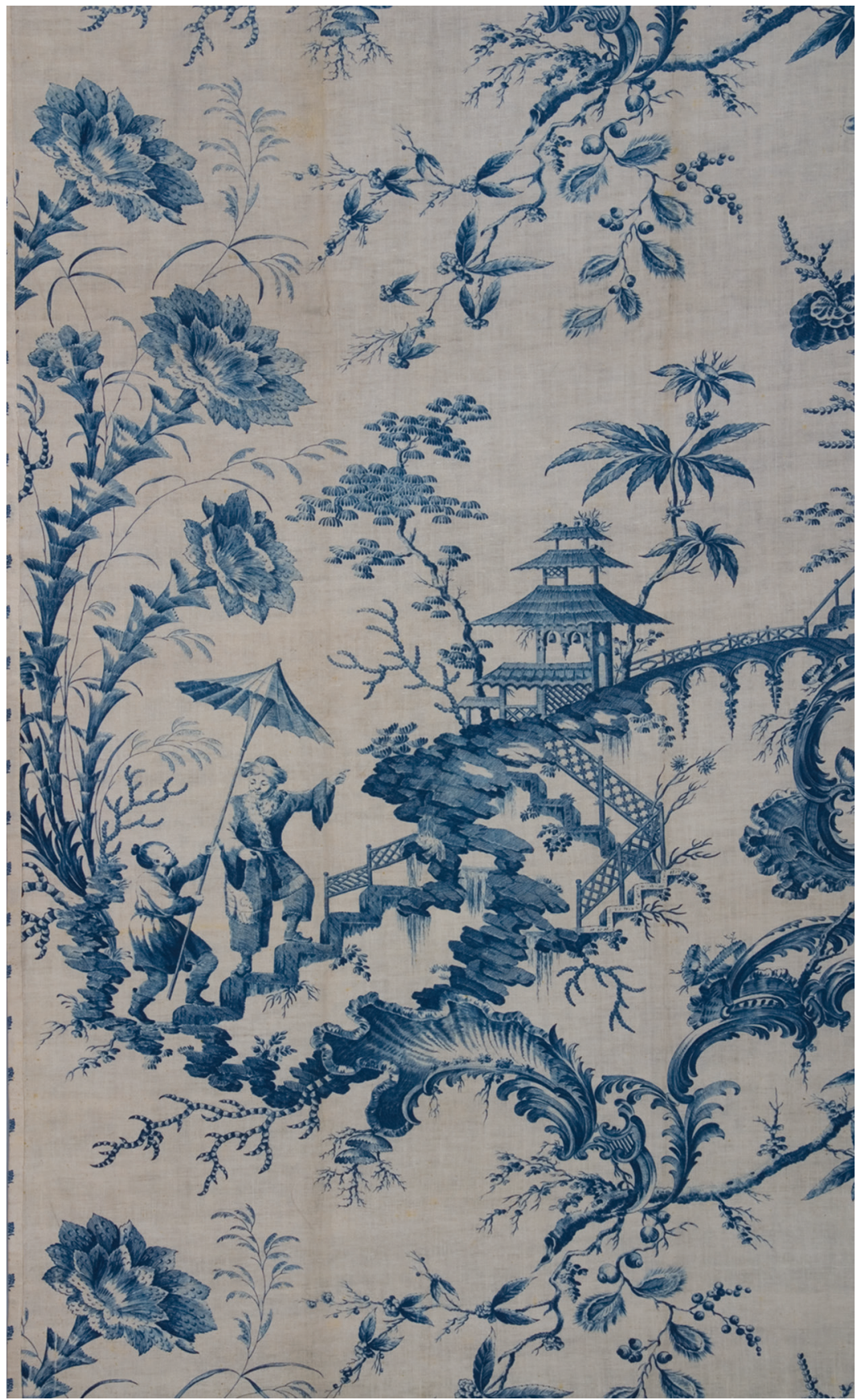

Fig. 20.2: Chinoiserie curtain panel (detail), c. 1765-1811, English for the American market. Bromley Hall, England, printer. Cotton; plain weave, copperplate printed. Chinese blue and white porcelain imported into Europe inspired a fashion for that coloration in other mediums, including textiles. Chinoiserie designs were produced in France throughout the 18th century, most famously by French artist Jean-Baptiste Pillement (1728-1808) (Courtesy of Cora Ginsburg, LLC, New York). 
homes of the wealthy. Shipping lists and account books record fans, shawls, stockings, handkerchiefs, and painted window shades among the silk goods imported from China in the first half of the 19th century. Silk damask dresses and waistcoats with decidedly Chinese patterns - auspicious symbols, dragons, peonies, for example - can be found in many New England museums (Fig. 20.3). These damasks were not imported in large quantities by merchants, instead they were most likely carried home one or two at a time by individual sailors as part of their 'private adventures' or allotment of space on board ship. The ship's captain, for example, might have four metric tons to bring home his own cargo of teas, silks and nankeens, while the cabin boy might have four square feet, into which he fit perhaps a tea set and a piece of silk for his mother. The survival of these goods is perhaps equally due to their exotic patterning and their emotional significance as a gift from a loved-one (Hartt, unpublished papers).

The taste for things "Oriental" continued through the 19th century and into the 20th. Publications such as August Racinet's Le costume historique - published between 1876-1888, and English architect and designer Owen Jones's 1856 publication, The Grammar of Ornament, encouraged familiarity with non-western traditions and design. No home with pretensions to gentility was without its "oriental" corner in the late 19th century. "Oriental corners" became fashionable in interior decoration. Furniture, prints, decorative objects, and silk textiles or garments from Eastern locales - China, Persia, or Turkey, for instance - established the aesthetic sense and genteel good taste

Fig. 20.3: Waistcoat, c. 1845, Americanmade of Chinese silk. Silk; figured satin damask weave. Nothing is known of the original wearer of this waistcoat, which descended in a family with China trade connections. Silk damasks with Chinese designs were usually brought back as gifts, not as cargo. Chinese-made silks imported for fashionable dress followed European styles in motif and color. Gift in memory of $\mathrm{Mr}$ and Mrs W. Frederick Williams, Jr. by their children 75.026.16 (Photo: Erik Gould; Courtesy of the Museum of Art, Rhode Island School of Design, Providence).

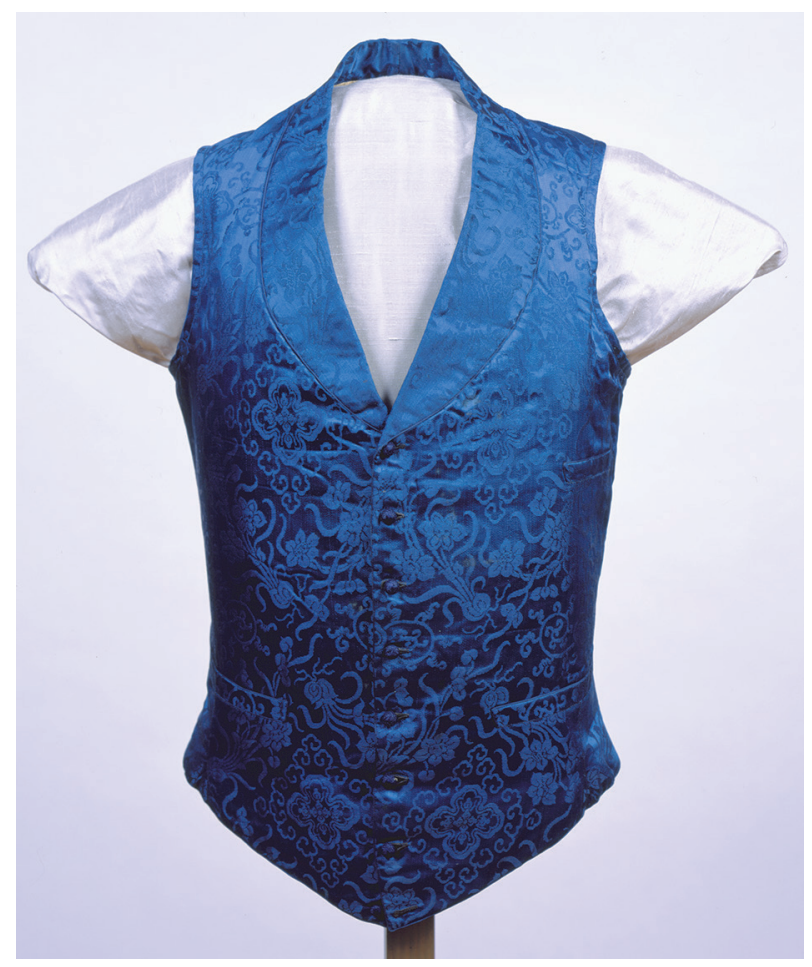


of the owner. These objects may also have implied wealth and the means to travel. In the late 19th century, most of the raw silk used in the expanding American silk industry's mills (such as Cheney Brothers of South Manchester, Connecticut) came from Japan. Representatives of the Connecticut mills often made long journeys to Japan, returning laden with presents of fans, vases, and kimonos. A "Japanese Corner", painted by John Haberle in New Haven, Connecticut, in 1898, may well have been the result of just such a trip that combined silk industry business with the pleasure of shopping for exotic souvenirs (Fig. 20.4).

Chinese robes and Japanese kimonos, first brought home by mariners as souvenirs and in the later 19th century imported in bulk, became popular for negligee wear among the avant-garde. In the early 20th century, the use of exotic costume by upper middle class women took on a different meaning: a personal exoticism and disregard of social norms. American women found these loose-fitting Eastern garments a comfortable contrast to the stiff corsets and layers of clothing to which they were confined by fashion. Adapted both for and by the western market, the word kimono became almost a synonym for dressing gown in the early 20th century, and even when they were made by western dressmakers and manufacturers, they often retained a hint of their exotic origins. The American Textile History Museum, in Lowell, Massachusetts, for example, has in its collections a woman's wrapper or kimono of thin plain weave silk printed with a design of Japanese lanterns and fans (Fig. 20.5). China also made embroidered silk crepe shawls specifically for the western market. Imported by the thousands, they were worn as exotic evening wraps even by middle class women.

Current events in some far off locality can act as a spur to the romantic imagination. Perhaps the most famous of these is the fevered desire of westerners for anything at all that was ornamented with designs from Pharaonic Egypt after the discovery and opening of the tomb of the 18th-dynasty pharaoh Tutankhamen between November 1922 and February 1923. Reports of this ancient tomb with its golden treasures thrilled people around the world, inspiring a fad known as Tutmania, and textiles with hieroglyphs and images from tomb paintings or temple carvings were produced by dozens of western manufacturers for use in interior decoration and for clothing. One American silk manufacturer, H. R. Mallinson, was on vacation in Egypt when the tomb was opened. He cabled home an enthusiastic description of its riches, published later in the New York Times. By February 19th, 1923 (only three days after Howard Carter opened the tomb's inner chamber) the company's New York showroom windows on Fifth Avenue were displaying the firm's new "Karnavar" line (playing on the names of Lord Carnarvon and the Temple of Karnak in Luxor, across the Nile from the Valley of the Kings). Window shoppers could view artifacts and photographs from the Valley of the Kings, the finished printed silk dress fabrics, and photographs of dresses by American garment manufacturers who were using the line for their Spring collections (Fig. 20.6).

Even before the beginning of the First World War, when they were to some degree cut off from European design, Americans began to look for the exotic in their own hemisphere. Designers and manufacturers began to look at the North and 


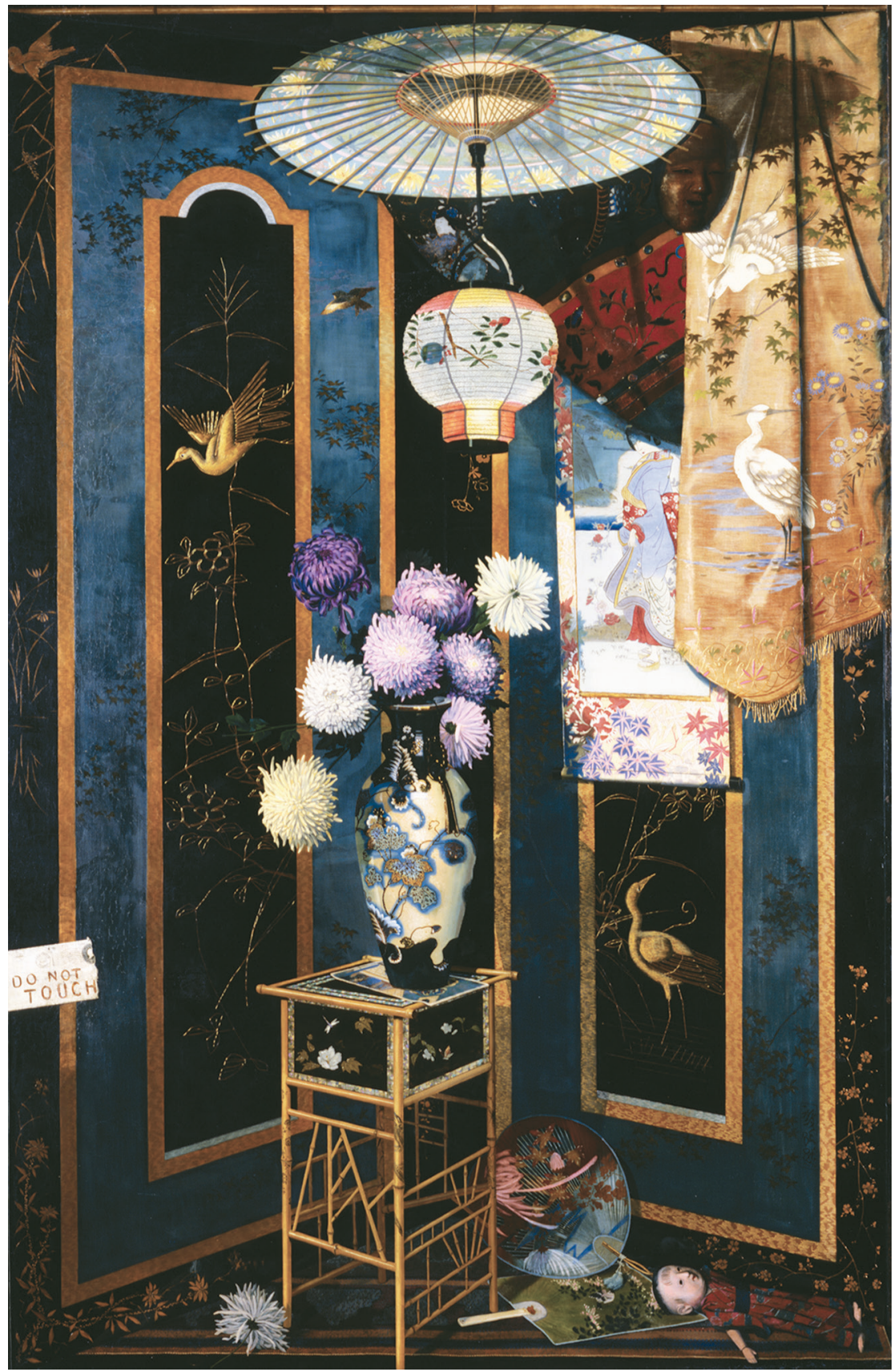

Fig. 20.4: Japanese Corner by John Haberle, 1898. Oil on canvas, 86.01. England's Aesthetic Movement, in the mid-to-late 19th century, inspired "Oriental Corners" in many homes. These assemblages of furniture, prints, decorative objects, and silk textiles or garments from exotic locales such as China, Turkey or Persia were encouraged by shops such as Liberty's of London, Vantine's in Boston, and the Japanese retailer Takashimaya (Michele and Donald D'Amour Museum of Fine Arts, Springfield, Massachusetts. Gift of Mr and Mrs Chauncey Steiger. Photography by David Stansbury). 


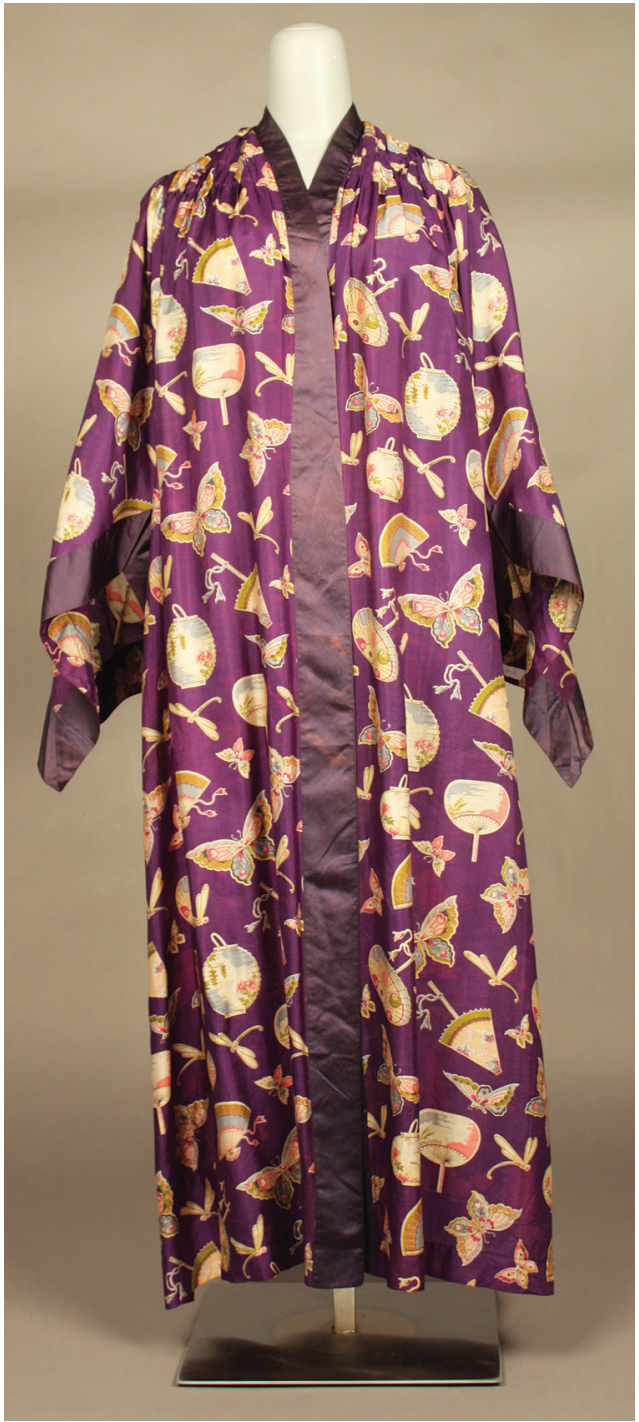

Fig. 20.5: Woman's dressing gown, c. 1910. American. Silk; plain weave, cylinder-printed. Loose-fitting dressing gowns or wrappers were often called kimonos in late 19th- and early 20th-century America. The printed design of Japanese lanterns and fans strengthens this wrapper's associations with the Far East, however, the fabric was probably woven and printed in an American mill. Chinoiserie and Japonisme designs were fashionable throughout this period. 2000.130.17 (Courtesy of the American Textile History Museum, Lowell, Massachusetts).
South American past for inspiration. They researched museum collections at the Newark Museum (New Jersey), the Brooklyn Museum, The Metropolitan Museum of Art, and the American Museum of Natural History (New York), making new textiles and fashions based on American Indian pottery, masks, beadwork, and weavings or on the styles worn by the native peoples of Mexico and Guatemala. In early 1914, for example, the firm headed by H. R. Mallinson (then called M. C. Migel \& Co.) introduced the Mexixe line. This print series took advantage of Mexico's prominence in the news with the American war against Pancho Villa. The designs were based on Aztec, Mexican and American Indian art, and although influenced by European modernism, particularly in the coloration, the underlying theme was an American original. The fabrics were used by Paris couturiers, endorsing this upstart American attempt at creative, original design. This critical and sales success for the company was a notable first for the American fashion industry. For the next 20 years, the Mallinson company remained in the forefront of inventive design in America based on inspiration from exotic locales and events.

Several technological changes in the 20th century put distant locales and the inspiration they provided within reach. First, transportation became faster and cheaper due to steamships and commercial airliners. Hawaii, for example, became more accessible via steamship and the Pacific air routes in the 1930s, and as a side effect, the Pacific Islands and Southeast Asia, especially 
Fig. 20.6: Advertisement, Karnavar series silks, 1923. American. H. R. Mallinson \& Co., Inc. American Silk Journal, February, 1923, p. 47. Pharaonic Egypt had been a source of exotic inspiration even before Napoleon's brief conquest of the country in 1798-1799. But nothing excited American imaginations like the discovery of the golden tomb of Tutankhamen in the winter of 1922-23. "Tutmania" inspired many products, but the first to be shown in New York was this line of printed silks (Courtesy of the Fleet Library at Rhode Island School of Design).

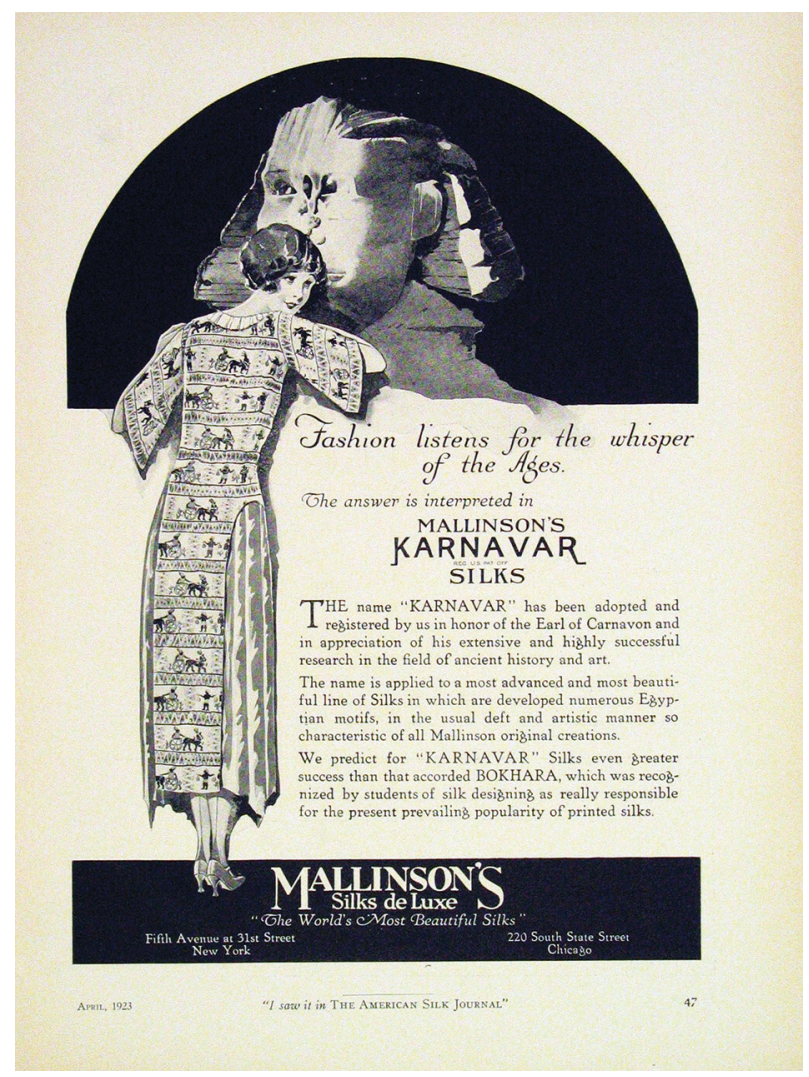

the Philippines and Indonesia, entered the western consciousness. The motion picture transported viewers who could not afford to travel. Finally, World's Fairs and Expositions held from the 1910s through the 1930s (such as the Panama Pacific Exhibition, San Francisco, USA, 1915; British Empire Exhibition, Wembley, UK, 1924; French Colonial Exhibition, Paris, France, 1931) also attracted large crowds and contributed to making even middle and working class westerners more aware of exotic cultures, and more interested in their arts and crafts. This was reinforced in the United States after World War II due to the huge numbers of servicemen and women who served abroad, especially in the Pacific, during the war.

One of the best traveled and most consistent users of exotic inspiration in her own design work was Carolyn Schnurer, who designed not only garments but also textiles for the fashion house run by her husband, Bert Schnurer, between 1940 and the late 1950s. Her collections included such ideas as a "cholo" coat derived from Andean dress in 1944, and both textile and apparel designs from India, Africa, Japan, Turkey, and even the Arctic regions of Norway. Her work appeared often in the magazine American Fabrics from the late 1940s into the 1950s - the magazine's editors saw her as a welcome antidote to a lack of innovation in the American fashion industry (Figs 20.7 and 20.8). 
Almost every season, the western taste for the exotic is displayed in the collections of fashion's top designers, Americans among them. Ralph Rucci, for example, designed an evening dress in 2003 with a large-scale pattern inspired by a Japanese painting of carp, while in 2004-05 Oscar de la Renta used traditional ikat-dyed silk textiles from Uzbekistan in his collection. In turn, American fashion icons, T-shirts and blue jeans, for example, have been adopted across the globe [see chapter 31 by Pogner in this book] - perhaps originally also seen as exotic. The human desire for novelty has fueled commerce and fashion for thousands of years, and shows no sign of coming to an end.

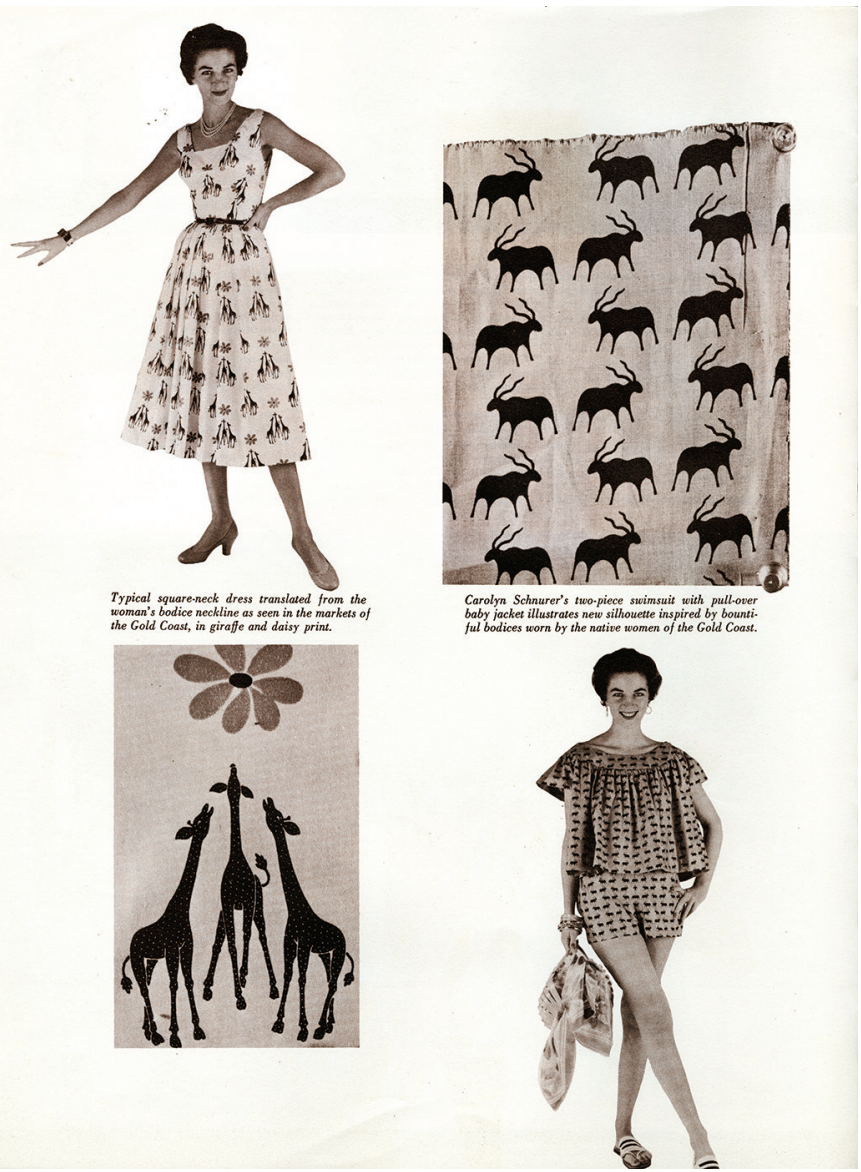

Fig. 20.7: "Carolyn Schnurer's African Trip", American Fabrics Magazine (later American Fabrics and Fashions) 1946-c. 1982, No. 24, 1952-53, pp. 35-52, Illustrations, swatches. Carolyn Schnurer was one of several American fashion designers who used the new freedom of air travel to bring design from around the world back to the American market. Refreshed by her contacts with other cultures, she created textile designs and garments that brought an exotic flavor even to everyday wear (Courtesy of the Osborne Library, American Textile History Museum). 


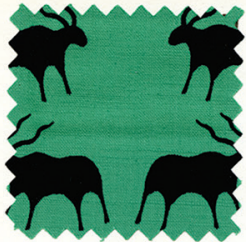

A band-box cotton with neverending charm. A Kudu (Afri-

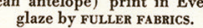
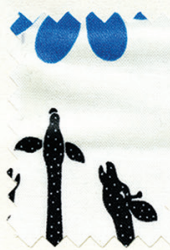

A well balanced giraffe print with distinctive character. From the collection of Buty. Chyne Everglaze cottons by ARTHUR BEIR \& $\mathrm{CO}$.

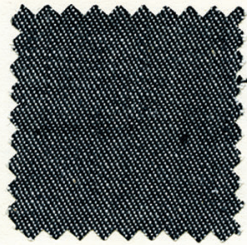

IRwIN's Everglaze Funwear, fashion-conscious denim in comfortable weight suitable year-round wear.

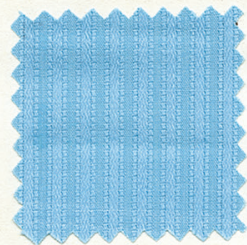

A lustrous self-stripe woven for interesting surface con trast. A J. P. STEVENS cotton
with all the inherent Everglaze qualities.
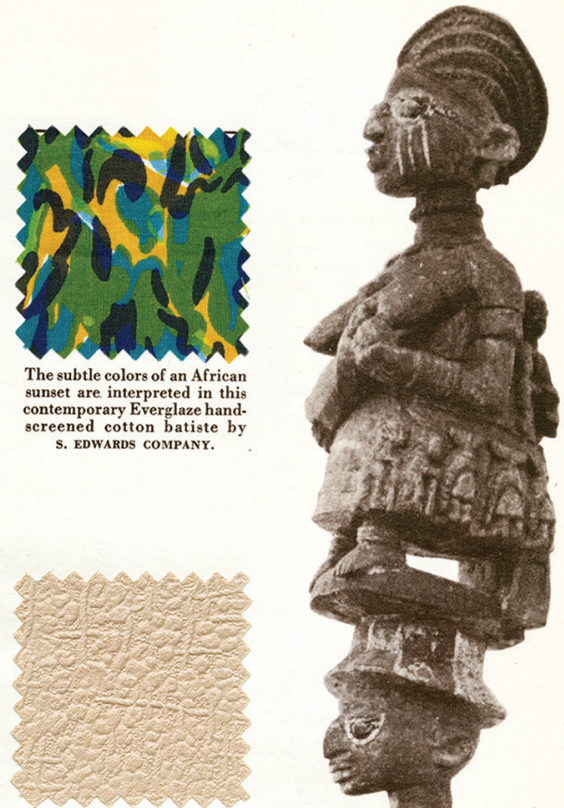

An imported pattern design is transferred into a carved satin with the shimmer and texture of matelassé. A Soap' 'n' $W$ ater Everglaze fabric by CROwN.
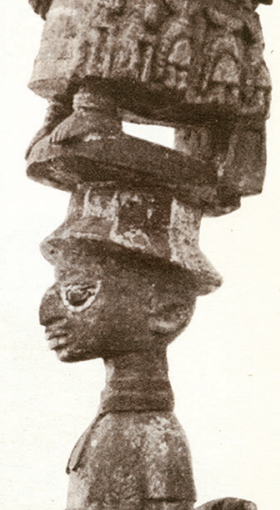
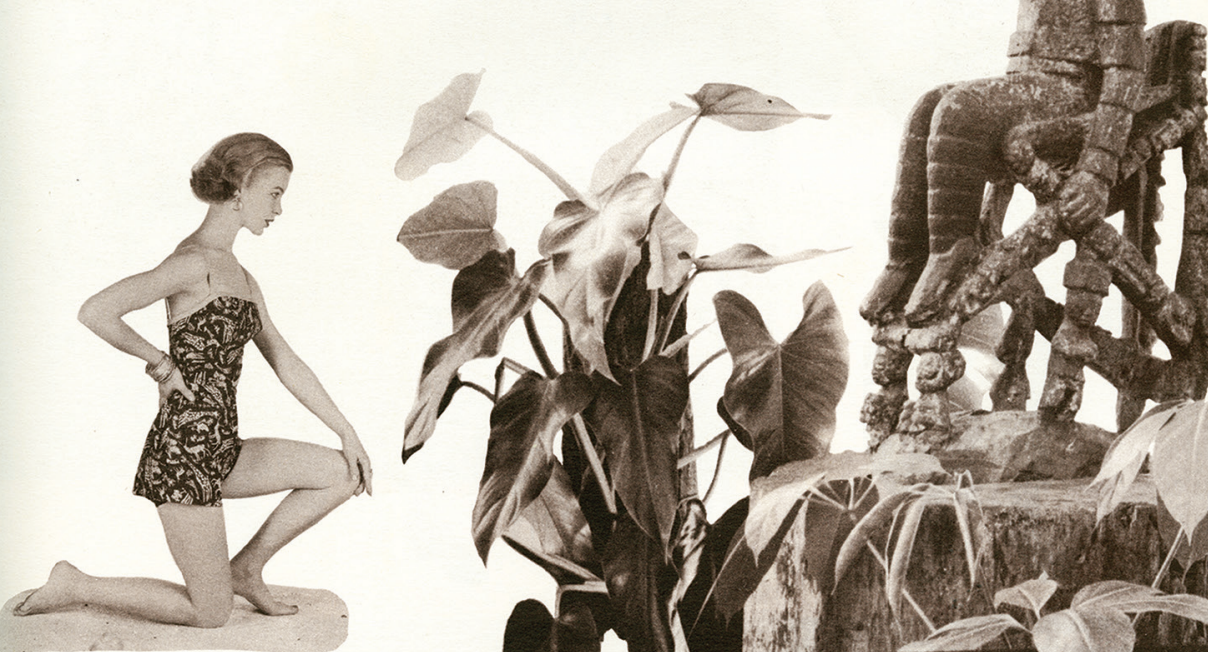

Print swimsuit inspired by a group of primi. tive wood carvings seen on the Gold Coast in Mam Pong in Akwapim.

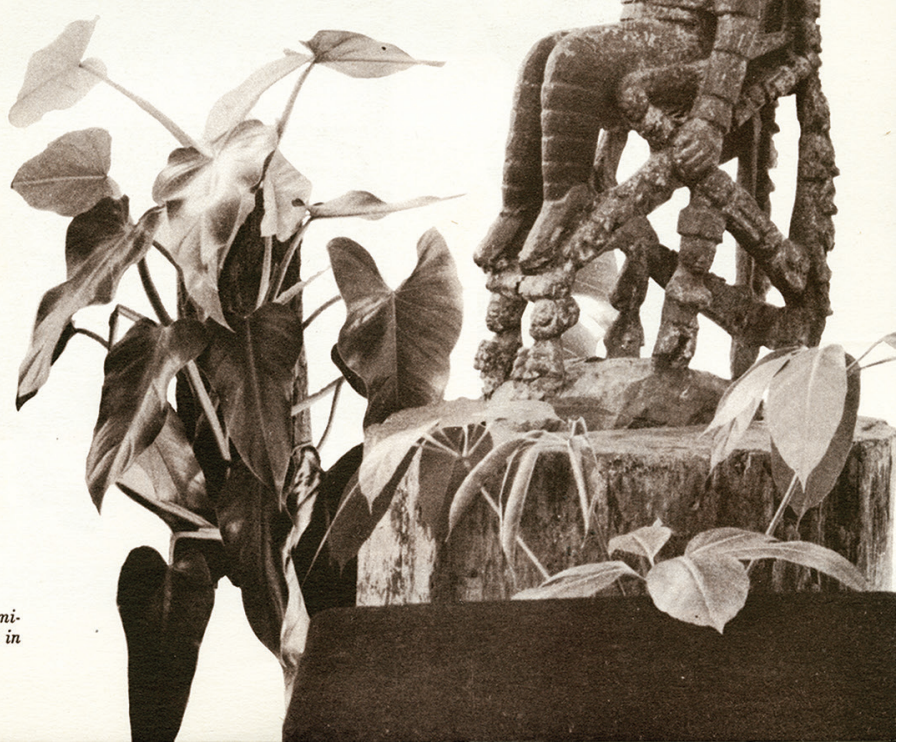

Fig. 20.8: Another image from "Carolyn Schnurer's African Trip", American Fabrics Magazine (later American Fabrics and Fashions) 1946-c. 1982, No. 24, 1952-53, pp. 35-52, Illustrations, swatches, p. 47. (Courtesy of the Osborne Library, American Textile History Museum). 


\section{Further Reading}

L. H. Butterfield, Marc Friedlaender and Mary-Jo Kline eds (1975) The Book of Abigail and John: Selected Letters of the Adams Family, 1762-1784.

Mattiebelle Gittinger (1982) Master Dyers to the World: Technique and Trade in Early Indian Dyed Cotton Textiles.

John Hartt (unpublished) Estimates of the Annual Exports from China to the U.S., 1815-16 to 1829-21. Brown Family Business Papers, Box 167, Folder 5. John Carter Brown Library, Brown University, Providence, RI.

Leanna Lee-Whitman (1982) The Silk Trade: Chinese Silks and the British East India Company, Winterthur Portfolio 17 (Spring), pp. 21-41.

Richard Martin and Harold Koda (1994) Orientalism: Visions of the East in Western Dress. Catalogue from the Metropolitan Museum of Art, New York.

Elizabeth Merritt ed. (1956) Proceedings of the Provincial Court of Maryland, 1677-1678, pp. 33-36.

Margreta Van Varick (1962) Inventory, January 7, 1695, Winterthur Newsletter, vol. 8, nos. 2 and 3 (February 26 and March 26, pp. 1-6; 1-13. 


\title{
2 Textile Symbolism and Social Mobility during the Colonial Period in Sydney Cove
}

\author{
JUDITH CAMERON
}

Judith Cameron is a direct descendant of the Scottish merchant Robert Campbell who brought Indian textiles to the fledging colony of New South Wales, the subject of her present article. She studied Archaeology at the Australian National University and has a Masters of Philosophy in Asian Studies, a graduate diploma in Chinese Art and Archaeology (SOAS) and a PhD in Archaeology. Her PhD Dissertation: Textile Technology in the Prehistory of Southeast Asia was the first systematic investigation into the archaeological evidence for spinning and weaving in Southeast Asia. Since then she has worked as the archaeological textile expert on many international archaeology projects in Southeast Asia and the Pacific, including the Origins of Angkor Project and the Niah Cave Project. Recently, she identified the earliest evidence for Indian textile technology at a site in Central Thailand which provided new insights into the movement of craftpersons across the Bay of Bengal during the Iron Age.

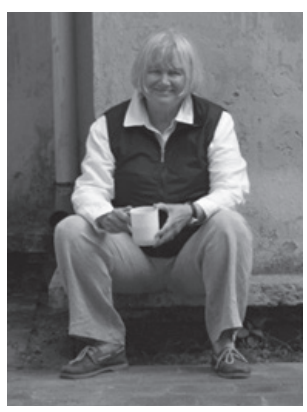
She is best known for the joint Australian/Nietnamese excavations in the Red River which produced a remarkably well preserved burial dressed in layers of clothing and wrapped in a complete burial shroud, the first for Vietnam and Southeast Asia. Among her recent publications are: The Archaeological Textiles from Ban Don Ta Phet in broader perspective, in B. Bellina, E. A. Bacus, T. O. Pryce and J. Wisseman Christie (eds), 50 Years of Archaeology in Southeast Asia: Essays in Honour of lan Glover, pp. 141-151 (2010, River Books, Bangkok); Bronze Age Spinning Tools, in C. F. W. Higham and A. Kijngam (eds), The Origins of the Civilization of Angkor. Volume IV: the Excavation of Ban Non Wat Part III. The Bronze Age, pp. 497-504 (2012, Bangkok); Textile Crafts in the Gulf of Tongking: The Intersection between Archaeology and History, in N. Cooke, Tana Li and J. Anderson (eds), The Tongking Gulf through History: Soundings in Time and Space, pp. 25-38 (2011, Univ. of Pennsylvania Press); New archaeological evidence for the movement of Yueh spinners into Mainland Southeast Asia, Taiwan and Island Southeast Asia during the late prehistoric period, in Proceedings of the International Academic Conference on the Topic of Navigation: Trace of Civilizations, pp. 1-13 (2011, the China-Maritime Museum International Academic Forum, Shanghai); Trans-Oceanic transfer of bark-cloth technology from South China-Southeast Asia to Mesoamerica?, in G. Clark, F. Leach and S. O'Connor (eds), Islands of Inquiry: Colonisation, Seafaring and the Archaeology of Maritime Landscapes, pp. 203-210. Terra Australis 29 (2008, ANU ePress, Canberra).

European culture with its intrinsic textile symbolism was transplanted into Australasia in 1778 when the First Fleet arrived in Sydney Cove to establish a penal colony, essentially a far-flung gaol for British criminals guarded by marines along with their respective families. In contrast to the Aboriginal inhabitants who did not wear clothing apart from skin cloaks in the cooler southern regions, British immigrants arrived in the colony resplendent in traditional European clothing deemed appropriate for their social status, although environmentally inappropriate and out of context in the 
warmer regions of the Antipodes. The British Government supplied and administered the clothing of convicts, naval personnel and civil officials but while bolts of material, such as untwilled English cotton known as "black Russia", were brought out on convict ships, little material survived the long sea voyages to replenish supplies. The 1790 s was a critical period; the colony experienced severe shortages in food and clothing, especially leather shoes that deteriorated rapidly in the sub-tropical climate of New South Wales, causing concern amongst officers pre-occupied with keeping up appearances. When basic supplies were almost depleted, Governor Philip (the first governor in the Colony) wrote to the Governor-General of India seeking permission to send a store ship, the Atlantic, to Calcutta to obtain essential provisions. In correspondence, he stipulated that male clothing for convicts should consist of woollen jackets, flannel drawers and worsted stockings. Clearly aware that cotton was better suited to the summer climate, the Calcutta merchants, Lambert Ross and Company, politely advised London in its tender for the contract that they would be able to fill the clothing order:

...provided the woollen requests could be dispensed with and from all accounts we can learn of the climate there does not appear to exist a necessity for them. In the meantime we have got made musters [samples] of shirts and trousers of the same size as those supplied to convicts, and have sent them to Governor Phillip together with three muster pairs of shoes and blankets' mentioning the prices (Lambert Ross and Co. Unpublished manuscript 1792, British Library).

The original samples of striped gingham intended for trousers ( 2 shillings and 6 pence a pair), white dungarees (denim), patna blankets and cotton handkerchiefs remain affixed to the original correspondence in the National Archives at Kew, London.

During this period, my Scottish ancestors were involved in the global textile trade, having recently established their merchant house, Campbell, Clark and Company, in Theatre Street, Calcutta. Although the East India Company held a monopoly on maritime trade, a number of Scottish merchants operated under licence out of trading stations on the banks of the Hughli River in Calcutta where they purchased cotton textiles, muslins, taffetas, chintzes, brocades, batiks and ginghams from Gujerat, Bengal, Golconda and the Tamil region for the European textile trade. In 1796, to compensate for the declining trade between India and Europe, Campbell, Clark and Company despatched the Sydney Cove, laden with a speculative cargo of Indian cloth, clothing and European haberdashery, to the fledging colony. Tragically, the vessel was wrecked en route off the Tasmanian coast. Although quantities of cloth were salvaged, washed and scoured before being placed in government stores for sale, supplies could not meet demand. In despatches to the British Home Secretary in charge of Colonies in London, Governor Hunter reported that although the people in the Colony were in perfect health, he was very concerned because they were virtually naked and in want of supplies of slop clothing and of bedding (Steven 1965).

Undaunted by the loss of his ship the Sydney Cove, my great-great-great-grandfather, Robert Campbell (then aged 26 years), assembled a crew of lascars (Indian seamen) from Bengal ports and loaded a second ship, The Hunter, with cattle, horses, rum, tea, sugar, calico, sheets, muslins and other Indian clothing and sailed it himself without incident into Sydney Heads on 10th June 1798. In accordance with standard practice, 
the officer corps compulsorily acquired all goods coming into the settlement for resale. A strong advocate of free trade and intent on breaking the officers' monopoly, Campbell subsequently obtained Hunter's permission to establish a permanent presence in the colony, and with access to private capital, constructed a wharf and warehouses at the Rocks (Dawes Point). Known as the first merchant and father of Australian commerce, Campbell was the first entrepreneur to combine the roles of naval officer, merchant, magistrate and colonial banker. Over the following decade, this canny, well-educated young Scot from Greenoch helped the colony's emerging elites to purchase sufficient fine cloth and lush trimmings to silently articulate their improved socio-economic status, effectively turning free settlers into gentlemen and convicts into dandies during this transitional period of Australian history. Fine clothing was such an integral symbol of emancipation that after a few decades, new arrivals in Sydney Cove frequently had difficulties distinguishing convicts from free settlers and government officials; clothing played an important role, silently articulating the notions of egalitarianism on which the Australian nation is firmly based.

During the early colonial period, several unsuccessful attempts were made to grow fibre-producing plants, manufacture dyes and weave cloth locally. Initially, convicts grew Linum usitatissimum (flax) for sailcloth but abandoned cultivation because of low productivity (convict women could only weave 100 yards of cloth a month). Futile attempts were also made to grow Gossypium spp. (cotton) before it was realised that the species required hotter temperatures. Repeated experiments to produce blue dye from indigenous plants that grew wild around Sydney Cove also failed, reportedly producing brown rather than blue colours. Attempts were also made to weave locally grown wool from Captain John McCarthur's wool clip but the master weaver, Edward Wise, appointed in London to develop the colonial industry, drowned on the passage out to Sydney Cove and a replacement was not found; only later did female convicts produce woollen cloth for convict clothing at the Parramatta factory (Burnard 1994).

The painting shown in Figure 21.1, considered to be the earliest sociological study of the settlement (Steven 1965), clearly illustrates the role costumes played articulating the prevailing social order of the early years in Sydney Cove. For centuries, the watercolour was attributed to my great-great-great grandmother Sophia Campbell whose brother was a bursar on the Sirius, the flagship of the First Fleet, which arrived in Sydney in 1788. Palmer, who was subsequently appointed Commissionary-General of New South Wales in Charge of the Colony's Stores, brought his sister, Sophia, to Sydney Cove in 1800 where she was to meet and eventually marry Merchant Campbell. However, after being sold through Sotheby's in 2009, art historians re-ascribed it to Edward Close who married Sophia's niece. In the painting, high-ranking gentlemen are distinguished by formal, fashionable clothing with exacting tailoring: singlebreasted, high-collared, long coats with tails, pantaloons and skin-tight breeches (extending over the knee) which were markedly different from the loose-cut trousers and drop-fronts worn by the labourers, and buckled shoes. Striped and embroidered 
waistcoats, fine shirts with high-stiffened collars were also symbols of wealth, high social position and refinement.

The fundamentals of hierarchical uniformity are epitomised in the uniforms of the two soldiers from Governor Macquarie's 73rd Regiment depicted in the painting (see Fig. 22.1). A naval officer is depicted in a tailored red woollen coat and tropical gear of trews (trousers). The second more imposing figure, identified as Governor Macquarie's aide-de-camp, is depicted in a tailored brown woollen coat and striking cocked hat called a bicorne which was de rigeur amongst military and naval officers throughout Europe and America from 1790 to 1914.

In Sydney Cove, regulation issue for convicts consisted of basic, ill-fitting, readymade clothing, similar in colour and style to standard British working class attire of the 1790s, intended to simultaneously distinguish and humiliate them for their transgressions. However, upstarts, particularly gentlemen convicts, regularly flaunted the sumptuary dress rules in the early days of the settlement leading Governor Hunter to officially complain; the system of social control contingent on all members of society complying with the rules.

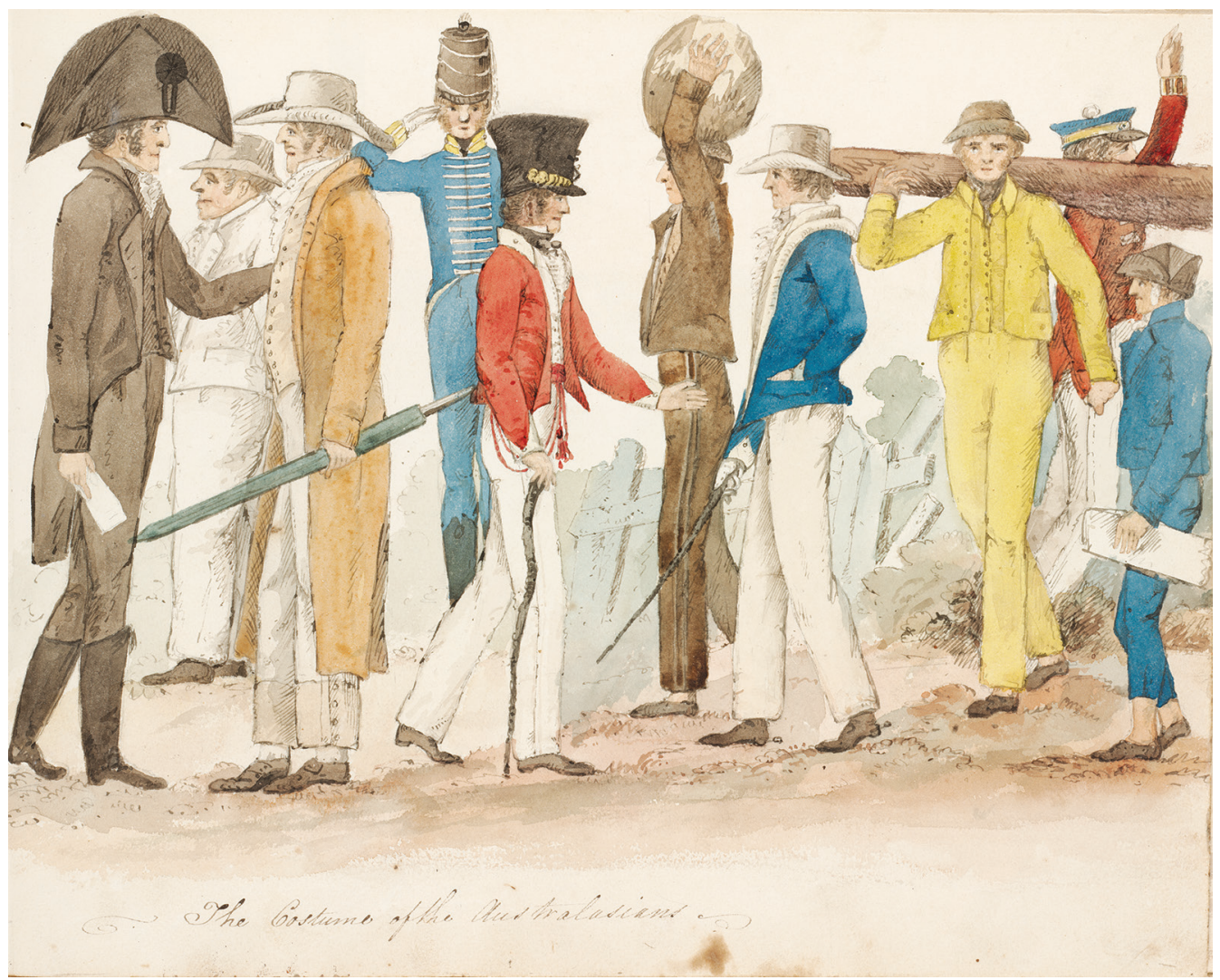

Fig. 21.1: The Costumes of the Australasians, watercolour by Edward Charles Close (Mitchell Library, State Library of New South Wales Call no. PXA 1187, Digital: a2821039). 
I would strongly recommend that convicts of every description should, from their first arrival here, wear some badge of distinction and disgrace. As those who may be under the first sentence should be clothed alike. This, I conceive, is the least punishment that ought to be inflicted on those long-coated Gentlemen who on their arrival in New South Wales assume the dress and consequence of persons of high rank and who look down upon their superiors with an air of contempt (Hunter 1798, Evidence of Mr R. Cartwright, J. P. Bonwick Transcripts, Series II, Box 23, Unpublished manuscript, Mitchell Library, Sydney).

Convicts also wore "slops" (a nautical term for marine's clothing but also sometimes referred to as clothing of deceased persons). Male convict prescriptions consisted of short jackets made of kersey - a coarse ribbed wool cloth - waistcoats, trousers of the type worn by naval ratings called "undress uniform", and coarse, cotton shirts. Later, re-offending convicts assigned to chain gangs were provided with distinctive half black and half white (magpie) uniforms. The Hyde Park Barracks Archaeology Collection (Historic Houses Trust of New South Wales) in Sydney houses an almost intact convict's blue and white striped Indian cotton shirt found under floor-boards during renovations of the barracks built to accommodate convicts in 1819. The shirt is of the type worn in Europe by sailors and the working class; loose-fitting, gathered from a high yoke with full sleeves and gathered wrist bands (Fig. 21.2). Convict trousers were stitched up the outside legs and fastened with buttons 6" apart, designed so

Fig.21.2: Convict shirt, maker unknown, c. 1840. An almost intact convict's blue and white striped Indian cotton shirt found under floor-boards during renovations of Hyde Park Barracks built to accommodate convicts in 1819. The shirt is of the type worn in Europe by sailors and the working class; loose-fitting, gathered from a high yoke with full sleeves and gathered wrist bands. Convict trousers were stitched up the outside legs and fastened with buttons 6" apart, designed so that shackled prisoners could get dressed without having their leg irons removed. As with other examples housed in museum collections, the shirt is stamped in ink on the inside right front panel 'WD' (War Department, United Kingdom) (Hyde Park Barracks Archaeology Collection, Historic Houses Trust of New South Wales; photo: (C) Alex Kershaw).

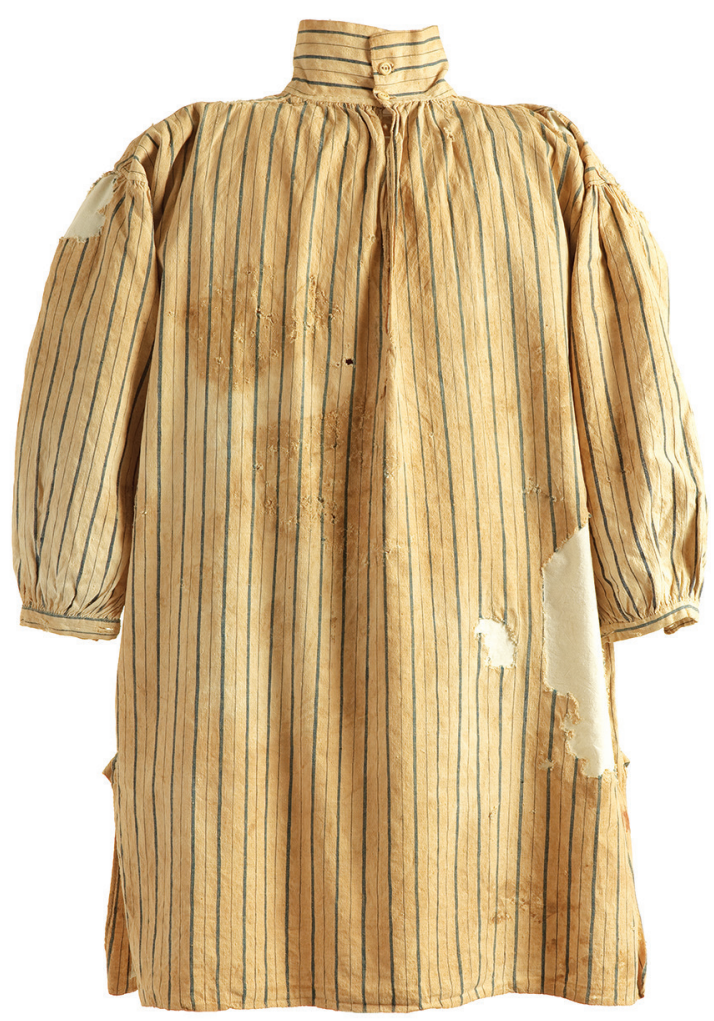


that shackled prisoners could get dressed without having their leg irons removed. As with other examples housed in museum collections, the shirt is stamped in ink on the inside right front panel "WD" (War Department, United Kingdom). When clothing supplies ran very low, convicts were issued with hastily dyed military uniforms. In 1801, convict overseers (rewarded such positions for good behaviour) were issued with coats of blue cloth and pantaloons of grey to demarcate them from other convicts. The yellow uniform worn by the convict in the painting was introduced into the colony repertoire in 1814 to be more conspicuous in the Australian bush.

This semiotic system was contingent on the availability of suitable fabrics and when supplies of clothing began to run out in the early period of settlement and the entire community was close to starvation, discipline was threatened. Clothing shortages made convicts difficult to distinguish from free settlers; some soldiers wore threadbare clothes and were without shoes. Despite women's demonstrable skills in patching clothes, all classes were distressed when store supplies were exhausted. Over subsequent decades, Campbell ships transported copious quantities of cloth, clothing and haberdashery to Sydney Cove. The first issue of the Sydney Gazette from 1803 features an advertisement (Fig. 21.3) announcing the sale of Campbell's cargo of Indian clothing and cloth from the Castle of Good Hope consisting of chintz and blue gurrah (cheap muslin) that was better suited to the climate. Although chintz is often synonymous with Europe, it is actually of Indian origin, imported into Britain by the East India Trading Company as early as 1619. The word chintz, derived from the Hindi chint or chitta, means "spotted or variegated". Subsequent shipments also met the colony's demand for high-end Indian textiles that had been exported to European elites since 1640, particularly Madras longcloth, cambric and muslin handerchiefs, pumjums (mats) and gunny bags (sacks).

Because Campbell held neither military nor emancipist allegiances, he sold his commodities to all classes and his mercantile business flourished. By 1804, he had effectively broken the British Officers' monopoly on trade by giving his customers six months' credit and accepting re-payments in grain. As Table 21.1 shows, in that year Campbell's godown contained

Fig. 21.3: Advertisement placed in the first issue of the Sydney Gazette Vol.1, no.1, Saturday 5 March 1803 (Mitchell Library, State Library of New South Wales Call no. F8/50). 


\begin{tabular}{|c|c|c|}
\hline Port Wine & $£ 1,750$ & $0 \mathrm{~s} \quad 0 \mathrm{~d}$ \\
\hline Madeira and Calcavella & $£ 1,600$ & $0 \mathrm{~s} \quad 0 \mathrm{~d}$ \\
\hline Sugar & $£ 26,388$ & $14 \mathrm{~s} 8 \mathrm{~d}$ \\
\hline Soap & $£ 250$ & $0 \mathrm{~s} \quad 0 \mathrm{~d}$ \\
\hline Cordage and Canvas, Twine, Loglines, etc. & $£ 870$ & $0 \mathrm{~s} \quad 0 \mathrm{~d}$ \\
\hline Tanned Hides & $£ 212$ & $0 \mathrm{~s} \quad 0 \mathrm{~d}$ \\
\hline Pepper and Salt Petre & $£ 503$ & $0 \mathrm{~s} \quad 0 \mathrm{~d}$ \\
\hline $\begin{array}{l}91 \text { Bales of piece Goods consisting of Dungarees, Chintzes, Nankeens, Long Cloth, Callicoes } \\
\text { for Shirting and Sheeting, Bandanoo Handkerchiefs, Muslins, Dungaree s, Frocks } \\
\text { and Trowsers Etc. Etc. }\end{array}$ & $£ 9,810$ & $0 \mathrm{~s} 0 \mathrm{~d}$ \\
\hline 10,105 Fur Seal Skins remaining exclusive of 10,030 ships by the Albion & $£ 4,140$ & $0 \mathrm{~s} 0 \mathrm{~d}$ \\
\hline 2 Boilers 270 Gallons & $£ 30$ & $0 \mathrm{~s} 0 \mathrm{~d}$ \\
\hline $\begin{array}{l}2 \text { Calcutta Teak Whale Boats copper fastened with Oars compleat constructed for carrying } \\
\text { Skins }\end{array}$ & $£ 140$ & 0s 0d \\
\hline
\end{tabular}

Table 21.1: Estimated value of property in Campbell and Co's gowdowns, Sydney, 16 August 1804 (After Historical Records of Australia. V, p. 106).

91 bales of piece goods (material and clothing) with an estimated value of $£ 9,810$ (Steven 1965).

Research into colonial consumer patterns reveals that convicts had a predilection for luxury consumables (silk handkerchiefs, laces and ribbons) that had previously been the prerogative of the upper classes, leading to the term "convict dandy" (Elliott 1995). As Table 21.2 indicates, large quantities of tough, durable, twill woven cotton called dungarees (denim) were also in demand amongst early settlers leading to them being known as "dungaree settlers".

Most information on female clothing comes from historical documents which record that female convicts were issued with simple dresses, jackets, petticoats (skirts), kerchiefs, caps and hats, whereas female settlers wore better quality cloth based on English country styles, less elaborate than that worn by elites. Spouses of officials and naval officers reportedly brought good quality wardrobes with them during transportation to be stylishly dressed in English finery of the period. To meet the demand for au courant material, the Gazette advertisement (Fig. 21.3) announced the arrival of Campbell's shipment of fashionable shawls and leghorn hats, marcella (for bedspreads), fine India prints and Pondicherry cloth.

An 1800 miniature of Sophia Campbell (Fig. 21.4), painted a year before she married Robert Campbell, illustrates the fashion of the elites. Sophia is depicted wearing a highwaisted, silhouette hugging dress made of diaphanous imported fabric (presumably muslin), conforming to the neo-classical style that began in the mid-18th century in Europe following the excavations of Pompei which reflected a larger cultural interest in the humanistic philosophies of this period.

Throughout the 19th century, muslin cloth woven in Dacca was in considerable demand. India had an important competitive advantage. Weavers from Santipur such as those depicted in the oil painting in Figure 21.5, hand-spun indigenous Indian cotton species (Gossypium arboreum, G. herbaceum) to produce fibres of superior strength and 


\begin{tabular}{|c|c|c|}
\hline & 1 pair shoes & $16 \mathrm{~s}$ \\
\hline August 1803 & 2 yds dungaree & $12 \mathrm{~s}$ \\
\hline \multirow[t]{2}{*}{18 October 1803} & $\begin{array}{l}1 \text { handkerchief in payment for felling straggling trees at the } \\
\text { lagoon }\end{array}$ & $5 \mathrm{~s} 6 \mathrm{~d}$ \\
\hline & 3 yards ribbon & $6 \mathrm{~s}$ \\
\hline 14 November 1803 & 1 pair of shoes & $15 \mathrm{~s}$ \\
\hline \multirow[t]{5}{*}{ December 1803} & Handkerchief & \\
\hline & pr shoes & $£ 20 \mathrm{~s} 6 \mathrm{~d}$ \\
\hline & check shirt & \\
\hline & 1 waistcoat & $20 \mathrm{~s}$ \\
\hline & 1 handkerchief & $6 \mathrm{~s} 5 \mathrm{~d}$ \\
\hline 18 January 1804 & $\begin{array}{l}\text { ? yds fine printed cotton and dimity petticoat in place of } 12 \\
\text { bushels wheat }\end{array}$ & $£ 416 \mathrm{~s}$ \\
\hline 3 June 1804 & black silk and ribbon & $£ 16 \mathrm{~s}$ \\
\hline 15 August 1804 & 2 calico shirts & $£ 110 \mathrm{~s}$ \\
\hline 17 August 1804 & $\begin{array}{l}\text { silk handkerchief } \\
\text { trousers }\end{array}$ & $£ 1.9 \mathrm{~s}$ \\
\hline 2 September 1804 & $1 \mathrm{pr}$ calico trousers & $18 \mathrm{~s}$ \\
\hline 8 October 1804 & 1 pr dungaree trousers & $14 \mathrm{~s}$ \\
\hline 21 October 1804 & 3 yds ribbon & $6 \mathrm{~s}$ \\
\hline 24 November 1804 & $\begin{array}{l}4 \text { yds dungaree } \\
1 \text { skein thread }\end{array}$ & $£ 110 \mathrm{~s}$ \\
\hline 14 December 1804 & $1 \mathrm{pr}$ gurrah trousers & $14 \mathrm{~s}$ \\
\hline \multirow[t]{8}{*}{24 December 1804} & Jacket & $£ 115 \mathrm{~s}$ \\
\hline & Shirt & \\
\hline & 6yds calico & $£ 116 \mathrm{~s}$ \\
\hline & white handkerchief & $10 \mathrm{~s}$ \\
\hline & flowered apron & $3 \mathrm{~s}$ \\
\hline & silk handkerchief & $10 \mathrm{~s}$ \\
\hline & $11 / 2$ yds ribbon & $3 \mathrm{~s}$ \\
\hline & cotton and petticoat to the value of 12 bushels of wheat & $£ 416 \mathrm{~s}$ \\
\hline 5 January 1805 & 1 pr duck trousers & $16 \mathrm{~s}$ \\
\hline 13 January 1805 & 3 yds ribbon & $6 \mathrm{~s}$ \\
\hline 5 February 1805 & $\begin{array}{l}\text { new blanket } \\
\text { silk handkerchief }\end{array}$ & $£ 2$ \\
\hline 15 March 1805 & $\begin{array}{l}2 \text { handkerchiefs } \\
\text { thread and needles }\end{array}$ & $\begin{array}{r}£ 1 \\
4 \mathrm{~s} 10 \mathrm{~d}\end{array}$ \\
\hline & 1 year 8 months total & $£ 34$ 16s 3d \\
\hline
\end{tabular}

Table 21.2: Purchases by Evan Evans, Labourer on George Hall's Farm, 1803-1804 (Source: Journal of George Hall, 1803-1805 in Steven 1965).

fineness to that spun with machines. The mechanised spinning machines in Europe could not produce cotton yarn strong enough to be used as warps, having to weave cloth with linen-warps and cotton-wefts (see Roy 1996).

Cloth played an important role articulating changes in social status in Sydney Cove and merchants, such as Campbell, facilitated change. Merchant Campbell clearly believed in equity; not only did he bring Scottish initiative and pertinacity 
Fig. 21.4: A miniature of Sophia Campbell at the age of 23, wife of Robert Campbell painted around 1800 not long after her arrival in Sydney Cove. Sophia accompanied her brother, John Palmer, who was in the British Navy and had taken up a position as Commissioner in charge of the colony's stores. Sophia was noted for her sunny disposition, remaining constant and cheerful throughout periods ranging from great affluence to bankruptcy (Private Collection).
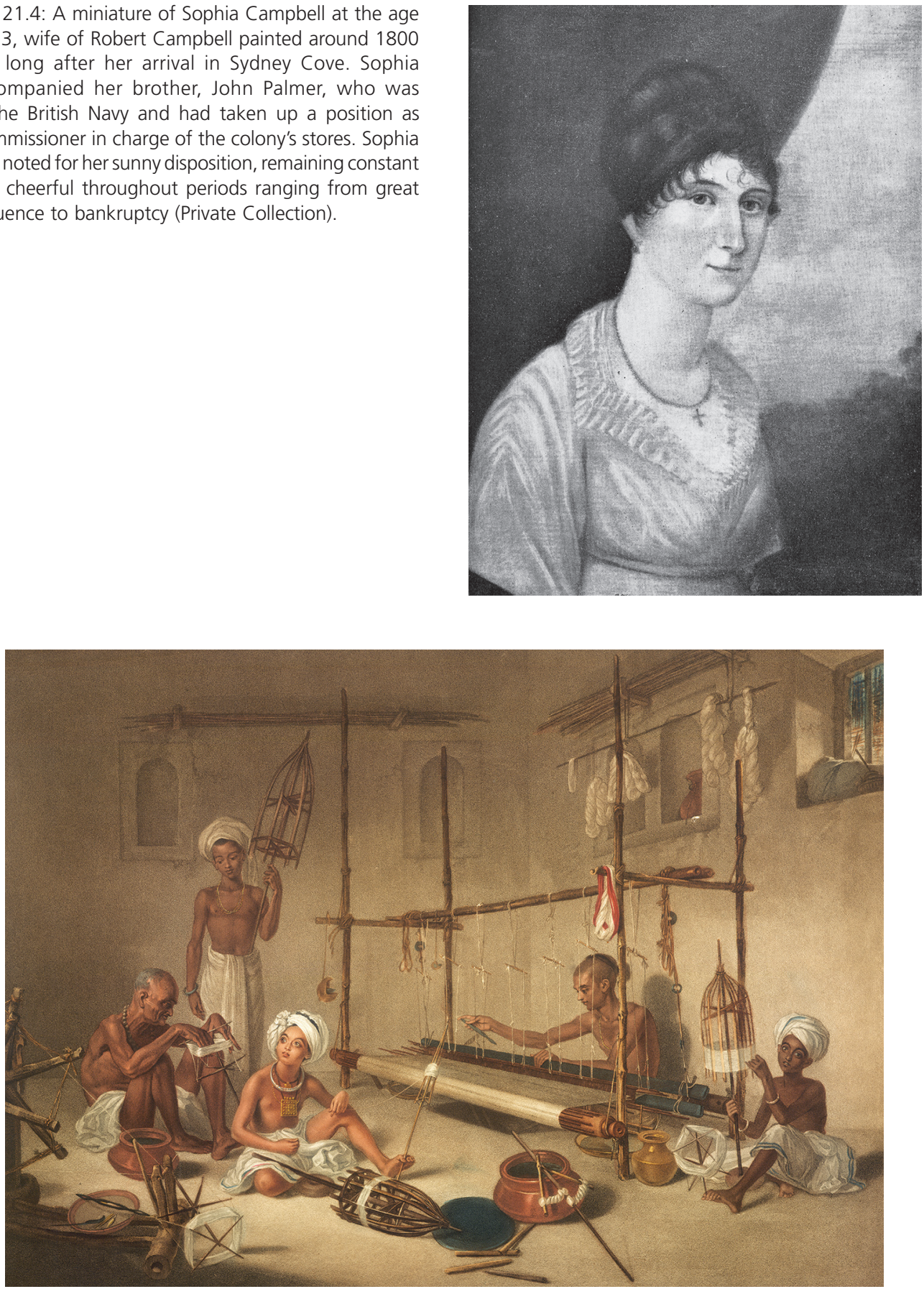

Fig. 21.5: Engraving depicting Muslin weavers of Santipur (near Dacca). The coloured stipple engraving, $A$ loom, with the process of winding off the thread is by P. W. Tomkins (1760-1840) after the painting by Arthur William Devis (1763-1822), British school. Originally published/produced in London, c. 1800. No. 074335 (@) The British Library Board, P805, All Rights reserved, 2014). 
to colonisation through trade and profited substantially from it, but as a product of the Scottish enlightenment, his business endeavours reflected his value system that improvements should be of practical benefit to both the individual and society.

\section{Further Reading}

Joyce Burnard (1994) Chintz and Cotton. India's Textile gift to the World.

Jane F. Elliott (1995) Was there a convict dandy? Convict Consumer Interests in Sydney 1788-1815.

Australian Historical Studies 26: 104, pp. 373-392.

Mary Schoeser (2003) World Textiles: a Concise History.

Margaret Steven (1965) Merchant Campbell 1769-1846. A Study of the Colonial Trade.

Tirthankar Roy (1996) Cloth and Commerce: Textiles in Colonial India. 


\title{
22 The Impact of British Rule on the Dressing Sensibilities of Indian Aristocrats: A case study of the Maharaja of Baroda's dress
}

\author{
TOOLIKA GUPTA
}

Toolika Gupta is currently following a PhD in History of Arts from the University of Glasgow. She holds a Master's degree in Textiles and Clothing from Delhi University (1996), after which she has worked as a fashion, textile and costume enthusiast. She has 17 years of industry and academic experience.

In 2005, she undertook full-time teaching at the National Institute of Fashion Technology, New Delhi, India, as an Associate Professor until June 2011, before leaving for the United Kingdom. She undertook a short course "Archaeology of Clothing" at Oxford University in 2011. She has also done a PG certificate course in "Introduction to Sanskrit" in 2012 so as to understand the etymology of Vedic Textiles. Her interest areas include History of Costume \& Textile, Fashion Trend research, Surface Design Techniques, Sustainable and Ethical Fashion and related Fashion Studies.

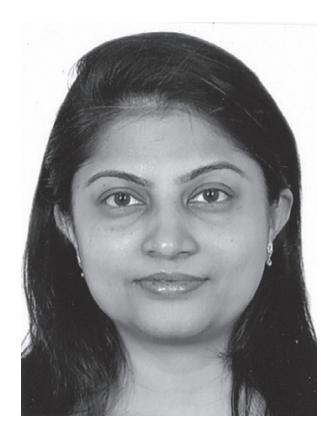

The rise of a westernized society in India was a result of the British taking over the reins of the country and ruling it for nearly 200 years. The British, like the Danes, the French, the Portuguese and the Spanish came to India as traders. The East India Companies of various European nations came with trading interests in mind, particularly for Indian spices and Indian textiles. All these countries established colonies in India along the vast coastline which the subcontinent has to offer. Although all these colonies were established with the basic purpose of trading and merchandising, there was a constant exchange of ideas, beliefs and culture. Slowly and steadily, all these colonies developed political interests and as a result there were continuous wars and treaties being signed by one colony or the other and finally, more by destiny than by design, the British became the rulers of India in 18th century. The various Indian kings and constituencies now had a head - the King or Queen of England to report to and became a part of the larger British Empire. As a result, the whole generation that grew up in India after colonization looked to the West for inspiration. Due to industrialization, Europe seemed more modern and thus the younger generation of India changed its dress habits to ape the mightier West. The British fashions were aped in order to reflect modernity and reject the traditional past (See Figs 22.2 and 22.4). 
"The process of imitation and adaptation are central to our understanding of creativity. Human cultures evolve through a continuous exchange of ideas, beliefs, habits and forms. Dressing habits in particular constitute a fertile plain in which this exchange takes place", writes textile historian Artemis Yagou (Yagou 2009, 325). It became a fashion statement among the Indian elites, to dress up in a more contemporary British fashion. The change started voluntarily with the aristocrats. The royal men and women of India were the first to adopt western fashion statements, but curiously always shifted to their traditional garb, during celebrations and ceremonies like birth, marriage and death. They felt that they were modern and had to have tastes like the British to reflect that, but they were not willing to give up their traditions completely. It was in fashion to dress up like the modern British, read English literature, smoke a pipe, and wear a hat and shoes. Eating with a fork and knife was considered fashionable and people who ate with their fingers were labelled barbarians.

The case study of the costumes of the Maharaja of Baroda - Sayajirao Gaekwad III (born Shrimant Gopalrao Gaekwad, 10 March 1863-6 February 1939) is an excellent example of British and Indian dressing of an aristocrat. He ruled Baroda (now in Gujarat in India) from 1875 to 1939, and is notably remembered for reforming much of his state during his rule. He did a great deal to improve and uplift the masses and was a forward thinking man. Baroda was founded in 1721 by a Maratha General, Pilaji Gaekwad after he conquered it from the Mughals. Although the British captured much of India, the Gaekwads made a separate peace with the British, and acknowledged British sovereignty in return for retaining local self-rule.

These two images (Figs 22.1 and 22.2) show the stark differences between the Indian and western attire and the photographs also speak of how completely at ease the maharaja was in both costumes. This traditional costume is known as angrakha. An Angrakha is like a tunic with full sleeves and gathered waist. This tunic opens from the front and overlaps like a housecoat and ties on either left or right. Muslims tied it on the right side while Hindus tied it on the left. The length varies from knee level to mid-calf level. This one is probably made in India and the textile is a brocade made with the technique of jalas or drawlooms as is still practised in Benaras and many other parts of India. The beautifully woven textile is highlighted at the cuffs, seams and openings with intricate gold embroidery. He is also wearing pearls as an Indian Maharaja. He is probably wearing a pyjama underneath. These are trousers, which in the case of the nobility would mostly be made of silk, embellished with gold. He also has a traditional Maratha headgear or turban.

As the painting by Raja Ravi Verma from the late 19th century shows, the cultures had begun to amalgamate and we see a unique blend of East and West in the new uniform which is British in silhouette, especially the trousers and the coat also represent a kind of fusion-wear between the East and the West (Fig. 22.3).

The trousers and boots of the maharaja are very western indeed. The same effect is felt in Figure 22.4. Here the maharaja can be seen with his own traditional headgear which was probably his red turban. 


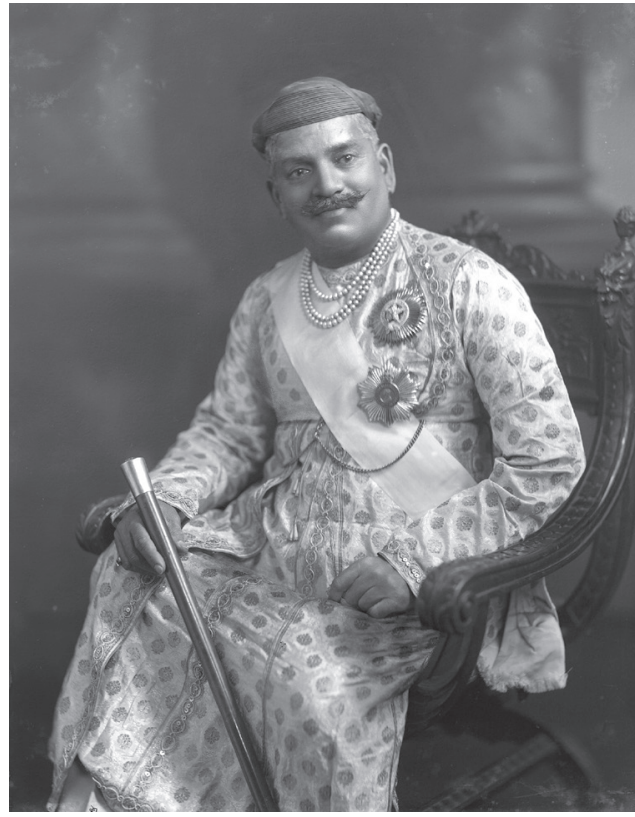

Fig. 22.1: H. H. Farzand-i-Khas-i-Daulat-i-Inglishia, Shrimant Maharaja Sir Sayajirao III Gaekwad, Sena Khas Khel Shamsher Bahadur, Maharaja of Baroda. Here the maharaja in his traditional attire - angrakha. This picture was taken in the Lafayette Studio, 179 or 160 New Bond Street, London on 26th November 1919. Medals: Star \& Riband (pale blue) of The Most Exalted Order of the Star of India; Star of The Most Eminent Order of the Indian Empire (Inv. no. 2006AC4945, Lafayette Portrait Archive, the James Lafayette Studio collection, the Victoria and Albert, London).

Fig. 22.3: This is a portrait of the maharaja painted by Raja Ravi Verma in 1881. Raja Ravi Verma was a well-known painter from Travencore in India during the colonial period. Here we see a young maharaja, clad in an Indo-western costume with an Indian turban and the sword - as the mark of bravery. His clothing consists of a heavily gold-embroidered silk jacket and silk trousers with rich gold embroidery along the side seams. His famous red turban with the jeweled kalgi or sarpench befits the Maratha king (Courtesy of http://www.oldindianphotos.in and http://www. facebook.com/pages/His-Highness-Shrimant-Maharaja-SayajiraoIII-Gaekwad/280742535304817).

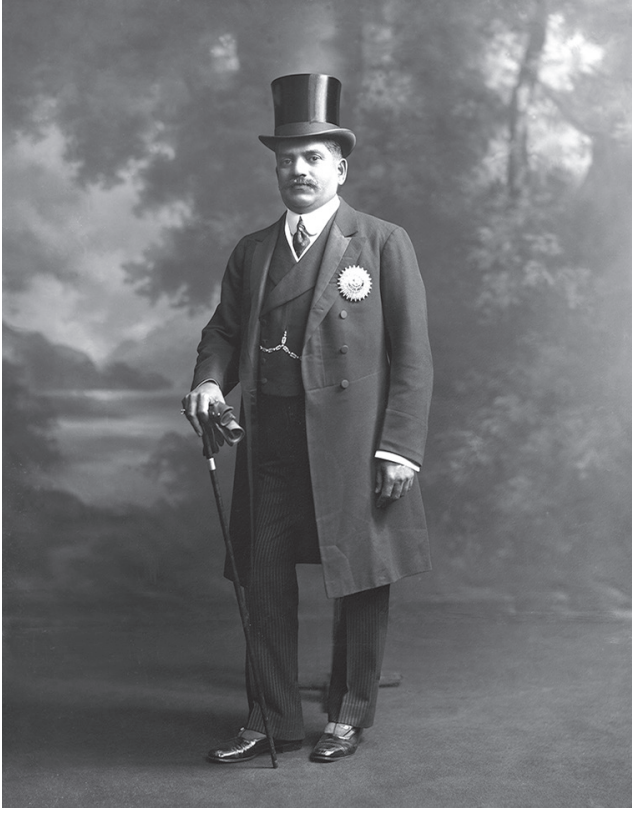

Fig. 22.2: The British Look - here the maharaja is in English attire as was the fashion of those years, complete with a top hat and shoes - not Indian at all. This photograph too was taken in 1919, at the Lafayette Studio in London (Inv. no. 2006BA0161, Lafayette Portrait Archive, the James Lafayette Studio collection, the Victoria and Albert, London).

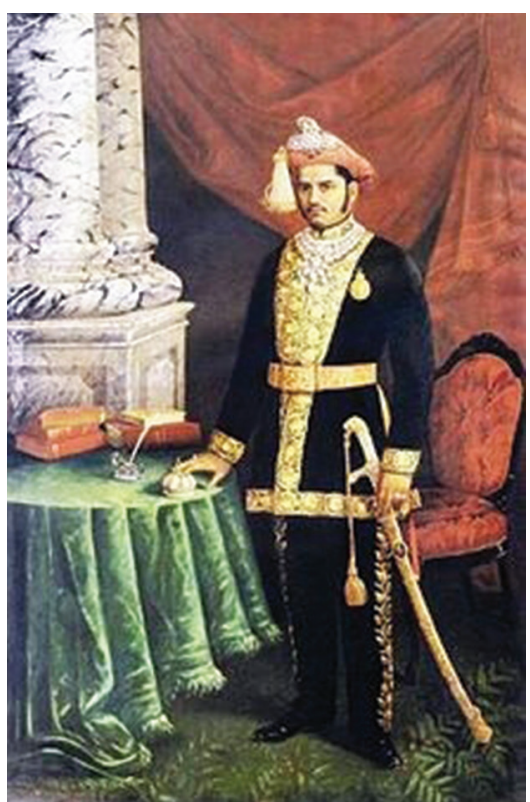




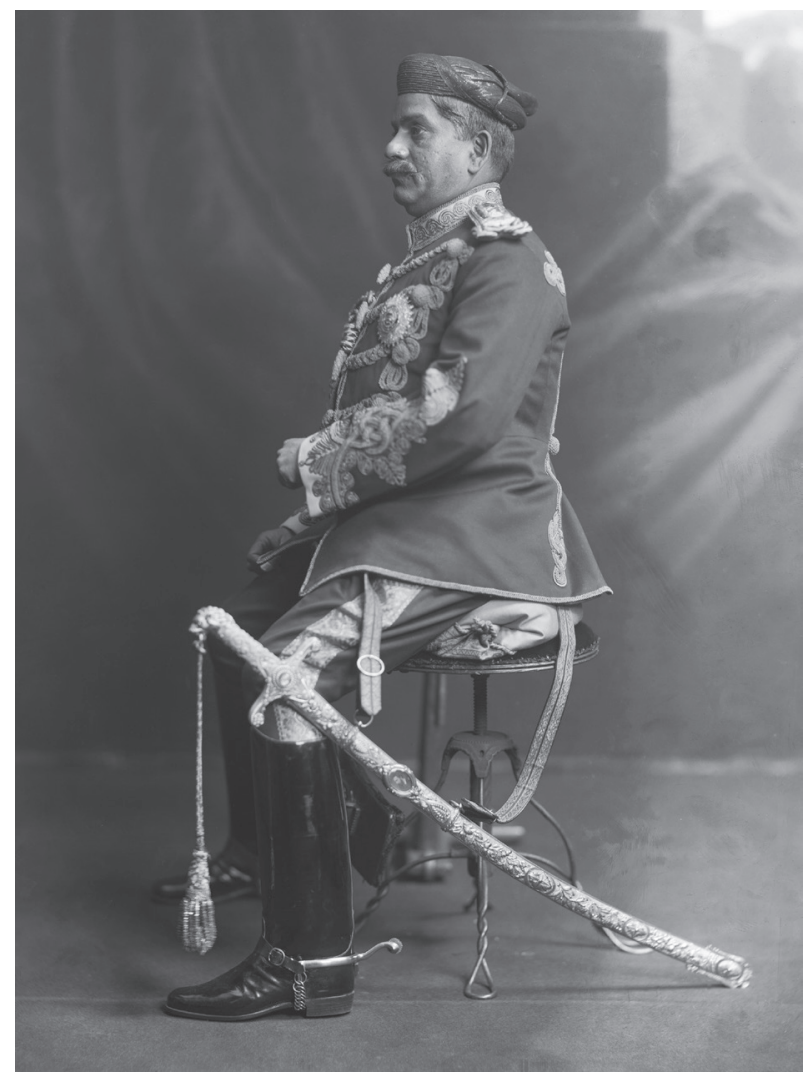

Fig. 22.4: This picture of the maharaja in an elaborate costume is from the first decade of the 20th century dated 4th November 1910. The maharaja's jacket in this picture shows elaborate surface design. The motifs seem to be a blend of Indo-western motifs, with a Baroda uniform in the style of the Bengal Cavalry with a Maratha style turban. The embellished sword also looks inspired from the west. This picture shows the blend of two cultures as adopted by the Indian aristocracy. This is the same sword that the maharaja holds in his portrait by Raja Ravi Verma (Inv. no. 2011EV4138, Lafayette Portrait Archive, the James Lafayette Studio collection, the Victoria and Albert, London).

Bernard S. Cohn writes in Colonialism and its forms of knowledge - The British in India (1996) that in 1911 when King George V travelled to India for the famous 'Durbar', Maharaja Sayajirao Gaekwar "was dressed in a plain white knee-length jacket and his 'traditional' red turban. He wore white European trousers and carried an English style walking stick". This was not taken very well by the British who thought of Indians as their subjects and rather wanted them to dress in their traditional attire.

After India gained freedom from the British in 1947, all the states were merged together and a single National Government formed. All the princely states were dissolved and formed part of the states of the newly formed nation. The British influence can still be seen in the logo developed for celebrating 150 years of the maharaja. The badge worn by the maharaja in the logo shows (Fig. 22.5) the medals given to the rajas by the British Crown. 
Fig. 22.5: This is the logo developed for celebrating 150 years of the Maharaja (Courtesy of http://www.oldindianphotos.in and http://www.facebook.com/pages/HisHighness-Shrimant-Maharaja-Sayajirao-IIIGaekwad/280742535304817).

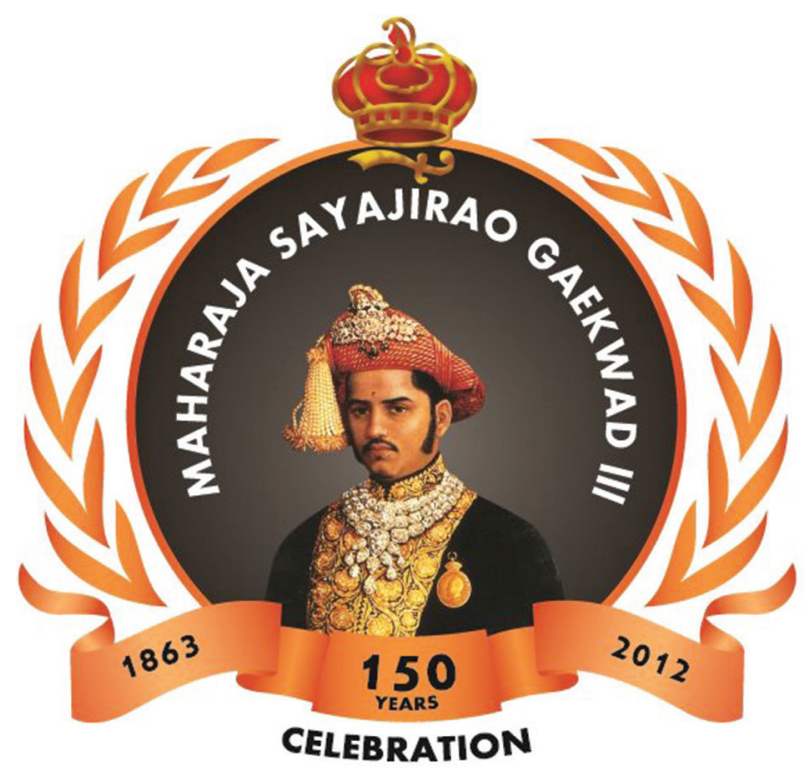

\section{Further Reading}

Archie Baron (2001) An Indian Affair: From Riches to Raj.

Bernard S. Cohn (1996) Colonialism and its forms of knowledge - The British in India.

Pratapaditya Pal and Vidya Dehejia (1986) From Merchants to Emperors: British Artists in India, 1757-1930. Emma Tarlo (1996) Clothing Matters: Dress and Identity in India.

Artemis Yagou (2009) On Apes and Aping: Fashion, Modernity and evolutionary theories in

Nineteenth Century Greece, Fashion Theory Vol. 13, Issue 3, pp. 325-344. 



\title{
23 Re-imagining the Dragon Robe: China chic in early twentieth- century European fashion
}

\author{
SARAH CHEANG
}

Sarah Cheang is Senior Tutor in the History of Design at the Royal College of Art, London. Her research focuses on cultural exchange between East and West, with a special interest in fashion and Chinese things in Britain. She has published numerous academic articles on the buying, selling and collecting of Chinese textiles, ceramics, hair and even Pekingese dogs in the West. In 2008, she curated the 20th century section of an exhibition at Brighton Royal Pavilion and Museum, 'Chinese Whispers', that showcased the history of British chinoiserie and featured many examples of fashion alongside the decorative arts. She is currently working on two new books. The first is called Sinophilia, and is a history of Western fascinations for China during the 20th century, focusing on women's fashions. The second, Fashion and Ethnicity, examines the variety of ways that ethnic identities can be expressed and explored using fashion. Contrary to many people's expectations, Sarah does not own a Pekingese dog or a mandarin robe, but she would not rule either of them out once her children have grown up and left home.

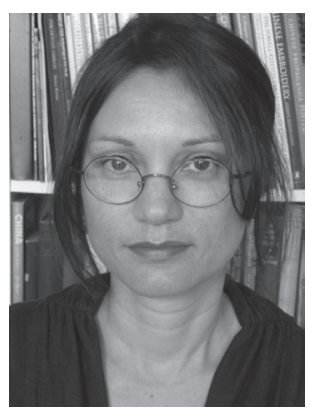

The first three decades of the 20th century saw a European fascination with all things Chinese. Chinese butterflies, flowers, dragons and landscapes appeared on wallpapers and upholstery; for women, the trend included the wearing of dresses, robes, coats and capes incorporating Chinese motifs and traditional Chinese garment shapes, Chinese earrings and even Chinese hairstyles. A range of embroidered Chinese textiles became fashionable within European homes, such as circles of embroidery used to decorate furniture. There was, however, particular interest in Chinese embroidered 'dragon robes', associated with the old Chinese court. At this time in China, many forms of traditional dress were being phased out in a new period of Westernisation and Republicanism. These emphatically old chinese garments became more available in Western markets and were integrated into modern European interior design and fashion.

Since regular sea trade with China began in the late 17th century, Chinese tea, ceramics, painted silk, lacquer, wallpapers, furniture and curiosities had been entering European homes in significant quantities. These luxury goods were mixed with European copies of Chinese things that were often quite fanciful, in a phenomenon known as chinoiserie (a term that refers principally to objects that were designed and 
made in the West but that looked Chinese). Faithful imitations of Chinese things, wild fantasies of China and actual objects from China all found a place within fashionable 18th- and 19th-century Western interiors.

The 20th-century craze for China drew from this European design history and also a new supply of objects from China. Chinese and chinoiserie wallpapers of the 18th century were reimagined in brighter colours and bolder patterns, and the brilliance and lustre of lacquer found a renewed relevance in interiors that once again looked to China in order to express European modernity. Mercantile and political relationships between China and the Western world were, however, very different from earlier trading periods. The Opium and Arrow Wars of the mid-19th century had repositioned China as a British colonial interest, and produced a pressure to Westernise and that changed many aspects of Chinese society, including dress codes. There were also military incursions by Western allied forces into Chinese imperial spaces, such as the Summer Palace [Yuanmingyuan] in 1860 and the Forbidden City in Peking during the Boxer Uprising in 1901. These added imperial loot to the array of desirable items that were being exported from China as the result of social upheaval and economic stress. Chinese embroidered garments were highly sought after as sources of embroidery motifs that could be cut out and applied to soft furnishings and clothing in Britain. An international trade developed in worn out or outmoded Chinese dress, but a new category of interest for European collectors of Chinese things was also emerging objects relating to the Chinese emperor and his court. Throne cushions, hangings, and in general any textiles that showed dragons, took on an especial significance within a narrative of Western imperial expansion.

The Dragon robe was an article of clothing associated with the emperor of China and Qing dynasty court etiquette. These long robes are instantly recognisable by their woven or embroidered designs that depict dragons, clouds, and also a broad striped border at the hem denoting wavy water. In the West, the dragon robe has been viewed as the pinnacle of Chinese hierarchical and bureaucratic dress, in terms of lavish decoration, cultural symbolism and social status. The notion that only the Emperor of China and his immediate family could use a five-clawed dragon motif, and that dragon robes were the exclusive dress of the mandarins, was used by museums and department stores alike to give dragon robes additional significance and monetary value. Possession of a Chinese dragon robe conferred status upon Western collections. In 20th-century Britain, dragon robes were marketed as valuable antiques from a fast-disappearing world, and as exotic and luxurious costume.

At Quex House, Kent, in south-east England, it is possible to see how dragon robes were prestigious souvenirs of China and formed part of British interior design schemes (Fig. 23.1). The drawing room of the house, a space usually reserved for receiving guests and displaying tasteful furniture, was decorated between 1894 and 1909 in an Oriental style, using Indian and Chinese carved-wood furniture, Japanese and Chinese lacquered furniture, and an Islamic-style ceiling. The room was encircled by Indian carved wood panelling which provided a frame for 25 specially designed panels of chinese embroidery, made by cutting out Chinese silk embroidered motifs and fixing 


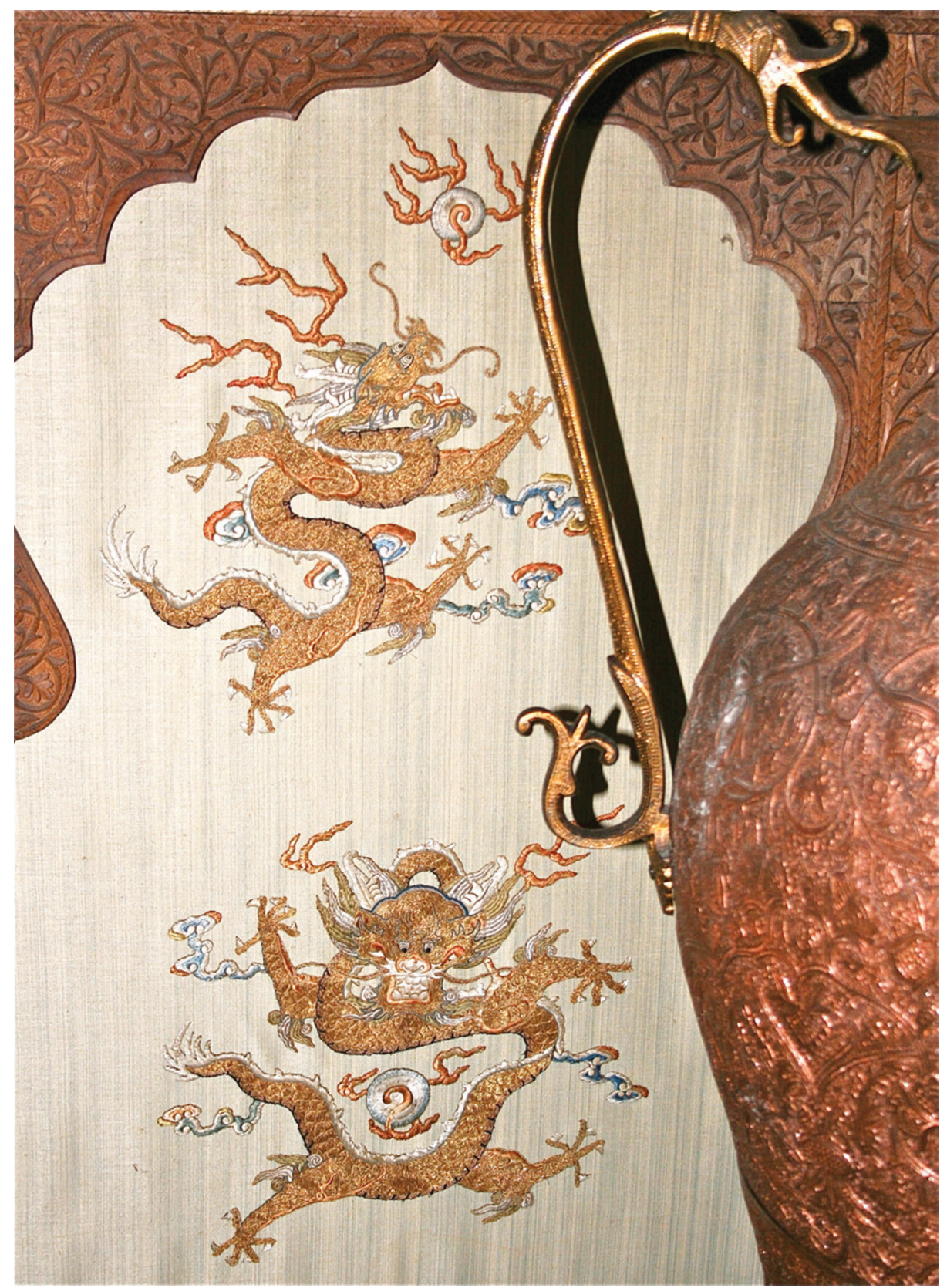

Fig. 23.1: Two embroidered dragons in the drawing room of Quex House, Birchington, Kent, United Kingdom. These dragons were probably cut from a Chinese dragon robe, so that they could be fixed to the wall in new arrangements. The original silk backing was replaced by French linen during restoration work in the 1970s. Quex House is now a museum that is open to the public, including the drawing room. In the current display, the furniture has been arranged to reflect Powell-Cotton's own scheme, and a visual sympathy can be seen between the complex stitching, curving limbs and claws of the embroidered dragons, the ornate carved wood panelling, and the other Eastern decorative objects of the room (With kind permission from the Trustees of the Powell-Cotton Museum, Quex House and Gardens; photo taken by the author). 
them onto a silk backing in new combinations and arrangements. Included among the many butterflies, bats, and flowers are a total of 8 five-clawed dragons that may have been sourced from a single dragon robe.

These designs were executed by the owner of the house, Major Percy Powell-Cotton. In 1891, as part of a touristic 'world tour', Powell-Cotton had spent three weeks in China where he shopped extensively for decorative objects, including embroidered clothing and textile pieces. Back in England, between 1907 and 1919, Powell-Cotton began cutting out the embroideries and gluing them onto the silk panels as a sporadic pastime. The Chinese embroidered motifs, reimagined within a Western aesthetic scheme, harmonised with the Eastern content of the room. In the late 19th and early 20th century, it was not particularly unusual for wealthy men to use African, Indian, Japanese and Middle-eastern décor in rooms for relaxation and recreation. These domestic spaces sometimes reflected leisure pursuits that took place in imperial territories, such as the exotic hunting trophies of tiger skins. Powell-Cotton's main activity was zoology, and he spent many years in India and Africa hunting animals that he studied, shot and stuffed for in his private museum. In his drawing room, a place for socialising and displaying good taste through fine things, the embroidered dragons are like shopping trophies - exciting objects that he tracked, caught and 'bagged', and then 'skinned' and remounted on the wall as souvenirs of global travel. Chinese dragons figure here as autobiographical elements within the creation of a room, and as pleasingly exclusive decorative highlights.

Powell-Cotton's embroideries had the authentic aura of a souvenir, in contrast to the appearance of the Chinese dragon within the fantasies of dress fashions. The Chimère evening dress was created by Paris fashion designer Jeanne Paquin. The garment's most prominent feature was a central band of beaded Chinese dragons on a blue-black ground that wraps around the bodice. Below, beaded cloud or wave shapes on a gold ground decorated the skirt. The design thus focused on two key elements of the dragon robe, and transposed them onto the tubular-shaped evening dress of 1920s Western fashion. The colours resonated with the yellow ground of Chinese imperial garments, but also reflected the heavy use of black and gold in 1920s European interior décor schemes that were probably partly inspired by lacquerware. The intricate beading and embroidery, and precious lustrous materials of silk and diamantés, speak of modern luxury and wealth (Fig. 23.2).

The Chimère dress was exhibited at the Exposition Internationale des Arts Décoratifs et Industriels Modernes in Paris in 1925 (the exhibition from which the term Art Deco has been derived). Within this showcase of cutting-edge modern design, Chimère's lavish materials and exotic decoration of Chinese dragons demonstrate the important role of Chinese design within the Eastern influences of the Art Deco style. The name of the dress is also revealing. In French, une chimère is a dream or illusion, perhaps referring to chinoiserie as an imaginary space for Western fantasies far removed from either Chinese or European realities. Chimère is also the French word for chimera, the composite beast of Greek myth that is composed from parts taken from several 
Fig. 23.2: Chimère dress designed by Madame Jeanne Paquin. The Chimère dress was created for exhibition at the Exposition Internationale des Arts Décoratifs et Industriels Modernes in Paris in 1925 (the exhibition from which the term Art Deco has been derived). It is now in the collections of the Victoria and Albert Museum, London (no. T.50-1948) and is often used in exhibitions to exemplify art deco fashion. The bottom edge of the skirt is cut to follow the shape of clouds that are very similar to those of Chinese robes, but are here traced in diamantes (Given by Mrs William Gordon (C) Victoria and Albert Museum, London).

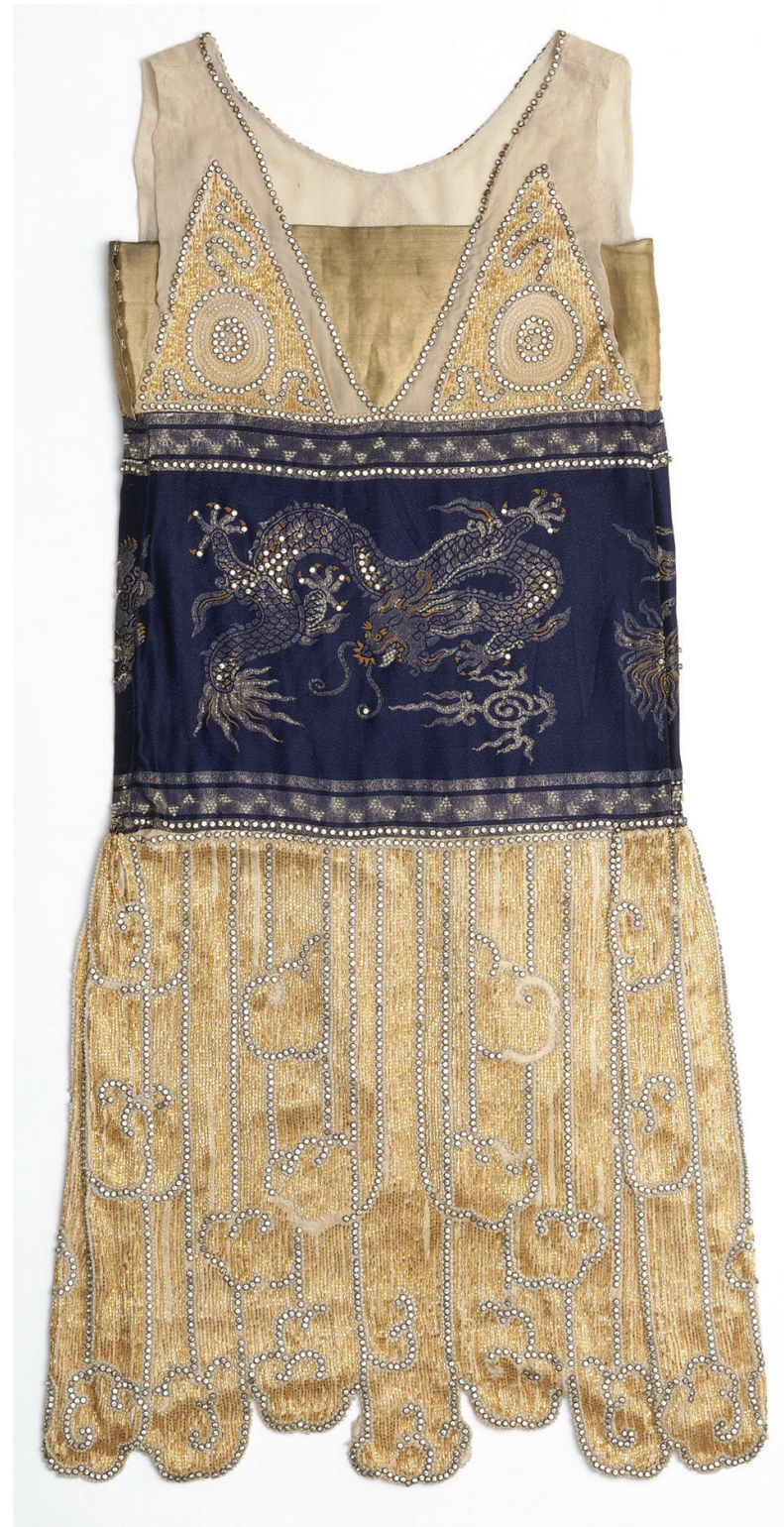

different animals. At the heart of this design, and this expression of French modernity, lies a very deliberate cultural hybridity.

The cultural exchange between Chinese dragon robes and Western fashion was not confined to motifs and materials, but can also be explored in the cut of 1920s garments. The loosening of women's dress, especially the abandoning of the corseted nipped-in waist, offered a new freedom of movement. This has often been related to 
the range of new physical freedoms available to elite women at this time, for example, smoking, wearing make-up, and dancing to jazz music. The loose lines of traditional Chinese jackets and robes suggest a further model for the less tailored fit of 1920s fashions, alongside the sportswear-derived designs of Chanel, and Middle-Eastern inspired garments of Paul Poiret. In the West, Chinese robes had been seen as fancy dress or luxurious dressing gowns, but during the 1920s, they began to be worn as loose evening coats as well (Fig. 23.3).

In July 1929, an image of Mrs Locker-Lampson appeared in the London edition of Vogue magazine, in a photograph taken by Cecil Beaton. She was shown actually wearing a 'mandarin' robe with its distinctive striped hem, sitting cross-legged with her hands in her lap in a pantomime of Eastern manners against a shiny, glittering backdrop curtain. Here, the robe offered an opportunity for both Chinese play-acting and Western fashion in a manner that combined glamorous modernity with nostalgia. In China, the establishment of a new Chinese Republic in 1912 effectively meant the end of the Chinese imperial court and its system of dress etiquette. More Western forms of official dress were pursued as part of a programme of reforms that sought to raise the status of China. Embroidered silk robes for men were being rejected as aspects of tradition that might give the wrong impression of China's potential for

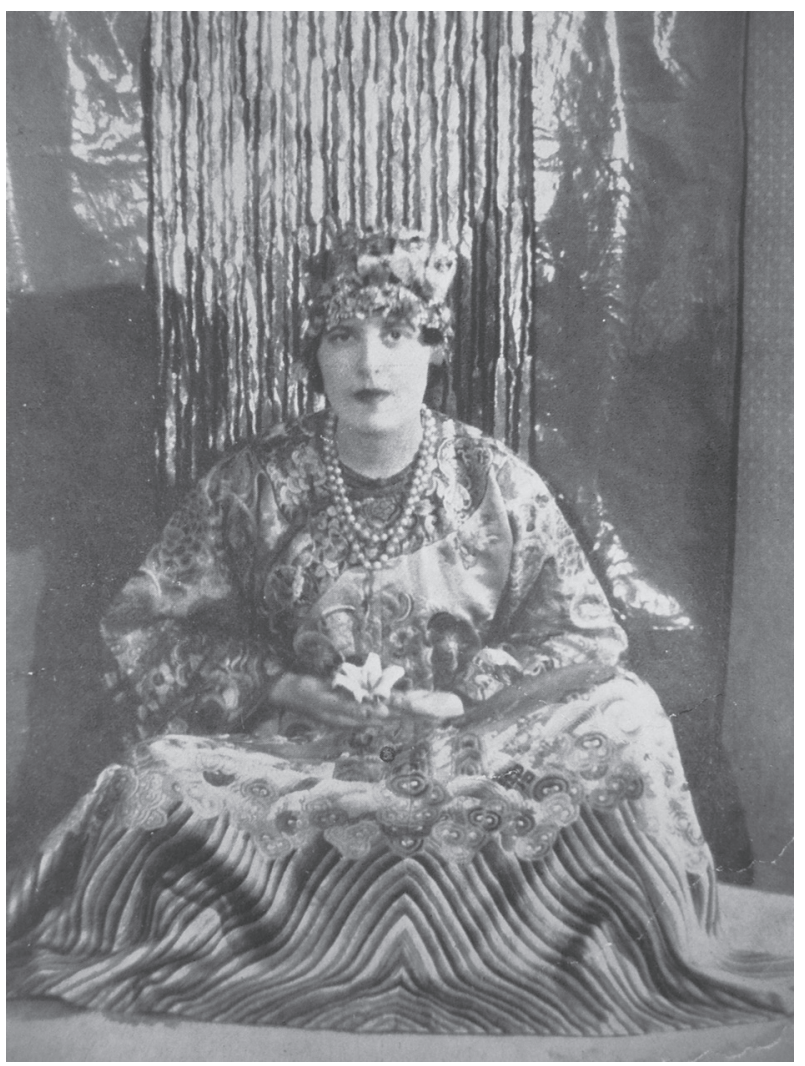

Fig. 23.3: Mrs Oliver Locker-Lampson portrayed by Cecil Beaton, Vogue (UK) July 1929. The original caption describes Mrs Locker-Lampson as "a brunette who always looks well in vivid colours, and is here seen photographed in a mandarin's coat and oriental headdress". The headdress is certainly not part of a mandarin's costume but has been added for additional oriental effect. Cecil Beaton, a leading portrait photographer and theatrical designer may well have provided these Chinese items of dress, but it is equally likely that they belonged to his sitter. Artists during the 1910s and 1920s also portrayed models and society ladies in Chinese gowns, which added a colourful and luxuriously exotic element to their pictures (Cecil Beaton/ Vogue () The Condé Nast Publications Ltd). 
forward-thinking modernity. Highly decorated gowns were associated with femininity in the West, and might undermine male Chinese authority on a world stage whose standards were being set by the Western powers. The 'mandarin' robe, along with the mandarin, belonged to old China.

The robe that Mrs Locker-Lampson was depicted in may have belonged to her or to the photographer. It might have been a diplomatic, military or touristic souvenir from China, or it could have been purchased from a specialist department store in London, such as Liberty. But, whatever its provenance, the Chineseness of the robe made it a fashionable and high-class item. Mr Locker-Lampson was a Member of Parliament, and the robe confirmed his American wife's status as an appropriately wealthy and prestigious figure. The court history attached to such a robe made it highly suitable for an upper class woman in Britain, appealing to notions of traditional authority, and the power to acquire expensive, rare and historical Chinese things. At the moment when dragon motifs and their associated robes were disappearing from clothing in China, they were entrancing European men and women anew. Exported to the West, these embroidered robes enabled Europeans to play the mandarin, celebrate global travel and adventure, and express cultural change.

\section{Further Reading}

Sarah Cheang (2008) Dragons in the Drawing Room: Chinese Embroideries in British Homes, 1860-1949. Textile History, 39 (2), pp. 223-247.

Richard Martin and Harold Koda (1994) Orientalism: Visions of the East in Western Dress.

Valerie Steele and John S. Major (1999) China Chic: East Meets West.

Verity Wilson (1999) Studio and Soirée: Chinese Textiles in Europe and America, in Ruth B. Philips and Christopher B. Steiner (eds), Unpacking Culture: Art and Commodity in Colonial and Postcolonial Worlds, pp. 299-242. 



\title{
2 Sari and the Narrative of Nation in 20th-Century India
}

\author{
AARTI KAWLRA
}

Aarti Kawlra has a PhD in social anthropology from the Indian Institute of Technology, Delhi (IITD). Currently she is a Fellow at the Nehru Memorial Museum and Library, New Delhi and formerly a Fellow at the International Institute of Asian Studies, Leiden, Netherlands. Her interest in the sari is part of a wider research focus on the politics of the handloom and a two-decade long engagement with India's craft traditions. She has been a faculty member of the National Institute of Fashion Technology in Chennai during which period she was a Mombusho Fellow (1999-2000) at the National Museum of Ethnology, Japan to study the kimono for a comparative understanding of textiles and clothing cultures. She has published in Design Issues (MIT Press), Fashion Theory (Berg Publishers) and Berg Encyclopedia of World Dress and Fashion: South Asia and South East Asia. She is presently working on a book manuscript on a weaving community in south India.

This paper explores the sari as the site for creation of a pan-Indian identity in nationalist imaginaries in pre-independence India and later, post-independence, in the shaping of the 'modern' Indian woman within a gendered code of aesthetics. The sari is viewed here as a cultural artifact within a wider politics of feminizing tradition and nation in modernity.

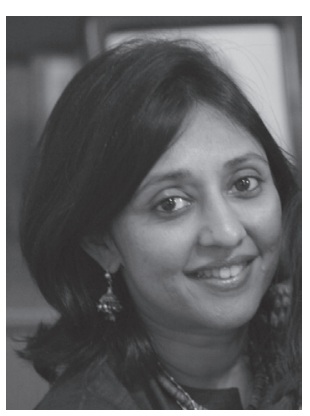

The sari, prior to its ascription as the dress of the Indian woman in the 20th century, was a medium of exchange for spices along the pre-industrial trade route between Europe and south-east Asia. From the 16th century onwards, the famed double-ikat or yarn-resist dyed and patterned silk patola saris, still woven in the town of Patan in the western port of Gujarat, were exchanged for gold and silver in India, by the Portuguese, the British East India Company and the Dutch East India Company and, in turn, traded for spices in the islands of Malaysia and Indonesia. Later, during the colonial period, silk and cotton saris were used as textile design references for British manufacturers in order to revitalize trade between the Empire and its colonies. This is evident in the set of 18 volumes of the Collections of Specimens and Illustrations of the Textile Manufactures of India produced in 1866 by Forbes Watson, the official reporter on the products of India. The documentation features swatches of saris that have been preserved and labelled as fabrics 'plain' and 'ornamental', 'coarse' and 'fine', and 'lower-class wear' and 'upper-class wear' and is intended for the facilitation of design replication and mass production in Britain. 
Saris were also integral to orientalist perceptions of the customs and manners of people under imperial rule and served to highlight dress as a marker of regional and occupational identities highlighting differences based on religion and caste. The Company paintings of the 18th and 19th centuries first brought to light by curator Mildred Archer of the Indian Department at the Victoria and Albert Museum in London depict this vividly (Fig. 24.1).

With the call for independence during the opening years of the 20th century, however, began the nationalist phase of obliterating regional differences of dress and identity as part of the anti-colonial struggle and search for a pan-Indian nationalist imaginary. The nationalist reclamation of culture and aesthetics generated a narrative of nation that was intimately linked with, and in fact inscribed upon, the sari which became the site for the articulation of 'tradition' through the reproduction of gender specific dress codes in modernity.

\section{Shaping a National Feminine Ideal}

In the imperial government's discourse, tradition was constructed as a historical past within a cartographic paradigm of disciplinary authority and control. It involved processes of spatial and temporal fixing of India's people and culture (including

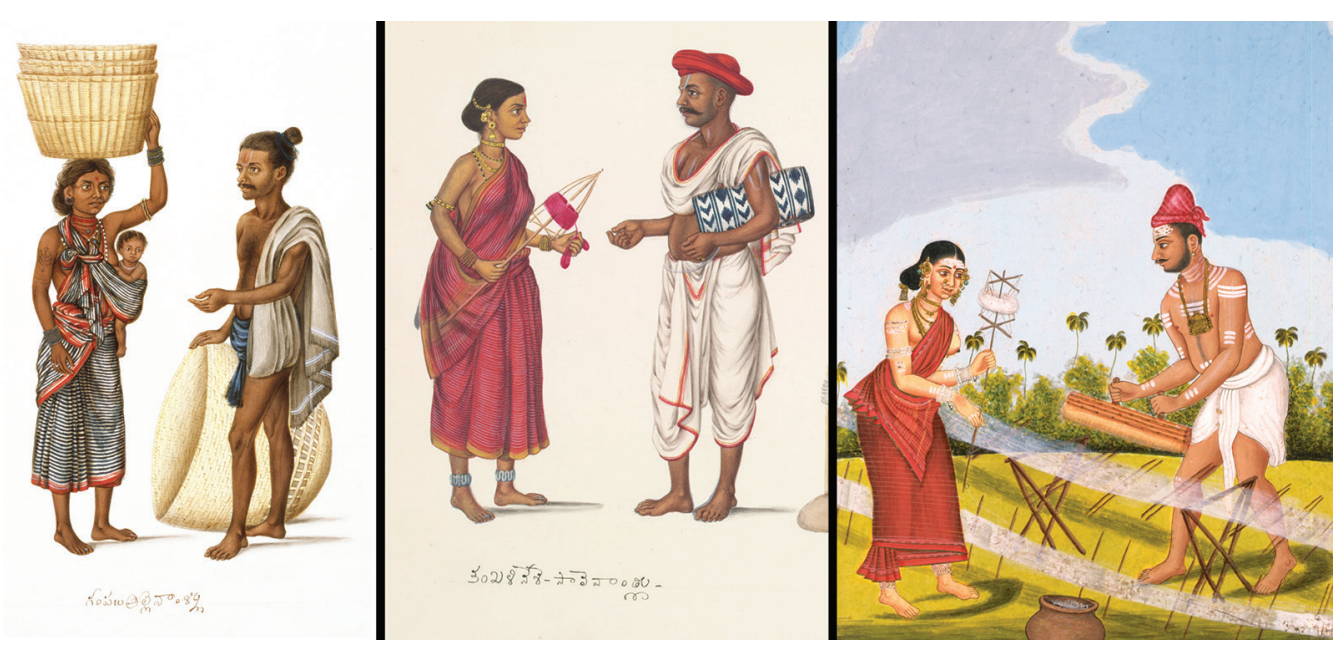

Fig. 24.1: Company paintings in folios of castes and occupations. Thanjavur, Tamil Nadu. Gouache and watercolour. A basket maker and his wife c. 1830. Museum no. IS.39:16-1987; a weaver and his wife c. 1830. Museum no. IS.39:12-1987; a carpet weaver and his wife c. 1800. Museum no. AL.8940N; Telugu inscriptions (C) Victoria and Albert Museum, London). An Indo-European hybrid style patronized by the British, these paintings were intended as souvenirs of life in the colony and produced as part of the colonial project of 'knowing' subject populations through taxonomic descriptions of 'natives' and their cultural milieu for consumption back home. Bound in albums or portfolios these paintings highlight sartorial differences among women belonging to specific occupational castes and tribes, such as dancing girls, weavers, agriculturalists, basket makers, fisherwomen etc., across the occupied territory. In these images, both women are wearing their saris high at the mid-calf level with pleats tucked in at the back in the typical style of the lower castes in south India. 
their dress) within a regionally identifiable and locally distinct taxonomic order to create an ideologically selective version of tradition. Nationalists, on the other hand, canonized tradition as an idealized past representing India's cultural and spiritual evolution, and used it to counter the colonial interpretation of Indian society as non-modern and 'backward'.

The intellectual climate of the 19th century, represented by the philosophical idealism (based on Christian, Hindu and Buddhist religious principles) of socialist and theosophist Annie Besant (1847-1933), cultural nationalism of poet and artist Rabindranath Tagore (1861-1841) and the traditionalism of art historian Ananda Coomaraswamy (1877-1947), had already paved the way for a nationalist revival that posited Eastern spirituality and cultural values in opposition to the material degradation of the West. For the anti-colonialists, the nationalist project was therefore predicated upon a selective appropriation of only those aspects of western modernity and Indian tradition that could be justified ideologically. By locating this reconstituted world of 'Indianness' within the home, understood as the untouched, authentic inner core of the nation, the nationalist discourse further proclaimed its keepers - women, as repositories of tradition together with the sari as a symbol of India's cultural ethos and feminine beauty. So central was the sari to the nationalist narrative that, from the early part of the 20th century, it was employed to create the persona of a 'proper' Indian woman within the frame of increasingly gendered societal norms.

Whereas Christian missionaries and colonial reformers emphasized the adoption of Victorian morality and feminine ideals through dress and social reform, the nationalist reformist agenda involved the feminization of women's bodies and their role in society. This had been the case, for instance in the upper/breast-cloth controversy, which saw frontal and mid-riff nudity as indecent and the Anti-Nautch campaign against the institution of devdasis, or dedication of young girls as temple dancers in south India on account of charges of child-prostitution. Women's sari-clad bodies were postulated by them as palimpsests for the inscription of gender-based standards of beauty recast as 'traditional' in a rapidly modernizing India.

Conformity within these gendered norms of familial propriety meant that women's bodies and their sexuality were bound within the framework and control of a patriarchal household as devoted mothers, wives and daughters, rendering any relation outside of it as both unnatural and immoral. Ideals of beauty and modesty were, therefore, drawn from upper-caste homes and role models to achieve a nationally appropriate figure representing both cultured upbringing and feminine grace. In Kerala for instance, while covering the breasts with an upper cloth was considered of utmost importance, the sartorial prescription was framed within a familial norm of monogamous relations and pursuit of conjugal harmony established upon the notion of an "ideally gendered" individuality within an emergent modern caste order. It demanded a sanitisation or aestheticization of the female body to suit modern male tastes and advocated "an idealised 'womanly' or 'manly' subjectivity, in the distinct spheres of the domestic and the public" (Devika 2005,462). 
The sari was vital to this project of the shaping of the modern Indian woman now increasingly educated and urbanized unlike her still 'traditional', often rural counterpart. Subjected to new patriarchal codes of conduct, the nationalist discourse located the new woman squarely within the domestic order of the home and family while connecting them to the outside world of the public. The emergent social order was projected in contradistinction to western society but also seen as distinct from the prevalent patriarchal order legitimized by tradition. The nationalist interrogation of tradition proposed a culturally discriminatory identity based upon an ancient cultural heritage that had been sanitized and secured against all charges of primitivism and regression.

The re-instatement of the sari as the dress of the 'cultured' Indian woman had its most conscious expression in Madras (now Chennai in south India) at Kalakshetra, the international academy of arts set up by Rukminidevi Arundale (1904-1986), as part of her efforts in the revival of the devadasi's solo dance or sadir and its re-constitution as the Bharata Natyam or traditional dance form of India. It was accompanied by the invention of a new dance costume - a sari styled along the lines of already existing elite sari varieties. The 'new' dancer at Kalakshetra was henceforth projected as the bearer of ancient traditions; her body disciplined and trained to perform a sacred practice in a pure and chaste state. Her dance costume was accordingly modified and divested of all associations with the by now ill-reputed devadasi community. Gradually, with the institutionalization of Bharata Natyam as a classical dance form of India' in both national and international circles, the costume of its highly acclaimed individual proponents too began to be recognized and emulated as the dress of the cultured and educated elite Indian woman.

The popularization and spread of a national ideal of feminine beauty based on 'tradition' was made possible initially by the printing press and later with cinema during the first half of the 20th century. The creation of iconic Indian beauty was achieved in the atelier of the modernist painter from the Travancore court, Raja Ravi Varma (1848-1906) whose paintings of iconic Indian women are examples of such an ideological narrative of 'tradition' that not only standardized 'Indian' womanhood but also established it as a marker of national culture through what Guha Thakurta (1991) has called the "domestication of divinity". Varma's feminine images exuded qualities of femininity associated with characters drawn from select texts or classics of Hindu myth and religion and very quickly became popular female figures representing social and political values of a nation-in-the-making. 'Tradition' was thus embodied in these mythic heroines whose iconography, even though regionally discernible, was intended to signify a pan-Indian, national ideal-type.

Visual stereotypes of women, type-cast as faithful wives and nurturing mothers, proliferated in homes across the country via calendars, magazines and films. Regional and local traditions of saris and their wearing styles were now articulated, their parameters modified and drawn into the fashioning of a pan-Indian model of classical beauty which not only feminized tradition but also the nation (Fig. 24.2). 
By the early part of the 20th century, the emergent ethos of nationhood was premised on a discourse of tradition feminized and visually represented through a national iconography of deified womanhood whose virtues were vital to the preservation and sustenance of 'national culture'. Women were designated in the nationalist discourse to be in service to their male counterparts at the helm of the colonial onslaught, as well as to the nation now imagined as motherland in the figure of Bharat-Mata, the epitomic 'mother' inspiring her 'sons' (citizens) to sacrifice their lives in the relentless struggle for freedom (Fig. 24.3).

Indeed the feminine embodiment of nation as 'Mother India' not only mediated between tradition and modernity but provided a powerful unifying symbol of national territory. The rhetoric of freedom frequently invoked by nationalists indexed Mother India's sari as a material symbol of nation, draped and duly contained from rapid erosion by English mill-made fabrics and the tyranny of colonial rule. National

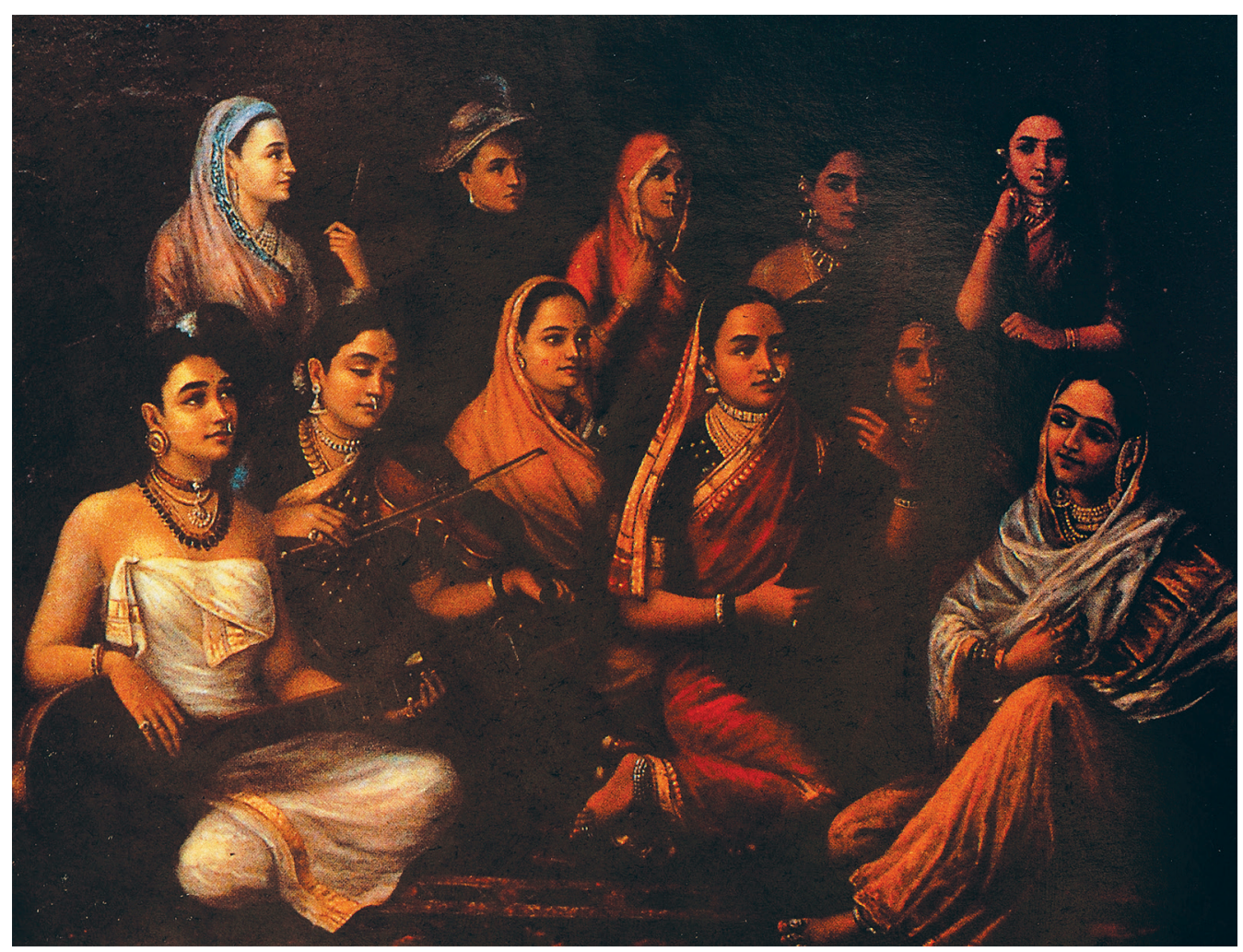

Fig. 24.2: Galaxy of Musicians. A painting by Raja Ravi Varma, c.1889. Oil on canvas (Jayachamarajendra Art Gallery, Mysore). A tableau of 11 women from diverse regions and communities in India represented through differences in dress for consumption in the colonial metropole, the painting is an allegory of a nation predicated upon the gendering of the nation as female. It presents within a single image an ethnographic pageant of 11 diverse stereotypes of oriental beauty in their regional sartorial finery while alluding to the emergence of a unified space of the Indian nation. 


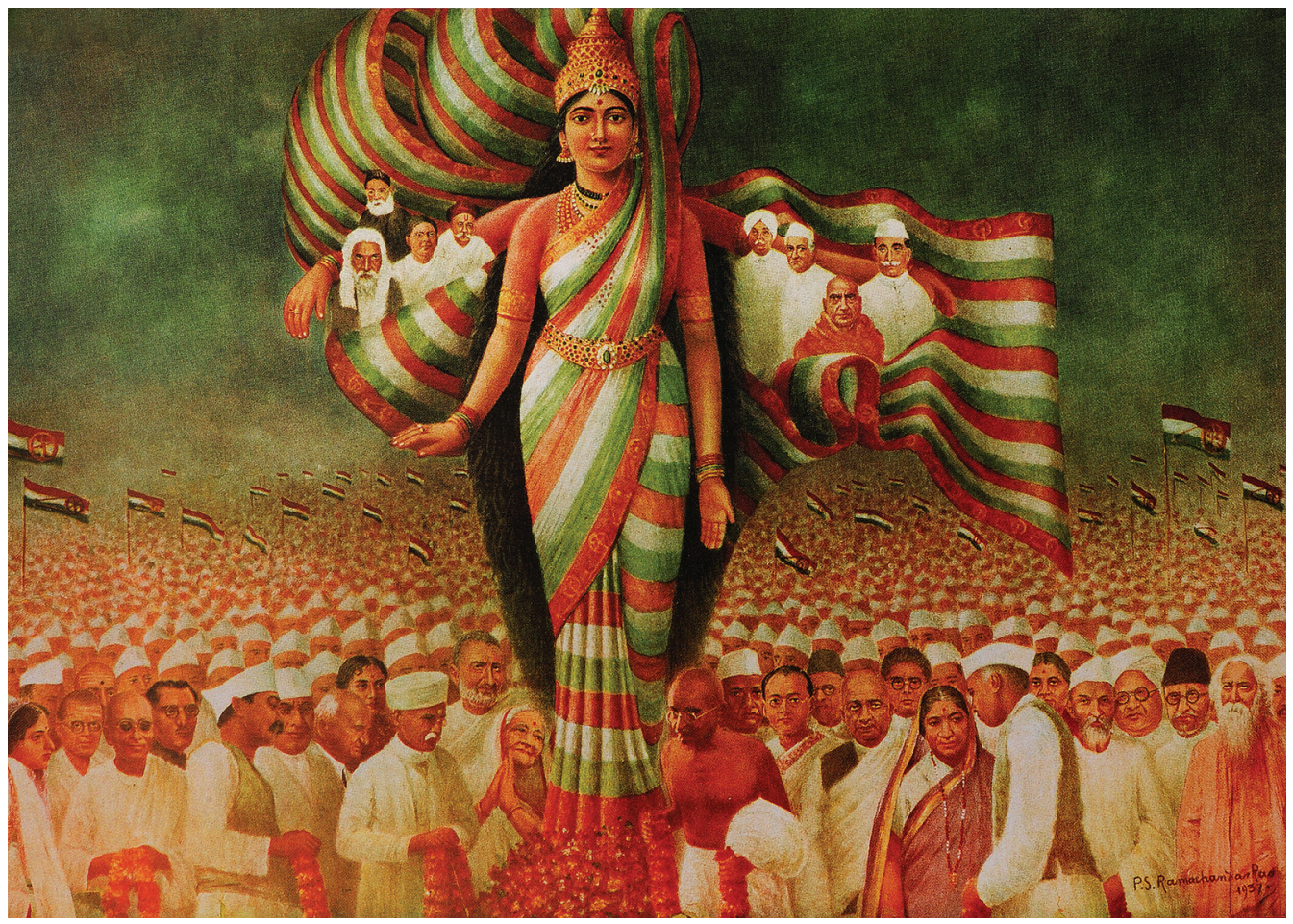

Fig. 24. 3: Vande Mataram, (I praise thee, Mother). Chromolithograph published by Rao Brothers, Coimbatore, Tamil Nadu, 1937. Painting of Mother India by P. S. Ramachandra Rao (Kind permission of Erwin Neumayer and Christine Schelberger, Vienna). The anthropomorphic representation of national space as a sari-clad Mother India is vivid in this patriotic visualization from the pre-Independence period. The sari as producing the geo-body of the emergent nation is evident in this poster produced possibly to celebrate the country-wide electoral victory of the Indian National Congress. Not only is Mother India installed as and within the cartographic outline of the nation, even her sari is the tri-coloured flag of the party espoused by M. K. Gandhi in the 1920s, a version of which later became the Indian national flag.

space was thus mapped as a feminized and divinized sari-scape via the image of Mother India and represented consistently as a desexualized, fair-skinned woman of an unspecified ethnic identity. The nationalist imagery was circulated via mass media as the divine personification of a motherland worthy of both worship and sacrifice. Mother India and her sari were now instruments of territorial integration, symbolizing the freedom struggle and the burgeoning of a nationalist spirit established upon a feminine ideal.

\section{Sari as 'Dress' of the Modern Indian Woman}

Thus far we saw how the sari was implicated in the discourse of tradition and nationbuilding within gendered socio-political norms and values. In this section, we examine nationalist strategies that shaped the contemporary wearing style of the sari within 
an internationally defined dress reform and fashion system of appropriate feminine attire. The Victorian morality of Christian missionaries and social reformers that saw upper-body nudity as indecent and seductive had paved the way for Hindu women to cover their breasts with 'blouses' which were earlier simply enwrapped in the sari. By the first half of the 20th century, the three-piece ensemble of sari, petticoat and blouse had become the norm for the educated urban woman whose clothing choices increasingly represented a progressive outlook while still emphasizing sartorial elements representative of 'Indianness'.

Many women from elite families began adopting the stitched blouse and petticoat as essential accoutrements within a gendered code of dress as a marker of emancipation and progress. The new mode of dress adopted was seen to be free from the somewhat restrictive aspects of regional traditions, and considered a more unifying wearing style for the gentlewomen in modernising India. Some women acquired their sartorial inspiration from the English memsahib's tailored outfit. They modelled their sari blouses with pleats, ruffles, fancy sleeves, elaborate necklines and corsets, complemented by accessories such as heeled footwear and sumptuous hairdos. Their sari drape and ensemble became more and more 'efficient' and 'dresslike' to accentuate their recognition of fashionable trends of the colonial metropole.

Others, more involved in the social reform movement from the second half of the 19th century in Bengal and other parts of the country, devised regional variations in draping styles and clothing ensembles to tactically mark differences in religion, caste, class, age and marital status while asserting the image of a modern, urban and educated, Indian woman (Fig. 24.4).

The dress of British women who came to live in India, on the other hand, either conformed to sartorial conventions of a memsahib or, as in the case of Annie Besant, was modified to suit their role in Indian society and politics. Their clothing practices often challenged prevailing notions of wifely and domestic duties within the context of empire and often served as counter-cultural interventions of a politically sensitized sociality for women negotiating colonialism (Fig. 24.5).

In the early years of nation-building, the nationalist ideology was largely integrationist and sought to use India's diverse regional textile traditions, evident in the continued presence and resilience of the hand-woven sari, as a marker of India's cultural unity. The creation of a new national dress thus involved the incorporation and refinement of regional and local sari (textile design) traditions while adhering to an emergent modernist ideal and sartorial conception of the Other, predicated upon a rhetoric of nation based on 'unity in diversity'. By postulating stitched clothing as the attire of foreign invaders of the ancient land - Mughals and the British, the discourse established an unbroken legacy and indigenous preference for the 'unstitched' or draped garment as emblematic of the emergent, primarily Hindu, nation. It now also featured the twin processes of specialization of India's regional diversity, on the one hand, and the development of a trans-regional, unifying dress, on the other.

While Gandhi called for the wearing of coarse khadi (hand-spun and handwoven) saris as a unified nationwide symbol of opposition to British manufactured 


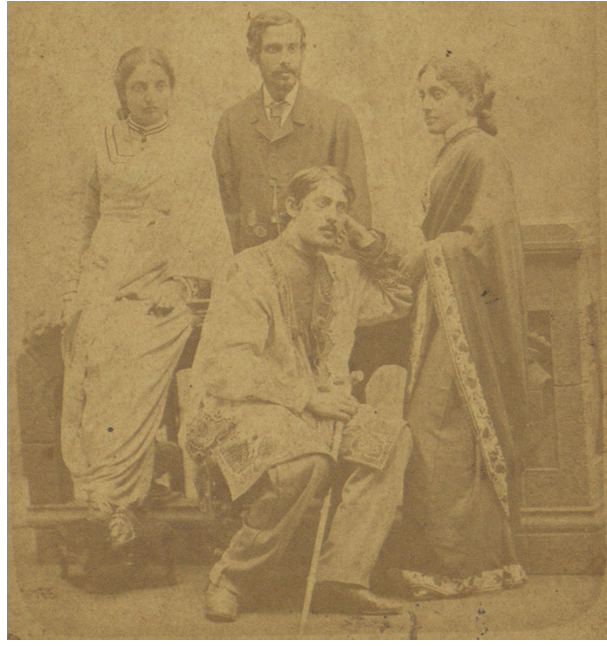

Fig. 24.4: Jnanadanandini Debi standing on the left dressed in a high-necked, long-sleeved blouse alongside her husband, Satyendranath Tagore, older brother of Rabindranath Tagore, first Indian to join the Indian Civil Service of the British Raj and contributor to the cause of women's emancipation. She is glancing in the direction of Kadambari Debi who is wearing a dark Parsi sari with the characteristic attached border of Chinese floral silk embroidery initially popularized by Parsi traders who brought back all-over hand embroidered saris from China in favorite motifs like the peony, butterfly and floral tendrils from the mid-19th century. Kadambari Debi is the wife of Jyotirindranath Tagore (another of the Tagore brothers) who is seen seated. The photograph was taken by P. Vuccino \& Co. in the early 1880 s (Rabindra Bhavan, Visvabharati, Shantiniketan). Jnanadanandini Debi, sister-in-law of poet and Nobel laureate Rabindranath Tagore in Calcutta, is known to have experimented with the regional (Bengal) drape and form of her sari to suit travel and appearances at public engagements with her civil servant husband in her role as a Bhadramahila (mother, wife, daughter of English educated professionals such as lawyer, doctors and government servants). She was influenced by prominent Parsi reformer Lady Bachoobai, known for her work in bringing English education to women at a time when they were still struggling for individual expression. Her dress innovation for the modern Indian woman of her time was an eclectic mix of English, Muslim and Bengali clothing and accessories while maintaining the ideal gender norms of a Bhadramahila. The drape of the sari on the left shoulder in the progressive Parsi manner, together with a blouse and an optional chador later came to be known as the "Thakurbarir sari" or the style adopted by the Tagore family.

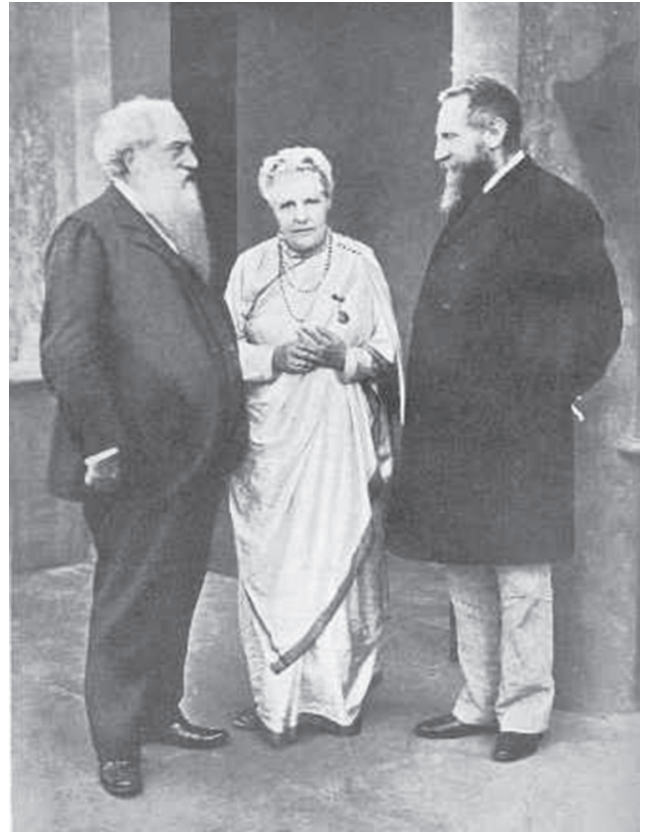

Fig. 24.5: Prominent British socialist, theosophist, women's rights activist, and supporter of Indian self-rule, Annie Besant is seen here wearing a sari with a long-sleeved shirt-blouse. She is flanked by Henry Steel Olcott to her right and Charles Webster Leadbeater to her left at the international headquarters of the Theosophical Society in Adyar, Chennai, December 1905. (From Wikimedia Commons, the free media repository: http://commons.wikimedia.org/ wiki/File:Olcott_Besant_Leadbeater.jpg). Annie Besant's involvement in politics in India as a member and later president of the Indian National Congress in 1917 necessitated a sartorial reworking of her public image as the forerunner of a cultural nationalism founded upon theosophical principles of the wisdom of the 'East'. In her later years, and particularly during her time in Adyar until her death in 1933, she divested her western dress in favour of saris and flowing ecclesiastical robes as appropriate wear for her speeches and campaigns across India. Her dress was indeed an affirmation of both her anti-imperial sentiment as well as a nationalist program for cultural awakening of women in India. 
clothing, as part of his programme for self-rule or swaraj, elite women members of the freedom movement sought to promote handloom saris from different regions as a means to reiterate India's cultural distinctiveness from the West. Social reformer and craft revivalist, Kamaladevi Chattopadhyaya (1903-1988) for instance, is known for providing new markets for artisanal products from remote corners of India. She is well known for her role in the creation of numerous cultural institutions dedicated to regional handicrafts, handlooms and performing art traditions in independent India. She used the sari as a visible symbol of women's participation in the freedom movement and insisted that women Congress party workers wear bright kesaria or saffron orange saris in contrast to the white ensemble worn by their male colleagues for their political work while also encouraging elite women, still entrenched in roles defined by patriarchy, to contribute by patronizing local weavers and dyers for their customary sari selections.

The post-independence era narrative of nation as 'unity in diversity' is best articulated in the wardrobe of India's first woman Prime Minister Indira Gandhi (1917-1984). Her collection of handloom saris emanate an aura of nationalist spirit and feminine respectability so central to her political image of a leader taking pride in the diversity of India's cultural heritage on the national and international stage (Fig. 24.6).

The middle-class appropriation of the sari as national fashion and the preferred dress of the modern Indian woman took place through mainstream Indian cinema and the rising popularity of mill-made saris, themselves products of mass production and aspirational consumption patterns. Early film heroines were modestly clad in saris with blouses and petticoats and the, by now ubiquitous, left shoulder drape, as epitomes of domestic complicity and conjugal sacrifice in sharp contrast to the antiheroine's seductive western outfit portraying the model of a blatantly liberal virago. Bollywood increasingly began employing mill saris, for the anonymity of provenance they provided, to accentuate the image of the voluptuous female ideal of full breasts, wide hips, fair skin and long flowing hair, first disseminated through Ravi Varma's chromolithographs. The stage was now set to propagate the image of a demure, yet alluring, icon of female sexuality for India's media-consuming masses (Fig. 24.7).

\section{'Miss India' and the 'Neo-Liberal Nostalgia' for Homeland}

The last decade of the 20th century has witnessed what may be called the creation of a transnational feminine ideal through the circulation of fashion and global capitalist consumption among the diaspora and cosmopolitan elite in India. Stripped of its regional identity of drape and weave, the sari is now recast as a six-yard textile canvas of 'art-to-wear' within a primarily global design aesthetic.

For the cosmopolitan Indian woman, the cultural semantics of the sari are rapidly changing as it becomes the site for articulating norms of beauty influenced by an international fashion media promoting an 'ideal' female body form. According to 


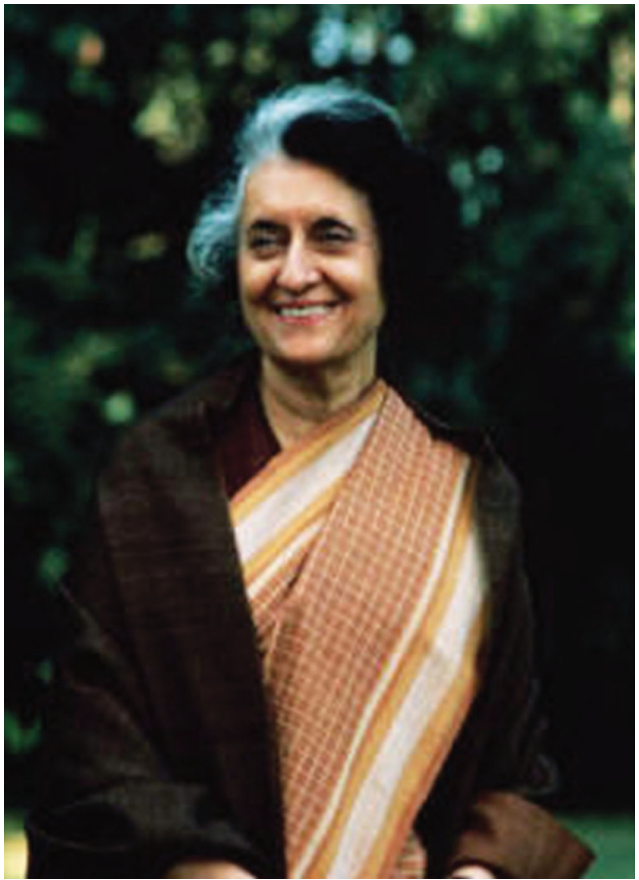

Fig. 24.6: Photo of the late Prime Minister Indira Gandhi clad in a cotton sari, hand-woven from south India as a symbol of the nationalist slogan "unity in diversity" (Courtesy of the Indira Gandhi Memorial Trust; photo: website of the Indian National Congress, <www.aicc. org.in/new/index.php>). Drawing upon the same spirit of an 'all India mind' with which Pandit Jawaharlal Nehru, her father and first prime minister of India articulated his political diplomacy in wearing a version of the Muslim sherwani, Indira Gandhi selected her saris in such a way that they represented the skill of the 'Indian' weaver and were sourced from each and every state in the country and were recognisable as such from their distinctive designs and styles. In the decades after her death, Mrs Gandhi's daughter-in-law, Sonia Gandhi, too has built her own public persona along similar lines to symbolize her political lineage and undisputed position as the current head of the oldest (Congress) party of the nation. Her own saris, often custom-woven by highly skilled weavers from different states, undoubtedly represent her allegiance to the cultural heritage of the nation through its various constituencies (the regionally distinct handloom weaving traditions), and continue to be an indispensable feature of her party's election image of a powerful but respectable woman leader of India.

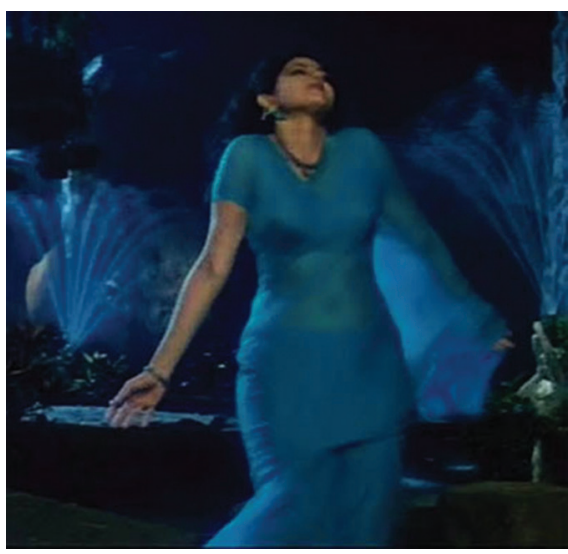

Fig. 24.7: Popular Bollywood actress Sridevi in a 'wet sari' song sequence in a mill-made blue chiffon sari from the blockbuster film titled "Mr. India", 1987 directed by Shekar Kapur (Photo: Courtesy of Mr. Boney Kapoor, Producer of Mr India; Shemaroo Entertainment, Mumbai: http://m. indiatoday.in/gallery/bollywoods-top-10-navels/4/4841.html). The eroticization of the sari often in 'wet sari' song sequences is attributed to the famous actor-director of Indian cinema Raj Kapur who is known to have acknowledged his debt to Ravi Varma's female body form (Dwyer, 2000). Even the wearing style of draping the end-piece over the left shoulder, now the overarching sari drape of the modern Indian women, is implicated in this depiction of feminine appeal as it reveals as much as it conceals the heroine's body for the benefit of 'Mister' India.

this new code of aesthetics, the sari is a sensuous wrap that enhances its wearer's experience of 'feeling beautiful' (Fig. 24.8).

The sari together with its tailored blouse is now seen as a fashion garment ensemble - its six-yard length a planar canvas for designers to explore their textile designing skills, while the blouse, a fashionable bustier reminiscent of a garment from western costume history. Indeed, the female mannequin or body form has been the nodal point of experimentations with the sari among fashion designers, such as Germana 
Fig. 24.8: A well-known media personality and female ambassador of India's national sport, cricket, is seen here wearing a designer sari graphically evoking the tricoloured flag of the nation. The image was not available either from the model or from the textile design studio on account of a national-level controversy and an artist's representation of the same has been reproduced here instead by Sidsel Frisch from CTR, Copenhagen: www. desipolitan.com/2009/02/ja-na-ga-na-ma-na.html). Among Indian fashion designer Satya Paul's numerous art-to-wear saris is the graphic interpretation of the national flag worn at an international sporting event by cricket ambassador and media personality, Mandira Bedi whose sari, unlike Bharat Mata's sari in Fig. 24.3, is not claiming the cartographic boundaries of the Indian nation but rather the contoured and sculpted body of the Indian female (fashion) model wearing it.

Marucelli in the 1950s and 1960s, Pierre Cardin and Zhandra Rhodes in the 1970s and 1980s and Gianni Versace in the 1990s, who pioneered reinterpretations of the Indian sari by employing western garment draping and construction techniques to arrive at novel sari drapes and blouses.

In its postmodern fashion articulation, the sari is now the dress of the cosmopolitan Indian woman whose body is also the site for variously scripting the nation across a transnational terrain of feminine beauty and gender codes. Miss India icons at international beauty contests and pageants are invariably sari-clad during the national costume round as they "perform India" even as they conform to an internationally 
accepted model of Indian elegance and womanhood that continues to hark back to the pre-independence rhetoric of the nation as the paragon of haloed femininity. Beauty queen contestants see themselves not only representing India but as embodying the nation in all its sovereign glory; “... at Miss Universe, you are India, you are everyone's idea of India and everything that it stands for" (Quoted in Runkle 2004, 156).

For the diaspora and cosmopolitan elite in India, the reconstitution of the sari as a transnational fashion garment provides an alternative to western wear while registering their allegiance to a shared cultural heritage. For the contemporary Indian woman of classic taste and refinement, the sari signifies the nostalgia of tradition while making a fashion statement of distinctiveness derived from the luxury of the handmade amidst mass produced options (Fig. 24.9).

The liberalization of the Indian economy and circulation of global capital, since the last decade of the 20th century, has created new consumption patterns among transnational elite and led to the expansion of a market for "cultural" goods, such as the handloom sari. The trend has fostered the design and production of a range of artisanal saris that conjure nation in the deft hands of handloom weavers whose products are increasingly being recast as culturally specific and geographically unique novelties for the Indian diaspora.

The framing of historically distinct cultural products like the Kanchipuram sari under the Geographical Indications of Goods or (GI) is part of a wider global trend to standardise production and consumption and to set them apart from cheap imitations. In India, the GI is part of a protective global circumscription of artisanal products within a state-supported neo-liberal paradigm for economic growth under which hand-woven saris, historically associated with specific localities and geographical regions in the country, are gradually being incorporated. According to this altered version of 'tradition', then the queen among silk handloom saris of India is now the Intellectual Property of the southern state of Tamil Nadu, who is both owner and arbitrator of a regional Indian artisanal heritage.

Confronted with global capitalist consumption and competition, the Indian sari, in all its local variations in the 21st century, promises to yet again be the site for the reclamation of nation through the GI's cartographic remapping of 'tradition' in order to spotlight 'nation' together with its (cultural) products in the global marketplace. Only this time, it prefigures a vastly altered version of the global, together with its norms of feminine beauty and morality. 


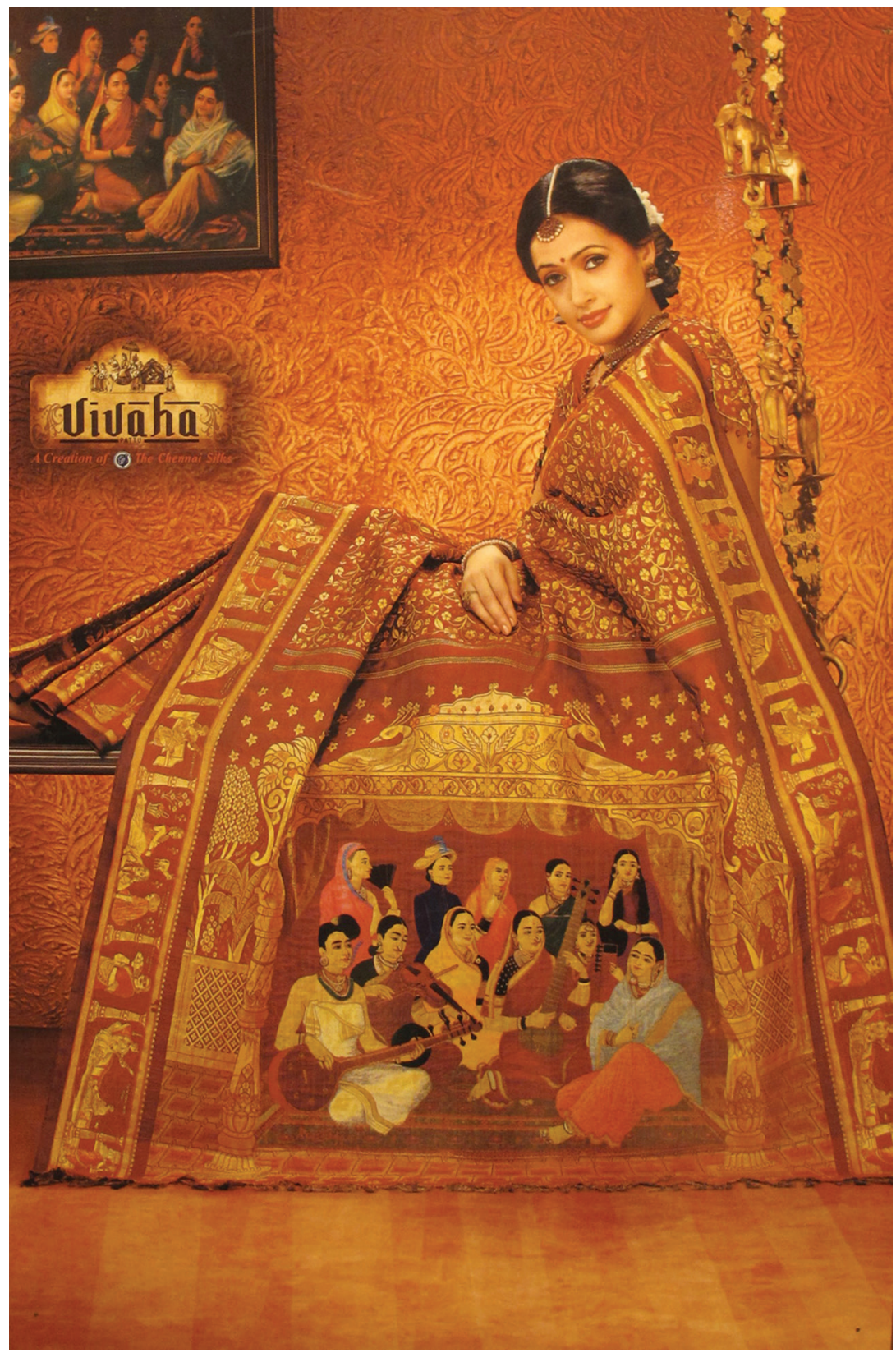

Fig. 24.9: The Raja Ravi Varma Sari, hand-woven in silk, gold and precious stones by Chennai Silks, Tamil Nadu India. Recognized under the Guinness Book of World Records, 2008 (Chennai Silks Showroom, Chennai; (c) Photo Kritika Sharma). 'Tradition' and 'nation' are both safely ensconced within the folds of this 'most expensive' sari studded with precious stones and created over a period of nearly 5000 hours of hand work by weavers hailing from the ancient town of Kanchipuram in southern India and officially protected under the Geographical Indications Act of 1999 as the Intellectual Property of the Indian nation. The national ideal of femininity and snapshot of nation exemplified by Raja Ravi Varma's painting A Galaxy of Musicians (Fig. 24.2) is now transfigured into a cultural product catering to a neo-liberal nostalgia for tradition. 


\section{Further Reading}

Partha Chatterjee (1992) The Nation and its Women. In The Nation and its Fragments. Colonial and Postcolonial Histories, pp. 116-134.

Sarala Devi Chaudhurani, Sukhendu Ray (translator) and Malavika Karlekar (2010) The Many Worlds of Sarala Devi: A Diary and The Tagores and Sartorial Styles: A Photo Essay.

Jayakumari Devika (2005) The Aesthetic Woman: Re-Forming Female Bodies and Minds in Early 20th Century Keralam. Modern Asian Studies 39:2, pp. 461-487.

Rachel Dwyer (2000) The Erotics of the Wet Sari in Hindi Films. Journal of South Asian Studies, 23:2, pp. 143-160.

Tapati Guha Thakurta (1991) Women as 'Calendar Art' Icons: Emergence of Pictorial Stereotype in Colonial India. In Economic and Political Weekly, 26:43, pp. 91-99.

Susan Runkle (2004) Making 'Miss India'. Constructing Gender, Power and the Nation. South Asian Popular Culture, 2:2, pp. 145-159. 


\title{
25 From Cool to Un-cool to Re-cool: Nehru and Mao tunics in the sixties and post-sixties West
}

\author{
MICHAEL A. LANGKJ/ER
}

Michael A. Langkjær has a background in men's fashion and a PhD in history. He is a lecturer at the Saxo Institute, History Section, University of Copenhagen. His field of research is fashion and costume history, focusing on rock military style in Anglo-American popular culture. Recent publications include, "Then how can you explain Sgt. Pompous and the Fancy Pants Club Band?" Utilization of military uniforms and other paraphernalia by pop groups and the youth counterculture in the 1960s and subsequent periods, Textile History, 41:1 (2010), Supplement: Textile History and the Military, pp. 182-213, and Гусар с гитарой. Мотивы стиля милитари в образе Джими Хендрикса (Guitar Hussar. Motives behind the military look of Jimi Hendrix), Теория моды: одежда, тело, культура. Выпуск 19. Весна 2011. Russian Fashion Theory: the Journal of Dress, Body \& Culture. Issue 19. Spring 2011, pp. 243-269. Together with ÆEsa Sigurjónsdóttir and Jo Turney, Langkjær has

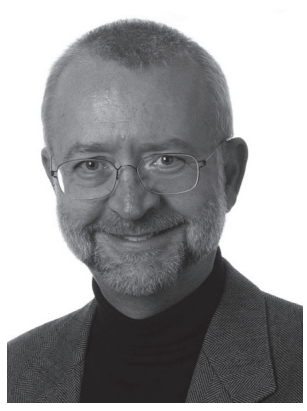
co-edited the volume Images in Time: Flashing Forward, Backward, in Front and Behind Photography in Fashion, Advertising and the Press, 2011. From 2011-2013

Reviews Editor of Catwalk: The Journal of Fashion, Beauty and Style, he is now member of the journal's Editing Board. Readers of this chapter may also be interested in Michael A. Langkjær, Rock Military Style: Motivations Behind the Military Look of 1960s Rock Musicians, in P. McNeil and L. Wallenberg (eds), Nordic Fashion Studies, 2012, pp. 271-291; and, A case of misconstrued Rock Military Style: Mick Jagger and his Evzone "little girl's party frock" fustanella, Hyde Park, July 5, 1969, Endymatologika/4. Endyesthai (To Dress). Historical, sociological and methodological approaches. Conference Proceedings, Athens, 9-11 April 2010, 2012, pp. 111-119. Guest editor with Mette Bruun of a theme issue on sportswear in Fashion Practice.

The Nehru tunic is modeled on the South Asian achkan worn by Jawaharlal Nehru, Prime Minister of India from 1947 to 1964. (The sources differ as to whether Nehru wore a Hindu achkan or Muslim sherwani. The majority of sources consulted for the present chapter have achkan. However, see Aarti Kawlra's chapter 24, Fig. 24.6 image text). Abstaining from the luxurious silk and gold brocades from which the Indian nobility had made their achkans Nehru distinguished his patrician identity with welltailored garments of a superior quality. Unlike the achkan which falls somewhere below the wearer's knees, the Nehru tunic is shorter to resemble a suit jacket and its standing collar has an interval exposing the throat, a shirt or a turtleneck, somewhat in the manner of a clerical collar.

Sun Yat-sen (or Sun Zhongshan), Provisional President of the new Chinese Republic proclaimed in 1911, is credited with the modernization of Chinese men's dress. By 
the early 1920s, the Sun Yat-sen suit (or Zhongshan zhuang) had a high turn-down military-style collar and four symmetrically placed gusseted patch pockets. Further modified post 1949 by Mao Zedong, it became the 'Mao suit', although the Chinese still refer to it as the Zhongshan suit (Fig. 25.1).

The Great Proletarian Cultural Revolution 1966-1976 was the time when the Chinese were seen as a human sea of blue-uniformed revolutionaries derided as "blue ants" by hostile westerners. Back in 1966, I had read the recently published Alonzo and the Army of Ants, about an anteater, who with the other animals of the Latin American jungle and pampas battled "the enemy", a ferocious horde of army ants in a none-too-subtle allegory on the monochromatic revolutionary masses of Communism.

Pictorial coverage of Nehru with Zhou En-Lai during their summits in the 1950s enables us to compare their tunics' cuts and collars directly (Fig. 25.2). The common denominator was dignity and power - that in plainness lay power. I shall now treat some interesting arcane aspects behind the Nehru and Mao vogues in the West.

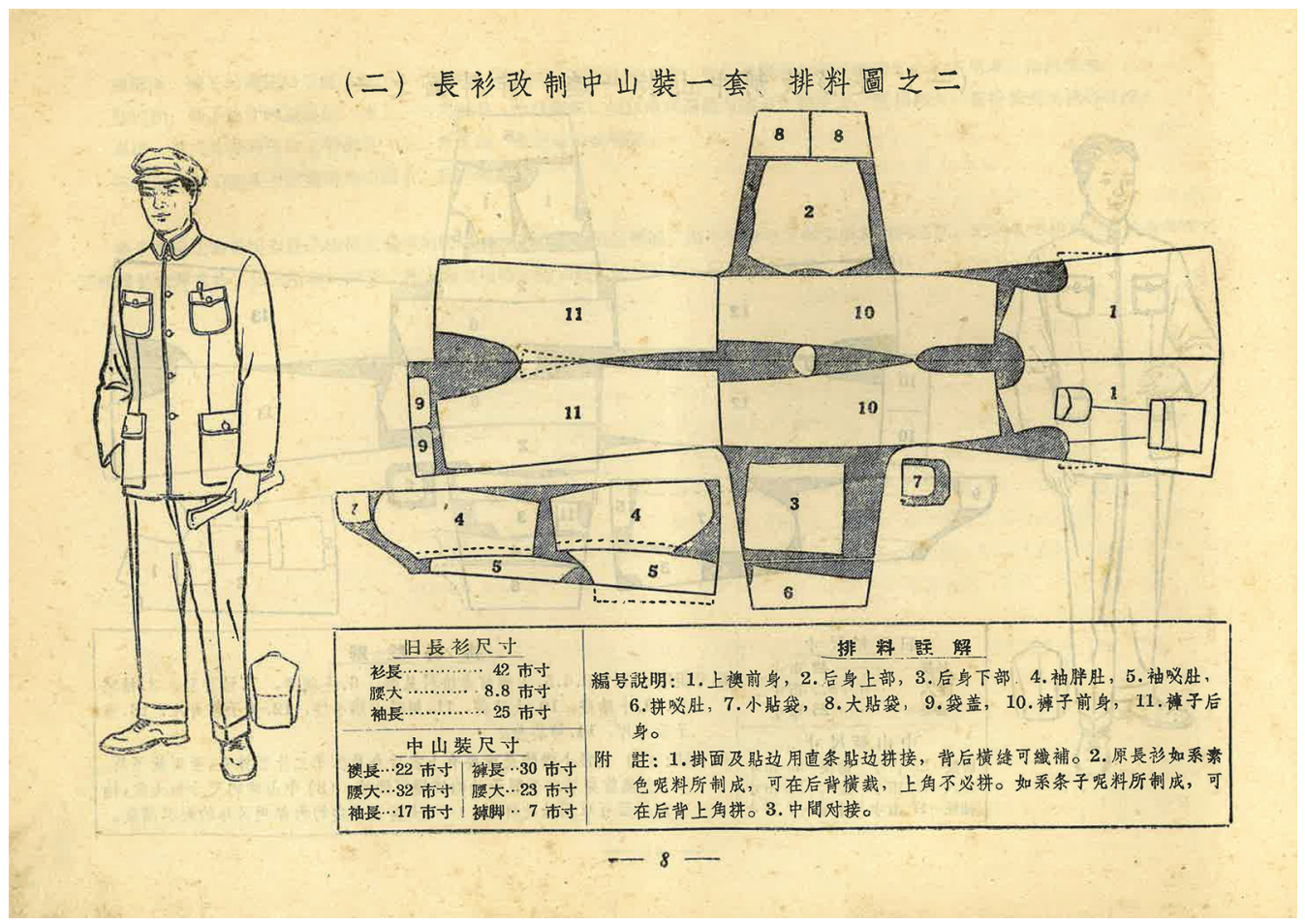

Fig. 25.1: A Mao suit in Chinese patternbook from 1957. 'Cutter's instruction \#2 for converting a [traditional long gown] changshan 长衫 into a [Sun Yat-sen suit] Zhongshan zhuang 中山装 [= Mao suit].' In the box at the bottom to the left are given measurements of respectively the gown, and the tunic 襖 and trousers 裤, and to the right are explanations of the numbers in the drawing itself along with some supplementary notes with additional explanations (Private Collection). I would like to thank Leif Littrup (Associate Professor Emeritus, Saxo Institute, University of Copenhagen) for his generous help in translating the Chinese text. 
Fig. 25.2: India's Jawaharlal Nehru (centre) using interpreter to speak with China's Zhou En-Lai (left) at the Bandung Conference in 1955 (Photo: All Over Press/Getty Images).

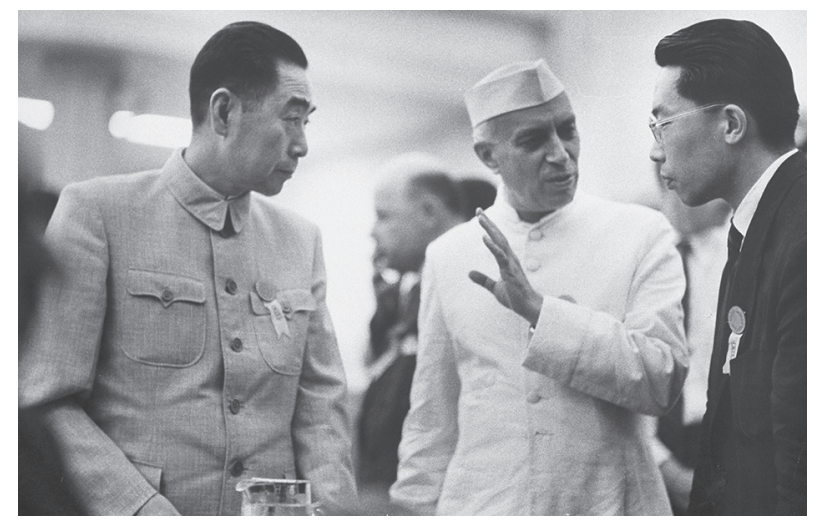

Famed sitar virtuoso Ravi Shankar had since 1956 begun touring Europe and America, thereby contributing towards making Indian music and culture known; in a Hollywood studio shot of Shankar and a couple of troupe-members in 1957, they sported Nehrucollared waistcoats and suit-jacket Nehru tunics. At the very start of the 1960s, the highly controversial comedian Lenny Bruce had worn a stage costume he dubbed a "Chinese rabbi suit", also described as "a black priestly modification of a Chairman Mao tunic" (Mottram 1992, 255 and 257). The five-button, mandarin-collared black linen tunic had by 1962 become Lenny's trademark; its resemblance to a clerical uniform fits well with his wish to make of himself "a functioning rabbi in secular drag" (Kofsky 1974, 87).

In 1964 Gilbert Féruch and the Italian house Caraceni alike were custom tailoring Nehru tunics for private clients. Among the trend-setters often cited as having launched the vogue for Nehru-tunics are the Beatles. Pierre Cardin-inspired showbiz tailor Dougie Millings made the Nehru-tunic costumes worn in 1965 in New York City's Shea Stadium as well as John Lennon's Nehru-collared and Mao patch-pocketed military-style suit for the 1965 Beatles' film Help! The Nehru tunic is also seen as having become 'in' around 1968, the time of the Beatles' pilgrimage to India; this is however, belied by the many instances of the style in evidence in the West prior to that year (Fig. 25.3). Others maintain that what really kicked off the popular Nehruvogue stateside was when, in 1968, television host Johnny Carson walked on stage to deliver his Tonight Show monologue wearing an Oleg Cassini-made Nehru tunic.

Mao-worship reached a peak in France in 1967 with Paris store windows full of 'Mao suits' and 'sino-blazers', many of which in fact were Nehru-tunics designated 'Mao' for political marketability; it was the idea that counted, so anything remotely Chinese-looking would in the loosest possible way be called "Mao". This holds well whenever Nehru-collared tunics are mentioned in countries not so closely bound up with the Indian tradition as was Great Britain.

The prevalence of the Nehru and virtual absence of the Mao tunic prior to 1967 is intriguing. I would like to suggest an early, broad-based cultural exposure to the Nehru (and Mao) styles through wide circulation media such as National Geographic and Life magazine as a possible factor. The Geographic's high-quality photojournalism 


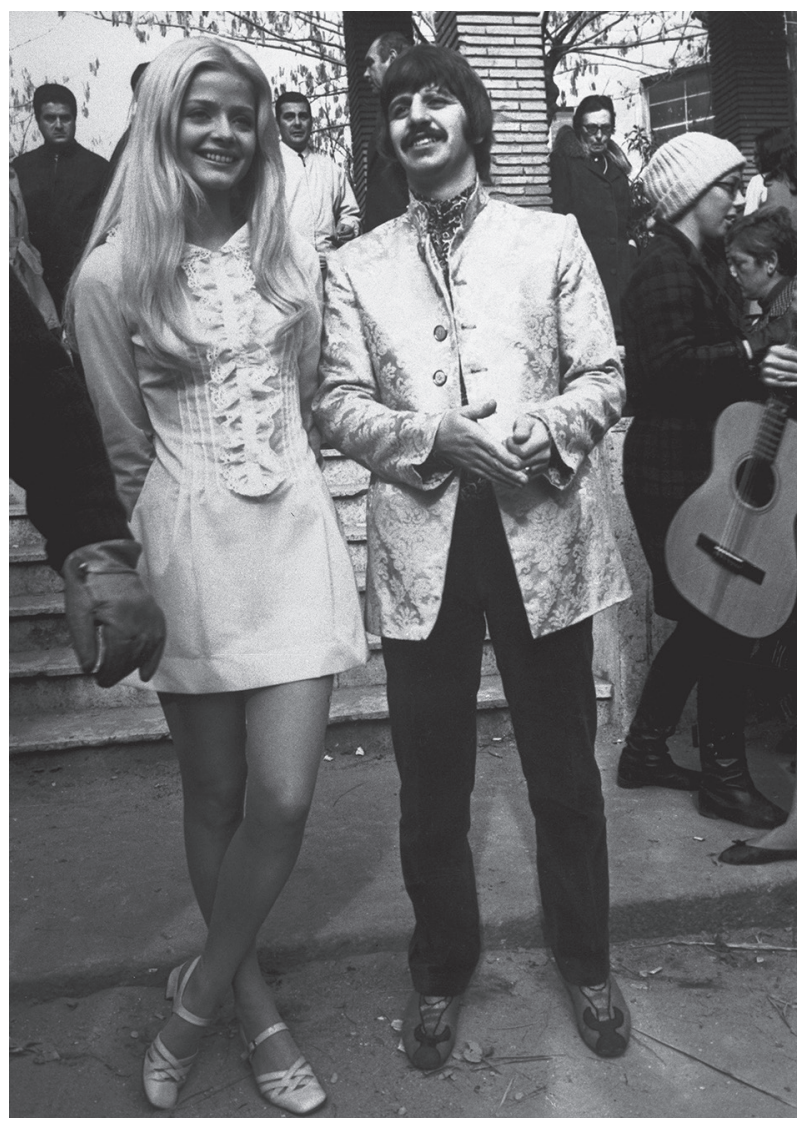

Fig. 25.3: Ringo Starr of the Beatles with young Swedish actresss Ewa Aulin in 1967 in Rome, Italy. Note the brocade Nehru-style jacket worn by Ringo (Photo: Bettman/ Corbis/POLFOTO).

provided tantalizing glimpses of princely India lustrously attired in Nehru-collared silken brocaded achkan coats. National Geographic Hindu eye-candy was supplemented by Life images of the suave and elegant Prime Minister Jawaharlal Nehru in his achkan bounding up the steps of the White House to grasp President Eisenhower's extended hand, and his cool energy and progressivism were in synch with the New Frontier of JFK. (Back in India, cartoonist Shankar waxed ironical about this, depicting an achkanclad, Gandhi-capped Nehru bolting off towards some unseen goal). Publicity shots of the Prime Minister of India in any one of his well-tailored Nehru-collared achkans together with the youthful Kennedys when he visited the Camelot White House in November, 1962 lent glamour to the Nehru-look (Fig. 25.4). Photo-ops of 'Queen of America' Jackie met by achkan-clad maharajas, Nehru and other worthies on the occasion of her trip to India, visiting the Pink Palace in Jaipur and riding elephants, would have enhanced stylish impressions of the achkan.

Pictorial essays in Life showed what was happening to the Red Chinese during the Great Leap Forward and the Cultural Revolution, amid "the oppressive regimentation imposed on them". That was not necessarily how those living under the red banner with the five yellow stars saw it; according to Ji Chaozhu, Chairman Mao's translator: 


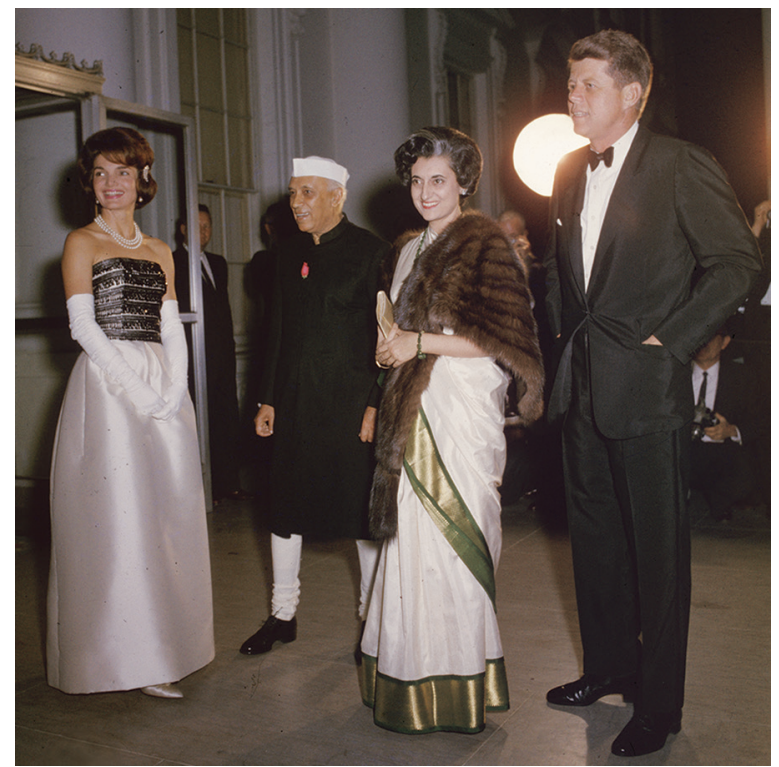

Fig. 25.4: American President John F. Kennedy (right) with his wife Jackie (left), India's Prime Minister Jawaharlal Nehru (centre-left) and Nehru's daughter Indira Gandhi (centre-right) (Photo: All Over Press/Getty Images).

the People's Suit, the Zhongshan...became popular in blue, symbol of patriotism and solidarity with the working class" and [I] wanted "to succeed through diligence, like [my] father's proverbial ant...a cog in the great machinery of revolution and nation-building...[in] a new blue Mao tunic and trousers (Ji Chaozhu (2008) The Man on Mao's Right: From Harvard Yard to Tiananmen Square, My Life Inside China's Foreign Ministry, 73-74 and 122).

In 1958, Danish globetrotter-writer-photographer for National Geographic Jørgen Bisch had found the people clad in drab blue uniforms, eliciting the title "blue ants" from critical visitors. On Bisch's return to China in 1964, as with Canadian Audrey Topping's reportage from 1971, there were still plenty of blue tunics. According to Topping, China's Premier Zhou En-Lai wore a neat gray Chinese tunic, of obviously good cut and high-quality cloth; Henry Kissinger would also describe it as "at once simple and elegant" (Kissinger 1979, 743). But even if Zhou could put a cosmopolitan face on Chinese Communism, the Mao-look had - particularly in its associations with excesses of the Cultural Revolution of the late 1960s and early 1970s - already been saddled with an unappealing reputation.

Oleg Cassini, in the journal Men's Wear, of June 7 1986, p. 57, claimed that, "The Nehru... is nothing more than a military uniform", noting its similarities to the "crisp military seaming and close-to-the body-fit of the precisely engineered World War I [doughboy] tunic". That "close-to-the body shape" (known as 'the bodyline') which "makes a man feel and look slimmer", may refer back to 'the Adonis complex', viz. a young male imagining himself as possessor of a young and beautiful body and ergo wanting clothes to adhere to his body, to show it off (Fig. 25.5). 


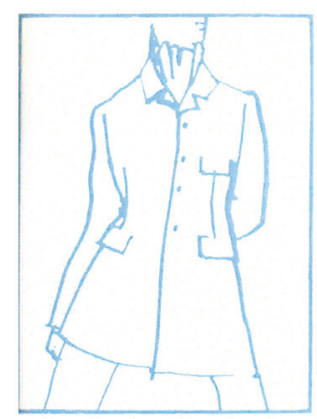

CASSINI:

"Post-Nehrus will have collars."

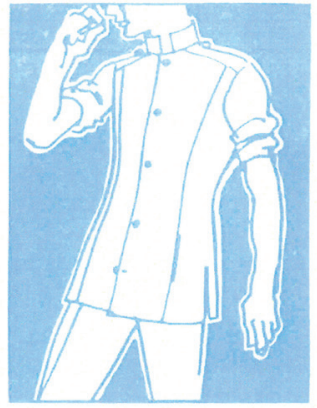

BLASS:

"A merger of

the doughboy

and tunic shirt."

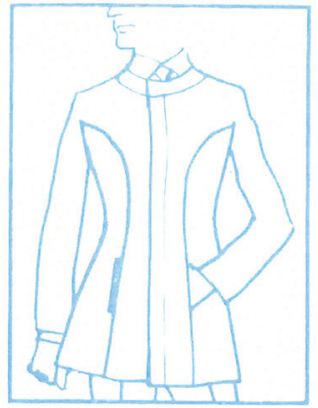

MILLER:

"I like a crewneck."

Fig. 25.5: Sketches of Nehru and Nehru-inspired jackets accompanying the editorial 'Next After Nehru: The Bodyline', in Men's Wear, a trade journal (now defunct), vol. 157, Feb-April 1968, pp. 55-59, p. 57 (Fairchild, The Condé Nast Publications Ltd, USA $\odot$, who however, are not held accountable or liable if a futute claim is made).

Back in 1967, when Penthouse fashion editor Rodney Bennett-England questioned a group of men's clothes designers about the look of the younger man of tomorrow, they supplied him with fashion sketches of 'with-it' suits where standing, Nehru, or standing fold-down collars predominated. These were "classless", "international", "light-weight", "functional" and "unfussy" (Bennett-England 1967, colophon and pp. 36, 58, 63-64, 72-73, 75-78, 80-81, 83, 86, 90-99, 100, 163, 223-224). In keeping with the conviction that design-styling and the functional side must go together, such future outfits would have a clean-cut look and be comfortable. With their minimalist cut, Nehru tunics exemplified the relative simplicity and coolness of 'Mod'. 'Mod' originated with the British working class teenager subculture 'Mods' c. 1960-66 whose vision of style included sharp Italianate suites, Vespa scooters, rock music of The Who, and pop-arty symbols such as the RAF roundel or 'target'. Within fashion 'Mod' became synonymous with the bold colours, clean, streamlined tailoring, and minimalist functionality of the youth-oriented designs of Swinging London. Along with miniskirts and Nehru tunics, the 'Mod' style featured bell-bottom pants, wide belts, wide 'kipper' ties, and bold industrial zippers. Among American youth, the 'Mod' appeal of the Nehru style may have derived some impetus from the Adventures of Jonny Quest, an animated cartoon series that had premiered in 1964. To the accompaniment of jazzy music, pre-teen Jonny travelled around the world with his scientist dad Dr Benton Quest aboard a supersonic plane with Dr Quest's assistant, 'Race' Bannon, the little dog, Bandit, and Jonny's East Indian friend, Hadji. Hadji, master of Hindumagic which included snake charming, levitation, magic, and hypnotism, was smart and spoke excellent English. He also wore a bejeweled turban and Nehru suit (Fig. 25.6). Jonny and Hadji seemed to be having so much fun on their adventures that we often wished we could be in their place. Jonny Quest along with Hadji and his Nehru expressed the sixties 'Mod' wave of style, and excitement spurred by modern advances - an ambience similar to that of the Bond films starting with Dr No; here 
mandarin-collared Nehru tunics add to the film's modern, exotic flair.

Another appeal is that of the mandarin-, Nehru-, or Mao-collared headstrong, defiant, genius supervillain. In The Mask of Fu Manchu from 1932, Fu Manchu had been the prototype stand-up collared evil genius. Actor Henry Brandon, who played Fu Manchu in Drums of Fu Manchu in 1940, claimed that the kids were on his side, because Fu Manchu was brighter than the others, and the kids went for intelligence, whether it was bad or good! Fu Manchu's film-costume was carried over to the mandarin-collared and later Mao tunics of the megalomaniac villains in Bond films.

The release in 1962 of $\mathrm{Dr}$ No would make this one of the first mass media exposures of the standing collared tunic: whether beige, with hidden buttons, and a rounded-edge mandarin collar, and a no-pocket minimalism as worn by the film's eponymously named villain or the somewhat less 'taut' version with exposed buttons and outside breast pocket for a neatly folded handkerchief as would befit the gentlemanly James Bond. The Mao tunic is in 1964 in Goldfinger worn by the Red Chinese agent Mr Ling, whose job it is to prime the nuclear device used to contaminate Fort Knox in 'Operation Grand Slam'. In You Only Live Twice and Diamonds Are Forever, from 1967 and 1971, recurrent arch-villain Blofeld sports beige or grey Mao suits (Fig. 25.7). To actor Jonathan Pryce, who played media mogul Elliot Carver of Tomorrow Never Dies from 1997, his allblack, sharply tailored Kenzo Mao-style costume represented "an NAR look: no acting required, because the image is so good it tells you everything" (Pearce 1997, 89).

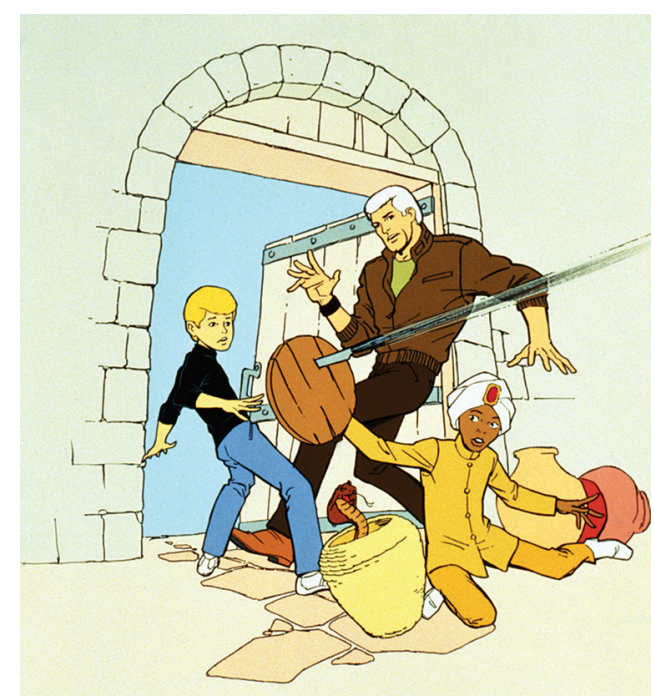

Fig. 25.6: Wearing a turban and Nehru tunic, Hadji's quick reaction saves Jonny Quest from an assassin's knife even before 'Race' Bannon can lend a hand, in Hanna-Barbera's JONNY QUEST (Licensed by: Warner Bros. Entertainment Inc. All Rights Reserved).

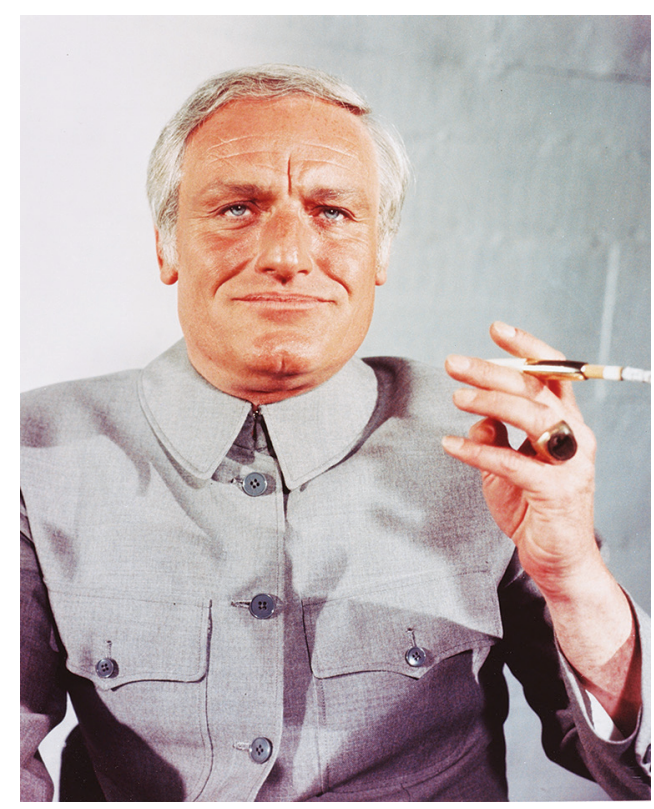

Fig. 25.7: Charles Gray as Blofeld in the James Bond film, Diamonds Are Forever (Photo: All Over Press/ Getty Images). 
The Nehru tunic was still, in the language of the times, considered a cool, real groovy outfit in a January 1969 Archie comic 'Archie in "Ding-A-Ling”', where Veronica 'Ronnie' Lodge thinks it looks great on Reggie Mantle, Archie Andrew's rival for her affections. One simply has to wear it for the school dance in order to keep up with the in-crowd, along with 'love' beads and a 'brotherly love' bell pendant. The exchange between Archie and his Dad is, however, suggestive: "No son of mine is going to wear beads! - But, Pop! Beads are in today! It's the latest fad!" - "Then you'll just have to start your own fad." So Archie ends up wearing a cow bell as the latest fad! This, and the title, "Ding-A-Ling" hinting at something or somebody eccentric or stupid, also suggests an incipient disenchantment with the Nehru look.

And perhaps the Nehru was too outlandish, by then. An extreme case of such aversion occurs in a 'Captain Action' 1968 super-villain action figure, the Spock-eared sinister invader of Earth 'Dr Evil' who, along with facial features resembling "those of a frog being squeezed" and an exposed brain, sported a shimmering blue Nehru tunic and trousers, hippie-like sandals, and a gold medallion that draped him in all the strangeness of the alien. His Mao-tunicked counterpart has come in the shape of the David android, eighth generation, created by the fictional Weyland Corporation in Ridley Scott's 2012 science fiction film Prometheus, prequel to his 1979 sciencefiction film classic Alien.

For Austin Powers: International Man of Mystery (1997), comedian Mike Myers outfitted his Dr Evil antagonist in a grey mandarin-collared tunic similar to that worn by Dr No. The self-aware bad taste of the Powers films would re-affirm the perception of the Nehru tunic as being (in a backhanded complimentary 1960s-retro sense) cool. Designer Joseph Abboud relates that some years ago, one of his young twenty-something designers had an idea: What about a band-collar jacket? Back in the 1960s, as Abboud recalled, there had been a band collar jacket, known in those days as the Nehru jacket - in light-blue polyester and an easy laugh. His young designer did not know what a joke it was then, and as far as Abboud was concerned, that was good - and lo and behold, a picture of Abboud's linen menswear collection spring/summer 1995 shows a Nehru cut. The Nehru tunic has made a serious bid for permanence in a monumental painting of three generations of the Danish Royal Family unveiled in 2012 which shows young Prince Christian in a nifty Nehru-style jacket together with his father, Crown Prince Frederik and grandmother, the reigning Queen Margrethe II.

Present efforts to render the Mao fashionably stylish play on its enduringly provocative ideological connotations. By dressing Mickey Mouse in a bright red 'Mao suit' for Hong Kong Disneyland for the Chinese lunar New Year - Year of the Rat 2008, designer Vivienne Tam took a 'long march' away from the anathematic days of the Cultural Revolution. And in the March 2012 issue of IHT Style Magazine, the world's most famous Chinese model Liu Wen is seen in a Céline Mao-tunic inspired belted jacket - female Maoist cadres had originally worn their tunics with belts to emphasize their waistlines - beneath a 'Mao Rushmore' statue of the Chairman in Changsha. 
So let me now conclude by briefly reiterating some main points and laying down one or two salient observations about the parallel, if somewhat different vicissitudes of cool, un-cool, and re-cool of the Nehru and Mao tunics. The intertwining of National Geographic, Life, and Jonny Quest, with notions of 'aristocracy', 'class', 'cool ambience', 'power', 'virtue', 'modernity', 'Adonis complexes', metaphorical 'ants', and James Bond super villains, mistaken identities and Parisian style mix-ups between and betwixt the Nehru and Mao, indicates that a multitude of factors and influences went into determining the shifting appeal of Nehru and Mao tunics. Nevertheless, their recurrence and, not least, their most recent revival as fashion items testifies to the fact that both tunics are perdurably stylish.

In retrospect, their vicissitudes as a 'look' would appear to have had a common base in their being similarly 'utopian' fashion concepts. This utopian character is most immediately apparent with the Mao tunic: either you were ideologically 'turned off' by its indissoluble ties with Communist totalitarian 'worker-ant' egalitarianism, or you were ideologically 'turned on' by its associations with the 'peoples' revolution' (or by the novelty and hipness of Red China thanks to diplomatic 'superstar' Henry Kissinger's re-opening of 'The Middle Kingdom' to the West as a Cold War ploy). The Nehru tunic had connotations of aristocracy that seamlessly meshed with postcolonial progressivism and 'democracy'. But here too, there were ties with some utopian notions back then in the 1960s, in particular of a 'Mod' technology-based future where everything was simply 'faster, bigger, higher' - just like the FrancoBritish supersonic airplane, the Concorde. This could not at length hold up against increasing awareness toward the end of the decade of ecological 'limits to growth'. In addition, the Nehru look had become stigmatized by its wearers' hedonistic lifestyle utopianism, which by 1970 had become outmoded, precisely for its having been too big a fad and perhaps too 'ethnically' alien as well. But, as it turns out, once both tunics had been completely divested of their 'utopian' connotations (or these had been replaced with a nostalgia for just such a utopianism which had been rendered totally innocuous by time and history), their qualities as stylishly cut and detailed alternatives to the standard Western suit endowed them with renewed appeal.

\section{Further Reading}

Anthony Bednall (2012) Fashion Revolution China.

Rodney Bennett-England (1967) Dress Optional: The Revolution in Menswear.

Farid Chenoune (1993) A History of Men's Fashion.

Alastair Dougall (2000) James Bond: The Secret World of 007.

Henry Kissinger (1979) The White House Years.

Frank Kofsky (1974) Lenny Bruce: The Comedian as Social Critic and Secular Moralist.

Eric Mottram (1992) The American Comedian as Social Critic, 1950-1970, in Dale Carter (ed.),

Cracking the Ike Age: Aspects of Fifties America, pp. 238-261.

Garth Pearce (1997) The Making of Tomorrow Never Dies.

Adolphe Clarence Scott (1958) Chinese Costume in Transition.

Valerie Steele ed., (2010) The Berg Companion to Fashion.

Emma Tarlo (1996) Clothing Matters. Dress and Identity in India. 



\title{
26 Too Old: Clothes and value in
}

\author{
Ingun Grimstad KLePP, LILL VRAmo and KiRSI LAitala
}

Research professor Ingun Grimstad Klepp is a researcher at the National Institute for Consumer Research (SIFO) in Oslo. She holds a PhD on cultural heritage in outdoor life from the University of Oslo. Her current field of research concerns clothing practices and material studies. Klepp has published in Russian and French in addition to Norwegian and English. Her most recent publication is on the entire value chain from sheep to yarn and clothes, Ingun Grimstad Klepp and Tone Skårdal Tobiasson, Ren ull (2013). Her work concerns a variety of subjects including clothing habits, washing habits, and social aspects of appearance and beauty. She has contributed multiple articles to Berg's Encyclopaedia on Clothing and has written a book in Norwegian on dirty clothing, which concerns changes in laundry habits - why and what kinds of clothing we wash - since the end of the 19th century. The following chapter is a continuation of her work on disposal durability and sustainable fashion which she has been concerned with since a report in 2001 on why clothes go out of use. Klepp has led many research projects in the area of clothing and the environment at SIFO.

Lill Margrethe Vramo is an anthropologist who has carried out research in Norway, India and Bangladesh. She is a research fellow at the National Institute for Consumer Research, Norway and is a PhD candidate at the University of Oslo. She is currently working on her PhD on Transnational Consumption, focusing on Indian Sikhs living in Oslo and their families and networks in India and Great Britain. In this article she draws on data from field work in the Indian Punjab (2010-2011) where she participated and interviewed informants before and after various events and parties related to seven different weddings, including shopping trips and dressing and undressing practices. She has undertaken research on areas related to material culture and ethical trade. Her relevant publications include: "Trade not Aid", an anthropological analysis of fair trade between Norway and Bangladesh (2006).

Kirsi Laitala holds a PhD from the Department of Product Design, Norwegian University of Science and Technology, and is a researcher at the National Institute for Consumer Research. She has an MSc in Textile, fibre and clothing engineering from the Tampere University of Technology in Finland. The Norwegian material in this article builds on her PhD project where she studied the possibilities of reducing the environmental impact of clothing consumption in Norway. She conducted a quantitative consumer survey and in-depth interviews combined with wardrobe studies, where detailed information of the clothing material flow of households was collected during a six-month period. Earlier she has researched and published on areas related to clothing quality, maintenance, safety, as well as fit and size issues.
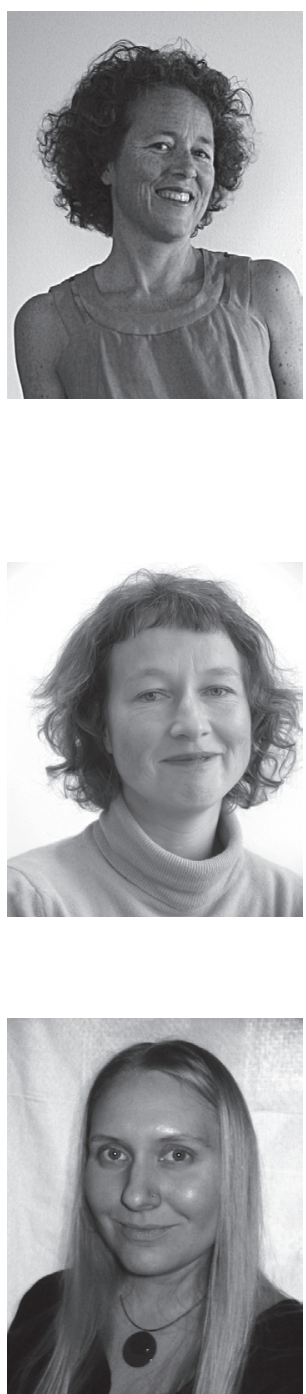
"This is old - and that is old", says Davinder as she makes a face and points to the folded salwar kameezes laid on the bed in her mother Balwinder's bedroom. "They have been used three times and now they are only suitable for wearing in the house", Balwinder explains. Her twenty-two-year-old son sits on the bedside, and clarifies: "People have already seen them." This scene is taken from a middle class family in the Indian Punjab in 2011.

Even though clothes in Norway often have a short lifespan, it is hard to imagine a similar conversation taking place in a Norwegian bedroom. Here, we compare the idea of age, value and obsolescence in today's Norwegian and Indian wardrobes. Making sure not to wear the same items "all the time" is also important in Norwegian clothing practice. However, as we show, there are different reasons and explanations behind this and therefore different solutions are sought among our Norwegian informants. We investigate the connection between social and technical lifespan and the connection between economic value and how long the garments are in use.

The fast turnover of clothes in the West is considered an environmental problem and is explained by fashion. Fashion is perceived as a characteristic feature of modern, western clothing. In Punjab and in Norway, traditional costume is in use as well as modern western clothing style. What is the connection between age and value in these different dressing concepts?

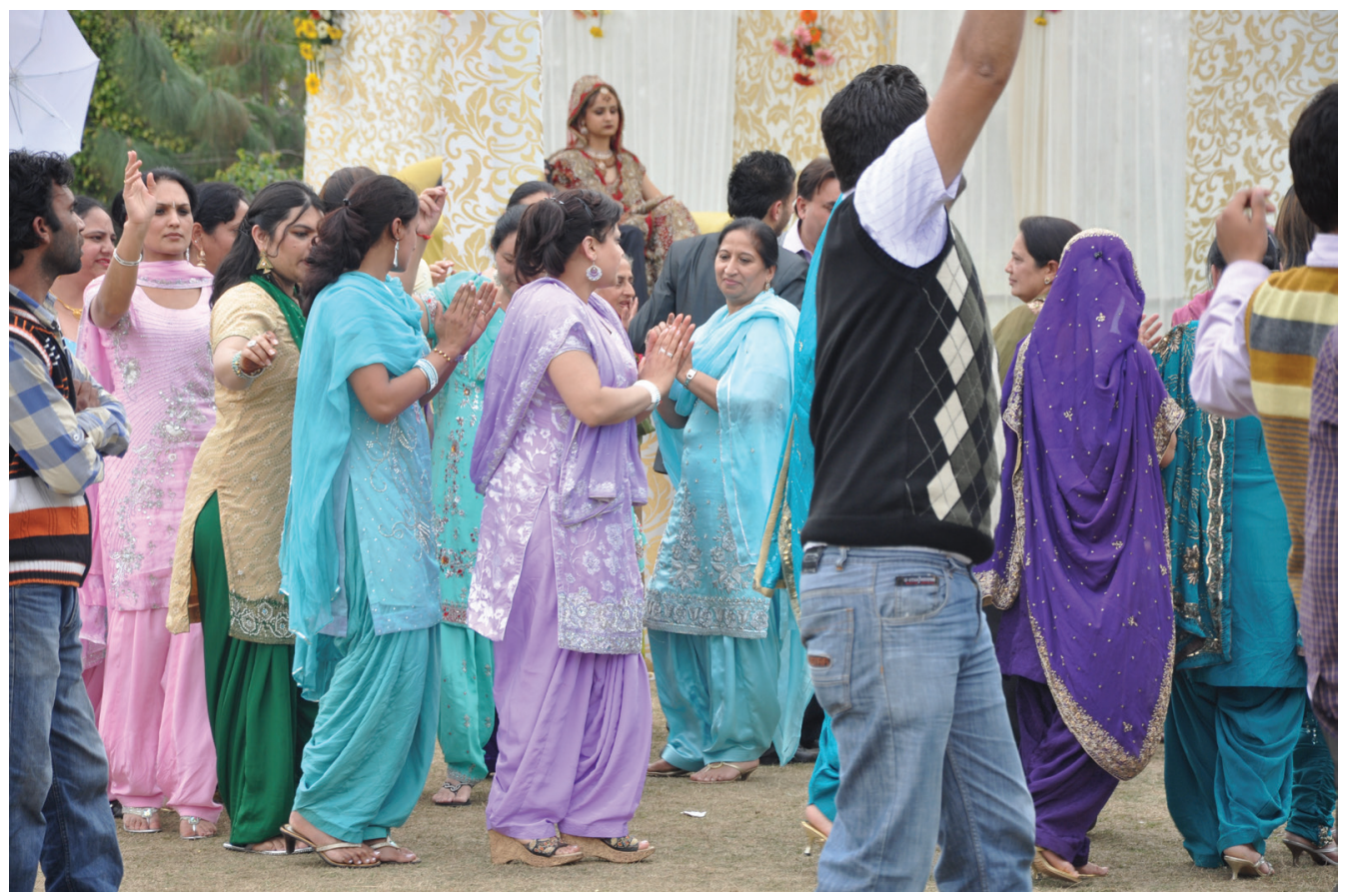

Fig. 26.1: Dancing at a wedding celebration in the Indian Punjab 2011 (Photo: () Lill M. Vramo). 


\section{Suit in the Indian Punjab}

A suit is a collective term used by our Punjabi informants in reference to various threepiece female costumes. Today's salwar kameez or suit has roots in Punjab from before the 1947 partition into an Indian and a Pakistani Punjab. While the salwar kameez is considered the national costume for all of Pakistan, it is considered a modern and functional outfit in India. Its status as festive attire in the Indian Punjab makes it a typical outfit for wearing in weddings in this region.

The term originates from the English term suit, meaning 'costume' or 'outfit', but can also be a verb meaning 'to fit, to dress, or to match together.' These three-piece costumes are spoken of as a suit both among Punjabis living in Norway and in Punjab. A suit is either a salwar kameez with dupatta or what is referred to as a frocksuit with panjabi trousers and dupatta. The three piece costume, salwar kameez is the official folk costume in Punjab, but it is also a popular female outfit in all the Indian states. Its popularity is explained by its practical design of baggy trousers and tunic style top. Since the eighties the salwar kameez has been associated with freedom and modernity (Banarjee and Miller 2004, 238-239). The costume is worn by diaspora Indians all over the world.

The suit is a common conversation topic among women, and has an obvious place in Punjabi women's wardrobes for everyday life and for parties. They spend much time purchasing and maintaining their suits.

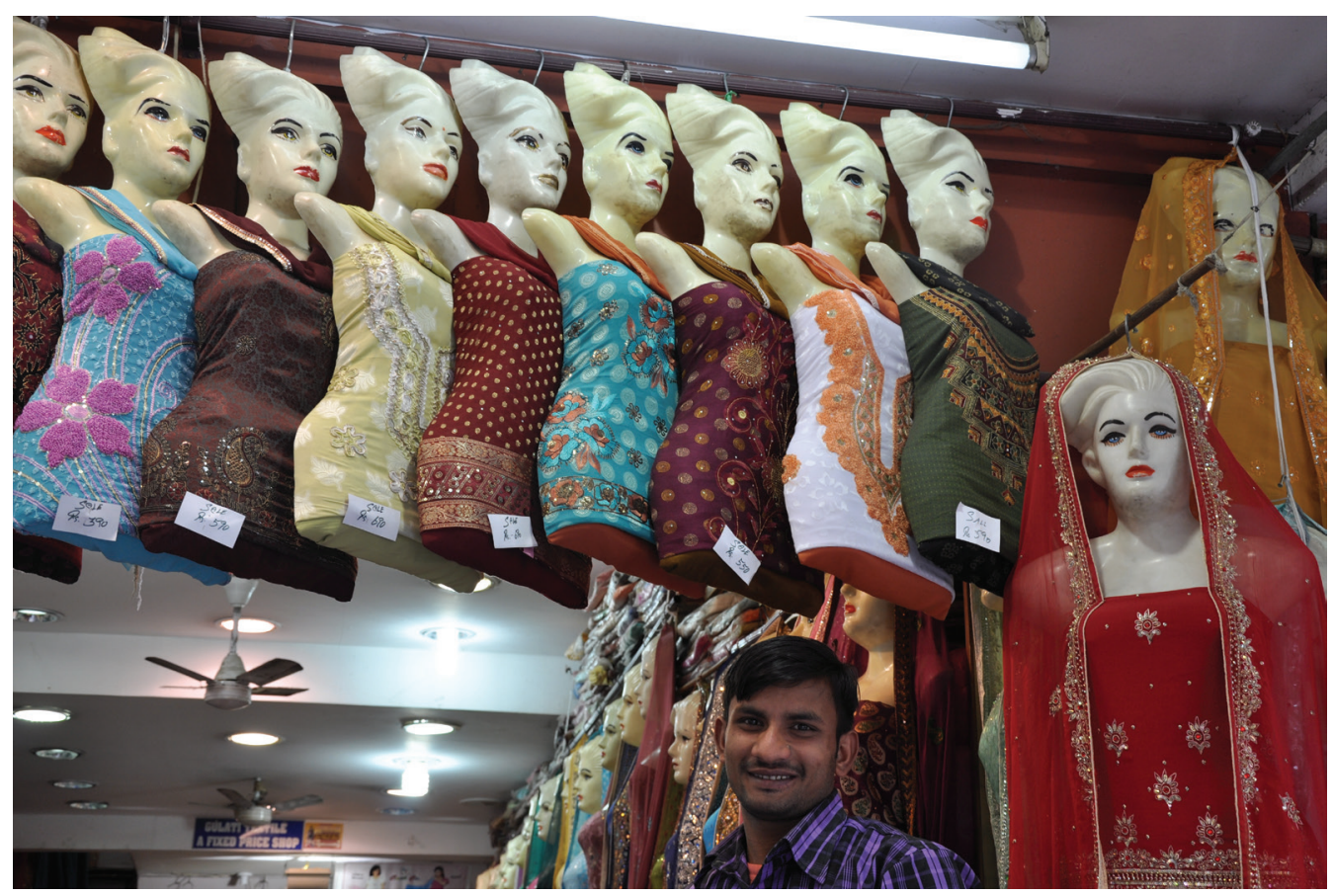

Fig. 26.2: Mannequins at the market in Indian Punjab 2011 (Photo: @ Lill M. Vramo). 


\section{Clothes in Norway}

Norway was formerly a poor country, but is now one of the richest countries in the world. Before the industrial revolution, clothing was an object of investment, and one of the most precious items a person could own. Today, clothing as a durable object of investment has been replaced by short life expectancy or a "buy and discard" mentality.

The clothing worn in Norway is much like the rest of the western world. Jeans, $\mathrm{T}$-shirts, and sweaters can be used both for leisure time and for liberal professions. In certain professions wearing a suit is expected, while in others a disbanded suit (jacket with jeans) is acceptable.

For parties, men often don a suit. Women's attire is more revealing and feminine, however, with more of a variety of colours and decorative techniques than is allowed for the formal neat attire. Dressing for parties in Norway differs from other Western countries, because folk costumes are used more frequently at family celebrations around Christmas, at baptisms, and for weddings and, not least, at the annual Norwegian National Day on May 17th. Children and female family members mostly wear Norwegian folk costumes, men mostly suits.

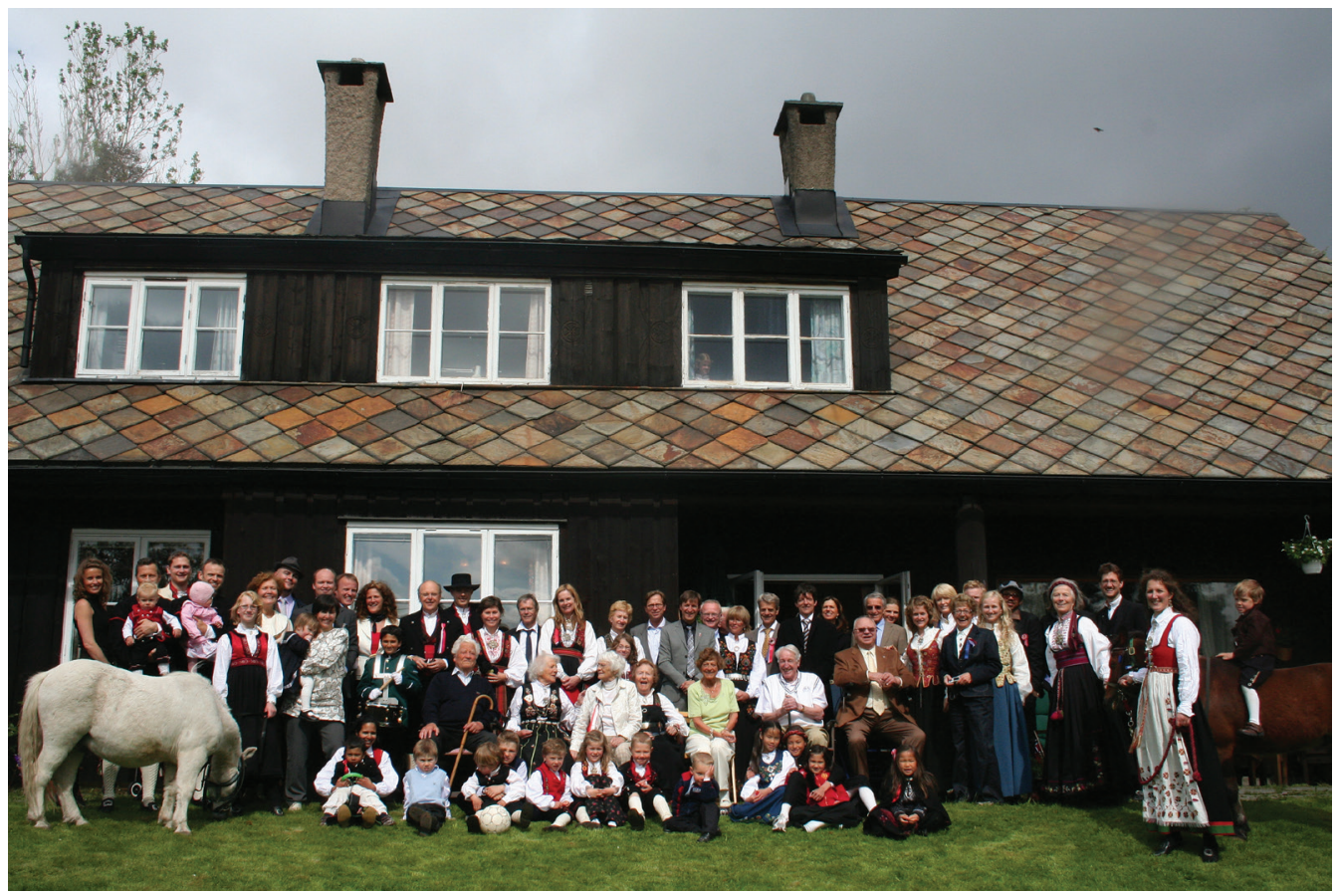

Fig. 26.3: "Posing for the photographer", a family gathering at the Norwegian National Day celebrations on the 17th May 2010 in Oslo, Norway. (Photo: Kristen Bjorå. Thanks to Tone Skårdal Tobiasson for kindly lending us the photo). 


\section{Parties, Clothes and Money}

India has a rising middle class with a growing spending power, leading to an increasing use of consumption goods and commercial services as a means for showing social status and economic abilities. Weddings can be seen as a "show off arena" for status and economy through the size of the events, the number of invited guests, the number and variety of dishes served as well as through the clothes, shoes, jewellery and other accessories worn. The phenomenon can also be understood as substitution consumption where women present their husbands' wealth through their clothes and jewellery.

When Davinder is asked to show the suits she owns, her mother brings out metal suitcases filled with different categories of the colourful garments. One contains old suits which she has kept despite them being categorized by her as too old. Another holds the summer suits made from light coloured cotton. The third suitcase contains suits which Balwinder uses around the house while doing housework. Some of these clothes may later be reused as nightwear, work wear, or given as gifts to servants or poorer relatives.

Davinder says that she buys between 15 to 20 suits a year. She buys these for what she terms 'functions' or 'parties' which can be wedding functions, or birthday parties among family or friends. While Norwegian weddings commonly have 50 to 150 guests, in India a middle class wedding will have from 300 to 1000 invited guests. Informants say that they have noticed an increase in the number of guests invited to Indian weddings, which means that they receive more invitations. Families with large networks, mostly with a high caste/class background are increasingly having to prioritize in relation to time and "who will go where" within the family in order to be able to maintain a duty to show up. Many individuals from the lower strata are also receiving more invitations to arenas where there is a demand to dress up. People who are economically worse off feel the social pressure to arrange large weddings. A typical wedding will include several functions during a week, and for closer kin and network, this implies that they will need more suits. An increase in wedding invitations causes an increase in the use of suits.

For Indian families, suits are a significant expense in the household budget. A suit can cost from 200 INR (4.5 USD) to tens of thousands of Indian rupees for designer suits, which is a growing market. In our study, married women of the middle class paid from 3500 INR to 8000 INR (77-177 USD) for a suit consisting of three pieces. They bought between 10 and 20 suits for their own use during a year. Punjab is considered one of the richest states in India with a per capita income of INR 43,092 (954 USD) in 2007-08. Even though this represents a significant proportion of family income, the male informants do not seem to question their female family members' consumption of suits. Instead, they (seem to) value the suit as a necessary article, a fact which underlines how women (have a) function as the family's exterior image representing the family outside the home.

Due to the import of clothes from countries with lower price levels, such as India, clothes are cheap in Norway in relation to income level. The import of clothing has 
grown rapidly and is currently on a level of $16.5 \mathrm{~kg}$ per person per year, roughly double of what was imported only two decades ago. The proportion of income spent on clothing has declined in the same period.

Although the total clothing consumption is high, party clothes do not have a high priority among our Norwegian informants. One reason is that: "It's pretty seldom that I dress up so much that I would wear a dress" (Camilla, 29). Men also place scant emphasis on parties as important occasions: "I am not a great party person, but the black suit is ready when needed" (Karl, 46). Much of family and social life takes place through outdoor activities and cabin trips, where being cosy and comfortable is important. For such occasions, (normal) everyday clothing or specific outdoor clothing is preferred. Norwegian women do not distinguish strictly between party wear and everyday wear: "A necklace or a pair of high-heeled shoes" (Barbara, 25) and "of course much more pronounced makeup and hair and shoes and bag and jacket" (Greta, 24). Several informants express a dislike of being "over-dressed", and the festive is not highlighted by wearing different clothes, but by dressing with nicer accessories.

However, there are festive occasions where other clothes are necessary. These are annual parties, such as the Norwegian National Day - May 17th; parties around Christmas and New Year's Eve; or family celebrations, such as baptisms, weddings and birthdays. Ladies' outfits for these occasions are usually a folk costume or a dress. Not all informants own a folk costume, and not everyone would use them for all these occasions. Nina describes a common dress code: "I wear a folk costume to the 17th of May and baptisms and if it is a larger celebration". The National Day is mentioned as the first choice for wearing a folk costume. "Then I would absolutely not wear anything else!" (Camilla, 29).

About $70 \%$ of Norwegian women own a folk costume which costs $20,000-50,000$ NOK (3640-9100 USD) without silver accessories or shoes. They are commonly received for the Confirmation (the Christian coming of age celebration). As the costume is supposed to last for an entire lifetime, it can be fitted and adjusted according to changes in the owners' body or to fit a new owner.

The Norwegian folk costume is largely fixed: shoes, jewellery, socks, etc., are strictly regulated. New accessories will thus be a result of the old ones being worn out, or because the owner does not yet have a full set of accessories. There is constant debate around whether one 'can' wear sunglasses, high-heeled shoes or earrings with the folk costume, and this debate is referred to by the term "the folk costume police". In practice, the variations are large, but there is a perception of something being 'right' and other things being 'wrong'. New costumes, however, have not necessarily a higher cultural value than old ones. Anita (35), for example, has a folk costume from the early 1950s: "Inherited from my grandmother. It is well used, but works fine and is in one piece and taken good care of." Within a family, it is common that several women share the same costume.

The alternative to the folk costumes are party dresses. These vary greatly in quality, design and price from NOK 100 (18 USD) in discount stores and up to several thousands. 
For NOK 400 (73 USD) you can find a large selection. Wedding dresses are more expensive and range usually from 8,000 to 15,000 NOK (1456-2730 USD) without accessories.

\section{Variation and Lifespan}

Ideally, the three parts of a suit should match and make up a complete entity. When shopping, the buyers consider how well the components match each other and constitute a fascinating ensemble. The double meaning of suit is present in the suit by being an actual material outfit, but also that the parts of a suit will match together to make it complete. The outfit is treated as an entity throughout its lifetime. The three parts live together and are passed on (to poorer relatives, for example) as a whole. In this way the suit follows a similar script as the Norwegian folk costume, even if its lifetime is significantly shorter. For suits, the 'folk costume police' is formed by other women's gazes that consider the different parts and check whether they match. There are, however, infinite combination possibilities, although ideally only between the separate suits.

A common piece of advice in Norwegian magazines is to go for a simple dress, the little black dress, which can be worn with different accessories, shoes, scarves, jewellery and jackets. These variations make it possible to use the same clothes over and over again without looking the same every time. The demand for variety is much greater today than in the mid-1900s. One way to understand this requirement is to see it as a way to show that you have changed clothes, and therefore have washed yourself. This is connected to an increased focus on cleanliness (Klepp 2007). As 39-year-old Lena explains: "To wear the same outfit like two days, no, I never do that... Perhaps people will think that I have not been at home the previous night or not changed clothes or showered". Another explanation is that changing clothes is a way to display wealth.

Variations in clothing are very often understood as a result of fashion change. That is not consistent with the findings of our research, where studies of disposed clothing items in Norway showed that changes in garments partly related to poor quality were over nine times more common a reason for disposal than fashion or style changes. The Indian informants regularly attend functions, where new and variations of suits are the norm. Quality is considered in relation to embroidery and decoration, the price of the suit, and if the material easily creases or not, and not in relation to its lifespan.

In Norway, the demand for variety and the notion of clothing being 'too old' and thus of little value because it has already been 'seen' by others several times, is associated with modern western clothing. All informants were able to relate to this fact: "I have actually had a dress that I have been very fond of and used it on many occasions. When I've had it on to four to five parties, I feel: No, I always have the same dress!" (Camilla, 29). Therefore, she thinks she must get a new "even though surely no one remembers it, but one thinks of it anyway". It is striking how the discussion here refers to external norms as something that is controlling them but to which they disagree. Although 
our Norwegian informants think the dresses are "very nice" and something they are "very fond of", they still feel that renewal is required. For the traditional Norwegian folk costumes, these rules do not apply. Instead, value is associated with tradition, craftsmanship and connection to places and clothes. The absence of a need for variation makes the folk costume a good alternative. It is "very nice not having to think about it actually" (Greta, 24). In India, however, an essential element of the 'traditional' dress includes the requirement of variety and value of newness.

Some informants say that they do not care if they use the same outfit many times, but "I had not wanted to go in the same outfit as someone else to a Christmas party (laughs), but it does not matter if I wear the same outfit twice in a row" (Heidi, 32). Here, another type of demand for variation becomes evident: one between women. This demand for variation does not apply to folk costumes. In areas with few migrants from other parts of Norway everyone will generally have exactly, or nearly the same costumes.

\section{New, Old and Traditional Clothing}

The opening conversation in Balwinder's bedroom is not so easily placed into a Norwegian bedroom, not because the idea of social obsolescence is strange here, but because it is difficult to imagine that the various family members will engage in this social obsolescence of the mother's party clothing. As we have seen, Norwegian women will not acknowledge obsolescence and refer instead to other people's opinions and standards. Instead, they emphasize that parties are not an important arena to show social status through clothing.

The two forms of traditional clothing used by our informants have different characteristics when it comes to age and cultural value. We have shown that a demand for variation in clothing is universal - and that such a demand has huge economic (and environmental) consequences. Our material shows that the proportion of clothing that is discarded because of fashion is often overestimated.

The demand for showing something new can also include 'traditional' non-western dressing concepts. To compare clothing practices across countries and cultures is highly valuable in order to question what is the taken for granted in our understanding of clothes and fashion.

\section{Further Reading}

Arjun Appadurai (2000) Introduction: commodities and the politics of value, in Arjun Appadurai (ed.), The social life of things, pp. 3-63.

Mukulika Banarjee and Daniel Miller (2004) The Sari.

Ingun G. Klepp (2007) Patched, louse-ridden, tattered: clean and dirty clothes. Textile: Journal of Cloth and Culture 5 (3), pp. 254-275.

Kirsi Laitala and Ingun G. Klepp (2011) Environmental improvement by prolonging clothing use period. Towards sustainability in the textile and fashion industry. <http://www.sifo.no/files/ file77517_laitala__klepp_-_prolonging_clothing_use_period.pdf> (Accessed 03.09.2013). 


\title{
27 A 'Stinging' Textile: Cultivation of nettle fibre in Denmark and Asia
}

\author{
ELLEN BANGSBO
}

Ellen Bangsbo is an independent researcher in Copenhagen, Denmark. She was educated at the Textile Department of the Art and Crafts School, Copenhagen (1978), and holds a BA in Tibetan (1997) and an MSc in Anthropology from the University of Copenhagen (2001). She has extensive fieldwork experience in Asian civil societies, Tibet, Nepal and India with research in education for Tibetans in Tibet and exile. She is the author of a book and numerous articles related to Tibet. She is an expert in textile design, weaving, spinning, the cultivation of plant fibres, and other textile handicrafts. Fieldwork abroad associated to the textile nettle project was conducted in Nepal 1979-80 and 2010, and an article on this subject was written: Allo-en bæredygtig nælde som tekstil i Nepal Nepal Vision vol. 21, no. 2, Winter 2012, pp. 28-30. She was a guest scholar at the Danish National Research Foundation's Centre for Textile Research, University of Copenhagen 2011/12.

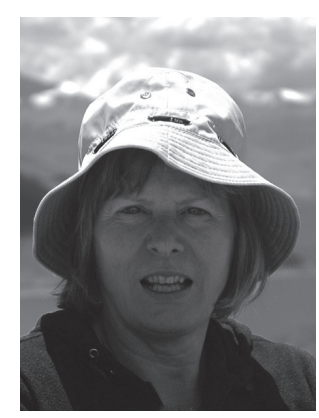

Most people regard the nettle as an unpopular perennial weed with an unpleasant sting, while others know the nettle as a useful herbal remedy, but nettle (Urticanceae) has yet another quality: as a textile fibre which was cultivated in Denmark back in the Scandinavian Late Bronze Age (900-700 BCE). Prospects of using the nettle as a textile plant might sound familiar from the fairytale 'The Wild Swans' by Hans Christian Andersen, where the brothers of the princess Elisa were bewitched and turned into swans by their stepmother, after which Elisa rescued them by knitting magic shirts made from stinging nettles, thereby turning them back into their human form.

Nettle is a plant that likes abandoned places. There are around 500 different species of the Urticaceae family worldwide, and the common name Urtica derives from the Latin word uro which means to burn, probably referring to the burning sensation on the skin when touching nettle. Plants of the nettle Urticaceae family of bast fibre are Girardinia, Boehmeria, Laportea and Urtica. The most common wild stinging nettle in Europe is Urtica dioica, while the 'Himalayan Nettle' (in the Himalayan regions) is Girardinia diversifolia (Fig. 27.1). Better known in China are the stingless nettle species 'Ramie', 'Rhea' or 'China grass', Boehmeria nivea. Since the Middle Ages, nettle has been known and valued in multiple ways, and its medical value has been scientifically researched and confirmed: as a tea and tonic, a herbal medicine, a pesticide, paper making and animal fodder to mention a few, as also documented in folklore, literature 
and etymology studies. Nettle spring shoots are known to be a nutritious diet; during the 11th century, the Tibetan saint Milarepa is said to have survived for many years on a solitary diet of nettles in the cold and remote Himalayan mountainous regions.

\section{Nettle Fibres Cultivated Since the Bronze Age}

Nettle is the only wild growing plant in

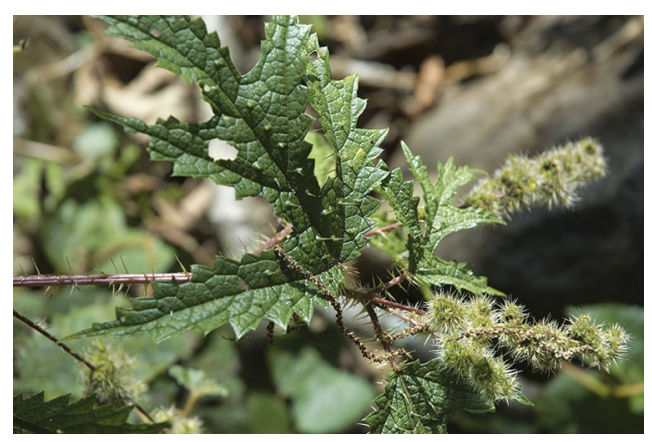

Fig. 27.1: The 'stingy' Himalayan Nettle Girardinia diversifolia (Photo: @) Ellen Bangsbo). Europe which can provide a reasonable fibre crop, although small; barely $5 \%$ of dry stalk mass. Historical records mention a long history of the use of nettle fibre. In Denmark, the earliest plant fibre textile is a find of nettle yarn in the Voldtofte grave urn dated to the second period of the Late Bronze Age (800 BCE) (Dreyer and Edom 2005). The Voldtofte nettle cloth was preserved due to it being in contact with a bronze vessel and its bronze oxide. However, laboratory examination of the Voldtofte nettle attests that the plant fibre is not of local origin (Bergfjord et al. 2012), suggesting trade in textiles. It seems that linen was introduced in Denmark in the Iron Age (500 BCE-850 CE), which could explain why the use of nettle as a fibre disappears. The earliest find (1929) proving the use of nettle as a culture plant in Scandinavia is a bundle of retted nettle stalks placed in a pre-Viking ship at Kvalsund in Norway, dated to the Late Iron Age (c. $850 \mathrm{CE}$ ).

Nettle cloth was produced in Denmark especially during the 18th and 19th centuries. During this time its craftsmanship reached such high levels that cloth produced in nettle fibre was compared to silk, and in 1917, the Danish government established a Nettle Commission to promote its production. During World War II, nettle fibre was used and cultivated in Denmark, but due to poor crops, technical difficulties, labour cost and low cost-effectiveness, the cultivation of nettle was abandoned at the end of the war.

\section{Nettle Fibre Cultivation in Asia}

The stinging wild nettle Urtica dioica is also common in Asia, but here the Himalayan Nettle Girardinia diversifolia flourishes at the moist sub-tropical and temperate Himalayas from Kashmir to Sikkim, in Bhutan, Assam and the Khasi Hills, Myanmar, Java and China, and from Marwar and central India down to Travancore and Sri Lanka (Singh and Shrestha 1988, 445). The Himalayan Nettle grows to a gigantic height of up to 3.5 metre being a component of the natural forest ecosystem. It produces a lustrous, smooth and very strong fibre $9-54 \mathrm{~cm}$ long, which is amongst the longest found in any plant. 
The tradition of extracting fibre from nettle has been practised for generations in Asian regions and is even said to be praised for its beauty and firmness in the Hindu epic Ramayana (Dunsmore 1993, 59). Native peoples of early India were acquainted with the arts of spinning and weaving, as proved by references in the Vedas, the ancient Indian scriptures (1500-500 BCE), and urticaceous fibres are known to have been used in Atranjikhera, the early civilization of the Upper Ganga Basin (c. 1200600 BCE) according to G. M. Buth and K. A. Chowdhury (Vishnu-Mittre 1974, 26). In Bhutan, old-time tunics predating the female dress kira dating to the 19th century were sometimes made from nettle (Myers et al. 1995,106).

A well-known nettle of the Urticanceae family known for its fibre in Asia is often referred to as "China Grass", Ramie or Rhea (Boehmeria nivea), here devoid of stinging hairs. Ramie is known to have been cultivated in India at least since the beginning of 1800s, where it was processed by hand, after which the government of India in 1869 had its first try at mechanical processing (Kozlowski et al. 2005, 208). Ramie has been cultivated in China for centuries. Today, the mechanical facilities available in China for processing nettle plant fibres from the stalk, provide the opportunity for some Nepalese business companies (dealing with nettle fibre) to regularly ship their own raw nettle bark ribbon to China for mechanical treatment.

\section{Allo, Nettle Fibre Cultivation in Nepal}

The Himalayan Nettle Girardinia diversifolia (Urticaceae) with the local Nepalese name Allo grows abundantly in the highland forests of the mid hills at $1400 \mathrm{~m}$ and high hills up to 2500-3000 $\mathrm{m}$ in western and eastern Nepal. The harvest takes place from August through December and is a tedious and unpleasant task trying to avoid leeches in the damp forest area and eventual allergic reactions caused by the stings (Fig. 27.2). Thick protective gloves are usually required for peeling the bark, but in one village I visited in the Midwestern region of Nepal, local women collected the bark ribbon without using gloves, indicating that a toxic resistance to allergic reactions from yearlong harvesting has developed, as cultivation of nettle fibre had taken place for generations in this area.

After harvesting, the bark ribbon is stored to dry. It is then boiled in a solution of wood ash. The fibre is then beaten with a wooden mallet, rinsed in water and left to dry in the sun. Caustic soda may be used instead of wood ash, which conveniently reduces the period of boiling to a mere half hour. This is of course attractive in a place where wood is increasingly scarce, but caustic soda is environmentally polluting and also affects the fibre in an unattractive way causing dryness and less shine in the fibre, and if used, the yarn cannot be classified as a sustainable product. A somewhat similar processing of the nettle stalk and fibre is done by the Bhutanese and the Mishmi or Deng ethnic group of Tibet and in India at Sikkim, Arunachal Pradesh, and the Indian Himalayas. The nettle fibre also carries a specific cultural value for the Nepalese Rai people, as they use it in their religious ceremonies. Finally, being a strong fibre, it is also used for fishing nets. 


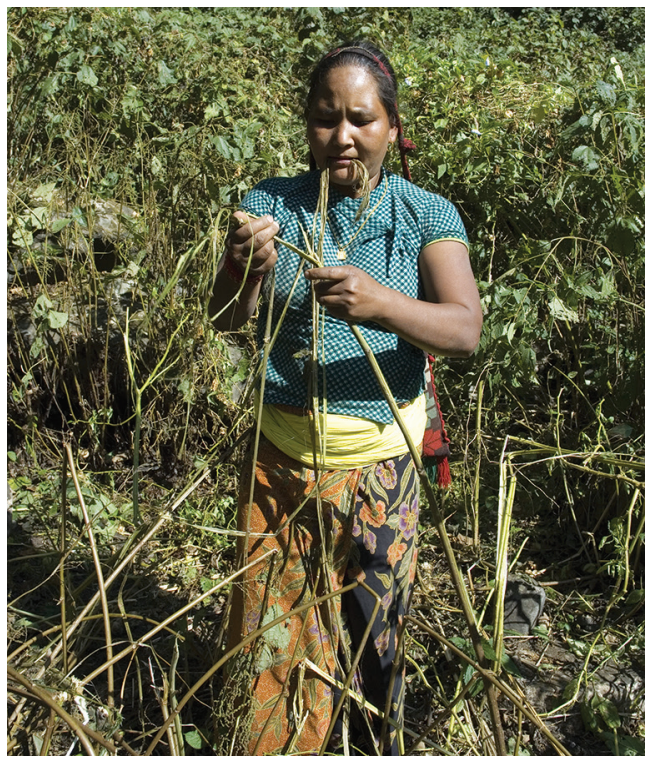

Fig. 27.2: The handling of the nettle plant starts with harvesting by peeling the fresh green nettle bark ribbon by hand, sometimes even teeth are used instead of a sickle or a knife to separate the fibrous material from the stalk. Nepal 2010 (Photo: (c) Ellen Bangsbo).

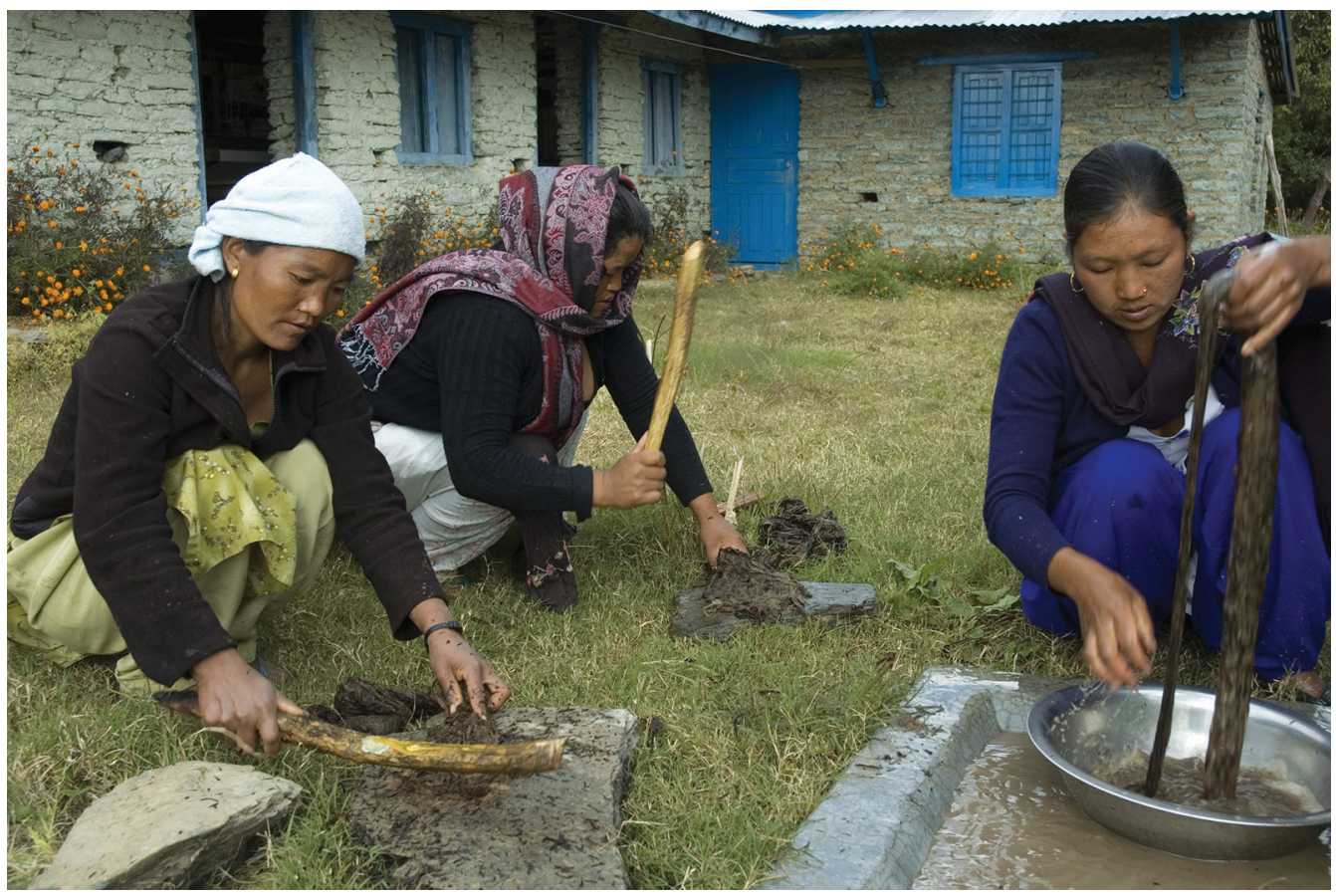

Fig. 27.3: The nettle bark ribbon is rarely boiled immediately, but preferably 2-3 days after harvesting or later with a wood ash solution for approximately three hours sometimes left for simmering overnight. The fibre is then beaten with a wooden mallet and extensively rinsed in water to remove the extraneous plant material, finally it is rubbed with micaceous clay/clay soil and left to dry in the sun. The adding of clay soil serves the purpose of softening and bleaching the fibre. The fibre now becomes very dusty, with clay comprising more than $40 \%$ of its weight (Photo: (c) Ellen Bangsbo). 
Textile project programs supporting the development of Allo production have been initiated by local and foreign NGOs, and the United Nations Development Programme in several Midwestern districts and especially in the Sankhuwasabha district in eastern Nepal. In some villages, Allo has become a major raw material for cottage industry. Here the traditional backstrap loom (Fig. 27.4) is replaced by the larger four-shaft treadle counterbalanced loom, which sometimes has been transported in bits and parts across hills on narrow paths (Fig. 27.5). The extraction of nettle bark ribbon and its processing methods for quality yarn and thread is difficult, tedious, labour intensive and still only provides a low profit for villagers and weavers. In spite of low salaries, Allo products are today an increasingly important commodity providing an income for many local ethnic groups living in the rural areas. Allo products are easily available in local markets in Kathmandu and Pokhara where consumers are mainly western, in addition to being available on the international market where especially knitted products are shipped to Japan (Fig. 27.6). As seen in European textile history, the use of nettle cloth in Asia is associated with a common humble lifestyle in marginal communities, and most Nepalese prefer to wear more lustrous clothing of soft pashmina wool and glistening velvet fabrics, acknowledging the former low status signal of poor rural descent by wearing Allo products.

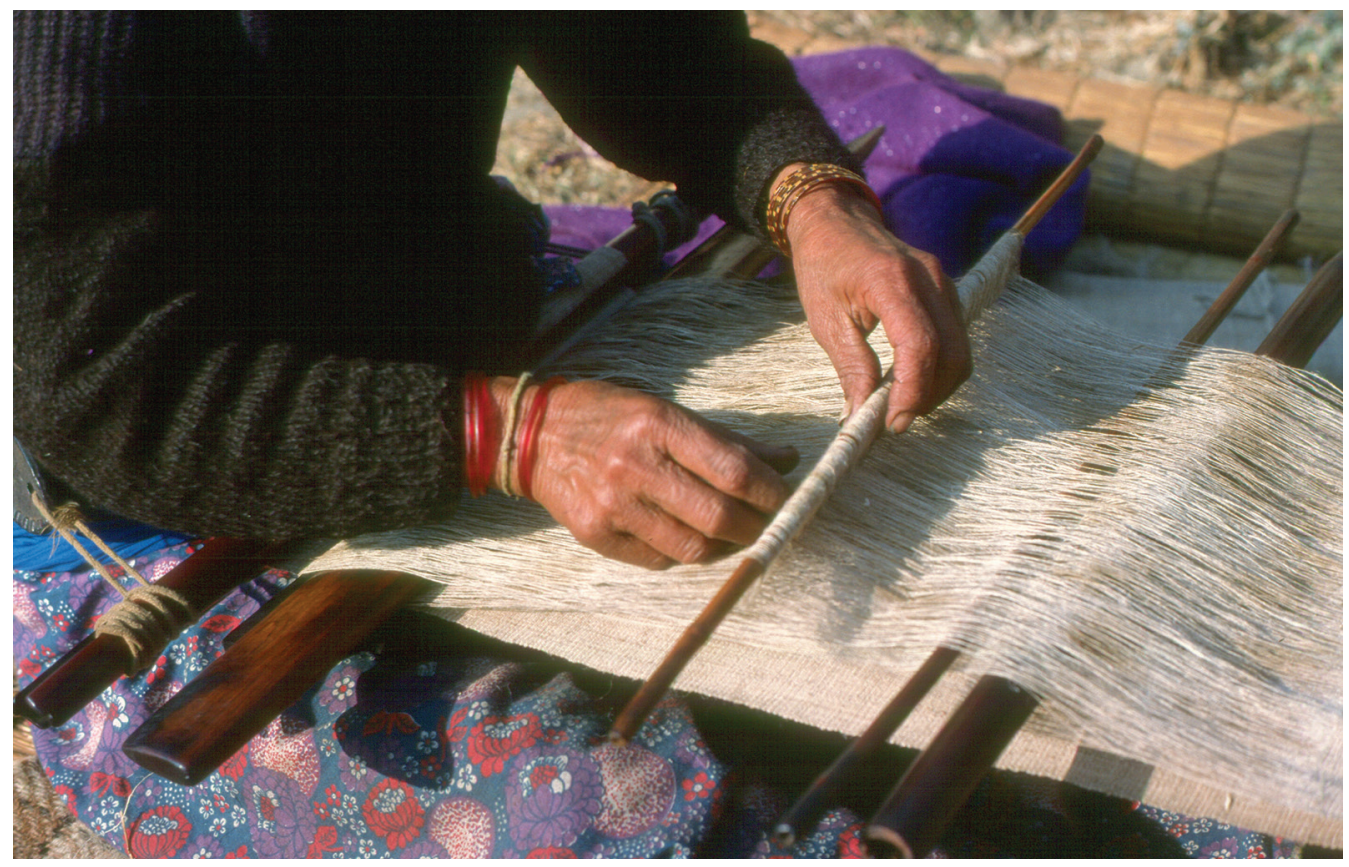

Fig. 27.4: In Nepal, the hand-spun Allo nettle yarn was traditionally woven on backstrap looms, an easily portable loom consisting simply of a warp secured to a beam and kept straight by the strap around the weaver's body. Backstrap looms were used to produce shawls, mats, sacks, headbands, and clothing by local ethnic groups such as Rai, Sherpa, Magar, and Gurung. This photo shows a woman weaving nettle cloth on a backstrap loom in Ghandrung, Nepal 1979 (Photo: (C) Ellen Bangsbo). 


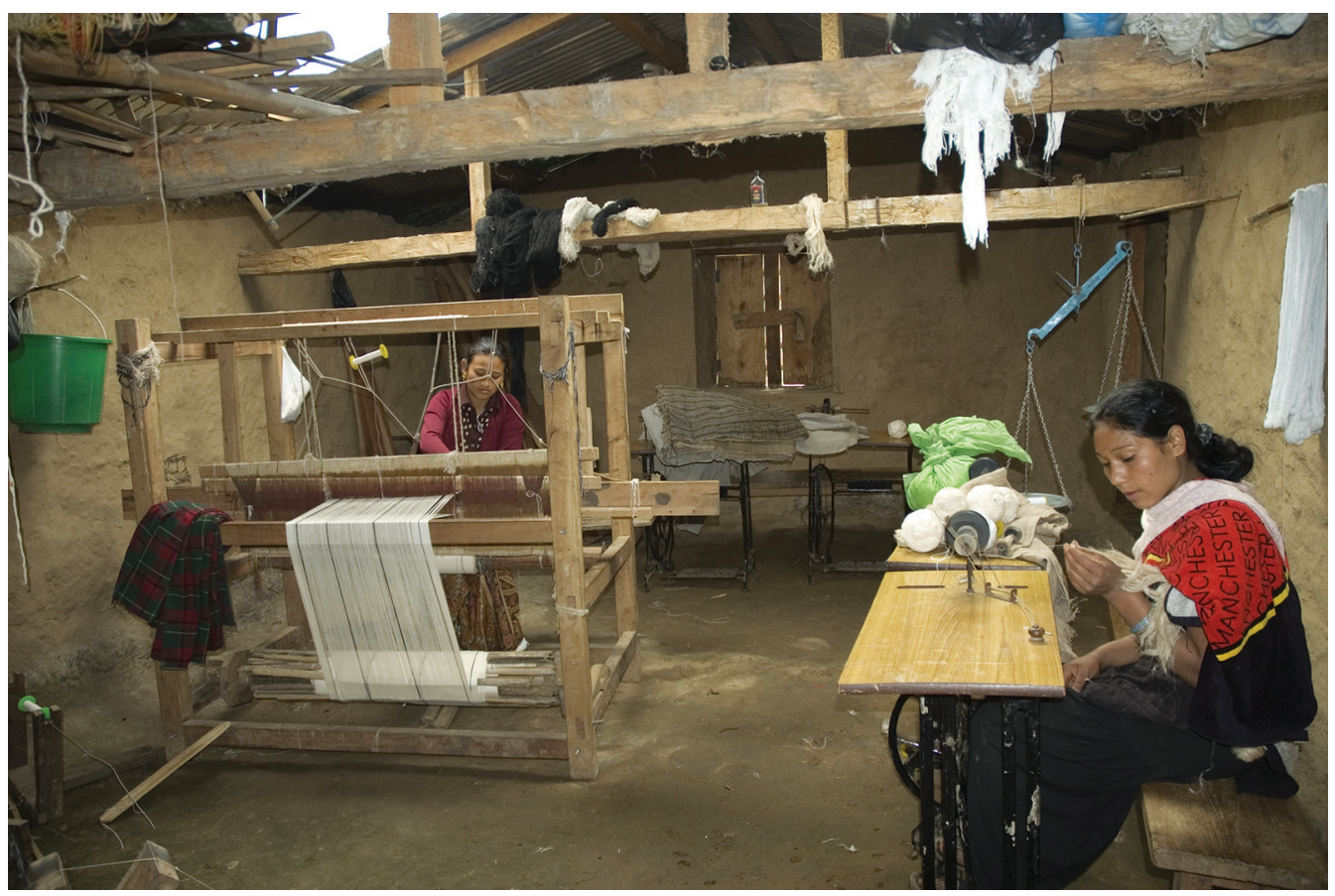

Fig. 27.5: Development projects in Nepal have introduced four shaft-treadle looms and spinning wheel used in more settled environments in the domestic sphere. Here, the fibre is spun by hand into a thread much faster than by the use of the traditional drop spindle. However, the drop spindle/hand spindle enables the person to spin while walking, shepherding or doing other tasks. Before spinning, the fibre bundle is untied by hand and the bundle is kept in order by twisting it around the foot and one toe (Photo: (C) Ellen Bangsbo).

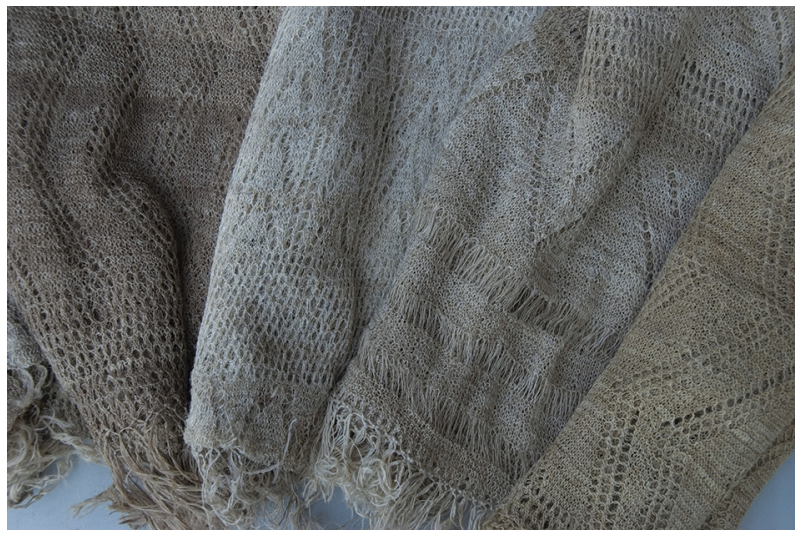

Fig. 27.6: Knitted shawls of hand-spun nettle yarn for sale in Kathmandu 2010. (Photo: (c) Ellen Bangsbo). 


\section{Nettle Fibre Cultivation in India and its Environs}

The Himalayan Nettle grows in the sub-tropical and temperate foothills of the Himalayas from Kashmir to Sikkim, in Assam and the Khasi Hills, and in the valleys of the river Sutlej in Kinnaur, Himachal Pradesh state, and from Marwar and central India to Travancore in the south, as well as in the nearby island state of Sri Lanka (Singh and Shrestha 1988, 445).

The Hindi name for the nettle is bichchhoo (बच्छ्छू), meaning scorpion and it is often used as fencing to keep out cattle. Nilgiri nettle (Urtica heterophylla) is found in the Nilgiri Hill area in southern India, and it may be assumed that nettle fibre was cultivated in South India. With the nettle growing in abundance in the foothills of the Indian Himalayas, local Indian women at Almora, Uttaranchal state, have since 1987 produced knitted shawls and purses made from nettle fibre for their livelihood. Now commercialized woven and knitted nettle textiles provide development and financial independence to local inhabitants, so that they are less dependent on the more traditional and laborious work such as agriculture and livestock.

Local practice, ancient ties and tradition often share the same geophysical environment and the contemporary political borders run across areas which centuries ago had a common history, language and religion, with close affinities of lifestyle, weaving and dress, including the cultivation of nettle fibre. The Lepcha people in the Indian state of Sikkim exhibit strong affiliations with the traditions of native people in south-eastern Bhutan; the North-eastern Indian hills are ecologically similar to Bhutan, with the eastern part of Bhutan linking the Mönpa and the Mishmi people of the adjoining Arunachal Pradesh state in eastern India: all these ethnic groups are familiar with the cultivation of nettle cloth. The constant flow over centuries of people, animals and trading of goods in these border regions is visible in their common clothing. Nettle fabric is often used for a wrapped garment sometimes called a 'carrying cloth' in Bhutan, Sikkim and Nepal, and the northern areas of Arunachal Pradesh, India. The nettle cloth is woven into a square and worn over the chest, and tied around the shoulders to form a fold at the back as a kind of knapsack or pouch, and while the garment brings warmth and protection to the body, the folding/pouch is used as a bag or large pocket (Figs 27.7-27.8).

\section{Nettle as a Future Sustainable Crop}

Nettle is of interest to the sustainable green textile industry, as it is environmentally friendly with a potential to become a much needed sustainable alternative to cotton, which, with its extensive use of water and pesticides, is a threat to the environment. Nettle, on the other hand, is a perennial plant and requires low resources. It needs phosphates and nitrates, but when grown wild requires neither fertilizer nor pesticides. Furthermore, its presence decreases soil erosion. The fibre possesses strength and durability, it is hollow, thus providing accumulation of air and a natural thermal insulation, and it is resistant to water. 


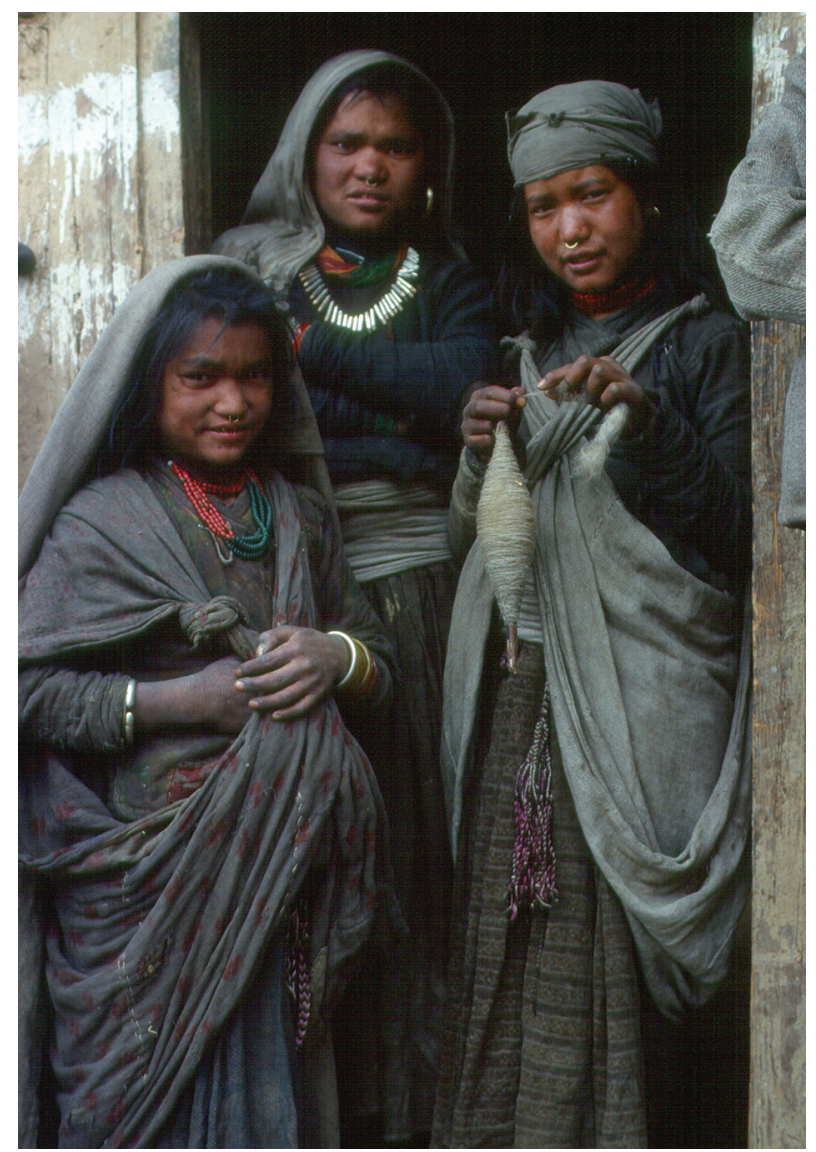

Fig. 27.7: Local village girls in Jumla 1979 dressed in nettle carrying cloth. (Photo: (c) Ellen Bangsbo).

The most groundbreaking pioneering research on using nettle for textile was conducted in Germany between 1927-1950 by G. Bredemann, who researched on interbreeding selected plants of Urtica dioica thereby developing a cloned cultivated high fibre nettle, and consequently increasing the crop from a mere $5 \%$ of the wild nettle to a more prosperous $15-17 \%$ of the dry stalk crop. This cloned nettle was named 'Fibre Nettle' (Urtica dioica convar. fibra) (Dreyer and Edom 2005, 332). This research, however, had to be abandoned in the 1950s due to poor crops, low costeffectiveness and the competitive appearance on the world market of cotton followed by synthetic fibres. The last decade has seen a renaissance in research of the Fibre Nettle. The EU project, IENICA (Interactive European Network for Industrial Crops and their Applications), was launched in 1999 with the planting of nettle fields in Austria using four nettle clones which originated from the breeding work of G. Bredemann. Another project, named STING (Sustainable Technology in Nettle Growing) was initiated in 2004 in the UK involving local farmers in nettle cultivation. Nettle cloth is now available from a large number of private firms worldwide, where it is often mixed with other fibres, such as cotton, flax, viscose, silk and bamboo. Nettle cloth 


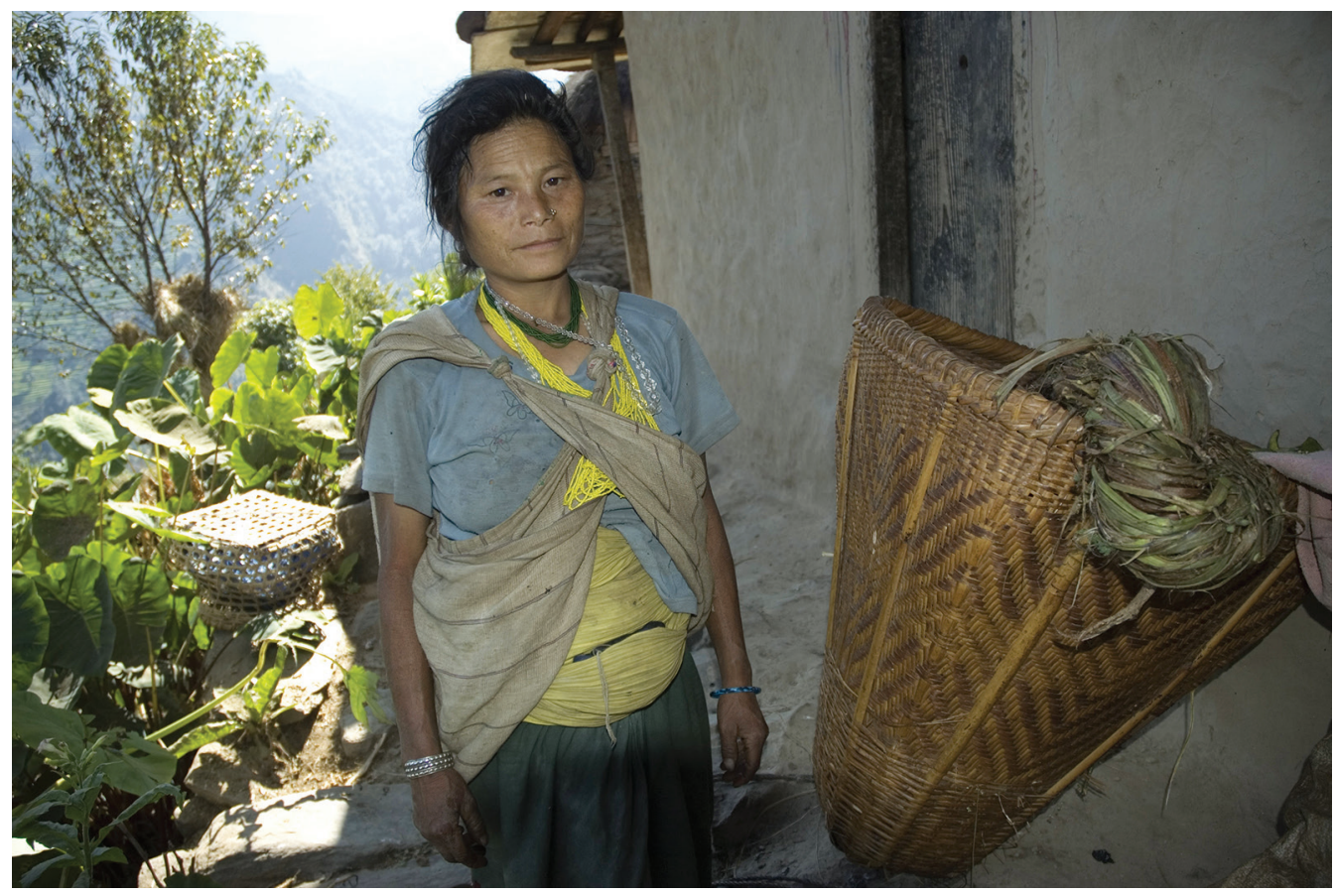

Fig. 27.8: Woman in mid-western Nepal 2010 wearing a nettle carrying cloth. Next to her, a basket with a bundle of freshly harvested raw nettle bark ribbon (Photo: (C) Ellen Bangsbo).

now appears in Italian fashion houses and denim products made of $10 \%$ nettle and $90 \%$ organic cotton are available today.

Cost effective processing techniques and improved spinning and weaving methods are still lacking in the smaller countries. In the short run, it might be tempting only to export fibre and raw bark ribbon rather than spun yarn and fabrics that require a more sophisticated technology. However, seen from a local perspective of the smaller Asian countries, this does not seem to be an attractive option for the future prosperity of local nettle industry.

Actual knowledge of the prospects of cultivation of nettle fibre is at present probably only familiar to a narrow circle of textile- and biochemical researchers as well as selected designers, but with an expanding use of nettle fibre in manufacturing denim trousers and various fashion designs, the potential of nettle fibre for textiles is reaching for the future.

\section{Acknowledgements}

I wish to thank the Danish National Research Foundation's Centre for Textile Research (CTR), Copenhagen for providing an inspiring base while working on this study and to the editors of this volume. 


\section{Further Reading}

Christian Bergfjord, Ulla Mannering, Karin M. Frei, Margarita Gleba, Marie-Louise Nosch, Annemette B. Scharff, Irene Skals, Jan Heinemeier and Bodil Holst (2012) Nettle as a distinct Bronze Age textile plant, Scientific Reports, open access journal, 2, 664; DOI:10.1038/srep00664.

Jens Dreyer and Gillian Edom (2005) Nettle, in Robert R. Franck (ed.), Bast and other plant fibres, pp. 331-342.

Susi Dunsmore (1993) Nepalese textiles.

Robert R. Franck ed. (2005) Bast and other plant fibres.

Diane K. Myers and Susan S. Bean eds, with Michael Aris, Françoise Pommaret and Susan S. Bean (1994) From the Land of the Thunder Dragon. Textile Arts of Bhutan.

Ryszard M. Kozlowski Rawluk and Jorge Barriga-Bedoya (2005) Ramie, in Robert R. Franck (ed.), Bast and other plant fibres, pp. 207-227.

Shailesh C. Singh and Rhidaya Shrestha (1988) Girardinia diversifolia (Urticaceae), a Nonconventional Fiber Resource in Nepal. Economic Botany (USA) vol. 42, pp. 445-447.

Vishnu-Mittre (1974) Palaebotanical evidence in India, in Sir Joseph Hutchinson (ed.), Evolutionary Studies in World Crops. Diversity and change in the Indian subcontinent, pp. 3-30. 


\title{
28 Fist-braided Slings from Peru and Tibet
}

\author{
LENA BJERREGAARD
}

Lena Bjerregaard has been employed as a textile conservator in the Archaeological American Dept. of the Ethnologisches Museum, Berlin since 2000. She is Danish by birth and studied American Indian languages and cultures at the University of Copenhagen and conservation at the Academy of Fine Arts in Copenhagen. She has published extensively on archaeological textiles, among others: Textiles from Laguna de los Condores - in the Leymebamba Museum (2007); Peruvian Archaeological Textiles in the National Museum of Copenhagen (2001); Eine altägyptische Perücke aus der Zeit um 1500 v. Chr., (The conservation of a 3,500 year old Egyptian wig), Restauro, pp. 49-52 (2004); Pre-Columbian Slings and other headbands in the Ethnologisches Museum, Berlin (2008); Fist-braided Bands Used as Headgear in Pre-Hispanic Peru, Archaeological Textiles Newsletter no. 51, pp. 1-14 (2010); Pre-Columbian hairnets in Ethnologisches Museum, Baessler Archiv, Band 58, pp. 39-51 (2011); Redecillas purpuras de la Costa Central, Jornadas Internationales sobre Textiles Precolumbinos V (2011).

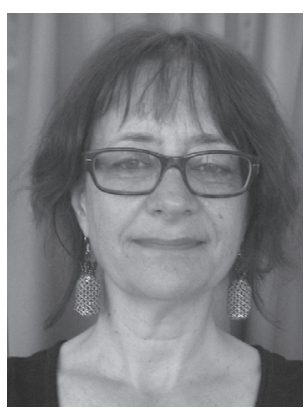

Fist-braided slings are - to my knowledge - only made in two places on earth: Tibet and the Andes area (Peru, Bolivia and Ecuador). Why this is so, is an open question. However, it is a fact that, natural surroundings and life in the two areas are very much alike - high mountains, highland plateaus, herding of highland livestock - llamas or yaks.

Braids are produced all over the world - from very early times and still today. Weaving, which actually simplified textile manufacturing, was invented thousands of years ago, but long before that, threads were wrapped, twined, twisted, looped or braided in intricate patterns, to create larger or smaller textiles. Most braids are worked from top to bottom, some with loose yarns, some with loops. Some braids have identical structures, but are made in alternating techniques, depending on their place of manufacture.

A very special form of braiding technique is fist-braiding. This technique is worked upwards, and with no special tools. It is accomplished just with the hands by manipulating from 12 to - at least - 92 loose strands.

A sling is a hunting weapon - it consists of a cord with a loop at one end (to hold the sling when throwing) and an extended area in the middle (the cradle) where a 
stone is placed. The two ends of the sling are held in one hand (one finger attached to the loop) and a stone is placed in the cradle. The sling is then whirled around the head of the thrower, and when he lets go of one end of the sling cord, the stone is whirled out towards its target (Fig. 28.1).

According to the colonial (1615) manuscript by Guaman Poma de Ayala, slings were used by Inca warriors, and also by farmers to keep small animals out of their crop or for hunting birds. Dr L Augusto Wadell - a medical officer in the Younghusband expedition to Tibet in 1903 and a leading Tibetologist - writes that, "slings were a common accessory of herdsmen and nomads", and were also used as weapons by Tibetan soldiers (Rocca 2006, 4-6). Today slings are sometimes still used in the Andean and Tibetan highlands for hunting small animals. But their main practical use is for herding livestock - i.e. sheep, goats and yaks in Tibet and llamas in the Andes.

slings, however, were and are also objects of beauty with high status and value in both Tibet and the Andes, and constitute more than mere weapons.

In pre-Columbian Andes (before the Spanish conquest of 1534) the functional slings were, probably for practical reasons, worn wrapped around the head, and elaborate fancy slings developed from this use (Fig. 28.2 and Fig. 28.3).

In Inca society, geographical affiliation as well as hierarchical position was expressed in clothing and especially in the headgear worn. Consequently, the slings wrapped around the head became more and more complicated, ending up as completely non-functional prestige objects, sometimes found as joined pairs, and, as such, devoid of any practical utility as weapons - only to be used as adorning headbands. Probably these exquisite slings also had some ceremonial purpose combined with magical powers.

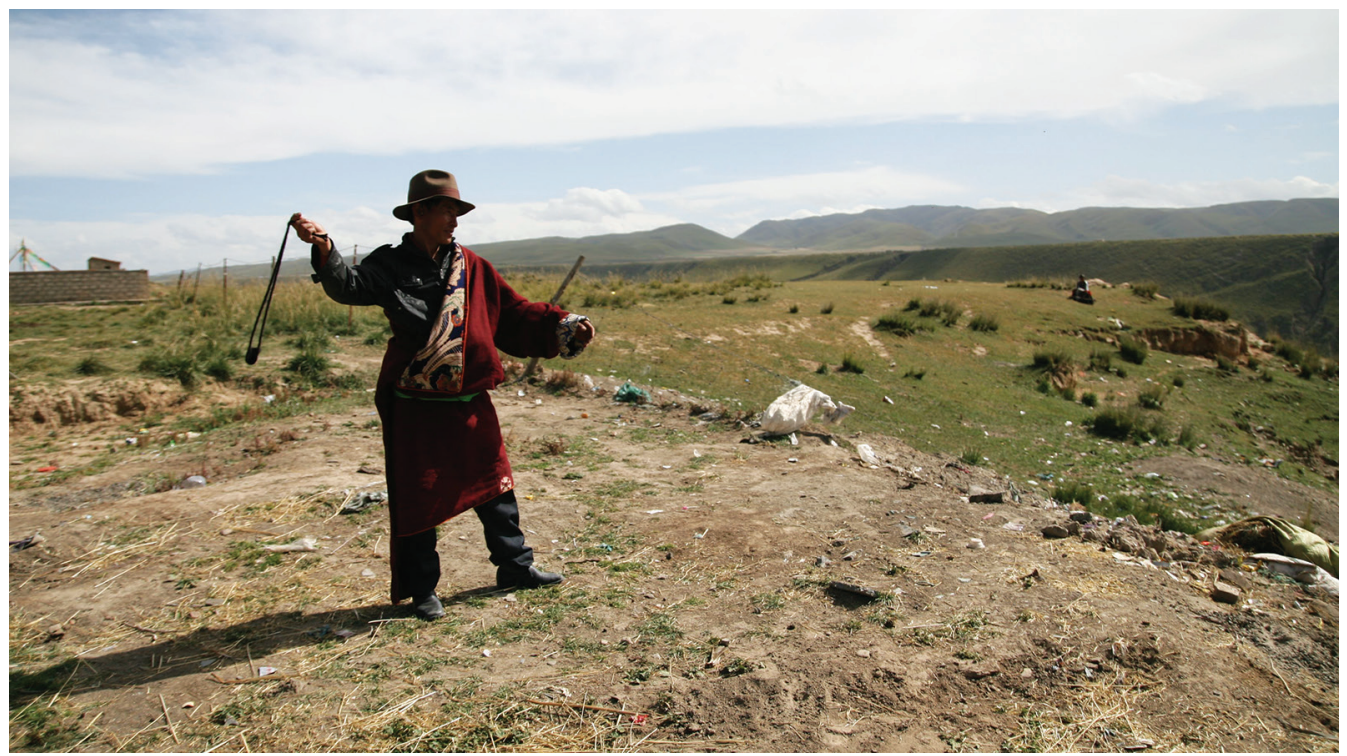

Fig. 28.1: A Tibetan herdsman swinging his sling (Photo: Klaas Steendam; <www.amdocraft.com>). 
Today, too, in ceremonial dances performed at Huancavelica in the high-lands of Peru, the traditional young women's costume still includes an ornamental sling worn diagonally over the shoulder. "In Incan-style dances in the Cuzco area, fancy slings are sometimes worn at the waist as belts, and sometimes they are swung high in the air between the hands. Elsewhere some are doubled and held between the hands, some are worn from the shoulders, and others are held in one hand", reports Adele Cahlander (1980, 7).

In Tibet, the slings were and are used by nomads and farmers when herding their yak and sheep. However, here too, the slings have additional functions. Asked directly, the Tibetan nomad producers of Amdocraft (<www.amdocraft.com>) in the eastern part of Tibet state that they would never wear or display the slings on themselves or their clothes. Slings are livestock herding objects and should be used as such. But some people will hang an especially nice sling on the wall of their

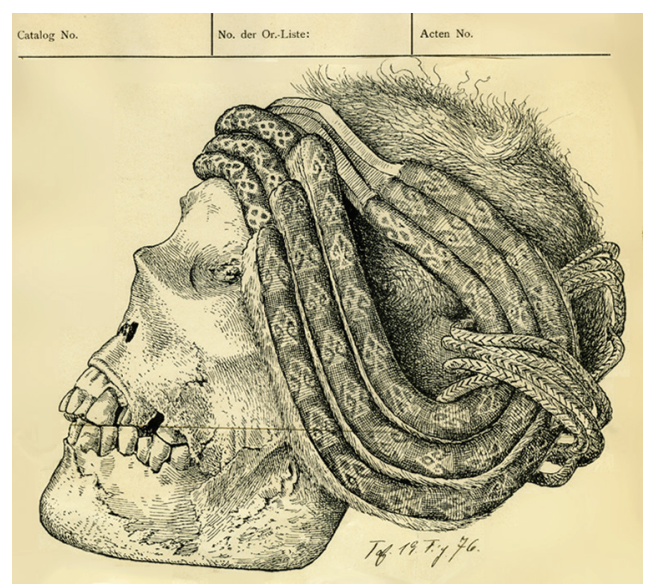

Fig. 28.2: Mummified head from Peru wearing an ornamental sling as head gear. Index card from Ethnologisches Museum, Berlin. The object is no longer in the collection.

Fig. 28.3: Mummy bundle from Chiquitanta, Peru wearing around its "false mummy head" (which is a stuffed pillow placed on top of the mummy bundle) a headband consisting of two elaborate, joined slings, V A 28464 (Ethnologisches Museum, Berlin; photo: Martin Franken).

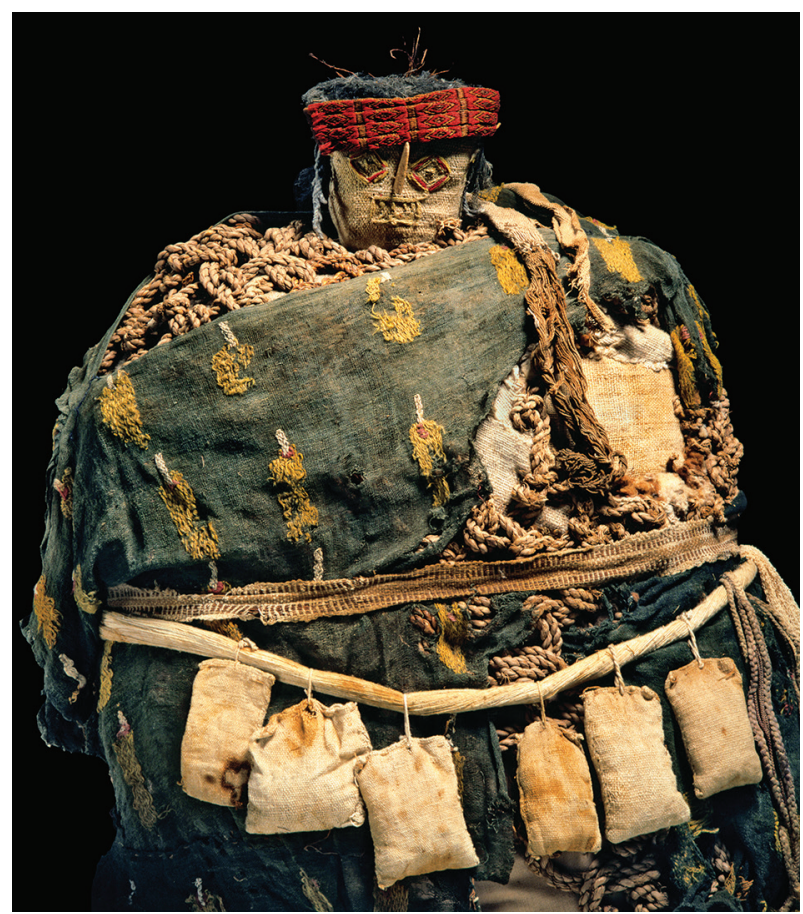




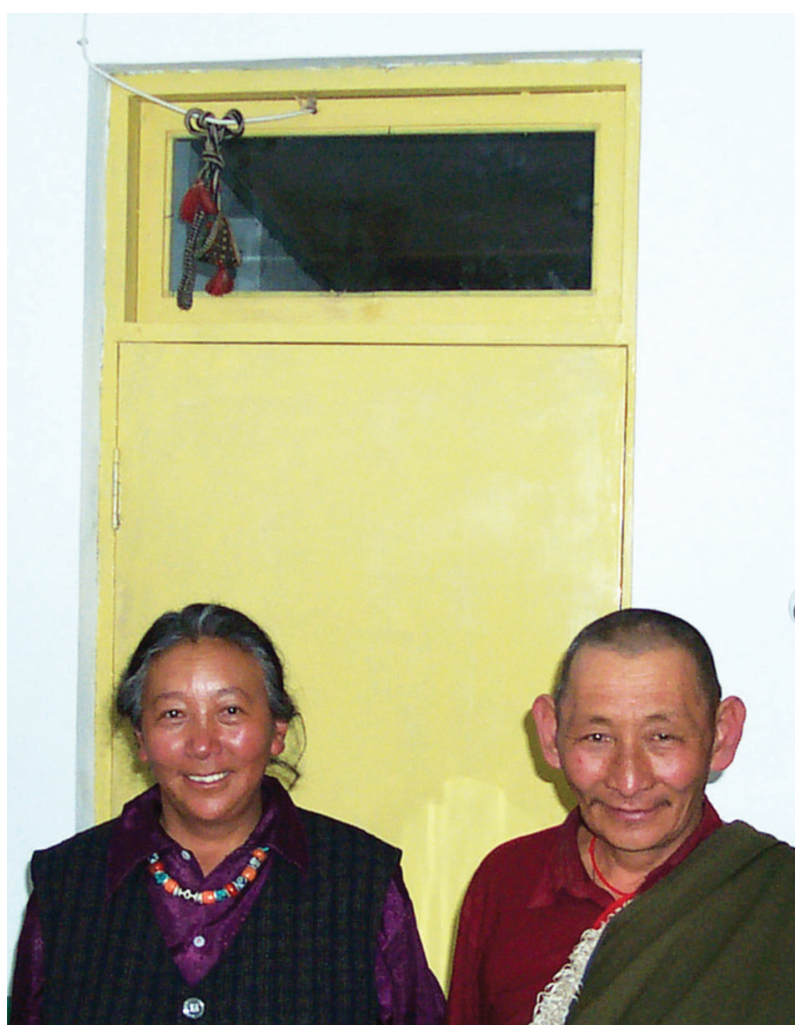

Fig. 28.4: The Tibetan doctor and monk, Amchi Karma Tsultrim and his wife, have hung a sling above the front door entrance, to keep away harmful spirits (Photo: Toni Huber).

home - and they do admire and compare slings with other people's slings. Formerly, slings were exchanged as seals of a treaty or covenant. When two kings or warlords would sign a peace treaty they would give each other a sling. And some months or years later (after the treaty) they would again exchange slings, saying that the treaty had not changed. This could also refer to a marriage covenant between man and wife. Thus, the meaning would be a sign of 'no change' (Fig. 28.4).

In the north-west part of Tibet slings are considered to have magical protective powers. Often a sling will be wound around a steering wheel of a car to prevent accidents, worn as a belt around the waist or draped over the neck or waist of a sleeping person to keep evil spirits from coming out of the ground and harming him/ her. Slings function according to the patterns braided into them, which all have names and special protective powers (Fig. 28.5).

\section{Material and Shapes}

In the Inca times (1400-1534 CE) the fist-braided Andean slings were made of plant fibre (Fourcreae Andina - a South American agave sort) and alpaca wool. Modern slings, braided in the Andean highland today, are mainly made of sheep's wool. Tibetan slings 


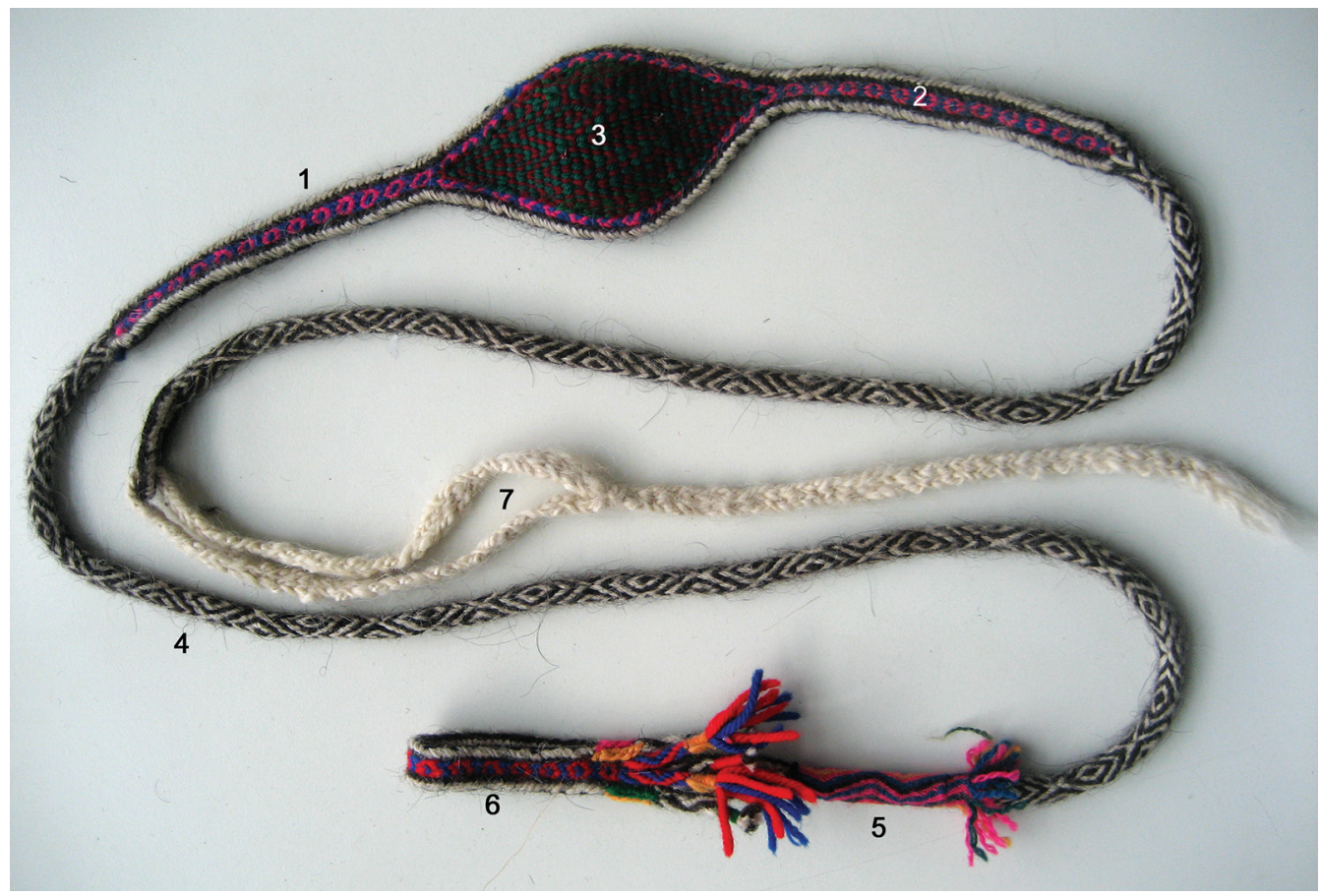

Fig. 28.5: This sling was made in the Dung mtsho region of western Tibet, and contains powerful protective patterns that each have a name: 1. gong dar gong nag ("white over black" - white and black edge pattern of the cradle); 2. brgyad leb rnying ma ("ancient eight-strand braiding" - small pink circles leading up to the cradle); 3. ur ldi mig brgya ("hundred-eyed sling cup" - diamond pattern of the cradle; particularly good for protection); 4. bcu drug mig brya ("hundred-eyed sixteen" - black and white pattern of the fist-braided, round cords on either side of the cradle); 5. mdud pa dgu dkri ("rolled nine knots" - pink, blue and yellow cylinder near the handle); 6. mchi mig dgu dkri ("rolled nine eye tears" - end loop knot with coloured tassels); 7. "ur lcags ("sling - whip" - white wool handle and whip). Personal communication, Prof Dr Toni Huber, Humboldt University, Berlin (Photo: Lena Bjerregaard).

are and were made of yak, goat or sheep's wool, and are a great deal coarser than the Andean slings.

In both regions and through all times the slings have round, fist-braided cords extending from the cradle; the cradle itself can then be flat, square or rectangular. In Tibet, the finger loop consists of a flat fist-braid, sometimes big enough for the hand to slip through, while in the Andes it is a finger-sized loop made in simple looping. In Tibet, the opposite cord to the one with the fist-braided loop has a thin braided extension about $50 \mathrm{~cm}$ long, which is used - like a whip - for producing a loud cracking sound.

The rectangular fist-braided cradles of pre-Columbian times were almost always split. Today, the sling cradles in the Andes are made in many different techniques, but are no longer fist-braided. Since 1900 (I do not know of older specimens) the cradle of the Tibetan sling consists of a diamond-shaped 2-strand warp twining attached by needle and thread to the fist-braided edges. 


\section{Technique}

The technique of fist braiding is simple and ingenious. It is done over the fist without using any other tools. The yarns are held in the fist, and are braided upwards - the braided band hanging under the fist and the loose strands over the fist.

The technique can be used to make round, as well as flat, square and rectangular braids.

Fist-braiding mostly employs units of four yarns, two hanging down on one side of the braid and the other two on the opposite side. In each movement, one of these yarns on each side is grasped; the two are twisted and laid down such that one of them is crossed over the top edge of the braid. Then the other two are grasped, twisted and laid down so that one is crossed over the top edge of the braid in the opposite direction from the first. When yarns from each of the parallel groups on two opposite sides of the braid have been similarly treated, those at right angles are then manipulated in the same way (Speiser 1983, 195-208). The basic technique produces a twined structure. A major group of twining units (of four strands each) is at right angles to another major group of twining units. The elements of one major group enclose those of the other major group

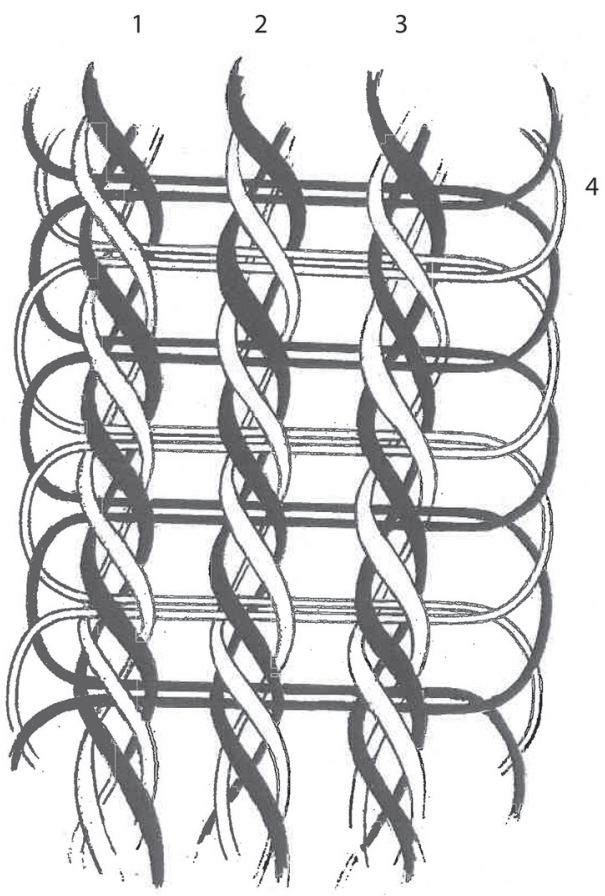

Fig. 28.6: Structure of a rectangular fist-braid with 3 twining units in the wide dimension and one in the narrow dimension; in total 16 yarns (Drawing: Ulrich Gebauer). and vice versa. As in normal four-strand twining, the elements float over two opposing elements at a time (Fig. 28.6).

If the same number of twining units is used on all sides, a square or round braid is produced, such as are common on the round braids extending from the sling cradle. For a round braid, the braiding proceeds in the same direction; for a square braid, the direction is altered by every twine. Flat or rectangular braids can also be created, however, using one or two units in a narrow dimension and a larger number of such units in a wide dimension.

The pre-Columbian rectangular fistbraided cradles of the Andean slings normally have 16-20 twining units (always an even number) on the wide dimension and two (occasionally three) twining units on the narrow dimension. Since there are four strands in a twining unit, the braid has a total of 72-92 strands to be manipulated. 


\section{Patterns}

Changing the direction of twining twist at intervals either horizontally or vertically creates geometric, zigzag or diamond patterns. Changing direction vertically after every second row untwists the yarns and causes the twined structure to disappear so that the result will more closely resemble interlacing. Further color and design variations are obtained by exchanging elements between adjacent twining units or even between major groups. Some braids have a core running through the centre of three by three twining units. Patterns can then be created by exchanging twining strands with core strands.

Patterns can be made with two-span floats and with three-span floats. Float spans refer to the number of times a vertical yarn skips a horizontal yarn in the braid - like in twill weavings.

Only in the Andes, however, are the three-span floats used. This technique permits the different coloured strands to be manipulated at will, so monochrome areas can be created. In this way, not only geometric patterns but also free figurative patterns can be created, showing up on either side of the braid in alternate colors. For instance, with the yarns set up accordingly, patterns made in black and white yarns using the three-span floats come out black on one side and as an identical pattern in white on the other side. In the pre-Columbian Andes, it was often designs of birds or llamas (Figs 28.7 and 28.8).

\section{Acknowledgements}

I would like to thank Prof Dr Toni Huber, Humboldt University, Berlin for his great help in Tibetean matters.

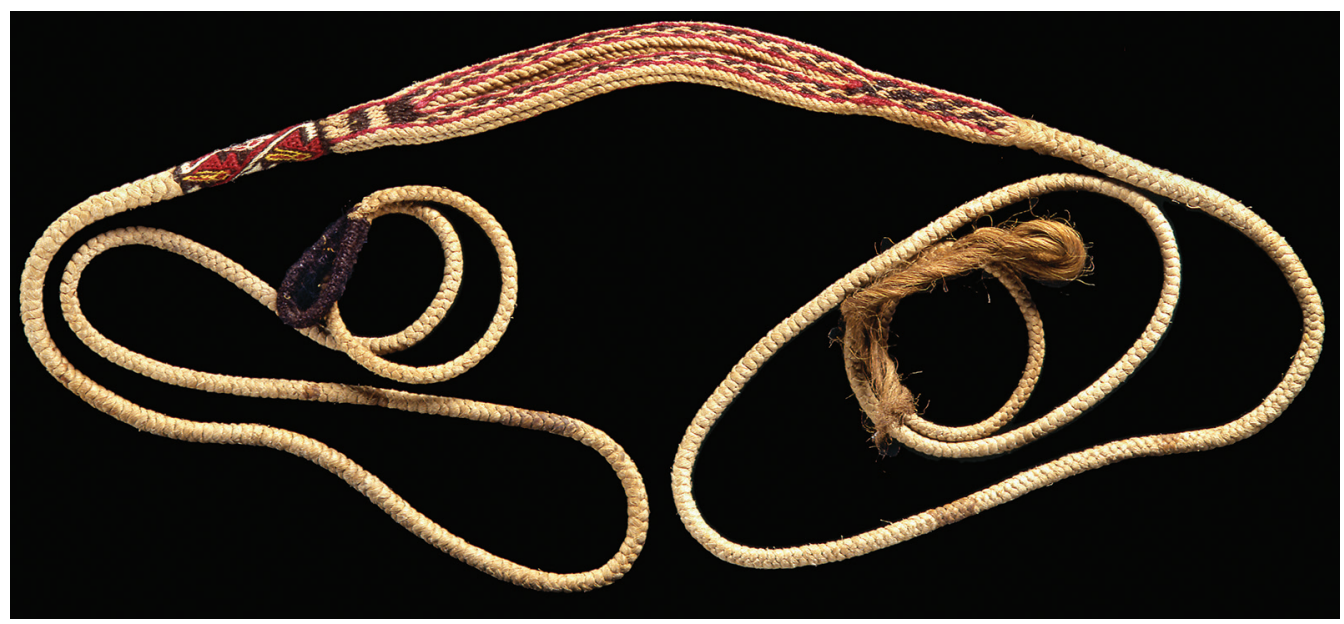

Fig. 28.7: Fist-braided Inca sling 1400-1500 CE, V A 47216 (Ethnologisches Museum, Berlin; photo: Martin Franken). 


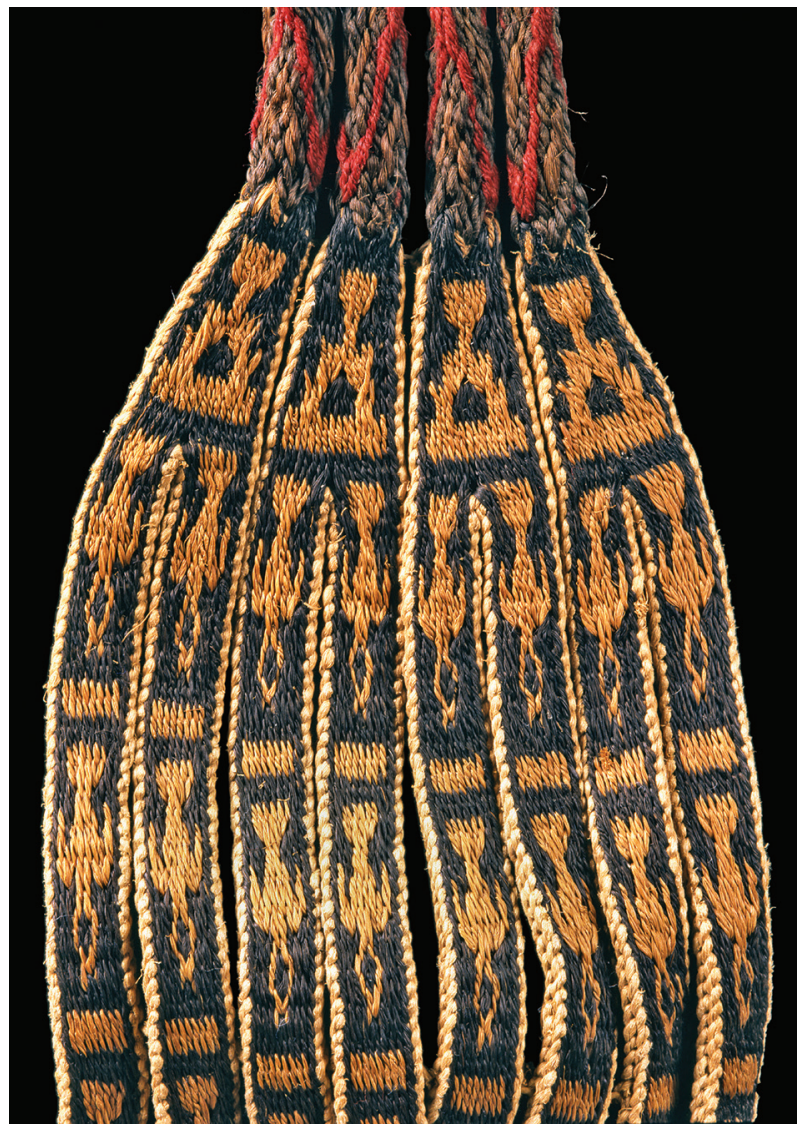

Fig. 28.8: Four Inca slings stitched together for a headband. Figurative bird design made in complimentary fist-braiding with three-span floats. V A 47221 (Ethnologisches Museum, Berlin; photo: Martin Franken).

\section{Further Reading}

Guaman Poma de Ayala (1615/2001) <www.kb.dk/elib/mss/poma/>.

Adele Cahlander, with Elayne Zorn and Ann Pollard Rowe (1980) Sling braiding of the Andes, Weaver's Journal, Monograph IV, Colorado Fiber Center, Boulder.

Schuyler Jones (1996) Tibetan Nomads, Carlsberg Nomad Series.

Donald J. Rocca (2006) Rediscovering the Arms and Armour of Tibet.

Noémi Speiser (1983) The Manual of Braiding.

Elayne Zorn (1982) Sling Braiding in the Macusani Area of Peru. Textile Museum Journal, vols. 10-20, 1980-81, pp. 19-20; 41-54. 


\title{
20 Parsi Embroidery: An intercultural amalgam
}

\author{
SHERNAZ CAMA
}

Shernaz Cama, PhD and Associate Professor, teaches at Lady Shri Ram College, Delhi University, India. She has been involved in cross-cultural and inter-religious studies at various levels since the time of her PhD research work on Blake and Zoroastrianism. She has edited and authored several books and has assisted senior scholars from India, Japan, Germany and France in their research projects on Zoroastrianism.

In 1999, Shernaz Cama was invited by UNESCO to initiate a project on the Preservation and Promotion of Parsi Zoroastrian Culture and Heritage, (UNESCO PARZOR). As honorary Director of the project, she guides researches in various aspects of Zoroastrian culture and demography all over India

She has produced three movies for the Parzor project and was the curator of the Parzor exhibition, Pictures with a Purpose. She has also headed an international six-country multinational Candidature for the UNESCO Award, Masterpieces of the Oral and Intangible Heritage of Humanity, while the Candidature Navroze has been declared in the Representative List of the Intangible Cultural Heritage of Humanity by UNESCO in 2009.

Shernaz Cama has been awarded the Mazda Education Foundation Award and Mancherji Edalji Joshi Memorial Award for Outstanding Contribution to the Zoroastrian community. She lives in New Delhi and has a son.

From early history, textiles have woven together the tapestry of humanity. The Parsi Zoroastrians, now a tiny minority of under 65,000 individuals in India, have saved, in their cupboards and trunks, this proof of our world's multicultural history. Complex roots and routes lie behind what we call "Parsi Embroidery" today. The tradition grew from Achaemenian Iran, travelled through the Silk Route into China and then came back with Indian and European influences, to its originators, the Parsi Zoroastrians of India.

Zoroastrians are followers of the Prophet Zarathustra. The loss of the Sasanian Empire led, in $936 \mathrm{CE}$, to a few Zoroastrians seeking refuge at Sanjan on the West coast of Gujarat in India. According to legend, the local ruler, Jadi Rana, presented them a bowl filled to the brim with milk. Their wise priest and leader slowly stirred in a spoonful of sugar, without allowing the milk to overflow. Thus, the Parsis or 'people from Pars or Fars', in Persia, mingled unobtrusively. One of the conditions of their refuge was that they would adopt Indian costume and language. Yet, the Parsis managed to create a distinct identity for themselves. Textiles, one of the key markers of cultural identity, have contributed greatly in this respect. 
Zoroastrianism celebrates the animal kingdom and the bounty of nature in its sacred texts, ceremonies and myths; revels in flowers and gardens, birds and beauty which provide the backdrop for its motifs. This Spenta or 'bountiful' world is to be treated with care, each tiny butterfly a manifestation of God's Goodness.

"Good Thoughts, Good Words, Good Deeds, Humata, Hukata, Huvarashta", the core and mantra of both the religion and its cultural attitudes, is believed to have power to transform negation, drive away evil and enable this world to reach ultimate joy. The Zoroastrian, therefore, must be a person of action. Respect for material creation as a manifestation of God's Goodness, is a cardinal tenet of the Zoroastrian faith. "He who sows corn, sows righteousness", says the sacred text, the Vendidad; to serve nature then is to serve God, and thus, reverence for nature became interwoven and embroidered into the costumes of daily life. Embroidery has, thus, always played a vital part in the Zoroastrian love of life. Despite their assimilation into India, the Parsis clung to their core cultural belief of a love of life in all its forms and continued to appreciate beauty in every aspect of their lives.

In the Zoroastrian homeland of Iran, the ijar or trousers were accompanied by a long jhabla or tunic, which reached the knees. The head was covered with a shawl and the entire costume embroidered with rustic, simple embroidery. Fish and bird motifs prevailed, as did flowers, roundel like emblems of Khurshid (the Sun) and tiny birds and animals. The Sasanian Empire (c. 3rd-7th century CE), brought Zoroastrian motifs into their textiles. By celebrating and thus regenerating this tangible world, the Zoroastrian defeats forces of negativity which try to stifle natural powers of expression as well as spiritual creativity. However, the Zoroastrians of Iran became a conquered people, forbidden from wearing bright colours as yardage. Their headdress became dark, navy or black, yet their love of life continued to be expressed in their embroidery. Here, in this wedding dress we see peacocks and exotic colourful creatures, embroidered onto a traditional wedding shawl with the sacred Ariz (or fish), emblem of fertility (Fig. 29.1).

In India, Parsi women's wardrobes contained ijars and jhablas and, only later, petticoats under their saris. Parsi women had adopted the sari when they migrated from Iran to Sanjan (Giujarat, India) but, in order to keep it distinct, wore their pleats on the right and made the pallav reach almost to the feet. When other women wore cottons or Indian silk, they stood out in distinctly patterned embroidered garments.

In many ancient cultures, women's crafts have links with sacred traditions. In a traditional Zoroastrian home, be it in Iran or India, the kusti weaving loom was an important part of the household, where women created the sacred girdle worn by all Zoroastrians. Even today, a girl is expected to hand-stitch her wedding sudreh, a sacred vest, its little Pocket of Good Deeds or gireban symbolizing the essence of this culture.

Craft traditions continued across generations and centuries. Fifty years ago, most Parsi homes had an embroidery cupboard. On its shelves stood Chinese lacquer boxes, wicker baskets with tools, and amazing colours and shades of embroidery thread. A shelf could contain embroidery pattern-books from all over the world. Here, in one corner, pressed into brown paper folders were butter-paper patterns, some home 


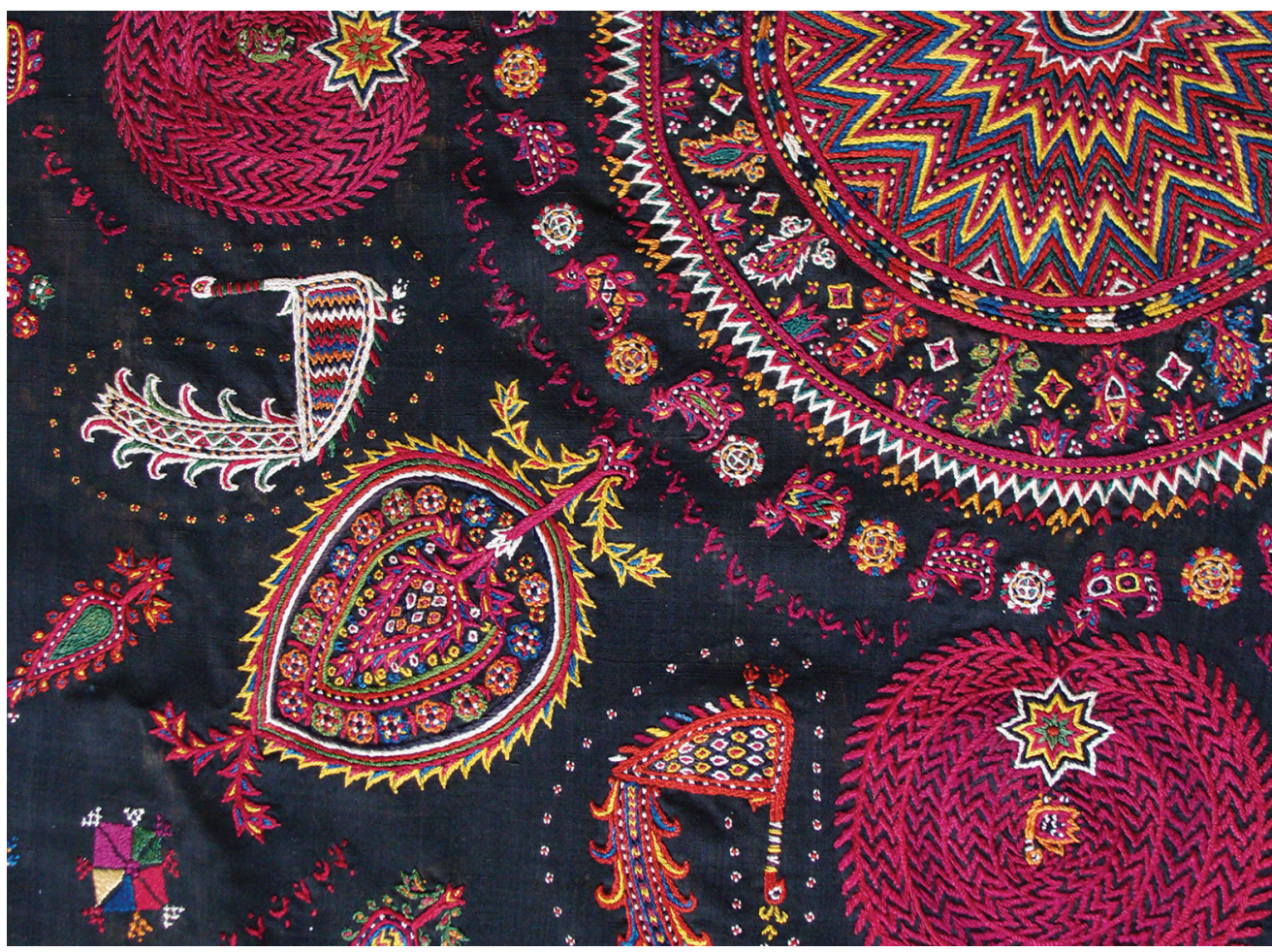

Fig. 29.1: This photograph is courtesy Elizabeth Gersivitch. It depicts a 19th-century wedding shawl collected from Iran and carefully preserved (@) UNESCO Parzor).
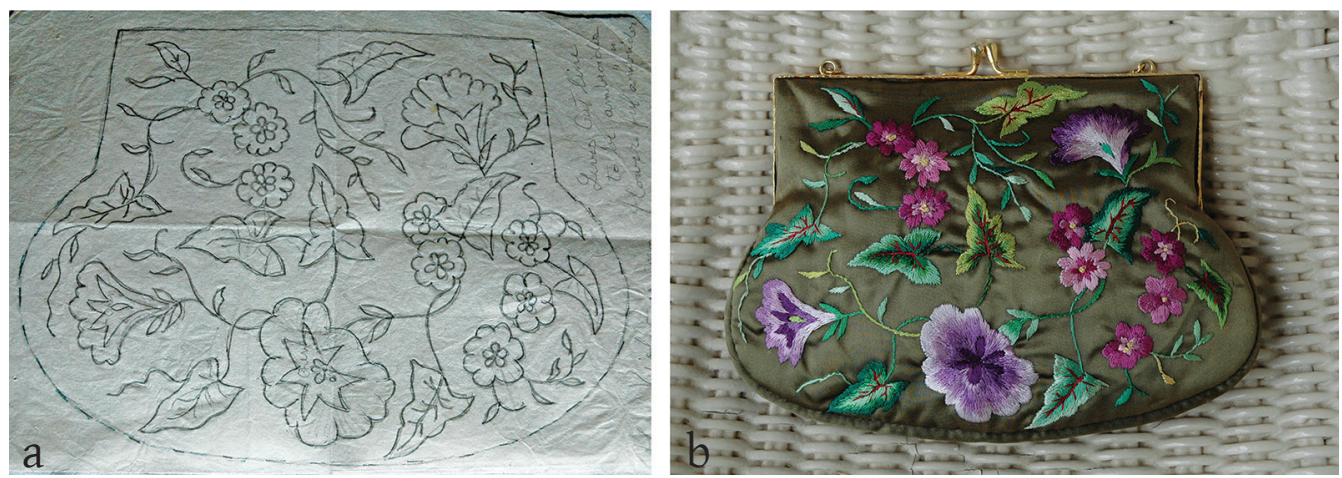

Fig. 29.2: Roshan Patel of Hyderabad kept the embroidery tradition alive till her death. Here we see: a) her tracing and b) the completed purse she designed and embroidered (@ UNESCO Parzor).

drawn, yellowed with age. They often had handwritten instructions about colour preferences, or initials and dates to indicate for whom and on what occasion the pattern or khakha had been created (Fig. 29.2).

The iconography of traditional Parsi embroidery comes to life through flowers, birds and animals, which are celebrated as emblems of power, protection and purity. 
The simurgh (senmurw) and rooster are sacred birds who provide health and protection. The rooster, when it crows every morning, slays the demon of darkness and becomes sacred to the archangel Yazata Sarosh. The simurgh ensures health and faithfulness. These protective powers make them a favoured emblem on children's clothing (Figs 29.3 and 29.4).

In the Bundahishn, the Pahlavi Text of Creation, each day is dedicated to an angel, symbolized in the material world by a flower. So, the red hundred-petalled rose stands for Din - Angel of Religion, the marigold for Atar - Angel of Fire, the white jasmine for Vohu Manah, The Good Mind (see Fig. 29.5). The Parthian (2nd century BCE) band of pearl discs and trellis grid patterns, seen in Iranian architecture and forest scenes, often found later on carpets, became popular in embroidery. Even when Islam became the religion of a conquered Persia and forbade portrayal of live figures, Zoroastrian motifs, animals and birds continued to be seen. As Allgrove McDowell states: "The textiles of conquered Persia preserved its original national identity and passed it on to future generations" (McDowell 1989, 157).

It was in the Tang and Song dynasties (618-1279 CE) that this Persian love of nature mingled with the skill of the embroidery schools of China across the Silk Route (McDowell 1989, 157-169). In this early stage of the intercultural amalgam, it can be seen how, after interaction between Persia and China, the satin stitch, the long and short stitch and the Parsi khakho or seed pearl stitch, began appearing alongside the Chinese chain stitch. Today, we have documented more than six forms of satin stitch in Parsi embroidery, while the khakho or 'forbidden stitch' no longer has any practitioners. Its intricacy resulted in women losing their eyesight; hence it was officially discouraged (see Figs 29.6 and 29.7).

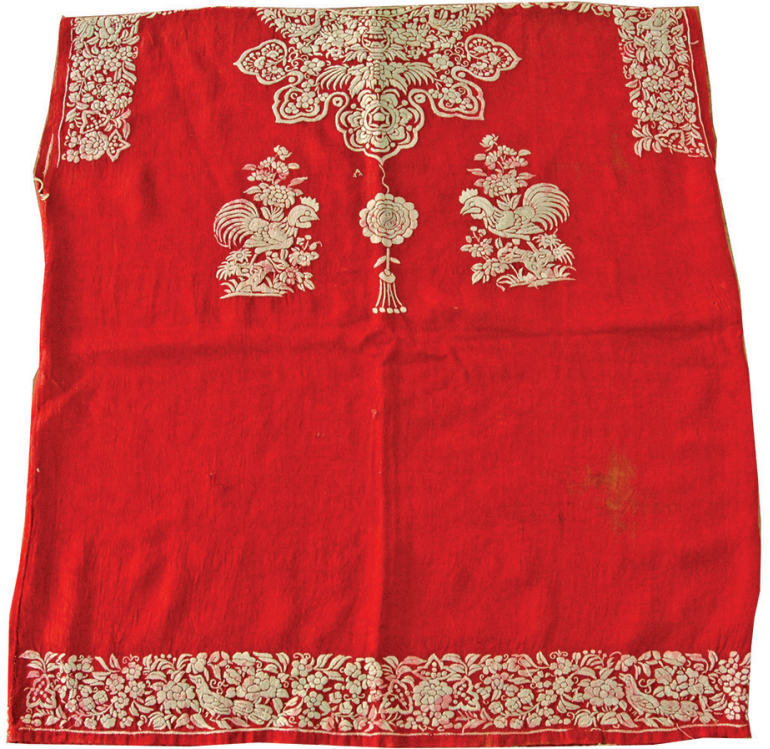

Fig. 29.3: Jhablas or tunics were worn particularly by children. This bright red jhabla combines two protective symbols: the rooster and the Chinese Divine Fungus (๑) UNESCO Parzor). 


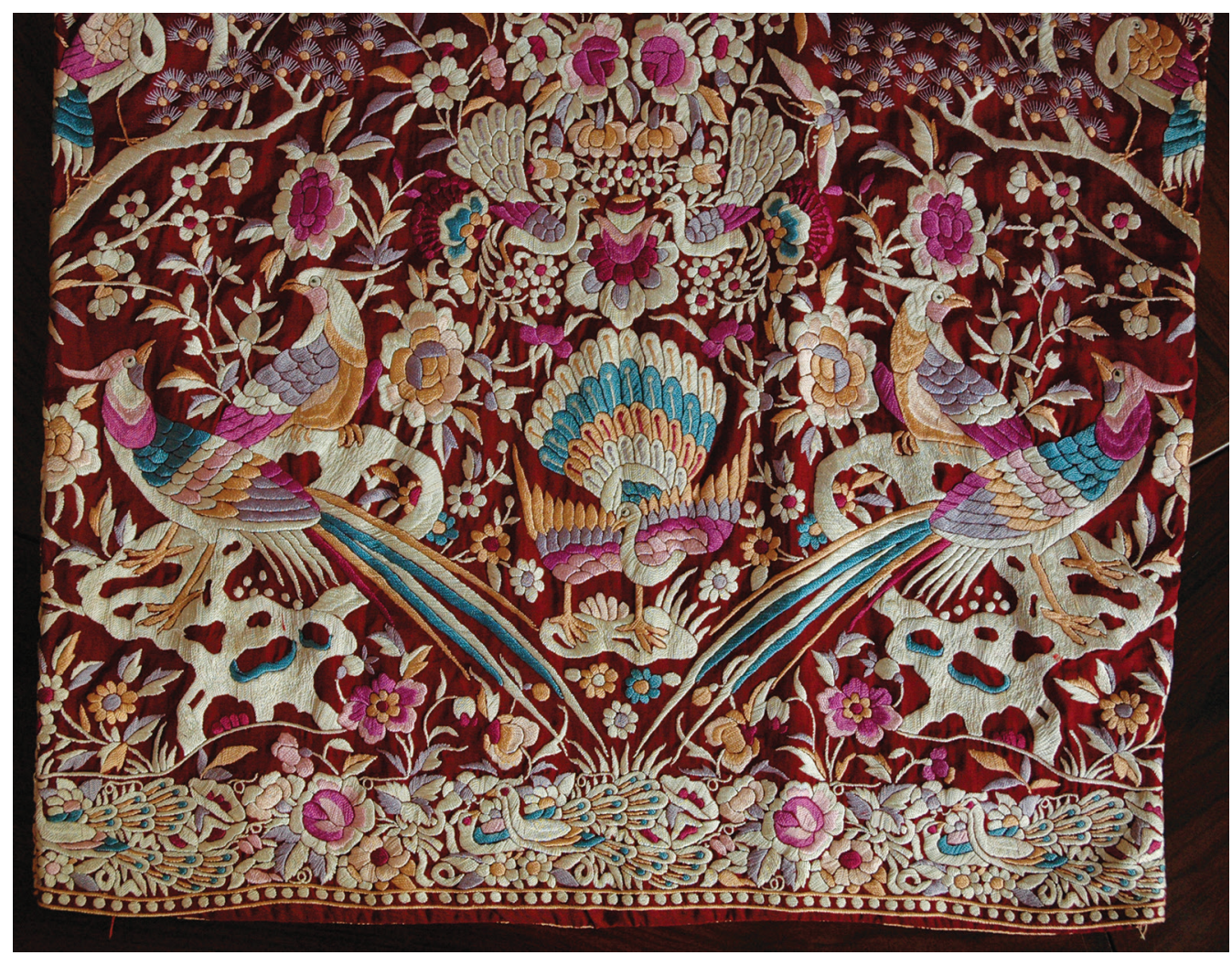

Fig. 29.4: This child's jhabla or tunic has an intercrossing simurgh (senmurw) as its pattern. It is richly embroidered and includes peacocks from the Indian tradition along with floral designs from Persia (C) UNESCO Parzor).

The Chinese connection with Persia was an overland trade link; this would change into a sea trade link with the later Indian Parsis. The first Parsi to sail for China was Hirji Jivanji in 1756. For almost 200 years, Parsi traders prospered, trading at Canton, Macao, Hong Kong and Shanghai. The Chinese had begun exporting their embroidery to Europe as early as the 13th century CE. By 1578, the Portuguese were allowed to trade from Canton and the city developed into an important centre for the export of

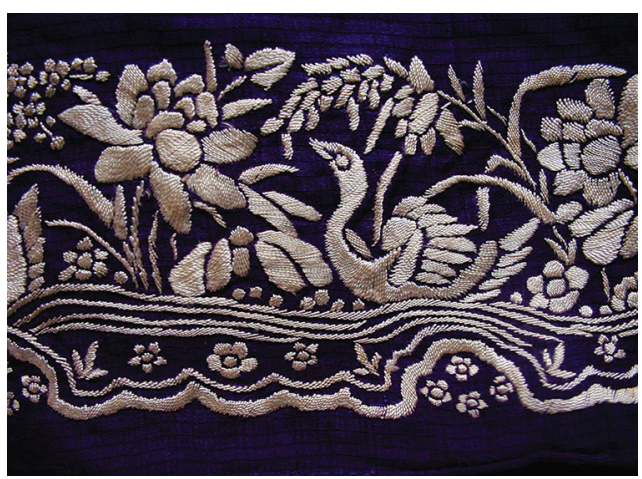

Fig. 29.5: Ava Yazad, Angel of Water, is depicted in this Parsi kor or border with the Water Lily, her representative flower (C) UNESCO Parzor). 


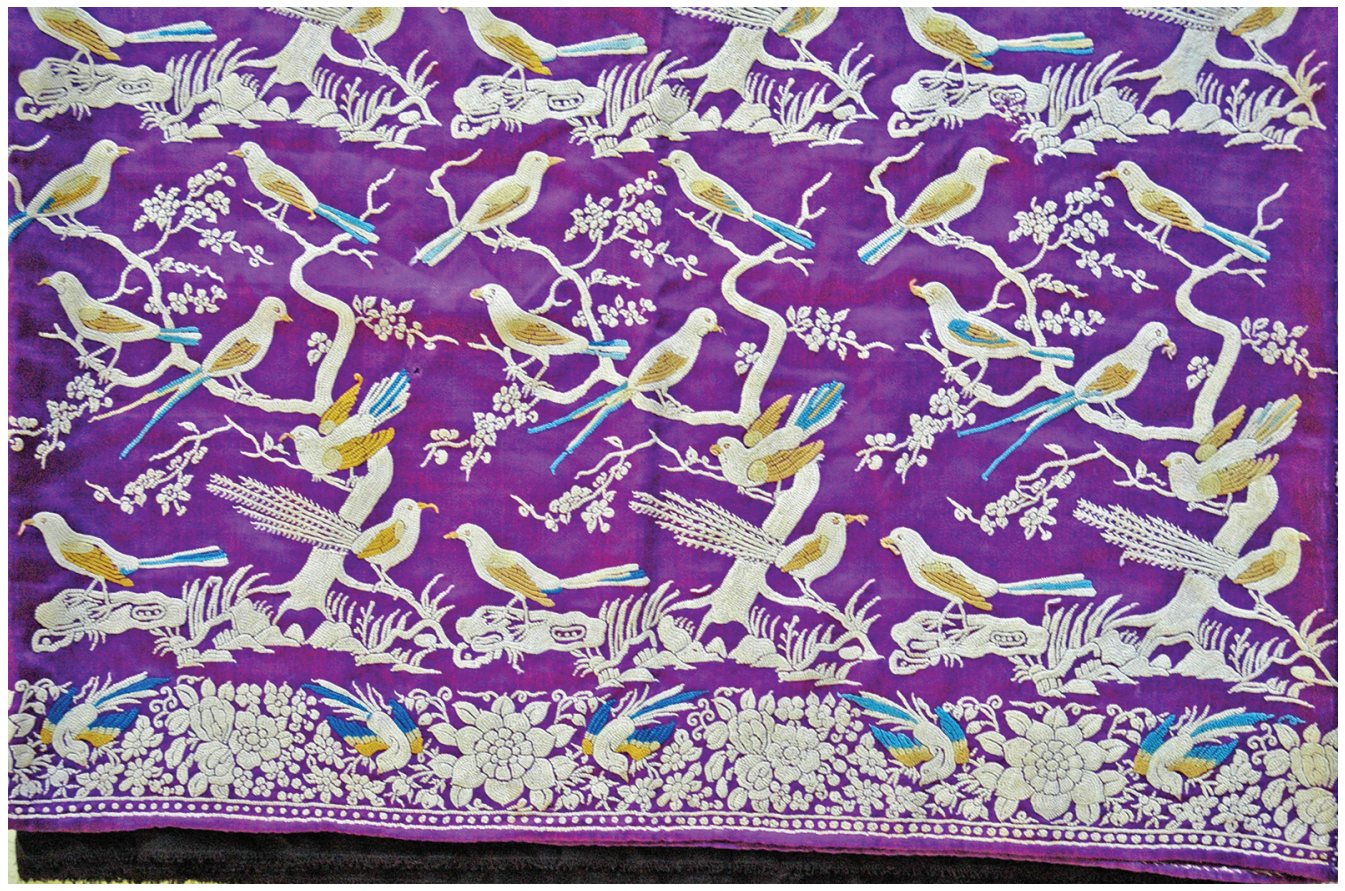

Fig. 29.6: An undated khakho jhabla. The birds, placed in a Gul-e-bulbul pattern, seem to be seated on an adaptation of the Chinese Divine Fungus image. This jhabla again represents the intercultural heritage of Parsi embroidery (@) UNESCO Parzor).

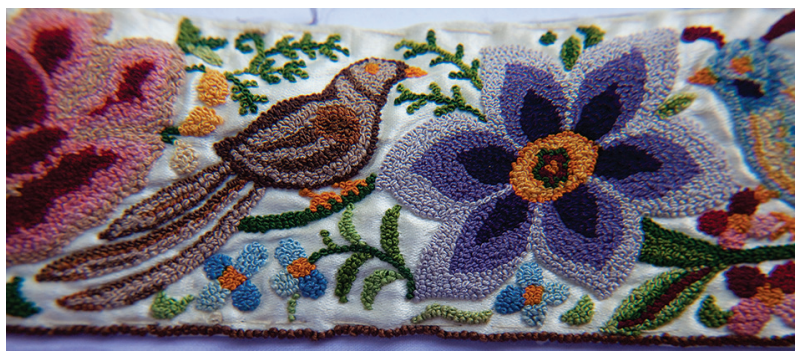

Fig. 29.7: This khakha stitch kor (border) was embroidered by Gulan Billimoria in the 1960s. She did beautiful embroidery but lost her eyesight towards the end of her life (C) UNESCO Parzor).

embroidered shawls, hangings, fire screens and other textiles, made for European clients and with increasingly western designs.

Legend has it that a Parsi trader in Canton, watching craftsmen embroider a rich textile, requested them to embroider six yards of silk as a sari for his wife in India. These first pieces, embroidered on satin, have no borders or pallavs and seem like yardage. These pieces often carried Taoist and Buddhist symbols of protection, such as the Divine Fungus (see Fig. 29.8).

The original name for a fully embroidered sari was badhi bhareli. In this, embroidered yardage was covered on all four sides as if bordered within a frame. This yardage is called gala in Gujarati and its enclosed patterned space gave its name to the gara. 
Fig. 29.8: The late Mrs Bhicoo Manekshaw of Delhi is the owner of this gara, made for an engagement in her family in the late 19th century. It includes motifs of the Divine Fungus and plants which symbolize fertility, as well as scenes of lovers (C) UNESCO Parzor).

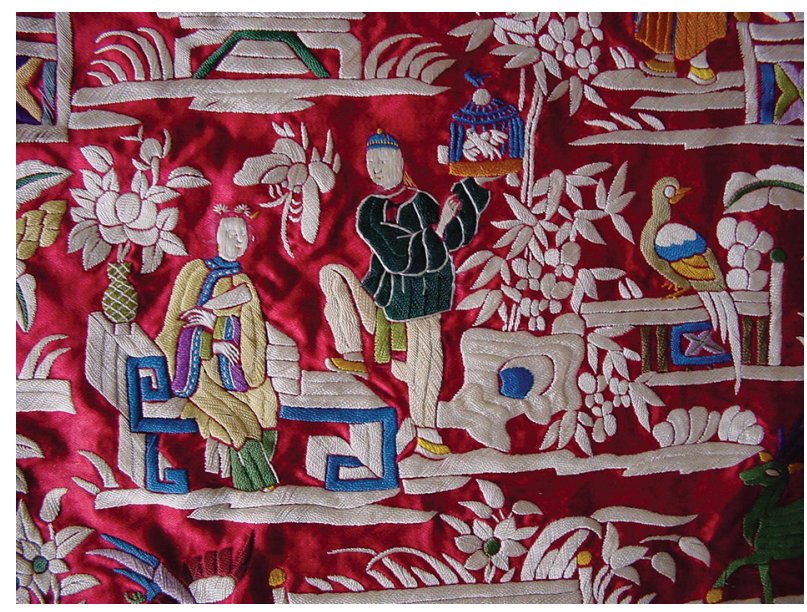

The oldest saris had a small width and required a narrow joint to be attached; these were called dodhpatti. As power looms developed, the width increased. To facilitate the wearer and customize this cloth into a sari, the top of this yardage was left unembroidered, as was one edge, to make it easier to tuck in at the waist. Parsi women, following Indian traditions, began designing kors (borders) to match the inner embroidery, as well as frontage or the pallav which would highlight the design. Soon, Chinese yardage had developed into the Parsi gara (sari).

The colours favoured in the Persian tradition were imperial purple and other rich shades. As Indian influence grew, the auspicious Indian kunku red or vermillion became a favourite, particularly for engagement saris. Parsis wear white, symbolizing purity, at their weddings, but began a tradition of using red for the engagement sari. Here, we can see a vermillion engagement gara which combines Persian trellis patterns, the flowers and birds from the Iranian tradition, with the Endless Knot from the Chinese cultural vocabulary (see Fig. 29.9).

Intercultural exchanges continued in other motifs too. The Indian Ambi and Persian Cypress combined to create powerful motifs for pallavs which included Chinese baskets symbolizing plenty. The Imperial presence of Europe brought an amalgamation of scallops, bows and ribbons, and thus, four cultures came together in the Parsi sari (see Figs 29.10 and 29.11).

The greatest amount of information collected on the China trade came during a research visit to Hong Kong in 2006, where Parzor textile researcher, Ashdeen Lilaowala met Parsis, who had been involved in the China trade for several generations. Dr Phiroza Nariman (née Tavadia) recounted how Shameen Island and Garden Island - British and French Concessions and parts of the Canton settlement - had been home to Europeans and Parsis. All around this area were villages from where men came regularly to take orders for embroidery and understand designs and colours from their Parsi clients. Parsi women preferred white and cream rather than typical Chinese multicoloured embroidery, because it matched the white lace sudrehs every 


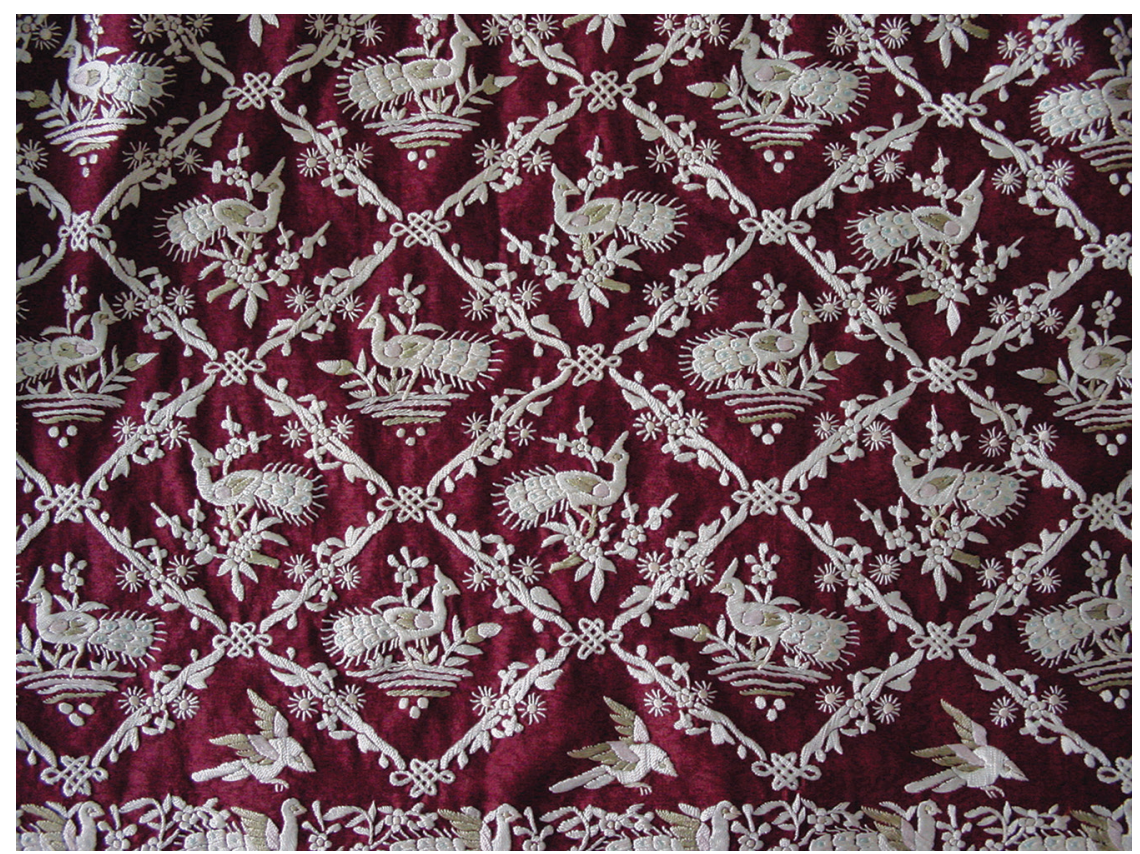

Fig. 29.9: Indian peacocks combine with Persian trellis and flowers, joined with the Endless Knot, to create a combination of auspicious symbols for this engagement gara (@ UNESCO Parzor).

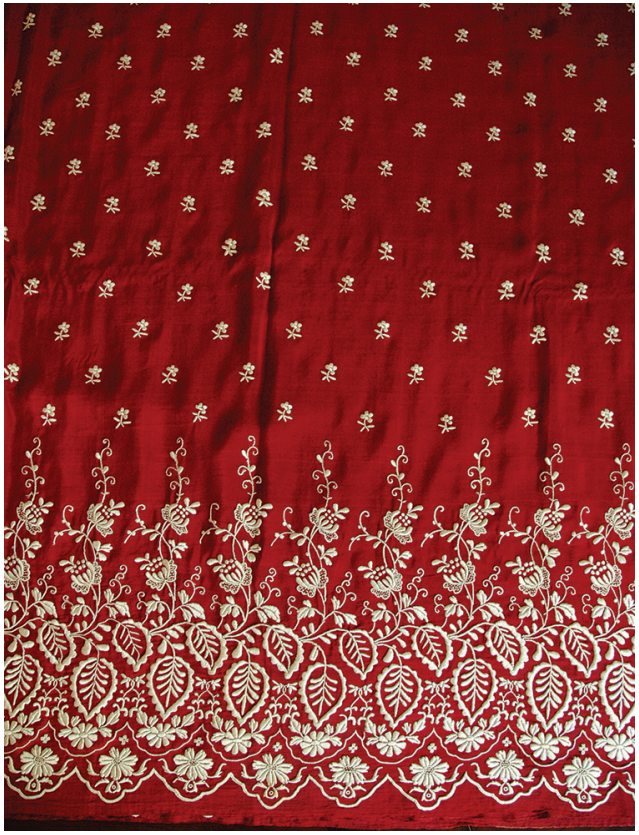

Fig. 29.10: European foliage and scallops form the base of this red embroidered gara (@ UNESCO Parzor). woman wore, showing under her blouse. It was here that Pestonjee Burjorjee Dhabhar began exporting garas and other embroidery materials to Hormusjee \& Sons and Karanjia in India. While the trade had been going on since the mid19th century, it became formalized by these shops during the early part of the 20th century. This trade was customized, as seals in Gujarati from the Chungtai area have been found on garments meant only for the Parsi trade.

Along with full garas, the border sari or kor became popular. Certain patterns in kors are found repeated in different colours according to individual preference. The cheena cheene (Chinese figures), kasab pakshi (birds), murgha batak (roosters and fowl) and flower kors were regularly made, while the kanda papeta type of sari, being less expensive than 
other varieties, acquired this 'common' nickname. (Figs 29.12 and 29.13)

Records of Parsi trading families tell us that the China trade flourished most when Parsi women actively participated in adapting Chinese yardage into designed garas. We have on record Roshan Guzder of Calcutta, who remembers stories of her grandmother travelling from Canton on a Chinese junk, and designing patterns for Parsi families in Bombay. These patterns were copied on tracing paper with neel (indigo) and then carried back to China for embroidery.

A cross-cultural dialogue was also to be found in the technical development in Surat of the saali gaj silk, a semitransparent silk fabric, light enough to be draped as a six-yard sari, yet strong enough to bear the weight of several kilos of heavy embroidery.

The designs over time were more and more influenced by the Parsi clientele. For many years it has been recognized

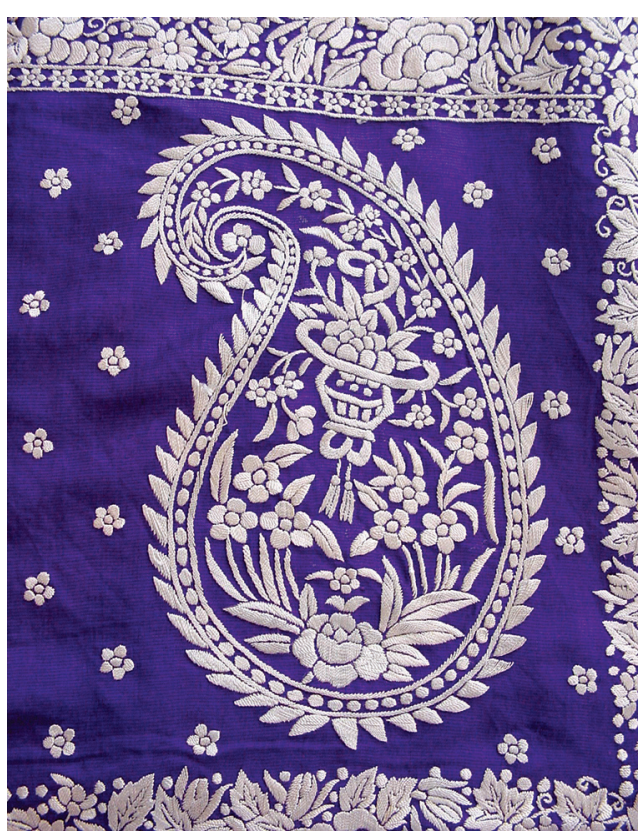

Fig. 29.11: The Chinese basket of plenty placed within an Indian Ambi or paisley is the primary motif on the sari pallav of this purple gara. The basket, like the Ambi, is an auspicious sign and would stand out dramatically in the Parsi Gujarati method of wearing a right handed or seedha hath pallav (C) UNESCO Parzor). that the Chinese gara and the Surti or Gujarati gara are individual products of the creative imagination. So, to understand how Chinese embroidery and Persian motifs blended with European design and Indian patterns to create 'Parsi embroidery' in India, we have to look at Surat and grassroot settlements of South Gujarat.

Until the early 1960s, Chinese pherawallas or textile vendors came regularly in the winter season to family homes across Gujarat, the Deccan, Bombay as well as Calcutta, wherever Parsi settlements were to be found. A man, in a white tunic and white trousers, with a small black skull cap, would arrive on the veranda early in the morning each week. Bejan Bodhanwala (b. 1928) recalls how in the Bharuch Parsi Vad, Chinese men carrying cane baskets with kors and saris artistically draped, would visit on foot or on bicycles. Mr Bodhanwala explained that the Chinese would come into Bharuch as a group but having divided the area into specific regions, only one Chinese trader would come regularly to a household.

In Bharuch, Parsis chose not to wear cotton and, to distinguish themselves from their Hindu and Jain neighbours, wore Chinese silk rather than Indian paaj. Several other elders across Gujarat recall Chinese men on bicycles who sold garas by weight. The heavier garas, with more embroidery, were more expensive. 


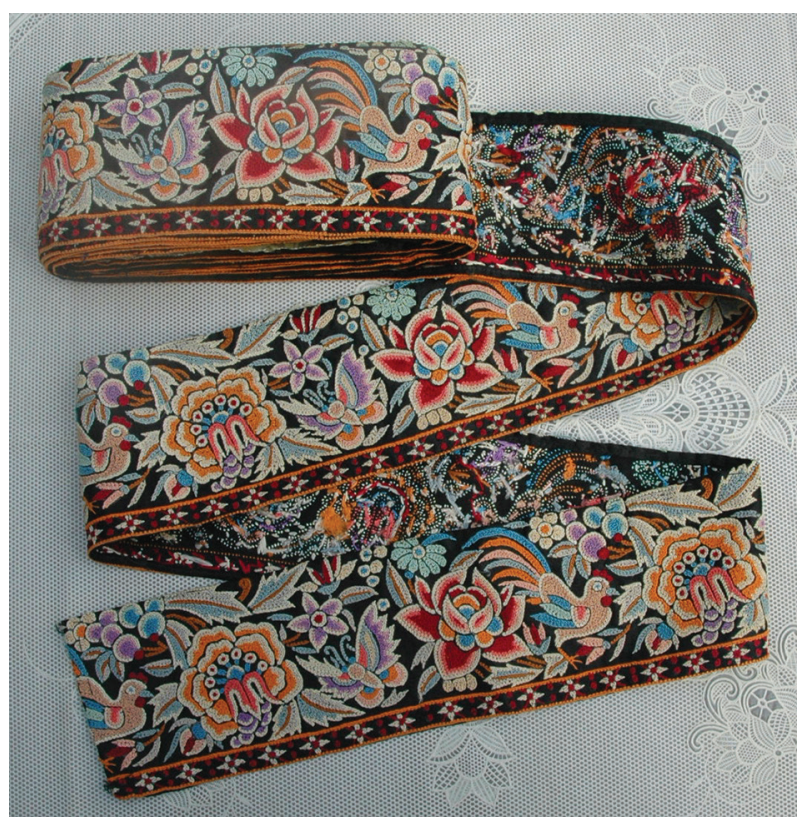

Fig. 29.12: The nine-yard kor which edges a Parsi sari is seen here with roosters, butterflies and floral motifs (C) UNESCO Parzor).

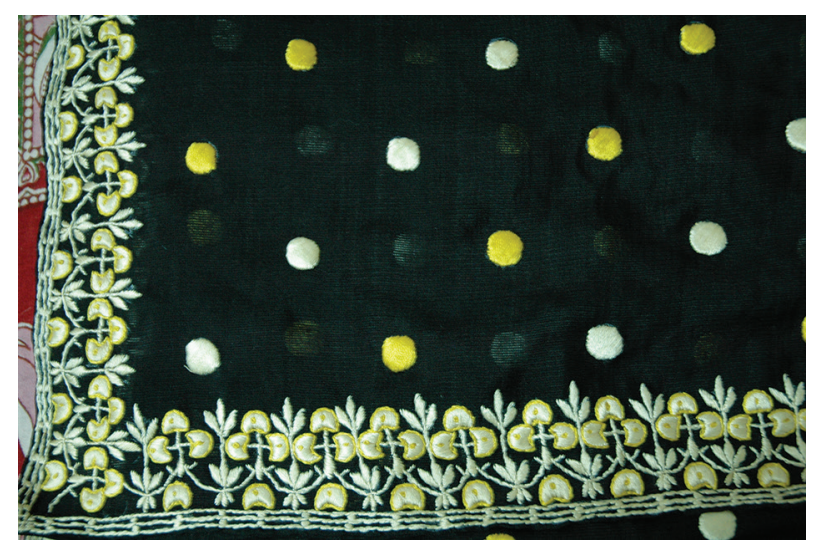

Fig. 29.13: Kanda papeta literally means onions and potatoes, and signifies simple embroidery (C) UNESCO Parzor).

Parsis provided a good income for these Chinese peddlers. Over the years, they developed a close relationship with their clients. Because they could not afford storage space, the Chinese would leave their heavy bundles of cloth on a particular veranda during their visits, returning there after the morning sales were done. In the heat of the afternoon, they rested on the otla, veranda, had their opium, and dozed. While waiting for the cool of the evening, they would take out little embroidery rings and start work. Parsi women, after completing the day's chores, would come out on the otla to watch the embroidery with interest. Bodhanwala knows that his mother Homai, learnt embroidery from these men. During the years 1938-1942, Chinese peddlers taught the women of his household certain stitches and motifs. The peddlers carried their original patterns on black cloth. Once they had finished copying a design, 
they leveled out the embroidery with small, sharp scissors. All these techniques and stitches were assimilated by Parsi women into their craft, adding their own myths and sacred symbols. Later, they incorporated the aari and mochi stitches, which they learnt from their Gujarati women friends. In the Deccan, Deccani Zari work began appearing on Parsi jhablas and children's prayer caps or topis.

It was in this way that Chinese embroidery became part of Parsi craft. Mothers learnt these special skills and passed them on to a new generation of women. They in turn used this craft, and with the education and freedom Parsi women enjoyed, created businesses or professions for themselves.

None of the people interviewed could provide dates for their collections or specific photographic proof of the Chinese peddlers. At the Victoria and Albert Museum, London, the archives contain a collection of Parsi embroidery which gives us some dates. The V\&A has its origins in The Great Exhibition, 1851. Several of the exhibits from this Exhibition were bought to create the nucleus of the V\&A collection. The Crystal Palace Exhibition of 1851 had provided the impetus to collect textiles from all parts of the British Empire. Its collection today contains many pieces acquired in Surat, done mainly in aari stitch. The earliest dates available on record are 1852, while a large archive was acquired in 1883. Several of the Parsi jhablas, ijars and kors state clearly 'Parsi women's embroidery' and these do not have typical Chinese motifs. Border or kor catalogues are still available with families in India but written records of sales did not exist except in retail stores. Most transactions were done mainly at home and, even today, sales of Parsi embroidery go undocumented.

As times changed, and with the movement of the Parsis away from Gujarat into small apartments in urban centres, a way of life was lost. The large embroidery cupboards neither fitted into the flats of Bombay, nor could they be carried when Parsis migrated abroad. All that remains today are the products - the garas, jhablas and ijars which carry the memory of a people and its culture.

As each culture faces the homogeneity of globalization, ethnic and cultural distinctions, including clothing, become a way of recalling identity. The UNESCO Parzor project has tried to draw the attention of the world to the Parsi community. The enthusiasm with which the ordinary Parsi has responded to Parzor's Craft Research and Revival Module provides hope that this fragile yet distinct thread in world textile encounters will continue to add worth to that tapestry which is India's multicultural heritage.

\section{Acknowledgements}

The author wishes to thank Ashdeen Lilaowala and Debapriya Das, co-travellers on this journey of discovery. The author and editors also wish to thank the publishers of Peonies \& Pagodas: Embroidered Parsi Textiles from the TAPI Collection edited by Shilpa Shah and Tulsi Vatsal (Garden Silk Mills Limited in association with Tapi Collection, Surat, 2010). This article is a condensed version based on the article "The Embroidery Cupboard: Oral Accounts of Parsi Embroidery" in the above-named book. All interviews 
have been conducted during Oral Tradition Recordings across India, China and Iran by researchers from the UNESCO Parzor Project. This article on embroidery draws upon Parzor oral heritage recordings over the past 10 years. These and the photographs are the copyright of UNESCO Parzor.

\section{Further Reading}

Yueh-siang Chang (2010) Exporting the Exotic: Embroidered Silks of China, in Shah and Vatsal (eds), Peonies and Pagodas, pp. 108-115.

Joan Allgrove McDowell (1989) Textiles, in Ronald W. Ferrier (ed.), The Arts of Persia, pp. 157-169. Piloo Nanavutty (1992) The Parsis.

Shilpa Shah and Tulsi Vatsal eds, (2010) Peonies and Pagodas: Embroidered Parsi Textiles from the TAPI Collection.

E. W. West (1977) trans./ed. Pahlavi Texts: The Bundahisn: Sacred Books of the East, Vol. 5, Part 1. 


\title{
30 The Navjote Ceremony and the Sudreh Kushti
}

\author{
LOTIKA VARADARAJAN
}

Lotika Varadarajan has had much exposure to tribal India and has undertaken in-depth studies of Indian looms and dye technology. She has interacted with colleagues at the Department of Anthropology, Cambridge University, UK; Centro de História de Além-Mar (CHAM), Universidade Nova, Lisbon and groups working on subjects of her interest, particularly ethnology, at the Maison des Sciences de l'Homme, Paris. Additionally, in Paris the late Krishna Riboud inducted her into the world of textile history and nominated her for membership of CIETA, Centre International d'Étude des Textiles Anciens, Lyon, France. Her expanding database in historic Indian textiles led her to the Museum of Printed Textiles, Mulhouse. She and Jacqueline Jacqué, the then Director of the Museum, have had several interactions while trying to understand various aspects of the hanging, Tapis Moghol. This culminated in the mounting of an exhibition of digitized images of the Tapis Moghol in April 2013 at the National Museum, New Delhi and the organization of a workshop in 2013 at the National Museum Institute, New Delhi. These two events resulted in a unique experiment inasmuch as a predominantly Indian group of scholars were brought together to engage in a multidisciplinary discourse to better comprehend a unique heritage item now housed in a French Museum. This led to the adoption of what was deemed to be a more apt nomenclature for the Tapis Moghol, now rechristened as The Safar Nama Textile.

Lotika Varadarajan has close contact with the Anthropological Survey of India, Kolkata as well as the Craft Museum, New Delhi. She has had the opportunity to interact with Kamaladevi Chattopadhayay and Pupul Jayakar, the two architects of traditional textile and handicraft institutions in post-Independence India. This has influenced her own Indian work agenda in which she has explored the knowledge systems embedded in occupations such as textile production and seafaring. Grounded on history, she has used her French experiences to mould her use of ethnology as a fertile tool of enquiry on Indian soil and this has yielded rich dividends in her chosen areas of work. She has been associated with the National Institute of Design, Ahmedabad and National Institute of Science Technology and Development Studies (NISTADS), New Delhi and is Member of the Advisory Board, Centre for Community Knowledge, Ambedkar University, New Delhi. She has recently been appointed Tagore Fellow to work on a Catalogue of the Textile Collection in the National Museum, New Delhi. She has been connected with several academic and government bodies and has authored seventy-six articles and twelve books.

A textile encounter of a religious nature between Central Asia and India lies at the heart of this chapter which deals with the sacred textiles used in the coming of age ceremony in the Parsi or Zoroastrian community today. Of the several variations of spelling of the term for the sacred girdle found in literature, kustig, kusti and kushti, I chose to use the term kushti which is most familiar to the Indian Parsi community. For those readers unfamiliar with the subject, a brief historical review becomes a 
necessary prelude, since the understanding of this term is intimately linked with Zoroastrian sacred texts.

It is believed that Zoroaster, also known as Zardusht and Zarathustra, was born in Central Asia somewhere around the mid-second millennia BCE and had a life span of about seventy years. Zoroaster preached through poetic compositions, gathas ( $g \bar{a} \theta \bar{a} \bar{s})$ or songs, in the Old Avestan language devoid of a script. The gathas were later divided into 17 häitis or chapters. Somewhere around the beginning of the Common Era, the haitis were amalgamated to form five units, each part being named after the opening word of the gathas concerned. Over the years more prayers were composed and the five gathas became part of a longer prayer, the yasna recited during rituals, including the coming of age ceremony, today.

The Yasna comprises a miscellany of texts found in the Avesta, the sacred writings of the Zoroastrian community. Divided into 21 books or nasks, the Avesta dates back at least to the 10th century CE, although references exist to earlier versions, for instance in the 9th-century Pahlavi text, Dēnkard. It was first composed in Avestan and rendered much later into the Pahlavi languages. The initial composition of the texts which led to the creation of the old Avestan texts could be ascribed to the mid-second millennium BCE, while that of the Young Avestan texts could be the end of the 2nd to the early part of the 1st millennium BCE. Many prayers in the Avesta written in Pahlavi, a middle Persian language, were compiled after the 5th century CE. The collection of such works was called Pāzand. There were also explanations and commentaries of the text, this corpus being called Zand. An alternative tradition traces the transmission to the Sassanian King, Khosrow or Anushirvan 531-579 CE, who declared Zoroastrianism as the court religion.

The kushti comes into play during the performance of the Yasna and is imbued with the symbolic value of the Avesta itself. The 72 ends of the warp used to make this tubular item are taken to represent the 72 haitis of the Yasna. However, it is only through the gateway of the initiation ceremony that the Parsi youth can grasp the full significance of the kushti which would lose its meaning in the absence of its necessary accompaniment, the sudreh.

\section{The Navjote Ceremony and the Sudreh-kushti}

Historically, there may be commonalities that may be traced between the ceremonies of transition among various religions, and other religions too have traditions of tying sacred threads or girdles. However, the Navjote ceremony as performed today has its own specific symbolic meaning. Thus, the Zoroastrian initiation ceremony marking the passage of infants of both sexes into the stage of understanding through the ceremony of Navjote is symbolically different to the Hindu rite of passage marked by the Upanayana ceremony when boys of the three upper castes are initiated into the stage of brahmacharya, entitlement to learn the Vedas. This rite is marked by the ceremony of conferment of the Yajñopavitam, the sacred thread. When, in old age, the 
male householder relinquishes the role of householder and enters the stage of sanyasa, he discards the yajñopavitam as, having fulfilled his duties as householder to the full, he relinquishes all worldly ties and retires to the forest to start on a new stage of spiritual quest and fulfilment. Nor can the Navjote from a symbolic perspective be compared today to the ceremony of tying the girdle around the waist to symbolise adherence to the three vows of chastity, obedience and poverty, in the case of Catholic religious orders when monks take their final vows and undergo the investiture ceremony.

In the case of the Parsis, the right to wear the sudreh and the kushti, are conferred through the performance of the ceremony of Navjote. This is an important rite of passage for members of both sexes. The first stage is when the child is handed over a sacred ceremonial garment called the sudreh (Figs 30.1 and 30.2). The kushti (Figs 30.3 and 30.4) or sacred girdle is then tied over the sudreh encircling the waist three times. The sudreh is an undergarment made of undyed cotton with its colour, cuts and folds constituting specific levels of symbolic meaning. There was similarly much play of symbolism in the kushti and the threefold manner of its wear. The hollow created by its tubular weave symbolised the space between the material and spiritual worlds. Today it is specified that the sudreh should be made of natural vegetal fibre while the kushti has to be woven in wool. The two items between them encompassed both the plant as well as the animal worlds.

After the initiation ceremony the kushti has to be ritually tied and untied at stated quotidian occasions. This ritual tying is called the Nirang-i Kusti, or

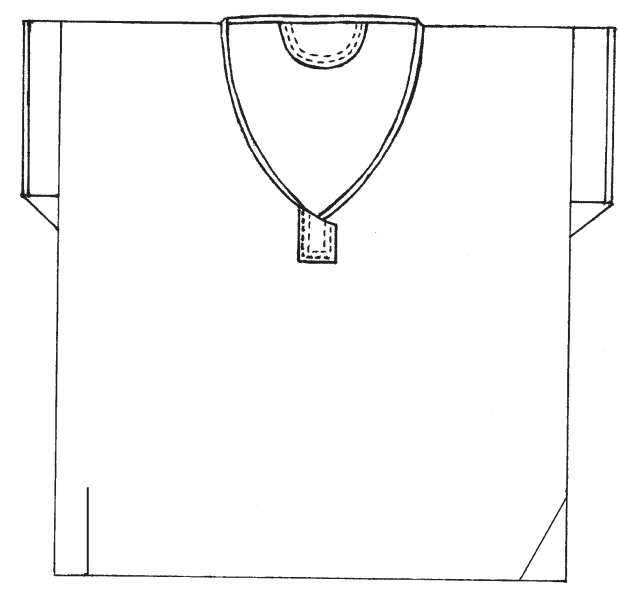

Fig. 30.1: The sudreh, the sacred garment (After Lilaowala 2013); photo: with kind permission (C) UNESCO PARZOR Project, Parzor Foundation, New Delhi).

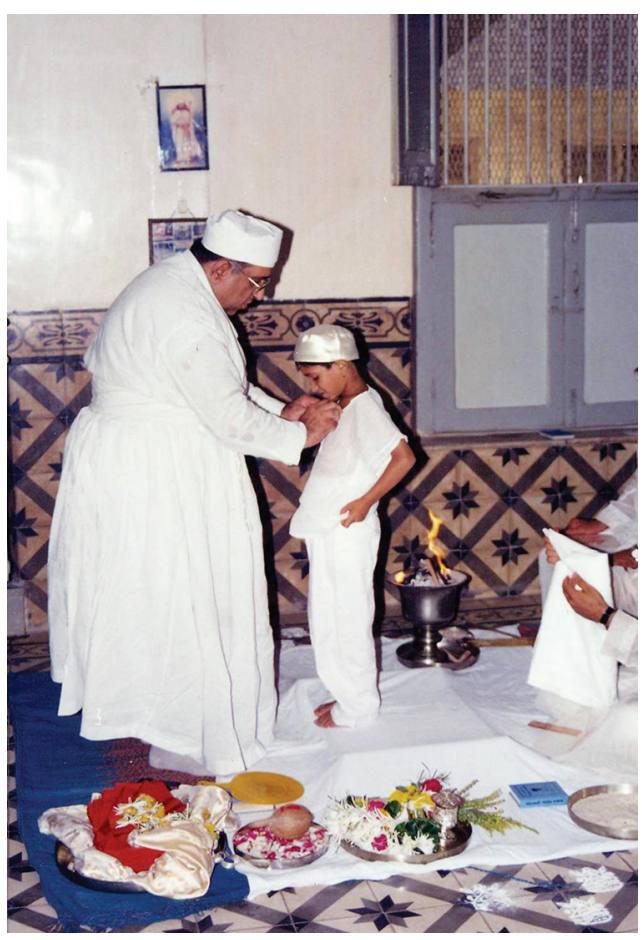

Fig. 30.2: Investiture of the sudreh, the sacred garment, at the time of the initiation ceremony (Zoroastrian Information Centre, Udvada, Gujarat; photo: Lotika Varadarajan). 


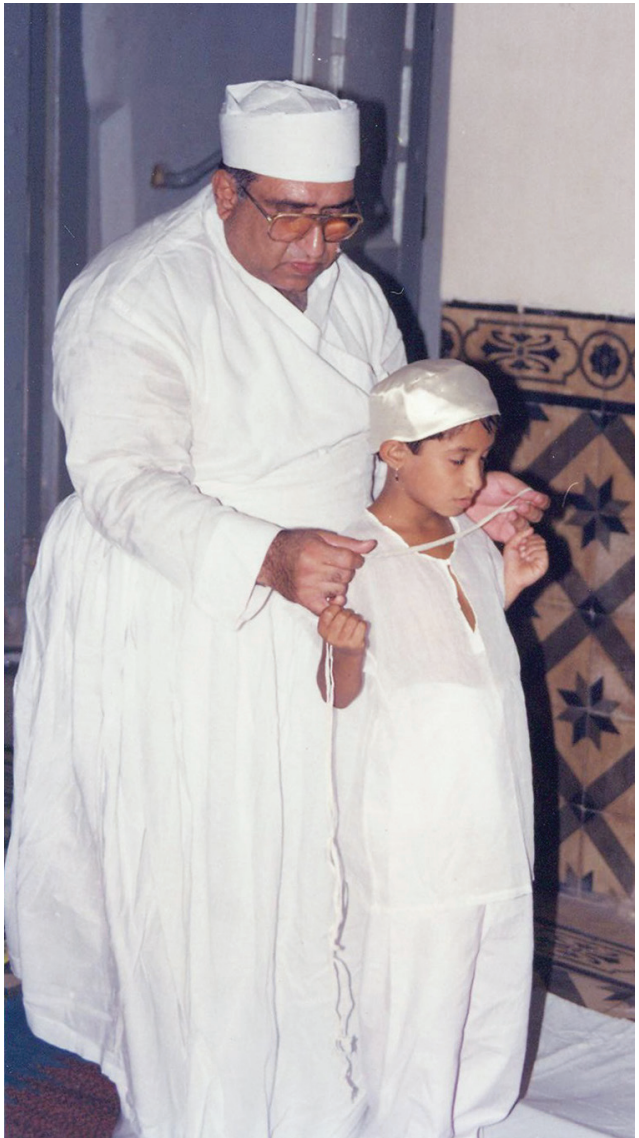

Fig. 30.3: The investiture of the kushti, the sacred girdle, at the time of the initiation ceremony (Zoroastrian Information Centre, Udvada, Gujarat; photo: Lotika Varadarajan). girdle formula, and is endowed with the signification of a religious rite. Moreover, the symbolical attributes of the sudreh and the kushti are subsequently invoked at all further rites of passage as when a girl attains puberty, at the marriage ceremony as well as during the funerary rituals. Their role is also invoked when a Dakhma, Tower of Silence, place of exposure of the dead is to be built. Similarly, during the initiation ceremony of entrance to the priesthood at the time of the Yasna ceremony, the priest reciting the Yasna, called the Joti (or Zot in Persian), brings the barsom, earlier a bundle of twigs now substituted by metal rods, tied together with a binder woven from date leaves, in front of the sacred fire. An analogy is now drawn between the barsom and the kushti.

\section{The Kushti}

The kushti is made from lambswool in India and also white camel hair in Iran. The length varies between three to six yards. Earlier, women of the priestly class alone wove these but now it has spread to other women among the Parsi laity.

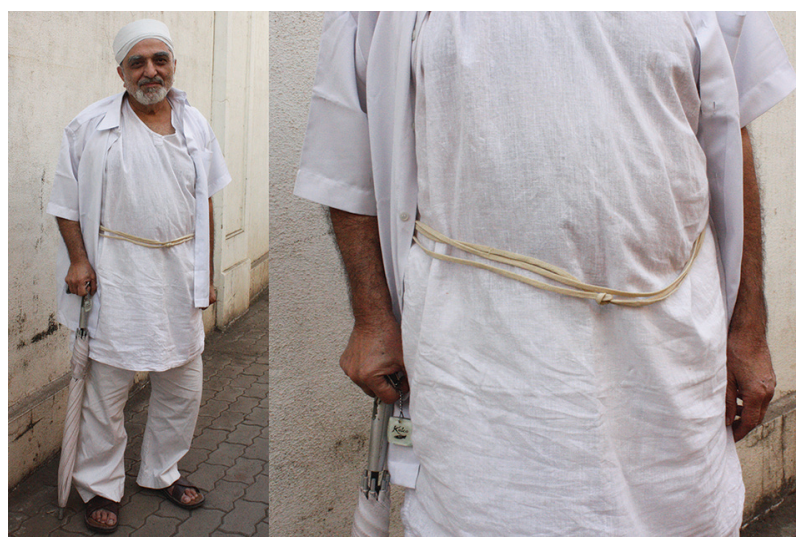

Fig. 30.4: Dastur Burjor Mirza on his way to the Iranshah Atash Behram (Fire Temple with the Most Sacred Fire). Note the sudreh and kushti, the sacred garment and girdle. (Photo: () Lotika Varadarajan at Udvada, Gujarat, 13 December 2012). 


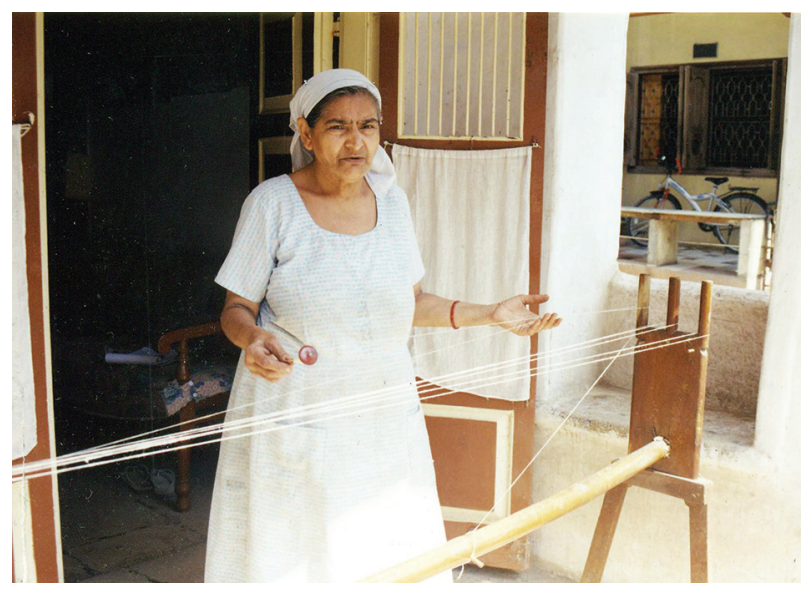

Fig. 30.5: Aligning of the warp on the junu jantar, the old type of loom (After Lilaowala 2013); photo: With kind permission (C) UNESCO PARZOR Project, Parzor Foundation, New Delhi).

The kushti is a tubular tape woven in a warp-faced plain weave. The first stage is spinning of the yarn, oon kantwanu, with a drop spindle called the chaaterdi.

\section{The Loom}

The earlier loom, the junu jantar (Figs 30.5 and 30.6), was a very basic frame loom and in Iran could have been aligned along the floor. Around 1930, the junu jantar was modified (Fig. 30.7). The procedures involved in the making of the Parsi kushti on the modified loom shown at the Exhibition, Zoroastrian Values and Traditions, held at the India International Centre, New Delhi, from 18-21 March 1989 were documented by this author on the basis of information supplied by Jer Kutar, a resident of Jamshedpur (Jharkhand), aged 74 at that time. The frame loom on display could be viewed at three levels, the continuous warp comprising 72 ends being manipulated and held in tension through the collective operation of a series of pulleys. At the

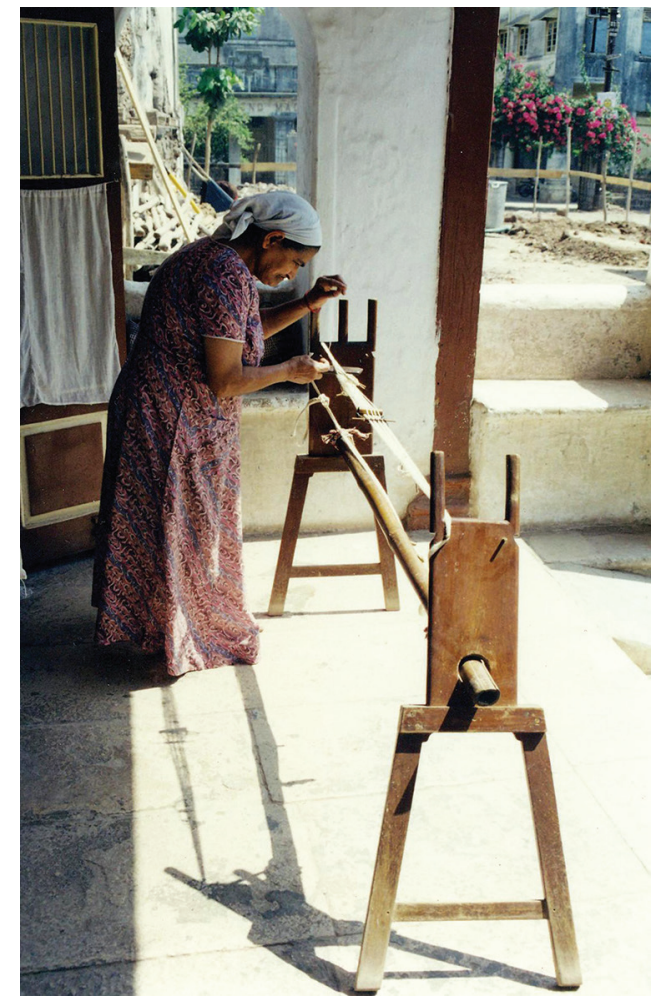

Fig. 30.6: The set up for weaving on the junu jantar, the old type of loom (After Lilaowala 2013); photo: With kind permission (C) UNESCO PARZOR Project, Parzor Foundation, New Delhi). 


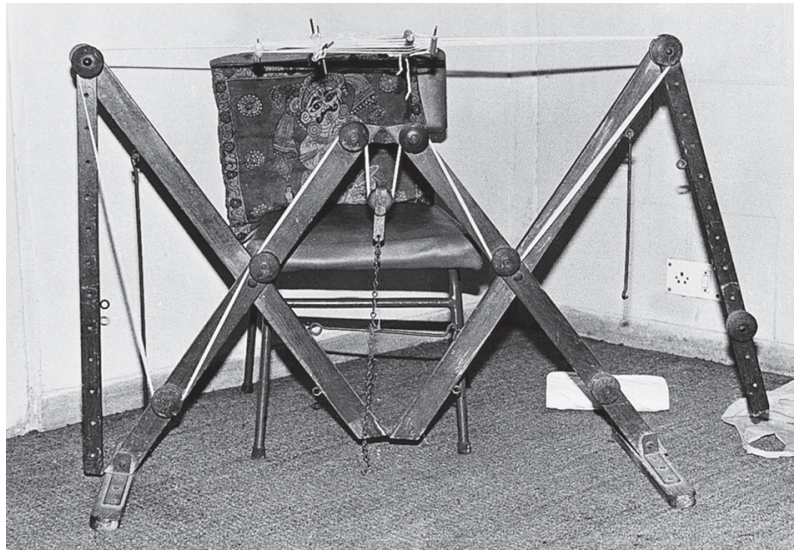

Fig. 30.7: Displacement of the junu jantar, the old type of loom, by a modified loom which has continued into the contemporary period (Photo: (C) Lotika Varadarajan at the Exhibition, Zoroastrian Values and Traditions, held at the India International Centre, New Delhi, 18-21 March 1989).

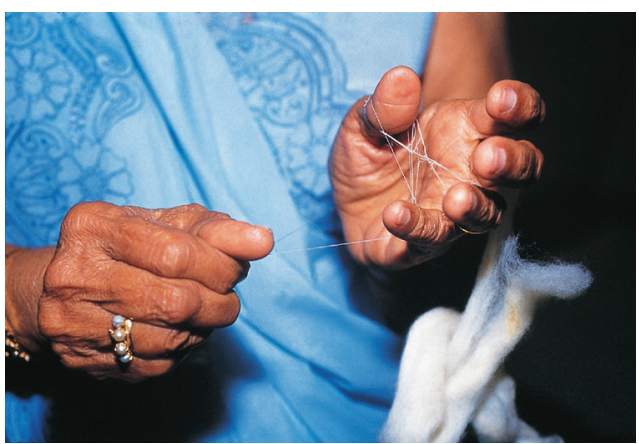

Fig. 30.8: Initial twining of the wool around the finger prior to transfer to the spindle (Photo: () Lotika Varadarajan at the Exhibition, Zoroastrian Values and Traditions, held at the India International Centre, New Delhi, 18-21 March 1989). uppermost plane, an adjustable pulley, the gargari, was suspended into position and adjusted as required to maintain tension. As demonstrated by Jer Kutar in Fig. 30.8, the lambswool was initially twined on the fingers before being transferred to the spindle (Fig. 30.8). At the first stage, wool from two spindles would be knotted at one end and wound into a ball. Twisting of this two-ply yarn would then be accomplished by means of a bigger and longer spindle. The loom would have a continuous warp of 72 ends (see Fig. 30.7).These would be divided into nine shafts, each shaft controlling eight ends (Fig. 30.9). In view of the fineness of the wool being woven, shed separators were made of light wood, such as sandalwood (Santalum album) or sisal (Agave sisalana). The shafts are manipulated for the introduction of the weft, the naru, through insertion of the shed separators (Fig. 30.10). The picks are gently compressed into position by the beater, the kateli (Fig. 30.11). Much experience is required to assess the correct degree of force, thok, required in this process.

After completing the desired portion in weaving, the tubular length is taken off the loom in loop form leaving unwoven a width comprising $23 / 4$ in. $(7 \mathrm{~cm})$ and length of $11^{1 / 2}$ in. $(c .29 \mathrm{~cm})$. The priest would then consecrate it by the recitation of the appropriate liturgical formulae. He would then cut the unwoven section with a knife dedicated to this purpose, usually made of ivory, leaving ends hanging at both points of termination. He would be paid a small fee for this purpose. In present times, the weavers themselves usually cut the kushti after reciting the appropriate prayers (Fig. 30.12). 


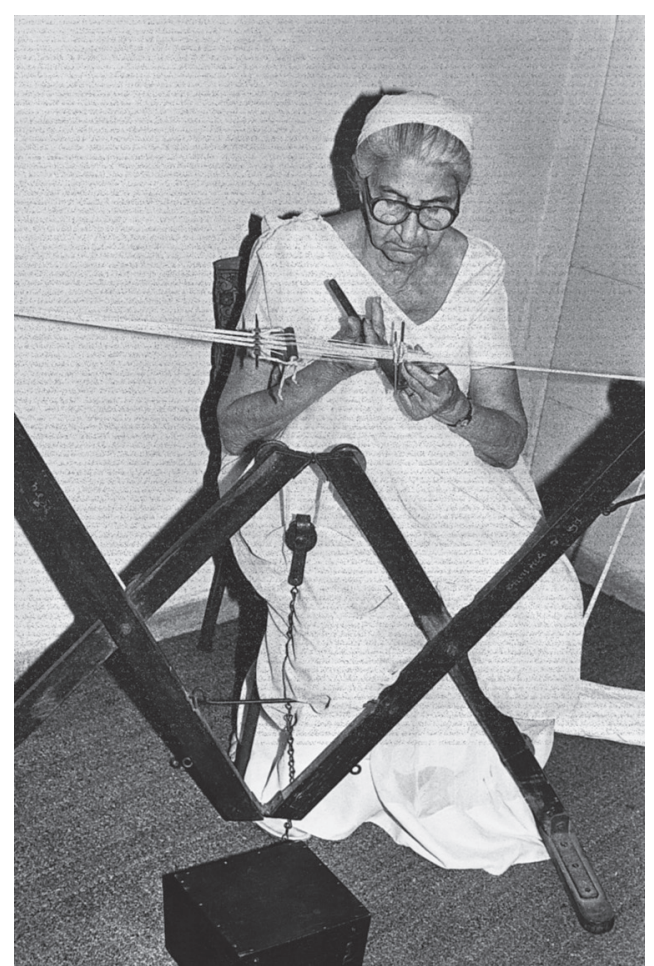

Fig. 30.9: Setting of shafts. Note the gargari, the adjustable pulley. Note that the weaver, Jer Kutar has covered her hair in view of the sacred nature of the item she is weaving (Photo: (C) Lotika Varadarajan at the Exhibition, Zoroastrian Values and Traditions, held at the India International Centre, New Delhi, 18-21 March 1989).

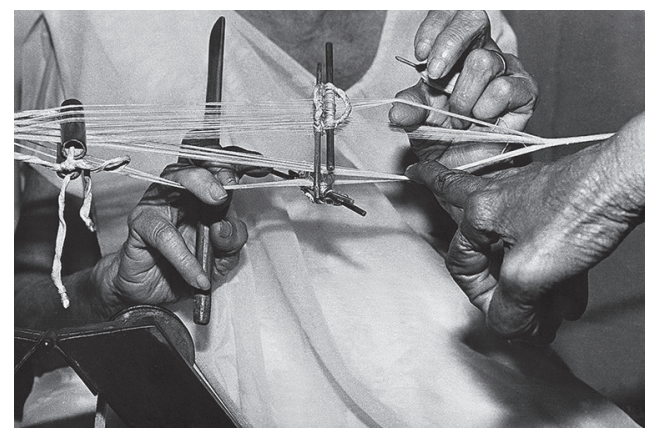

Fig. 30.10: Demonstration of shed formation. Note the weft bobbin in the hand of the weaver (Photo: (C) Lotika Varadarajan at the Exhibition, Zoroastrian Values and Traditions, held at the India International Centre, New Delhi, 18-21 March 1989).

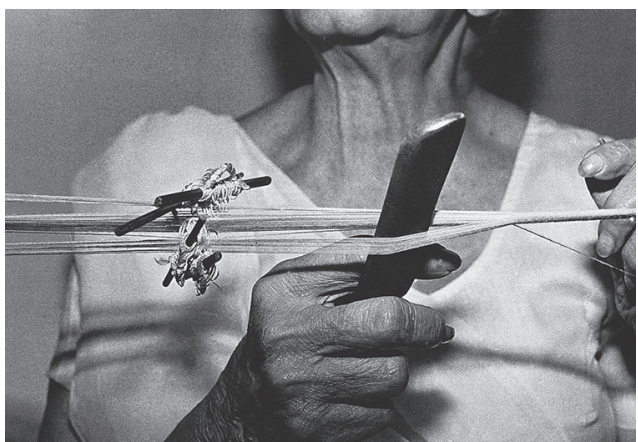

Fig. 30.11: Compression of the picks with the kateli, the beater (Photo: (C) Lotika Varadarajan at the Exhibition, Zoroastrian Values and Traditions, held at the India International Centre, New Delhi, 18-21 March 1989).

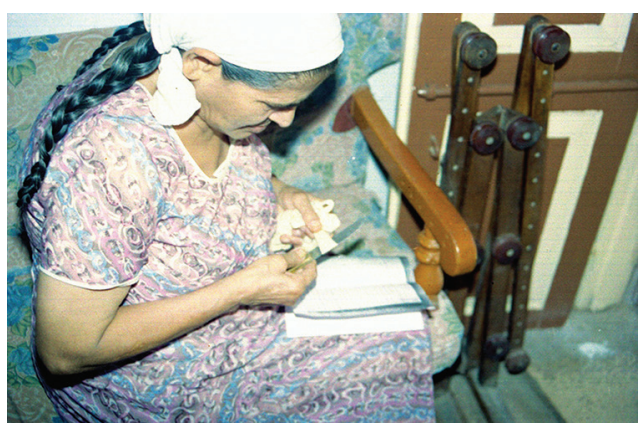

Fig. 30.12: Cutting the kushti, the sacred girdle, by the weaver after recitation of the appropriate prayer (After Lilaowala 2013; photo: With kind permission (C) UNESCO PARZOR Project, Parzor Foundation, New Delhi).

After the process of consecration, the kushti would be gradually turned inside out with the help of a large sewing needle, the suioo. This process, kushti otlavanu is considered to be the most difficult process in the weaving of the kushti. The free ends called lars are divided into nine parts and finely plaited, the points of termination being left hanging after being secured with a string (Fig. 30.13). The item would then be washed. The last phase is smoking, which has a bleaching effect. In a small utensil burning charcoal is placed on a 


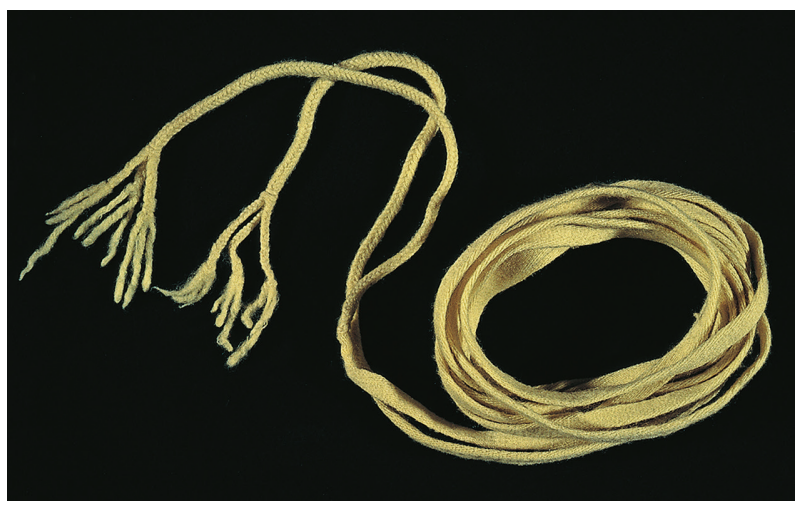

Fig. 30.13: The final product. Note the finish of the lars, the unwoven ends (After Varadarajan and Amin-Patel (2008), fig. 2.19 p. 64; photo: kind permission of the National Institute of Design (NID), Paldi, Ahmedabad, India and (C) Tanaaz Irani, Pune).

bed of ash to which sulphur is added. The utensil is covered. The kushti, wrapped in muslin, is left on this for about ten to fifteen minutes covered by a larger circular vessel. This process of bleaching is called dhupvanu.

The article is now ready for use, the sacred context never being out of mind throughout the process of manufacture being recalled through a complex series of symbolism appropriate to each stage of its making from its initial to its final stage of completion and use. The making of sacred textiles used in a religious ceremony today not only affords us a glimpse into the Zoroastrian community worldwide, but also sheds light into the nature of the precious relationship between textiles and human spirituality through the ages.

\section{Further Reading}

Soli Bamji, Tenets of Zoroastrianism <http://www3.sympatico.ca/zoroastrian/Gathas.htm> Pallan R. Ichaporia, Sudhra and Kushti <http://www.w-z-info-c.page.tl/Sudhra-and-Kushti.htm> Ashdeen Z. Lilaowala (2013) Threads of Continuity: A Study of Textiles used in Rituals and Customs of the Zoroastrian Community, A UNESCO PARZOR Project Monograph.

Prods Oktor Skjærvø: Avestan primer (2003) < http://www.fas.harvard.edu/ iranian/Avesta/> especially his introduction: <http://www.fas.harvard.edu/ iranian/Avesta/a02_introduction.pdf>. Lotika Varadarajan and Krishna Amin-Patel (2008) Of Fibre and Loom: The Indian Tradition. 


\title{
31 Globalization, Identity and T-Shirt Communication
}

\author{
KARL-HEINZ POGNER
}

Karl-Heinz Pogner (<www.cbs.dk/en/staff/kpikl>) holds a PhD from Odense University, Denmark. His thesis was published in 1999 as Schreiben im Beruf als Handeln im Fach [Writing in the workplace as acting in the professional domain]. The thesis shows that writing is not only an adjunct to action, but is a form of (inter) action in itself. He has lectured at Odense University and the Southern Denmark Business School in Sønderborg, Denmark. In 1998, he joined the Department of Intercultural Communication and Management, Copenhagen Business School, as Associate Professor. He is the Academic Program Director of the BSc and MSc study programmes, Business Administration and Organizational Communication and one of the founders of the "ComCaseCompetition".

His primary research and teaching interests are in the areas of text production, writing in the workplace, corporate communication, organizational communication, media and digital communication, public-private partnerships, co-branding, cocreation, engaged scholarship, i.e. research that contributes both to academia and to professional domains.

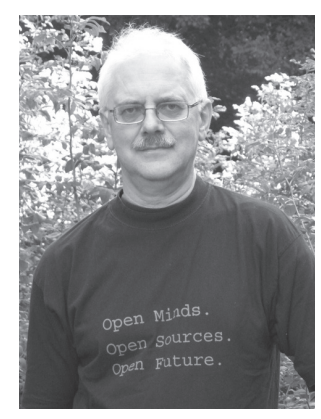

The global production and sale of cotton T-shirts and their enormous economic and even political impact is well researched, documented and analyzed. In particular, in her seminal book Pietra Rivoli (2006) follows her T-shirt's life across three continents. At the same time, she tells her story about globalization, politics, trade and markets. However, there is a need for more knowledge when it comes to consumption. More specifically, we need to learn more about how T-shirts have become an icon of globalization, not only for producers, but also for consumers, or better: prosumers (Ritzer and Jurgenson 2010). From being a 'traditional' piece of Western underwear, the T-shirt has moved to the surface and has become a globally used tool to express the personal and social identity of the person wearing it.

\section{The T-shirt is the Message}

A global textile perspective on T-shirts has to consider them not only as an item of clothing (ornament, costume, fashion), but also as dress (body modifications and supplements) in order to develop a holistic approach and to avoid ethnocentric 
shortcomings (Eicher 2010). Taking such a holistic and primarily communicative perspective as the point of departure, the following important observations can be made: $\mathrm{T}$-shirts are used by their wearers to encounter and express cosiness, casualness and leisure or sports. Wearing special brands (both textile ones but also other commercial and non-commercial brands) show the affiliation to a specific social group (age, gender, class, ethnicity) or a specific brand community. Some T-shirt wearers display pieces of art, high-end design and fashion - even haute couture.

T-shirts are also a means to invite others to communicate by sending messages about fashion, lifestyle, or making personal, social, or political statements. They are also used as an instrument of ironic critique, travesty, and 'adbusting' (adbusters are street art-groups who 'bust' by defamiliarizing, parodying, re-arranging corporate or political advertisements in order to turn their meanings into the opposite and to make fun of them). Last, but not least, they can be used as a tool to express concerns about climate change and other serious environmental issues.

Furthermore, consumers, who can afford it, increasingly become co-creators of these messages and invitations. The consumers can even become designers or codesigners of their own T-shirts.

These truly global trends became possible because of technical inventions and perhaps more important - because of the active use of T-shirts by the "unmanageable consumers" (Gabriel and Lang 2006). Sometimes, the wearers are actually 'prosumers', i.e. consumers who take an active part in the production and use of the goods and services they consume. Often they use T-shirts as communication tools and canvasses for creating their personal and social identities (see Giddens 1991 and Featherstone 1991).

In the following pages, I would like to relate several stories about the T-shirt becoming an identity marker and identity creator. At the same time, these stories tell a great deal about T-shirt communications as multi-voiced global phenomena, which leave space for local, even individual expression and creation. I will outline the history of T-shirt consumption, and the T-shirt as a commercial and non-commercial communication tool. The main questions will be: How do we in the 21st century use textile to communicate identity? How does the T-shirt at one and the same time display individuality and be part of mass marketing and mass consumption?

\section{T-shirts Here, T-shirts There, T-shirts Everywhere}

We all know it, we all wear it; we attach many (often good) memories to it. The (cotton) $\mathrm{T}$-shirt, the symbol of casual clothing and dress, has managed to rise from underwear over outerwear to the Olympic heights of the designer and fashion industries. And it seems to be omnipresent.

Just like jeans, T-Shirts became one of the 20th century's most universal and mythical items of clothing - with more than two billion a year sold worldwide. An extraordinary fate for this unassuming cotton tube shaped like a T that began its career in the men's underwear department (Brunel 2002,11). 
In 2004, over 2 billion T-shirts were produced globally. No doubt, the T-shirt is continuing its triumphant march in the 21st century, even at a higher speed. The contemporary, unmanageable consumers use it as a communication tool to show their different faces as, e.g. hedonists/artists, communicators, identity seekers, activists, rebels and citizens (Gabriel and Lang 2006). T-shirts and the messages, which they themselves send and which are posted on them, are used for self-portraying, identity negotiation and identity expression, and they operate as a (cotton!) canvas for cultural, social, political or personal - sometimes intimate - opinions (Fig. 31.3).

\section{The Historical Ones}

The history of the T-shirt is, to a certain extent, quite similar to the history of jeans and clearly connected to the popularity of blue jeans in the 20th century. Both T-shirts and jeans developed from being every day and working clothes over becoming a part of youth cultures and anti-fashion to eventually acquiring the status of (even high) fashion. In addition to this interrelated fashion history, the popularity of T-shirts are also related to technical innovations (especially digital printing) that made it possible to individualize, even personalize a mass production good.

The modern T-shirt accelerated the above-mentioned triumphant march around the world after World War II as the 'Army style T-shirt' produced of $100 \%$ cotton with a round neck and three-quarter sleeve became the official underwear of the US Army. The T-shirt expressed at that time an image of masculinity, (sexual) attractiveness, comfort and practicability, but it was considered tasteless to show up in a T-shirt outside the private sphere. The only exceptions at this time were sportsmen and (male) workers.

The non-conformist, so-called "Wild Ones" in the USA changed that profoundly. Young music rebels, film and rock stars (James Dean, Marlon Brando and Elvis Presley) became icons wearing their T-shirts as outerwear. On the female side, Marilyn Monroe, Brigitte Bardot and particularly Jean Seberg in Jean-Luc Godard's film A bout de souffle followed quickly and contributed to the sexy image of the T-shirt (Brunel 2002, 50-77).

T-shirts became more and more common everyday dress. However, the status of an everyday dress (in the Sixties sometimes hand-made, hand-dyed, hand-printed by the wearers or their mother or friends) is not the end of the story. Nor is the image of the T-shirt as a practical and inexpensive expression for a relaxed and casual lifestyle. Already in the Thirties, the famous fashion designer Coco Chanel wore a striped T-shirt. Since the Sixties, many famous fashion designers have been working with designing avant-garde or high fashion T-shirts. Designers, such as Issey Miake and Yohij Yammamoto, have deconstructed T-shirts by cutting and slashing, Pierre Balmain, Christian Dior, Domenico Dolce and Stefano Gabbana; Christian Lacroix, Giorgio Armani, and Vivienne Westwood have designed 'T-shirt Couture' and thereby promoted a 'luxurious-casual-style'. Fashion brands like Dior, Gap, Calvin Klein, Lacoste (logo: crocodile) have accompanied the first-mover, Fruit of the loom (logo: fruits). 


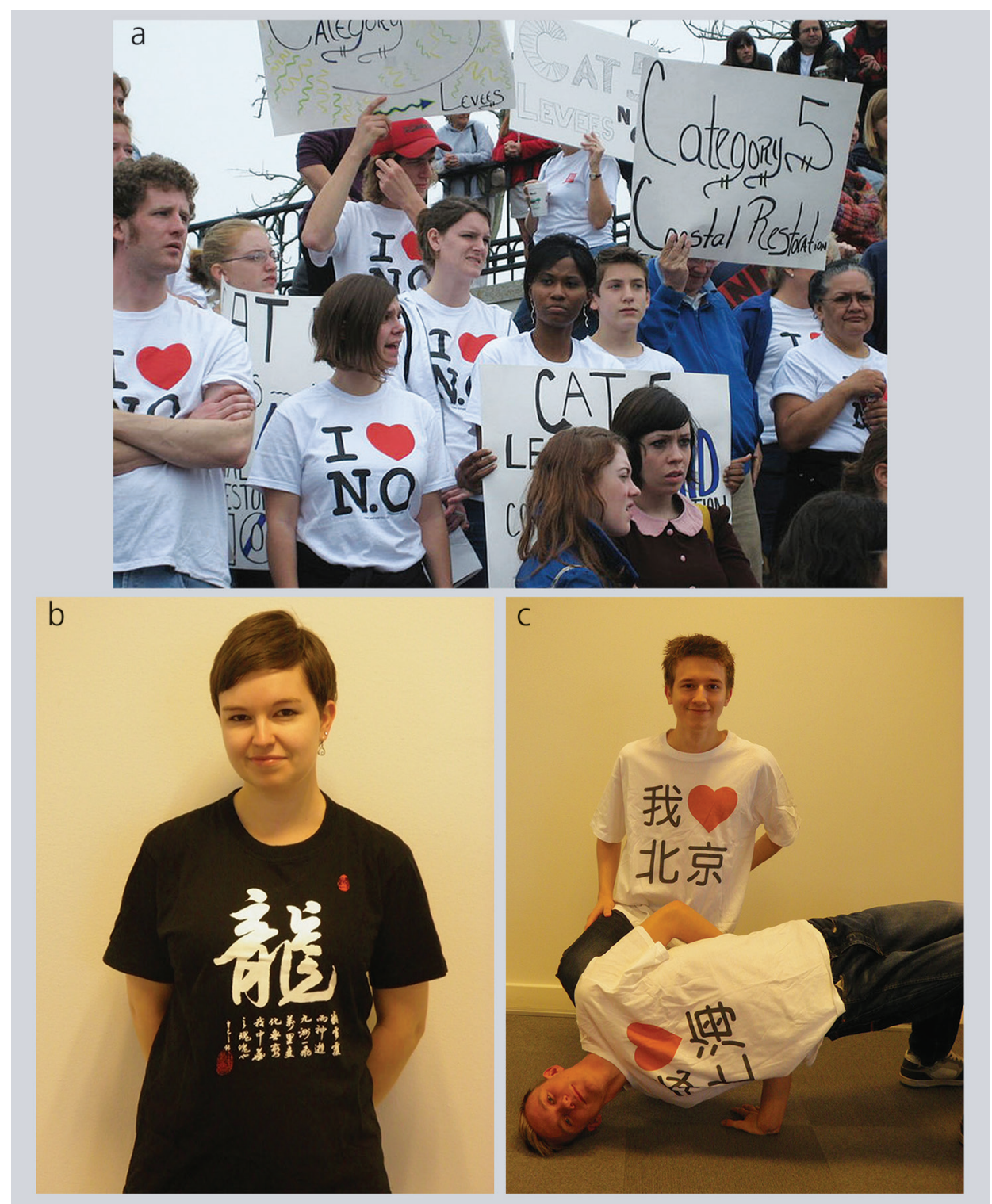

Fig. 31.1: These T-shirts tell different stories about glocalization. They show a global trend to reproduce almost the same design (originally by Milton Glaser for New York for almost every town in the world). a. The "I love (heart) N.O." T-shirts both refer to the city of New Orleans but at the same time express the citizens' demand for better flood control in New Orleans in the aftermath of Hurricane Katrina at a rally on the levee on 12th January 2006 (Photo by Infrogmation, http://commons.wikimedia.org/wiki/File:LeveeRally8.jpg, Creative Commons GNU free documentation Licence); b. The Shanghai dragon was bought at the International Airport Shanghai Pudong. It reads very poetically: "Travelling throughout the country and play around with the the weather, flying with boundless change, my soul - the Dragon: 翻云覆雨神游九州, 一飞万里变化无穷, 我心中的魂也一一一 一龙" (C) Photo: Ziff Jonker, T-shirt modelled by Maria Lykke Andersen); c. The issues with the Chinese letters relate to another interesting story: the T-shirts are unique as they have been made by a Chinese tailor. He decided to use the golden-orange colour because the red colour was not availble for him at short notice (@ Photos by Ziff Jonker, T-shirts modelled by Simon Jonker and Martin Henrik Andersen). 
Interestingly enough, many of these logo shirts are produced and bought as unlicensed copies or in second-hand shops, and a great deal of them ends up as donations (that nevertheless often are sold (!) in Africa).

On its journey from underwear to outerwear, the apparel and dress T-shirt has turned into a widely distributed billboard for advertising, marketing, and branding, as well as into a user-owned canvas for displaying preferences, comments, opinions and other messages. This was made possible by technological innovations (silk-screen printing, hot-iron transfer-technique, fast-heat pressure press, flocking, bubble coating, digital printing and digital-mechanical embroidery). These techniques allow for the printing of almost every possible motif.

Imprinted T-shirts are used for advertising and branding products (everything from ball-point pens to photocopy machines), companies, and organizations (including parties, presidential candidates, universities, non-governmental organizations, and social movements; countries, cities, museums, and other places). They are also used as tools for public and commercial campaigning, brand marketing, and merchandise (of, for example football clubs, movies, rock and other music stars and bands, exhibitions, trade fairs).

The imprinted T-shirt is a crucial driver in the development of the T-shirt from an item of clothing and dressing to a communication tool and identity marker. Today, one can not only communicate and express casualness that may include luxury, sportiness, non-conformism and conformism, with his or her T-shirt (form). Increasingly, one can also individually decide which message to communicate on his/her T-shirt (content).

The T-shirt has not only its own history; as an imprinted T-shirt it can record, relate or comment on history too. The most used image is the Coca-Cola logo, but on the second rank we find the famous Che Guevara photo by Alberto Cordas (Fig. 31.3f); and still today Ho Chi Minh is honoured and adored as part of many Vietnamese families ("Uncle Ho") - also on T-shirts. Some political icons have achieved almost pop star status. The green-alternative newspaper die tageszeitung in Berlin supported the renaming of a street in Berlin by a T-shirt with a street sign showing the name of Rudi Dutschke, a famous leader of the oppositional West-German student movement in the Sixties. In a more ironical-nostalgic manner, another T-shirt from Berlin playfully interacts with the official title of an East-German "Working Class Hero" from the German Democratic Republic (1949-1990) by making this title accessible (actually: 'buyable') for everybody who thinks s/he deserves it.

\section{The Advertising and Campaigning Ones}

Advertising and branding T-shirts exist for almost every thinkable products, commercial names, and slogans (Brunel 2007, 150-173): The range reaches from ball-point pens (BIC) over beer brands (Budweiser, Carlsberg, Heineken) and other beverages (Coca Cola) to magazines (Playboy) and supermarkets (Tati) or rock bands 
(the famous tongue of the Rolling Stones). Today, almost every company/label can print its name, logo or slogan on T-shirts as a contribution to its branding programme. Cities use it ("I Love New York" and all the global imitations, "adbustings" and parodies); as do museums (e.g. the Guggenheim Collection) and universities (compare the global imitations of the American typographic design on university sweatshirts and T-shirts). T-shirts are also brought into play by sport event organizers (e.g. Tour de France) or the souvenir industry in their place branding or event branding strategy (e.g. Shanghai and EXPO 2010).

The wearers of these T-shirt billboards not only co-produce advertising for the label, place or event, but go further. They utilize the consumption products actively to express their personal and/or social identity and lifestyle. For example (Enjoy it! Coca Cola), by expressing consumption preferences ( $\varnothing l$ [Danish for beer] or nostalgia (Solgryn [a traditional Danish brand of oatmeal, which almost every Danish child was brought up with in former times]).

Every big music festival or art exhibition has its own T-shirt, which gives the wearer a chance to position him/herself by means of his/her music and art taste. Some T-shirts have reached such a high cult status that this has led to their mass production as a plagiarism.

Avant-garde artists have explored T-shirts as a canvas in the literarily sense. Following the words of the German performance and multi-artist Joseph Beuys "Everybody is an artist" and of the French multi-artist Colonel (= Thierry Geoffrey) "Everybody can paint", some artists ask their audience to 'paint' their own T-shirts. T-shirt communication not only is a part of a participatory or democratic culture, but also a contribution to the concept of participatory art and co-creation of art experiences.

Consumption critics and Non-Governmental Organizations (NGOs) as well as many non-profit or non-commercial organizations contribute to such a participatory culture. They utilize imprinted T-shirts in order to reach their goals. Ad-busting is used by activists in an ironic-underground, inter-textual strategy as a critical form of 'Guerrilla-Marketing'. Well-known brands and slogans appear in travesty version: "Hell" instead of "Shell", "Enjoy Cocaine" instead of "Enjoy Coca-Cola"; "McLenin's" instead of "McDonalds", "Sexsi" instead of "Pepsi" etc. These T-shirts give their wearers/consumers the chance to display critical and humorous sides of their identity and personality (Fig. 31.2).

More seriously formulated messages, too, can be borne on your chest - near your heart! Environmental groups (e.g. the Danish Rain Forest Group, Nepenthes; the East German Peace Movement ("Schwerter zu Pflugscharen" [Swords to Ploughshares] T-shirt has made its way to the Historic Museum in Leipzig!), the Open-SourceMovement in the field of software development ("Open Minds, Open Sources. Open Future."), local, international or global bike associations ("Cycling Power - Yes please!") and many more NGOs and movements create attention for their causes and aims. At the same time, they give the consumers the opportunity to express their identification with, and support for the causes and aims of the groups and organizations in question. 


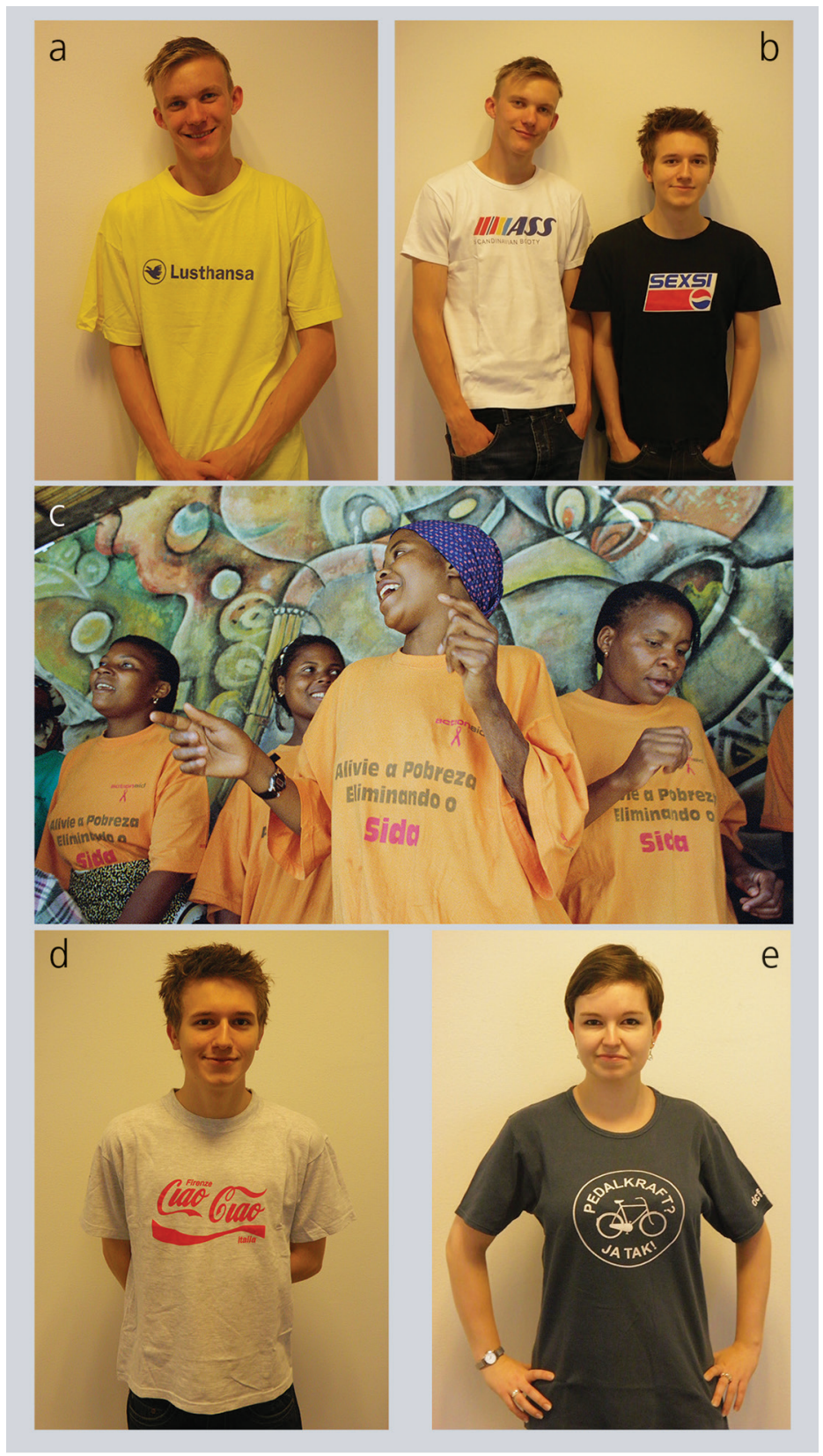

Fig. 31.2: These "ad-busting" T-shirts are ironic treatments of consumerism, logo mania, and brand mania (a. Lusthansa instead of Lufthansa, b. ASS instead of SAS, Sexsi instead of Pepsi, d. Ciao Ciao instead of Coca Cola). They criticize the brands in question and certain trends in society. The displayed NGO-T-shirts promote causes and goals in a more direct manner, e.g. c. "Alivie a Pobreza Eliminano o Sida" Street vendors trained as AIDS educators by Action Aid performing in Bobole, Mozambique, 1st October 2001 wearing T-shirts calling for the elimination of poverty, and e. "[Bicycle] pedal power: Yes please!" as a counterpart to the well-known: "Nuclear Power: No thanks!" (@) Photos: a, b, d and e by Ziff Jonker; modelled by Martin Henrik Andersen, Maria Lykke Andersen and Simon Jonker; c. Photo by (c) Gideon Mendel/Corbis). 


\section{The Political Ones}

American presidential candidates were probably the first to have printed their slogans on T-shirts. Nowadays, the constituents have begun to fight back, e.g. in 2004 with "100 reasons not to vote for Bush" - printed on T-shirts and underpants. In this particular US election campaign, catwalks, boutiques and concerts were explored and exploited as political forums, where the constituents as consumers could combine their fashion statement with their political statement. Today, almost every political message can be found on T-shirts. If not, it can easily be printed on a T-shirt either by low-tech or high-tech means.

The selling and wearing of T-shirts with direct or indirect political messages can, under certain circumstances, have far-reaching consequences because they are seen as a provocation in the public discourse:

Human rights activists from the Coalition for Change in Gambia were in August 2011 accused of high-treason, which could result in capital or lifelong punishment for printing (not wearing!) T-shirts. In Gambia in 2011/12 it not only proved dangerous for opposition groups or parties to wear T-shirts with critical political statements, but it was even dangerous to announce the intention to produce and to distribute them.

In 2006, a T-shirt with the so-called Mohammed-caricatures triggered bloody riots and a violent attack against the Italian Embassy in the Libyan town, Benghazi. It also resulted in the resignation of the Italian Minister for the Reform of the Constitution, who had worn this T-shirt during a TV interview.

Political activists (e.g. Greenpeace or the Fighters and Lovers) or consumer activists (like Fairtrade promoters) increasingly use the semiotics of the fashion industry. However, political mottos, slogans, and symbols can turn into lifestyle accessories of a 'radical chic'. It becomes increasingly difficult for activists and organizers of charity and benefit matches, concerts, dinners etc. to escape the close relation between political activism and branding. It is becoming more difficult to see the differences between an activist and a label manager. The same counts the other way round. Often, a company promoting 'social fashion' is not only featuring a good cause, but the cause is also promoting the company.

\section{The Global and the Fair Ones}

The T-shirt has become a symbol of globalization. In her travel report, Pietra Rivoli (2006) follows the journey of a T-shirt, before it gets into the shop and after it has left the collection of second-hand clothes centres. As a very important spin-off, she describes the complex structures, markets and (trade) politics of the globalized world economy (see the globalization critical movie T-shirts travel by Grassroots Pictures).

Mass media constantly report environmental pollution and extreme, inhuman working conditions in cotton and T-shirt production facilities in the global textile and apparel industry. Three different reactions on these critical reports can be observed: 
First, some Non-Governmental Organizations (NGOs) promote the Fairtrade concept and the Fairtrade label in order to guarantee a fair price for the goods and labour, and a sustainable development for the farmers and workers. Famous actors and actresses, musicians and leading businessmen and businesswomen and other celebrities promote the Fairtrade campaign - of course, dressed in a "Fairtrade Fighter" T-shirt!

Secondly, some labels and some retailers have started initiatives for sustainability, ecology, fair working conditions and prices through the whole supply chain - under the headline of Corporate Social Responsibility (CSR). Those initiatives and projects involve both their core business and the rest of the value-chain (suppliers and other stakeholders). Sometimes, these projects lead to rather unexpected collaborations, e.g. the Swedish global retail-clothing chain Hennes \& Mauritz has co-operated with "Designers against Aids" in order to sensitize young people to the dangers of unprotected sex - and of course to improve its own image. Interestingly, this campaign aims at the so-called industrialized countries. But the T-shirts will surely travel globally - and via collections of old clothes and non-commercial aid projects and/or commercial second-hand trade companies find their way to other developing countries, where AIDS/HIV is a serious problem. A Danish Sushi restaurant chain does not only use messages on T-shirts to promote its sustainability projects, but also to give input to social and political debates within society, e.g. with a travesty of a job announcement focusing on ethical issues: "Denmark: Prosperity we have; kindness we are looking for" (Fig. 31.3e).

Finally, some companies try to produce in a sustainable, social and environmental responsible manner, e.g. in the Indian company Indigreen, a designer and an entrepreneur produce sustainable T-shirts of organic cotton and fabrics with the goal of paying fair wages, using eco-friendly paints, and supporting local NGOs. They also promote local artists and local Indian values with a heavy portion of Bollywood kitsch with a series of T-shirts with hand-painted canvases designed by Bollywood poster painters, who were made redundant because of the digital production of Bollywood advertising.

The story of the Indigreen T-shirts shows both the opportunities and threats of globalization. On the one hand, it is a local answer to global social, environmental and economic inequalities. On the other hand, it poses a dilemma: How to obtain organic cotton at a price that would help the producers to offer products that are affordable to the local consumers? How to be able to pay fair fees and wages without making the product unaffordable to the (local) customers? At the same time, Indigreen is a typical example of "glocalization", a concept that stands for individuals, groups, organizations, communities or ecological, social and political movements, who follow the "think globally and act locally" maxim, and for a perspective on globalization that stresses the interdependency of global trends and local contexts, needs and actions. 


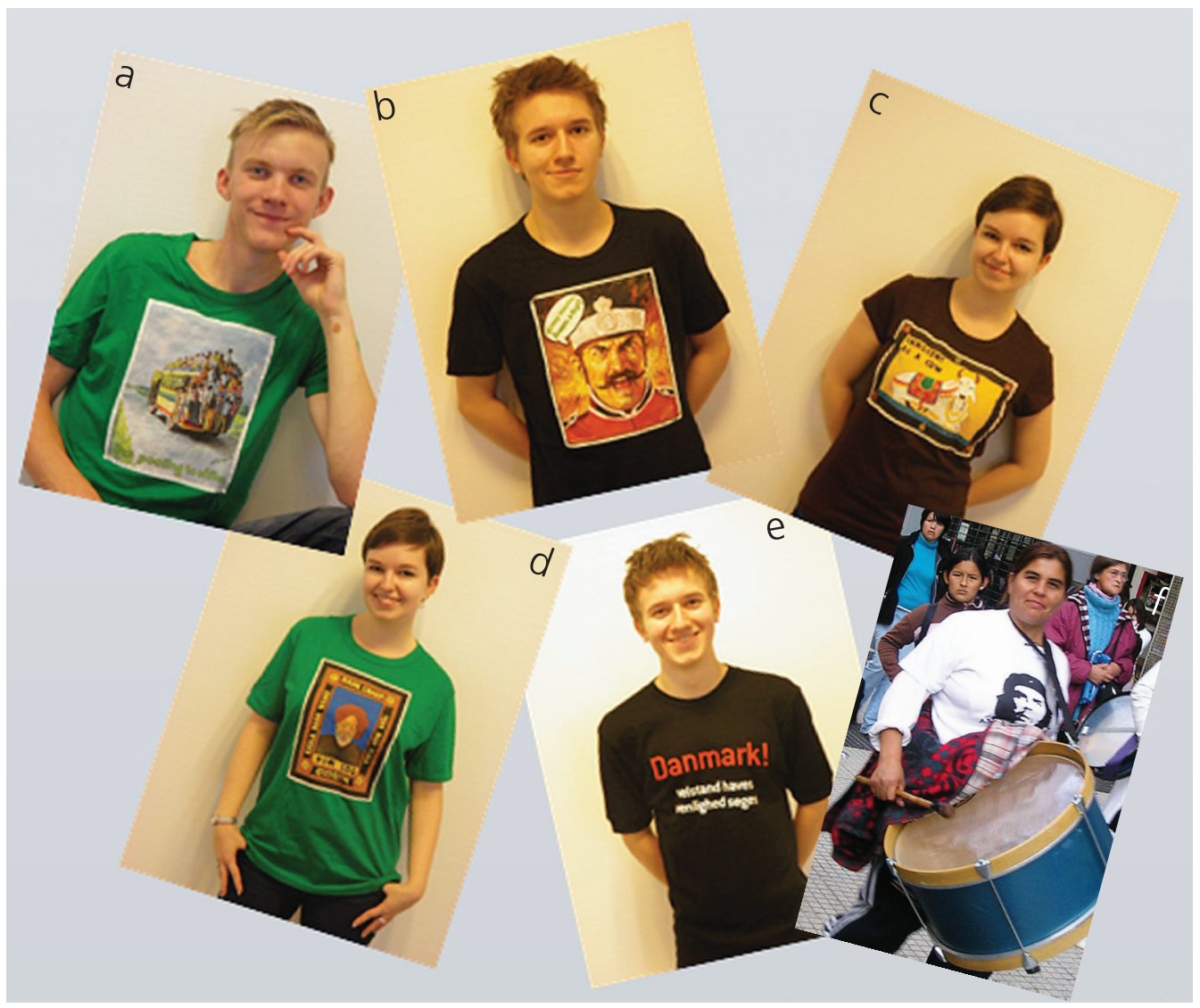

Fig. 31.3: a-d. The sustainable and eco-friendly products of Indigreen (a commercial spin off of an Indian Climate NGO) T-shirts have glocal messages on their (literary) canvases: "Bus pooling to Office" is a humorous comment on the Western concept of carpooling by relating to a funny Indian commercial. "Mangal Panday" is inspired by a Bollywood film about the revolt of 1875 against the British Raj in India (led by Mangal Panday) and shows the anger to support the message "Global warming; Bugger and blast". "Innocent as a Cow" is a tribute to the holy cows in India, whom Hindus worship and see as a symbol of the Divine Mother. "Dada Chaap" is part of Indigreen's Anti-Corruption collection, saying: "You, who earn Black Money, may your face also be black". That means that corrupt persons should be shamed in public. The Sticks ' $n$ ' Sushi T-shirt (e) shows that the restaurant chain also wants to engage with humorous comments and travesty (of job announcements) in ethical debates in Danish society. "Prosperity we have; kindness we are looking for." (@ Photos: Ziff Jonker; modelled by Martin Henrik Andersen, Maria Lykke Andersen and Simon Jonker). f. Argentinians still use Che Guevara as an icon in 2006 when celebrating the revolution of 25 May 1810 (Photo: Pepe Robles; Wikimedia Commons, public domain). 


\section{The reflexive ones and the glocal perspective}

T-shirts have turned into a canvas, with and on which wearers, citizens and consumers display and transport an almost endless range of social, political, and personal messages. Like fashion, fashion labels, and other consumer goods, wearers use their T-shirt to show their lifestyles (Featherstone 2007, 81-92), opinions, jokes, and communities, sense of belonging or protest and dissociation.

In this sense they are utilized for three reasons:

First, they are a means and ends to expressing, seeking and creating identity in societies, where the Self had become a "reflexive project" (Giddens 1991, 5, 52-55, 244). $\mathrm{T}$-shirts can be an important communication tool in these projects. The social identity (belonging to a group or culture, to be like others) as well as the personal identity (to be unique, to be like anybody else) can be expressed. Identity is always created together with others, in this sense T-shirt communication is one of the places where this co-creation can take place. At least, T-shirts can stimulate conversations about matters that are important for the wearers, with those who look at the wearers' T-shirt.

Secondly, sociologists have observed an increasing individualization in late modernity in the West. This individualization has almost no limitations in the field of T-shirt communication. In special shops and virtual companies, you can design and produce your own individual T-shirt. Or, you can create your own individual T-shirt either with low or high tech. Traditional printing techniques used wooden or other stamps (e.g. cut-out potatoes) or textile painting to create individual T-shirts or T-shirts for a group or community. In cities, transfer film to be imprinted on your own printer and to be ironed on a T-shirt can be bought in several Do-it-Yourself or copy shops. In specialized shops and on the web, there are producers who allow you to design your own T-shirt: they contribute to the individualization of mass goods by the customers and the co-creation of these goods by utilizing the potential of e-commerce and digitalizing designing and printing.

Finally, this trend shows that the T-shirt at the same time is a means and an end of a more participative culture or fashion, and of democratic design or participative design trends. Regrettably, these democratic and participative trends at the same time have led to very serious environmental and social problems. In this sense, the non-sustainability of mass production (unsustainable cotton farms and industries, pesticides, sweatshops, poor and life-threatening working conditions, dyeing chemicals, an obscure labyrinth of subcontractors) and mass consumption (transport, cleaning, water waste, chemicals, competition with small local textile producers, waste) challenge the triumphant march of the (cotton) T-shirt in the future.

The triumphant march might therefore not continue and the T-shirt might be replaced. Or, it might continue in another form, when sustainable local production and consumption contribute more to the global phenomenon of the T-shirt as an identity creator where prosumers and co-creators will become really central players. 


\section{Acknowledgements}

The author would like to thank Associate Professor Lise Skov from the Copenhagen Business School for her outstanding and constructive comments on an earlier version of this article. The author also expresses his gratitude to Martin Henrik Andersen, Maria Lykke Andersen and Simon Jonker for kindly agreeing to model the T-shirts for this article. The author encourages readers to send him photos of - and stories about - their favourite T-shirt to <tshirt@cbs.dk> or <https//www.facebook.com/ storyofmytshirt>.

\section{Further Reading}

Charlotte Brunel (2002) The T-Shirt book.

Joanne B. Eicher ed. (2010) Global perspectives (Berg Encyclopedia of world dress and fashion, vol. 10)

Mike Featherstone (2007) Consumer Culture \& Postmodernism.

Yiannis Gabriel and Tim Lang (2006) The unmanageable consumer.

Anthony Giddens (1991) Modernity and self-identity: Self and society in the late modern age.

Cesar Padilla ed. (2010) Ripped: T-shirts from the Underground.

George Ritzer and Nathan Jurgenson (2010) Production, consumption, prosumption. Journal of Consumer Culture, 10:1, pp. 13-36.

Pietra Rivoli (2005) The travels of a T-Shirt in the global economy: An economist examines the markets, power, and the politics of world trade. 


\title{
32 India to Africa: Indian Madras and Kalabari creativity
}

\author{
JOANNE B. EICHER
}

Joanne B. Eicher, Regents Professor Emerita, Department of Design, Housing and Apparel, College of Design, University of Minnesota, specializes in cultural aspects of dress with interest and expertise in Asia and Africa. She conducted research in West Africa, specifically Nigeria, and lectured in the USA, Europe, Africa, and Asia. She is Editor-in Chief of the World Encyclopedia of Dress and Fashion 2010 published in hardcopy and also online within the BergFashionLibrary.com, consulting editor, Dress, Body, Culture book series, (Berg), and associate editor, Scribner's Encyclopedia of Clothing and Fashion (2005). She co-authored The Visible Self, (4th ed. 2014), edited Dress and Ethnicity (2005), and co-edited Fashion Foundations: Early Writings on Dress (2003), Dress and Gender (1992), Dress and Identity (1995), and Beads and Beadmakers (1998). She authored Mother, Daughter, Sister, Bride: Rituals of Womanhood, National Geographic, (2005). Readers of this chapter will find her following publications of special interest: (2005) Kalabari Identity and Indian Textiles in the Niger Delta, in Rosemary Crill (ed.), Indian Trade Textiles, pp.153-171; (2014) The Sacred Use of Indian Textiles by the Kalabari of Nigeria, in Jasleen Dhamija (ed.), Sacred Textiles, pp. 94-105.

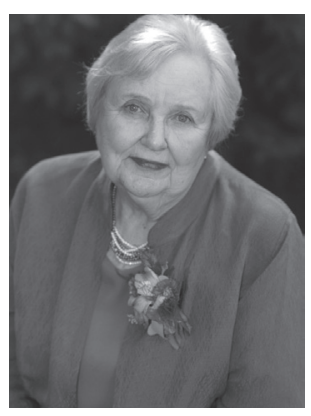

"Intorica", a label created from the words "India to Africa", placed on specific textiles, hand-woven in India, has been prized by many Nigerian consumers who buy and use these check and plaid fabrics for both men's and women's wrappers. The Kalabari people of the Niger Delta specifically seek certain colors and patterns of the fabrics in order to produce a design by subtraction, that they call pelete bite, meaning cutthread cloth.

A brief history of textile production in India and trade to Nigeria provides an introduction to pelete bite, an important textile for the Kalabari and the women who create the designs, the process, the patterns preferred, and motifs imposed on the fabrics. I conducted the research during eight trips from 1980-1991 (with a preliminary visit in the 1960s), to Kalabariland, an area of islands found in southeastern Nigeria within the mangrove swamps of the Niger River as it winds toward the Atlantic Ocean. Many Indian textiles have been and still are imported into West Africa in the 21st century, and the Kalabari prefer specific colors of indigo, burgundy, and reds mingled with white and other colors to form definite plaid design patterns and have been choosing them for as far back as the early 1800s. The Kalabari people give Kalabari 
names to the plaid or checked designs used, such as amasiri, igodoye moru, and ikaki mgbe, not all of which have English translations (like the first two examples), although the last one means "tortoise bones". They also give names to the motifs that they create on the textiles from which they remove threads, with English words such as "cross", "bowtie", "wine glass". Again, some have Kalabari names like etere (floor mat), ikoli (chain) or sangolo (fish gills).

Historians and textile scholars have conducted research on this trade. Of particular interest has been the cotton textiles investigated by Sandra Evenson, traded from the 17th to the 19th centuries, first called "Guinea Stuffs" and even more specifically, Callowaypoose, Nicanees, and Populees (terms no longer in use, but used in the 18th century for striped, checked or plaid cotton cloth) that appeared to be of higher quality. As part of a long history in trade with Portuguese, Dutch, and English sea merchants, indigenous Nigerian traders thus had a wide variety of textiles from an array of European countries available to them in their exchange process. Among several types of velvets, silks, and cottons, particularly attractive to the Kalabari traders of the Niger Delta, were the Indian plaid and check cotton fabrics later called "madras" from India. These textiles were hand loomed by Indians and exported to England and then traded to Nigeria.

The Kalabari call the hand-loomed and yarn-dyed madras fabrics of $100 \%$ cotton either injiri in Kalabari or Real India in English, whereas Indians in the Indian production and export system call it RMHK, an abbreviation for Real Madras Handkerchief. The term is used because the repeat of the plaid or checked patterns has been on a 36 inch square repeat, referred to as handkerchief size, although seemingly a rather large one. The lengths woven are ordinarily, 8, 16, or 24 yards. The Kalabari have called these textiles Real India because they come from the looms in India and are not woven on power looms in Europe or the UK, which they call imitation madras. Some yarns of the hand-woven Indian cloths were also dyed with indigo and had a distinctive odor that the power loom cloths with synthetically dyed fibres did not have.

Although madras plaid was and is still worn by several ethnic groups in Nigeria, both Kalabari men and women use them for daily wear as wrappers (Fig. 32.1), because their tutelary deity is the only one who can wear 'prints'. For special occasions, often for the final day funeral parade or when sequestered as a new mother, women wear madras plaid as a special ensemble to indicate their status (Fig. 32.2).

In other cases, they select the plaid and checked patterns that have had additional designs formed by cutting and pulling white and bright threads. This results in leaving small, open, and lacy spaces (Fig. 32.3). The specific textile patterns with names like those given above were and still are chosen and requested year after year. In addition, the women cutting the motifs draw inspiration from household artifacts and the surrounding environment, which includes imported (bow-tie) as well as domestic items (floor mat). Usually women are those who execute the cutting of motifs on the textiles, but occasionally a man may choose to learn to do this as well.

The Kalabari people are the only African group known to have devised this technique of design by subtraction, an example of what my colleague, Tonye V. 


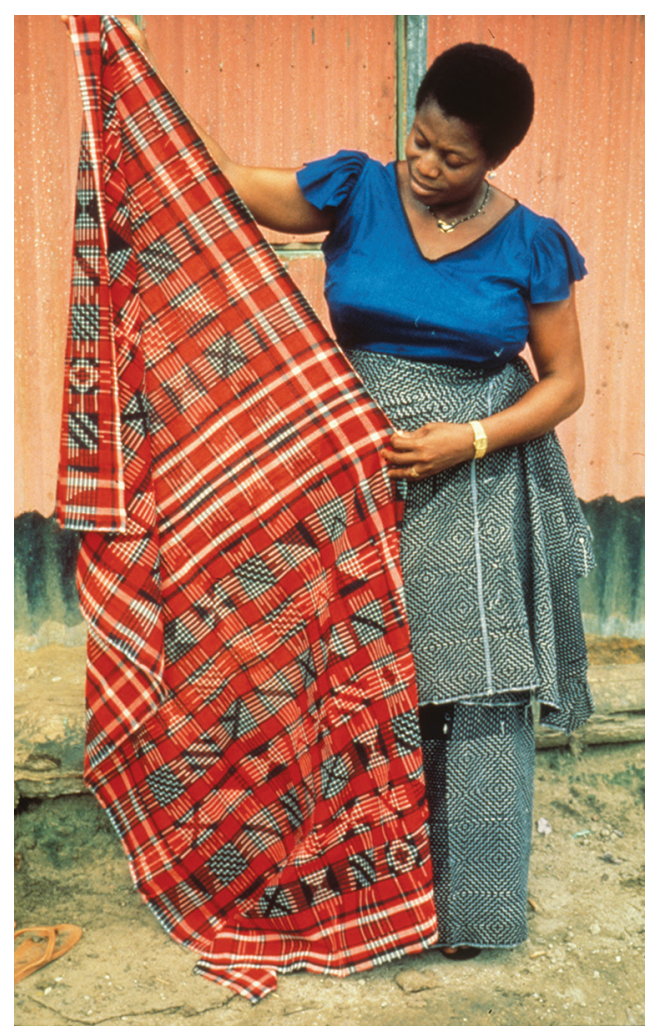

Fig. 32.1: Amonia Akoko, Buguma, Nigeria, is well known for her expertise in designing and cutting Indian madras to make Kalabari pelete bite. She is wearing a wrapper of her own design as well as displaying one with many motifs (Photo: (c) Joanne B. Eicher).

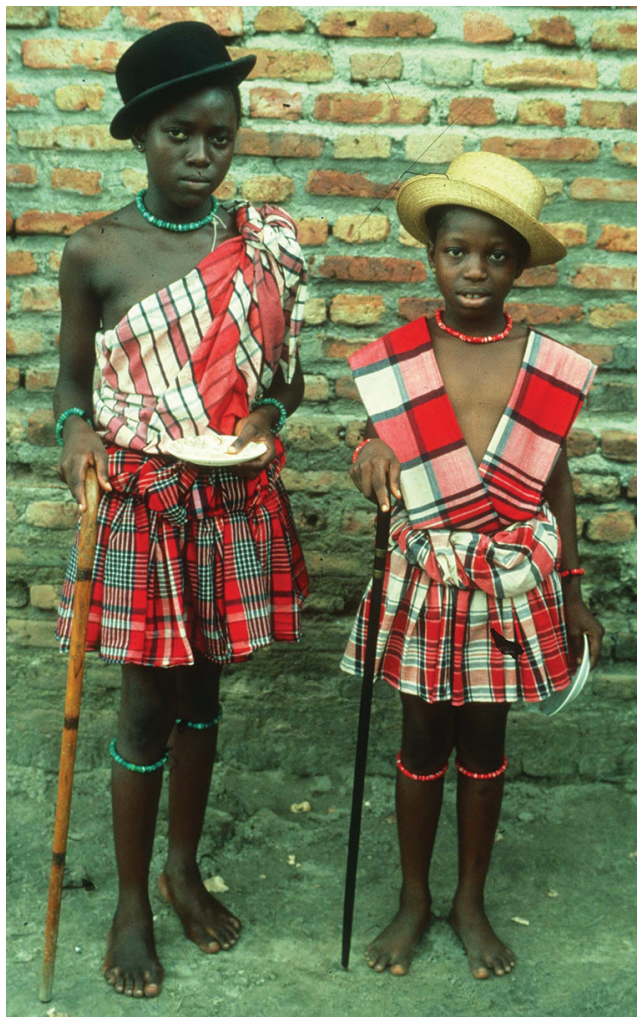

Fig. 32.2: Two Kalabari girls dressed in madras outfits to march in a final day funeral parade, Buguma, Nigeria (1983) (Photo: (C Joanne B. Eicher).

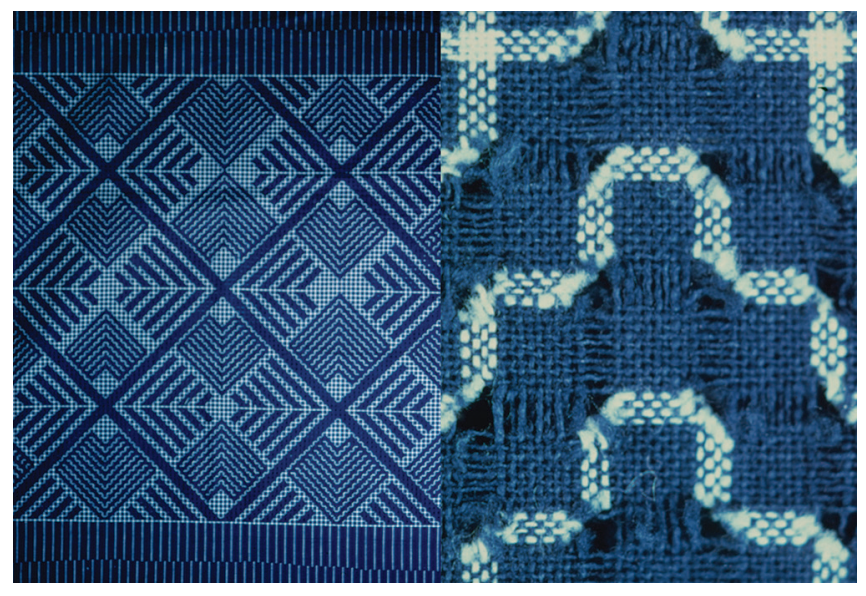

Fig. 32.3: Pelete bite example of the indigo and white cut cloth on the left and a detail showing open spaces on the right (Photo: (C) Joanne B. Eicher). 
Erekosima and I have called "cultural authentication". This concept analyzes an item or a process that seemingly has been borrowed from elsewhere, but instead acknowledges and highlights the final result or product as being different from the original that was borrowed. This indicates that the result has become authentically an artifact of the group that had imagination and crafted this new variation or product. The four aspects of cultural authentication involve the process of selection, of characterization (or naming), of incorporation into the culture, and transformation that accounts for the item's differentiation. One item, such as the textile that the Kalabari call pelete bite and the focus of this article, can be culturally authenticated, but so can an ensemble such as those worn by various ethnic groups around the world where the men's bowler hat, originally British, has become an integral part of the total outfit worn by women in several South American groups.

The cultural authentication of Indian madras that becomes pelete bite by the Kalabari occurs when a woman selects one of the named (characterized) and preferred textiles and with a needle and choice of a cutting instrument, either a razor blade or penknife, uses the needle to lift a thread to cut one end and then the other and pulls it out, leaving an empty or lacy space, depending on how many threads have been removed, thus transforming it (Figs 32.4 and 32.5).

By deciding on the image of empty space that she wishes to leave, such as a "cross", she then continues to extract threads until she has completed one motif after another on the selected textile. Sometimes she will repeat only one motif on the yardage chosen, often this is the case with young girls or women who are beginning to learn the craft. Other times, she may decide to use a variety of motifs as she desires, as happens with skilled artisans. The extracted threads leave a shadowy pattern on the textile that has primarily dark threads remaining (Fig. 32.6). The hand-loomed cloth is tightly woven, with a high thread count, allowing the cut textile to have enough strength that it will not shred or tear easily. Not only does the cut-thread textile have

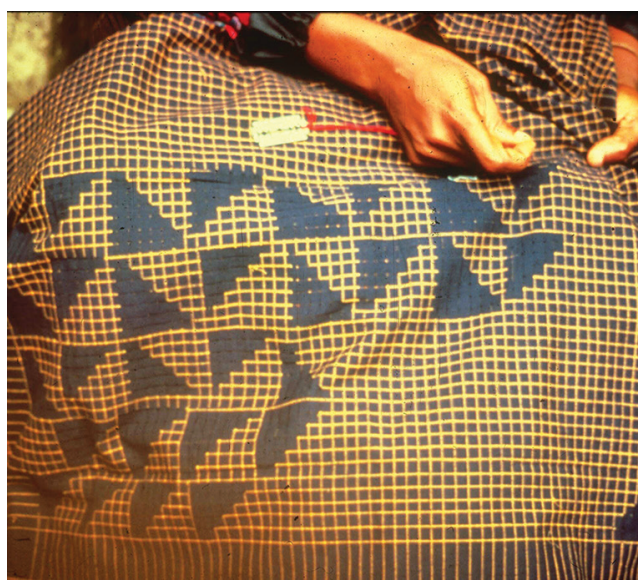

Fig. 32.4: Amonia Akoko making pelete bite by using a razor blade to cut threads (Photo: (c) Joanne B. Eicher).

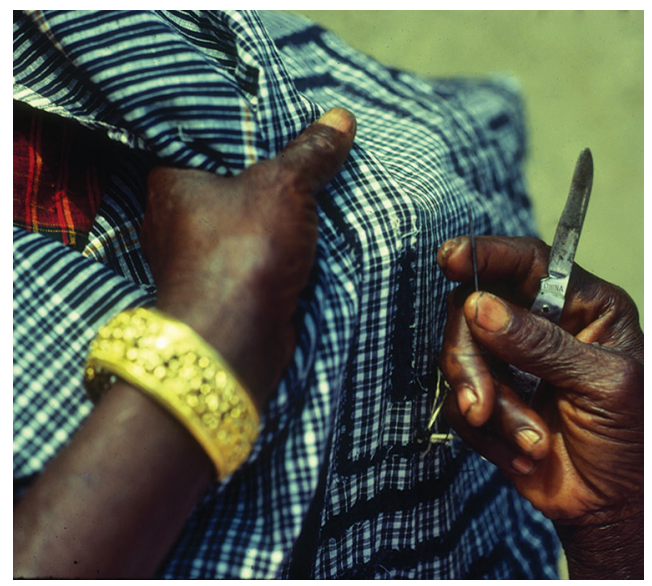

Fig. 32.5: Making pelete bite by using a penknife blade to cut threads, Buguma, Nigeria (Photo: (C) Joanne B. Eicher). 
its name, pelete bite, in Kalabari, but the chosen fabrics for cutting and the motifs cut on them also have names, thus characterization has taken place at several levels. These cut textiles have become incorporated in Kalabari cultural practices, because they are treasured for special occasions.

The occasions where pelete bite is expected or demanded to be worn include family rituals, particularly funerals for distinguished elders where cloth of many kinds, particularly from India is featured. It is a custom for the family mourners from the extended family, both men and women, to wear wrappers of pelete bite when they accompany the deceased from the mortuary or waterside to lie in state at home. Female mourners march along behind the casket, and male mourners carry it to be placed on a bed to be opened for later viewing of the corpse and visiting by family and community members. With these wrappers, the male mourners wear white shirts,

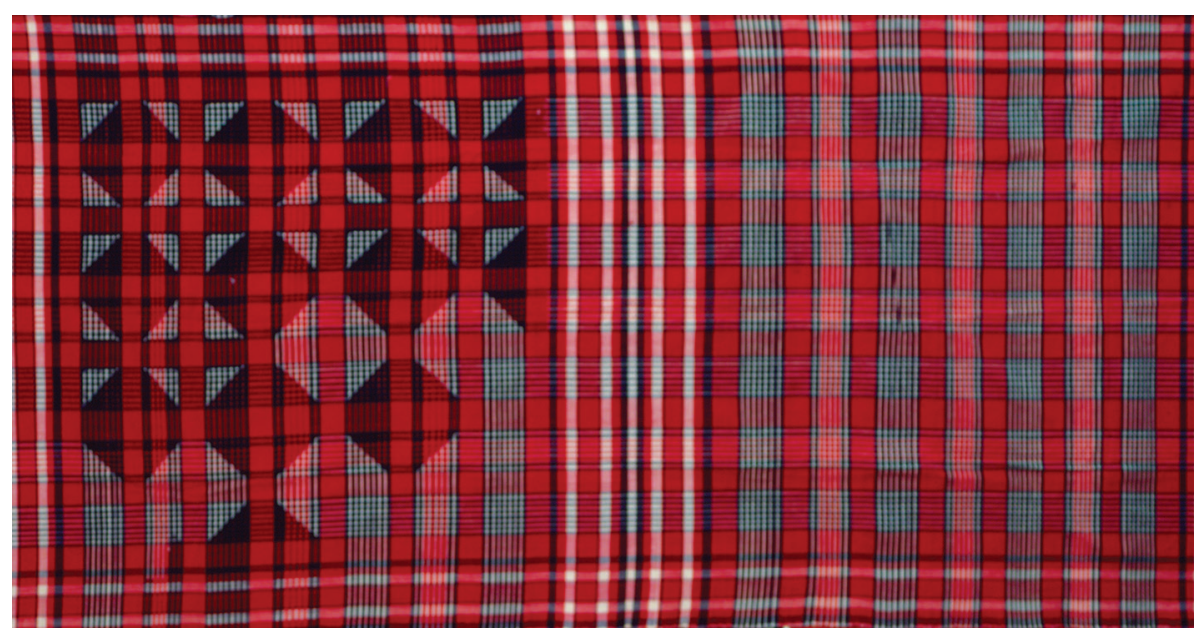

Fig. 32.6: (above) Pelete bite example of a length of madras that is partially cut on the left and completely uncut on the right (Photo: (C) Joanne B. Eicher).

Fig. 32.7: Kalabari women wearing pelete bite wrappers, madras plaid headties, and eyelet blouses or T-shirts stamped with portrait of the deceased. They are escorting the deceased in a coffin to lie in state in the family home before burial (Photo: (C) Joanne B. Eicher).

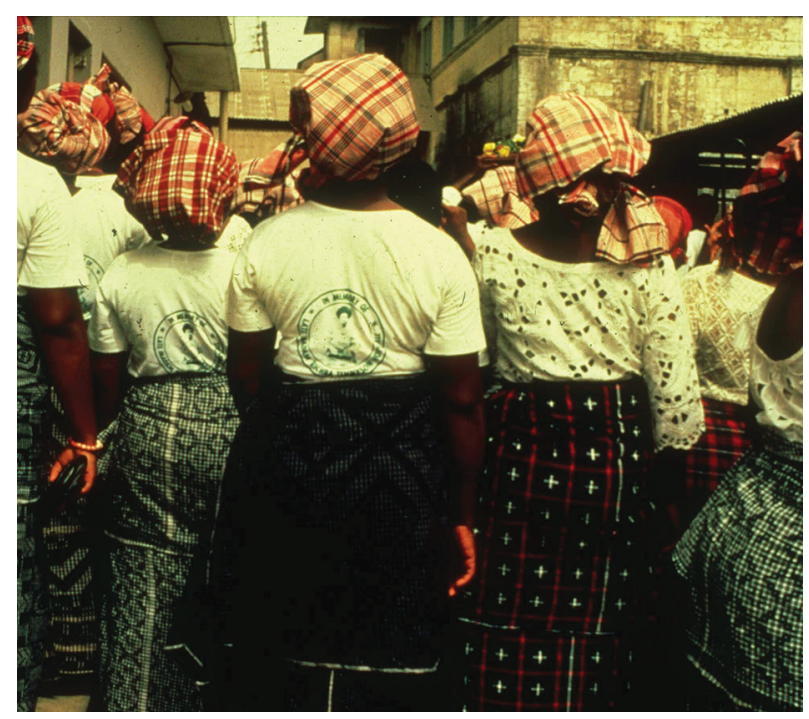


and females, white lace or eyelet blouses. An alternative for both can be a white T-shirt with the portrait of the deceased on it when the family provides it (Fig. 32.7).

During yearly masquerade festivals, pelete bite is often placed over the face of a masquerader when participating in the festival. Because the fabric has a lacy effect after the threads are removed, the masquerader can see through the fabric easily, but the onlookers cannot see his features and it provides the necessary anonymity expected for a dancer (Fig. 32.8).

If a family has a special event, such as a party, family members may also be asked to wear pelete bite. When the family is celebrating as a family unit, commonly a specified one is required to display family unity. This custom dates back to the early trading times when a prominent trader appropriated a designated textile pattern and declared it as his own with the consequence that it became known as that family's cloth and was so designated as "belonging" to John Bull or Douglas or Ombo families, for example. One textile from the John Bull family, cut in the early 1830 s by Osonta, one of the wives of the prominent trader, John Bull, is in the Fowler Museum, University of California Los Angeles collection (Figs 32.9 and 32.10).

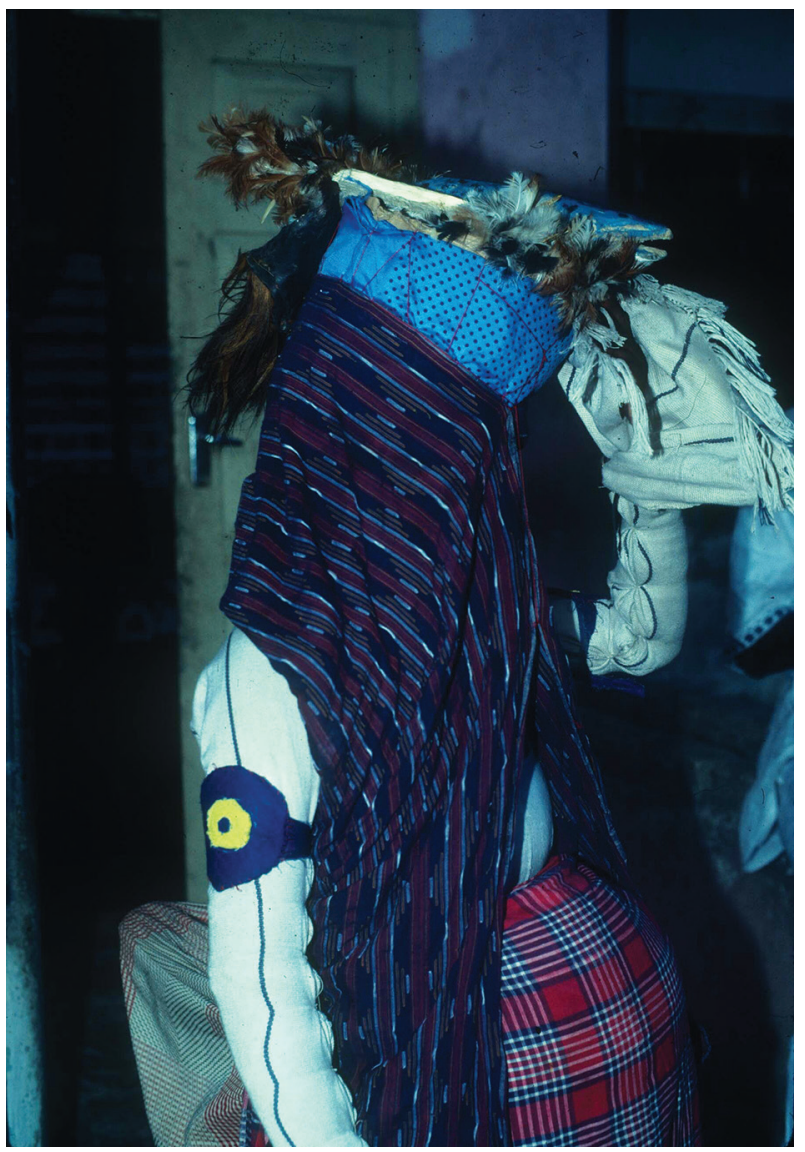

Fig. 32.8: Masqueraders are always male and may wear pelete bite to cover their faces instead of a wooden mask. The costuming sometimes indicates, as in this case, being both female and male, displaying a bulging belly and a significant rear protrusion (Photo: (c) Joanne B. Eicher). 


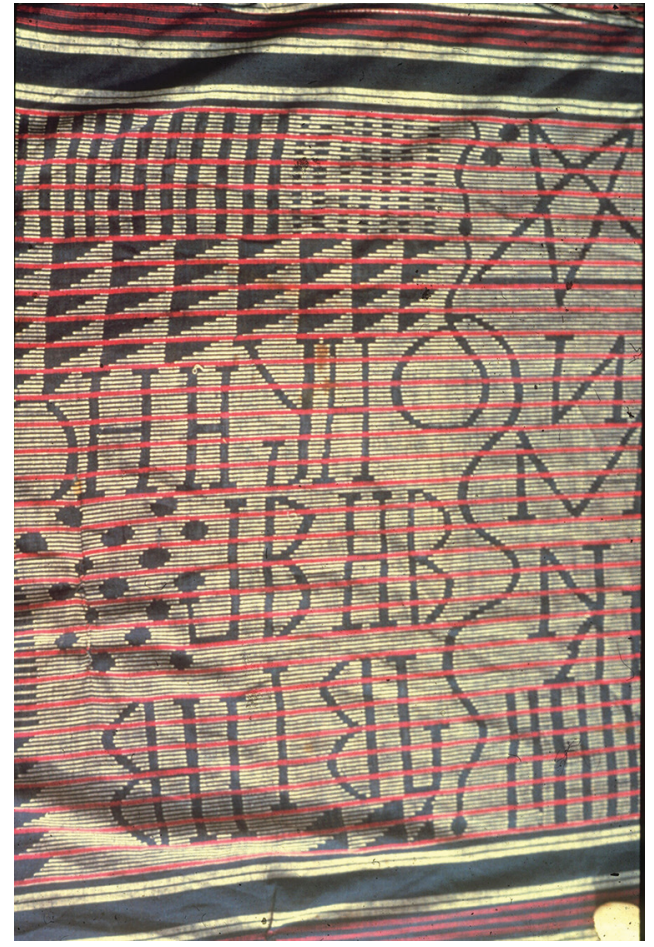

Fig. 32.9: A pelete bite example, said to be cut in early 1830s for John Bull, prominent Kalabari trader by his wife, Osonta. Note initials J. B. cut into cloths (Photo: Joanne B. Eicher, 1980 - later acquired by the Fowler Museum, University of California, Los Angeles).

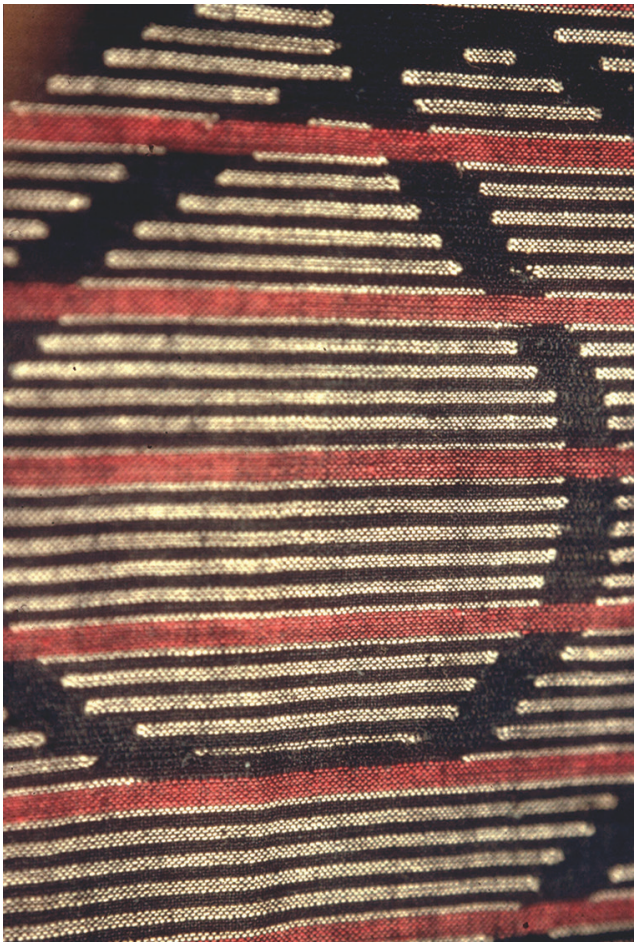

Fig. 32.10: Detail of the loop in Fig. 32.9 (Photo: (C) Joanne B. Eicher).

These textiles are treated as precious commodities and worn only for special events. Often they are not washed but aired on bushes or clotheslines after use, because wearers are careful when wearing them. They are individually owned when first purchased and commissioned for cutting, but after death, it is expected that they go into the family 'cloth boxes', in the 'box room', where they are treated as heirlooms and brought out to be worn when needed. Occasionally in the case of the death of an older female, the extended family members may have enough pelete bite wrappers to adorn the bed of the deceased to honor her when she lies in state (Fig. 32.11).

The trade between southern India and the area around the city once called Madras, now Chennai, and the islands of the Niger Delta where the Kalabari still live, is a superb example of global trade encounters. Toward the end of the 20th century, Nigeria declared textile imports illegal, but the demand for the prized Indian madras textile was so high that smuggling from neighboring countries where there was not a ban still allowed eager Kalabari consumers to continue to satisfy their desires for the fabric they call Real India, and this continues in the 21st century. 


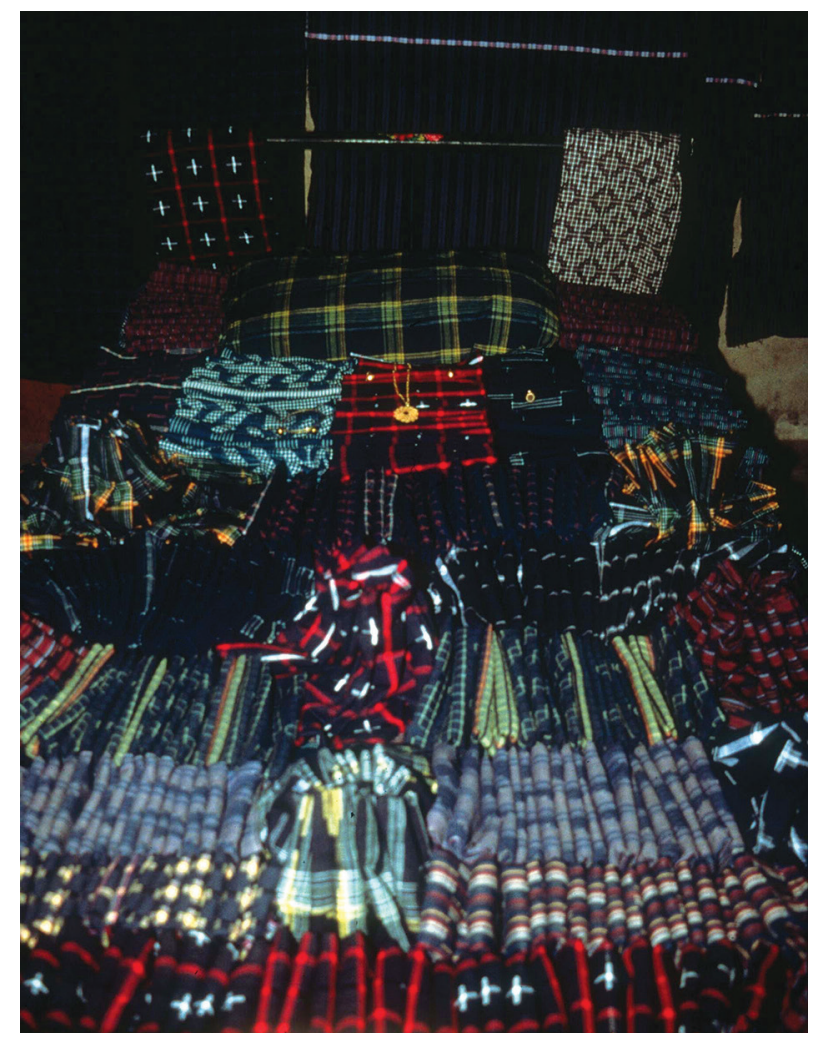

Fig. 32.11: Pelete bite wrappers folded to adorn the funeral bed of a deceased female during the funeral celebration week, after the burial of the corpse (Photo: (c) Joanne B. Eicher).

\section{Acknowledgements}

Thank you to the late Tonye V. Erekosima and his family who introduced me to Kalabari culture and supported our research throughout. Thank you also to Sandra Lee Evenson for her kind help in explaining some historic textile terms no longer in use. Author photo by Patrick O'Leary.

\section{Further Reading}

D. M. Amalsad (1926) The Development of the Madras Handkerchief and Lungy or Kaily Industry in the Madras Presidency.

Joanne B. Eicher and Tonye V. Erekosima (1995) Why do they call it Kalabari? Cultural authentication and the demarcation of ethnic identity, in Joanne B. Eicher (ed.), Dress and ethnicity, pp. 139-164. Joanne B. Eicher and Tonye V. Erekosima (2002) Fitting Farewells, in Martha Anderson and Philip Peek (eds), Ways of the Rivers: Arts of the Niger Delta, pp. 307-329.

Tonye V. Erekosima and Joanne B. Eicher (1981) Kalabari cut thread cloth: An example of cultural authentication. African Arts, 14 (2), pp. 48-51.

Sandra L. Evenson (2007) Indian madras plaids as "Real India", in Donald C. Johnson and Helen B. Foster (eds), Dress sense: Emotional and sensory experiences of the body and clothes, pp. 96-108.

Elisha P. Renne (2001) “Our Great Mother...tied this cloth:” Pelete Bite Cloth, Women, and Kalabari Identity, in Susan J. Torntore (ed.), Cloth is the Center of the World; Nigerian Textiles, Global Perspectives, pp. 29-41. 


\title{
33 Textile: The non-verbal language
}

\author{
JASLEEN DHAMIJA
}

Jasleen Dhamija is known internationally as a Philosopher of Living Cultural Traditions and a specialist in the History of Textiles. She began her work in 1954 with the Government of India soon after independence to develop and revive traditional crafts, researching in the field throughout India in handicraft, handloom industry, folk art, performing art, community development and women's employment. She is one of the pioneers of the movement to develop cottage industry as an alternative means for development in rural based economies. After working in India for 19 years, she worked with the United Nations Development Programme in Iran, Middle East, Central Asia, South East Asia, the Balkans, as well as 21 countries in Africa. She has advised many governments on applied art and multi-cultural creative expression.

She taught the History of Textiles and Costumes in a number of Universities. She was Advisor to the Farabi University on Textiles in Tehran from 1974 to 1977.

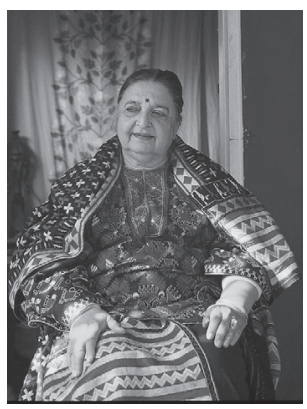
She was Visiting Faculty for the National Institute of Design, Ahmedabad. She was awarded the Hill Professorship, University of Minnesota for her work on World Textiles. She was appointed to the Faculty of the History of Indian Textiles and Costumes at the newly opened National Institute of Fashion Technology, New Delhi. She was also visiting fellow at Canberra School of Arts, Canberra, Wollongong University and Sydney School of Art on History of Textile. She has lectured extensively at universities in USA, Australia and India and at National Museums in among others the UK, USA, France, Switzerland, Iran, Turkey, India, Philippines, Japan, South Korea, Thailand, Laos, Egypt and South Africa.

She has written and published extensively on Indian textiles, Iranian textiles and South Asian textiles and Southeast Asian textiles. She has recently edited the Berg World Encyclopaedia of Dress and Fashion Volume IV, South Asia and Southeast Asia (2010) where she has contributed several articles of interest to readers.

She organized major exhibitions, Woven Magic: The Affinity between Indian and Indonesian Art. 5000 Years of Indian Textiles at Manila National Museum. Power Cloths of the Commonwealth at the Commonwealth Games, Melbourne at the RMIT, Melbourne. Exhibition of Sacred Textiles at the International Festival of Sacred Arts, New Delhi.

She was appointed President of the Jury for Award to the Finest Textile Designers and Weavers for their Creativity and appointed Co-Chairperson for Handloom Development Working Group for the 12th Plan Planning Commission, Government of India, for evolving a development programme for 1 million handloom weavers.

Textiles are a non-verbal language of a people. In fact being one of the oldest techniques mastered by the human race, it has given the vocabulary to some of the esoteric philosophical concepts. In India, a very large part of the vocabulary and imagery of philosophical and religious thought is taken from textile terminology. Yantra, the esoteric diagram used for meditation is derived from the Sanskrit word for the loom. Till today the ritualistic kushti, woven for use by the Zorastrians, is woven 
on the loom that is known to them as yantra. Sutra, to string together, is the name for the Buddhist texts. Tantra is derived from word for the warp, tantu. The main warp beam is known as stamba, and that is the axis mundi.

A traditional textile conveys to the knowing eye a great deal about not only the creators, but also about those for whom it is created. The materials used, the weight and texture of the cloth tell us of the geo-climatic conditions in which it was made. The woven motifs, the use of colour, convey the origins of the people, their cultural history and their beliefs. It also announces in some society the status of the user, for instance are they single, married or widowed, to which ethnic group do they belong.

The finely woven cotton Bengali sari worn by the women in Bengal, Eastern India, is woven in white, and carries a broad red border. It is worn by the married woman and signifies her marital status. In the case of the widow, it is a plain unbleached piece of cloth and thus devoid of colour, for white is also a colour. The significance is that her life as a widow is devoid of colour, as traditionally the widow did not remarry and lived more or less a living death, as she was deprived of colour, as well as deprived of spices in food.

Fabrics also contain power, which is imbued in them by the use of colour and design. The sari with three colours woven in three equal sections, mubakkam in Southern India, yellow, red and black, stand for triguna, the three salient aspects of the human being, satvic, rajas and tamas. The colour yellowish orange is satvic, signifying introversion, withdrawal and attraction to asceticism. Red is rajas, powerful, passionate, full of joy and the essence of life. Blue black stands for tamsic, which is brooding, intense and all encompassing. All three are essential for a balanced persona. These colours are combined in a sari to be worn by the women and are meant to create a balance in their being and imbue them with power, shakti to deal with any situation.

The red and yellow checked sari is the puja sari worn for performance of rituals. The plaid or check, which in Hindi is chowk, is the mandala, the sacred grid, associated with a close connection with the elements. The two horizontal parallel lines running parallel to the earth cross two parallel vertical lines emerging from the earth and moving upwards. The crossing and linking create the powerful dominant energy. The central square is the house of the Bindu, the seed from which all life emerges. It is the focal point of the mandala (Fig. 33.1). The squares on four sides of the central square create the shape of the fire altar, as well as the mandala used for performing all Vedic rituals. The placing of squares on all four sides of the altar creates the nine squares, which are the houses of the nine constellations, nakshatras, the planets, which according to astrology influence our lives. Thus the importance of the checkered cloth or the square is evident in practically all traditional cultures of South East Asia and South Asia. This holds true from India right across to West Africa, where the checkered cloth plays a significant role in the rites of passage. Vettapalam in the Andhra located in Southern India area was the centre of the production of ritual textiles for West Africa for a millennium, according to available records. Even today, nearly 10000 persons are involved in this trade. This is the RMHK, the Real Madras Handkerchief, known also as George Cloth, which was exported to Nigeria and was 
Fig. 33.1: Puja Sari woven in silk and gold thread, in Kanchipuram, Tamilnadu, by the traditional Padmasali handloom weavers. The sari is woven for ritual purposes. The two colours are red and orange, which signify two important aspects of the human nature. Red is the rajas colour, which signifies power, passion, joy and the very essence of life, thus worn by young brides, while the orange is associated with the satvic temperament, signifying introversion, withdrawal and asceticism. Red dominates, while the orange is controlled, this signifies that the woman is youthful and married. The main body of the sari is covered with a checkered pattern, which signifies the sacred grid, known as chowk and also forms the mandala, the sacred diagram for meditation or for creating a powerful ritual space. Each square has a golden dot, which is the bindu, the core of the mandala, or the beeja, the seed from which the universe emerges. The cross border carries sacred symbolic motifs, which further sanctifies the sari. There is the hamsa, the sacred swan, quite distinct from the Islamic and Jewish Khamsa. It is associated with possibly the golden egg floating on the eternal ocean, as the beginning of life. It is also associated with Lord Brahma, Lord of Creation, and Goddess Saraswati, goddess of Knowledge, as their vehicle.

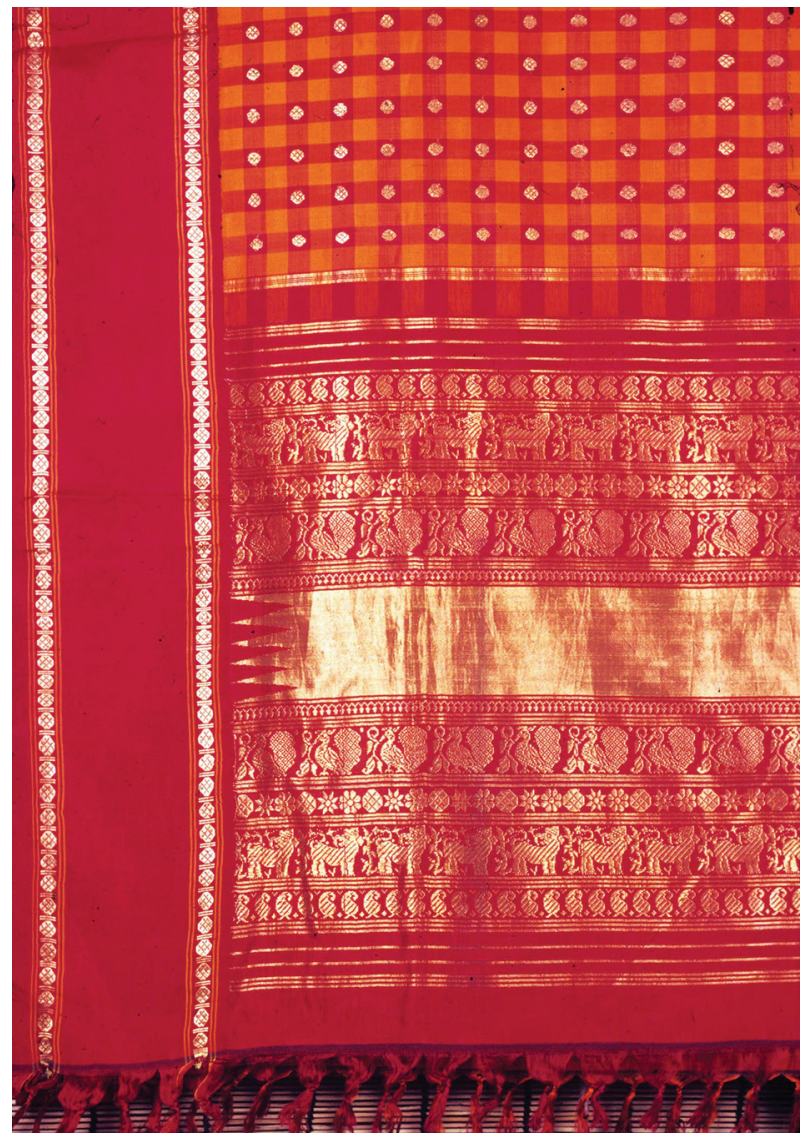
Next is a row of the Lion, the vehicle of the Goddess of Shakti, power. A small border carries the sacred motifs of the rudhraksh, the sacred energy prayer bead, associated with Shiva, the lotus representing the sun, also associated with Buddha, as well with the goddess Lakshmi of prosperity and the star. In the centre is a wide golden weave ending with the temple shikhar, a spire, associated with the mountain and in some cases the flame. The sari is worn by the woman of a household while performing an auspicious ritual for the household (Photo: (c) Jasleen Dhamija).

an important part of the rites of passage from birth to death of the Kalabari people of the Niger Delta. (See also the chapter by Joanne Eicher in this book).

The act of creating a cloth is in itself a ritual. The original loom, which was the back strap loom, was used primarily by women. Their body became the yantra, the loom. Their biorhythms were woven into the fabric and the act of weaving became a form of Yoga and the creation of the cloth an act of giving birth.

Embroidery became a multifaceted mode of expression, as well as a tool. It mirrored the inner and outer world of the woman and was her creative expression. It also became a means of protecting the user. The quilt wrapper, kantha, made for the unborn child is made from worn out cloths of pious men, and is embroidered with auspicious patterns, which protect the child (Fig. 33.2). 
Later when the cloth was woven by professional weavers, a whole ritual evolved. In the case of the professional weavers of Uttar Pradesh, the Ansaris, the raw silk hanks were bought from the outside. These were washed and degummed, an operation performed in the outer public area used for dealing with the outside world. Once the hank had been washed and degummed, it was brought to the inner part of the house. It was now a part of their weaving traditions.

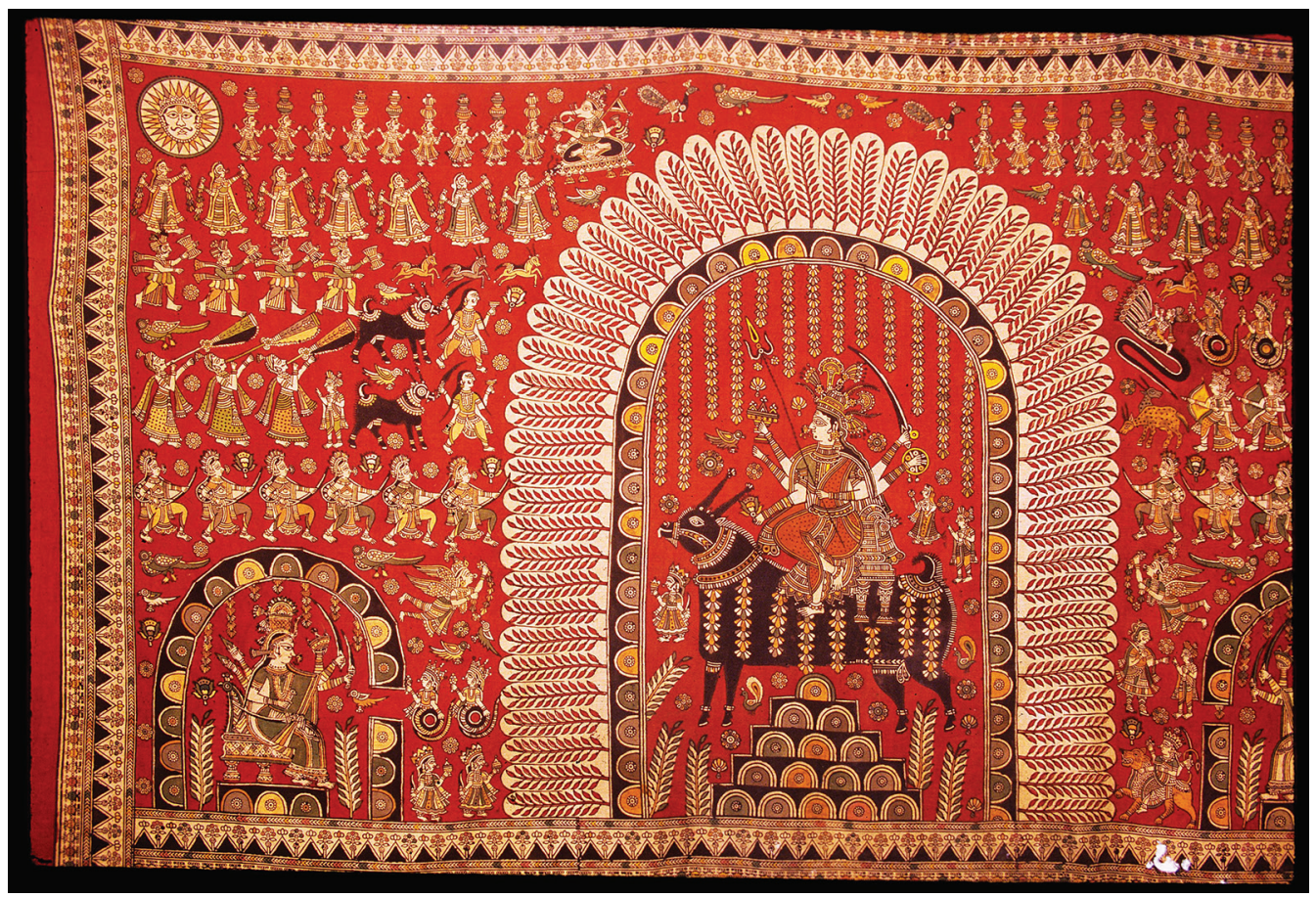

Fig. 33.2: The Mother Goddess hanging, is an iconic figure for worship by the Vagaries, a nomadic community, of Western India. The white cotton fabric is bleached and then treated with mordants. The creator is the priest of the Vagaries and is a member of the community. The creation in itself is a ritual. The priest has a purificatory bath, prays to the goddess to descend unto him, giving him the inspiration to create her presence on earth. He initiates the work by first defining the outline of the cloth with the use of wooden printing blocks. He then divides the inner area into three parts. The central panel has the main figure of the mother goddess. In this case, it is Sagatha Mata, the powerful goddess, who rides on a male buffalo. The form of goddess is drawn with the use of a reed dye pen in black. Once the main figures have been created and the other figures printed in, the background red colour is filled in by the women helpers. The dyes used are non-chemical and created by the family. The black dye is created by iron oxidisation, the red and yellow are from the roots of plants. The dominant goddess in the central niche is ready for battle with the trishul, the evil forces, the trident in one hand, and the sword in the other. The goddess seated on a peacock throne, though having the attributes of her warlike qualities, is in repose. Many elements of the vast Hindu mythology can be seen in the field. Above the central niche is Lord Ganesha, the elephant-headed son of Shiva. Every ceremony, ritual or creative activity has to begin with his presence. At the top corner is the Sun to signify the presence of the goddess in the cosmic space. Rows of women with sacred water pitchers on their heads dance and below rows of women dance beating rhythm with tasselled cymbals. Men beat the rhythm with damru, the hourglass drum of Shiva, while others sound the trumpets, calling the community to celebrate the victory of the Goddess. Women worshippers dance with naked swords. A heavenly apsara carries a garland, while two nagins, serpent maidens, make offerings to the seated goddess (Photo: () Jasleen Dhamija). 
The reeling was begun by the oldest woman of the household. She sat with the spinning wheel in the inner room where the newly-weds normally slept. Sitting in a squatting position, the position used traditionally for giving birth, the first bobbin was reeled, which was called giving birth to the cloth. The final separation of the cloth from the fixed warp threads was another ceremony, the ceremony of separation from the umbilical cord. The shuttle that they threw sang. The creating of the pattern was likhai, the written word, which was always sacred. Amongst the weavers, there was an entire hierarchy of the cloth woven for the use of the family, for rites of passage. Who weaves what, for birth, for puberty ceremonies, for marriage and then the shroud? Weaving was not only a profession, it was a way of life and closely linked with the ancestors and their progenitor.

Take the case of the traditional silk weavers of Southern India, the Padmashalis, the lotus born. Their progenitor was Bhawana Rishi, who emerged from the ashes of the great sacrifice made by Markandaya, a great sage, who had been asked by the gods to create clothes for them. He rose from the ashes carrying in his hand a ball of thread made from the stem of the lotus which rose from the navel of Vishnu, the Great Preserver on which was seated Brahma, the God of Creation. It was from this that they wove the first cloth, thus their name. This legend still lives on with them. Every time a young weaver is initiated, the great legend from Markandaya Purana is recited. This practice continues till today. There are special Markandaya scrolls and priests who recite the legend. They also have temples that belong to the Padmashalis. Once, while interviewing a silk master weaver about their weaving practices, he said, "We are connected to the umbilical cord of the great lord Vishnu, so we have to offer the very best when we sit on our loom".

India has been colonized by many cultures whose influence has added to its own richness. The visible influence today is due to the last 100 years or so, when the British educational system became to a great extent universal throughout India. The import of mill cloth adversely affected the textile weavers, the dyers and printers of India and a large number of weavers lost their livelihood. However, those who continued to weave did not lose their traditions and they have continued to weave. Though new designs, improved and varying techniques were introduced, the rituals associated with their practice of weaving were not lost. The Padmashalis, lotus born, Devangas, god's creatures, nakshabandhas, the descendants of the great Sufi Bahaudin Naqshabandi, the Ramnamis and many others, continue their traditions. The importance of traditional textiles used for ritual purposes has not been lost. In fact, it was these traditional textiles, which survived for they had their regular clientele (Fig. 33.3).

The power of the cloth and attire has been demonstrated by Mahatma Gandhi, the father of the freedom movement in India, when he used the khadi, the handspun and hand-woven cloth as the livery of the freedom struggle and thus it evolved a political significance. He recognized the importance of working with the hands and introduced spinning as a part of the discipline for everyone who worked for the freedom movement. This brought about the use of over a million spinning wheels throughout India. 


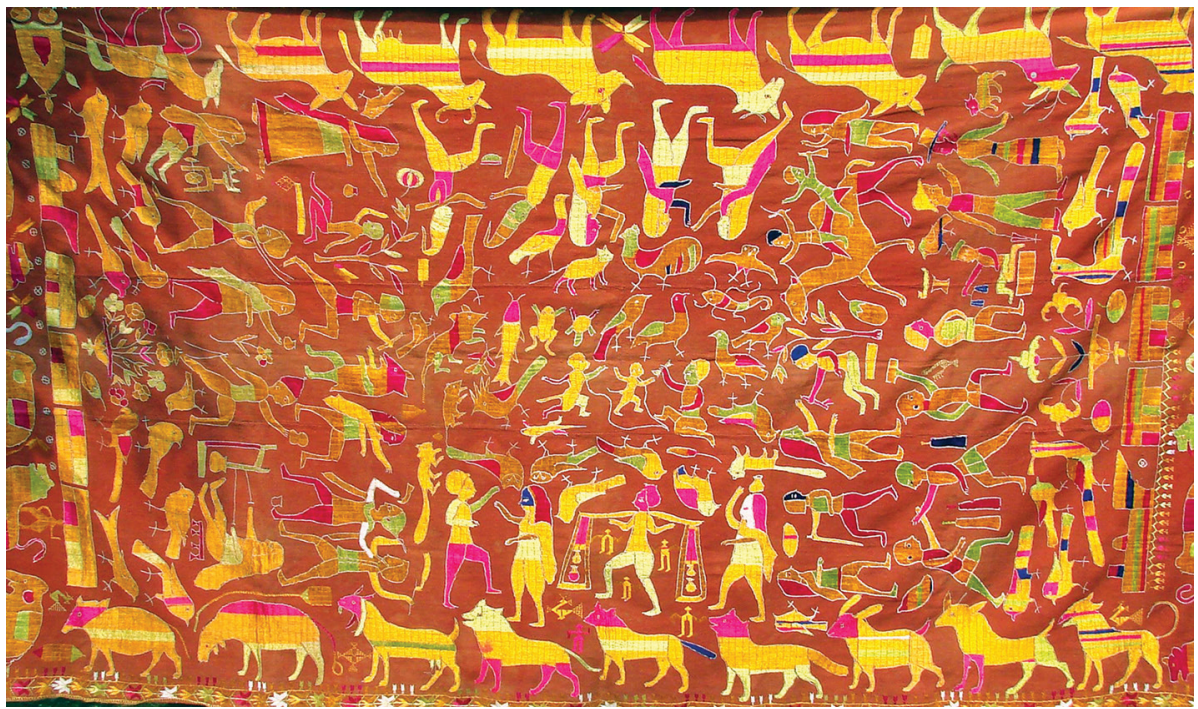

Fig. 33.3: Embroidered Hanging from eastern Punjab, also known as pictorial Phulkari, is a creative expression of the women. The embroidery is created on handspun handwoven cloth dyed with local dyes and embroidered with untwisted silk in satin stitch. Myriads of motifs recreate the life of the women. The border on both the length shows the movement of the sheep and goats and the protective dogs, with a furtive fox in one corner. The width-wise border is of a train, which the women see pass across the horizon with a longing to also go on journeys with their beloved, who probably travels away from home. A number of scenes are depicted in the central section; A woman seated on a stool churns butter; A lover greets his veiled beloved; A seller of sweetmeats carries his goods on his shoulders and children are seen around him; Two wrestlers demonstrate their skills; Itinerant performers make the monkeys dance; while another demonstrates the antics of a bear. In the corner is a European couple wearing hats; The man holds a rolled umbrella, while the long-skirted lady leads a dog on a leash (Photo: (C) Jasleen Dhamija).

The simple Gandhi cap became a factor for unifying the different ethnic, religious and regional people throughout India when it replaced the turban, which identified and separated the castes, the classes, and the different religious groups. It is interesting that the Gandhi cap, which in the 1930s signified a freedom fighter, Gandhi's follower of non-violence and the path of Dharma, of Truth, has in the last 30 years changed its meaning. It has now become associated with political corruption and hypocrisy.

Cloth and its use has always expressed the identity of a personality. This identity is double edged. How does society see the person in the pinstripe suit, the rolled umbrella contrasted with the identity of the individual as expressed by their choice of colours, design, the manner in which it is worn, that indicate the traditions and the personality of the wearer, which even the dictates of fashion have not been able to erase.

\section{Further Reading}

Nasreen Askari and Rosemary Crill (1997) Colours of the Indus.

Ruth Barnes (1997) Indian Block Printed Cotton Fragments in Egypt. The Newberry Collection in the Ashmolean Collection.

Jasleen Dhamija and Jyotindra Jain (1989) Handwoven Fabrics, India. 


\section{Dedication}

We dedicate this book to the memory of the late Irene Good (1958-2013), an enthusiastic supporter of the Global Textile Encounters project who intended to write an article on "Templates of Garment in Early Inner Asia: a Social History of Indo-Iranian Dress" and submitted the following abstract to us before her untimely death:

Dress, and the evolution of its various forms, is a hallmark of human history. It is embedded with a deep stratigraphy of social and material cultural histories. Within Eurasia, several typological streams of dress can be distinguished. These developments in garment form reflect historical trends, both in social influence as well as social isolation and purposive differentiation. Indo-Iranian dress is manifold in variation, and yet is also distinctive when compared to dress in eastern and western Asia. One striking aspect of Indo-Iranian dress is the shalvar-chemise - a long, loose tunic draped over trousers, which are then tucked into high boots, often fitted prominently with a belt around the waist. This basic template derives ultimately from the Eurasian steppelands

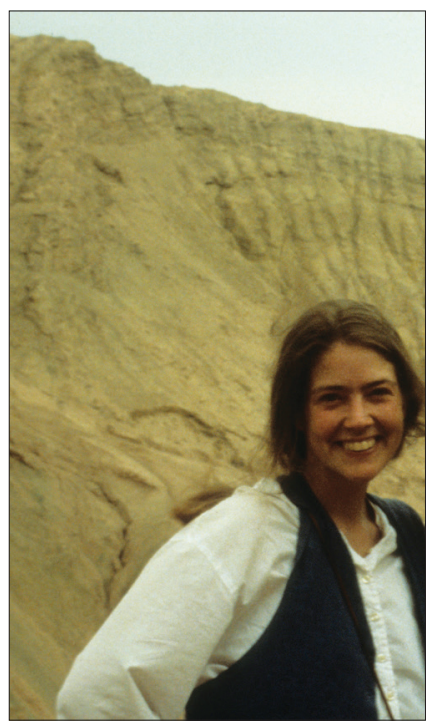

Irene Good out in Xinjiang, June 1995 (Photo: Courtesy of Elizabeth Wayland Barber). and highlands. Most of what we know about dress in the ancient world is seen through the lens of figurative art from special contexts, such as bas reliefs of ritual or court ceremony. However there is also evidence from the frozen Siberian tombs and the desertic mummified graves of Xinjiang. A composite picture of Indo-Iranian dress is emerging which shows a continuous evolution of dress from the early Bronze Age through the late pre-Islamic period. This article reviews and reflects upon both iconographic evidence and extant garment forms of prehistoric Eurasia, and contextualizes the development of Persian dress within the larger oecumene of Indo-Iranian peoples. 



\section{Acknowledgements}

The editors and publisher gratefully acknowledge the permission granted to reproduce the copyright material in this book. Every effort has been made to trace copyright holders and to obtain their permission for the use of copyright material. The publisher apologizes for any errors or omissions and would be grateful if notified of any corrections that should be incorporated in future reprints or editions of this book.

We are grateful to HM the Queen of Denmark and Prince Henrik Fund, the Lillian og Dan Finks Fond, c/o Det Kongelige Danske Videnskabernes Selskab, H. C. Andersens Boulevard 35, Copenhagen 1553 K; the Fonden af 29. December 1967, Denmark; The Danish Council for Independent Research; the EU-funded project, Fashioning the Early Modern; and the Danish National Research Foundation for their generous sponsorship of the project, Global Textile Encounters.

We would also like to thank:

Our anonymous reviewers and all those who helped in our search for contributors, both in-house at CTR and in the academic and museum community worldwide; Textile scholar and artist, Jorie Johnson <Www.JoiRae.com>, Japan; author John Man, UK, Prof. Alatan, Inner Mongolia University, Huhote, China; Jenifer S. Salvo-Eaton of the Kansas City|Miller Nichols Library, University of Missouri, USA, Cosima Glaister, Condé Nast, U.K.; Prof. Emeritus Richard Tapper, Prof. Nicholas Sims Williams and Prof. Rachel Dwyer of SOAS London, and Rosemary Crill V\&A London for their kind help, advice and information; visiting Phd students Cai Xin and Wu Manlin (Riki) for translating the texts into Chinese; Xu Wenyue, China National Silk Museum Library for Chinese language help; Peder Flemestad, CTR's resident linguist and editor for help with translating Norwegian and Italian; Mette Bruun, CTR's administrator for helping with the innumerable administrative tasks in connection with obtaining images and image rights; Weaver and art historian Ulrikka Mokdad who corrected several textile technical inconsistencies during her internship at CTR; CTR's publication team: Picture Editors Sidsel Frisch and Ziff Jonker, together with Cassandra Schrøder Holm, Niels Møldrup Petersen, Julie Bjørg Raith, Stine Bøtte, Camilla Toft Sørensen, Luise Ludvigsen, Mim Tosting, Philip Kristian Dons Madsen, Line Lerke, Egzona Haxha for their assistance, and especially editorial assistant Cherine Munkholt for the initial idea of this book and for copyediting and coordinating the project.

On behalf of fellow editors, Zhao Feng (China) and Lotika Varadarajan (India) and myself Prof. Marie-Louise Nosch, Director,

DNRF's Centre for Textile Research,

University of Copenhagen,

10th January 2014.

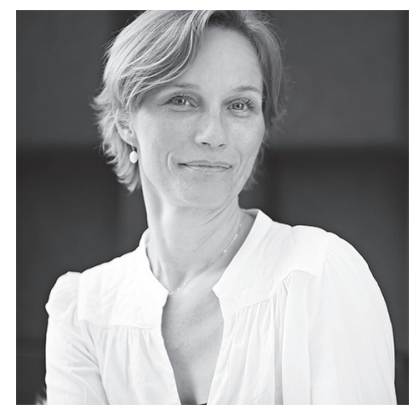


